\title{
Finite Element Modelling of the Fire Resistance of Double Skin Composite Walls Subjected to Monotonic Compressive Loading
}

By

\author{
Mohamed Yanis Bournas \\ Bachelor of Applied Science in Civil Engineering, \\ University of Toronto, Toronto, Ontario, 2015
}

A thesis

presented to Ryerson University

in partial fulfillment of the requirements for the

degree of Master of Applied Science in the program of Civil Engineering

Toronto, Ontario, Canada, 2018

(C) Mohamed Yanis Bournas, 2018 


\section{AUTHOR'S DECLARATION FOR ELECTRONIC SUBMISSION OF A THESIS}

I hereby declare that I am the sole author of this thesis. This is a true copy of the thesis, including any required final revisions, as accepted by my examiners.

I authorize Ryerson University to lend this thesis to other institutions or individuals for the purpose of scholarly research

I further authorize Ryerson University to reproduce this thesis by photocopying or by other means, in total or in part, at the request of other institutions or individuals for the purpose of scholarly research.

I understand that my thesis may be made electronically available to the public. 


\title{
Finite Element Modelling of the Fire Resistance of Double Skin Composite Walls Subjected to Monotonic Compressive Loading
}

Mohamed Yanis Bournas, 2018

Master of Applied Science

Civil Engineering

Ryerson University

\begin{abstract}
The fire resistance of double skin composite wall (DSCW) system composed of two profiled steel sheets and concrete infill is investigated through use of finite element (FE) methods. The fire resistance of DSCW when exposed to elevated temperature and a constant axial compressive load with different infill materials such as self-consolidating concrete (SCC), engineered cementitious concrete (ECC) and ultra-high performance concrete (UHPC) is investigated. The influence of parameters such as load level, thickness of steel sheets, depth of concrete core and fastener arrangement on the fire resistance of the DSCW are established. The performance of SCC-based DSCW has the best fire resistance followed by ECC and UHPC-based composite walls. The increase in load level decreases the fire resistance while the increase in depth of concrete infill increases the fire resistance of the composite wall. The fastener arrangement and steel thickness have no significant influence on the resulting fire resistance.
\end{abstract}




\section{ACKNOWLEDGMENTS}

I would like to extend my sincere appreciation to my supervising professor, Dr. Khandaker M. Anwar Hossain, for his valuable comments that helped me improve and finish my thesis. I truly believe that this thesis is fully based on Dr. Hossain's image. If I can take one positive from my time with Dr. Hossain it would be the ability to seek perfection in all aspects of work.

I would also like to extend my thanks to Dr. Hesham Marzouk and Dr. Arnold Yuan for agreeing to be part of my examination committee and for providing me with comments to improve my thesis.

I would like to thank my parents for their unconditional support, both moral and financial without which it would have been very difficult to complete my master of applied science (MASc.) program. I am deeply and forever indebted to my parents for their love, encouragement and supports throughout my entire life.

Throughout my endeavours in seeking an MASc., I did experience disappointment, negativity and various difficulties on an educational point of view. It is through such difficulties that I was able to learn more about myself. Although facing difficulties and surrounded by negativity with only a glimmer of positivity, it was essential to maintain positivity as I believe that surrendering to the negative environment would have been an easy way to give up. Thank you Almighty God for everything, for giving me strength and health while doing my MASc. and for guiding me in completing my thesis as well as answering my supplications.

Finally, I would like to thank Dr. Shahryar Rafiei for giving me insight in preforming finite element analysis using Abaqus®. Although little time was spent together, the provided models were of great help in a time where I was struggling. 


\section{TABLE OF CONTENTS}

AUTHOR'S DECLARATION FOR ELECTRONIC SUBMISSION OF A THESIS .................. ii

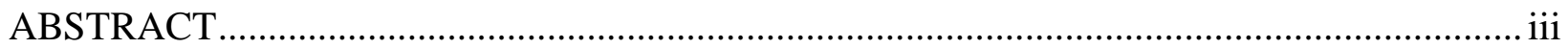

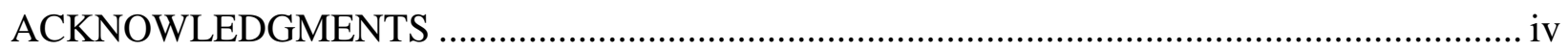

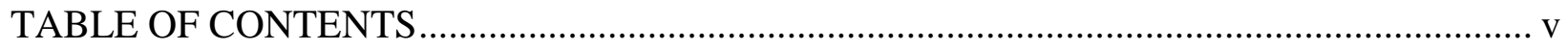

LIST OF SYMBOLS AND ABBREVIATIONS .......................................................... ix

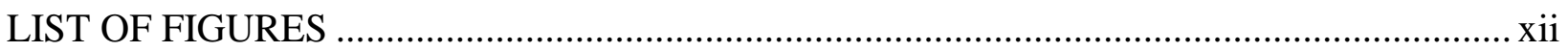

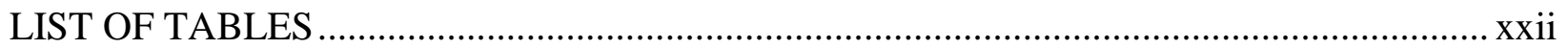

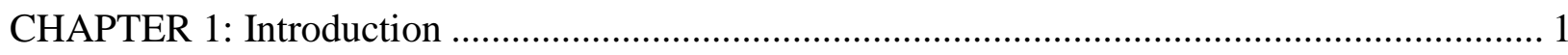

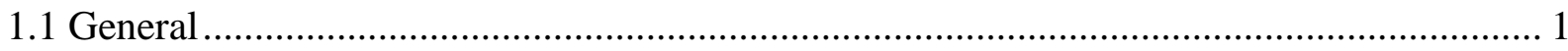

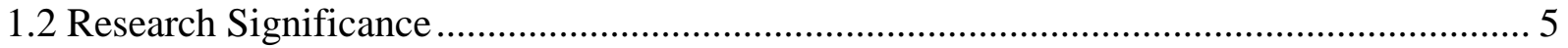

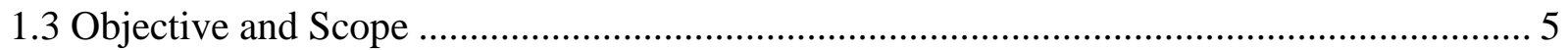

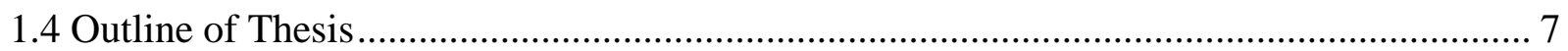

CHAPTER 2: Literature Review ...................................................................................... 9

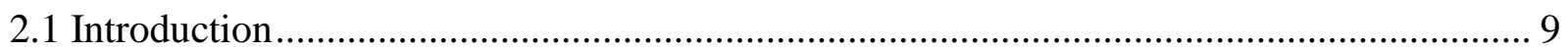

2.2 Axial Behaviour of Composite Walls .................................................................... 9

2.3 Fire Resistance of Concrete Filled Steel Tubular Columns ......................................... 19

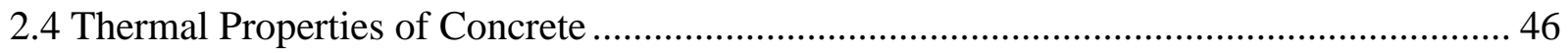

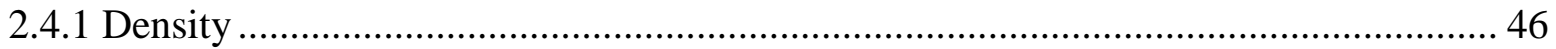

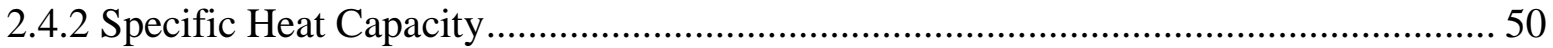

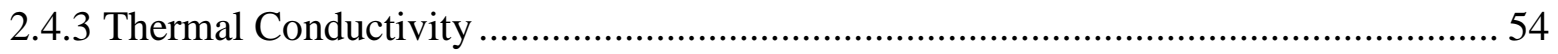

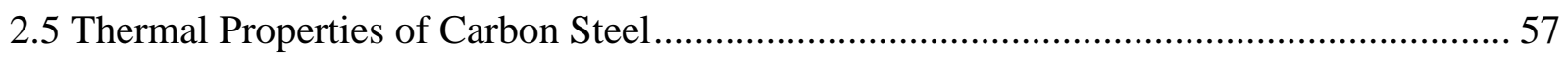

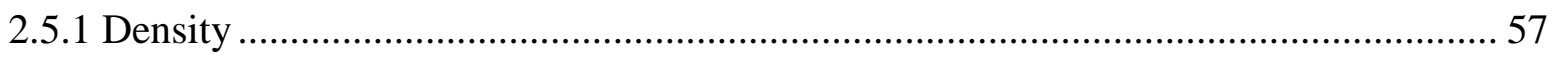

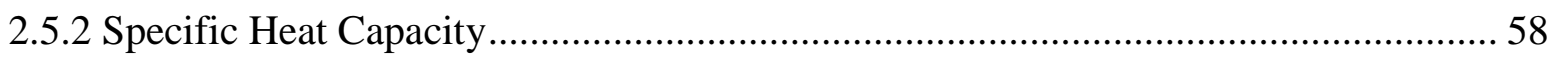




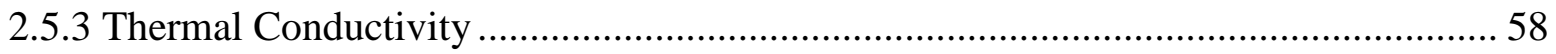

2.6 Mechanical Properties of Concrete and Steel at Elevated Temperature .............................. 58

2.6.1 Thermal Expansion Coefficients.................................................................................. 59

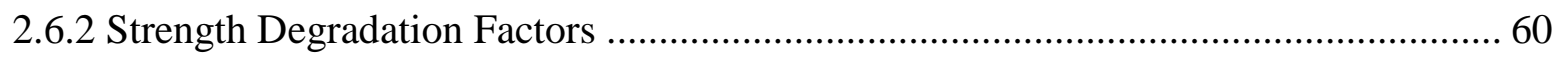

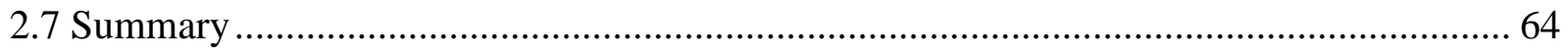

CHAPTER 3: Validation of Finite Element Modelling of the Compressive Behaviour of DSCW

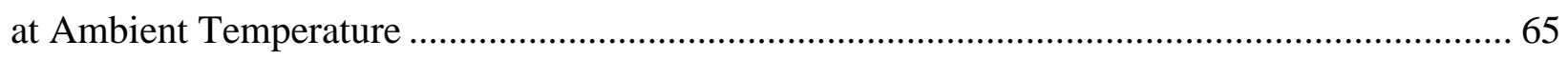

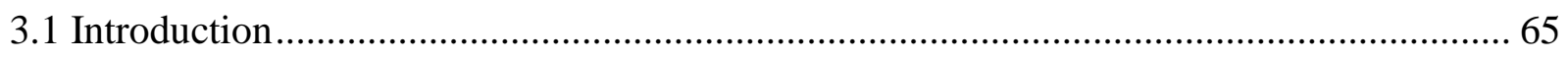

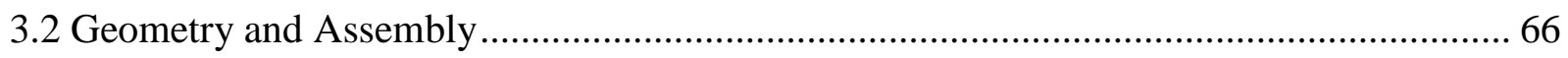

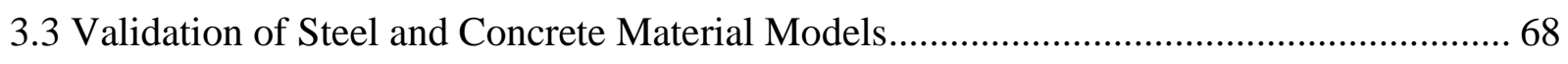

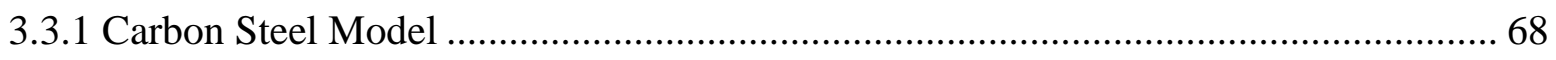

3.3.2 Validation of Carbon Steel Model ............................................................................ 71

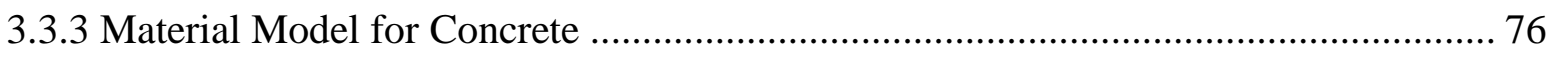

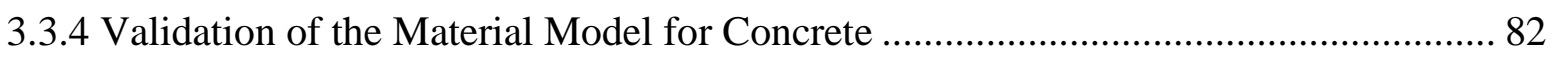

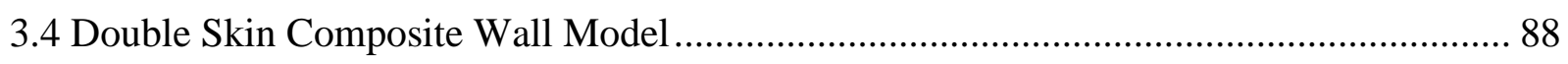

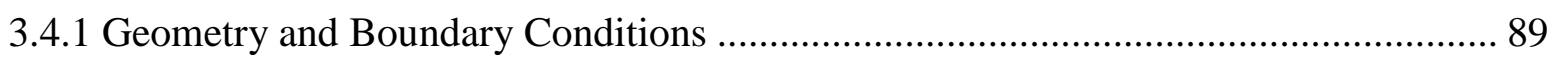

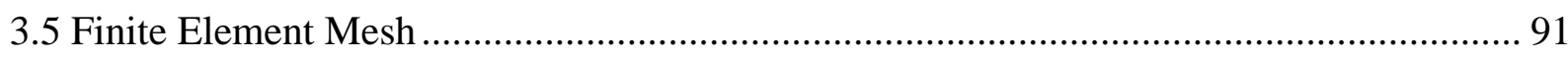

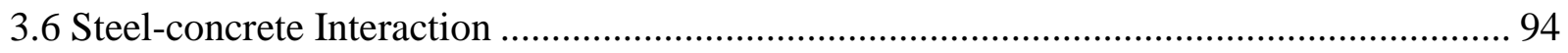

3.7 Finite Element Modelling Approach …………………................................................... 95

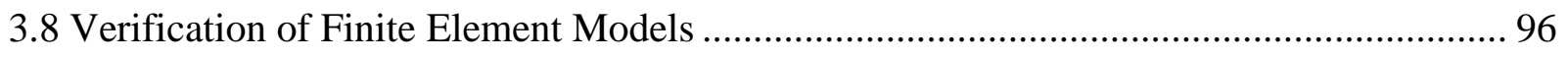

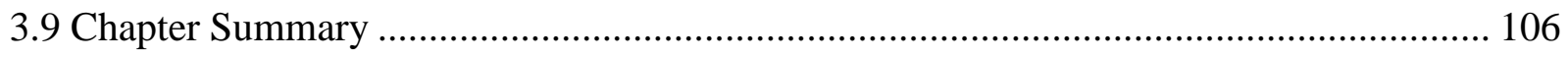

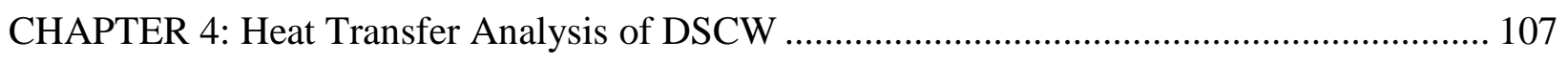

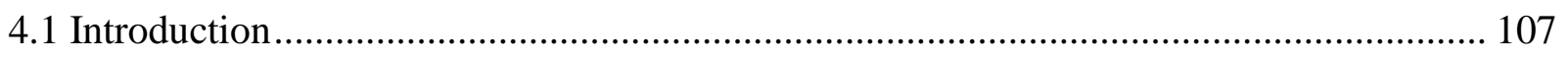

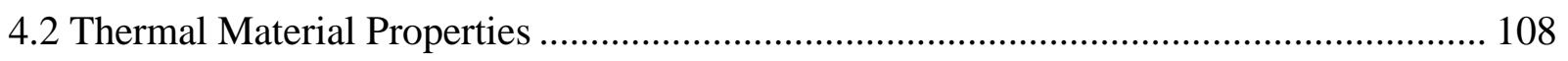

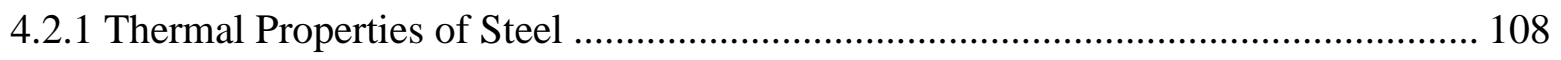


4.2.2 Thermal Properties of Concrete ………………................................................ 110

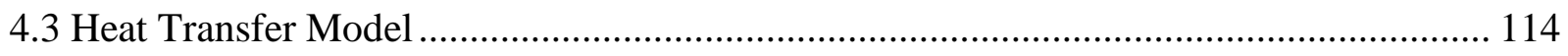

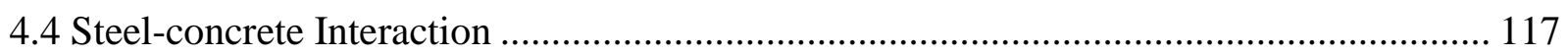

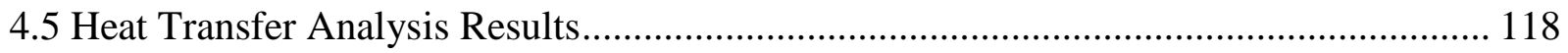

4.6 Validation of Heat Transfer Analysis ........................................................................... 123

4.7 The Effect of Cross-sectional Shape on Heat Transfer Analysis ..................................... 134

4.8 Thermal Distribution in CFST/CFDST Cross-sections ................................................ 136

4.9 Analysis and Discussion of Heat Transfer Results for DSCW Models........................... 139

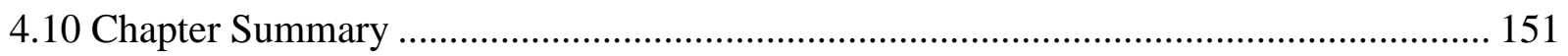

CHAPTER 5: Fire Resistance of Double Skin Composite Wall ................................................ 152

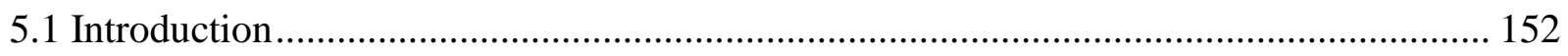

5.2 Material Model....................................................................................................... 153

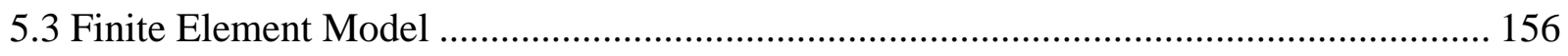

5.4 Results of the Sequentially Coupled Analysis ................................................................. 158

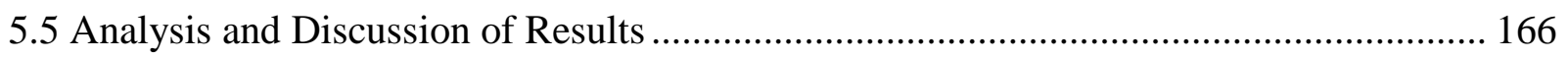

5.6 Core Temperature of DSCW Models at Failure …………………………………..... 170

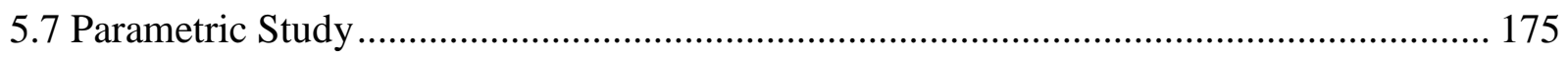

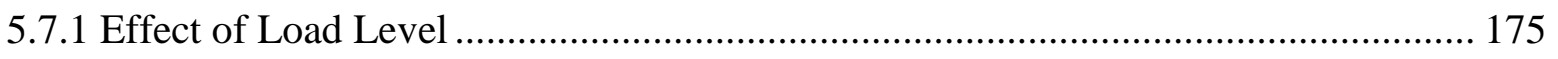

5.7.2 Effect of Thickness of Steel Sheets ...................................................................... 179

5.7.3 Effect of Varying Concrete Depth ........................................................................ 181

5.7.4 Effect of Varying Arrangement of Fasteners ........................................................... 184

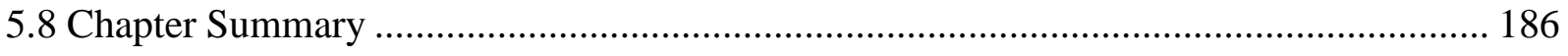

CHAPTER 6: Conclusions and Recommendations for Future Studies ...................................... 188

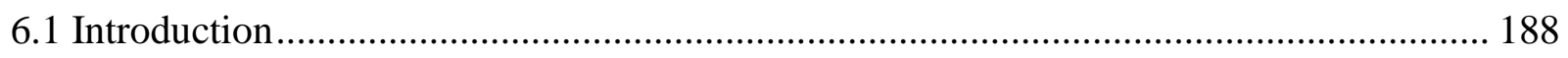

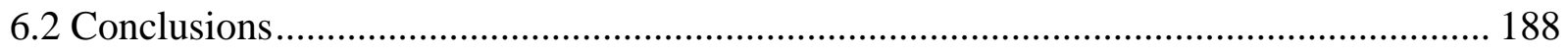


6.3 Recommendations for Future Research Studies

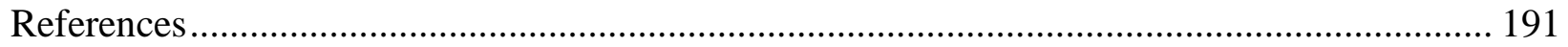




\section{LIST OF SYMBOLS AND ABBREVIATIONS}

$a, b, c$ Coefficients for parabolic curve

$A_{c} \quad$ Cross-sectional area of concrete core

$A_{s} \quad$ Cross-sectional area of steel tube/profiled sheets

$\beta: \quad$ Factor for shear retention

$b_{w} \quad$ Width of hole in wall

$C_{d} \quad$ Wave speed of material

$C_{p} \quad$ The specific heat

$d_{c} \quad$ Damage variable in compression

$d_{t} \quad$ Damage variable in tension (Figure 3.11)

$D_{o} \quad$ Outer diameter of concrete filled single/double tubular column(Figure 2.19)

$D_{i} \quad$ Inner diameter of concrete filled double tubular column (Figure 2.19)

$d_{\max }$ The maximum aggregate diameter

$d_{v} \quad$ Effective shear depth/width of the wall

$\varepsilon_{f} \quad$ Emissivity coefficient for fire

$\varepsilon_{m} \quad$ Emissivity coefficient of steel

${ }_{\varepsilon}^{p l} \quad$ Plastic strain used in Abaqus ${ }^{\circledR}$

$\varepsilon_{t h} \quad$ Thermal expansion coefficient

$E_{c} \quad$ Modulus of elasticity of concrete

$E_{S} \quad$ Modulus of elasticity of steel

$f_{c k} \quad$ Characteristic compressive strength

$f_{c m} \quad$ Mean compressive strength

$f_{c, T} \quad$ Concrete compressive strength when exposed to temperature, $\mathrm{T}$ 
$f_{t, T} \quad$ Concrete tensile strength when exposed to temperature, $\mathrm{T}$

$f_{y, T} \quad$ Steel yield strength when exposed to temperature, $\mathrm{T}$

$f_{p, T} \quad$ Proportional limit of steel when exposed to temperature, $\mathrm{T}$

$G_{F, T} \quad$ Fracture energy of concrete when exposed to temperature, $\mathrm{T}$

$h_{w} \quad$ Height of hole in wall

$K \quad$ Slope of the stress-strain curve

$k_{t} \quad$ The thermal conductivity

L Length of composite wall

$M_{i} \quad$ Instantaneous mass when exposed to temperature

$M_{0} \quad$ Mass at ambient temperature

$n \quad$ Curve fitting factor,

$N_{u, t} \quad$ Ultimate compressive strength of the composite wall when exposed to temperature, $\mathrm{T}$

$\rho_{e} \quad$ Density of the element with the largest value

$\rho_{c T} \quad$ Density of concrete when exposed to temperature, $\mathrm{T}$

$\rho_{s} \quad$ Density of steel

$Q_{h} \quad$ Heat flux

$q_{\text {radiation }}$ Radiation

$\sigma \quad$ Stefen-Boltzman constant

$\sigma_{\text {true }} \quad$ True stress used in Abaqus ${ }^{\circledR}$

$\sigma_{\text {nom }}$ Nominal/engineering stress obtained from test experiment

t Thickness of steel sheet

$t_{c} \quad$ Average uniform thickness of profiled concrete panel

$T_{f} \quad$ Temperature of fire

$T_{o} \quad$ Temperature of steel 
$t_{r} \quad$ Fire resistance time of the composite wall

$t_{s} \quad$ Thickness of steel sheet

$V_{c} \quad$ Shear resistance of profiled concrete

$V_{s} \quad$ Shear resistance of steel sheets

W Width of composite wall 


\section{LIST OF FIGURES}

Figure 1.1: Double skin composite wall in steel frame building (Rafiei, 2011)......................... 2

Figure 1.2: Axial shortening curves for CFST, concrete and hollow steel tube columns (Han et al.

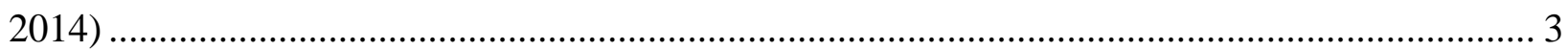

Figure 1.3: Fire resistance of a typical unfilled, filled with plain concrete and filled with reinforced concrete circular and square steel tubular column (Zhao et al. 2010) ....................... 4

Figure 2.1: Geometric measurements of the DSCW specimens (Rafiei et al. 2015).................. 10

Figure 2.2: Comparison between "tie" and "hard contact" surface interactions (Rafiei et al. 2013)

Figure 2.3: Four set of fastener arrangement investigated (Rafiei, et al. 2013) ....................... 12

Figure 2.4: Shear load vs. displacement curves for the four set of fastener arrangement with steel yield strength of a) $280 \mathrm{MPa}$ and b) $350 \mathrm{MPa}$ (Rafiei et al. 2013) ......................................... 12

Figure 2.5: Load vs. displacement curves for tested specimens (Rafiei et al. 2015)................. 14

Figure 2.6: Pierced and non-pierced concrete walls (Hossain et al. 2015) ............................. 15

Figure 2.7: Comparison of pieced and non-pierced walls (Hossain et al. 2015) ...................... 16

Figure 2.8: The effects of varying the height and width of hole on the axial load vs. deformation

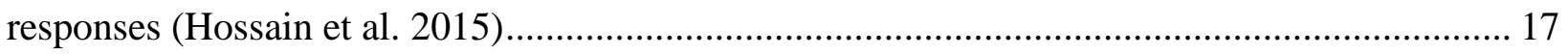

Figure 2.9: Geometry of composite wall panel (Yang et al. 2016)....................................... 18

Figure 2.10: The sets of fastener arrangements used (Yang et al. 2016)................................. 18

Figure 2.11: Load vs. displacement curves for the axial behaviour of the composite wall panels (Yang et al. 2016)

Figure 2.12: Deformation vs. time curves for the 9 tested CFT specimens (Huo et al. 2009) ..... 21

Figure 2.13: Residual compressive strength as function of temperature (Huo et al. 2009) ......... 22

Figure 2.14: Residual stiffness as a function of temperature (a, b) and axial load level (c, d) (Huo et al. 2009) ..... 23 
Figure 2.15: Types of specimen tested (Liu et al. 2010) 24

Figure 2.16: Compressive load (N) vs. strain $(\varepsilon)$ curves for circular stub columns (Liu et al. 2010) 25

Figure 2.17: Compressive load (N) vs. strain ( $(\varepsilon)$ curves for square stub columns (Liu et al. 2010) 26

Figure 2.18: Cross-section of circular CFDST column (Liang, 2017) .................................... 27

Figure 2.19: Comparison between predicted and test results (Lu et al. 2011)........................... 28

Figure 2.20: Load level vs. fire resistance (min) curves for a) circular (CHS) and b) square (SHS)

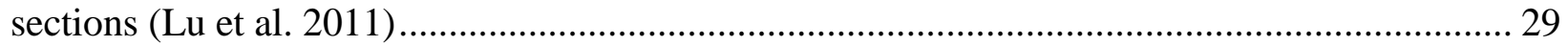

Figure 2.21: Slenderness vs. fire resistance (min) curves for a) circular and b) square sections

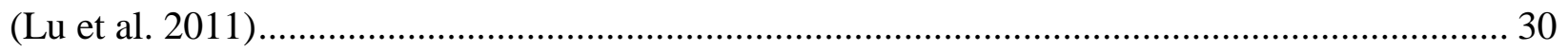

Figure 2.22: Inner steel tube capacity vs. fire resistance for circular (CHS) and square (SHS)

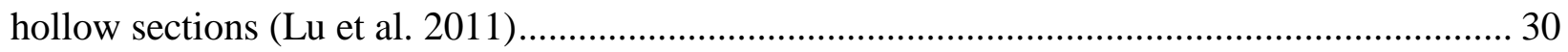

Figure 2.23: Outer steel tube capacity vs. fire resistance for circular (CHS) and square (SHS)

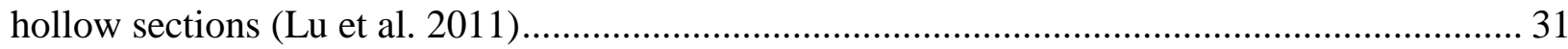

Figure 2.24: Types of cross-sections investigated (Dai et al. 2012) ........................................ 32 Figure 2.25: Fire behaviour of different types of cross-sections under Group 1 criterion (Dai et

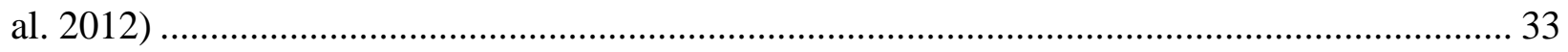

Figure 2.26: Fire behaviour of different types of cross-sections under Group 2 criterion (Dai et

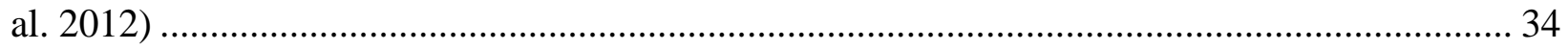

Figure 2.27: Fire behaviour of different types of cross-sections under Group 3 criterion (Dai et

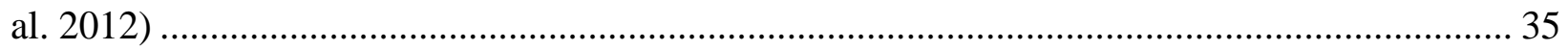

Figure 2.28: Varying steel yield strength as a function temperature (Wang and Young, 2013) .. 36 Figure 2.29: Fire resistance curves with alternating steel yield strength (Wang and Young, 2013) 37

Figure 2.30: Change in fire resistance time with respect to concrete compressive strength (Wang

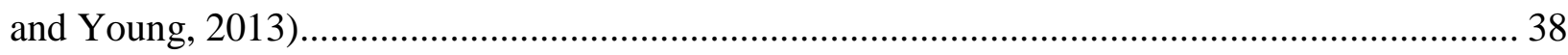


Figure 2.31: Axial displacement for carbonate and silicate based concrete mixtures (Wang and Young, 2013) 38

Figure 2.32: Influence of moisture content on the axial displacement of CFST columns (Wang

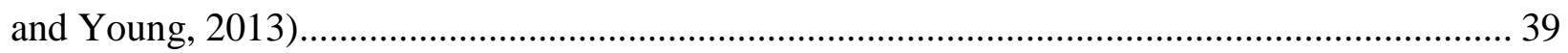

Figure 2.33: Effect of slenderness of the fire resistance of the column (Yao et al. 2016)........... 41

Figure 2.34: Effect of load ratio on the fire resistance of the column (Yao et al. 2016) ............. 41

Figure 2.35: Effect of eccentricity on the fire behaviour of CDFST columns (Yao et al. 2016) . 42

Figure 2.36: Strength of external steel tube vs. fire resistance of CFDST columns (Yao et al. 2016) 43

Figure 2.37: Strength of internal steel tube vs. fire resistance of CFDST columns (Yao et al. 2016) 44

Figure 2.38: Strength of internal steel tube vs. fire resistance of CFDST columns (Yao et al. 2016) 45

Figure 2.39: Influence of Ain/Aout on the fire resistance of CFDST columns (Yao et al. 2016) 46

Figure 2.40: Percent mass loss (\%) for ECC at elevated temperature (Şahmaran et al. 2009).... 47

Figure 2.41: Percent mass loss (\%) of SCC at elevated temperature (Taormina, 2012) ............. 48

Figure 2.42: Effect of fibre content and compressive strength on the spalling property of UHPC

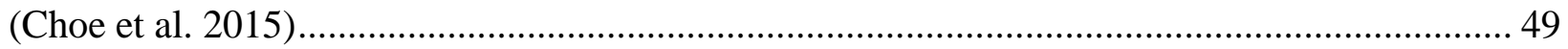

Figure 2.43: Percent mass loss (\%) of UHPC at elevated temperature (Taormina, 2012) .......... 50

Figure 2.44: Thermal conductivity of concrete at elevated temperature (Eurocode 2, 2005) ...... 56

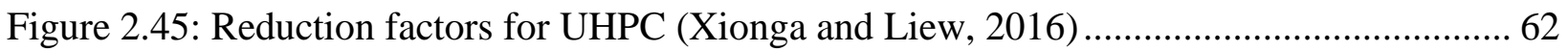

Figure 2.46: Tensile reduction factors for NSC (Eurocode 2, 2005) .......................................63

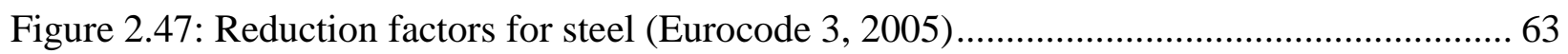

Figure 3.1: Dimensions of cross-section of profiled steel panel [mm] (Taormina, 2012).......... 67

Figure 3.2: Profile view with bolt alignment of DSCW system (Taormina, 2012).................. 67 


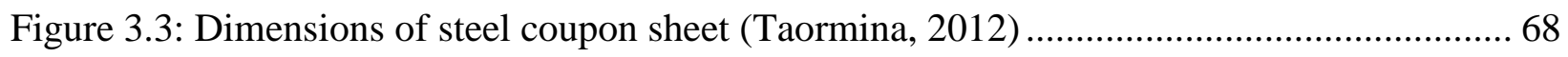

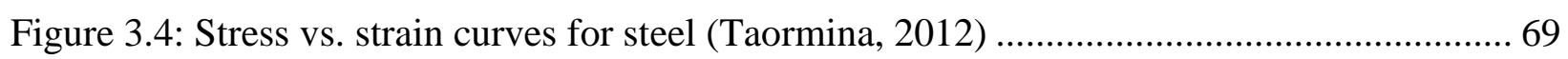

Figure 3.5: Stress vs. strain curve for carbon steel according to Eurocode 3 ........................... 70

Figure 3.6: EC3 and experimental stress vs. strain curves for steel at room temperature

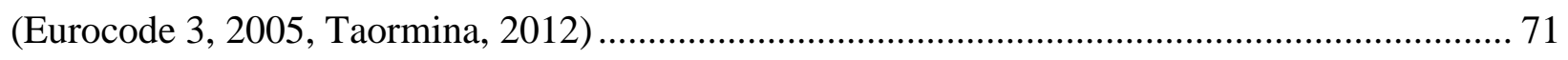

Figure 3.7: Meshing set-up for coupon sheet (a), boundary conditions of the coupon sheet (b) . 72

Figure 3.8: Stress and strain contour at a) $50 \%$ yield stress, b) yield stress and c) time analysis is

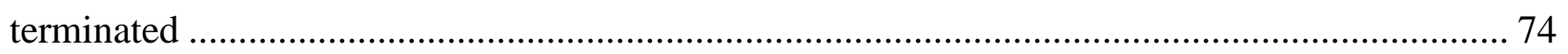

Figure 3.9: Stress vs. strain results obtained from experimental and FE simulation.................. 75

Figure 3.10: Calculation of fracture energy from tensile stress vs. cracking strain curve (Kang, et

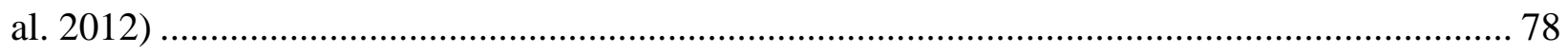

Figure 3.11: Typical uniaxial tensile curve for concrete (Rafiei, 2011) .................................. 79

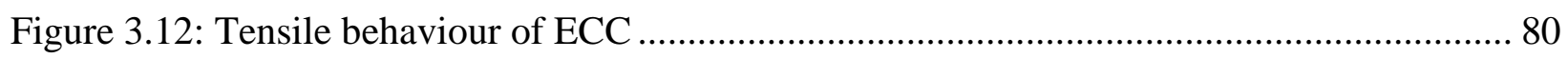

Figure 3.13: Stress vs. strain curve for SCC at ambient temperature .................................... 81

Figure 3.14: Stress vs. strain curve for ECC at ambient temperature ................................... 81

Figure 3.15: Stress vs. strain curve for UHPC at ambient temperature ................................. 82

Figure 3.16: Mesh set-up for simulated concrete cylinder .............................................. 83

Figure 3.17: Boundary conditions of concrete cylinder................................................ 83

Figure 3.18: Contours of ECC cylinder for (a) displacement along the z-direction and (b) stress

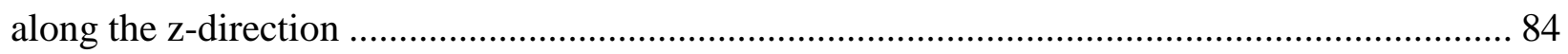

Figure 3.19: Contours of SCC cylinder for (a) displacement along the z-direction and (b) stress

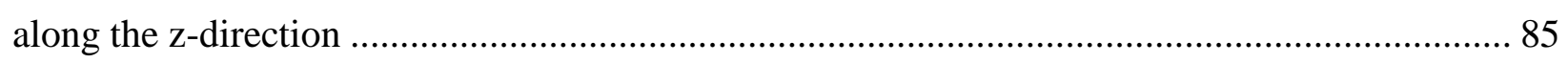

Figure 3.20: Contours of UHPC cylinder for (a) displacement along the z-direction and (b) stress

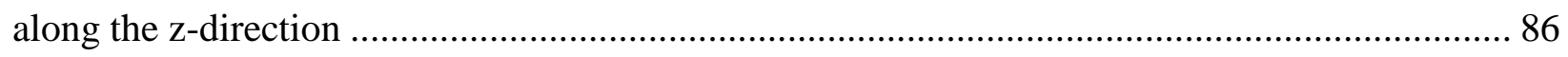

Figure 3.21: Stress vs. strain results obtained from experimental, FE simulation and predicted

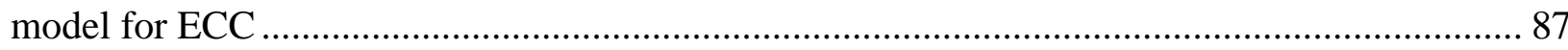


Figure 3.22: Stress vs. strain results obtained from experimental, FE simulation and predicted model for SCC 87

Figure 3.23: Stress vs. strain results obtained from experimental, FE simulation and predicted model for UHPC 88

Figure 3.24: Sketch of the components of the composite wall ............................................. 89

Figure 3.25: Boundary conditions and coupling of assembled model................................... 91

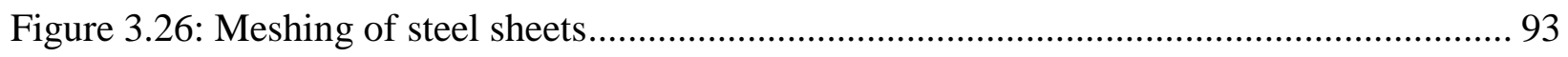

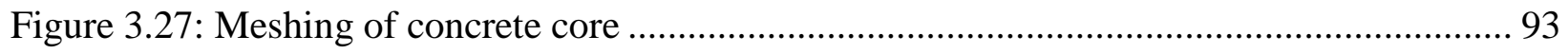

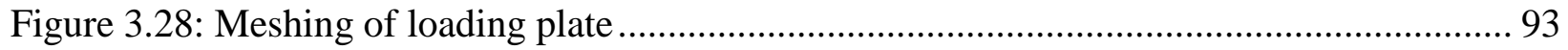

Figure 3.29: Axial load vs. deflection curve for SCC composite wall ................................... 96

Figure 3.30: Axial load vs. deflection curve for ECC composite wall .................................. 97

Figure 3.31: Axial load vs. deflection curve for UHPC composite wall ................................ 97

Figure 3.32: The contours for stress and strain in the y-direction at load level of (a) $204 \mathrm{kN}$ (b)

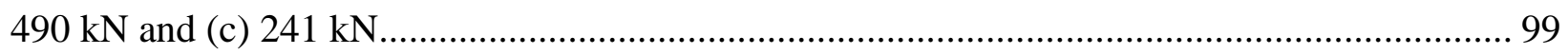

Figure 3.33: The contours for deformation after (a) $2 \mathrm{~mm}$ and (b) $4 \mathrm{~mm}$ of applied displacement

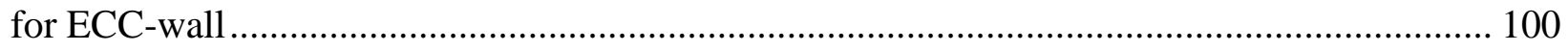

Figure 3.34: Experimental and FE failure shape for ECC-wall ....................................... 100

Figure 3.35: The contours for stress and strain in the y-direction at applied load of (a) $195 \mathrm{kN}$ (b)

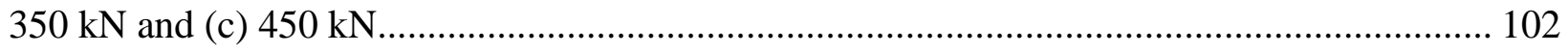

Figure 3.36: Experimental and FE failure shape for SCC-wall ....................................... 103

Figure 3.37: The contours for stress and strain in the y-direction at applied load of (a) $377 \mathrm{kN}$ (b)

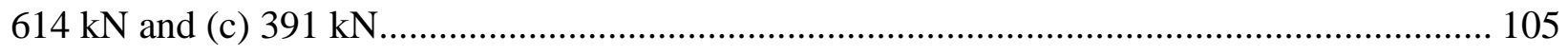

Figure 3.38: Experimental and FE failure shape for UHPC wall ...................................... 106

Figure 4.1: Thermal conductivity of steel (Eurocode 4, 2005) ........................................... 109

Figure 4.2: Specific heat of steel (Eurocode 3, 2005)..................................................... 109

Figure 4.3: Percent (\%) mass loss vs. temperature curves for ECC, SCC and UHPC ............. 111 
Figure 4.4: Thermal expansion vs. temperautre curves

Figure 4.5: Thermal conductivity vs. temeprature curves

Figure 4.6: Specific heat vs. temperature curves ..

Figure 4.7: Assembled model for heat transfer analysis

Figure 4.8: Meshing setup for concrete core 116

Figure 4.9: Meshing setup for steel sheets 116

Figure 4.10: Thermal contact conductance along the contact interface (Tao et al. 2013) ........... 118

Figure 4.11: Desired points for temperature vs. time curves .................................................. 119

Figure 4.12: Temperature curves used in heat transfer analysis.

Figure 4.13: Temperature in SCC specimen when subjected to a) fire temperature, b) $800^{\circ} \mathrm{C}$ temperature curve, c) $600^{\circ} \mathrm{C}$ temperature curve d) $400^{\circ} \mathrm{C}$ temperature curve and e) $200^{\circ} \mathrm{C}$ temperature curve. 120

Figure 4.14: Temperature in UHPC specimen when subjected to a) fire temperature, b) $800^{\circ} \mathrm{C}$ temperature curve, c) $600^{\circ} \mathrm{C}$ temperature curve, d) $400^{\circ} \mathrm{C}$ temperature curve and e) $200^{\circ} \mathrm{C}$ temperature curve.

Figure 4.15: Temperature in ECC specimen when subjected to a) fire temperature, b) $800^{\circ} \mathrm{C}$ temperature curve, c) $600^{\circ} \mathrm{C}$ temperature curve, d) $400^{\circ} \mathrm{C}$ temperature curve and e) $200^{\circ} \mathrm{C}$ temperature curve.

Figure 4.16: Meshing for NSC specimen with diameter of $159 \mathrm{~mm}$ and steel thickness of $6 \mathrm{~mm}$ 124

Figure 4.17: Meshing for NSC specimen with width of $200 \mathrm{~mm}$ and steel thickness of $5 \mathrm{~mm}$. 125 Figure 4.18: Meshing for UHPC specimen with outer diameter of $219.1 \mathrm{~mm}$ and steel thickness of $16 \mathrm{~mm}$ 125

Figure 4.19: Meshing for UHPC specimen with outer width of $200 \mathrm{~mm}$ and steel thickness of 12 $\mathrm{mm}$ 125 
Figure 4.20: Comparison between predicted and experimental results for heat transfer of SCCbased CFST

Figure 4.21: Comparison between predicted and experimental results for heat transfer of UHPCbased CFST... 130

Figure 4.22: Comparison between predicted and experimental results for heat transfer of NSCbased CFST 132

Figure 4.23: Temperature profile $\left({ }^{\circ} \mathrm{C}\right)$ for circular and square sections 135

Figure 4.24: Temperature profile $\left({ }^{\circ} \mathrm{C}\right)$ for double circular and square sections 135

Figure 4.25: Temperature profile $\left({ }^{\circ} \mathrm{C}\right.$ ) for NSC-SC-273.1 at time period of (a) 60 min and (b) $120 \mathrm{~min}$ 136

Figure 4.26: Temperature profile $\left({ }^{\circ} \mathrm{C}\right)$ for SCC-DC-219.1/101.6 at time period of (a) 60 min and (b) $120 \mathrm{~min}$. 137

Figure 4.27: Temperature profile $\left({ }^{\circ} \mathrm{C}\right)$ for NSC-SS-250 at time period of (a) $60 \mathrm{~min}$ and (b) 120 $\min$ 137

Figure 4.28: Temperature profile $\left({ }^{\circ} \mathrm{C}\right)$ for SCC-DS-150/90 at time period of (a) 60 min and (b) $120 \mathrm{~min}$ 138

Figure 4.29: Temperature profile $\left({ }^{\circ} \mathrm{C}\right)$ for UHPC-SC-219.1 at time period of (a) 60 min and (b) $120 \mathrm{~min}$ 138

Figure 4.30: Temperature profile $\left({ }^{\circ} \mathrm{C}\right)$ for SCC composite wall after fire exposure time of a) 10 min, b) $30 \mathrm{~min}$, c) $60 \mathrm{~min}$ and d) $120 \mathrm{~min}$. 140

Figure 4.31: Temperature profile $\left({ }^{\circ} \mathrm{C}\right)$ for UHPC composite wall after fire exposure time of a) 10 min, b) $30 \mathrm{~min}$, c) $60 \mathrm{~min}$ and d) $120 \mathrm{~min}$. 141

Figure 4.32: Temperature profile $\left({ }^{\circ} \mathrm{C}\right)$ for ECC composite wall after fire exposure time of a) 10 min, b) $30 \mathrm{~min}$, c) $60 \mathrm{~min}$ and d) $120 \mathrm{~min}$. 142

Figure 4.33: Heat flux $\left[\mathrm{W} / \mathrm{m}^{2} \mathrm{~K}\right]$ vs. time $[\mathrm{hr}]$ for SCC composite wall 143

Figure 4.34: Heat flux [W/m²K] vs. time [hr] for UHPC composite wall 143 
Figure 4.35: Heat flux $\left[\mathrm{W} / \mathrm{m}^{2} \mathrm{~K}\right]$ vs. time $[\mathrm{hr}]$ for ECC composite wall 144

Figure 4.36: Heat flux contours for SCC composite wall after fire exposure time of a) $10 \mathrm{~min}, \mathrm{~b}$ ) $30 \mathrm{~min}, \mathrm{c}) 60 \mathrm{~min}$ and d) $120 \mathrm{~min}$. 145

Figure 4.37: Heat flux contours for UHPC composite wall after fire exposure time of a) $10 \mathrm{~min}$, b) $30 \mathrm{~min}$, c) $60 \mathrm{~min}$ and d) $120 \mathrm{~min}$ 146

Figure 4.38: Heat flux contours for ECC composite wall after fire exposure time of a) $10 \mathrm{~min}, \mathrm{~b}$ ) $30 \mathrm{~min}, \mathrm{c}) 60 \mathrm{~min}$ and d) $120 \mathrm{~min}$. 147

Figure 4.39: Areas of high heat flux occurring on $45^{\circ}$ diagonals in CFST 149

Figure 4.40: Time at which core temperature reaches surface temperature 151

Figure 5.1: Stress vs. strain curves for carbon steel at elevated temperatures. 153

Figure 5.2: Stress vs. strain curves for SCC at elevated temperatures 154

Figure 5.3: Stress vs. strain curves for ECC at elevated temperatures 154

Figure 5.4: Stress vs. strain curves for UHPC at elevated temperatures 155

Figure 5.5: Tensile stress vs. strain curves for ECC at elevated temperatures (Eurocode 2, 2005) 156

Figure 5.6: Axial deformation as a function of exposure time for SCC composite wall 158

Figure 5.7: Axial deformation as a function of exposure time for UHPC composite wall........ 159

Figure 5.8: Axial deformation as a function of exposure time for ECC composite wall 159

Figure 5.9: Stress (S22, Pa) and deformation (U, m) contours for ECC composite wall at a) 60 min and b) $120 \mathrm{~min}$ of exposure to $400^{\circ} \mathrm{C}$ temp. curve 161

Figure 5.10: Stress (S22, Pa) and deformation (U, m) contours for ECC composite wall at 24 min of exposure to ISO-834 fire temp. curve 162

Figure 5.11: Stress (S22, Pa) and deformation (U, m) contours for SCC composite wall at a) 60 min and b) $120 \mathrm{~min}$ of exposure to $400^{\circ} \mathrm{C}$ temp. curve 163 Figure 5.12: Stress (S22, Pa) and deformation (U, m) contours for SCC composite wall at a) 18 min and b) 42 min of exposure to ISO-834 fire temp. curve. 164 
Figure 5.13: Stress (S22, Pa) and deformation (U, m) contours for UHPC composite wall at a) 60 min and b) $120 \mathrm{~min}$ of exposure to $400^{\circ} \mathrm{C}$ temp. curve 165

Figure 5.14: Stress (S22, Pa) and deformation (U, m) contours for UHPC composite wall at (a) $60 \mathrm{~min}$ and b) $120 \mathrm{~min}$ of exposure to $400^{\circ} \mathrm{C}$ temp. curve .................................................... 166

Figure 5.15: Axial deformation vs. time response for category 1 ............................................. 167

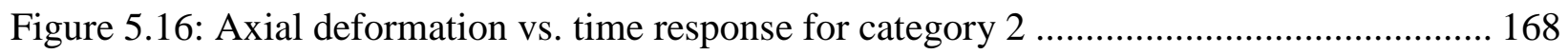

Figure 5.17: Axial deformation vs. time response for category 3 ............................................ 169

Figure 5.18: Typical axial deformation response for CFST columns (Ghannam, 2015) ........... 170

Figure 5.19: Temperature distribution at core for ECC, SCC and UHPC when exposed to ISO-

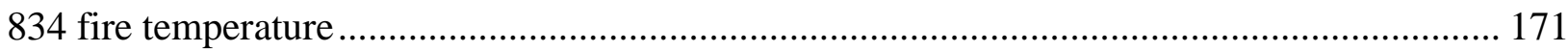

Figure 5.20: Temperature distribution at core for ECC, SCC and UHPC when exposed to $800^{\circ} \mathrm{C}$

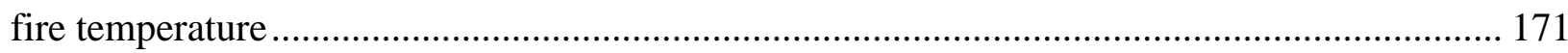

Figure 5.21: Post-fire compressive strength reduction factors for SCC, ECC and UHPC-based

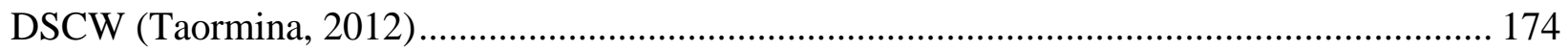

Figure 5.22: Axial deformation vs. time curves for 0.2 load level ............................................ 176

Figure 5.23: Axial deformation vs. time curves for 0.4 load level ............................................ 177

Figure 5.24: Axial deformation vs. time curves for 0.5 load level ........................................... 177

Figure 5.25: Axial deformation vs. time curves for 0.6 load level ........................................... 178

Figure 5.26: Axial deformation vs. time curves for 0.8 load level ............................................ 178

Figure 5.27: Load level vs. fire resistance time ..................................................................... 179

Figure 5.28: Fire resistance vs. steel sheet thickness.............................................................. 180

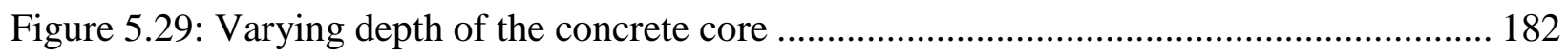

Figure 5.30: Axial deformation after varying concrete depth for ECC-based DSCW ............... 183

Figure 5.31: Axial deformation after varying concrete depth for SCC-based DSCW ............... 183

Figure 5.32: Axial deformation after varying concrete depth for UHPC-based DSCW ............ 184 
Figure 5.33: Varying fastener arrangement with the number of fasteners of (a) 30, (b) 54 and (c)

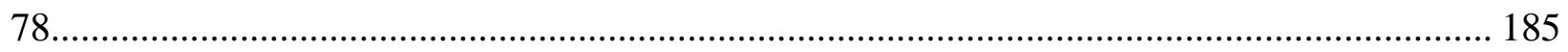

Figure 5.34: Relationship of fire resistance with varying fastener arrangement .................... 186 


\section{LIST OF TABLES}

Table 2.1: Summary for dimensions of cross-sections (Dai et al. 2012) ................................... 32

Table 2.2: Specifications of SCC as proposed by JSCE (JSCE, 1998) ................................... 53

Table 3.1: Equations for stress according to EC3 ........................................................... 70

Table 3.2: Number, type and approximate size of elements used ........................................ 72

Table 3.3: Elastic and plastic properties of steel............................................................ 73

Table 3.4: Material properties for ECC, SCC and UHPC (Taormina, 2012) .......................... 76

Table 3.5: Parameters for CDP model ................................................................................ 77

Table 3.6: Equation for tensile strength and fracture energy for alternative concrete types ........ 78

Table 3.7: Number, type and approximate size of elements used ........................................ 83

Table 3.8: Summary of number and type of elements ................................................. 94

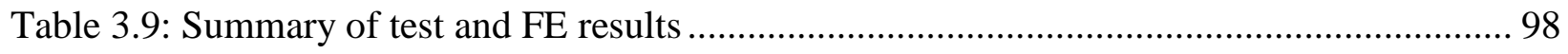

Table 4.1: Density of concrete at elevated temperature ................................................... 111

Table 4.2: Summary of number and type of elements ................................................. 116

Table 4.3: Summury of test data for CFST columns ................................................... 126

Table 4.4: Summury of element size for all generated FE models ...................................... 127

Table 4.5: Surface temperature at 60 and $120 \mathrm{~min}$ for selected CFST/CFDST specimen ......... 139

Table 5.1: Summary of predicted values for fire resistance ............................................ 160

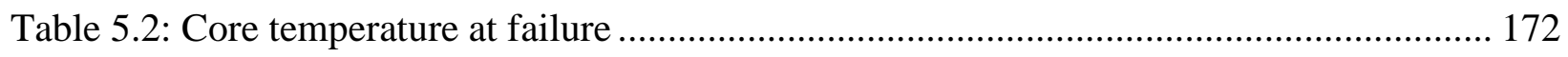

Table 5.3: Summary of applied load level with resulting fire resistance $\left(\mathrm{t}_{\mathrm{r}}\right) \ldots \ldots \ldots \ldots \ldots \ldots \ldots \ldots \ldots . . . \ldots \ldots$

Table 5.4: Summary of applied load level with resulting fire resistance $\left(t_{r}\right)$ and alternating steel

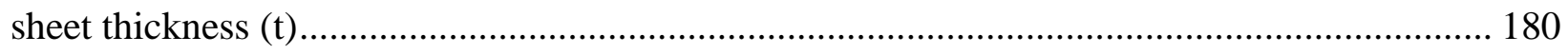

Table 5.5: Summary of fire resistance $\left(\mathrm{t}_{\mathrm{r}}\right)$ results when varying depth .............................. 184 


\section{CHAPTER 1: Introduction}

\subsection{General}

Double skin composite walls (DSCWs) are widely used in the construction of high rise buildings due to their ability to withstand lateral and axial loads (Bruneau et al. 2016; Ding et al. 2011; Hossain et al. 2015; Ji et al. 2017). The DSCW system comprising of a concrete core sandwiched between two profiled steel sheets were proposed and investigated. (Hossain et al. 2015) (Figure 1.1). The use of such composite walls originated from the idea of composite flooring (Hossain et al. 2015). In fact, within a construction environment, DSCW is characterized as "fast construction" due to its advantages in workability and ease of construction when compared to conventional reinforced concrete (RC) walls (Rafiei, 2011; Wright, 1998). The use of DSCW provides increased compressive strength and lateral resistance relative to $\mathrm{RC}$ walls when subjected to axial and seismic loads, respectively (Hossain et al. 2015). The profiled steel sheets and concrete core act together in resisting the applied load. The profiled sheets provide confinement to the core, while the concrete provides support to the steel to prevent buckling (Rafiei et al. 2015). RC walls are cost effective but more susceptible to tension cracks and compression crushing due to the unconfinement of the concrete (Rafiei et al. 2015). This reduces the structural performance and durability of the structure. The ability to carry shear and in-plane axial loads renders the DSCW system as ideal shear or core wall in steel frame buildings (Figure 1.1) (Hossain et al. 2015; Wright, 1998). The use of profiled DSCW provides advantages during the construction and in-service stages by acting as formwork prior to casting concrete and as a load resisting structural component within a steel frame building (Hossain and Wright, 2004; Wright and Gallocher, 1995).

The practice of implementing the newly developed classes of concrete such as ultra-high performance concrete (UHPC), self-consolidating concrete (SCC) and engineered cementitious concrete (ECC) can improve the strength, durability and ductility of DSCW systems or structures compared to the conventional normal strength concrete (NSC) (Kodur and Khaliq, 2011; Taormina, 2012). SCC is characterized by its flowing ability, passing ability, and segregation resistance with no vibration needed to spread into places between the steel sheets or congested reinforcements (Shen et al. 2015). According to a study by Long, the compressive strength of 
SCC should be higher than that of NSC due to the low water-to-cement ratio (w/c) (Long et al. 2013). ECC is characterized as a very flowable and ductile concrete with a high durability (Şahmaran et al. 2009). This increases workability and resistance to seismic loads while maintaining longer life span of structures (Yuan et al. 2013). ECC has 300 to 500 times greater strain capacity than that of conventional concrete (Özbay et al. 2012). UHPC is a flowable concrete with compressive strength higher than $100 \mathrm{MPa}$ (Kodur and Khaliq, 2011; Taormina, 2012). Low w/c ratio and small aggregate sizes (with fineness modulus of the fine aggregate within 2.5 to 3.2 ) are contributing factors to generate such a high strength in UHPC (Khaloo et al. 2017). High strength concretes (HSCs) are widely used in the construction of high-rise buildings (Ji et al. 2017) especially in casting columns and shear walls in the lower storey levels where high compressive resistance is required.

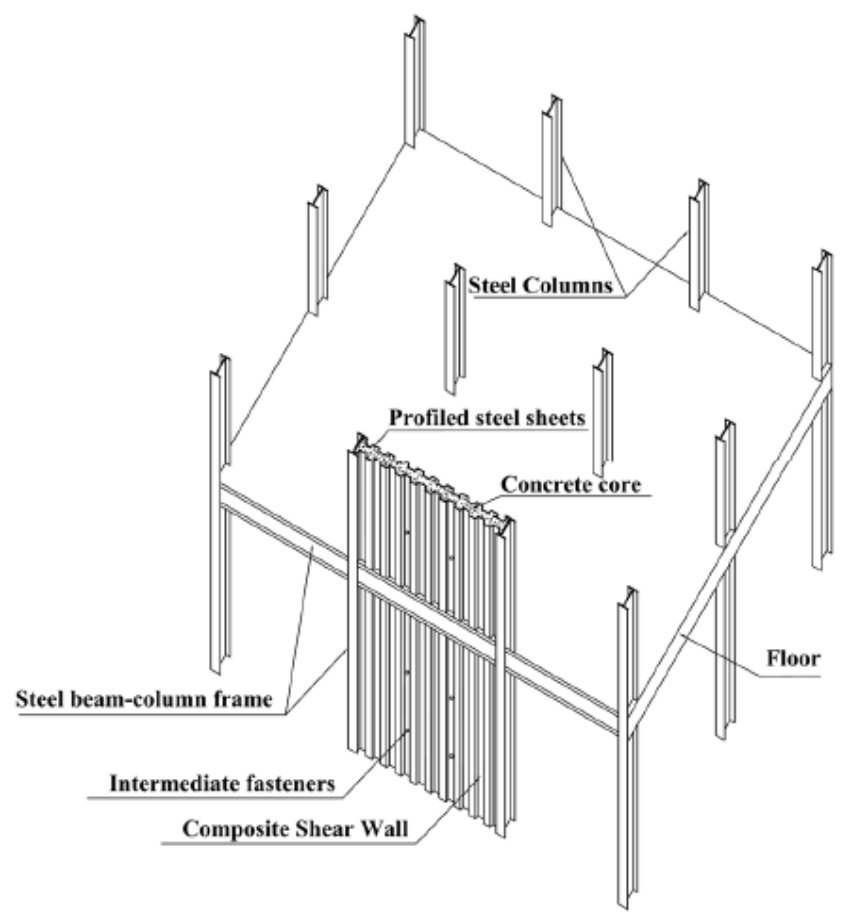

Figure 1.1: Double skin composite wall in steel frame building (Rafiei, 2011)

Studies by Kodur concluded that a change in temperature causes physical and mechanical changes within the material matrix, thus resulting in the deterioration of the mechanical and thermal properties of steel and concrete (Kodur and Khaliq, 2011). The fire resistance of the high strength concretes is different due to varying percentages of fibre reinforcement, moisture content and aggregate size (Kodur and Khaliq, 2011). ECC is characterized as a fiber reinforced 
composite and the fire resistance of such material is assumed to be similar to that of normal strength concrete (NSC) (JSCE, 2008). While extensive experimental studies were conducted on the structural behaviour of DSCW under axial and cyclic loading, very little knowledge on the fire behaviour of such wall system is available in the literature (Taormina, 2012). As such, the fire behaviour of concrete filled steel tubular (CFST) columns are used as means to validate the proposed finite element (FE) heat transfer models for DCSW used in this research as described in Chapter 4. CFST columns are composed of a concrete core confined by an outer hollow steel tube. Similar to DSCW, the steel component acts as confinement to concrete while the concrete core prevents the buckling of the hollow steel tube. The confinement of concrete increases the strength of the column as the compressive strength of confined concrete is measured to be significantly higher (Han et al. 2014). The typical axial compressive strength vs. deformation curves for hollow steel tube, concrete and CFST column are shown in Figure 1.2.

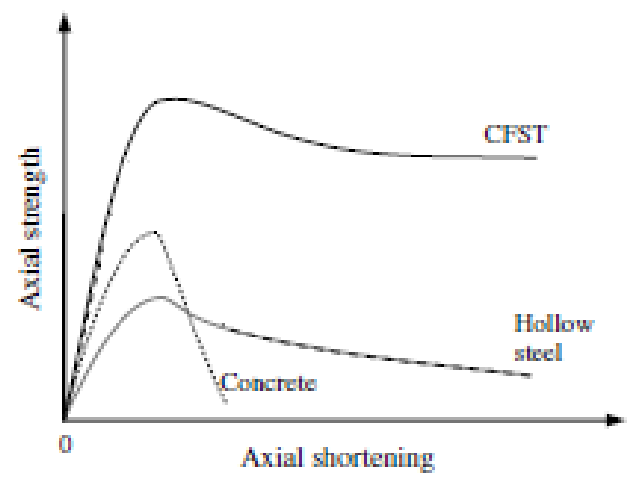

Figure 1.2: Axial shortening curves for CFST, concrete and hollow steel tube columns (Han et al. 2014)

As shown in Figure 1.2, CFST columns encompass the highest bearing capacity enabling such structural components to withstand higher compressive loads when compared to the conventional reinforced concrete columns. For construction purposes, the steel tube acts a formwork for the infill concrete neglecting the need for additional cost of formwork needed for generating concrete structures. Due to the advantages in structural behaviour and constructability, the use of CFST columns has become popular in the building of heavy civil engineering structures such as bridges and tall buildings (Ghannam, 2015). 
The presence of the concrete core in DSCW and CFST columns increases the fire resistance of such structural components. When exposed to elevated temperature, the concrete core acts as a heat sink where the applied heat energy is absorbed by the concrete (Ghannam, 2015). This is represented by having higher values of fire resistance when higher depth of concrete is present. Although the outer steel becomes directly vulnerable when exposed to elevated temperature, the confining nature of the steel acts as protection against concrete spalling which occurs at different temperatures depending on the type of concrete infill (Taormina, 2012). This prevents early collapse that would otherwise occur in reinforced concrete columns/walls. Such response to fire exposure is highlighted in Figure 1.3 (Zhao et al. 2010) where concrete filled columns have higher fire resistance values when compared to "unfilled" hollow tube columns. Figure 1.3 shows the fire resistance values for typical hollow steel tube, CFST column and reinforced concrete filled steel tube column. In Figure 1.3, "unfilled" refers to the hollow steel tube, "Filled with plain concrete" refers to a typical CFST column while "Filled with steel reinforced concrete" refers to a reinforced CFST column. The grey bars in Figure 1.3 refer to square sections while the stripped bars indicate the fire resistance of circular components.

Disadvantages associated to CFST and DSCW structural components are related the geometric constraints imposed in construction environments. For CFST, the diameter of the column is dependent on the available building/floor space as high diameters are less favourable due to the space constraints and aesthetic appeal. DSCWs are constrained based on the geometry of the steel frame of the building. In this case, the limit state design of the steel frame governs the overall depth of the wall included within the building frame.

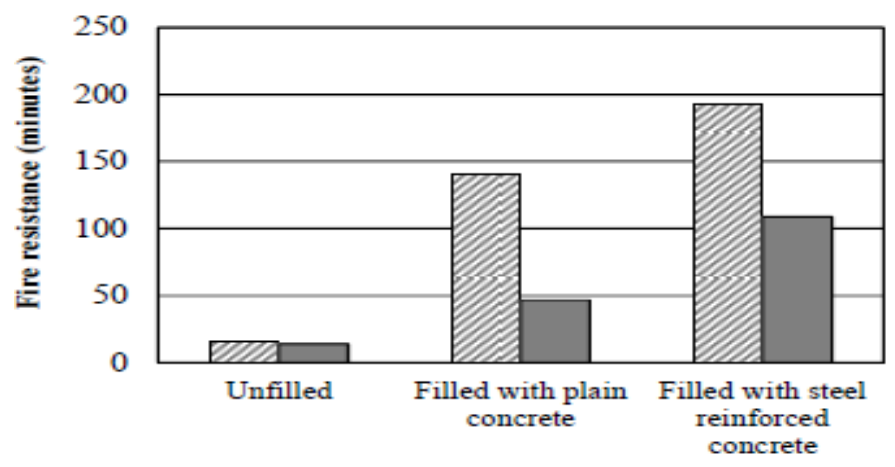

Figure 1.3: Fire resistance of a typical unfilled, filled with plain concrete and filled with reinforced concrete circular and square steel tubular column (Zhao et al. 2010) 


\subsection{Research Significance}

Structural components are subjected to various loads and hazardous events such as fire. The National Research Council of Canada (NRCC) has been developing methods to predict the fire resistance of structural components for several years (Lie, 1994). Due to the high number of fire events in recent years, especially in high-rise buildings, the design for fire safety has become an important factor in assessing preliminary designs of a given structure. Fire events cause damage in the structural stability of buildings and in some cases, such events lead loss of human life. According to the National Fire Protection Association (NFPA), there were a total of 345,500 reported fire events in the United States (US) accounting for 3,280 civilian deaths and \$14.3 billion in property damage (NFPA, 2017).

To the best of the author's knowledge, no experimental and numerical researches are currently available in the literature on the fire resistance of DSCWs under the combined effects of elevated temperature and applied load. However, post-fire residual axial load resistance of ECC/SCC/UHPC based DSCWs were studied experimentally (Taormina, 2012; Taormina and Hossain, 2013). No mathematical methods/models currently exist on predicting the fire resistance of such composite walls while subjected to combined fire and axial compressive loads. Current study focuses on determining the fire resistance of DSCWs made with various types of concrete infill (SCC/ECC/UHPC) through use of finite element (FE) methods validated through available experimental results. This will contribute immensely in understanding of the effects of material and geometric parameters (of DSCWs) and hence, will help in developing fire design specifications for practical applications.

\subsection{Objective and Scope}

The objective of the current study is to determine the behaviour of DSCW systems exposed to elevated temperature while axial concentric compressive load is maintained at a constant level throughout the exposure period. In terms of motivation, no research currently exists in the literature that defines the fire resistance of DSCWs and there is an urgent need for conducting additional research on this topic. Due to limitations in lab experiments, the application of compressive load on the DSCW specimens while exposed to different elevated temperatures for 
different durations was not possible in previous studies conducted at Ryerson University (Taormina, 2012; Taormina and Hossain, 2013). The research presented in this study is fully based on results obtained from FE modelling using Abaqus®. FE modelling simulating axial mechanical compressive loading, heat transfer and sequentially coupled thermal mechanical behaviours are conducted. In fact, the research presented in this thesis offers an extension and another dimension to the past experimental studies (Taormina (2012; Taormina and Hossain, 2013). The goal of the present study is to use FE modelling to develop fundamental understanding of the fire resistance of DSCWs made of different high performance concrete cores (SCC, ECC and UHPC) sandwiched between two profiled steel sheets. The axial deformation response with time under the combined effect of various temperatures and levels of axial compressive load is obtained to evaluate fire resistance through extensive FE study using Abaqus ${ }^{\circledR}$ software. The following tasks were performed to accomplish the stated research objective:

1. Obtain material models defining the compressive behaviour of ECC, SCC, UHPC and steel at ambient temperature (room temperature, $20^{\circ} \mathrm{C}$ ).

2. Material models defined in task 1 are validated through FE simulations of the concrete compressive crushing and steel tensile coupon tests performed by Taormina (2012). Verification of the models is performed by comparing test and FE load vs. deformation curves. Stress and deformation contours for the concrete cylinder and steel coupon at different points along the load vs. deformation curves are presented and analyzed.

3. Using the material models defined in task 1, three dimensional (3D) FE models of the DSCWs are generated with similar geometry to those tested by Taormina (2012). Validity of the FE procedure is tested against experimental load vs. deformation data of DSCWs (loaded to failure under monotonic compressive loading) obtained from Taormina (2012). Once validated, stress and deformation contours at different points along the load vs. deformation curve are portrayed and analyzed. No parametric study on the compressive behaviour of the DSCW was performed.

4. Thermal properties of ECC, SCC and UHPC when exposed to elevated temperature are defined using available models in the literature.

5. Similar to task 3, heat transfer analysis using Abaqus ${ }^{\circledR}$ is conducted for the DSCWs tested by Taormina (2012) with similar geometry and ECC/SCC/UHPC infill. 
Temperature vs. time responses for three points within the cross-section of the composite wall under the exposure of five different temperature curves are described. The thermal and heat flux isotherms at different exposure time are portrayed for ECC, SCC and UHPC-based DSCWs with explanations. No parametric studies were performed on the heat transfer behaviour of DSCWs.

6. Due to a lack of available experimental data on the heat transfer characteristics of DSCWs, the validation of the heat transfer procedure used in task 5 is assessed by generating FE heat transfer models of CFST columns (from previous research studies) with varying shapes and cross-sectional dimensions. The FE results of the CFST columns are compared with experimental data on the heat transfer of CFST columns obtained from the literature in terms of temperature vs. time curves. Thereby validating the heat transfer model presented task 5. Thermal and heat flux contours at different exposure time periods for CFST columns are also illustrated and described.

7. Strength degradation factors for steel, ECC, SCC and UHPC components due to the applied temperature are defined through use of available models obtained from the literature.

8. Nodal temperature results obtained in task 5 are uploaded into the $3 \mathrm{D}$ compressive stress model defined in task 3 to determine the fire resistance of DSCW through use of a sequentially coupled thermo-mechanical analysis with the material models for steel, ECC, SCC and UHPC defined in task 7. Fire resistance is determined through use of axial deformation vs. time curves for ECC, SCC and UHPC-based DSCWs. Stress and deformation contours for the DSCWs at different time periods are exhibited. Fire resistance response is discussed by highlighting three distinctive types in behaviour. Extensive parametric study is then conducted on the effects of various parameters such as level of axial loads, steel sheet thickness, fastener arrangement and cross-sectional shape of DSCWs on the fire resistance. The fire resistance of DSCWs are then discussed based on the influence of these parameters and concrete types.

\subsection{Outline of Thesis}

This thesis is composed of six chapters. A summary of each of the chapters is presented below: 
Chapter 1: The structural components (DSCW and CFST) whose fire resistance is investigated in this thesis are introduced. The significance of the research is described followed by objective and scope introducing various tasks.

Chapter 2: An extensive literature review on experimental and FE studies on the fire resistance of CFST columns is included in this chapter. The fire behaviour of typical CFST columns is analysed by comparing experimental and FE results from different research papers. Shear and axial load behaviour of DSCW are also investigated from available research papers. Several FE models on the thermal and compressive behaviour of ECC, SCC, UHPC and carbon steel materials that have potential to be used in this thesis are determined.

Chapter 3: This chapter includes a summary of past experimental tests conducted. Relevant results and findings of the conducted experiments on the axial compressive load behaviour of DSCW are summarized in this chapter. This includes the definition of important 3D stress properties for steel, ECC, SCC and UHPC when axially loaded to failure. This is followed by a 3D stress FE model performed to determine the axial compressive response of the DSCWs tested in previous research study. The validity of the 3D stress model is then described based on a comparative study between the obtained FE and experimental results.

Chapter 4: Heat transfer analysis of the DSCW specimens studied in previous research when subjected to various temperature curves is included in this chapter. Verification process is performed through use of available heat transfer database obtained from the literature on concrete filled steel tubular (CFST) columns.

Chapter 5: The process to conduct a sequentially coupled thermo-mechanical analysis is summarized in this chapter. This chapter combines the validated heat transfer (Chapter 4) and 3D stress (Chapter 3) FE models to determine the fire resistance of DSCW specimens. FE models for the fire resistance of DSCW are generated and discussion of results is presented along with an extensive parametric study. The effects of parameters such as load level, steel profile thickness, steel-concrete fastener arrangement and cross-sectional shape on the fire resistance of DSCW are summarized in the form of design curves.

Chapter 6: Conclusion, summary of results and findings are presented with suggestions for future works. 


\section{CHAPTER 2: Literature Review}

\subsection{Introduction}

This chapter summarizes results and findings of finite element (FE) and experimental analyses of past studies relevant to the research conducted in this thesis. Brief discussions on the results of experimental tests on the axial load behaviour of various types of composite walls including double skin composite wall (DSCW) are included. This is followed by a discussion on experimental and finite element (FE) studies on the fire resistance of concrete filled steel tubular (CFST) columns. Experimental tests on the mechanical and thermal properties of engineered cementitious concrete (ECC), ultrahigh performance concrete (UHPC), self-consolidating concrete (SCC), normal strength concrete (NSC) and carbon steel relevant to current research topic are included in this chapter.

\subsection{Axial Behaviour of Composite Walls}

A research on the shear behaviour of double skin composite wall (DSCW) followed by a development of FE models was conducted by Rafiei et al. (2013). FE models of the tested composite walls were generated to examine additional parameters influencing the shear behaviour of the wall in question. A total of three double skin composite walls with similar geometrical parameters (length of $1626 \mathrm{~mm}$ and width of $720 \mathrm{~mm}$ ) were investigated. The shear behaviour of three test specimens referred to as DSCW-1, DSCW-3 and DSCW-5 composed of various types of concrete and steel materials was determined through the application of a displacement along the top left corner on the wall as shown in Figure 2.1. The DSCW-1 wall specimen was composed of self-consolidating concrete (SCC) with compressive strength, tensile strength and modulus of elasticity of 51.9, 4.9 and 30,670 MPa, respectively. The profiled sheets were composed of high strength steel with yield strength and modulus of elasticity values of 552 and 202,940 MPa, respectively. Similar material properties were used for test specimens DSCW3 and DSCW-5. Shear load vs. displacement curves obtained from experiments were used as means to validate the proposed FE model. Good agreement was observed when compared to test results thus validating the proposed FE model. Upon validation, the effects of steel-concrete 
interaction model and arrangement of intermediate fasteners on the shear resistance of the composite walls were determined.

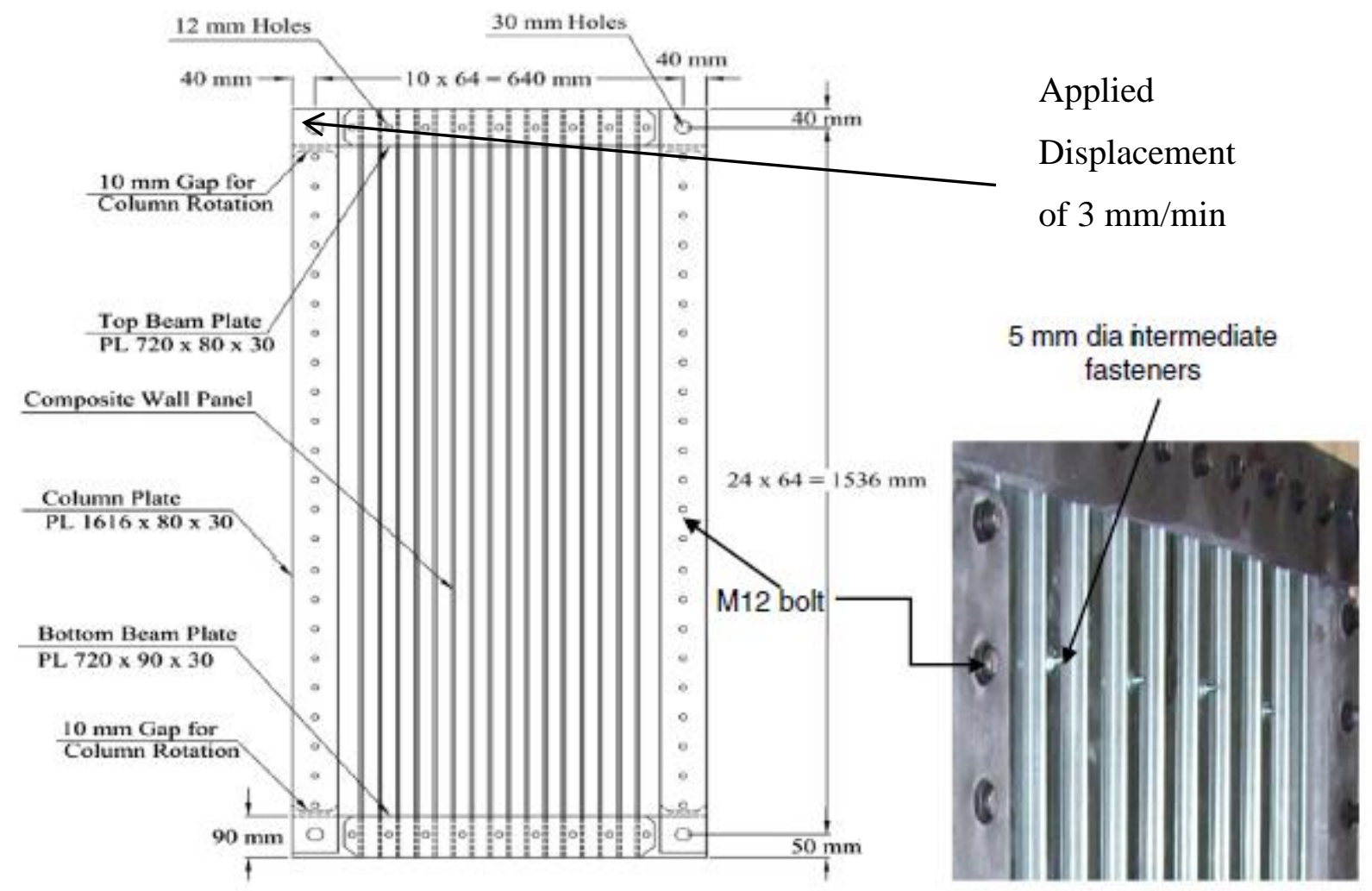

Figure 2.1: Geometric measurements of the DSCW specimens (Rafiei et al. 2015)

A parametric study on the use of the appropriate modelling definition for the interaction existing between the steel and concrete core was performed in the research by Rafiei et al. (2013). In this case, the use "hard contact" and with no tangential friction was compared with the built-in tie constraint used in Abaqus ${ }^{\circledR}$ software. FE results obtained from each simulation were compared with the load vs. deformation curves obtained from tests. It was observed that the use of "hard contact" for definition of normal behaviour offered better and more accurate FE results. Figure 2.2 presents a comparison of the load vs. deflection curves for the DSCW-1 specimen with each of the three cases, where the "blue", "red" and "green" plot lines refer to the experimental results, FE with "hard contact" definition and FE with tie constraint definition respectively. 


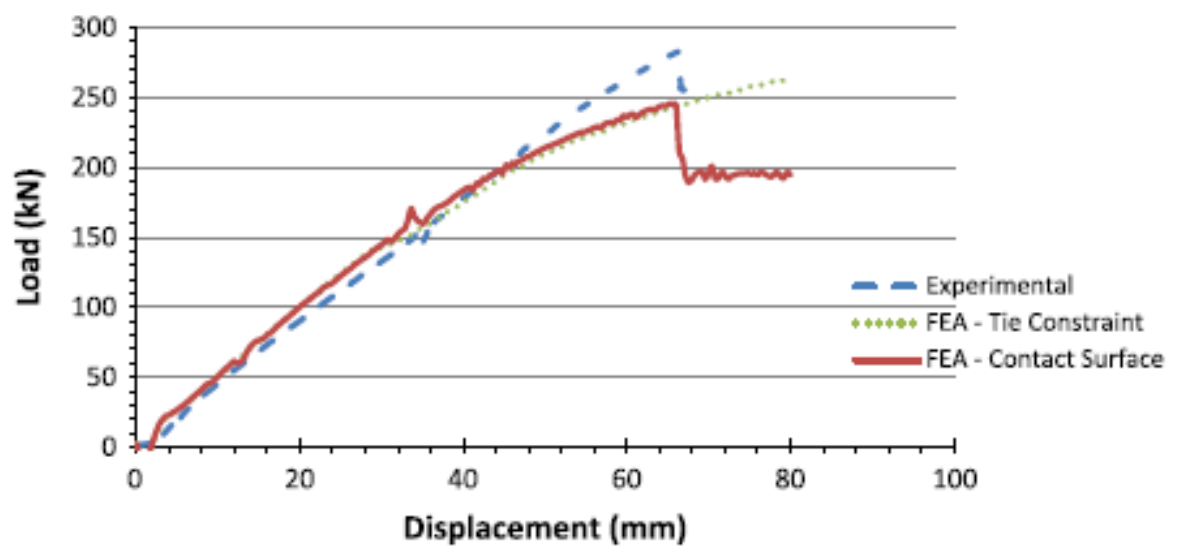

Figure 2.2: Comparison between "tie" and "hard contact" surface interactions (Rafiei et al. 2013) The use of "hard contact" to define the interaction between the steel and concrete resulted in more accurate values in ultimate shear capacity of the tested wall specimen. In fact, the ratio of experimental to predicted ultimate shear load for DSCW-1, DSCW-3 and DSCW-5 were calculated to be 1.01, 1.14 and 1.18, respectively (Rafiei et al. 2013).

The effect of varying the arrangement of fasteners along the composite wall profile under the application of shear loading was also investigated by Rafiei et al. (2013). A total of four different arrangements were considered and compared relative to the load vs. deflection curve resulting from each simulation. Figure 2.3 shows the alternative arrangement of fasteners considered in the study by Rafiei et al. (2013). Prototype "a" was considered to determine the effect of using no fasteners on the double skin composite wall. Prototypes "b", "c" and "d" were generated to determine the effect of increasing the number of fasteners from 20 to 207.

It was observed that the shear response of the composite wall with no intermediate fasteners was mainly related to the compressive strength of concrete while the steel component had minimal effect on shear resistance (Rafiei et al. 2013). On the other hand, an increase in shear capacity was noted for other simulations where increased number of fasteners was included. In this case, the highest ultimate shear load of $158 \mathrm{kN}$ for steel yield strength of $280 \mathrm{MPa}$ was observed for the simulation that included the highest number of fasteners (Rafiei et al. 2013). This was expected as the increase in the number of fasteners led to an improved composite action between the steel and concrete. In fact, simulations having 44 and 207 fasteners resulted in a 30\% increase in shear resistance when compared to prototype "b" (Rafiei et al. 2013). Figure 2.4 shows a comparison of the load vs. displacement curves obtained for all four prototypes with 
figures "a" and "b" incorporating a steel yield strength values of 280 and $350 \mathrm{MPa}$ while the compressive strength of concrete was maintained at $20 \mathrm{MPa}$ for all simulations.

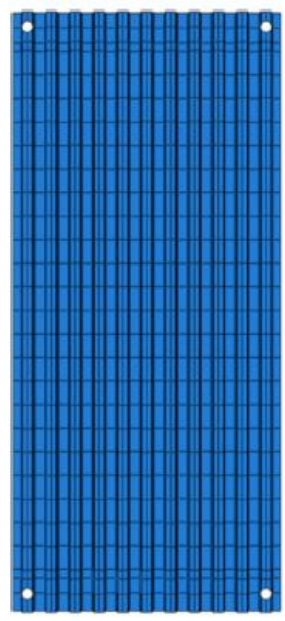

(a)

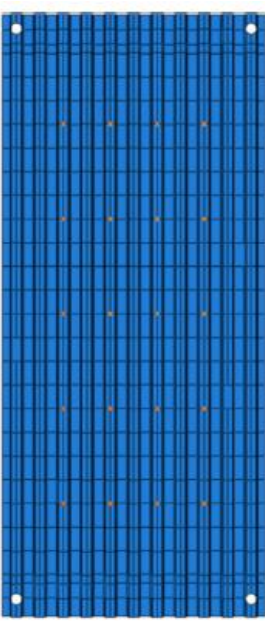

(b)

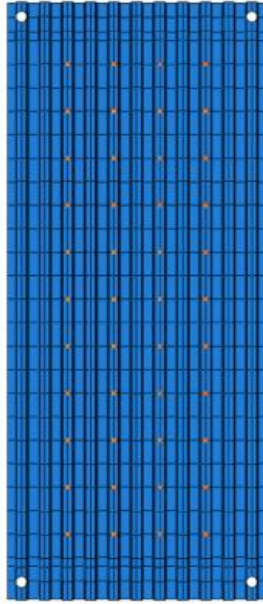

(c)

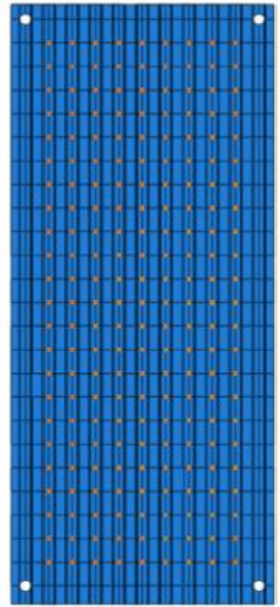

(d)

Figure 2.3: Four set of fastener arrangement investigated (Rafiei, et al. 2013)

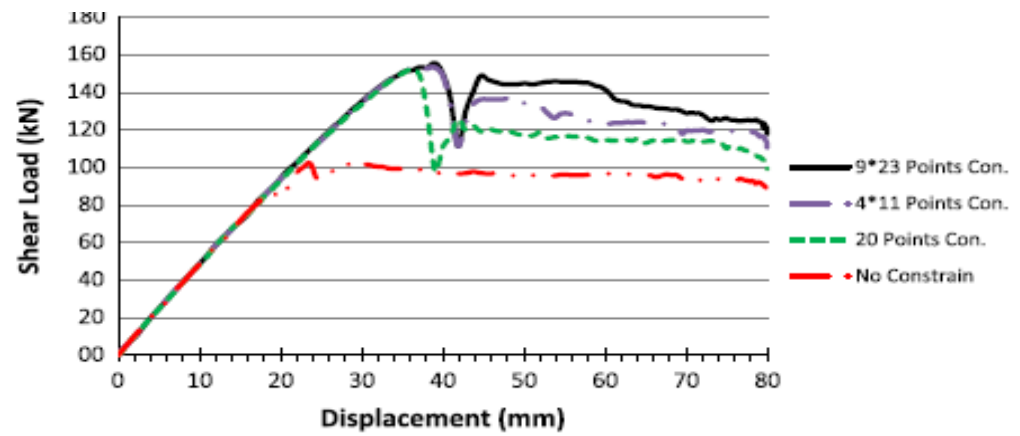

(a)

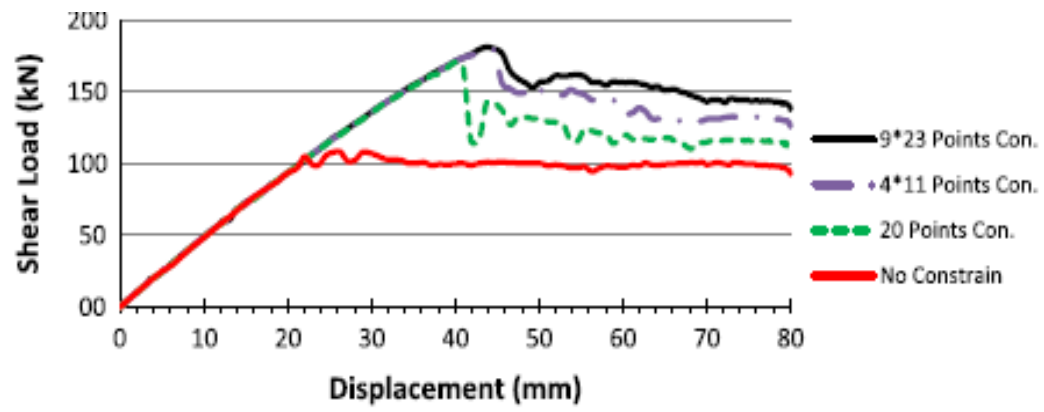

(b)

Figure 2.4: Shear load vs. displacement curves for the four set of fastener arrangement with steel yield strength of a) $280 \mathrm{MPa}$ and b) $350 \mathrm{MPa}$ (Rafiei et al. 2013) 
An experimental study on the behaviour of double skin composite wall (DSCW) structures under the effect of monotonic shear loading was performed by Rafiei et al. (2015). This was followed by an analytical study where equations were developed to determine the shear resistance of DSCW systems (Rafiei et al. 2015). The analytical study was validated when compared with results obtained from lab tests. In this case, a total of three DSCW test specimens referred to as DSCW-1, DSCW-3 and DSCW-5 were tested under the influence of in-plane monotonic loading (Rafiei et al. 2015). The double skin composite wall structure was composed to two skin sheets and a concrete core (Rafiei et al. 2015). All three tested specimens had similar geometry to the previous study by Rafiei et al. (2013) where the length of the composite wall was $1626 \mathrm{~mm}$ and the width was $720 \mathrm{~mm}$ (Rafiei et al. 2015). Figure 2.1 shows the geometry and main components of the tested DSCW. The shear behaviour of the composite wall composed of engineered cementitious concrete (ECC) and self-consolidating concrete (SCC) was investigated (Rafiei et al. 2015). In fact, the effects of using high strength along with mild strength steel material for sheeting on the shear behaviour of DSCW was also investigated (Rafiei et al. 2015). DSCW-1 was composed of self-consolidating concrete (SCC) and high strength steel for sheeting (Rafiei et al. 2015). The concrete compressive strength, tensile strength and modulus of elasticity were measured as 48.0, 3.9 and 25,100 $\mathrm{MPa}$ while steel yield stress and modulus of elasticity were determined to be 577 and 202,940 MPa respectively (Rafiei et al. 2015). On the other hand, DSCW-3 was composed of engineered cementitious concrete (ECC) and high strength steel for sheeting (Rafiei et al. 2015). The concrete compressive strength, tensile strength and modulus of elasticity were measured as 40.2, 5.4 and 24,500 MPa while steel yield stress and modulus of elasticity were determined to be 577 and 202,940 MPa respectively. Finally, the third specimen referred to as DSCW-5 was composed of SCC concrete and mild strength steel for sheeting. The concrete compressive strength, tensile strength and modulus of elasticity were measured as 35.7, 3.3 and 25,010 MPa while steel yield stress and modulus of elasticity were determined to be 354 and 206,980 MPa, respectively. As shown in Figure 2.1, a displacement rate of $3 \mathrm{~mm} / \mathrm{min}$ was applied on the top left corner of the DSCW specimens with shear load vs. displacement curves obtained through use of computer aided data acquisition system (Rafiei et al. 2015). A total of six strain gages were used to obtain the stress characteristics of the composite wall during the experimental procedure. A proposed analytical procedure was then developed and validated against the obtained test results - good agreements were observed. 
Comparison of the load vs. displacement curves obtained from tests performed on specimens DSCW-1, DSCW-3 and DSCW-5 showed an improved performance for ECC-based composite wall systems (Rafiei et al. 2015). It was observed that the DSCW-3 (ECC-based specimen) exhibited improved ductility and structural performance when compared to SCC-based composite wall specimens such as DSCW-1 and DSCW-5 (Rafiei et al. 2015). Figure 2.5 shows the load vs. displacement curves obtained from experimental tests. It was observed that the ECCbased composite wall had higher ductility and ultimate load values of $100 \mathrm{~mm}$ and $282 \mathrm{kN}$ relative to the SCC-based composite walls (Rafiei et al. 2015). Such behaviour was expected since ECC is a ductile material with high energy absorption characteristics. Through use of results plotted in Figure 2.5, it was also observed that the use of mild steel was indeed preferred over high strength steel due to the added ductility of the material (Rafiei et al. 2015). In this case, mild steel provided higher ductility leading to a higher displacement prior to failure (Rafiei et al. 2015). Such behaviour was observed in the DSCW-3 plot located in Figure 2.5.

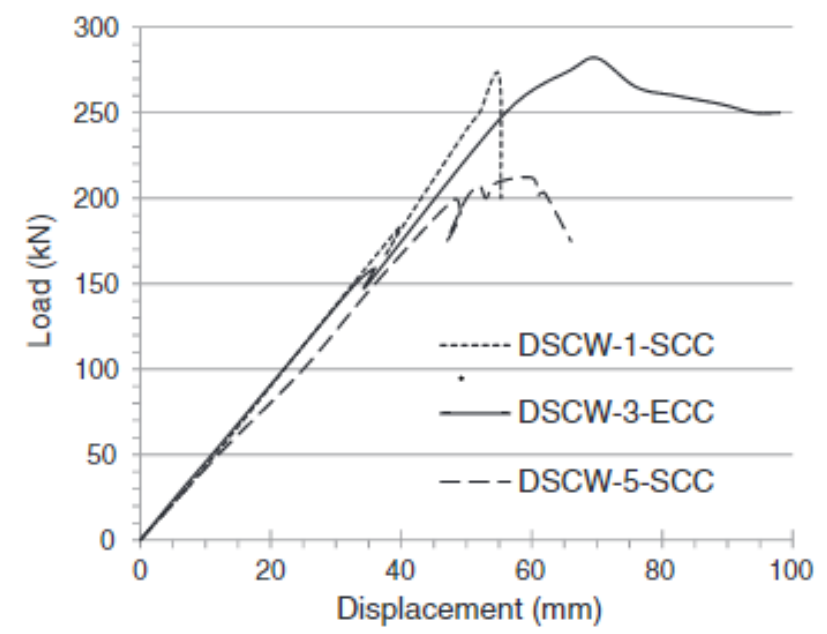

Figure 2.5: Load vs. displacement curves for tested specimens (Rafiei et al. 2015)

Analytical models for the shear resistance of the steel sheets and profiled concrete were generated and compared with results obtained from test experiment (Rafiei et al. 2015). Given the presence of fasteners linking the two steel sheets and concrete core, an analytical model for the shear resistance of the entire composite wall was determined by combining the shear resistance of the steel and concrete components of the composite wall (Rafiei et al. 2015). Equation 2.1 shows the derived analytical model to determine the shear resistance of a double skin composite wall system (Rafiei et al. 2015). 


$$
V_{w}=2 V_{s}+V_{c}=2 \frac{f_{y}}{\sqrt{3}} t_{s} d_{v}+\beta \sqrt{f_{c}^{\prime}} t_{c} d_{v}
$$

In Equation 2.1, $V_{s}$ : shear resistance of steel sheets $[\mathrm{N}], V_{c}$ : shear resistance of profiled concrete $[\mathrm{N}], f_{y}$ : steel yield stress $[\mathrm{MPa}], t_{s}$ : thickness of steel sheet $[\mathrm{mm}], d_{v}$ : effective shear depth/width of the wall [mm], $f_{c}^{\prime}$ : Compressive strength of concrete [MPa], $\beta$ : factor for shear retention and $t_{c}$ : average uniform thickness of profiled concrete panel [mm].

Results of the given analytical model in Equation 2.1 were compared with values of shear capacity obtained from test specimens. It was observed that analytical values were within a $10 \%$ range from the results obtained from lab tests (Rafiei et al. 2015). Through use of Equation 2.1, it was computed that the shear resistance of DSCW-1, DSCW-3 and DSCW-5 were 283, 310 and $202 \mathrm{kN}$ while the shear resistance values obtained from test results for all three wall components were 272, 282 and $212 \mathrm{kN}$ respectively (Rafiei et al. 2015). This suggested ratios of experimental/analytical results of $0.95,0.92$ and 1.02 for all three wall specimens, respectively (Rafiei et al. 2015).

An experimental research by Hossain et al. (2015) presented the axial load behaviour of pierced and non-pierced double skin composite wall (DSCW) system. A total of nineteen specimens with varying wall height, strength, types of profiled steel sheets, load transfer device and size/orientation of opening/holes are tested to failure while subjected to compressive axial loading (Figure 2.6) (Hossain et al. 2015).

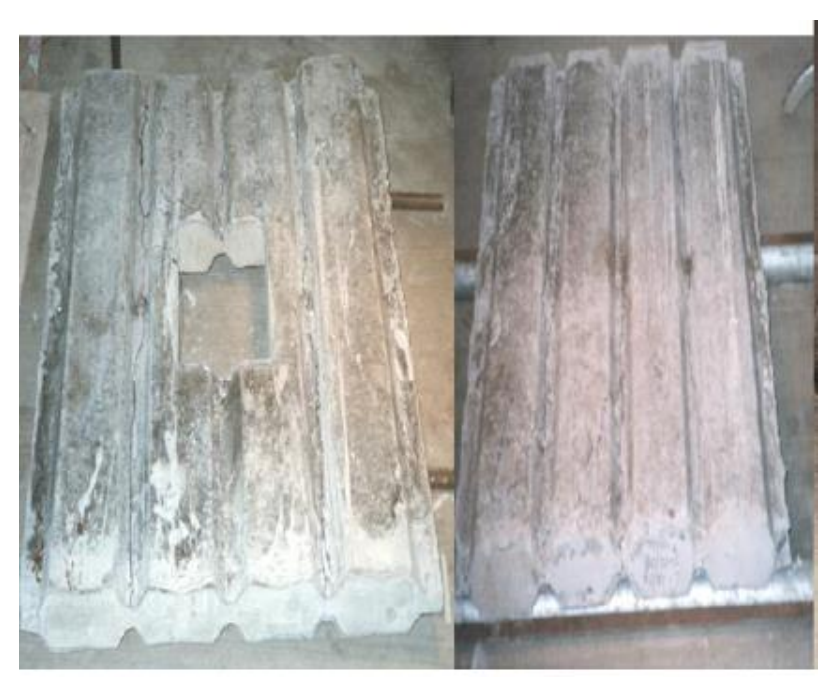

Figure 2.6: Pierced and non-pierced concrete walls (Hossain et al. 2015) 
Results showed that buckling and tearing of the steel sheets occurred at an earlier stage in the pierced wall compared to non-pierced walls (Hossain et al. 2015). The comparison in axial loaddeformation curves for pierced and non-pierced walls is shown in Figure 2.7, where walls 1 and 2 are the curves for non-pierced walls while walls 5 and 6 represent the curves for a pierced wall. Higher ultimate load was shown in non-pierced walls when compared to pierced walls (Figure 2.7) (Hossain et al. 2015).

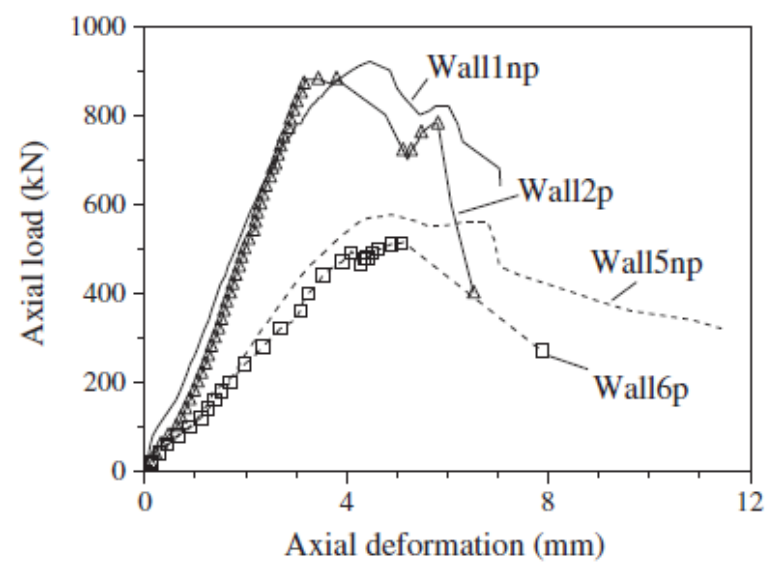

Figure 2.7: Comparison of pieced and non-pierced walls (Hossain et al. 2015)

The effect of slenderness was investigated by varying the wall height from 900 to $1200 \mathrm{~mm}$, thus increasing the slenderness ratio from 1.32 to 1.76 (Hossain et al. 2015). The size of the holes in pierced walls was kept constant. Results indicated a decrease in the ultimate load/strength when slenderness ratio was increased (Hossain et al. 2015). In this case, a percentage decrease of $27 \%$ was observed for pierced walls while $30 \%$ decrease was observed non-pierced walls (Hossain et al. 2015).

The research study by Hossain et al. (2015) also investigated the effect of hole size on the peak deformation and ultimate axial compressive capacity of pierced walls. A total of 9 specimens with varying pierced hole height and width were axially loaded to failure (Hossain et al. 2015). It was observed that the increase in the overall area of the rectangular hole was shouldered with a subsequent decrease in load carrying capacity and peak deformation. According to experimental results, a $13 \%$ increase in hole area led to a total percent decrease in axial load capacity of 55\% (Hossain et al. 2015). Figure 2.8 shows the axial load vs. axial deformation of 9 wall specimens with varying hole width and height. In Figure 2.8 , the ratio of the hole height to width $\left(h_{w} / b_{w}\right)$ 
for Wall9p, Wall6p, Wall10p, Wall11p and Wall12 are defined as 0.62, 1.23, 1.50, 2.48 and 0.83 while Wall5np is defined as a non-pierced wall (Hossain et al. 2015).

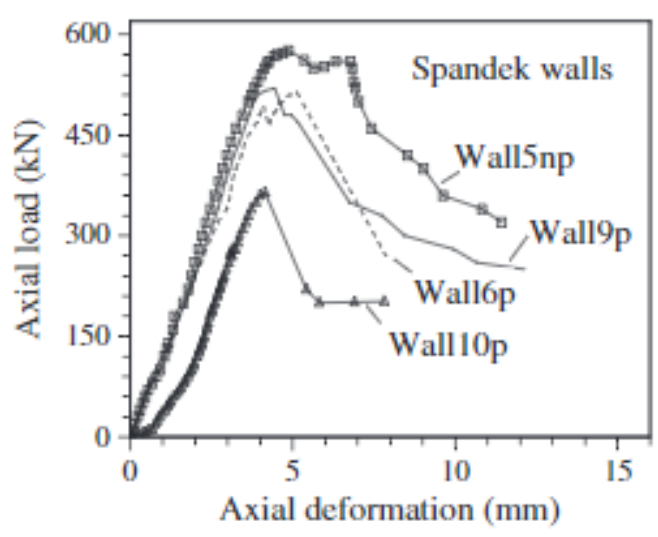

(a) Variation in hole height

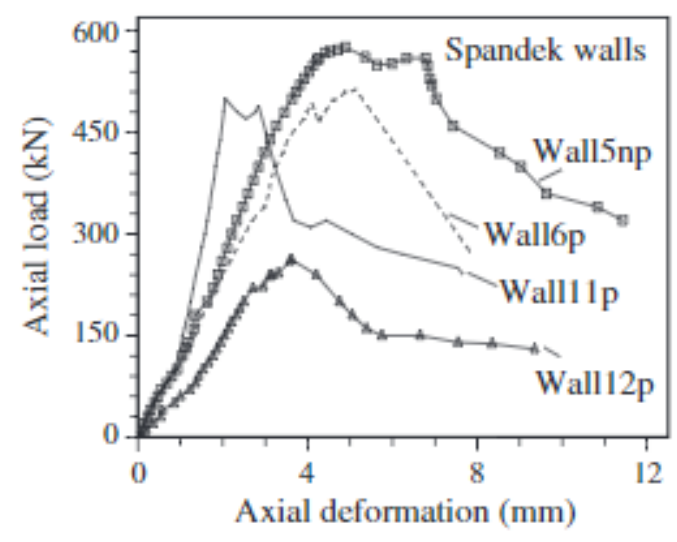

(b) Variation in hole width

Figure 2.8: The effects of varying the height and width of hole on the axial load vs. deformation responses (Hossain et al. 2015)

A study conducted by Yang et al. (2016) shows the effects of fastener arrangement on the axial load behaviour of composite wall panels. The composite wall is composed of two surface panels, two side panels and one top and bottom plate with concrete infill acting as core. The length, width and thickness (L/W/t) where " $\mathrm{L}$ " refers to the length, "W" refers to the width and " $\mathrm{t}$ " refers to the thickness of the surface panel, side panel and top/bottom plates are measured as 1200/1240/4, 1200/240/12 and 1240/240/12 (mm), respectively. The plates are composed of steel with varying yield stress $\left(f_{y}\right)$ and thickness. Different plate thickness values of 4, 6 and $12 \mathrm{~mm}$ were investigated with $f_{y}$ measured as $409.5,348.4$ and $339.0 \mathrm{MPa}$, respectively. The compressive strength $\left(f_{c u}\right)$ of the concrete infill was measured to be varying between 35.9 and 43.3 MPa. Figure 2.9 shows a three dimensional (3D), front, side and cross-sectional view of the composite wall panel. In Figure 2.9, the dots along the front and 3D view refer to the location of fasters/connector along the profile of the composite wall. Throughout this research, the change in buckling behaviour of the composite wall in question is studied by alternating parameters of ratio of connector spacing (B) and surface steel plate thickness ( $t$ ). The failure mode and load vs. deflection curves are used to determine the changes in bucking behaviour. 10 panel specimens were tested by alternating plate thickness and shear stud arrangements where the behaviour of vertical, horizontal and staggered arrangements are investigated. Figure 2.10 shows two of the 
three different sets of fastener arrangement investigated in this research. Overall, the research by Yang et al. (2016) investigated the axial compressive behaviour under square, rectangular and staggered fastener arrangements.
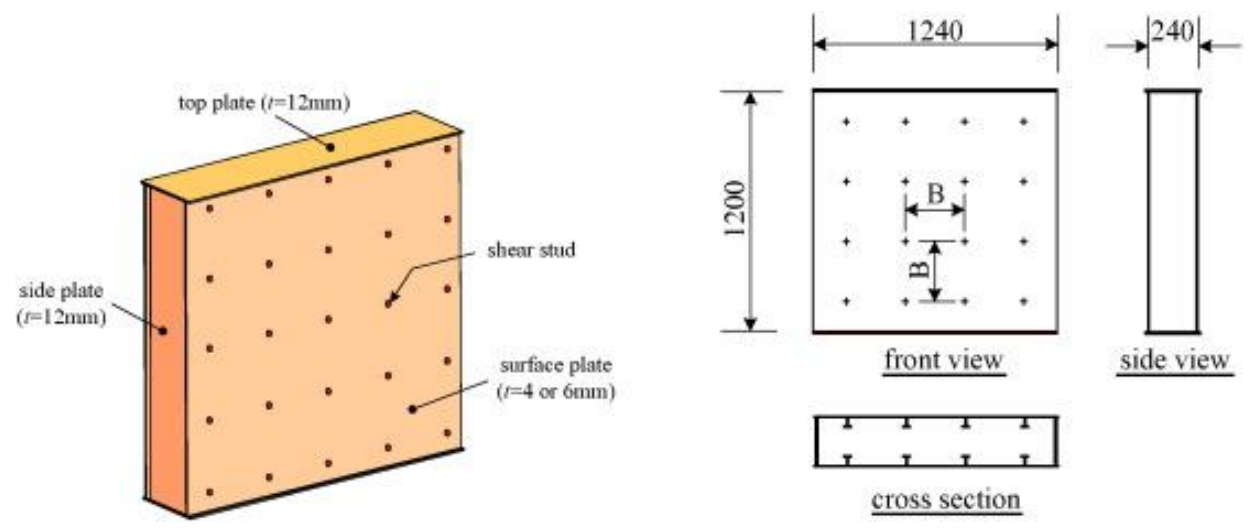

Figure 2.9: Geometry of composite wall panel (Yang et al. 2016)

The compressive behaviour of the 9 tested specimens was modelled using finite element analysis. Comparison of test and FE results of the behaviour of the composite wall panel in terms of observed buckling behaviour and axial load vs. deflection response were found to be in good agreement, thus indicating adequacy of the FE model for further parametric studies (Yang et al. 2016).
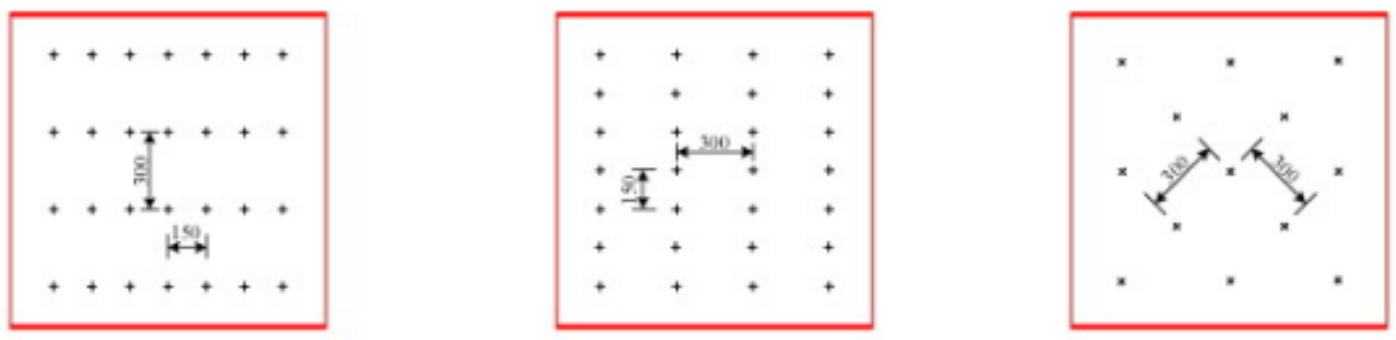

Figure 2.10: The sets of fastener arrangements used (Yang et al. 2016)

Results in terms of load vs. displacement curves for the various test specimens are shown in Figure 2.11. In Figure 2.11, "DCS4-150" refers to the tested specimen name with the number " 4 " referring to the thickness of the steel plate and the number " 150 " referring the distance (B) separating the fasteners/connectors, while the number "150-300" refer to the width (B) and length (L) separating the fasteners. Depending on the arrangement of the connector, the term " $\mathrm{X}$ " denotes a staggered arrangement. Results indicated that the behaviour up to the buckling load is fully dependent on the thickness of the steel panels (Yang et al. 2016). The spacing and 
arrangement of shear studs did not affect the shape of the curve prior to reaching the buckling load (Yang et al. 2016). The load vs. deflection curves show a constant stiffness until bucking of the steel panels occurs (Yang et al. 2016). Upon researching the bucking point, the stiffness of the composite wall changes slightly, indicating that a large part of the load is now being carried by the concrete core (Yang et al. 2016). According to Figure 2.11, the change in stiffness is highlighted by the curved part between the buckling point and ultimate compressive load (Yang et al. 2016). Upon reaching the ultimate load, the composite wall panel could no longer hold any additional load, which led to failure as characterized by the descending branch of the curves shown in Figure 2.11 (Yang et al. 2016). Finally, according to FE parametric studies, the use of staggered arrangement provided better protection from buckling of the steel panels when compared to the squared arrangement (Yang et al. 2016).

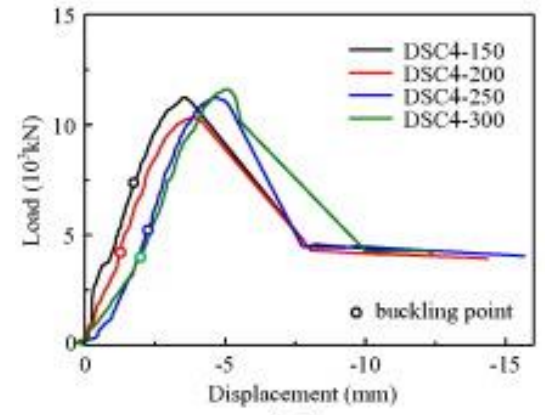

(a)

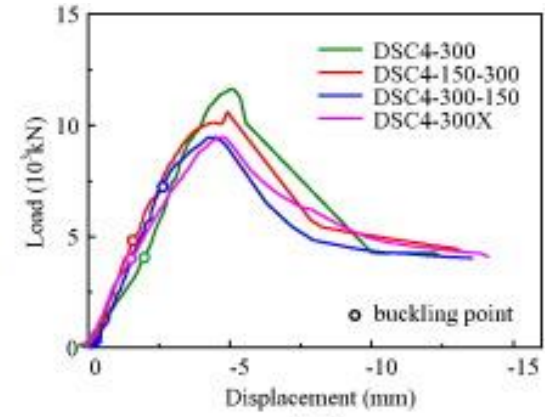

(b)

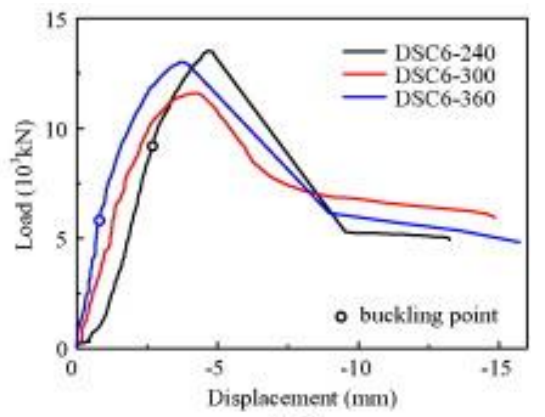

(c)

Figure 2.11: Load vs. displacement curves for the axial behaviour of the composite wall panels (Yang et al. 2016)

\subsection{Fire Resistance of Concrete Filled Steel Tubular Columns}

An experimental investigation followed by a finite element (FE) modelling on the effects of sustained load on the fire and post-fire resistance of concrete filled tubular (CFT) stub columns was performed by Huo et al. (2009). An extensive FE investigation associated with a total of 18 lab tests was used to evaluate the effects of varying the pre-load and cooling phase on the post fire behaviour of CFT stub columns. 18 stub columns with varying parameters of cross-sectional dimension, level of applied axial load and degree of temperature exposure were tested to failure. The load level is defined as the ratio of applied compressive load $(\mathrm{N})$ to the ultimate compressive capacity $\left(N_{u}\right)$ of the column. The test specimens were heated through use of electric furnace to 
desired elevated temperatures and then cooled down to room temperature all the while an applied compressive load was kept constant. Upon cooling, the specimens were then loaded to failure through use of a $2000 \mathrm{kN}$ capacity testing machine to determine the residual strength and stiffness of the CFT stub columns. The diameter, thickness of steel tube and length of the column were varied between 108-150 mm, 3-6 mm and 300-330 mm respectively (Huo et al. 2009). The cross-sectional diameter to steel tube thickness ratios were selected ranging between 36 to 37.5 $\mathrm{mm}$ in such manner to limit slenderness of column and avoid global buckling failure (Huo et al. 2009). The applied load level was varied from 0 (i.e. no pre-load is applied) to 0.6. Specimens were heated at rates of $5-10{ }^{\circ} \mathrm{C} / \mathrm{min}$ until desired temperatures of $400,600,700,800^{\circ} \mathrm{C}$ were reached and upheld for alternating periods of 60,120 and 180 minutes. Upon reaching the desired maximum temperature time period, changes in the furnace were performed to reduce temperature of subject to $20^{\circ} \mathrm{C}$ in a controlled cooling process. Through use of coupon tests, the properties of $4 \mathrm{~mm}$ thick steel material was measured as $375 \mathrm{MPa}$ while the ultimate tensile strength was calculated as $461 \mathrm{MPa}$ with a modulus of elasticity of $200 \mathrm{GPa}$ (Huo et al. 2009). Alternating concrete types referred to as C40 and C30 having compressive strengths of 42 and 33 MPa were used as concrete infill in CFT stub columns. The modulus of elasticity of 35,000 MPa was measured for the $\mathrm{C} 40$ and $\mathrm{C} 30$ concrete types (Huo et al. 2009).

The post-fire behaviour of CFT stub columns were investigated through use of axial deformation $(\delta)$ vs. time (t) curves. It was observed that specimens with a selected pre-load had a much higher residual displacement when compared to tests with no applied pre-load (Huo et al. 2009). Depending on the applied compressive load level, different rates of expansion/contraction were observed. In this case, rapid expansion of the stub column was observed for specimens where the applied compressive load ratio was lower than 0.4 , while early compression was found to take place for higher values of load level (Huo et al. 2009). Due to degradation of strength, compressive displacement governed at time period of $40 \mathrm{~min}$ and above for all tested specimens (Huo et al. 2009). Figure 2.12 shows the deformation $(\delta)$ vs. time (t) curves for 9 test specimens and FE models. CF142, CF162, CF244, CF246, CF262, CF266, CF264 and CF282 were used to define the various tested specimens with the "-FE" referring to the results obtained from the FE modelling of the same specimen. 


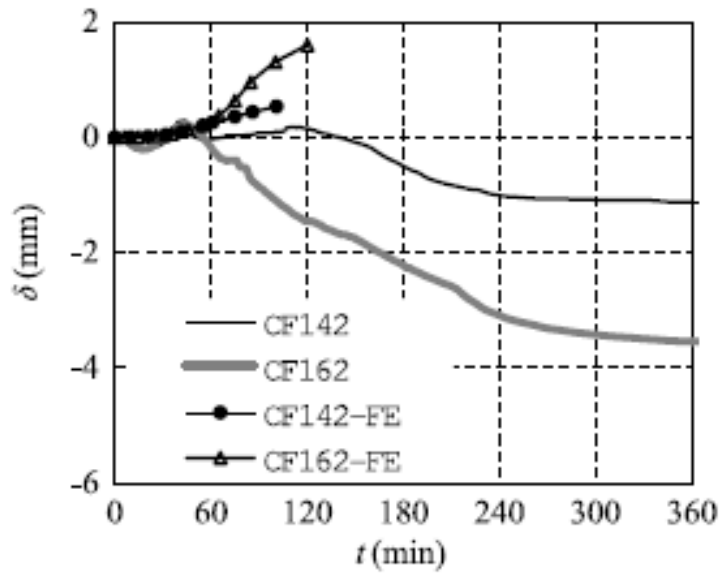

(a) CF1 series specimens.

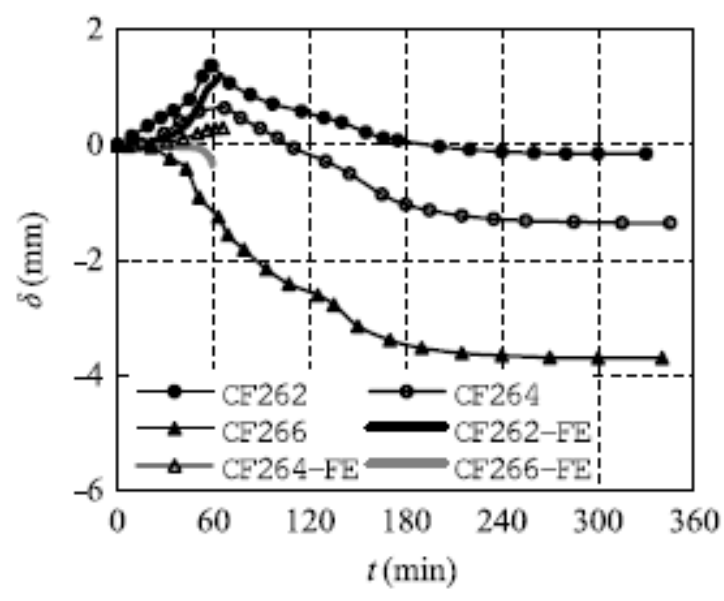

(c) CF26 series specimens.

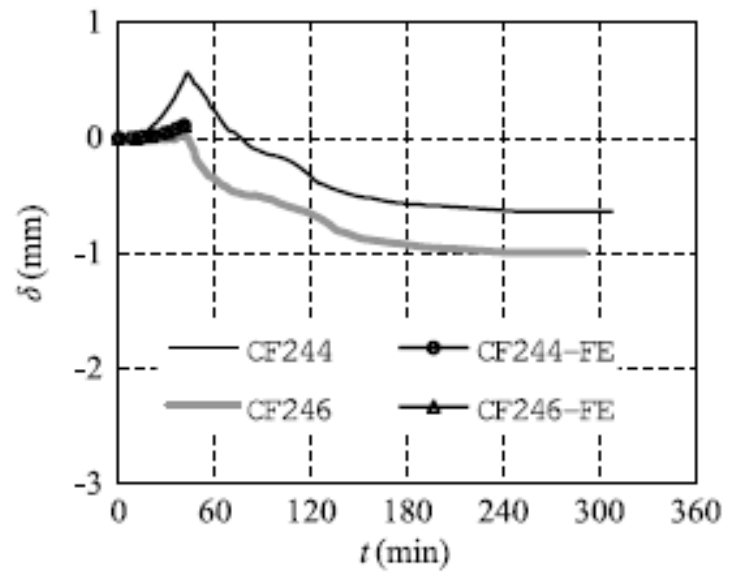

(b) CF24 series specimens.

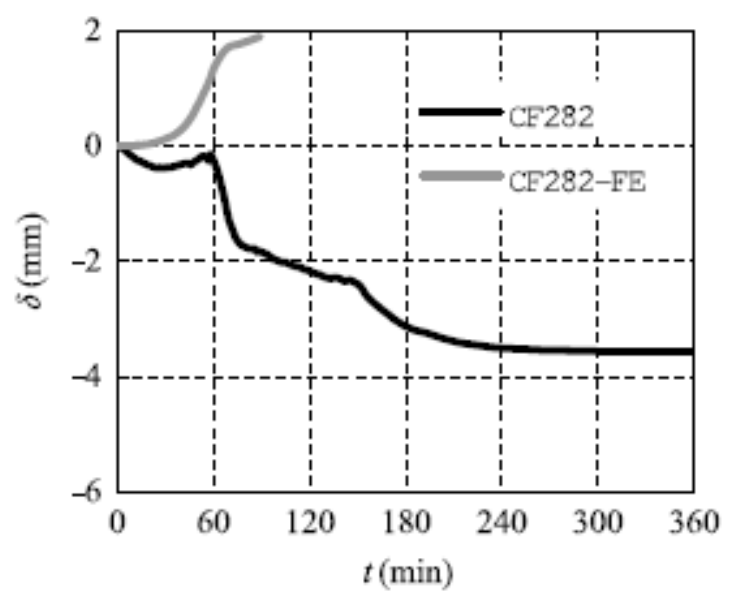

(d) CF28 series specimens.

Figure 2.12: Deformation vs. time curves for the 9 tested CFT specimens (Huo et al. 2009)

The proposed FE model intended for the study of the effect of further parameters affecting the post-fire behaviour of CFT stub columns was evaluated against the experimental deflection vs. time curves and cross-sectional temperature distributions. As shown in Figure 2.12, the proposed FE model was not able to predict the post-fire behaviour of the tested specimen. This was due to the lack of introduction of creep model for concrete and failure of obtaining adequate mechanical models for steel and concrete appropriate for the cooling period of the process (Huo et al. 2009). In fact, the comparison of the results obtained from experimental and FE model did put in question previous research study conducted by Yin et al. (2006) where it was suggested that creep strain could be ignored if fire duration was kept short. To account for such limitation, the proposed FE model was only used to determine the fire resistance of CFT columns where the cooling phase and influence of pre-load were omitted (Huo et al. 2009). Under suggested 
conditions, comparison between FE and experimental axial deformation vs. strain curves resulted in good agreement, thus validating the proposed FE model for predicting the fire resistance of CFT stub columns.

The influence of varying temperature and compressive load level on the residual strength of the stub column was investigated in the experimental study by Huo et al. (2009). The residual compressive strength was computed through use of the ratio of predicted ultimate strength $\left(N_{u e}\right)$ to tested ultimate strength $\left(N_{u c}\right)$. Figure 2.13 shows curves of residual compressive strength relative to temperature $\left({ }^{\circ} \mathrm{C}\right)$ and applied pre-load level (n). CF1 and $\mathrm{CF} 2$ series refer to the test columns having equal diameters of 150 and $108 \mathrm{~mm}$, tube thickness of 4 and $3 \mathrm{~mm}$ and finally, an overall column length of 330 and $320 \mathrm{~mm}$ respectively. According to Figure 2.13, it was observed that the change in temperature and axial load ratio had no significant influence on the residual compressive strength of the stub column (Huo et al. 2009).

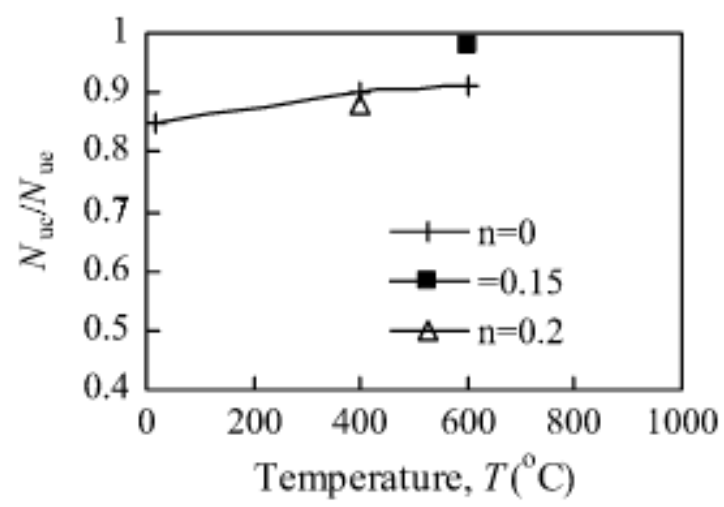

(a) CF1 series.

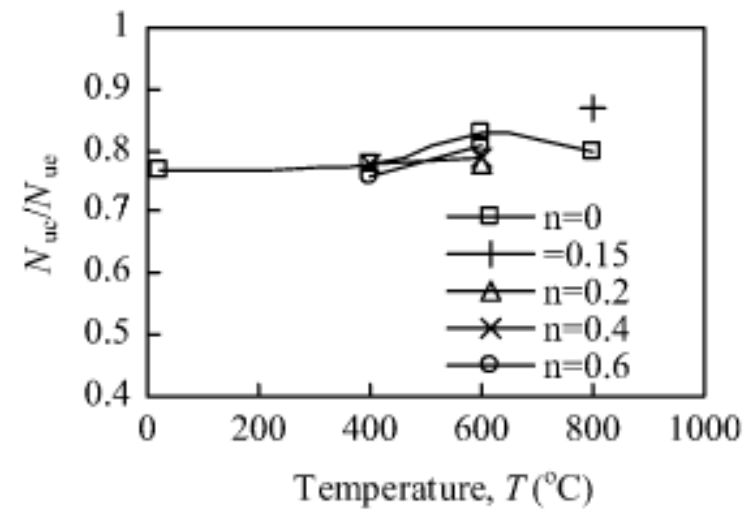

(b) CF2 series.
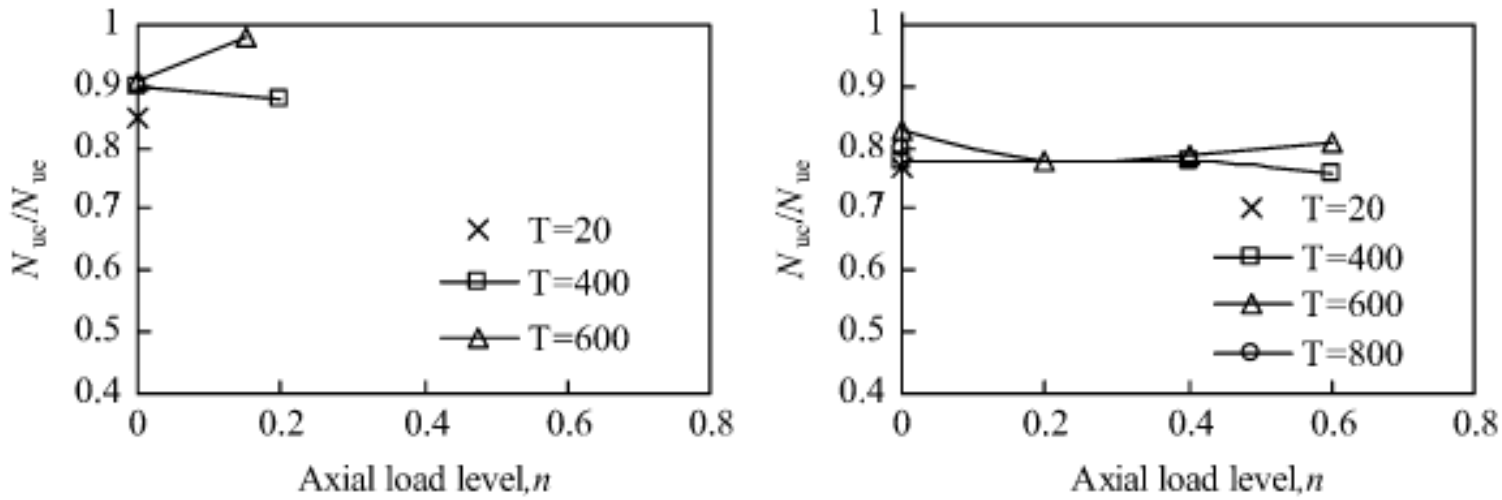

(c) CF1 series.

(d) CF2 series.

Figure 2.13: Residual compressive strength as function of temperature (Huo et al. 2009) 
The effects of temperature and axial load level did however show a significant impact on the resulting residual stiffness of the stub column. In this case, the residual stiffness was computed as the ratio of the predicted to tested compressive stiffness $\left(E A_{c} / E A_{e}\right)$ (Huo et al. 2009). Figure 2.14 shows the existing relationship between the ratio of $\left(E A_{c} / E A_{e}\right)$ relative to temperature and level of applied pre-load. It was also observed that under a load level ranging between 0-0.2, a decrease in the ratio of $\left(E A_{c} / E A_{e}\right)$ took place while the opposite increase in stiffness was observed for pre-load levels ranging between 0.2-0.6 (Huo et al. 2009). This suggested that the post-fire behaviour of pre-loaded stub column resulted in an increase in residual compressive strength when a pre-load level was kept below 0.2, while a subsequent decrease in residual compressive strength resulted for alternative values of load level (Huo et al. 2009).

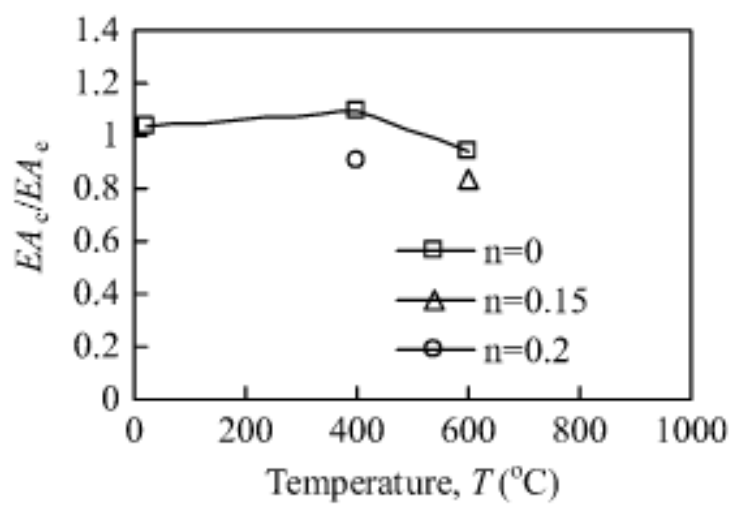

(a) CF1 series.

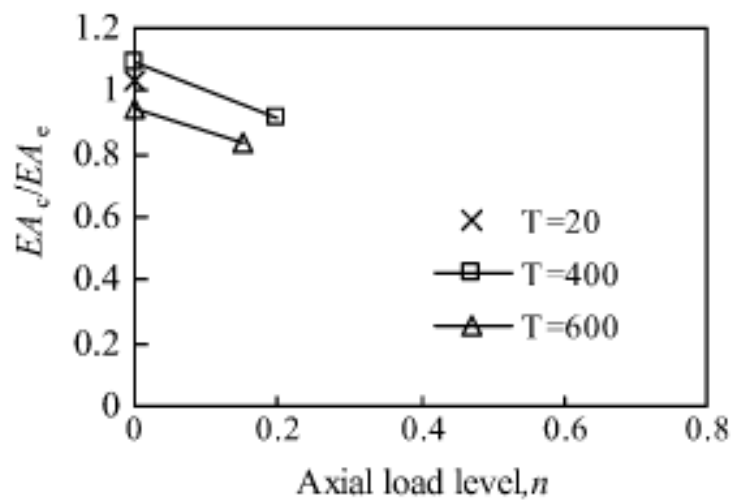

(c) CF1 series.

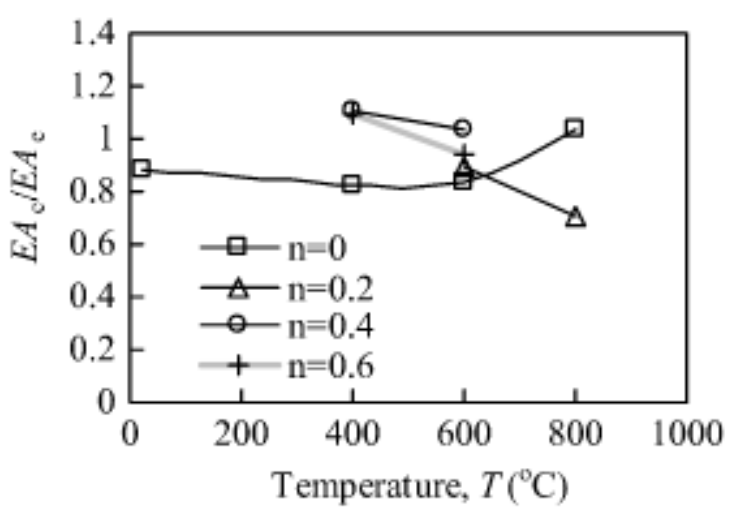

(b) CF2 series.

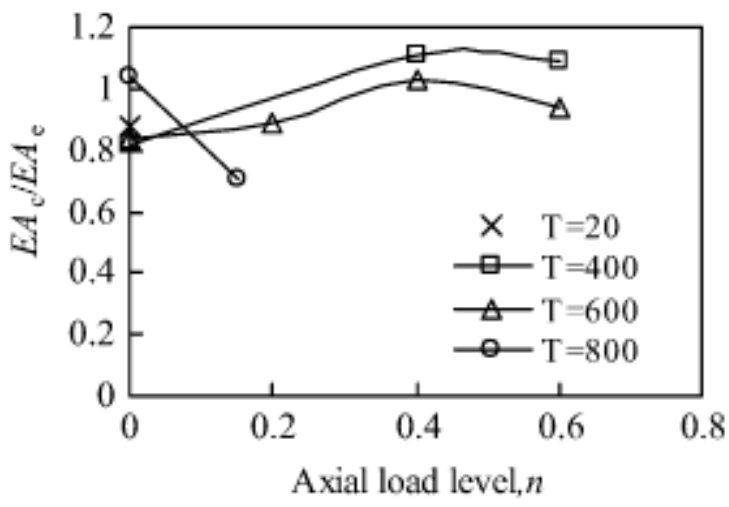

(d) CF2 series.

Figure 2.14: Residual stiffness as a function of temperature (a, b) and axial load level (c, d) (Huo et al. 2009) 
An experimental study conducted by Liu et al. (2010) investigated the influence of various parameters on the axial compressive behaviour of both circular and square steel tube reinforced concrete (STRC) stub columns (Figure 2.15). The effects of diameter/width to thickness ratio of steel tubes, compressive strength of concrete and height to diameter/width ratio of the separated tubes on the compressive behaviour of the stub columns were investigated by conducting experimental tests on a total of 40 specimens (Liu et al. 2010). Test specimens included a total number of 20 circular and square tube stub columns in each category. The circular and square tube test specimens were divided in 5 groups referred to as A-STRC-1, A-STRC-2, A-STRC-3, A-STRC-4, A-STRC-5 for square sections and A-CTRC-1, A-CTRC-2, A-CTRC-3, A-CTRC-4, A-CTRC-5 for circular sections. In order to investigate the effects of friction and bond strength, the steel tube was spliced at different height measurements (Liu et al. 2010). The measured height of individually separated steel tubes was computed through use of height to diameter/width (h/D) ratio with the column height maintained at a constant value for all specimens (Liu et al. 2010). Four test specimens are included in each group with each sample having a different ratio of h/D defined as type A, B, C and D (Liu et al. 2010). As shown in Figure 2.15, specimens in group types A, B and C only showed differences in the height of the exterior steel tube (Liu et al. 2010). Specimens of type A and D shouldered similar values for $\mathrm{h} / \mathrm{D}$ with the amount of rebar reinforcement in the concrete infill being the only difference (Liu et al. 2010). In this case, type D specimens were filled with plain concrete with no added reinforcement (Figure 2.15) (Liu et al. 2010).

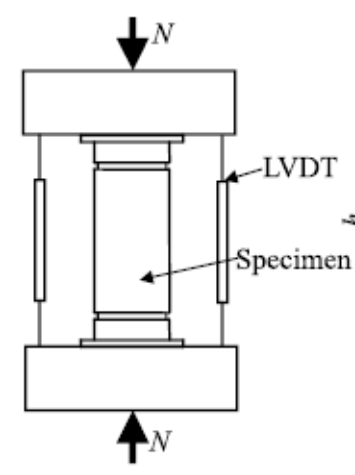

Test set-up

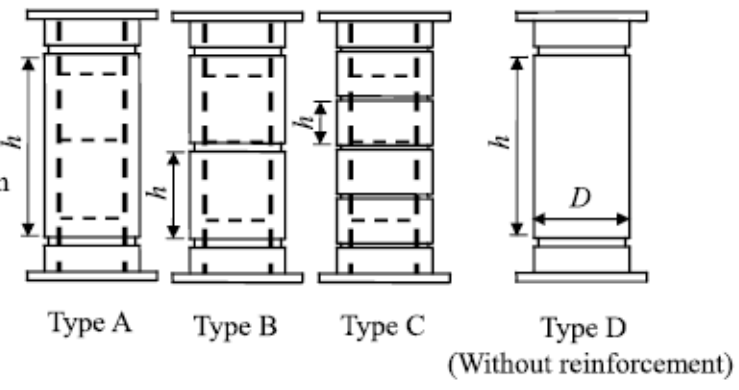

(Without reinforcement)

Figure 2.15: Types of specimen tested (Liu et al. 2010)

The effect of $\mathrm{h} / \mathrm{D}$ ratio on circular and square stub columns was determined through use of axial load (N) vs. compressive strain curves shown in Figure 2.16 and 2.17 respectively. In Figures 
2.16 and 2.17, specimen names are defined as a coalition of 6 parametric terms. For instance, in the specimen name c-150-3-80-a-235, the parameters "c", 150, 3, 80, "a" and 235 refer to crosssection type (i.e. circular/square), diameter/width $(\mathrm{mm})$, thickness of steel tube $(\mathrm{mm})$, the nominal cubic strength of the concrete and the nominal yield strength of the steel tube respectively (Liu et al. 2010). It was observed that changing ratio of h/D had little influence on the compressive behaviour of both circular and square stub columns (Liu et al. 2010). In addition, a change in ductility was also observed, which suggested that the increase in $\mathrm{h} / \mathrm{D}$ ratio was shouldered with a decrease in ductility (Liu et al. 2010). This was to be expected as a reduction in steel confinement allowed for concrete brittle failure to take place. The benefit of splicing the steel tube is to reduce the longitudinal stress owing to the bond friction existing between the concrete and steel tube (Liu et al. 2010). In fact, according to the curves in Figure 2.16 and 2.17, it can be observed that splicing the steel tube to reduce frictional strength had no significant effect on the compressive capacity of the stub column, thus rendering such structural changes unnecessary in real life scenarios.
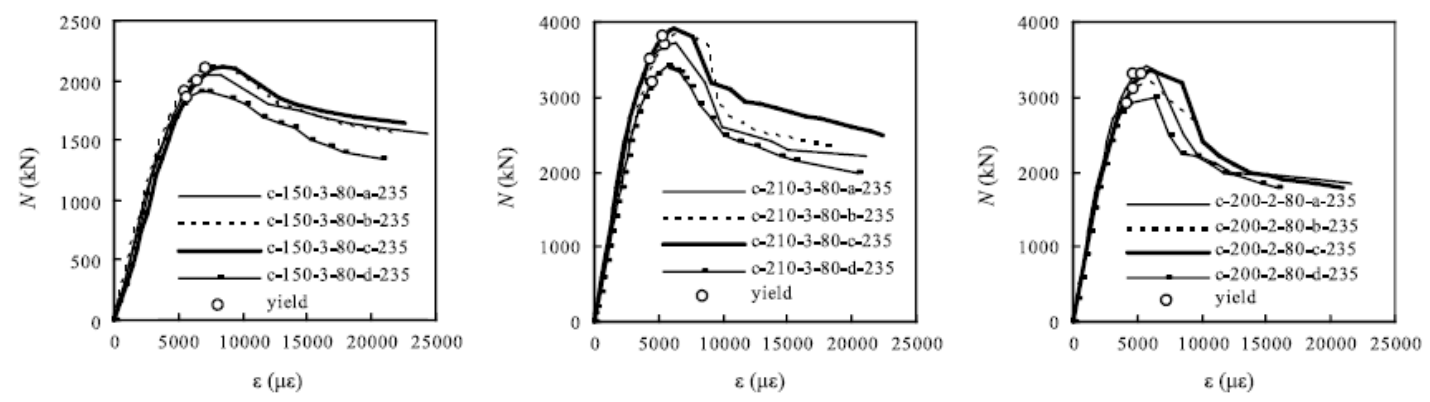

(a) A-CTRC-1.

(b) A-CTRC-2.

(c) A-CTRC-3.

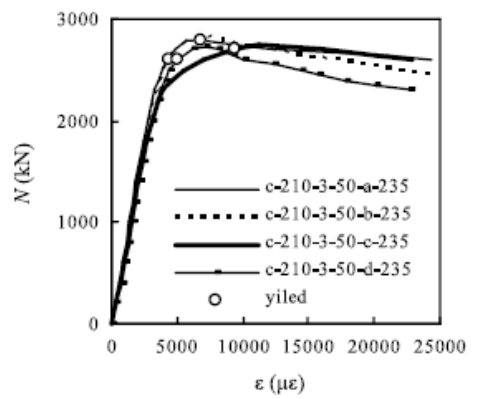

(d) A-CTRC-4.

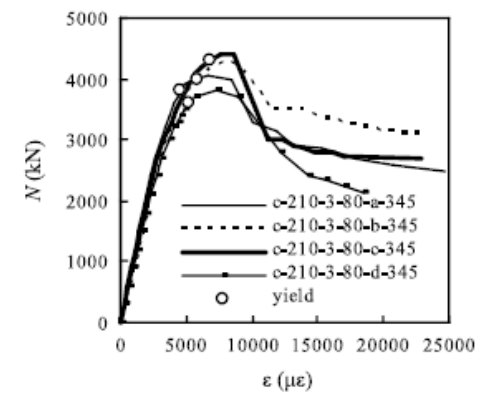

(e) A-CTRC-5.

Figure 2.16: Compressive load (N) vs. strain $(\varepsilon)$ curves for circular stub columns (Liu et al. 2010) 

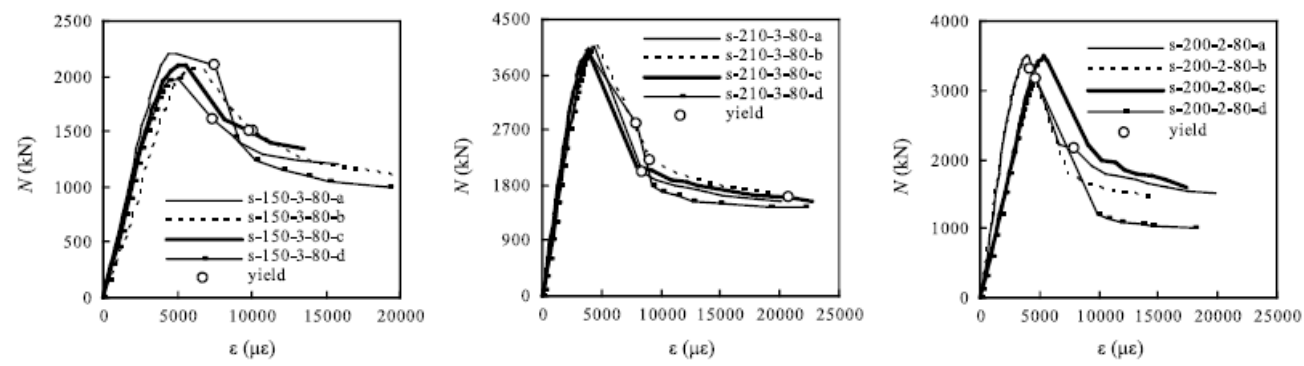

(a) A-STRC-1.

(b) A-STRC-2.

(c) A-STRC-3.

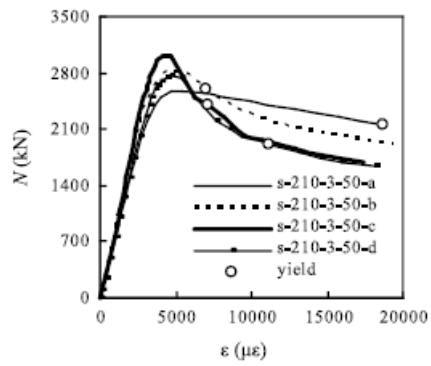

(d) A-STRC-4.

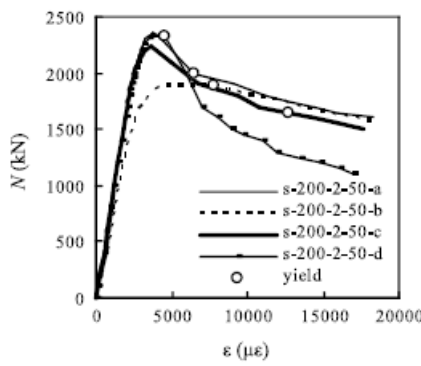

(e) A-STRC-5.

Figure 2.17: Compressive load (N) vs. strain ( $\varepsilon$ ) curves for square stub columns (Liu et al. 2010)

Figures 2.16 and 2.17 also show the effects of increased concrete compressive strength on the axial compressive behaviour of circular and stub columns. Stress vs. strain curves for groups ACTRC-4, A-CTRC-5, A-STRC-4 and A-STRC-5 were used as means of comparing the compressive behaviour of circular and square stub column with the concrete compressive load varied from 50 to $80 \mathrm{MPa}$ (Liu et al. 2010). As can be expected, an increase in concrete strength increased the axial load capacity of the stub column and subsequently decreased the ductility (Liu et al. 2010).

A finite element (FE) investigation on determining the fire resistance of concrete filled double steel tubular (CFDST) columns was performed by Lu et al. (2011). Such structural components are composed of two concentrically placed steel hollow sections with concrete filled in the gap existing between the tubes. Figure 2.18 shows a typical CFDST column with two concentric circular steel tubes and concrete filled in between. $D_{i}, D_{o}, t_{i}$ and $t_{o}$ represent the inner tube diameter, outer tube diameter, inner steel thickness and outer steel thickness, respectively. FE models on the behaviour of stub and slender CFDST columns when subjected to ISO-834 fire temperature and axial compressive loading simultaneously were developed and verified against test results ( $\mathrm{Lu}$ et al. 2011). Stub columns are defined by having a ratio of diameter/width to column length of lesser or equal to 5, while slander columns are defined by having a 
diameter/width to length ratio higher than 5. Test results of six CFDST columns and 16 CFDST stub columns obtained from $\mathrm{Lu}$ et al. (2010) were used as means to validate the generated FE models. The temperature fields, axial deformation and fire resistance obtained from FE models were compared against lab results where good agreements were observed thus validating the proposed FE procedure.

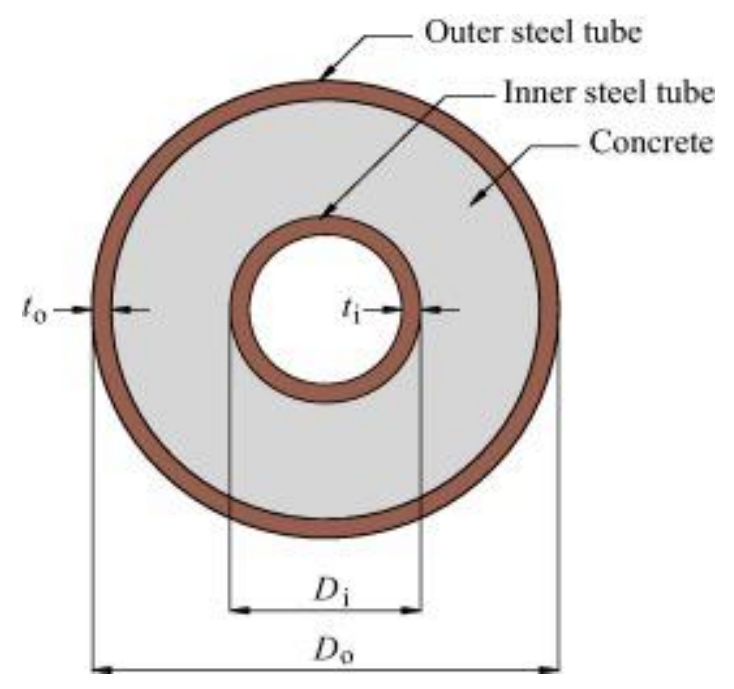

Figure 2.18: Cross-section of circular CFDST column (Liang, 2017)

The slender columns were composed of alternating square and circular inner and outer hollow steel sections with a fixed length of $3810 \mathrm{~mm}$ (Lu et al. 2010). A total number of three columns composed of circular inner and outer steel hollow sections were studied by alternating the applied load level and changing the inner and outer diameters of the steel tubes (Lu et al. 2010). Similarly, the effect of using square inner and outer steel hollow sections was also investigated by determining the fire behaviour of two slender columns with fixed inner and outer widths of 280 and $140 \mathrm{~mm}$ respectively (Lu. et al 2010). Finally, the combination of square outer section and circular inner section was also studied by conducting fire resistance test on a slender column with an outer tube width of $280 \mathrm{~mm}$ and an inner tube diameter of $140 \mathrm{~mm}$ (Lu et al. 2010).

A total of 16 stub CFDST columns reported in Lu et al. (2010) were used as means to evaluate the proposed FE procedure where eight of them were composed of two concentric circular tube sections while the remaining stud columns were composed of two concentric square tube sections ( $\mathrm{Lu}$ et al. 2010). The length of the stub columns was maintained at a constant value of $700 \mathrm{~mm}$. The stub columns were exposed to combined ISO-834 fire temperature and axial 
compressive loading until failure. FE results proposed in Lu et al. (2011) showed good agreement when compared to the measured fire resistance from lab experiments, thus validating the used FE procedure. Figure 2.19 shows a comparison between the FE and test results. The dotted line represents the predicted results while the square and circular dots represent test results for stub and slander columns respectively. Upon validations, FE models were generated to analyze the effect of several parameters such as varying outer tube width/diameter, inner tube width/diameter, applied load value and load eccentricity on the fire resistance of the column (Lu et al. 2011).

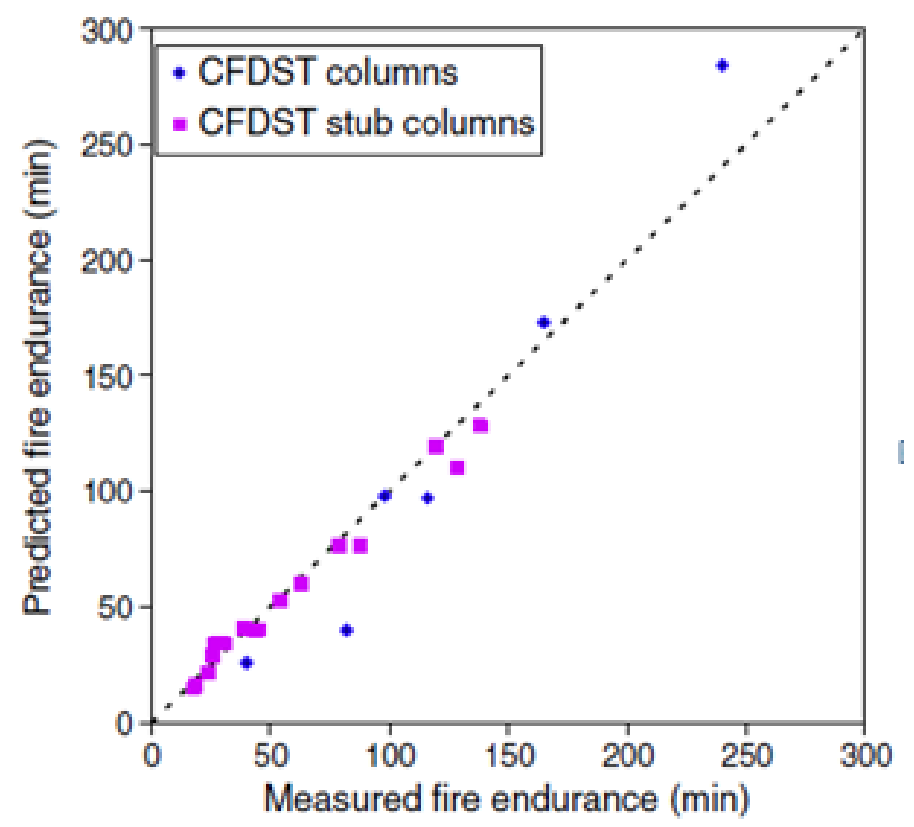

Figure 2.19: Comparison between predicted and test results (Lu et al. 2011)

The load level is defined as the ratio of applied load to ultimate compressive capacity at ambient temperature. According to FE results, varying the load level had a significant impact on the fire resistance of the column ( $\mathrm{Lu}$ et al. 2011). Figure 2.20 shows the fire resistance vs. applied load level obtained from FE models for a circular and square CFDST column where $D_{i}, D_{o}, t_{i}, t_{o}$, $f_{y o}, f_{y i}, f_{c}$, and $\mathrm{L}$ represent the inner tube diameter, outer tube diameter, inner steel thickness, outer steel thickness, yield stress of outer steel tube, yield stress of inner steel tube, compressive strength of concrete and column length respectively (Lu et al. 2011). The increase in applied load drastically decreased the fire resistance of the column. In fact, such results were expected since a higher load level led to higher stresses in the concrete and steel components. This resulted in a 
reduced fire exposure time since less time is required for the material strength to deteriorate under high stress levels (Lu et al. 2011).
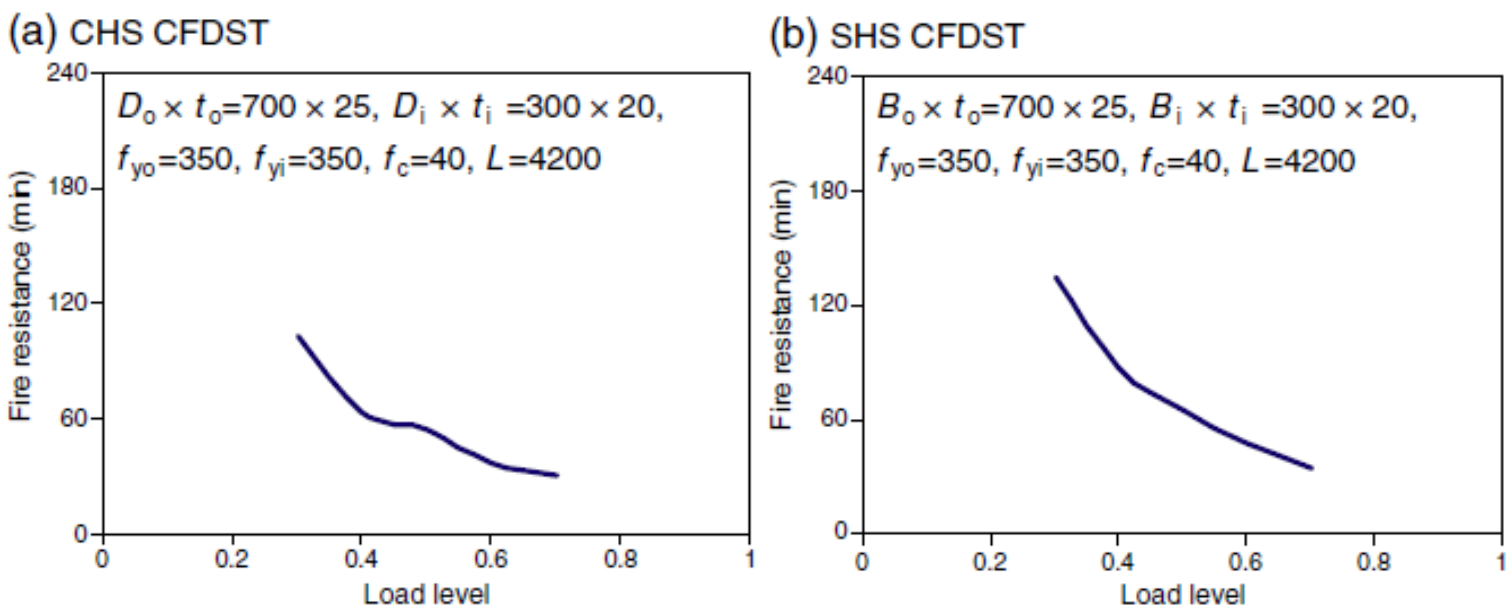

Figure 2.20: Load level vs. fire resistance (min) curves for a) circular (CHS) and b) square (SHS) sections (Lu et al. 2011)

The effect of slenderness was studied by varying values of the outer width/diameter of the CFDST columns ( $\mathrm{Lu}$ et al. 2011). The change in fire resistance with respect to the ratio of column length to diameter/width was used to assess the influence of slenderness on the fire behaviour ( $\mathrm{Lu}$ et al. 2011). FE results indicated that an increase in the slenderness led to a decrease in the fire resistance of the CFDST columns. Figure 2.21 shows the obtained relationship existing between the slenderness and the fire resistance of the columns with similar terms defined earlier. Minimal effect on the fire behaviour was observed in stub columns were length to diameter/width ratio was less than 5 (Figure 2.21). However, with larger values for the ratio of length to diameter/width $(>5)$, a significant decline in fire resistance was observed (Figure 2.21) (Lu et al. 2011).

The effect of the capacity of the inner steel tube was also investigated by Lu et al. (2011). In this case, the capacity of the inner steel tube was determined by the yield stress and the thickness of the steel tube. Results showed that an increase in the capacity of the inner steel tube led to an increase in the fire resistance of the column ( $\mathrm{Lu}$ et al. 2011). Figure 2.22 shows the obtained fire resistance values for various steel thickness and yield stress while maintaining constant load levels and outer steel tube perimeter (Lu et al. 2011). The terms " $t$ " and " $f_{y}$ " are defined as the 
thickness and yield stress of the inner steel tube where CHS and SHS refer to circular and square hollow sections.
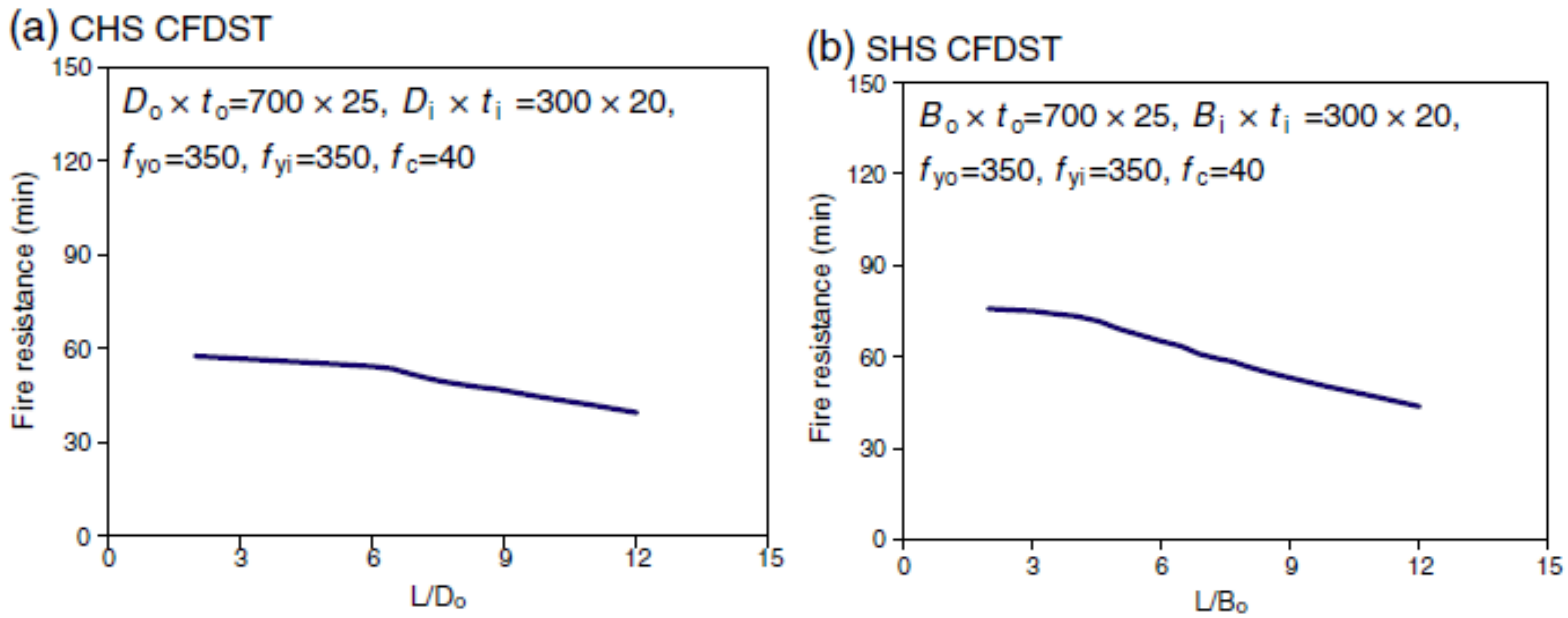

Figure 2.21: Slenderness vs. fire resistance ( $\min$ ) curves for a) circular and b) square sections (Lu et al. 2011)

It was also observed that increasing the thickness had a more significant impact on fire resistance when compared to the subsequent increase in yield stress ( $\mathrm{Lu}$ et al. 2011).

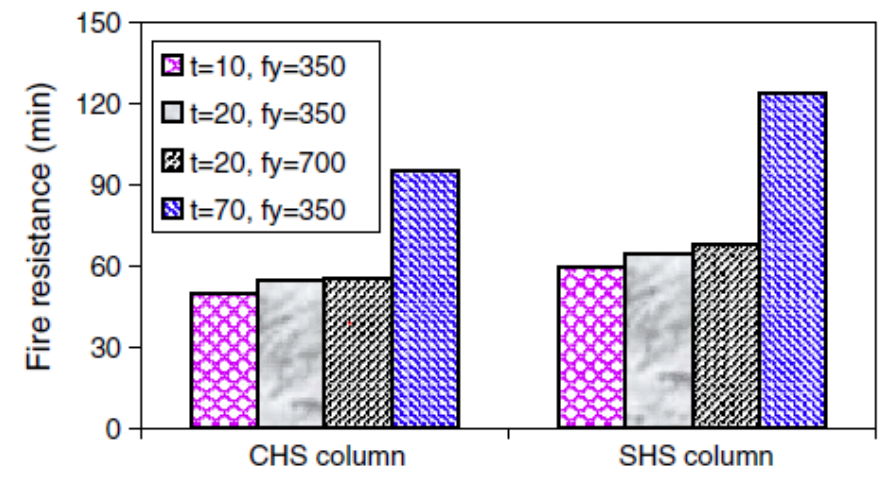

Figure 2.22: Inner steel tube capacity vs. fire resistance for circular (CHS) and square (SHS) hollow sections (Lu et al. 2011)

Finally, according to the FE study conducted by Lu et al. (2011), the effects of the capacity of the outer steel tube on the fire behaviour of CFDST columns was also investigated. Steel thickness and yield stress were varied while perimeter of inner steel tube and applied load were kept constant ( $\mathrm{Lu}$ et al. 2011). FE results indicated that the increase in the capacity of the outer steel tube lead to a decrease in the fire resistance of the column ( $\mathrm{Lu}$ et al. 2011). Figure 2.23 shows the obtained results for fire resistance under different thickness and yield stress values 
with terms defined earlier (Lu et al. 2011). It is also observed that increasing the tube thickness had a much higher influence on the fire behaviour of the column when compared to the subsequent increase in yield stress (Lu et al. 2011).

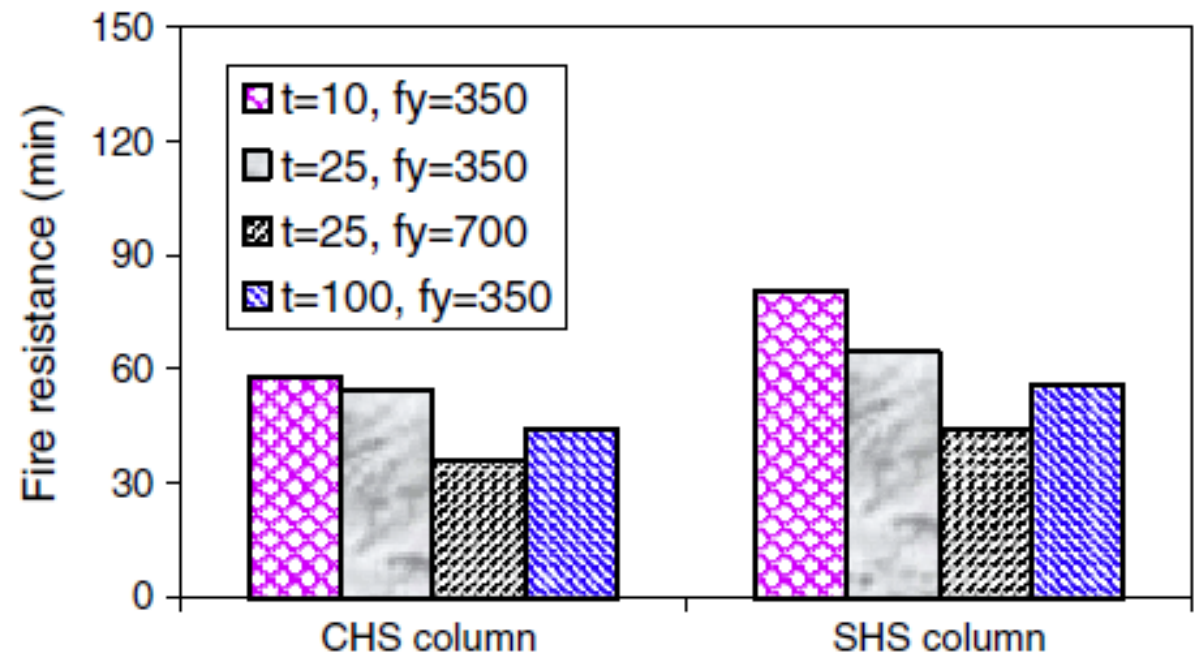

Figure 2.23: Outer steel tube capacity vs. fire resistance for circular (CHS) and square (SHS) hollow sections (Lu et al. 2011)

According to a study conducted by Dai et al. (2012) on the effects of cross-sectional shape on the fire resistance of concrete filled steel tubular (CFST) columns, the use of circular cross-section provided the highest fire resistance. Circular $(\mathrm{CH})$, elliptical (EH), square (SHS) and rectangular (RHS) cross-sections shown in Figure 2.24 were investigated using finite element modelling. The comparison of the fire behaviour of the different cross-sections was established while maintaining constant compressive strength $\left(N_{y}\right)$ (Group 1), constant steel area $\left(A_{s}\right)$ (Group 2) and constant concrete area $\left(A_{c}\right)$ (Group 3) individually (Dai et al. 2012). Finite element (FE) models of heat transfer and sequentially coupled thermal-mechanical analysis of such geometric cross-sections with a length of $500 \mathrm{~mm}$ and a steel tube thickness of $5 \mathrm{~mm}$ were generated (Dai et al. 2012). The ratio of the longer to shorter diameter for EH and RHS cross-section was maintained at 2. The values of depth, width and radius of cross-section were calculated for each shape while maintaining constant compressive strength $\left(N_{y}\right)$, constant steel area $\left(A_{s}\right)$ and constant concrete area $\left(A_{c}\right)$ individually. Table 2.1 summarizes the geometric dimensions associated to each group criteria (Dai et al. 2012). 


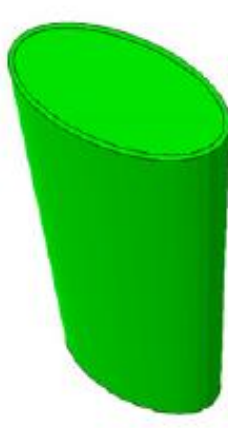

$\mathrm{EH}$

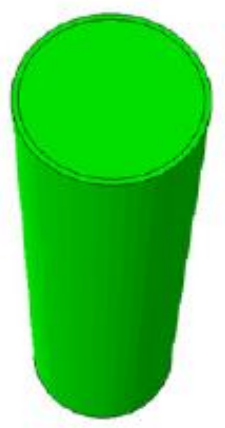

$\mathrm{CH}$

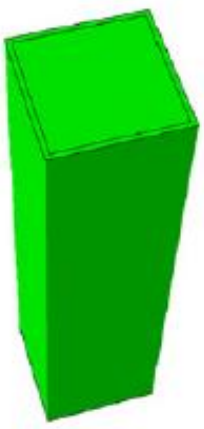

SHS

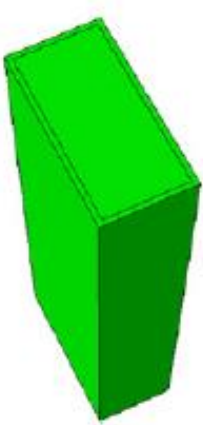

RHS

Figure 2.24: Types of cross-sections investigated (Dai et al. 2012)

The steel yield strength $\left(f_{y}\right)$ and initial modulus of elasticity (E) were taken as $350 \mathrm{~N} / \mathrm{mm}^{2}$ and 210,000 N/mm² respectively (Dai et al. 2012). The reduction factors in accordance to (Eurocode $4,2005)$ for strength and stiffness of carbon steel at elevated temperature were used to define the stress vs. strain curves at different temperatures (Dai et al. 2012). The compressive strength of concrete $\left(f_{c}\right)$ was taken as $30 \mathrm{~N} / \mathrm{mm}^{2}$ with a corresponding compressive strain $\left(\varepsilon_{c}\right)$ value of 0.0025 (Dai et al. 2012). The reduction factors for strength and stiffness of concrete were obtained from Eurocode 4, (2005) design standards (Dai et al. 2012).

Table 2.1: Summary for dimensions of cross-sections (Dai et al. 2012)

\begin{tabular}{|l|l|l|l|l|}
\hline & $\begin{array}{l}\text { Elliptical cross-section } \\
(\mathrm{EH})(\text { width, depth, } \\
\text { thickness })[\mathrm{mm}]\end{array}$ & $\begin{array}{l}\text { Circular cross-section } \\
(\mathrm{CH})(\mathrm{depth}, \text { thickness }) \\
{[\mathrm{mm}]}\end{array}$ & $\begin{array}{l}\text { square cross-section } \\
(\mathrm{SHS})(\mathrm{depth}, \mathrm{depth}, \\
\text { thickness) [mm] }\end{array}$ & $\begin{array}{l}\text { Rectangular cross- } \\
\text { section (RHS) (width, } \\
\text { depth, thickness) [mm] }\end{array}$ \\
\hline Group 1 & $200 \times 100 \times 5$ & $145 \times 5$ & $123 \times 123 \times 5$ & $169 \times 84.5 \times 5$ \\
\hline Group 2 & $200 \times 100 \times 5$ & $150 \times 5$ & $118.9 \times 118.9 \times 5$ & $158.5 \times 79.3 \times 5$ \\
\hline Group 3 & $200 \times 100 \times 5$ & $140.8 \times 5$ & $125.9 \times 125.9 \times 5$ & $179 \times 89.5 \times 5$ \\
\hline
\end{tabular}

Axial deformation vs. time curves were generated under each group condition for each considered cross-sectional shape. The behaviour of such columns under the effects of combined fire exposure and constant load was investigated by applying the standards ISO-834 fire temperature curve for a time period of $60 \mathrm{~min}$ while maintaining a constant compressive load on the columns. Axial deformation curves for constant loads of 500, 600, 800 and $1000 \mathrm{kN}$ were generated and reported in Figure 2.25. 
Results for Group 1 showed that circular cross-sections were measured to have the longest fire resistance with time periods of 27.123, 24.196, 20.348 and $15.533 \mathrm{~min}$ when subjected to axial compressive loads of 500, 600, 800 and $1000 \mathrm{kN}$, respectively (Dai et al. 2012). Elliptical crosssections were measured to have the second longest fire resistance, followed by square and rectangular sections (Dai et al. 2012). Such observation is the result of the uniformity of the temperature distribution along the profile of the steel tube and high distance of $72.5 \mathrm{~mm}$ to the core of the concrete in circular sections (Dai et al. 2012). The longer the path to the core of the concrete, the higher the fire resistance of the section, as a longer time period is required to change the temperature of the concrete core. Values for the shortest path existing between the steel surface and concrete core for square, rectangular and elliptical cross-sections are 61.5, 42.25 and $50 \mathrm{~mm}$ (Dai et al. 2012). This suggested that circular cross-sections provided the highest fire resistance, while rectangular cross-sections provided the lowest fire resistance when sectional shapes are compared with equal compressive capacity (Group 1) (Dai et al. 2012). Figures 2.25, 2.26 and 2.27 show the axial load vs. time curves for elliptical hollow section (EHS), circular hollow section (CHS), square hollow section (SHS) and rectangular hollow section (RHS) subjected to the combined effect of ISO-834 fire curve and constant load of $600 \mathrm{kN}$ under Group 1, Group 2 and Group 3 criteria respectively (Dai et al. 2012).

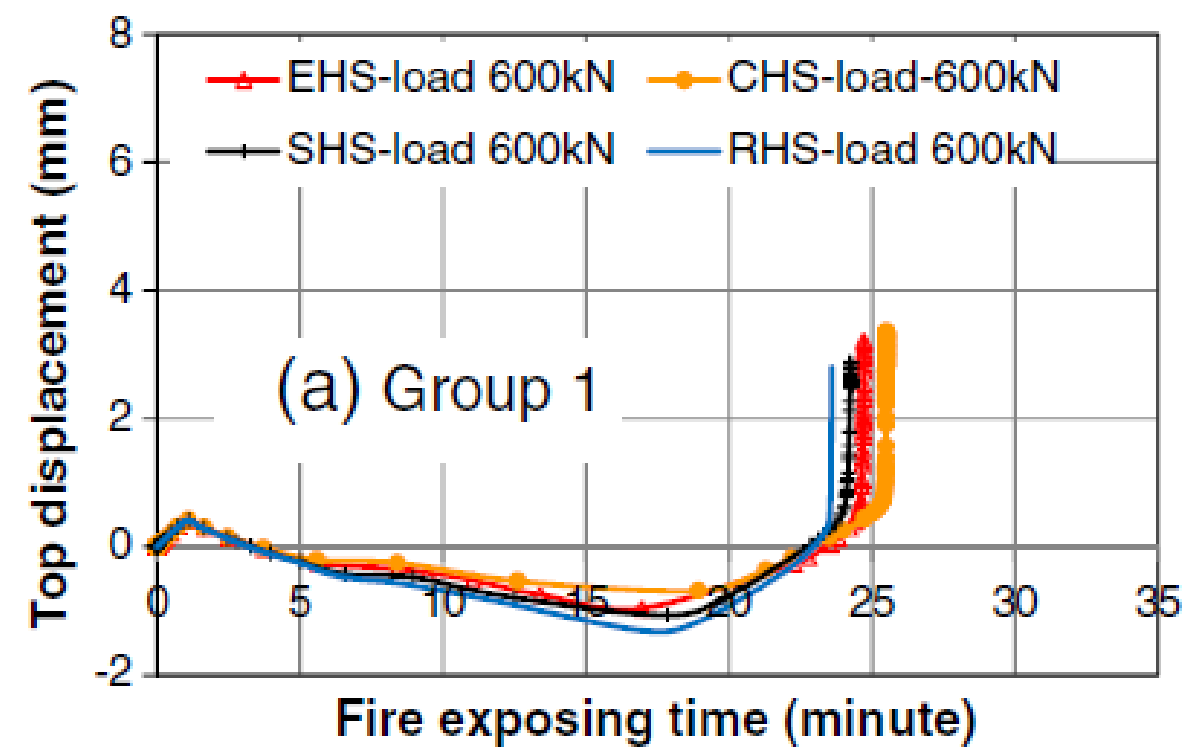

Figure 2.25: Fire behaviour of different types of cross-sections under Group 1 criterion (Dai et al. 2012) 
Similar results are observed for fire behaviour according to Group 2 criterion where comparison is conducted based on equal steel sectional areas. Circular cross-sections were measured to have the highest fire resistance of $30.102 \mathrm{~min}$, while rectangular cross-sections had the lowest calculated fire resistance value of $26.18 \mathrm{~min}$ (Dai et al. 2012). Elliptical and square crosssections had fire resistance values of 27.789 and 28.984 min respectively (Dai et al. 2012). This indicated that with equal steel cross-sectional areas, fire resistance was dependent on the measured path to the concrete core (Dai et al. 2012). In this case, circular cross-sections had the highest measured path to core with a value of $75 \mathrm{~mm}$.

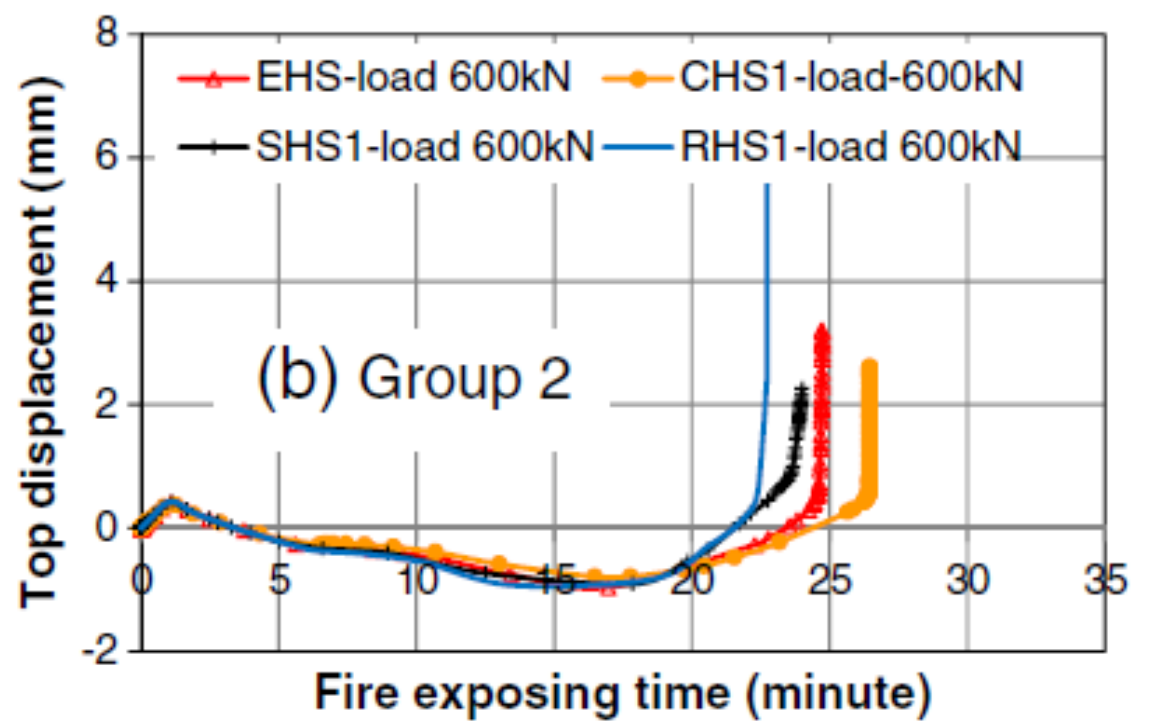

Figure 2.26: Fire behaviour of different types of cross-sections under Group 2 criterion (Dai et al. 2012)

Different results were observed for Group 3 where the gross area of concrete is maintained constant in all sectional shapes. In this case, it was observed that fire resistance was mainly governed by the cross-sectional area of steel (Dai et al. 2012). This was to be expected as a higher amount of steel would lead to a higher compressive capacity of the tubular column, thus emphasizing the importance of hollow steel sections. Steel areas of 2278, 2133, 2418 and 2585 $\mathrm{mm}^{2}$ were recorded for elliptical, circular, square and rectangular cross-sections respectively (Dai et al. 2012). Due to the higher amount of steel, rectangular and square shapes had a higher fire resistance when compared to circular and elliptical shapes (Dai et al. 2012). The fire resistance of square and rectangular sections were computed as 28.069 and $29.05 \mathrm{~min}$ 
respectively while the fire resistance of circular and elliptical shapes were computed as 27.861 and 27.789 min, respectively (Dai et al. 2012).

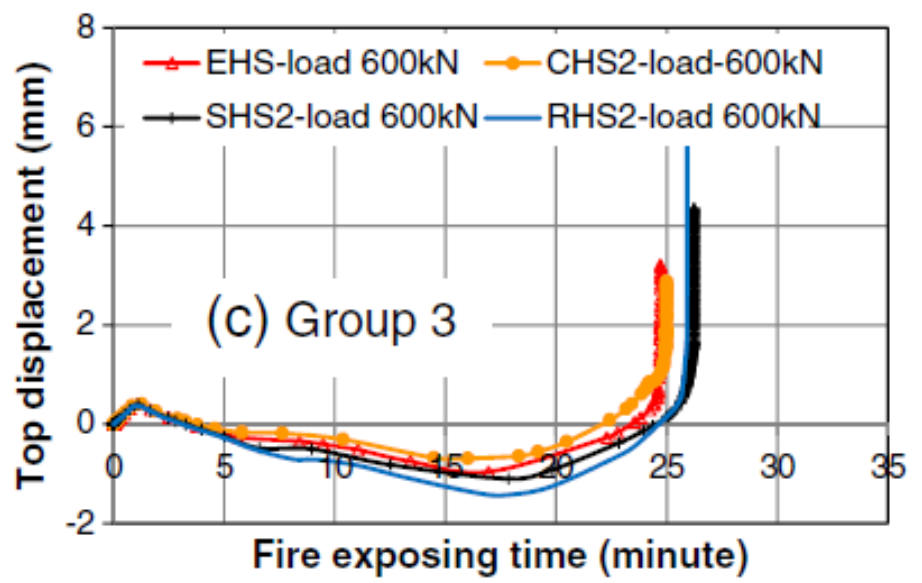

Figure 2.27: Fire behaviour of different types of cross-sections under Group 3 criterion (Dai et al. 2012)

Under equal compressive strength and steel area, the use of circular shapes provided the longest fire resistance when compared to elliptical, square and rectangular shapes (Dai et al. 2012). This was mainly due to the high diameter of the circular section when compared to the lowest distance to core in square, rectangular and elliptical sections (Dai et al. 2012). However, under equal concrete gross area, it was found that the amount of steel directly affected the calculated fire resistance (Dai et al. 2012). In this case, to maintain constant gross area of concrete in the crosssection, higher amount of steel was recorded in rectangular and square sections, leading to higher computed fire resistance when compared to circular and elliptical sections (Dai et al. 2012).

A finite element (FE) study on the fire resistance of concrete filled steel tubular (CFST) columns was performed by Wang and Young (2013). In this FE study the effects of applied load, strength of steel material, slenderness, concrete moisture content and concrete aggregate type were all analyzed and compared in terms of the resulting fire resistance time (Wang and Young, 2013). FE models of CFST columns were generated and validated against experimental data reported by the National Research Council of Canada (NRCC) (Lie et al. 1988). A total of 35 FE models were generated and categorized in 5 groups with Group 1- Group 5 (G1-G5) encompassing 12, 12, 5, 4 and 4 FE models in each group respectively. Specimens included G1 and G3 were characterized by having a constant diameter of $400 \mathrm{~mm}$ and steel tube thickness of $13 \mathrm{~mm}$. G2, G4 and G5 included FE models with a fixed diameter of $200 \mathrm{~mm}$ and steel tube thickness of 5 
$\mathrm{mm}$. Within each specified group, the steel yield strength and concrete compressive strength were varied from 275 to $690 \mathrm{MPa}$ and from 30 to $50 \mathrm{MPa}$ respectively (Wang and Young, 2013). To evaluate the effects of steel strength, the columns were tested under constant applied load and constant load ratio conditions separately. A decrease in fire resistance time was observed when load ratio was maintained at a constant value, while an increase in fire resistance was observed when the applied load was kept constant (Wang and Young, 2013). This was to be expected since the increase in load ratio led to a subsequent increase in applied load due to the higher yield strength. This in turn led to an increase in the stress resisted by the column thus leading to premature failure (Wang and Young, 2013). Figure 2.28 shows the influence of the increase in steel yield strength with respect to the observed fire resistance for specimens in G1 and G2 respectively. In this case, specimens $S_{x}$ refer to the FE models with a varying loads ranging from 1622 to $6206 \mathrm{kN}$ computed in such manner leading to load ratios of 0.3 and 0.5 .
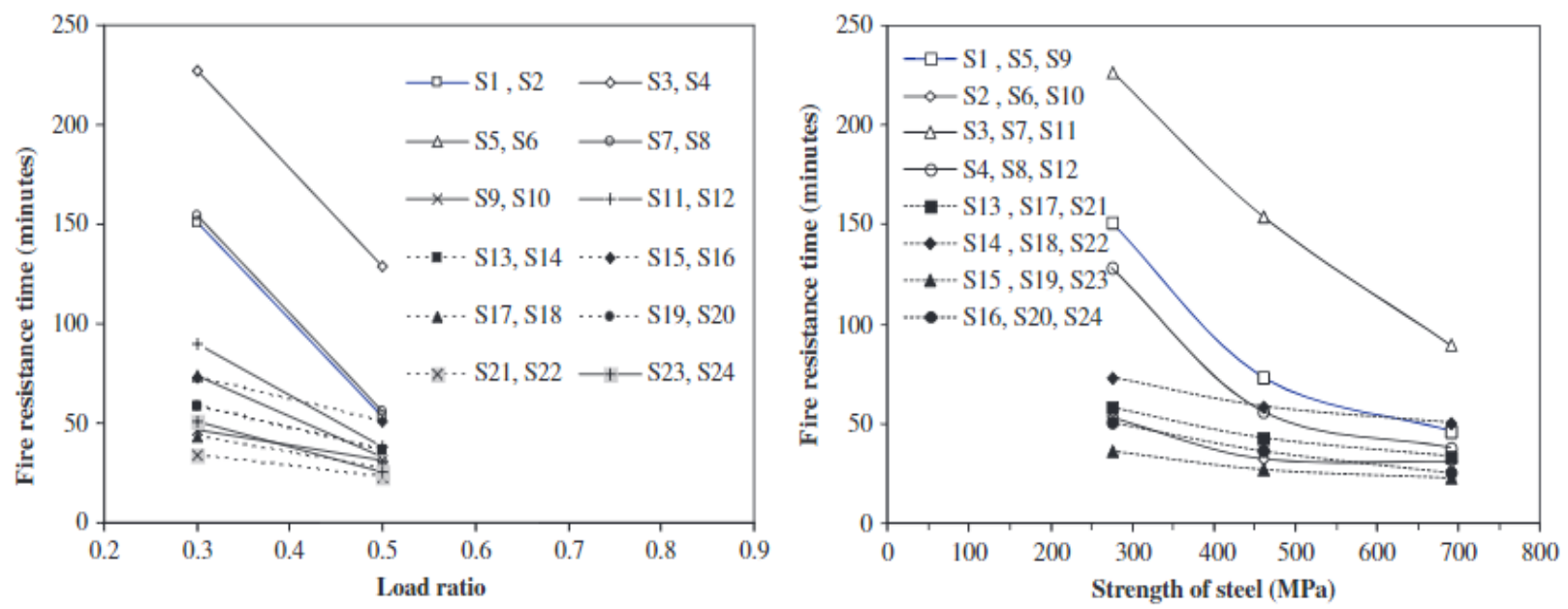

Figure 2.28: Varying steel yield strength as a function temperature (Wang and Young, 2013)

The importance of increasing the yield strength of steel was however demonstrated in conditions where the applied load was kept constant. Figure 2.29 shows the axial deformation vs. time curve for G3 and G4 where a constant load of $2933 \mathrm{kN}$ was applied to each FE simulation. In this case, a significant increase in the fire resistance was observed when the improved yield strength of 690 MPa was compared to that of $275 \mathrm{MPa}$ (Wang and Young, 2013). Figure 2.29 shows the axial deformation vs. time curves for S4 and additional specimens in G4. S275, S460 and S690 represent the 275, 460 and $690 \mathrm{MPa}$ alternates for the yield strength of steel tubes. From Figure 2.29 , it was observed that the maximum displacement of S690 steel was about double in value 
when compared to that of S275 steel. In addition, the fire resistance time for S690 was about 20 min longer than that of S275 steel, indicating a better fire behaviour for tubes with higher steel yield strength when applied load is kept constant.

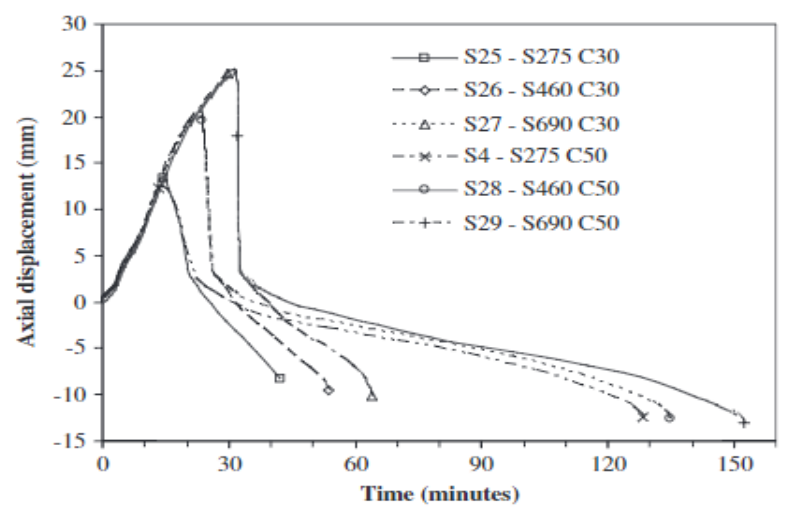

Figure 2.29: Fire resistance curves with alternating steel yield strength (Wang and Young, 2013) The effect of increasing the compressive strength of concrete was also noted in the FE study conducted by Wang and Young (2013). FE models included in G1 and G2 were used as means to determine the influence of the compressive strength on the fire behaviour of the column. The compressive strength of the specimens varied between 30 and $50 \mathrm{MPa}$ with alternating load ratios of 0.3 and 0.5 . It was observed that an increase in the strength of concrete correlated with a significant increase in the fire resistance of the column (Wang and Young, 2013). This was to be expected as the higher strength in concrete was able to withstand the applied load for a longer period of time before collapse (Wang and Young, 2013). It was also observed that models in G1 demonstrated a much improved fire resistance when compared to the models from G2 (Wang and Young, 2013). This was attributed to the large diameter of $400 \mathrm{~mm}$ for G1 specimens which resulted in crushing failure and thus a much higher load resistance whilst G2 had a fixed diameter of $200 \mathrm{~mm}$ encouraging a global buckling failure (Wang and Young, 2013). This led to a much reduced resistance in applied load relative to stub columns (Wang and Young, 2013). Figure 2.30 shows the existing relationship between the fire resistance time and concrete compressive strength. A parametric study on the use of carbonate and siliceous aggregate in concrete was also investigated in the FE research by Wang and Young (2013). Different material models obtained from Eurocode part- 4 standards were designated for siliceous and carbonate based concrete material. It was observed that carbonate based concrete showed a higher fire resistance when compared to siliceous based concrete (Wang and Young, 2013). This was to be 
expected as the carbonate aggregate had a higher specific heat value and thus a higher thermal resistance. Figure 2.31 shows the axial deformation vs. time curves for carbonate and silicate based concrete mixture with $\mathrm{C} 30$ and C50 refereeing to compressive strength of 30 and $50 \mathrm{MPa}$ respectively.

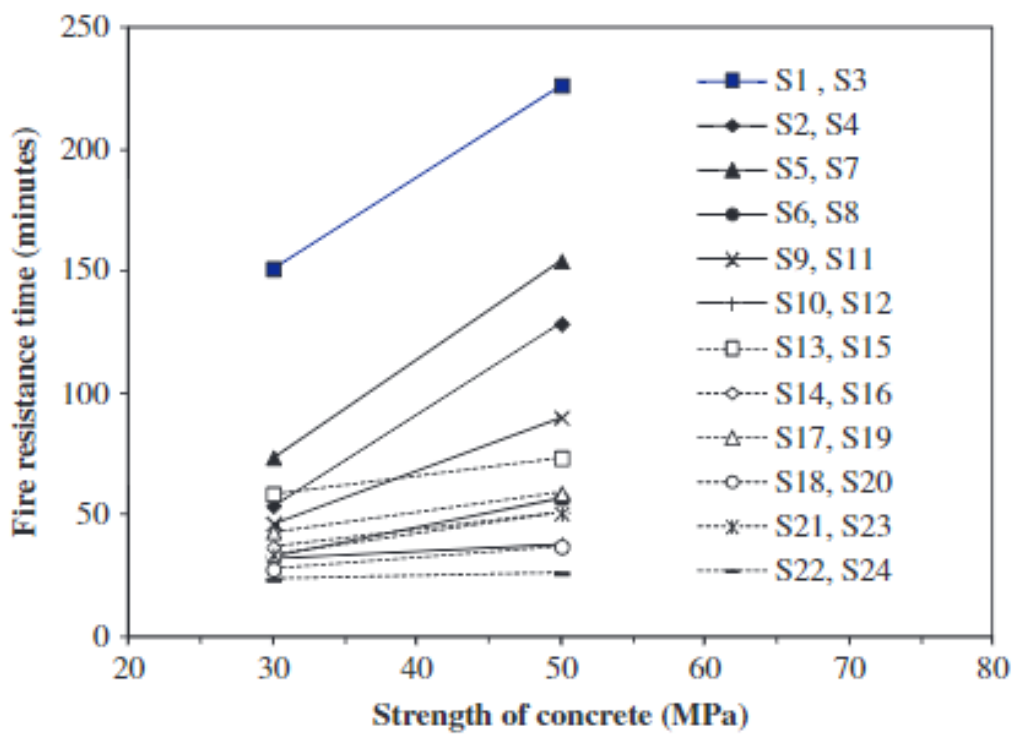

Figure 2.30: Change in fire resistance time with respect to concrete compressive strength (Wang and Young, 2013)

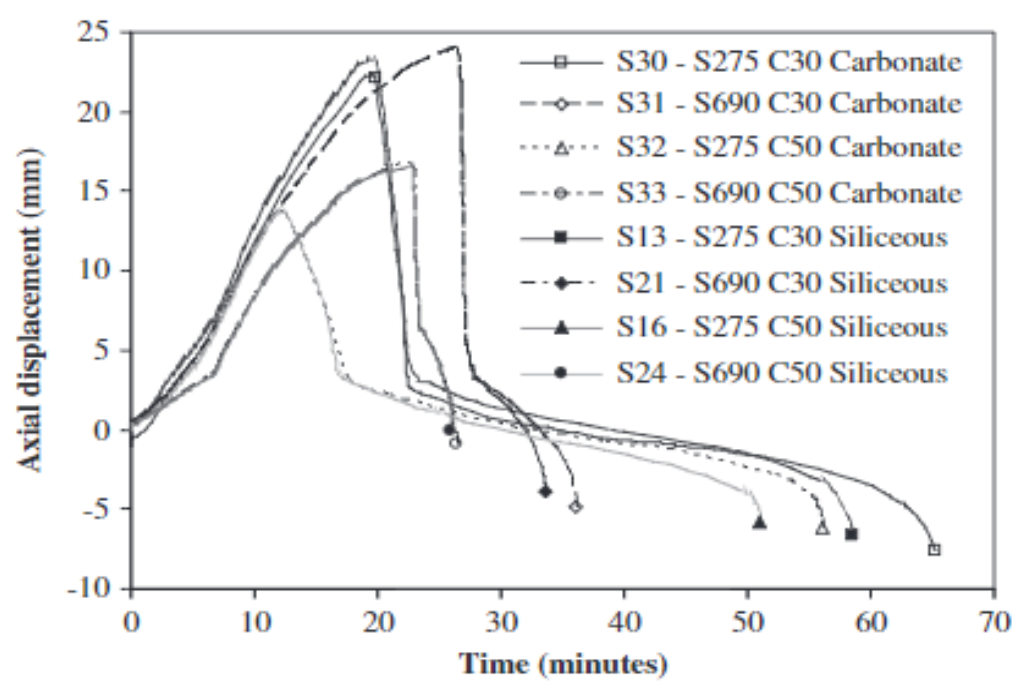

Figure 2.31: Axial displacement for carbonate and silicate based concrete mixtures (Wang and Young, 2013) 
The effect of percentage moisture content by mass of concrete on the fire resistance of CFST columns is also another parameter that was investigated in the FE study by Wang and Young (2013). A total of 6 FE models were generated with varying moisture content "u" of 0,5 and $10 \%$ as well as varying steel yield strength of 275 and $690 \mathrm{MPa}$. It was observed that the increase in the moisture content correlated with a subsequent increase in the fire resistance of the column (Wang and Young, 2013). Since the moisture content is directly linked with the volume of water in the concrete, a high moisture content meant higher water content which acted as a heat absorbent thus leading to additional resistance to the heat transfer in the concrete. The high water content increased in the specific heat of the concrete which meant higher thermal energy was then required to propagate the temperature throughout the concrete cross-section. Figure 2.32 shows the influence of the moisture content on the fire resistance time of the column.

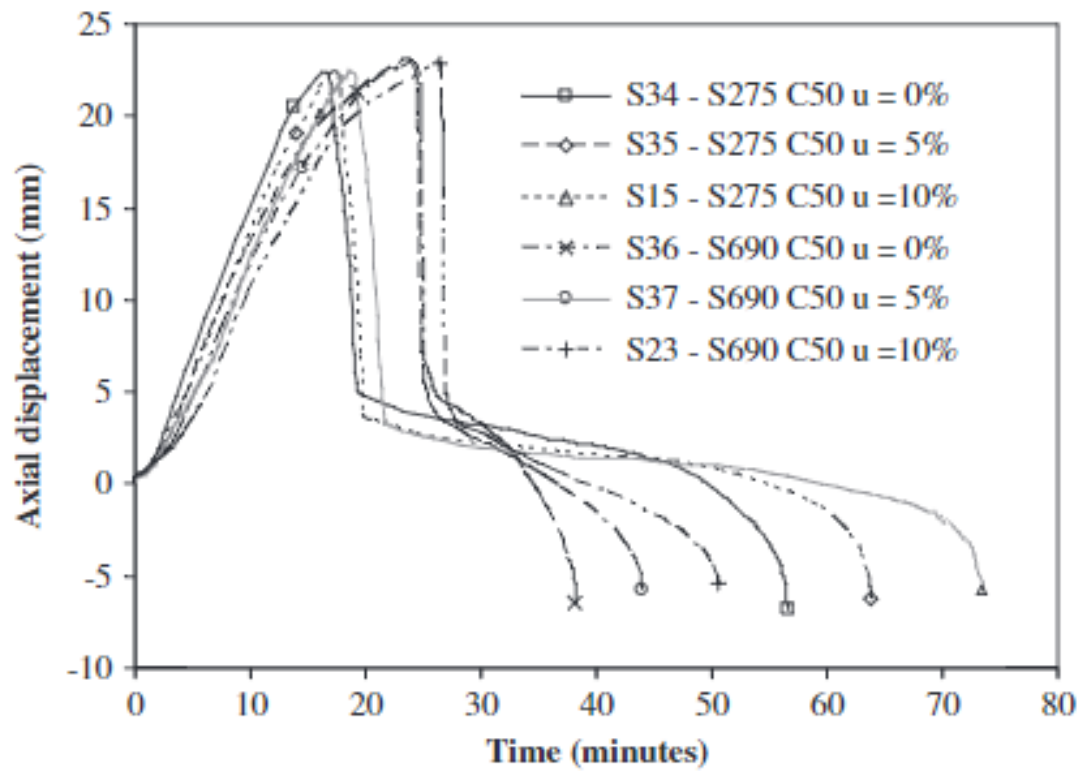

Figure 2.32: Influence of moisture content on the axial displacement of CFST columns (Wang and Young, 2013)

Another FE study on the fire behaviour of concrete filled double steel tubular (CFDST) columns was performed by Yao et al. (2016). FE models were generated to determine the fire resistance of CFDST stub columns under the combined effect of ISO-834 fire temperature and axial compressive loads. Heat transfer and 3-dimensional (3D) stress models were validated based on experimental tests obtained from $\mathrm{Lu}$ et al. (2010). Test results for three columns with inner and outer circular tube sections and three columns with square inner and outer steel tube sections 
were used to validate the proposed FE procedure (Yao et al. 2016). The length of the tested columns was $800 \mathrm{~mm}$ while the diameter/width of the inner and outer steel tubes were varied between 200 and $406 \mathrm{~mm}$ (Lu et al. 2010). The thickness of the steel tube ranged between 5-8 and 3-5 $\mathrm{mm}$ for outer and inner steel sections respectively ( $\mathrm{Lu}$ et al. 2010). Results were compared in terms of predicted and tested failure mode, temperature distributions along the cross-section and axial displacement vs. time curves (Yao et al. 2016). FE results showed good and reasonably accurate results when compared with test data, thus validating the outlined FE procedure (Yao et al. 2016). An additional total number of $42 \mathrm{FE}$ models were then generated to conduct parametric studies on the effects of slenderness, load ratio, load eccentricity, material strength and steel tube thickness on the fire resistance of the CFDST columns.

Slenderness is defined as the ratio of the column length (L) to the width/outer diameter length $\left(D_{o}\right)$. Fifteen FE models referred to as $\mathrm{S} 1, \mathrm{~S} 12, \mathrm{~S} 23, \mathrm{~S} 3, \mathrm{~S} 14, \mathrm{~S} 25, \mathrm{~S} 4, \mathrm{~S} 15, \mathrm{~S} 26, \mathrm{~S} 5, \mathrm{~S} 16, \mathrm{~S} 27$, S6, S17, S28 were generated to establish the influence of slenderness on the fire behaviour of the column (Yao et al. 2016). Such models were arranged in five groups where slenderness was the variable in each group while the load ratio, eccentricity and column capacity at ambient temperature were kept constant (Yao et al. 2016). CFDST columns referred to as S1, S12 and S23 were included in a single group with relative slenderness ratios of $0.11,0.27$ and 0.41 respectively. Results indicated that the increase in slenderness led to significant decrease in the fire resistance of the column. Figure 2.33 shows existing relationship between the slenderness and fire resistance time ( $\mathrm{min}$ ) (Yao et al. 2016). This was due to the loss of stiffness caused by the global buckling of the column which in turn led to a reduction in column capacity when compared with alternative columns with lower relative slenderness (Yao et al. 2016).

The effect of applied load on the fire resistance of CFDST columns was determined by altering the load ratio while maintaining constant material properties and slenderness ratio (Yao et al. 2016). Eight FE models referred to as S1, S2, S12, S13, S23, S24, S34 and S35 were generated to investigate the effects changing the value of applied load in the obtained fire resistance (Yao et al. 2016). It was observed that an increase in the load ratio led to a drastic decrease in the fire resistance of the column (Yao et al. 2016). 


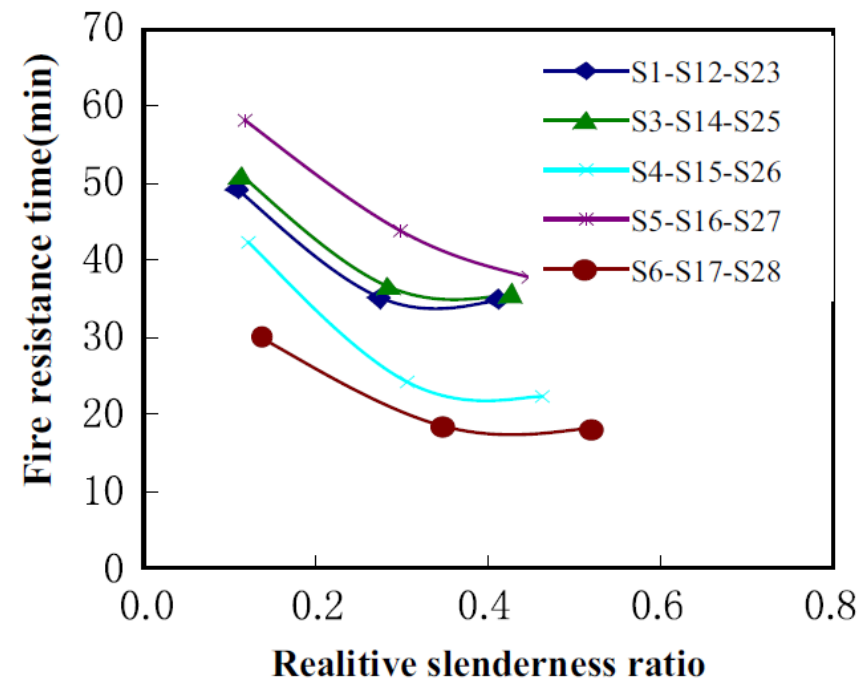

Figure 2.33: Effect of slenderness of the fire resistance of the column (Yao et al. 2016)

Figure 2.34 shows the results for the effects of varying load ratios with respect to fire resistance. Such observed behaviour was to be expected as the increase in load ratio led to a decrease in the bearing capacity of the column (Yao et al. 2016). In fact, the observed response is consistent with the other FE study by (Dai et al. 2012; Huo et al. 2009; Liu et al. 2010; Lu et al. 2011; Wang and Young, 2013) that was described earlier where the increase in load ratio led to the subsequent decrease in fire resistant of the column. The consistency in observed results further validates the concluding argument of a significant decrease in fire resistance when applied load increases.

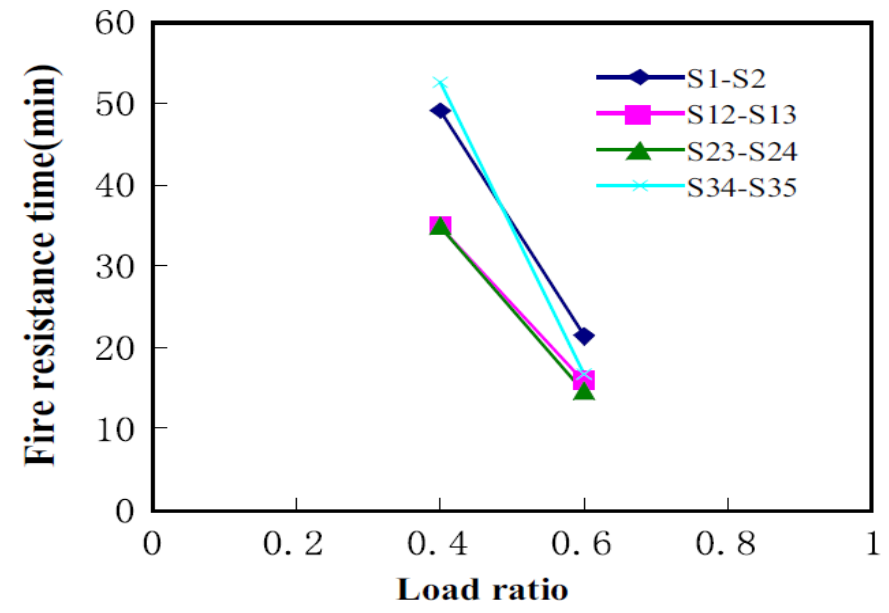

Figure 2.34: Effect of load ratio on the fire resistance of the column (Yao et al. 2016) 
Eight FE models were generated to determine the effects of load eccentricity on the fire behaviour of CFDST columns (Yao et al. 2016). FE of columns with loads applied concentrically and at a distance of $75 \mathrm{~mm}$ from the centre of gravity of the cross-section were generated (Yao et al. 2016). Figure 2.35 shows the fire resistance time associated to each FE simulation. S1, S8, S12, S19, S23, S30, S34, S41 are FE simulations comprised of four groups where the applied load and material properties are kept constant while eccentricity is alternated from 0 to $75 \mathrm{~mm}$ (Yao et al. 2016). It was observed that eccentricity had an insignificant influence on the fire resistance of the column (Yao et al. 2016). Such behaviour was observed due to the addition of the inner steel tube which acted as a resisting component to the additional bending moment caused by the eccentricity (Yao et al. 2016). This was attributed to the low increase in temperature of the inner steel tube (Yao et al. 2016).

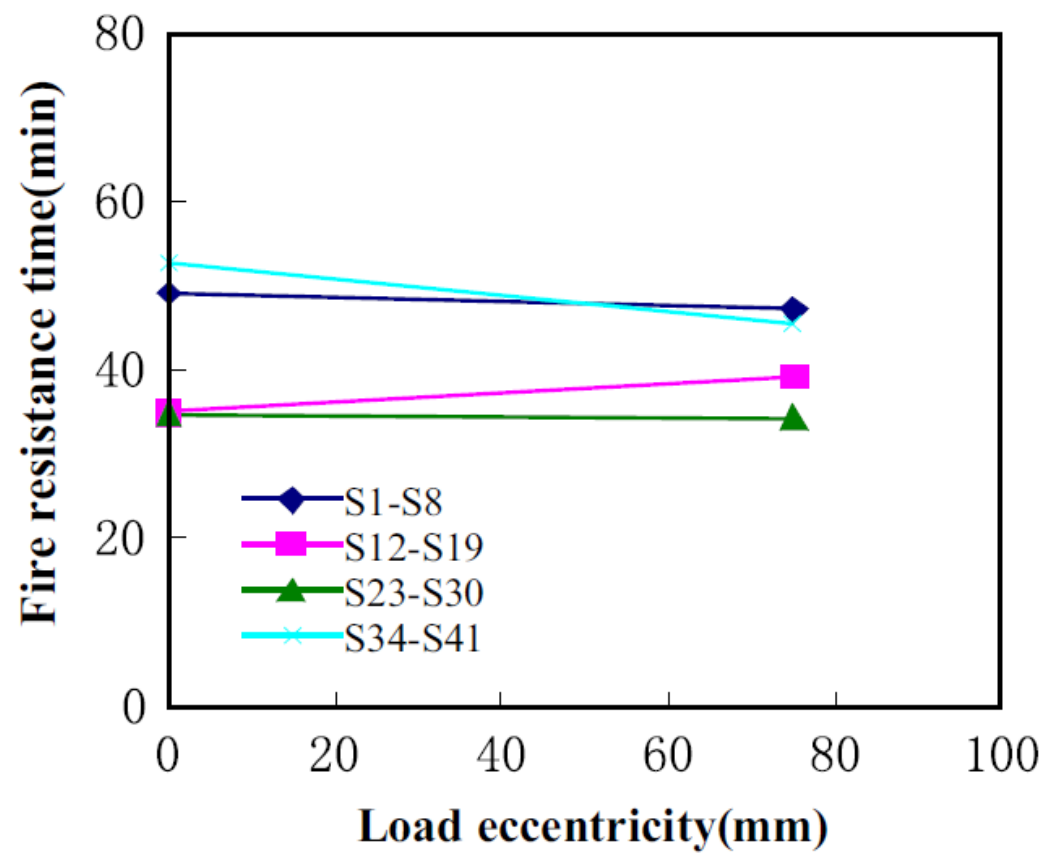

Figure 2.35: Effect of eccentricity on the fire behaviour of CDFST columns (Yao et al. 2016)

The change in the fire behaviour of CFDST columns linked to the increase in the strength of the outer steel tube was also investigated in the FE study proposed by Yao et al. (2016). Twelve FE models arranged into four groups were generated to assess the fire resistance relative to the strength of the external steel tube (Yao et al. 2016). FE simulations were referred to as S1, S4, S6, S12, S15, S17, S23, S26, S28, S34, S37 and S39 with strength of external steel tube varied from 275 to $630 \mathrm{MPa}$ while the strength of internal steel tube and concrete core were kept 
constant (Yao et al. 2016). Figure 2.36 shows the effects of the strength of external steel tube with respect to fire resistance of the column. It was observed that the higher the strength of the outer steel tube, the lower the fire resistance of the column (Yao et al. 2016). This was to be expected since the outer steel was directly exposed to fire, the increase in strength was of no benefit (Yao et al. 2016).

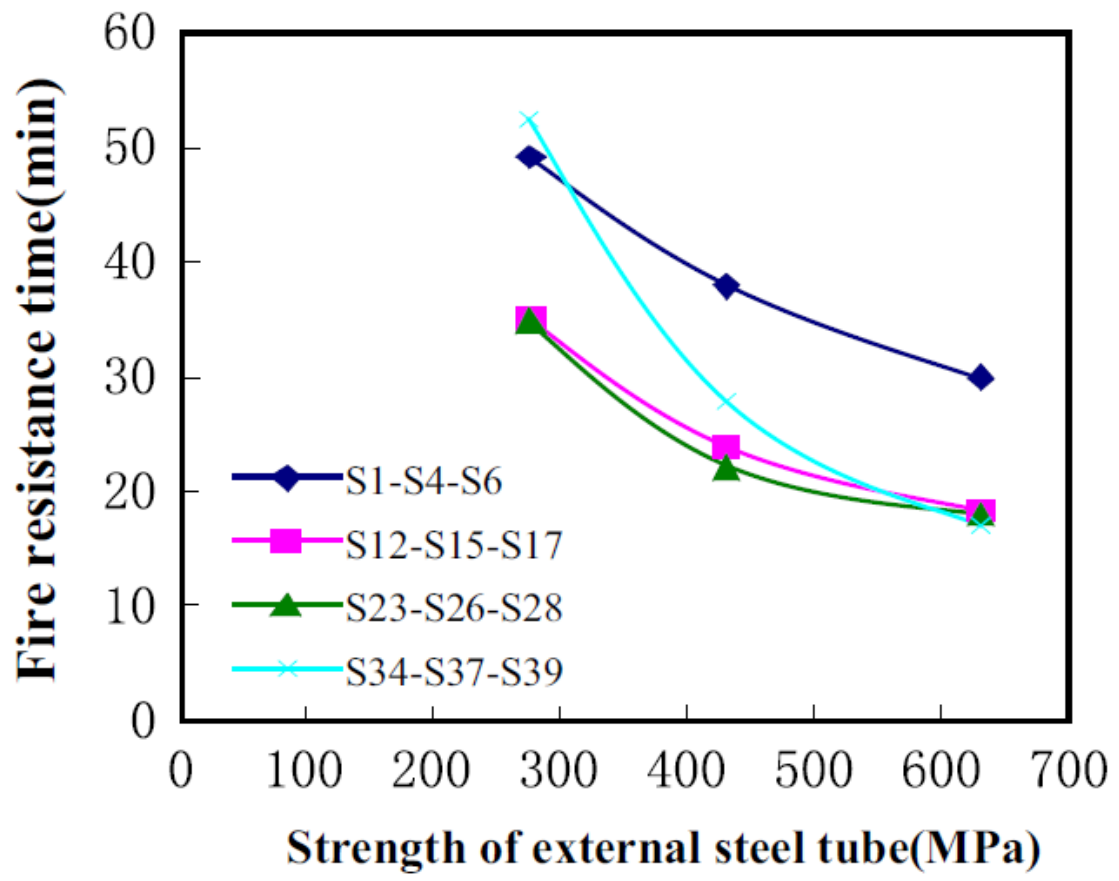

Figure 2.36: Strength of external steel tube vs. fire resistance of CFDST columns (Yao et al. 2016)

Different results were observed when the strength of the inner steel tube was increased (Yao et al. 2016). In fact, the opposite behaviour was observed where the increase in the steel strength led to an increase in the fire resistance of the column (Yao et al. 2016). Figure 2.37 shows the relationship existing between the strength of the inner steel tube and the fire resistance of the column. In Figure 2.37, S1, S3, S5, S12, S14, S16, S23, S25, S27, S34, S36 and S38 are FE simulations where the strength of the inner steel tube was varied from 270 to $630 \mathrm{MPa}$ while all other properties were kept constant (Yao et al. 2016). Such results were to be expected since the applied fire temperature has a reduced effect on the mechanical properties of the inner steel tube due to the presence of the surrounding concrete acting as a protective coat. 


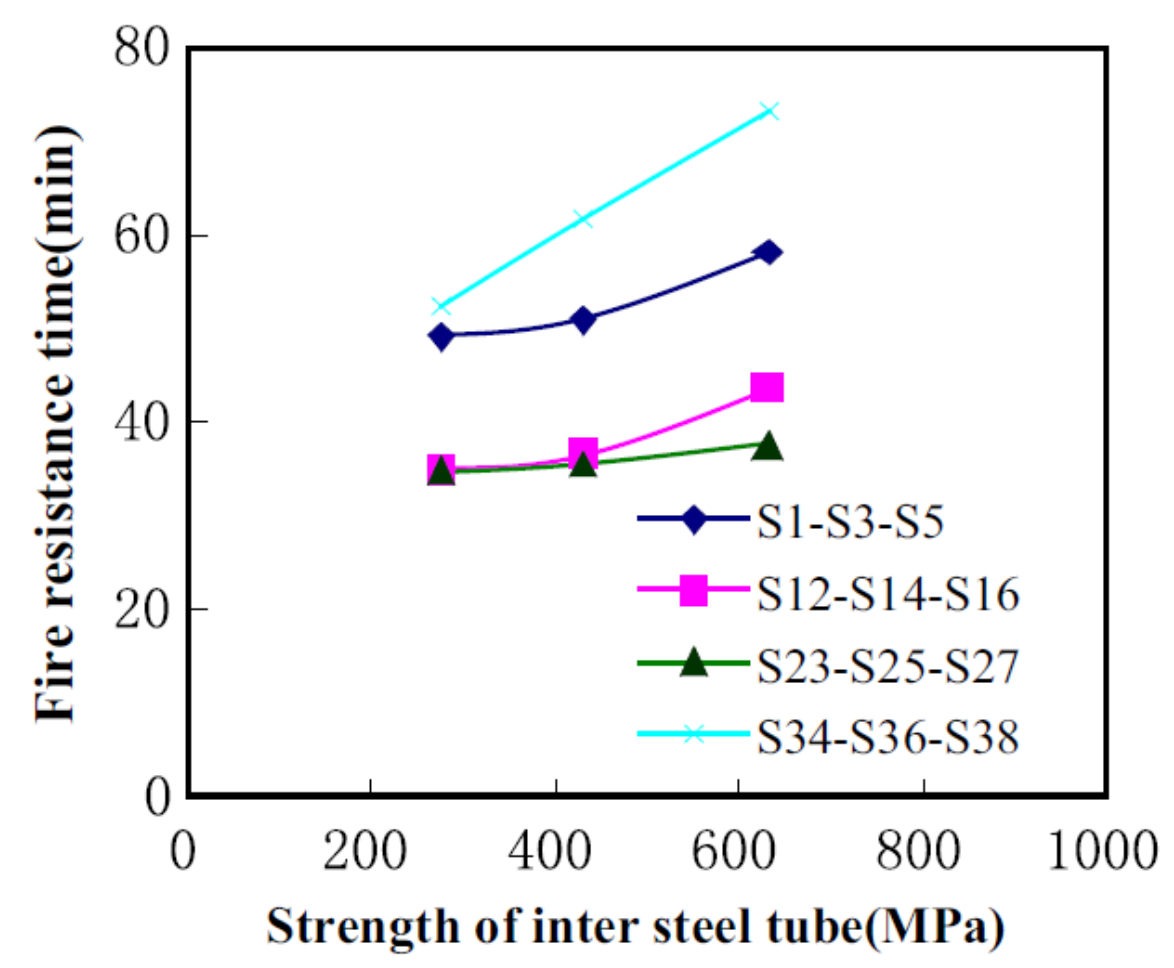

Figure 2.37: Strength of internal steel tube vs. fire resistance of CFDST columns (Yao et al. 2016)

The effect of concrete strength on the fire behaviour of CFDST columns was also illustrated by the FE research study conducted by Yao et al. (2016). In this case, eight FE simulations referred to as S1, S7, S13, S18, S24, S29, S34 and S40 were generated to investigate the changes in fire resistance when concrete strength was varied from 30 to $60 \mathrm{MPa}$ (Yao et al. 2016). In this case, the strength of concrete is the only varied parameter with all other parameters such as load ratio, column geometry and mechanical properties of steel were kept constant (Yao et al. 2016). Figure 2.38 shows the effects of concrete strength on the fire resistance of CFDST columns for all eight FE simulations while arranged into four groups (Yao et al. 2016). It was observed that the increase in concrete strength did not have a significant impact on the fire resistance of the column (Yao et al. 2016). Since the load ratio was kept constant, the increase in concrete strength was countered by a subsequent increase in applied load (Yao et al. 2016). This limited the change in fire resistance time to a negligible value (Yao et al. 2016). 


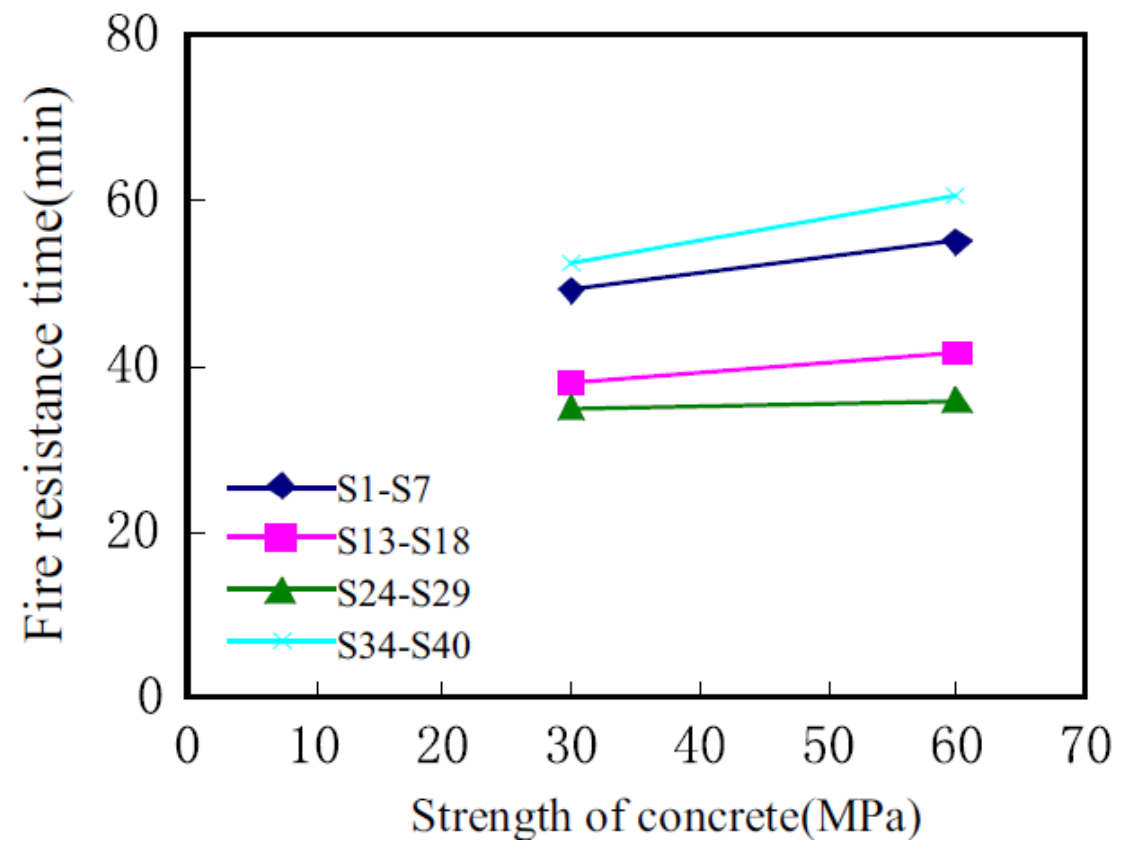

Figure 2.38: Strength of internal steel tube vs. fire resistance of CFDST columns (Yao et al. 2016)

The influence of the thickness of the inner and outer steel tube was also investigated in the FE study presented by Yao et al. (2016). The influence of such parameter was computed by obtaining the ratio of the inner to outer steel tube cross-sectional areas (Yao et al. 2016). Eight FE simulations referred to as S1, S9, S12, S20, S23, S31, S34 and S42 were developed with steel thickness being the only varying parameter while all other parameters such as material strength and geometry were kept constant (Yao et al. 2016). Figure 2.39 shows the influence of steel tube thickness relative to fire resistance. In Figure 2.39, $A_{\text {in }}$ and $A_{\text {out }}$ refer to the inner and outer steel tube cross-sectional areas. It was observed that increase in the ratio of $A_{\text {in }} / A_{\text {out }}$ resulted in a drastic increase in the fire resistance of the column (Yao et al. 2016). As such, it can be inferred that the increase in the thickness of the inner steel tube had a significant increase in the fire resistance time (Yao et al. 2016). This observation was to be expected since the increase in the thickness of the inner steel tube was related to an increase in strength which was proven to be directly linked to an improved fire resistance of the column (Yao et al. 2016). This was shown in Figure 2.39 where the strength of the inner steel tube was compared to the fire resistance of the CFDST column. 


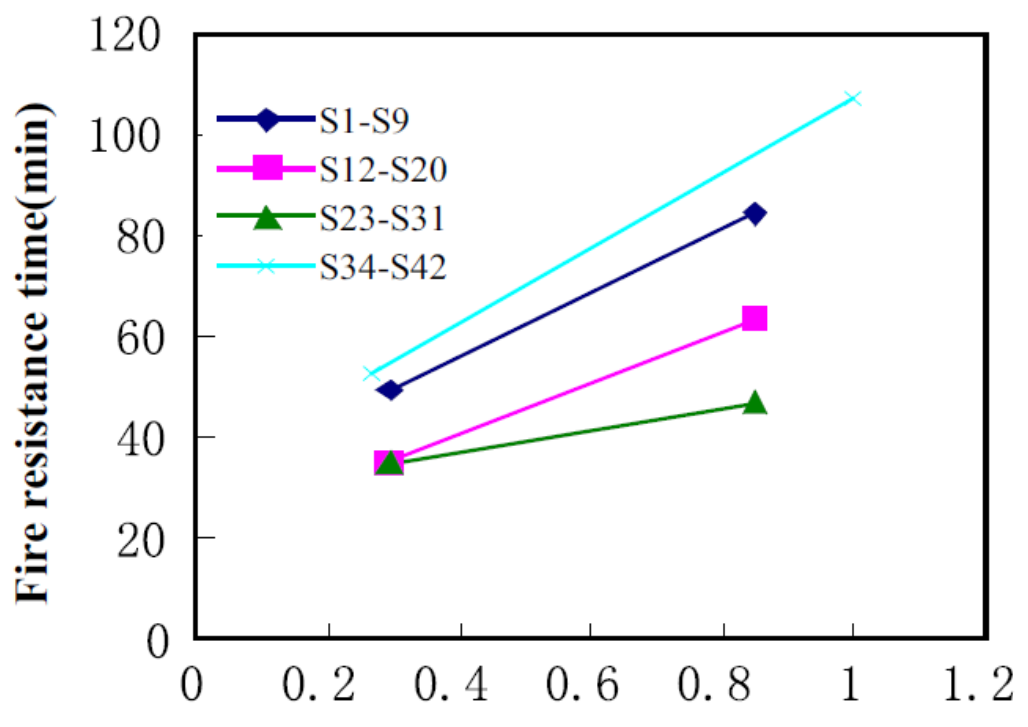

Ain/Aout

Figure 2.39: Influence of $A_{\text {in }} / A_{\text {out }}$ on the fire resistance of CFDST columns (Yao et al. 2016)

\subsection{Thermal Properties of Concrete}

The thermal properties of self-consolidating concrete (SCC), engineered cementitious concrete (ECC), ultra-high strength/performance concrete (UHPC) and normal strength concrete (NSC) are described and defined in this section. Changes in the density, thermal conductivity and specific heat when exposed to elevated temperature for all four concrete alternatives are summarized in the following.

\subsubsection{Density}

According to an experimental study by Şahmaran et al. (2009), the change in density of typical self-consolidating engineered cementitious concrete referred to as M45 when subjected to elevated temperatures was directly attributed to the percentage mass loss of the specimen. In this case, $50 \mathrm{~mm}$ cubes composed of engineered cementitious concrete were cast and heated through use of a computer controlled electrically heated furnace to desired target temperatures of 200, 400, 600 and $800^{\circ} \mathrm{C}$ (Şahmaran et al. 2009). Specimens were heated at a rate of $15^{\circ} \mathrm{C} / \mathrm{minute}$ until desired temperature was reached. The target temperature was then maintained constant for a period of 60 minutes, after which the specimen was exposed to room temperature where uncontrolled cooling occurred (Şahmaran et al. 2009). Figure 2.40 shows the measured 
percentage of mass loss values for the tested ECC specimens. Percentage mass loss $\left(M_{i} / M_{0}\right)$ is defined as the ratio of the mass after exposure to high temperature $\left(M_{i}\right)$ relative to the specimen mass prior to temperature exposure $\left(M_{0}\right)$.

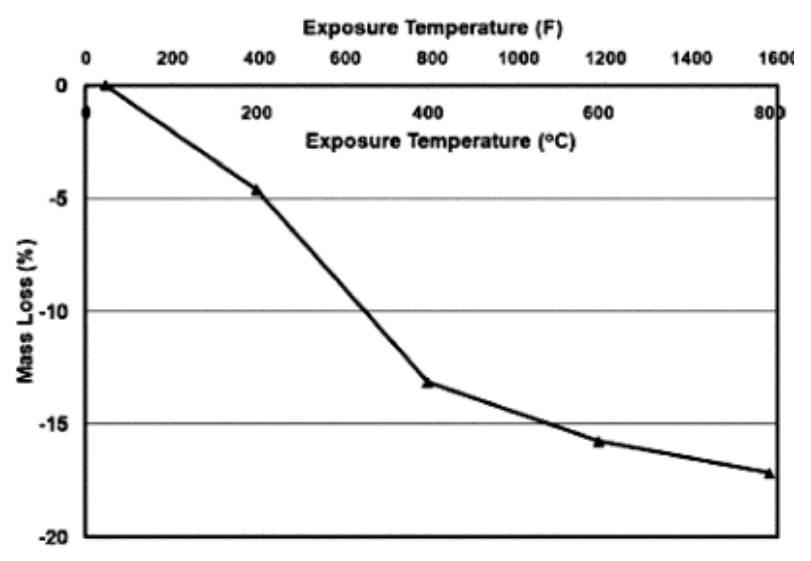

Figure 2.40: Percent mass loss (\%) for ECC at elevated temperature (Şahmaran et al. 2009)

According to Li et al. (2008), the density of ECC was measured to be ranging between 900 and $2300 \mathrm{~kg} / \mathrm{m}^{3}$. Such wide range was the result of different combinations of the mix designs available to generate various alternative ECC mixtures such self-consolidating and lightweight ECC (Li et al. 2008). According to an experimental research study by Boughanem et al. (2011) on the physical characteristics of ECC, it was determined that the average density of ECC was $1900 \mathrm{~kg} / \mathrm{m}^{3}$. Such value was obtained by performing density calculations on a total of $19 \mathrm{ECC}$ specimens.

Experimental data on the percentage of mass loss of SCC when exposed to elevated temperature obtained from Taormina (2012) is shown in Figure 2.41. In this study, concrete cylinders with dimension of $100 \times 200 \mathrm{~mm}$ (diameter $\mathrm{x}$ height) were exposed to elevated temperatures (Taormina, 2012). The percent mass loss for SCC was obtained by exposing the concrete cylinders to elevated peak temperatures of 400,600 and $800^{\circ} \mathrm{C}$ (Taormina, 2012). An electric kiln was used to heat up the concrete specimens with a rate of increase $2.5 \%$ until desired peak temperatures were reached (Taormina, 2012). The peak temperature was then maintained constant for a period of 1 hour after which the concrete specimen was exposed to room temperature $\left(20^{\circ} \mathrm{C}\right)$ where uncontrolled cooling took place (Taormina, 2012). The change in mass loss was computed by measuring the weight of the concrete specimen at ambient temperature $\left(20^{\circ} \mathrm{C}\right)$ and after exposure to desired elevated temperature. The ratio of differential 
change in weight with respect to original weight of concrete at elevated temperature indicated the percent mass loss for SCC shown in Figure 2.41 (Taormina, 2012).

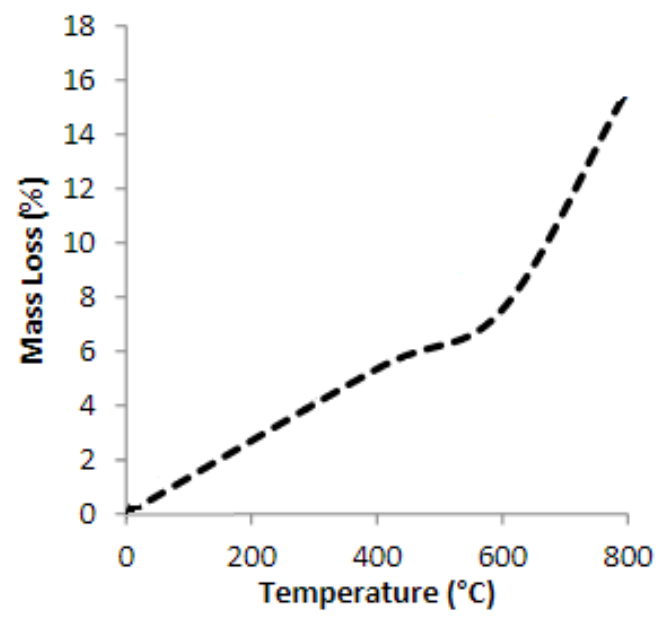

Figure 2.41: Percent mass loss (\%) of SCC at elevated temperature (Taormina, 2012)

The density of SCC at ambient temperature is mainly dependant on the type of aggregate used in the mix design. According to an experimental study performed by Kim et al. (2010) on the characteristics of SCC, the density in accordance to 9 SCC mix designs was ranging between 1965 and $2300 \mathrm{~kg} / \mathrm{m}^{3}$.

According to an experimental study on the effects of elevated temperature on ultra-high strength/performance concrete (UHPC), the percent mass loss (\%) at elevated temperature was relative to the amount of spalling the specimen experienced (Choe et al. 2015). In this case, concrete cylinders with dimensions of $100 \times 200 \mathrm{~mm}$ (diameter $\mathrm{x}$ height) were heated in accordance to the ISO-834 fire temperature (Choe et al. 2015). It was observed that the level of spalling that the concrete specimen experienced was directly related to the amount of fibre present within the mix design and the compressive strength of concrete cylinder (Choe et al. 2015). The test specimens were exposed to the ISO-834 fire temperature for a period of $50 \mathrm{~min}$ before cooling occurred (Choe et al. 2015). The mass loss was determined by evaluating the differential in weight of the concrete specimen before and after exposure to temperature. Test results indicated that no spalling occurred for specimens with compressive strength range of 100$150 \mathrm{MPa}$ and percent volume in fibres of $0.15 \%$ (Choe et al. 2015). The total percentage of weight loss was mainly due to the evaporation of water with a maximum value of $6 \%$ mass loss observed for such concrete specimens (Choe et al. 2015). However, for concrete specimens with 
compressive strength of $200 \mathrm{MPa}$ and percent volume in fibre of $0.15 \%$, surface spalling did occur exhibiting total percentage of mass loss of $20 \%$ (Choe et al. 2015). Figure 2.42 shows the spalling propriety of UHPC relative to peak compressive strength and percent volume of fibres and when exposed to ISO-834 fire temperature for a period of $50 \mathrm{~min}$.

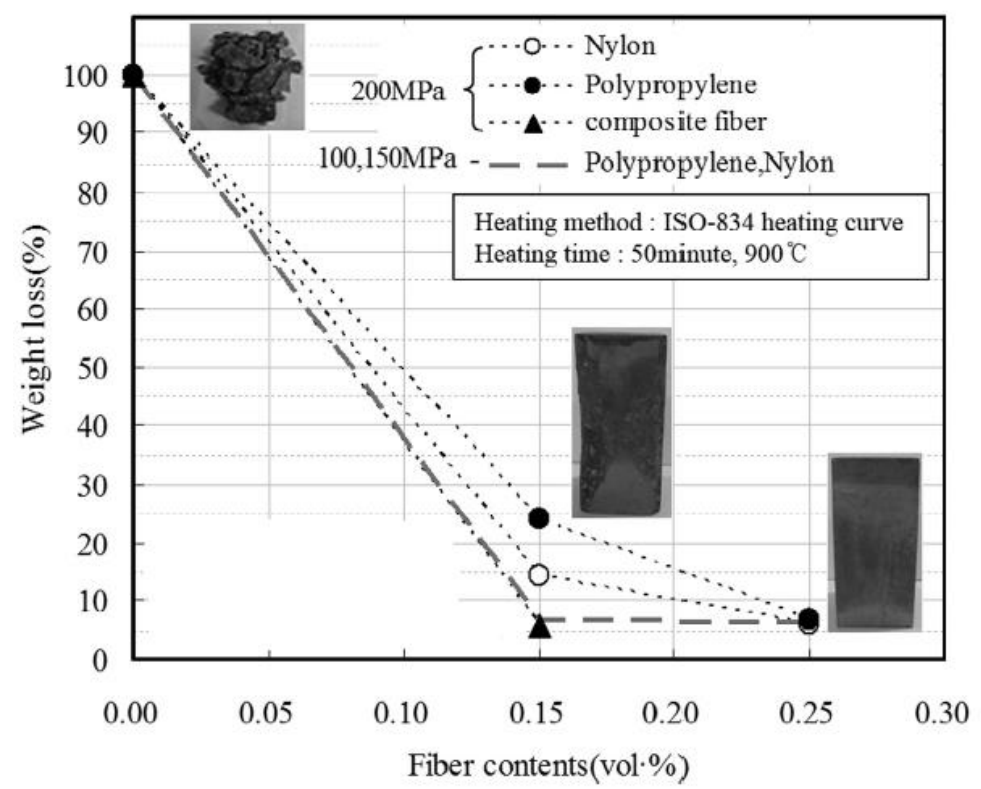

Figure 2.42: Effect of fibre content and compressive strength on the spalling property of UHPC

(Choe et al. 2015)

Figure 2.42 summarizes the effects of using alternative types of fibres and compressive strength on the spalling property of UHPC when exposed to elevated temperature. Alternative fibres such as the use of nylon, polypropylene and composite fibre were evaluated against spalling when the concrete specimen was exposed to fire temperature (Choe et al. 2015). As shown in Figure 2.42, concrete specimens with compressive strength values of 100, $150 \mathrm{MPa}$ with polypropylene and nylon fibre content of at least $0.15 \%$ performed best with no spalling observed at elevated temperature (Choe et al. 2015).

In the experiment by (Taormina, 2012), percent mass loss (\%) was obtained for temperatures below $400^{\circ} \mathrm{C}$. The mass loss for higher temperatures could not be acquired due to the spalling nature of the concrete specimen (Taormina, 2012). When exposed to elevated temperatures higher than $400^{\circ} \mathrm{C}$, spalling occurred, rendering the specimen inadequate (Taormina, 2012). Figure 2.43 shows the percent mass loss for UHPC for peak temperatures below $400^{\circ} \mathrm{C}$. 


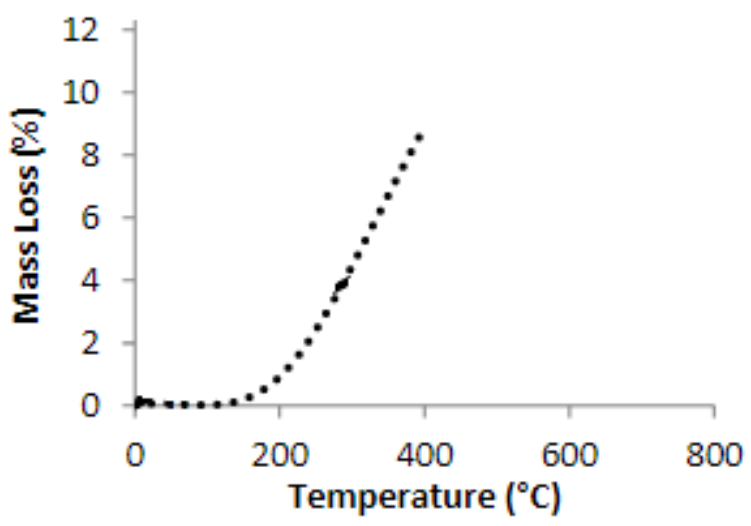

Figure 2.43: Percent mass loss (\%) of UHPC at elevated temperature (Taormina, 2012)

Although there is very limited information on the varying density of ECC, SCC and UHPC in the literature, several model currently exist to define the change in density of normal strength concrete (NSC) when exposed to elevated temperature. According to the Eurocode 2 (2005) standards, the density of NSC is dependent on the temperature of exposure. The change in density is attributed to the evaporation of water and de-carbonation of carbon dioxide. Equation 2.2 is used to determine the change in density with respect to elevated temperature where $\rho(\theta)$ refers to the density at elevated temperature.

$$
\begin{array}{ll}
\rho(\theta)=\rho\left(20^{\circ} C\right) & \text { for } 20 \leq \theta \leq 115^{\circ} C \\
\rho(\theta)=\rho\left(20^{\circ} C\right) \cdot(1-0.02(\theta-115) / 85) & \text { for } 115 \leq \theta \leq 200^{\circ} C \\
\rho(\theta)=\rho\left(20^{\circ} C\right) \cdot(0.98-0.03(\theta-200) / 200) & \text { for } 200 \leq \theta \leq 400^{\circ} C \\
\rho(\theta)=\rho\left(20^{\circ} C\right) \cdot(0.95-0.07(\theta-400) / 800) & \text { for } 400 \leq \theta \leq 1200^{\circ} C
\end{array}
$$

In Equation 2.2, $\rho\left(20^{\circ} \mathrm{C}\right)=2300 \mathrm{~kg} / \mathrm{m}^{3}$ (Eurocode 2, 2005).

Another model proposed by the American Society of Civil Engineers (ASCE) could also be used to determine the density of NSC at elevated temperature. In this case, the value of the density is independent of the temperature (ASCE, 1992). As a result, the density of NSC is maintained constant at a value of $2300 \mathrm{~kg} / \mathrm{m}^{3}$ throughout all elevated temperatures (ASCE, 1992).

\subsubsection{Specific Heat Capacity}

According to an experimental study performed by Kodur and Khaliq (2011), the specific heat of concrete was mainly affected by the presence of moisture, type of aggregates used and density of 
concrete. Specific heat within a solid element is determined through use of the differential scanning calorimetry (DSC) method which consists on measuring the differential heat flow of the tested specimen relative to a reference material. The specimen is placed in a DSC test chamber where calibrated heating occurs all the while a data acquisition system is used to record energy changes within the specimen (ASTM, 2011).

According to the Eurocode 4 (2005) standards, the specific heat of NSC is dependant on the moisture content of concrete. The changes in moisture content are defined by changes in the peak point of the specific heat $\left(\mathrm{C}_{\mathrm{c}}\right)$ curve. This peak point occurs between temeprature ranges of 115$200^{\circ} \mathrm{C}$. The value of the peak specific heat $[\mathrm{J} / \mathrm{kgK}]$ as defined in Equation 2.3 is depandent on the percent moisture content in the concrete.

$C_{c, \text { peak }}=900 \quad$ for $0 \%$ moisture content

$C_{c, \text { peak }}=1470 \quad$ for $1.5 \%$ moisture content

$C_{c, p e a k}=2020 \quad$ for $3 \%$ moisture content

$C_{c, p e a k}=5600 \quad$ for $10 \%$ moisture content

The specific heat model in terms of $[\mathrm{J} / \mathrm{kgK}]$ for NSC under dry condition ( $0 \%$ moisture content) is computed through use of Equation 2.4 in accordance to Eurocode 4, 2015.

$$
\begin{array}{ll}
C_{c}=900 & \text { for } 20 \leq \theta_{c} \leq 100^{\circ} C \\
C_{c}=900+\left(\theta_{c}-100\right) & \text { for } 100 \leq \theta_{c} \leq 200^{\circ} C \\
C_{c}=1000+\left(\theta_{c}-200\right) / 2 & \text { for } 200 \leq \theta_{c} \leq 400^{\circ} C \\
C_{c}=1100 & \text { for } 400 \leq \theta_{c} \leq 1200^{\circ} C
\end{array}
$$

The ASTM standards can also be used to determine the specific heat of NSC under the effects of high temperature. In this case, the ASTM standards take into account the type of aggregate used in the normal strength concrete mix design. Since the concrete mixture can take different material propreties, the ability of withstanding exposure could also be different from one NSC mixture to another. ASTM standard takes into account the variability of concrete by specifiying whether the mixture is based of carbonate or siliceous aggregates. Carbonate aggregate is composed of dolomite and limestone which tend to have higher strength and fire reistance when compared to silicious concrete which is composed of standstone and granite. In fact, according to 
the Portland Cement Association (PCA), the strength of silicious concrete can decrease to 50\% full capacity when exposed to peak temepratures higer than $430^{\circ} \mathrm{C}$ while carbonate based concrete was observed to retain most of its strength up to peak temepratures of $650^{\circ} \mathrm{C}$ (Bilow and Kamara, 2008). As a result, different specific heat models were defined for carbonate and silicious aggregate based NSC. Equation 2.5 is used to define the specific heat model for silicious concrete while Equation 2.6 is used to define the specific heat model for carbonate concrete with both equations retrieved from section A2 of the structural fire protection manual (Bilow and Kamara, 2008).

$$
\begin{aligned}
& \rho_{c} c_{c}=(0.005 T+1.70) \times 10^{6} \quad \text { for } 20 \leq T \leq 200^{\circ} C \\
& \rho_{c} c_{c}=2.70 \times 10^{6} \quad \text { for } 200<T \leq 400^{\circ} \mathrm{C} \\
& \rho_{c} c_{c}=(0.013 T-2.50) \times 10^{6} \quad \text { for } 400<T \leq 500^{\circ} \mathrm{C} \\
& \rho_{c} c_{c}=(-0.013 T+10.50) \times 10^{6} \quad \text { for } 500<T \leq 600^{\circ} C \\
& \rho_{c} c_{c}=2.70 \times 10^{6} \quad \text { for } 600<T \leq 1000^{\circ} C \\
& \rho_{c} c_{c}=2.566 \times 10^{6} \quad \text { for } 20 \leq T \leq 400^{\circ} \mathrm{C} \\
& \rho_{c} c_{c}=(0.1765 T-68.034) \times 10^{6} \quad \text { for } 400<T \leq 410^{\circ} \mathrm{C} \\
& \rho_{c} c_{c}=(-0.05043 T+25.00671) \times 10^{6} \quad \text { for } 410<T \leq 445^{0} C \\
& \rho_{c} c_{c}=2.566 \times 10^{6} \quad \text { for } 445<T \leq 500^{\circ} \mathrm{C} \\
& \rho_{c} c_{c}=(0.01603 T-5.44881) \times 10^{6} \quad \text { for } 500<T \leq 635^{\circ} \mathrm{C} \\
& \rho_{c} c_{c}=(0.16635 T-100.90225) \times 10^{6} \quad \text { for } 635<T \leq 715^{0} C \\
& \rho_{c} c_{c}=(-0.22103 T+176.07343) \times 10^{6} \quad \text { for } 715<T \leq 785^{\circ} C \\
& \rho_{c} c_{c}=2.566 \times 10^{6} \quad \text { for } T>785^{\circ} \mathrm{C}
\end{aligned}
$$

In Equations 2.5 and 2.6,

$\rho_{c}$ refers to the density of the concrete at instantanious temperature $\left[\mathrm{kg} / \mathrm{m}^{3}\right], c_{c}$ refers refers to the specific heat capacity of concrete $[\mathrm{J} / \mathrm{kgK}]$ and $\rho_{c} c_{c}$ refers to the thermal capacity of concrete $\left[\mathrm{J} / \mathrm{m}^{3} \mathrm{~K}\right]$.

Similar to NSC, the specific heat of SCC can be determined through use of experimental research study conducted by Khaliq and Kodur (2011). The experimental research consisted of exposing SCC to temperatures ranging between $\left(20-800^{\circ} \mathrm{C}\right)$. Mathematical model of the specific heat with respect to temperature were obtained based on measured data. It is important to note 
that SCC can only be generated if appropriates properties of tested specimen are coherent with the specifications proposed by Japan Society for Civil Engineers (JSCE) (JSCE, 1998). To be classified as SCC, the tested concrete specimen must comply with a range of volume of coarse aggregate per unit volume $\left(\mathrm{m}^{3} / \mathrm{m}^{3}\right)$, slump flow $(\mathrm{mm})$ and segregation resistance ability (s). Depending on constructability, three classes of SCC are available to specify the required range of values that the volume of coarse aggregate, slump flow and segregation resistance of the tested specimen can fall into. Table 2.2 shows the required properties of SCC for class 1,2 and 3 construction/design requirements.

Table 2.2: Specifications of SCC as proposed by JSCE (JSCE, 1998)

\begin{tabular}{|c|c|c|c|c|}
\hline & & 1 & 2 & 3 \\
\hline \multicolumn{5}{|c|}{ Class of filling ability of concrete } \\
\hline \multirow{2}{*}{ Construction condition } & Minimum gap between reinforcement (mm) & $30-60$ & $60-200$ & $\geq 200$ \\
\hline & Amount of reinforcement $\left(\mathrm{kg} / \mathrm{m}^{3}\right)$ & $\geq 350$ & $100-350$ & $\leq 100$ \\
\hline \multicolumn{2}{|c|}{ Filling height of U-box test (mm) } & $\geq 300$ (rank R1) & $\geq 300$ (rank R2) & $\geq 300$ (rank R3) \\
\hline \multicolumn{2}{|c|}{ Absolute volume of coarse aggregates per unit volume of SCC $\left(\mathrm{m}^{3} / \mathrm{m}^{3}\right)$} & $0.28-0.30$ & $0.30-0.33$ & $0.30-0.36$ \\
\hline Flowability & Slump flow $(\mathrm{mm})$ & $650-750$ & $600-700$ & $500-650$ \\
\hline \multirow[t]{2}{*}{ Segregation resistance ability } & Time required to flow through V-funnel (s) & $10-20$ & $7-20$ & $7-20$ \\
\hline & Time required to reach $500 \mathrm{~mm}$ of slump flow (s) & $5-25$ & $3-15$ & $3-15$ \\
\hline
\end{tabular}

Due to varying nature of the mix design available to generate SCC, variations in the thermal resistance are to be expected. As such, the heat transfer model generated by Khaliq and Kodur (2011) was generalized to mimic the averaged specific heat response of various SCC mixtures. Equation 2.7 obtained from Khaliq and Kodur (2011) is used to define the specific heat $\left(C_{p}\right.$, $\mathrm{MJ} / \mathrm{m}^{3}-{ }^{\circ} \mathrm{C}$ ) of SCC.

$$
C_{p}= \begin{cases}2.4+0.001 T & 20 \leq T \leq 400^{\circ} C \\ 0.6-0.006 T & 400 \leq T \leq 800^{\circ} C\end{cases}
$$

The thermal properties for UHPC differ from that of conventional concrete due to low water-tocement ratio. Little information on the thermal properties of UHPC is available in the literature. As such, the thermal behaviour of ultra-high strength is used to mimic that of ultra-high performance concrete. According to a study by (Xionga and Liew 2016), specific heat of high strength concrete (HSC) can be used for UHPC by implying a $0 \%$ moisture content. This was done to increase the conductivity of UHPC when compared to the conventional HSC (Xionga and Liew 2016). Material model presented by Kodur and Khaliq (2011) is thus used to determine 
the specific heat of UHPC at elevated temperatures. Equation 2.8 is used to compute the specific heat $\left(C_{p}, \mathrm{MJ} / \mathrm{m}^{3}{ }^{\circ} \mathrm{C}\right)$.

$$
C_{p}=\left\{\begin{array}{cc}
2.4+0.0002 T & 20 \leq T \leq 400^{\circ} C \\
1+0.0043 T & 400 \leq T \leq 800^{\circ} \mathrm{C}
\end{array}\right.
$$

\subsubsection{Thermal Conductivity}

According to the experimental results obtained from the research study by Kim et al. (2010), the thermal conductivity of concrete was mainly affected by the volume of aggregate and moisture content. In this case, a QTM-D3 device manufactured in Japan was used to measure the thermal conductivity of concrete where two probes were inserted in the sample with one acting as heat source while the other acting as a temperature sensor (Kim et al. 2010). According to experimental results, a decrease in thermal conductivity was observed with the increase in temperature (Kim et al. 2010). In fact, according to research reported by Morabito (1989), a linear decrease in thermal conductivity was observed with a subsequent increase in temperature.

The research by Kim et al. (2010) examined the influence of the volume of aggregate on the measured thermal conductivity of concrete. Specimen mixtures were prepared with aggregate fractions ranging from $0-0.71$ and were exposed to varying temperatures of 20,40 and $60^{\circ} \mathrm{C}$ while the moisture content was kept constant (Kim et al. 2010). Results showed a linear relationship between the volume of aggregates and thermal conductivity regardless of the changes in temperature (Kim et al. 2010). As such, it can be concluded that increase in the number of aggregates would result in an equivalent increase in the thermal conductivity of concrete (Kim et al. 2010). The effects of water to cement (w/c) ratio was also investigated in the study by Kim et al. (2010). It was observed that a reduction in water to cement ratio led to a subsequent increase in the measured thermal conductivity of concrete (Kim et al. 2010). Such results were to be expected as a reduction in w/c ratio means an increase in the amount of cement in concrete. Since the thermal conductivity of cement is about twice that of water, the increase in amount of cement caused an increase in the thermal conductivity of concrete (Kim et al. 2010; Naus, 2006). According to the experimental study by Kim et al. (2010), the change of moisture content proved to be the factor with the most significant influence on the measured thermal conductivity of concrete. In this case, a drastic increase in the thermal conductivity was observed 
when the moisture content of the specimen was increased. Such drastic change was attributed to increase in water content and decrease in voids present in the concrete (Kim et al. 2010; Naus, 2006). As the water content in the concrete is increased, the air voids within the concrete structure become filled with water, thus reducing the number of air voids of the concrete.

Limited information currently exists in literature on the thermal conductivity of ECC under the effects of elevated temperature. A model for the thermal conductivity of fire-resistant ECC (FRECC) was proposed by (Han et al. 2007). The proposed model was validated by comparing test results with FE models generated through use of defined analytical equations for the thermal conductivity of ECC. Equation 2.9 obtained from Han et al. (2007) is used to determine the thermal conductivity of ECC concrete for temperatures ranging from 0 to $1200^{\circ} \mathrm{C}$. In Equation 2.9, " $\mathrm{T}$ " represents the temperature in $\left[{ }^{\circ} \mathrm{C}\right]$ while $\lambda_{c}$ represents the thermal conductivity of concrete $\left[\mathrm{W} / \mathrm{m}^{\circ} \mathrm{C}\right]$.

$$
\lambda_{c}=\left\{\begin{array}{cc}
1.5-3.2 \times 10^{-3}(T) & 0 \leq T \leq 190{ }^{\circ} C \\
0.9-2.0 \times 10^{-3}(T-190) & 190<T \leq 240{ }^{\circ} C \\
0.8-8.7 \times 10^{-4}(T-240) & 240<T \leq 560^{\circ} C \\
0.5-2.6 \times 10^{-4}(T-560) & 560<T \leq 1200^{\circ} C
\end{array}\right.
$$

Due to the lack of information and experimental data on the thermal conductivity of ECC at elevated temperature, the study by JSCE (2008) suggests the use of thermal models for normal strength concrete (NSC) to approximate the thermal behaviour of ECC under elevated temperature. Since ECC has a smaller thermal conductivity and a higher value for specific heat, it was then assumed that fire resistance of ECC can then be closely represented by the thermal properties of NSC.

Several models currently available in the literature are used to determine the thermal conductivity of NSC at elevated temperature. The thermal conductivity model obtained from Eurocode 2 (2005) is shown in Figure 2.44. In this case, the conductivity is defined by upper and lower limit curves. According to a research study on the identification of the thermal properties of concrete conducted by Achenbach et al. (2017), the lower limit was a reference plot for plain concrete members, while the upper limit was used for composite members. In Figure 2.44, " $\theta$ " represents the temperature in $\left[{ }^{\circ} \mathrm{C}\right]$ while " $\lambda_{c}$ " represents the thermal conductivity of concrete in 
$\left[\mathrm{W} / \mathrm{m}^{\circ} \mathrm{C}\right]$. Equations 2.10 and 2.11 are used to determine the upper and lower limits of the thermal conductivity of concrete (Eurocode 2, 2005).

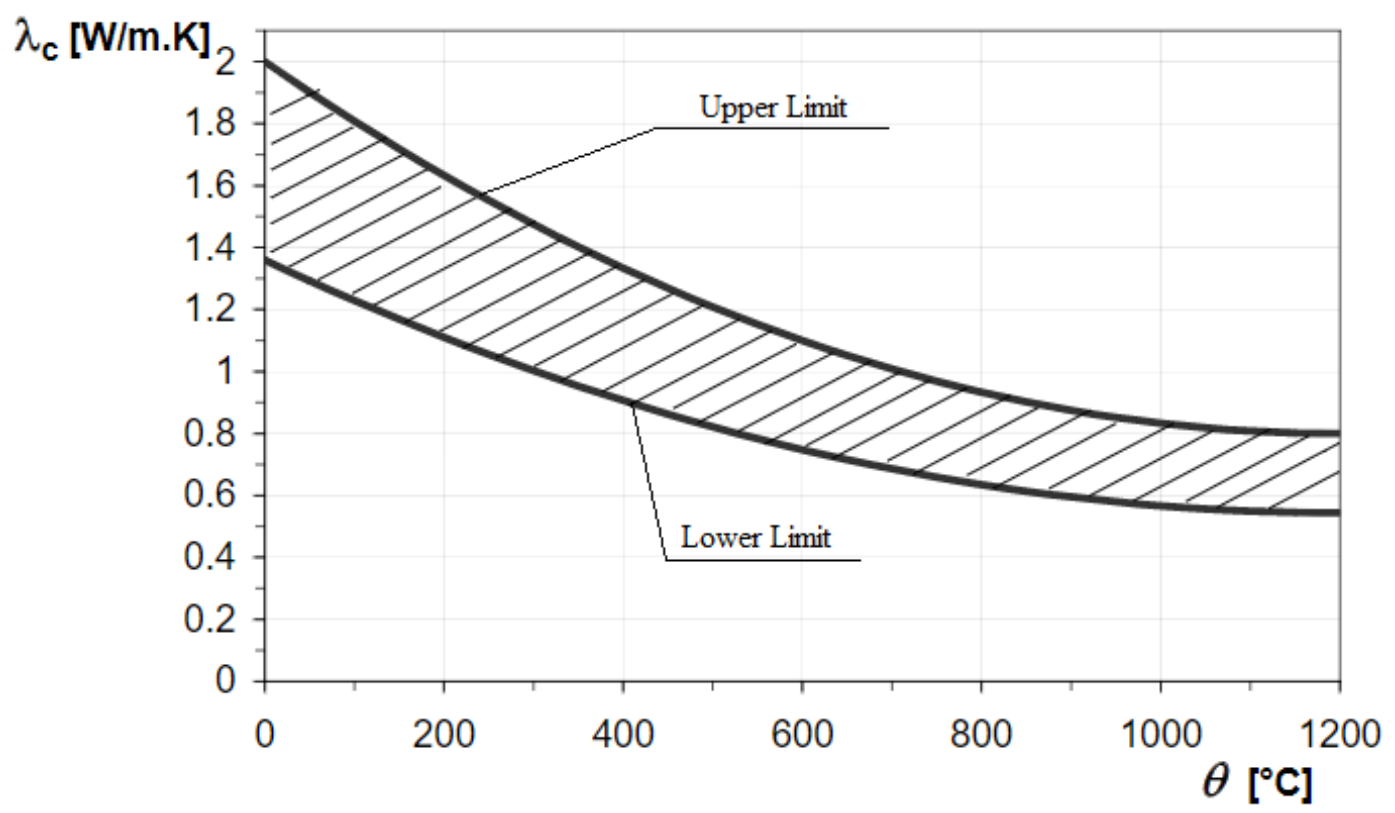

Figure 2.44: Thermal conductivity of concrete at elevated temperature (Eurocode 2, 2005)

$\lambda_{c}=2-0.24(T / 120)+0.012(T / 120)^{2} \quad 20 \leq T \leq 1200^{\circ} C$

$\lambda_{c}=1.36-0.163(T / 120)+0.0082(T / 120)^{2} \quad 20 \leq T \leq 1200^{\circ} C$

The model presented by the American Society of Civil Engineers (ASCE) manual can also be used to determine the thermal conductivity of concrete (Kodur and Khaliq, 2011). As indicated earlier, the thermal conductivity is affected by the types of aggregate used in the concrete mix design (Kodur and Khaliq, 2011). Different thermal conductivity for siliceous and carbonate aggregate-based concrete alternatives was provided by the ASCE manual (Kodur and Khaliq, 2011). Equations 2.12 and 2.13 are used to compute the thermal conductivity for siliceous and carbonate based concrete respectively.

$$
\begin{aligned}
& \lambda_{c}=\left\{\begin{array}{cc}
-0.000625 T+1.5 & 20 \leq T \leq 800^{\circ} C \\
1.0 & 800^{\circ} C<T
\end{array}\right. \\
& \lambda_{c}= \begin{cases}1.355 & 20 \leq T \leq 293^{0} C \\
-0.001241 T-1.7162 & 293^{0} C<T\end{cases}
\end{aligned}
$$


In Equations 2.12 and 2.13,

$\lambda_{c}$ : Thermal conductivity of concrete $\left[\mathrm{W} / \mathrm{m}^{\circ} \mathrm{C}\right]$ and $\mathrm{T}$ : Temperature of exposure $\left[{ }^{\circ} \mathrm{C}\right]$.

Similar to the specific heat properties of SCC, the generalized model by Kodur and Khaliq (2011) can be used to determine the thermal conductivity of SCC when exposed to elevated temperature. Equation 2.14 obtained from the experimental research conducted by Kodur and Khaliq (2011) is used to determine a model for specific heat at elevated temperature. Equation 2.14 defines the conductivity $\left(k_{t}, \mathrm{~W} / \mathrm{m}-{ }^{\circ} \mathrm{C}\right)$ of SCC.

$k_{t}=\left\{\begin{array}{cc}3.12-0.0045 T & 20 \leq T \leq 400^{\circ} \mathrm{C} \\ 3-0.0025 T & 400 \leq T \leq 800^{\circ} \mathrm{C}\end{array}\right.$

Due to the limitations on the available information, it was established that the model for HSC could be used to predict the thermal conductivity of UHPC. The conductivity model presented by Kodur and Khaliq (2011) computed through use of Equation 2.15 can be used to predict the thermal conductivity of UHPC. Equation 2.14 defines the conductivity $\left(k_{t}, \mathrm{~W} / \mathrm{m}-{ }^{\circ} \mathrm{C}\right)$ of UHPC.

$k_{t}= \begin{cases}2.5-0.0033 T & 20 \leq T \leq 400^{\circ} C \\ 2.3-0.002 T & 400 \leq T \leq 800^{\circ} C\end{cases}$

\subsection{Thermal Properties of Carbon Steel}

The thermal properties of carbon steel are defined in this section. Changes in the density, thermal conductivity and specific heat when exposed to elevated temperature are summarized in the following.

\subsubsection{Density}

According to Eurocode 3 (2005) and ASCE (1992), the density of steel is independent of temperature of exposure. This is attributed to the steel high temperature melting point of $1600^{\circ} \mathrm{C}$. Thus, a constant value of $7850 \mathrm{~kg} / \mathrm{m}^{3}$ for the temperature range of $20 \leq T \leq 1000^{\circ} \mathrm{C}$ is specified in accordance to Eurocode 3, 2005 and ASCE, 1992. 


\subsubsection{Specific Heat Capacity}

The specific heat of steel increases with increase in the temperature of exposure. In fact, according models presented by Eurocode 4 (2005) a linear trend was observed for temperatures up to $750^{\circ} \mathrm{C}$. Upon reaching this specific temperature, a phase change within the molecular structure of the steel occurs with atoms transitioning from cubic centred to body centered cubic structure. High energy is required for this process to take place; this is characterized by a spike in the specific heat value at this temperature. According to Eurocode 4 (2005), the specific heat of steel $\left(\mathrm{C}_{\mathrm{a}}\right)$ can be computed through use of Equation 2.16.

$$
\begin{array}{ll}
c_{a}=425+7.73 \times 10^{-1} \times T^{2}-1.69 \times 10^{-3} \times T^{3} & \text { for } 20 \leq T \leq 600^{\circ} \mathrm{C} \\
c_{a}=666+\frac{13002}{738-T} & \text { for } 600<T \leq 735^{\circ} \mathrm{C} \\
c_{a}=545+\frac{17820}{T-731} & \text { for } 735<T \leq 900^{\circ} \mathrm{C} \\
c_{a}=650 & \text { for } 900<T \leq 1200^{\circ} \mathrm{C}
\end{array}
$$

\subsubsection{Thermal Conductivity}

The thermal conductivity of metallic materials is proportional to the number of alloys within a specific material. Since carbon steel is characterized as a low-alloy material, an inverse linear relationship with increase in temperature is observed for peak temperatures reaching up to $800^{\circ} \mathrm{C}$. Upon reaching the $800^{\circ} \mathrm{C}$ temperature mark, a constant value for the specific heat of steel is observed. Equation 2.17 obtained from Eurocode 4, 2005 defines the changes in specific heat $\left(\lambda_{\mathrm{a}}\right)$ relative to temperature of exposure.

$$
\begin{array}{ll}
\lambda_{a}=54-3.33 \times 10^{-2} \times 10^{-2} \times T & \text { for } 20 \leq T \leq 800^{\circ} \mathrm{C} \\
\lambda_{a}=27.3 & \text { for } 800<T \leq 1200^{\circ} \mathrm{C}
\end{array}
$$

\subsection{Mechanical Properties of Concrete and Steel at Elevated Temperature}

The mechanical properties of self-consolidating concrete (SCC), engineered cementitious concrete (ECC), ultra-high strength/performance concrete (UHPC) and normal strength concrete (NSC) when exposed to elevated temperature are defined in this section. Thermal expansion coefficients and strength degradation factors are summarized in the following. 


\subsubsection{Thermal Expansion Coefficients}

Several models currently available in the literature are used to determine the thermal expansion coefficient of NSC when exposed to elevated temperature. Given that concrete is a heterogeneous material, the expansion coefficient of the material is the sum of the individual components that make up the overall material. In this case, the main components such as the cement paste and aggregates encompass different values for thermal expansion, rendering the process of determining the overall expansion coefficient of concrete difficult to obtain. As such several researchers have opted in using a constant value for the thermal expansion of concrete under all temperature ranges. In fact, the use of such method was also adopted by the Architectural Institute of Japan (AIJ) standards (AIJ, 1997). Although, defining the thermal expansion in such manner does lead to good results when compared to lab test, the use of temperature varying models to define the expansion factor for concrete show more accurate results.

The model presented by Eurocode 2 (2005) can be used to determine the varying expansion factors of NSC when exposed to elevated temperature. Similar to models for specific heat and thermal conductivity, the thermal expansion coefficients are defined based on the type of aggregates used in the concrete mixture. Equations 2.18 and 2.19 are used to compute the thermal expansion of NSC for silicate and carbonate aggregates respectively.

$$
\begin{array}{ll}
(\Delta l / l)_{a}=1.8 \times 10^{-4}+9 \times 10^{-6} \times T-2.3 \times 10^{-11} \times T^{3} & \text { for } 20^{\circ} \mathrm{C} \leq T \leq 700^{\circ} \mathrm{C} \\
(\Delta l / l)_{a}=14 \times 10^{-3} & \text { for } 700^{\circ} \mathrm{C}<T \leq 1200^{\circ} \mathrm{C} \\
(\Delta l / l)_{a}=1.2 \times 10^{-4}+6 \times 10^{-6} \times T-1.4 \times 10^{-11} \times T^{3} & \text { for } 20^{\circ} \mathrm{C} \leq T \leq 805^{\circ} \mathrm{C} \\
(\Delta l / l)_{a}=12 \times 10^{-3} & \text { for } 805^{\circ} \mathrm{C}<T \leq 1200^{\circ} \mathrm{C}
\end{array}
$$

In Equations 2.18 and 2.19, $l$ : original length of steel component; $\Delta l$ : length of the steel component and $T$ : temperature of steel $\left[{ }^{\circ} \mathrm{C}\right]$.

The mathematical model for the thermal expansion of SCC were obtained based on measured experimental data retrieved from Kodur and Khaliq (2011). Equation 2.20 is used to compute the thermal expansion $\left(\varepsilon_{t h}, \%\right)$ of SCC.

$\varepsilon_{t h}=-0.1+0.0015 T \quad 20 \leq T \leq 800^{\circ} \mathrm{C}$ 
The thermal expansion model for HSC is used to predict the thermal expansion of UHPC. Similarly, the model presented by Kodur and Khaliq (2011) presented in Equation 2.21 is used to compute the thermal expansion of UHPC at elevated temperature.

$$
\varepsilon_{t h}=-0.05+0.001 T \quad 20 \leq T \leq 1000^{\circ} \mathrm{C}
$$

The mathematical model for the thermal expansion of carbon were obtained based on constitued model presented by Eurocode 3 (2005). Equation 2.22 is used to compute the thermal expansion $\left(\varepsilon_{t h}, \%\right)$ of carbon steel.

$$
\begin{array}{ll}
\varepsilon_{t h}=1.2 \times 10^{-5}+0.4 \times 10^{-8} \times T^{2}-2.416 \times 10^{-4} & \text { for } 20^{\circ} C \leq T \leq 750^{\circ} C \\
\varepsilon_{t h}=1.1 \times 10^{-2} & \text { for } 750^{0} C<T \leq 860^{0} C \\
\varepsilon_{t h}=2 \times 10^{-5} \times T-6.2 \times 10^{-3} & \text { for } 860^{0} C<T \leq 1200^{0} C
\end{array}
$$

\subsubsection{Strength Degradation Factors}

The strength of the material deteriorates when exposed to elevated temperature. Deterioration factors are defined for carbon steel, NSC, ECC, SCC and UHPC in terms of reductions in modulus of elasticity and stress vs. strain curves.

According to a study by Lu et al. (2009) on the fire behaviour of CFST columns, the constitutive material model proposed by Han et al. (2003) is preferred in determining the reduction factors for compressive strength and modulus of elasticity for SCC, ECC and NSC. Equation 2.23 is used to determine the reduction factors applied to the compressive strength of the concrete (Lu et al. 2009). The modulus of elasticity is defined at the secant modulus from point zero stress to a point representing $40 \%$ peak stress (Lu et al. 2009).

$$
R\left(f_{y}\right)=\left\{\begin{array}{cc}
1 & T<200^{\circ} C \\
\frac{0.91}{1+6 \times 10^{-17} \cdot(T-10)^{6}} & T \geq 200^{0} C
\end{array}\right.
$$

In Equation 2.23; $R\left(f_{y}\right)$ : the reduction factor for compressive strength and $T:$ temperature $\left[{ }^{\circ} \mathrm{C}\right]$ (Lu et al. 2009). 
As the modulus of elasticity decreases with the exposure to elevated temperature, the strain at peak compressive stress $\left(\varepsilon_{0}\right)$ will then increase. Equation 2.24 proposed by Han et al. (2003) is used to determine the strain at peak compressive stress.

$\varepsilon_{0}=\left(1300+12.5 f_{c}^{\prime}+800 \cdot \alpha^{0.2}\right) \times 10^{-6} \times\left(1.03+3.6 \times 10^{-4} \cdot T+4.22 \times 10^{-6} \cdot T^{2}\right)$

In Equation 2.24, $f_{c}^{\prime}$ : The compressive strength of concrete [MPa] and $T$ : Temperature $\left[{ }^{\circ} \mathrm{C}\right]$.

The paramter $\alpha$ refers to the ratio of confinement of steel sheets on the concrete core. This paramter is defined in Equation 2.25.

$\alpha=\frac{A_{s} \cdot f_{y}(T)}{A_{c} \cdot f_{c k}}$

In Equation 2.25, $A_{s}$ : cross-sectional area of the surrounding steel, $A_{c}$ : cross-sectional area of the concrete core and $f_{c k}$ : characteristic strength of concrete $[\mathrm{MPa}], f_{c k}=0.67 \cdot f_{c}^{\prime} \cdot f(T)(\mathrm{Han}$ et al. 2003).

Using Equations 2.24 and 2.25, the peak compressive stress is defined through use of the following Equation 2.26.

$\sigma_{0}=f_{c}^{\prime} /\left[1+9.45 \times 10^{-8}(T-20)^{2.66}\right]$

In Equation 2.26, $\sigma_{0}$ is the peak compressive strength of concrete [MPa] at elevated temeprature $\mathrm{T}\left[{ }^{\circ} \mathrm{C}\right]$.

Strength reduction factors for UHPC when subjected to elevated temperature are defined according to the experimental research by Xionga and Liew (2016). Concrete cylinders with height of $200 \mathrm{~mm}$ and diamter of $100 \mathrm{~mm}$ were loaded while subjected to the standard ISO-834 fire curve by means of a servo-hydrolic testing machine and a split-tube furnace (Xionga and Liew, 2016). Based on the failure load, the strength reduction factors relative to ambient state are obtained. Results indicate that the reduction factors for compressive strength of UHPC closly follow that of HSC (Xionga and Liew, 2016). This is mainly due to the presence of bauxite aggregates that have higher melting point and thus improved heat resistance relative to conventional HSC (Xionga and Liew, 2016). Similar behaviour for the reduction factors of the modulus of elasticity are observed when compared to HSC. A sharp reduction at early 
temeperature exposure was also observed in reduction factors for modulus of elasticity and compressive strength behaviour. This is due to the build-up of internal pressures caused by the evaporation of water (Xionga and Liew, 2016). As such, the reduction factors for HSC defined in Kodur and Khaliq (2011) can be used to determine the strength reduction factors for UHPC. Figure 2.45 summurizes the reduction factors for UHPC used in this study.

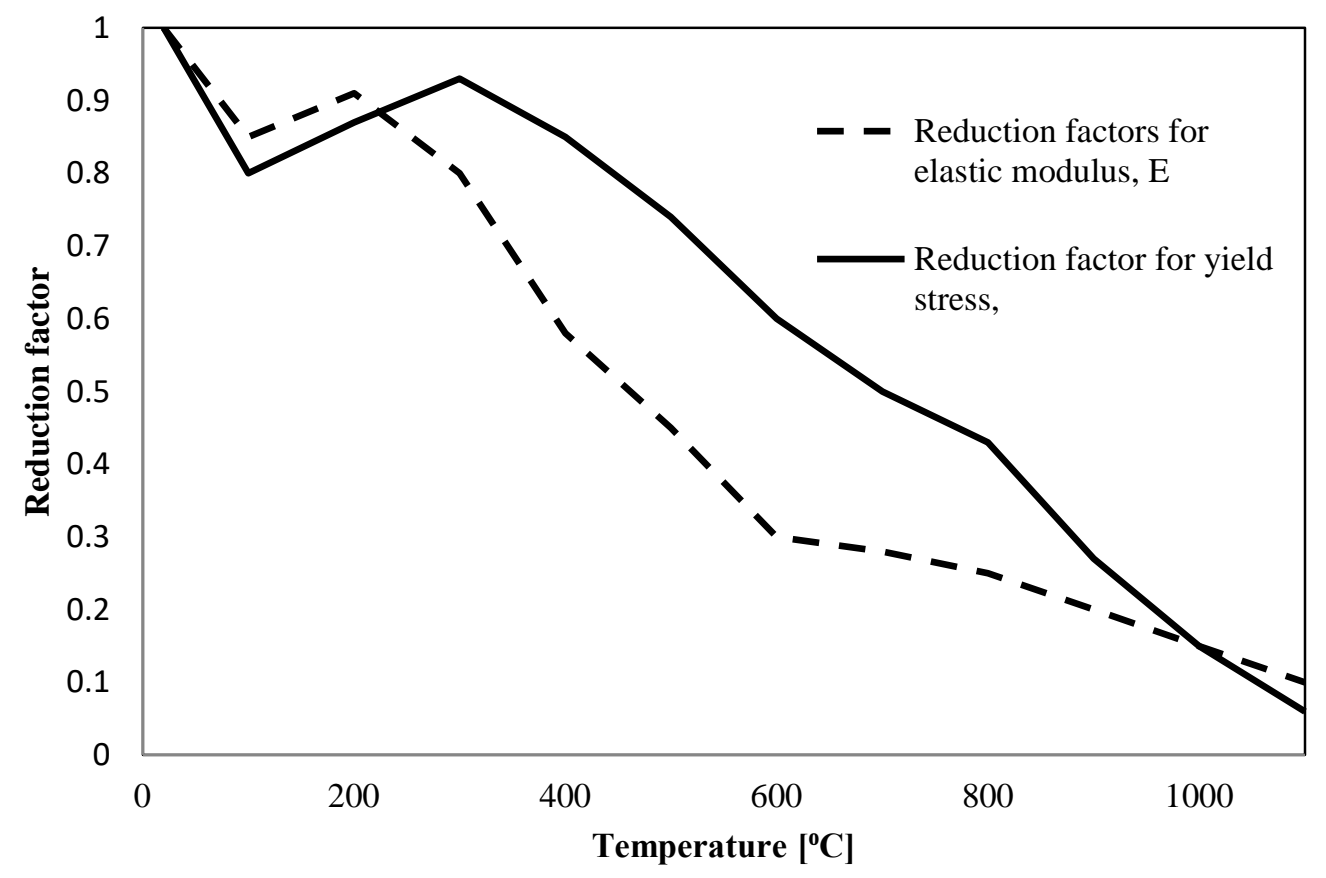

Figure 2.45: Reduction factors for UHPC (Xionga and Liew, 2016)

There is very little information on the effect of temperature on the tensile strength of concrete. According to Eurocode 2 (2005), the tensile strength of NSC when exposed to elevated temperature can be approximated through use of factors shown in Figure 2.46. 


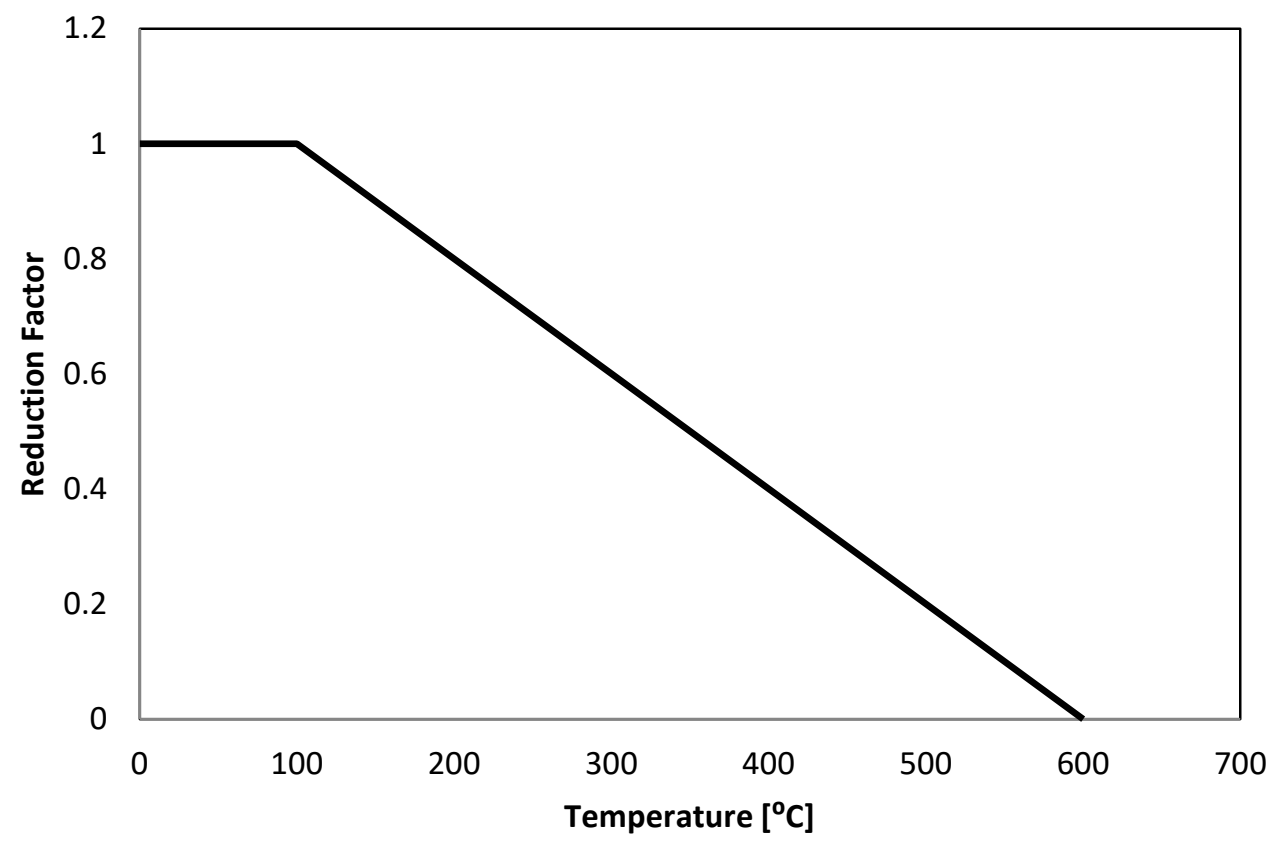

Figure 2.46: Tensile reduction factors for NSC (Eurocode 2, 2005)

The reduction factors for carbon steel for modulus elasticity and yield strength of steel subjected to elevated temperatures obtained from Eurocode 3 (2005) are summarized in Figure 2.47.

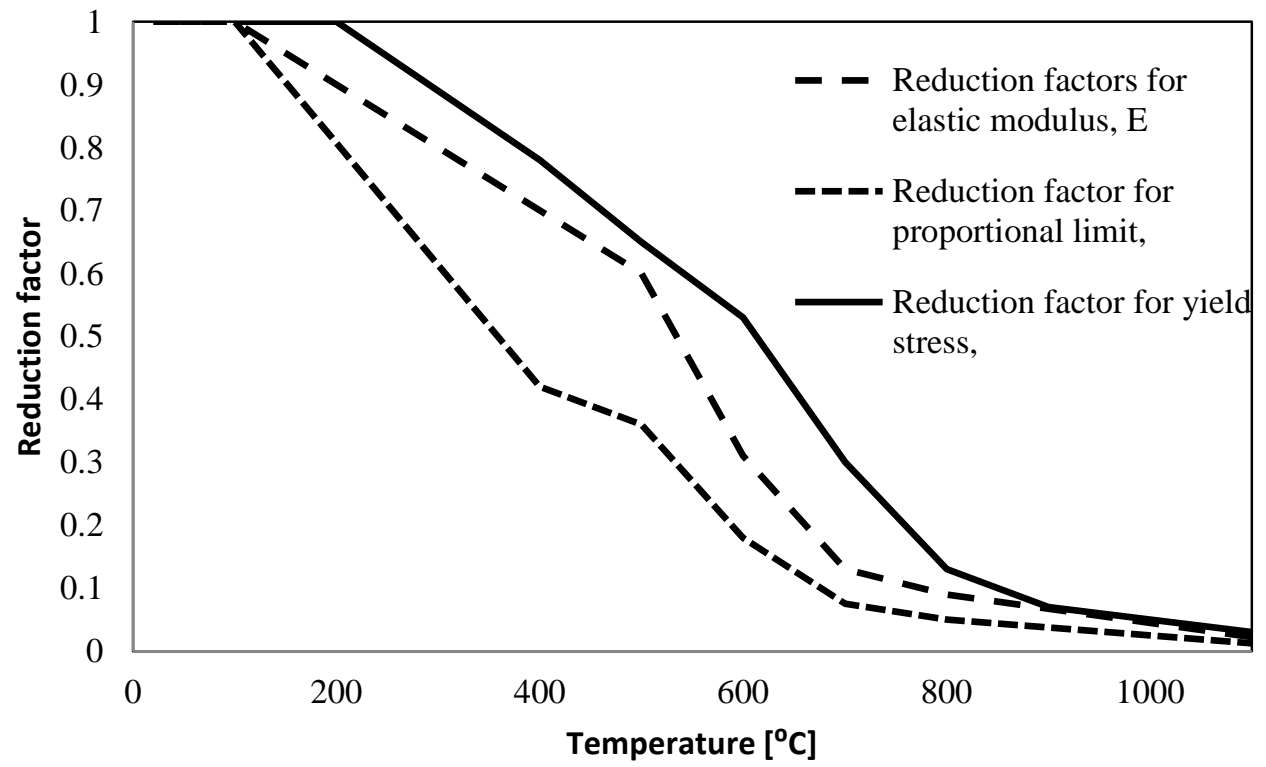

Figure 2.47: Reduction factors for steel (Eurocode 3, 2005) 


\subsection{Summary}

According to the literature review, various research studies were conducted to assess the axial compressive, cyclic and shear behaviour of double skin composite wall (DSCW) systems. Similarly, extensive experimental and finite element (FE) studies on the fire resistance of concrete filled steel tubular (CFST) columns are currently available in the literature. In fact, such extensive database highlights the importance of determining the fire resistance of structural components. However to date, no research available addresses the combined influence of applied compressive loading and high temperature on DSCW systems made of various concrete alternatives such as ECC, SCC and UHPC. Additional research is required on this topic as knowledge of the fire resistance of such structural components is vital in building sound and safe structures. The study presented has intent of bridging a very small amount of the vast void surrounding fire resistance of DSCW structures. 


\section{CHAPTER 3: Validation of Finite Element Modelling of the Compressive Behaviour of DSCW at Ambient Temperature}

\subsection{Introduction}

This chapter describes finite element (FE) modelling of the axial compressive behaviour of double skin composite wall (DSCW) system made of engineered cementitious composite (ECC), ultra-high performance/strength concrete (UHPC) and self-consolidating concrete (SCC) acting as concrete infill. Three non-linear finite element models of DSCW specimens are generated using commercially available Abaqus ${ }^{\circledR}$ software package in an attempt to simulate the compressive behaviour obtained through lab experiments conducted by Taormina (2012). All three FE models have the same cross-sectional and profile dimensions compared to the specimens tested by Taormina (2012). The goal of this chapter is to develop reliable FE models that mimic the experimental results. The work of numerous researchers are used in defining meshing setup, element types, steel-concrete interaction and optimizing compilation to feasible time periods (Hossain et al. 2015; Huang and Liew, 2016; Rafiei et al. 2013). Material models intended for software use for steel, ECC, SCC and UHPC are developed in terms of stress vs. strain curves, facture energy and biaxial response. The DSCW geometry and test assembly used in the experimental program conducted by Taormina, (2012) are presented in the following sections. The validity of the developed material models is assessed by comparing the test results obtained from Taormina (2012) and FE simulations of concrete compression and steel tensile coupon tests. Once the material models are validated, a full scale three-dimensional FE model of DSCW with different types of concrete infill is generated and the results are compared with those obtained from experimental program by Taormina (2012). Reliability and accuracy of the FE models is thus assessed. This is followed by a set of figures depicting contours and peak values for displacement and stress, retrieved from the FE simulations. Finally, the failure mode for composite wall is determined and compared with experimental results followed by detailed discussions on the analytical results. 


\subsection{Geometry and Assembly}

The DSCW system tested in the experiment by Taormina (2012) was composed of a concrete core and two skin sheets confining the concrete. The skin consisted of two profiled steel sheets were obtained from Canam Group. These profiled steel sheets were made of several arrays of troughs and crests that form the cross-sectional geometry of the panel. In this case, a customized panel of the commercially available P-3012 Steel Deck was used in the experiment. The sheet panel consisted of a flute depth of $14 \mathrm{~mm}$ and a length of $64 \mathrm{~mm}$ for each trough/crest iteration. The thickness of each panel is $0.61 \mathrm{~mm}$ which corresponded to steel deck of type 24 . The length of panel consisted of 5 trough /crest iterations which led to a total length of $320 \mathrm{~mm}$ (Taormina, 2012). The height of the panel was selected as $540 \mathrm{~mm}$ after being customized to laboratory limitations and slenderness ratio of 1.69. The cross-sectional and profile views of the wall system with the indicated dimensions are shown in Figure 3.1 and Figure 3.2, respectively. Alternative concrete types such as ECC, SCC and UHPC were used as core to evaluate the effect of the various concrete types on the performance and behaviour of the wall. The average compressive strength of the ECC was $60.3 \mathrm{MPa}$ with a modulus of elasticity of $25.0 \mathrm{GPa}$ and a maximum compressive strain of 2779 microstrain (Taormina, 2012). On the other hand, the average compressive strength of the SCC was $61.5 \mathrm{MPa}$ with a modulus of elasticity of $33.6 \mathrm{GPa}$ and a maximum compressive strain of 1828 microstrain. As for the UHPC used, the average compressive strength was measured to be $119.6 \mathrm{MPa}$ with a modulus of elasticity of $42.4 \mathrm{GPa}$ and a maximum compressive strain of 2655 microstrain (Taormina, 2012). The skin steel sheets were composed of carbon steel with a yield strength of $393.5 \mathrm{MPa}$ and a modulus of elasticity of 207.6 GPa (Taormina, 2012).

As shown in Figure 3.2, the wall system was composed of 5 layers of fasteners used to enhance the friction interaction between the concrete core and the steel sheet panels. The fasteners were also used when assembling the wall system prior to casting concrete. Each layer comprised of 5 bolts separated at an equal distance of $64 \mathrm{~mm}$ from center to center. The first layer was located $20 \mathrm{~mm}$ from the top edge of wall with a distance of 110, 250, 390 and $500 \mathrm{~mm}$ to the second, third, fourth and fifth layer of the wall system, respectively. 


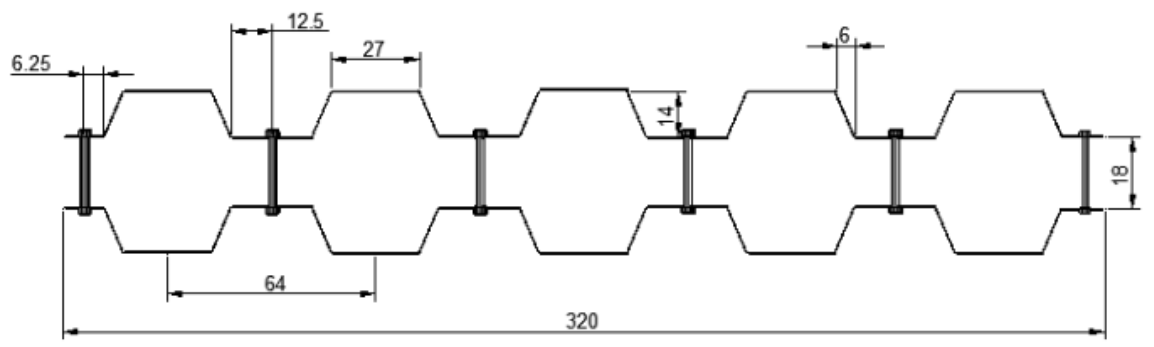

Figure 3.1: Dimensions of cross-section of profiled steel panel [mm] (Taormina, 2012)

Once the DSCW system was assembled, the wall was carried to an actuator through use of a crane available in the laboratory. After which, a force controlled test took place where a gradual force of $50 \mathrm{kN} / \mathrm{min}$ was applied until failure took place. The load vs. displacement curve was then obtained from which the compressive behaviour of the wall specimen could be determined.

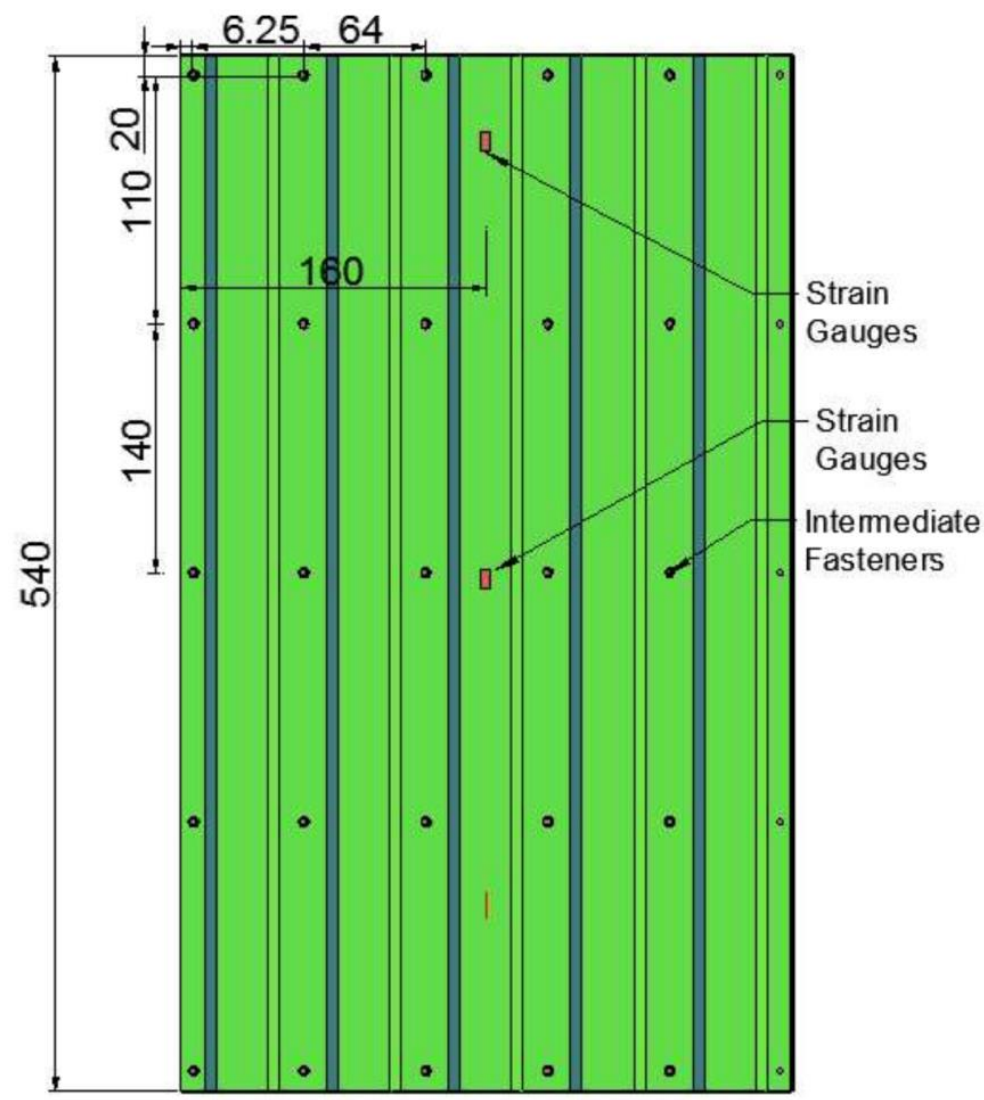

Figure 3.2: Profile view with bolt alignment of DSCW system (Taormina, 2012) 


\subsection{Validation of Steel and Concrete Material Models}

The material models needed for the development of FE models of DSCW for carbon steel and concrete alternatives are presented. Properties for steel and concrete obtained from steel coupon tests and concrete crushing tests conducted by Taormina (2012) are used as means to generate the required material models for steel and concrete. Once generated, the validity of the proposed material models is then tested through use of FE simulations of the coupon and concrete crushing tests performed by Taormina (2012).

\subsubsection{Carbon Steel Model}

The stress vs. strain curves of the steel sheets are obtained through the tensile coupon tests reported by Taormina (2012). Steel coupon sheets with similar material properties that encompass the profile steel sheet component of DSCW structures with dimensions highlighted in Figure 3.3 were tested in tension using a tensile pulling test until rupture occurred (Taormina, 2012). The tensile behaviour of the steel was then retrieved in terms of stress ( $\sigma_{\text {nom }}$ ) vs. strain $\left(\varepsilon_{\text {nom }}\right)$ curves. The modulus of elasticity, yield strength and yield strain proprieties of the steel were then computed as $207,000 \mathrm{MPa}, 394 \mathrm{MPa}$ and 2860 microstrain, respectively (Taormina, 2012). In accordance to Eurocode 3 (2005), the value of poisson's ratio for steel is taken as 0.3 .

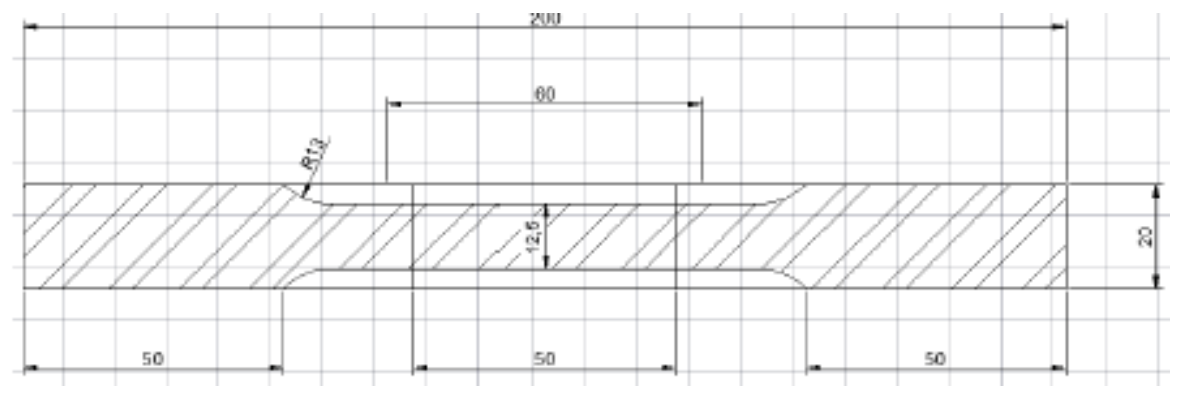

Figure 3.3: Dimensions of steel coupon sheet (Taormina, 2012)

Values are included in Abaqus ${ }^{\circledR}$ in terms of true stress $\left(\sigma_{\text {true }}\right)$ and true plastic strain $\left(\varepsilon^{p l}\right)$. The measured values from the coupon test are based on the initial cross-sectional area, thus only engineering stress $\left(\sigma_{\text {nom }}\right)$ vs. strain $\left(\varepsilon_{\text {nom }}\right)$ curves are obtained. These curves were converted into true stress vs. true strain using equation 3.1 and 3.2, respectively. The true plastic strain is determined through use of equation 3.3. 


$$
\begin{aligned}
& \sigma_{\text {true }}=\sigma_{\text {nom }}\left(1+\varepsilon_{\text {nom }}\right) \\
& \varepsilon_{\text {true }}=\ln \left(1+\varepsilon_{\text {nom }}\right) \\
& \varepsilon^{p l}=\varepsilon_{\text {true }} \angle \frac{\sigma_{\text {true }}}{E}
\end{aligned}
$$

The elastic behaviour of the steel sheeting is defined with the modulus of elasticity reported by Taormina (2012). The non-linear behaviour of steel is determined through the built-in plastic model in Abaqus ${ }^{\circledR}$. The true stress vs. true plastic strain is incorporated into the plastic model to define the non-linear behaviour of the steel material. A comparison between engineering stress vs. strain, true stress vs. strain and true stress vs. true plastic strain curves from a typical coupon test is shown in Figure 3.4. In Figure 3.4, the "Test" curve is obtained from the experiment conducted by Taormina (2012) where steel coupon tests were subjected to a pulling test until failure.

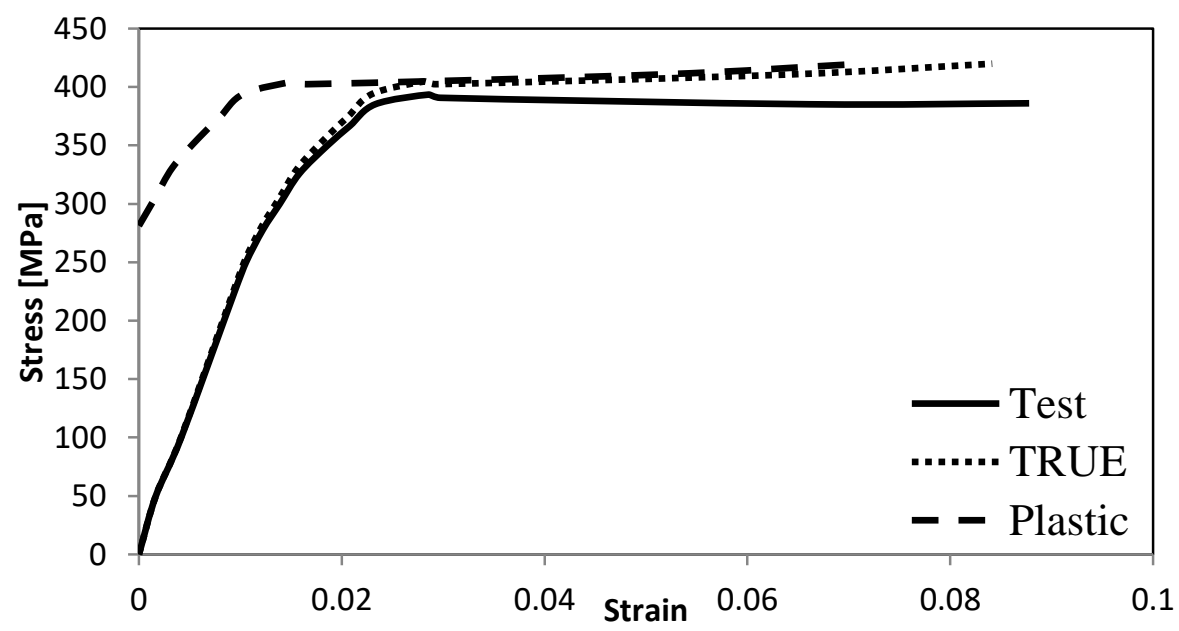

Figure 3.4: Stress vs. strain curves for steel (Taormina, 2012)

Although experimental results can define material properties for steel, numerous other existing models can also be used to that extent. In this case, the EC3 (Eurocode 3, 2005) is used as an alternative to define the material model for steel. Figure 3.5 represents the typical stress vs. strain curve where the key points in the graph are determined through use of equations summarized in Table 3.1 (Eurocode 4, 2005; Kodur et al. 2010). The tension stiffening part is ignored since test results do not exhibit such behaviour. 


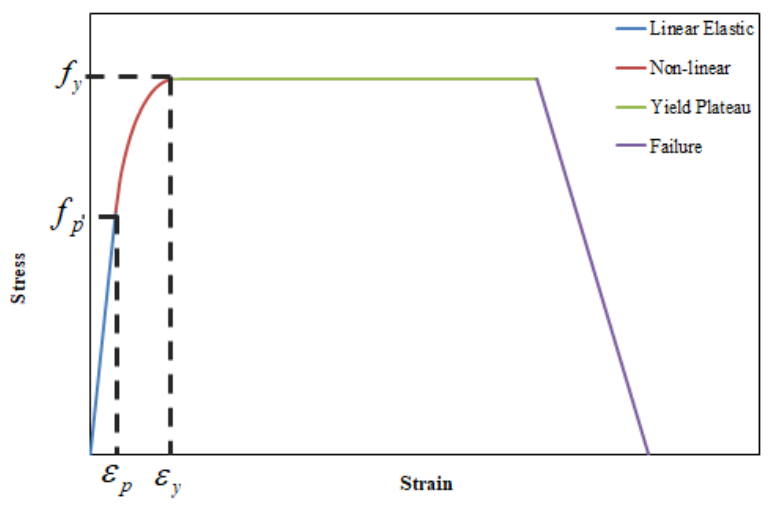

Figure 3.5: Stress vs. strain curve for carbon steel according to Eurocode 3

Figure 3.6 shows a comparison between experimentally determined stress vs. strain curve for steel at room temperature against one determined through use of equations presented in Table 3.1 .

Table 3.1: Equations for stress according to EC3

\begin{tabular}{|c|c|}
\hline Strain range & Stress $\left(\sigma_{s}\right)$ \\
\hline$\varepsilon \leq \frac{F_{p, T}}{E_{s, T}}$ & $E_{s, T} \times \varepsilon$ \\
\hline$\frac{F_{p, T}}{E_{s, T}}<\varepsilon<c_{1}$ & $F_{p, T}-c+\frac{b}{a} \sqrt{a^{2}-\left(c_{1}-\varepsilon\right)^{2}}$ \\
\hline$c_{1}<\varepsilon<c_{3}$ & $\frac{\left(F_{u, T}-F_{y, T}\right) \cdot \varepsilon+c_{3} F_{y, T}-c_{1} F_{u, T}}{\left(c_{3}-c_{1}\right)}$ \\
\hline$c_{3}<\varepsilon \leq c_{4}$ & $F_{u, T}$ \\
\hline$c_{4}<\varepsilon<c_{5}$ & $F_{u, T} \times \frac{\left(c_{5}-\varepsilon\right)}{\left(c_{5}-c_{4}\right)}$ \\
\hline $\begin{array}{l}c=\frac{\left(F_{y, T}-F_{p, T}\right)^{2}}{\left(c_{1}-\frac{F_{p, T}}{E_{s, T}}\right) \cdot E_{s, T}-2 \cdot\left(F_{y, T}-F_{p, T}\right)}, \\
b^{2}=c\left(c_{1}-\frac{F_{p, T}}{E_{s, T}}\right) \cdot E_{s, T}+c^{2} a^{2}=\end{array}$ & $\begin{array}{l}=0.02, c_{3}=0.04, c_{4}=0.15, c_{5}=0.2 \\
\left.1-\frac{F_{p, T}}{E_{s, T}}\right)\left(c_{1}-\frac{F_{p, T}}{E_{s, T}}+\frac{c}{E_{s, T}}\right)\end{array}$ \\
\hline
\end{tabular}


Terms in the Table 3.1 are defined as follows:

$F_{u, T}$ : ultimate strength; $F_{y, T}$ : yield point; $F_{p, T}$ : proportional limit; $E_{s, T}$ : modulus of Elasticity; $c_{1}$, $c_{3}, c_{4}$ and $c_{5}$ : parameters used in equations; $a, b$ and $c$ : coefficients for parabolic curve.

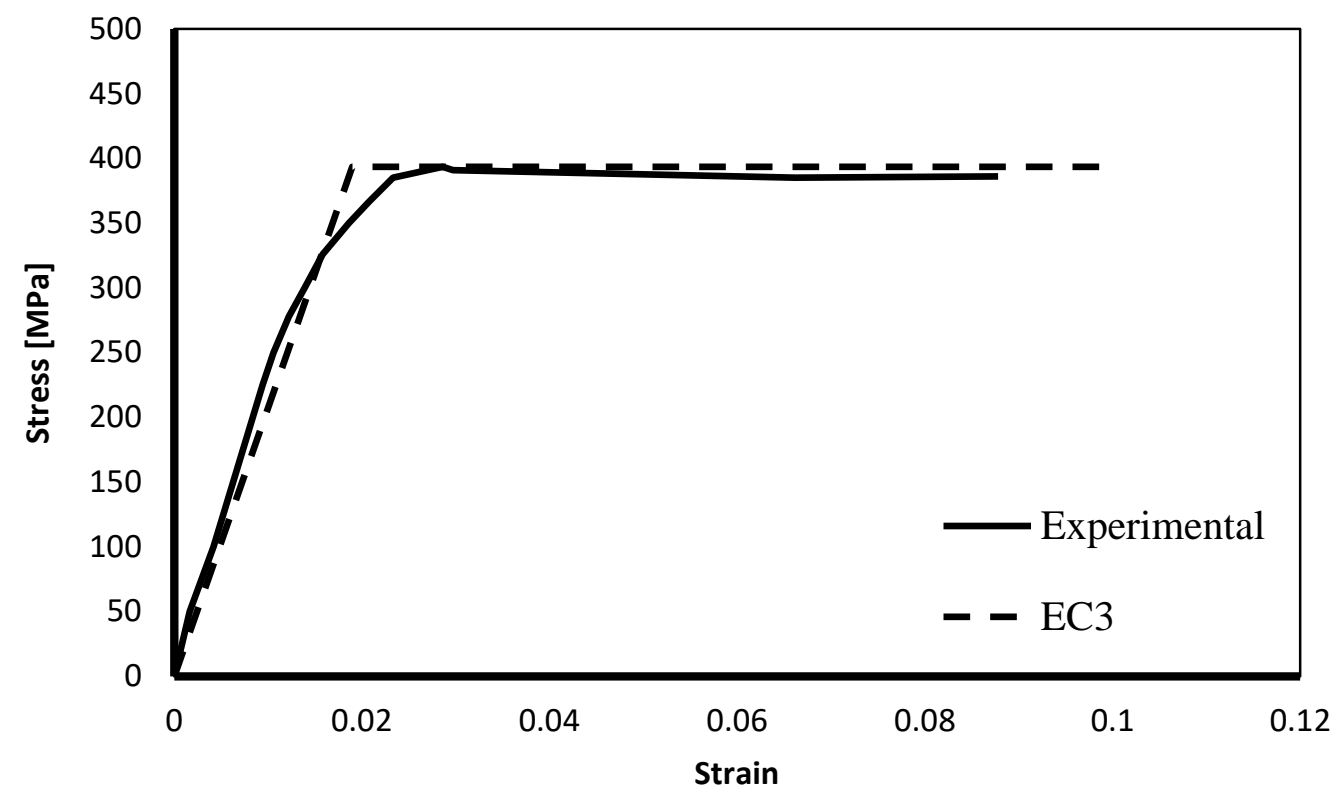

Figure 3.6: EC3 and experimental stress vs. strain curves for steel at room temperature (Eurocode 3, 2005, Taormina, 2012)

In Figure 3.6, the "Test" curve is obtained from (Taormina, 2012) while the "EC3" is developed through the use of Eurocode 3, 2005 model discussed earlier.

It should be noted that the stress vs. strain model generated according to EC3 is dependent on the temperature of the steel at loading. Since no experimental measurement was conducted for the behaviour of steel under high temperature, EC3 model is used as basis for modelling of steel in Chapter 5.

\subsubsection{Validation of Carbon Steel Model}

In this section, a FE simulation of the tensile coupon test conducted by Taormina (2012) is generated to judge the validity of the material model proposed in section 3.3.1. The geometry of the coupon sheet shown in Figure 3.3 is regenerated. The meshing set-up is shown in Figure 3.7a. Table 3.2 shows the number of elements, the type of element and the approximate element size used in the meshing process. The boundary conditions of the coupon sheet model are 
summarized in Figure 3.7b with "Cell 1" being constrained in all direction expect U2/y-direction while "Cell 2" is treated as fixed with all directions constrained against motion. A displacement is applied on the y-direction of "Cell 1 " to initiate the pulling behaviour and generate similar results to the test experiment. The elastic and plastic material properties of steel are summarized in Table 3.3.

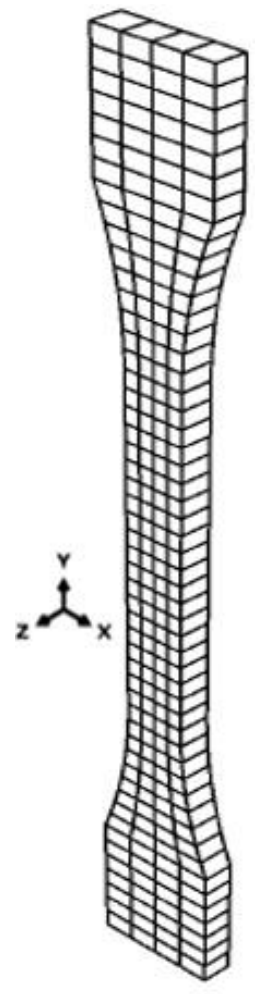

(a)

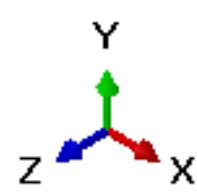

(b)

Figure 3.7: Meshing set-up for coupon sheet (a), boundary conditions of the coupon sheet (b)

Table 3.2: Number, type and approximate size of elements used

\begin{tabular}{|l|l|l|}
\hline Number of elements & Element type & Approximate element size [mm] \\
\hline 795 & $\begin{array}{l}\text { C3D8R: 8-node linear brick, } \\
\text { reduced integration, hourglass } \\
\text { control. }\end{array}$ & 3.4 \\
\hline
\end{tabular}


Table 3.3: Elastic and plastic properties of steel

\begin{tabular}{|l|l|l|}
\hline \multicolumn{2}{|c|}{ Elastic properties } \\
\hline $\begin{array}{l}\text { Modulus of elasticity } \\
{[\mathrm{MPa}]}\end{array}$ & $\begin{array}{l}\text { Poisson's } \\
\text { ratio }\end{array}$ & $\begin{array}{l}\text { Density }\left[\mathrm{kg} / \mathrm{m}^{3}\right] \\
\text { (Eurocode 4, 2005) }\end{array}$ \\
\hline 207,000 & 0.3 & 7850 \\
\hline \multicolumn{3}{|c|}{ Plastic properties } \\
\hline Yield stress & Plastic strain \\
\hline 295.52 & 0 \\
\hline 349.25 & 0.00037237 \\
\hline 389.55 & 0.00097237 \\
\hline 396.27 & 0.00137237 \\
\hline 396.27 & 0.00657237 \\
\hline 396.27 & 0.25 \\
\hline
\end{tabular}
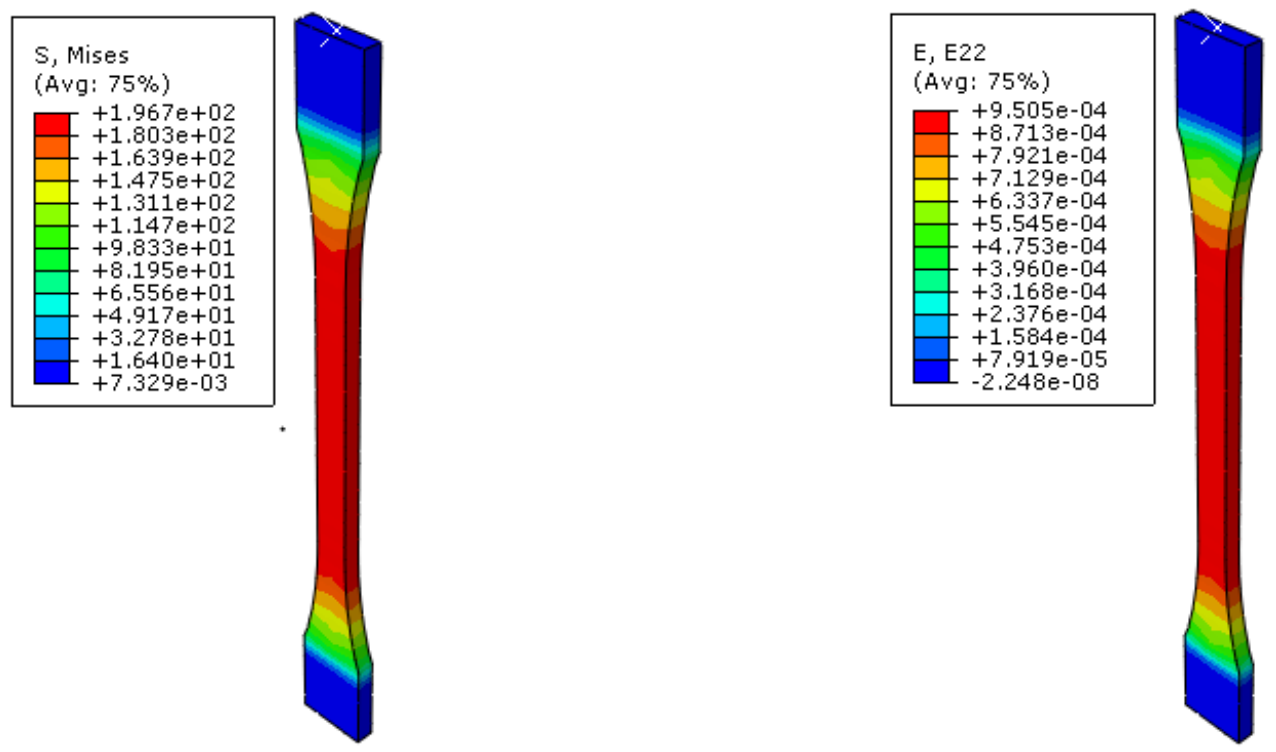

(a) 

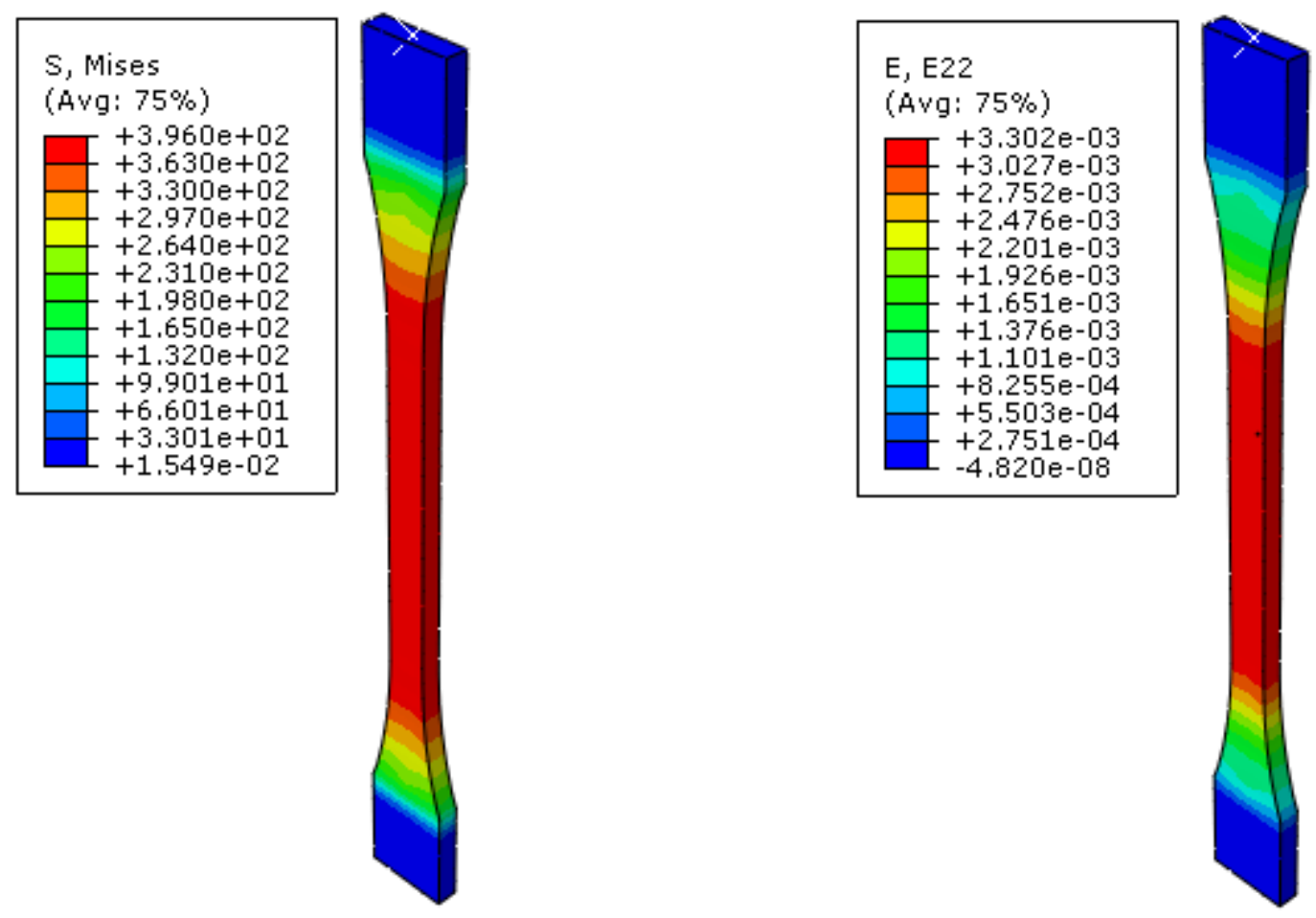

(b)
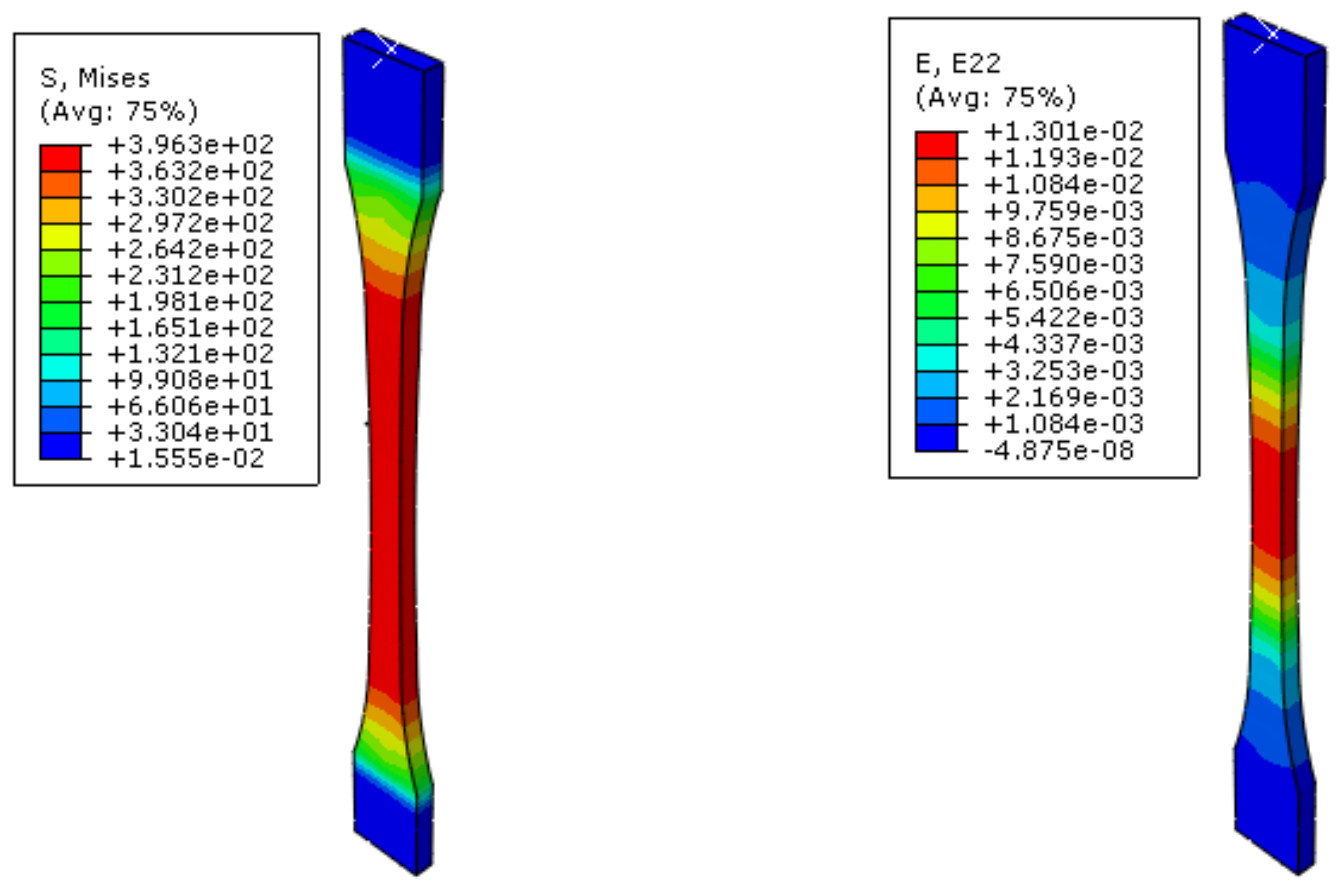

(c)

Figure 3.8: Stress and strain contour at a) 50\% yield stress, b) yield stress and c) time analysis is terminated 
The resulting stress and strain contours for the coupon sheet at stress values of 196 and $390 \mathrm{MPa}$ indicating $50 \%$ and $100 \%$ of yield strength are shown in Figures 3.8a and 3.8b, respectively. "S" is the von misses stress in units of $\mathrm{MPa}$ while "E22" refers to strain in y-axis with axis system defined in Figure 3.7. The contour for the stress and strain at time where FE analysis is terminated is shown in Figure 3.8c. As shown in Figure 3.8a, the values stress and strain at about $50 \%$ of yield stress are $197 \mathrm{MPa}$ and 950 microstrain, respectively. This is coherent with stress vs. strain curve obtained through use of simulated FE tensile coupon test. In fact, as observed in Figures $3.8 \mathrm{~b}$ and $3.8 \mathrm{c}$, the stress vs. strain values upon reaching yield stress and upon terminating the FE analysis are also coherent with the values shown in stress vs. strain curve shown in Figure 3.9. In this case, values for stress and strain of $396 \mathrm{MPa}$ and 3302 microstrain are observed upon reaching yield stress while values of $396 \mathrm{MPa}$ and 13010 microstrain are observed when analysis is terminated. Due to the low strain presented in the experimental curves in Figure 3.6, it can be observed that no necking has yet initiated. The validity of the proposed material model for carbon steel is assessed by comparing the stress vs. strain curve obtained from the simulated FE and experimental tensile coupon test. Figure 3.9 shows the comparison between FE and test results. Good agreement exists between the experimental and FE results suggesting that the proposed model is indeed capable of predicting the structural behaviour of carbon steel.

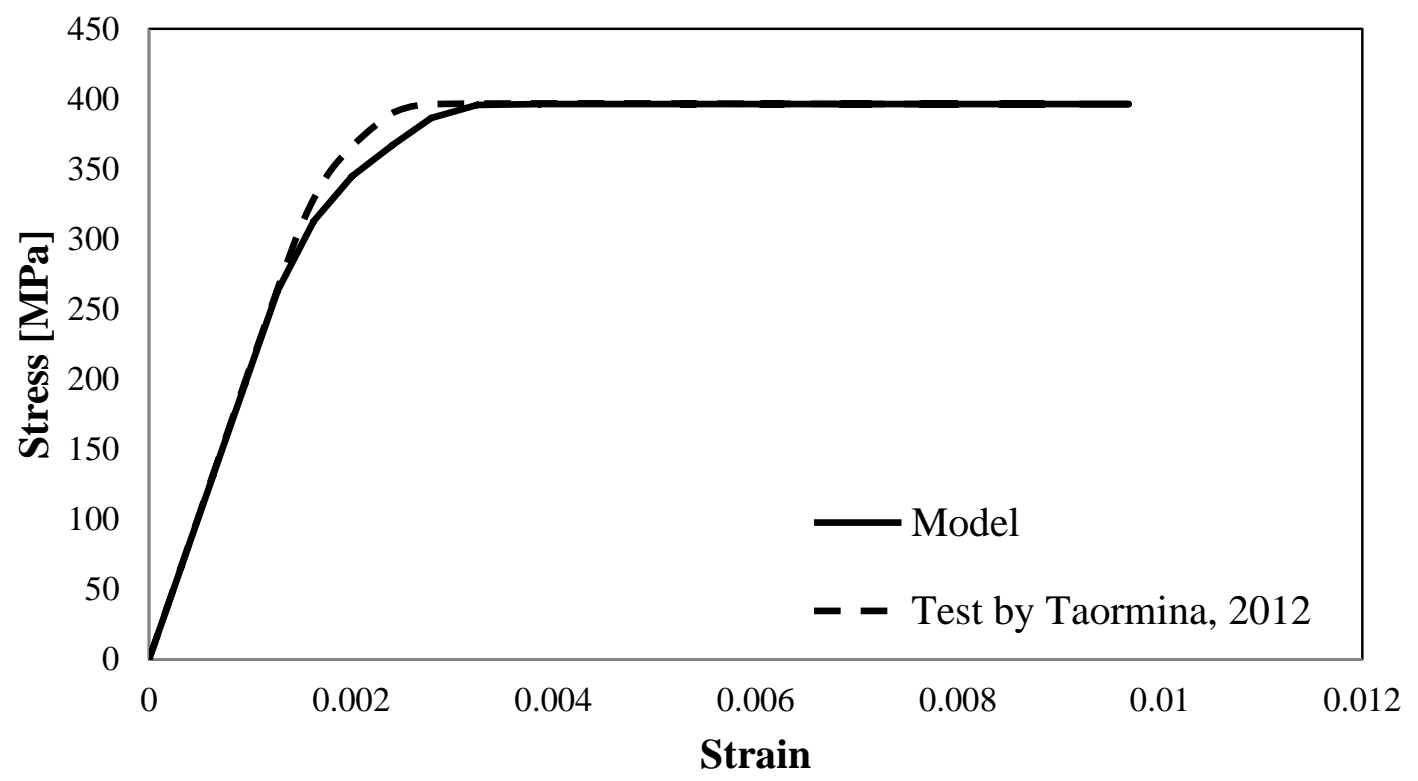

Figure 3.9: Stress vs. strain results obtained from experimental and FE simulation 


\subsubsection{Material Model for Concrete}

The material properties for SCC, ECC and UHPC mixtures referred to in this study were obtained through use of concrete compression tests performed by Taormina (2012). Concrete cylinders with dimensions of $100 \times 200 \mathrm{~mm}$ were cast and cured in accordance to the (ASTMC192, 2007). Upon reaching the maturity age of 28 days, the cylinders were then compressively loaded until failure. The measured modulus of elasticity, ultimate compressive stress and strain for SCC, ECC and UHPC are summarized in Table 3.4.

Table 3.4: Material properties for ECC, SCC and UHPC (Taormina, 2012)

\begin{tabular}{|l|l|l|l|}
\hline Material property & SCC & ECC & UHPC \\
\hline Modulus of elasticity (E, GPa) & 33.6 & 25.0 & 42.4 \\
\hline $\begin{array}{l}\text { Ultimate compressive strength } \\
\left(f_{u}, \mathrm{MPa}\right)\end{array}$ & 61.5 & 60.3 & 119.6 \\
\hline $\begin{array}{l}\text { Ultimate compressive strain }\left(\varepsilon_{u},\right. \\
\text { microstrain })\end{array}$ & 1828 & 2779 & 2655 \\
\hline
\end{tabular}

The elastic response of concrete is obtained through modulus of elasticity, Poisson's ratio and density values while the inelastic behaviour is obtained through use of stress vs. strain curves. A kinematic isotropic material response is used to describe the damage plasticity and inelastic behaviour of concrete. The non-linear mechanical behaviour and failure mechanisms of concrete cracking and crushing are defined by the built-in concrete damaged plasticity (CDP) model in Abaqus ${ }^{\circledR}$ (ABAQUS, 2014). The use of this model enables the simulation of the irreversible damage that concrete sustains upon fracture. A total of four parameters are needed to define the CDP model with the dilatation angle $(\beta)$ and eccentricity of plastic potential surface $(m)$ intended to describe the shape of the flow potential (ABAQUS, 2014). The parameters of stress ratio $(\alpha)$ and shape factor $(\gamma)$ are intended to describe the shape of the yield function (ABAQUS, 2014).

Uniaxial tensile and compressive concrete tests are needed for the specific concrete mix design used in this study to obtain the values of $\beta$ and $m$. $\beta$ is the angle of the p-q plane resulting from confined compressive tests generated through the lab experiments (ABAQUS, 2014). No 
available uniaxial tensile or confined compressive tests were conducted for the concrete mixes analysed in this study. According to Othman and Marzouk (2017), the parameters needed for the CDP model are determined and presented in Table 3.5. Through measurements resulting from biaxial compressive and uniaxial compressive tests, the parameter $\alpha$ is determined by computing the ratio of biaxial compressive strength to uniaxial compressive strength (ABAQUS, 2014). Since no biaxial test experiments were conducted with the specified mix designs referred to in this study, the value used for this parameter is obtained from research performed by Othman and Marzouk (2017). Finally, a full triaxial test of the concrete with the specified mix proportions is needed to define the shape factor $(\gamma)$. The value obtained is presented in Table 3.5 (Othman and Marzouk, 2017). Viscosity parameter of 0.001 is used to minimize convergence problems (Huang and Liew, 2016). Tensile and compressive stress vs. strain curves also need to be determined for a full definition of the material model for concrete.

Table 3.5: Parameters for CDP model

\begin{tabular}{|l|l|l|l|l|}
\hline Dilatation angle $(\beta)$ & Eccentricity $(m)$ & Ratio $(\alpha)$ & Shape factor $(\gamma)$ & Viscosity $(\kappa)$ \\
\hline $30^{\circ}$ & 0.1 & 1.16 & 0.667 & 0.001 \\
\hline
\end{tabular}

The tensile behaviour of concrete material can be defined by fracture energy model and tensile stress vs. strain curves. In this case, a definition for the tensile behaviour of concrete is required to simulation the FE model in Abaqus ${ }^{\circledR}$. The fracture energy approach minimizes convergence problems in FE models that result from the use of traditional stress vs. strain curves (Othman and Marzouk, 2017). Thus, the latter method is preferred in defining the tensile behaviour of the various concrete types. The fracture energy $\left(G_{F}\right)$ is defined as the energy required to produce a continuous crack until failure occurs. This can also be defined as the area under the tensile stress vs. cracking strain curve as shown in Figure 3.10 (Kang et al. 2012). Equations used to compute the tensile strength and fracture energy of various concrete alternatives used in this study are presented in Table 3.6. According to Othman (2016), the CEB-FIP model is quite adequate to represent the fracture energy of UHPC. As such, equation depicting the axial strength and fracture energy of UHPC obtained from (CEB-FIP, 1993) is used. The tensile strength equation obtained from ACI 318 (1991) is used to predict the tensile strength for SCC, ECC and UHPC. 
The validity of using this model for ECC was tested against experimental tensile strength values for several ECC mixtures included in Sahmaran et al. (2009). The fracture energy model presented by Eurocode 2 (2005) is used to depict the fracture energy for SCC. Although experimental research has been performed on the fracture energy of ECC, there are still no existing models or equations in the literature to define the fracture energy in question (Sherir et al. 2014). The tensile behaviour of ECC is determined through stress vs. strain curves.

Table 3.6: Equation for tensile strength and fracture energy for alternative concrete types

\begin{tabular}{|l|l|l|}
\hline Concrete type & Tensile strength [MPa] & Fracture Energy, [N/mm] \\
\hline SCC & $f_{c t}=0.56 \sqrt{f_{c}^{\prime}}($ ACI 318, 1992) & $G_{F}=10 \cdot d_{\text {max }}^{0.33} \cdot f_{c k}^{0.33}$ (Eurocode 2, 2005) \\
\hline ECC & $f_{c t}=0.56 \sqrt{f_{c}^{\prime}}($ ACI 318, 1992) & - \\
\hline UHPC & $f_{c t}=0.56 \sqrt{f_{c}^{\prime}}($ ACI 318, 1992) & $G_{F}=73\left(f_{c m}\right)^{0.18}(\mathrm{CEB}-\mathrm{FIP}, 2010)$ \\
\hline
\end{tabular}

From Table 3.6, $f_{c}^{\prime}$ : concrete cylinder strength at ambient temperature [MPa], $f_{c k}$ : characteristic compressive strength $[\mathrm{MPa}], f_{c m}$ : mean compressive strength $[\mathrm{MPa}], f_{c t}^{\prime}$ : concrete tensile strength $[\mathrm{MPa}], G_{F}$ : fracture energy $[\mathrm{N} / \mathrm{m}]$ and $d_{\text {max }}$ : the maximum aggregate diameter $[\mathrm{mm}]$.
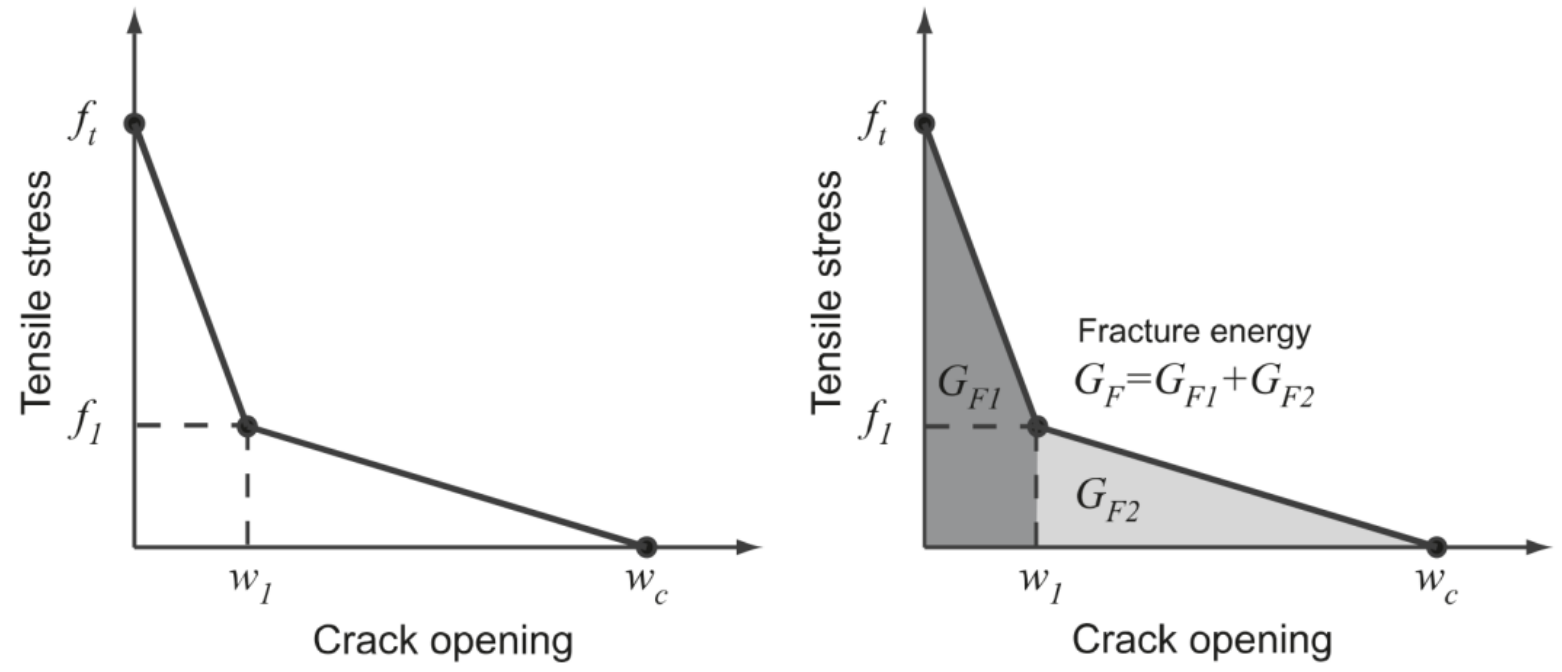

Figure 3.10: Calculation of fracture energy from tensile stress vs. cracking strain curve (Kang, et al. 2012) 
The tensile behaviour of concrete follows the typical stress vs. strain curve in Figure 3.11. Linear elastic behaviour is observed until tensile strength is reached. This is then directly followed by a tensile softening part where permanent damage $d_{t}$ occurs. $d_{t}$ is a measure of the damage that concrete sustains. A higher damage will lead to a lower modulus of recovery. This damage variable ranges from 0 , indicating undamaged material to 1 , indicating fully damaged material with a total loss in strength (Rafiei, 2011).

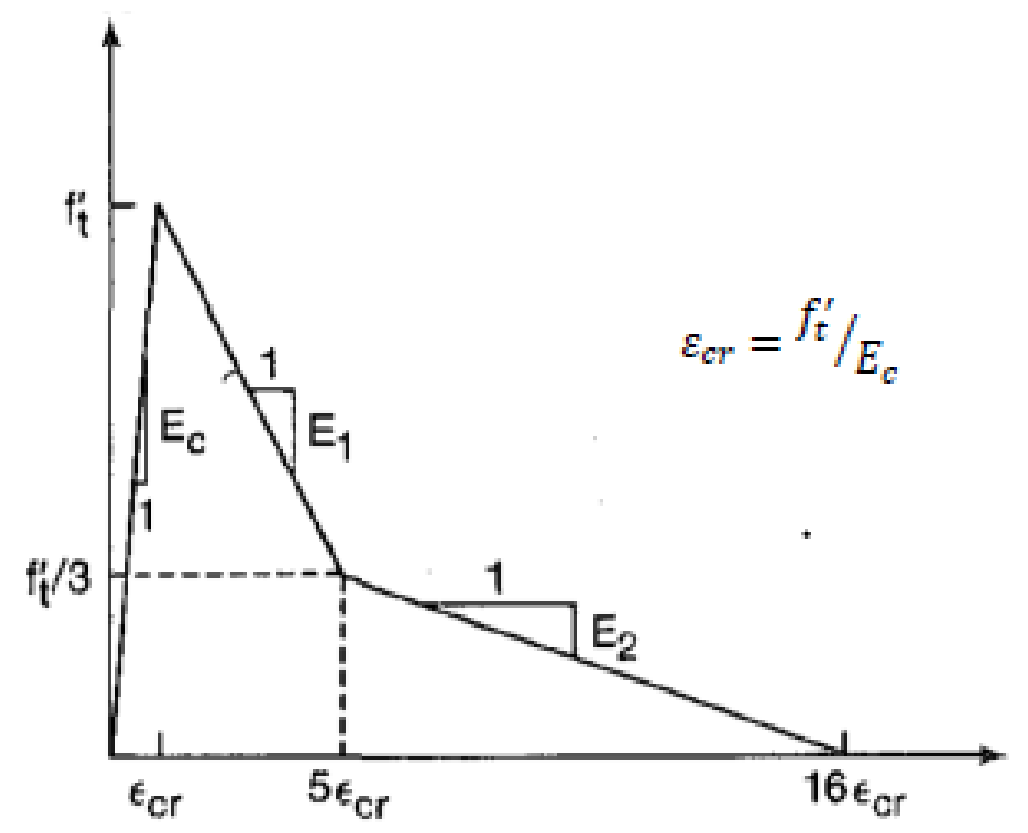

Figure 3.11: Typical uniaxial tensile curve for concrete (Rafiei, 2011)

In Figure 3.11, the cracking strain $\tilde{\varepsilon}_{t}^{c k}$ is computed by subtracting the elastic strain $\left(\tilde{\varepsilon}_{t}^{e l}\right)$ of undamaged material from the total strain that the concrete experiences. This is then plotted against the tensile stress values to generate the required tensile stress vs. strain curve used in Abaqus®. Due to the high ductile nature of ECC, higher strain values are observed from the stress vs. strain graph. This behaviour differs from typical concrete alternatives as such a factor of $100 \cdot\left(f_{t}^{\prime} / E_{c}\right)$ is applied to the total strain. This renders the generated model relatively comparable to one obtained through test measurements (Rafiei, 2011). Based on the material properties of ECC obtained by (Taormina, 2012) as summarized in Table 3.4 and the tensile properties shown in Figure 3.11, the tensile stress vs. strain curve for ECC used in this study is shown in Figure 3.12. Figure 3.12 shows the tension stiffening part of the stress vs. strain curve of ECC that is incorporated into the Abaqus ${ }^{\circledR}$ software. 


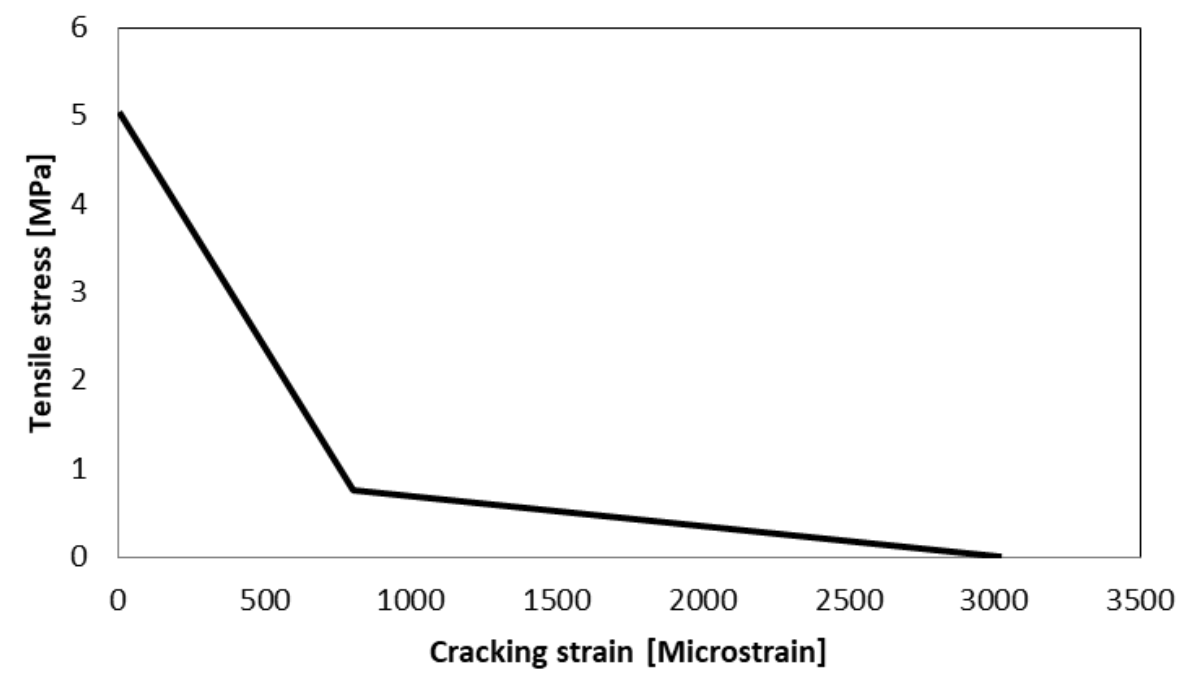

Figure 3.12: Tensile behaviour of ECC

It is important to note that the compressive test results by Taormina (2012) for ECC, SCC and UHPC cylinders only consider the compressive behaviour up to peak point with no post peak response (Figures 3.13 and 3.14). For this reason, a compressive model must be generated to predict the full compressive response of the concrete cylinders. There are several models able to predict the compressive behaviour of concrete. In this case, the model proposed by Popovics (1973) is used as it is proven to have accurate response in estimating the behaviour of the concrete alternatives as presented in the study by Rafiei et al. (2013). Equation 3.4 includes the definition used to determine the response in question (Popovics 1973).

$$
\frac{f_{c}}{f_{c}^{\prime}}=\frac{n_{f}\left(\frac{\varepsilon_{c}}{\varepsilon_{0}}\right)}{n_{f}-1+\left(\frac{\varepsilon_{c}}{\varepsilon_{0}}\right)^{n K}}
$$

In Equation $3.4, f_{c}$ : compressive stress of concrete, $f_{c}^{\prime}$ : ultimate compressive strength of concrete; $n_{f}$ : curve fitting factor, $n_{f}=0.8+\frac{f_{c}^{\prime}}{17} ; K$ : slope of the stress-strain curve, $K=0.67+$ $\frac{f_{c}^{\prime}}{62}$ and $\varepsilon_{0}$ : strain at ultimate compressive stress. 
Using the model obtained from Popovics (1973), the compressive stress vs. strain curves for the alternative concrete types presented in this study is obtained. Figures 3.13, 3.14 and 3.15 demonstrate the stress vs. strain curves in relation to the one determined through experimental test by Taormina (2012). Although, unloading curve from test measurement was not obtained, very good agreement exists for SCC and ECC. No data was obtained from UHPC due to lab limitations thus only the curve obtained from Popovics model is portrayed.

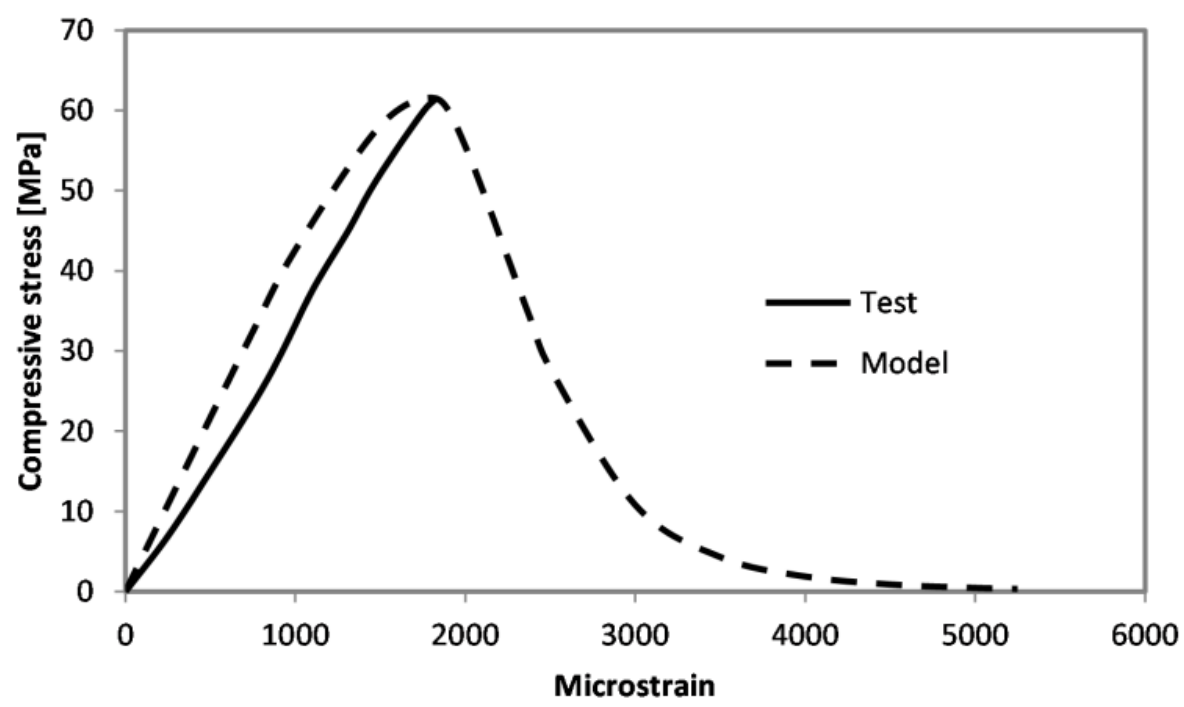

Figure 3.13: Stress vs. strain curve for SCC at ambient temperature

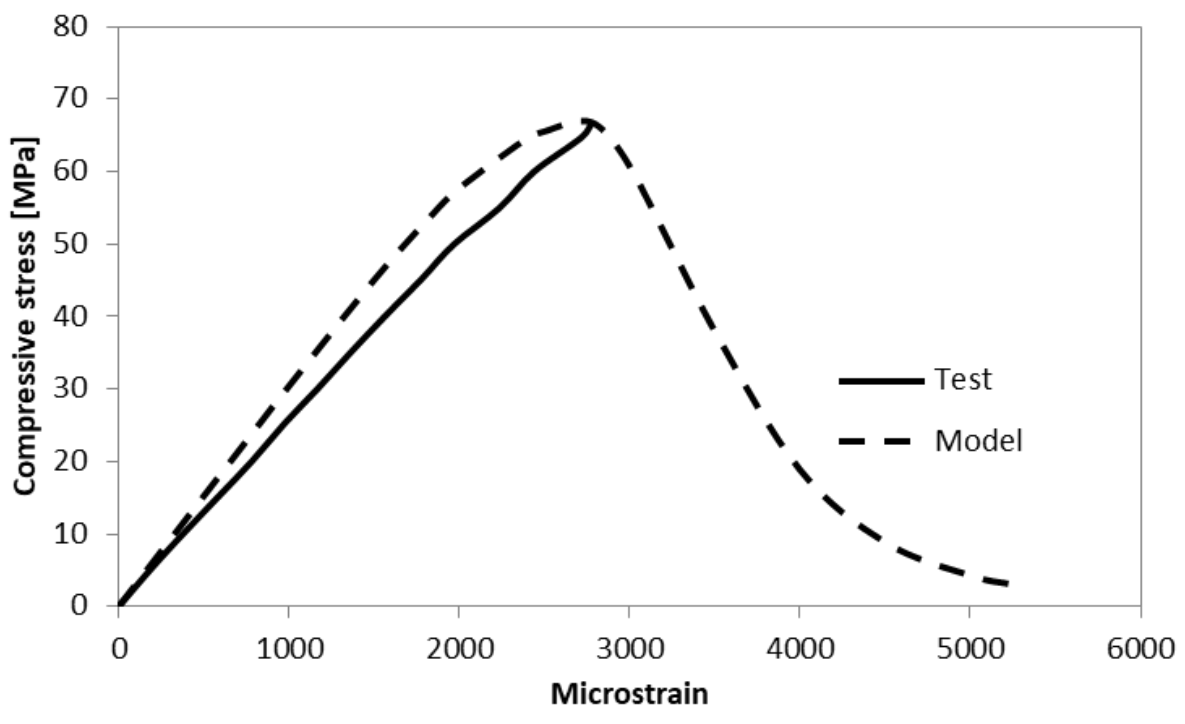

Figure 3.14: Stress vs. strain curve for ECC at ambient temperature 


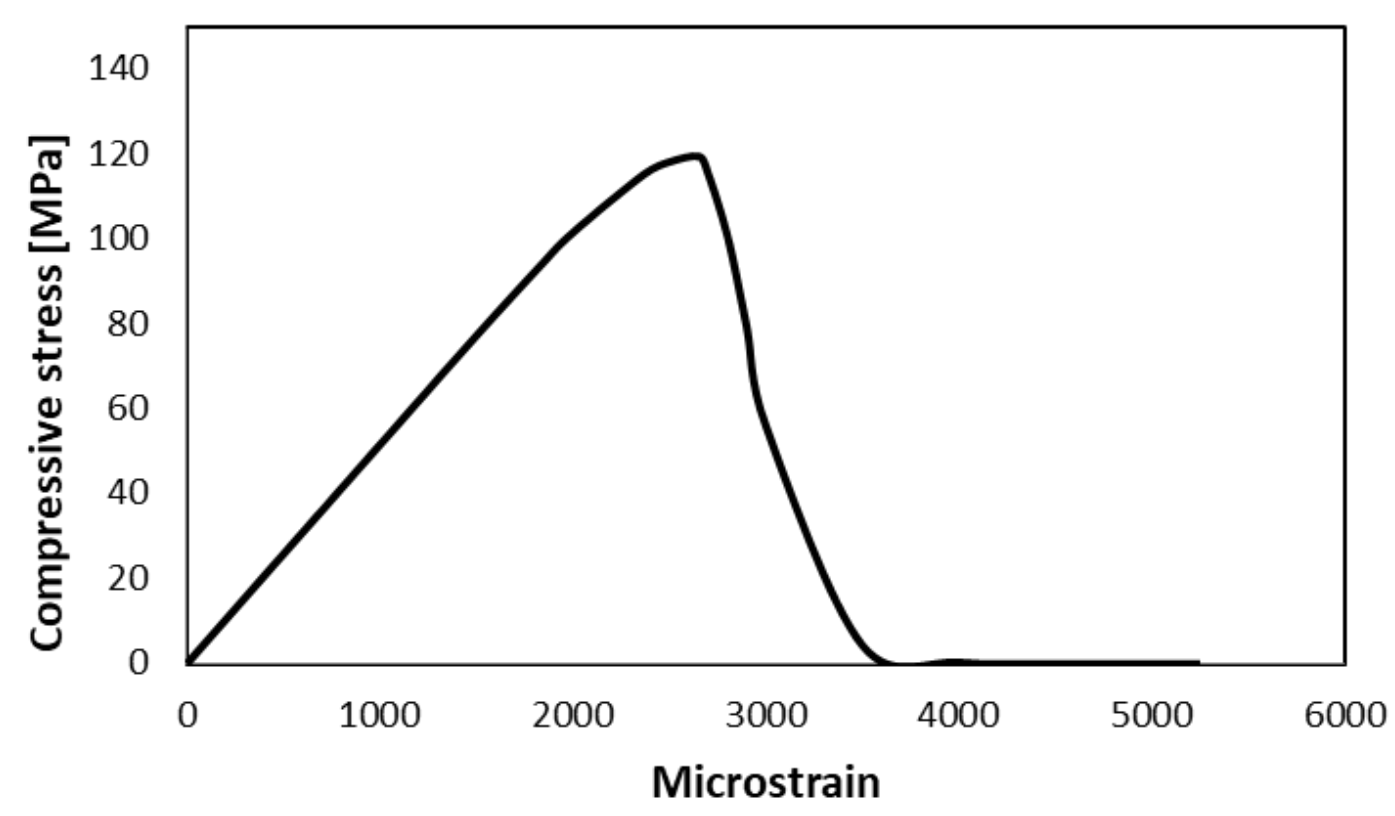

Figure 3.15: Stress vs. strain curve for UHPC at ambient temperature

\subsubsection{Validation of the Material Model for Concrete}

The proposed model for ECC, SCC and UHPC is validated by simulating the compression test conducted by Taormina (2012). Concrete cylinders with dimensions of 100x200 mm in diameter and length are generated with mesh set-up shown in Figure 3.16. Table 3.7 shows the number of elements, the type of element and the approximate element size used in the meshing process. The boundary conditions of the concrete cylinder model are summarized in Figure 3.17. A displacement is applied on the z-direction on the top and bottom surface of the cylinder to initiate the compressive test. Stress and strain contours for ECC, SCC and UHPC are shown in Figures 3.18, 3.19 and 3.20, respectively where "S" and "E33" refer to the von-Mises stress in unites of MPa and the compressive strain in the z-direction. The resulting stress vs. strain curves of the simulated FE test is compared with the proposed stress vs. strain curves of concrete. Figures 3.21-23 show the comparison in stress vs. strain curves for ECC, SCC and UHPC, respectively. 

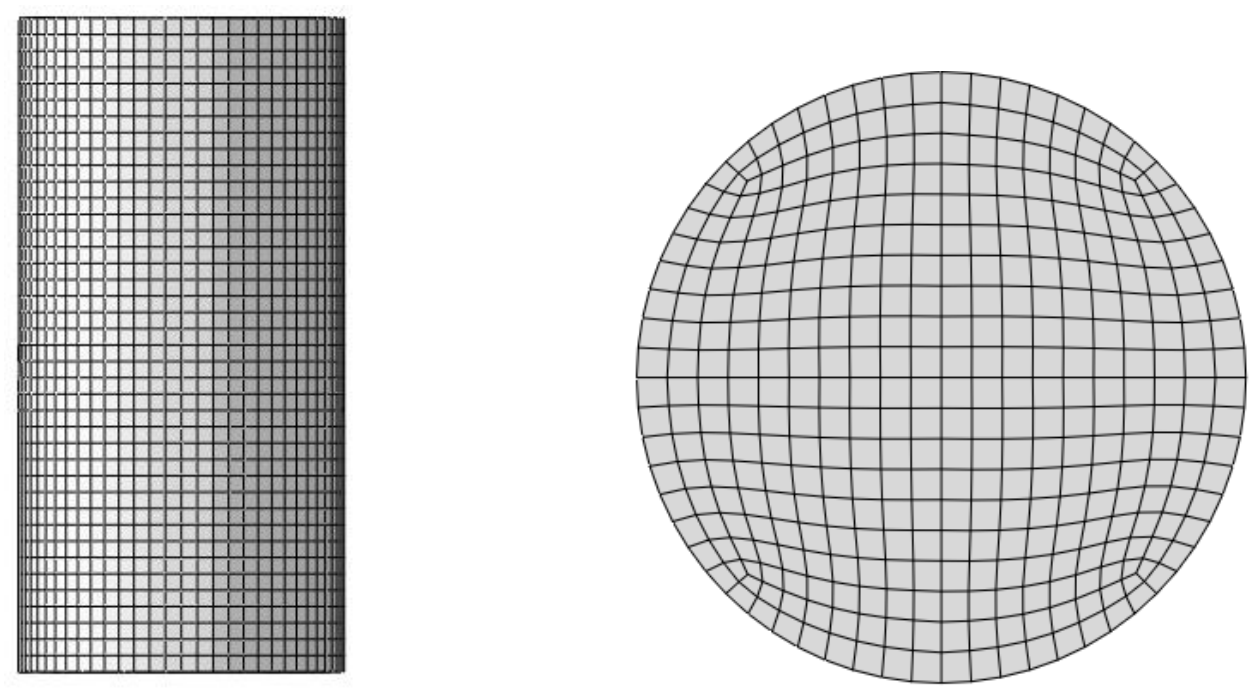

Figure 3.16: Mesh set-up for simulated concrete cylinder

Table 3.7: Number, type and approximate size of elements used

\begin{tabular}{|l|l|l|}
\hline Number of elements & Element type & Approximate element size [mm] \\
\hline 15360 & $\begin{array}{l}\text { C3D8R: 8-node linear brick, } \\
\text { reduced integration, hourglass } \\
\text { control. }\end{array}$ & 5 \\
\hline
\end{tabular}

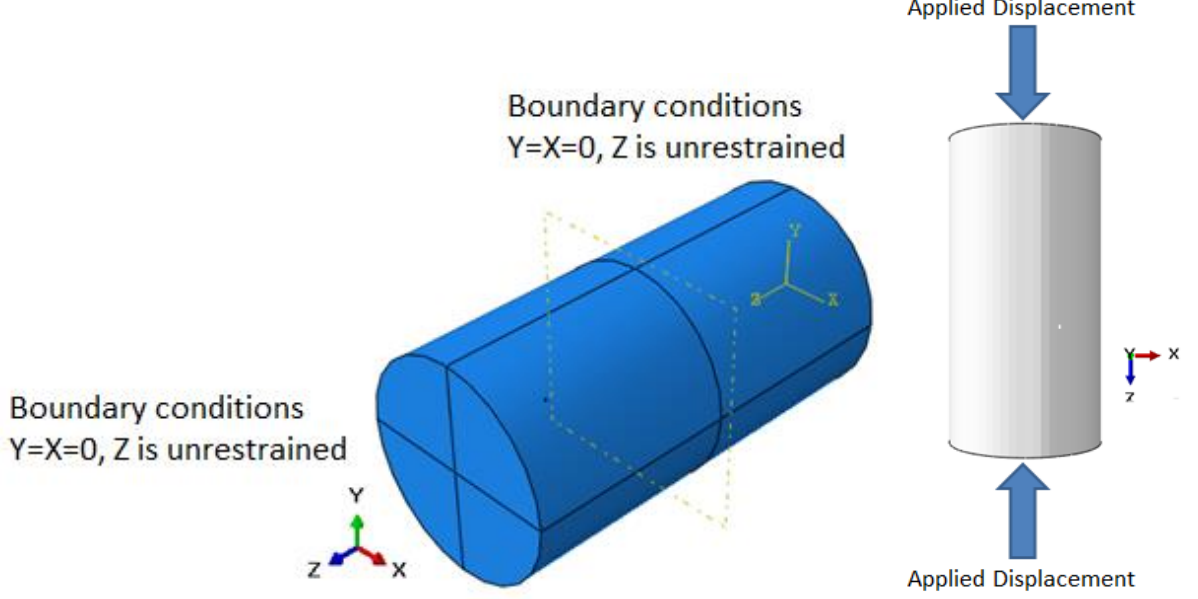

Figure 3.17: Boundary conditions of concrete cylinder 


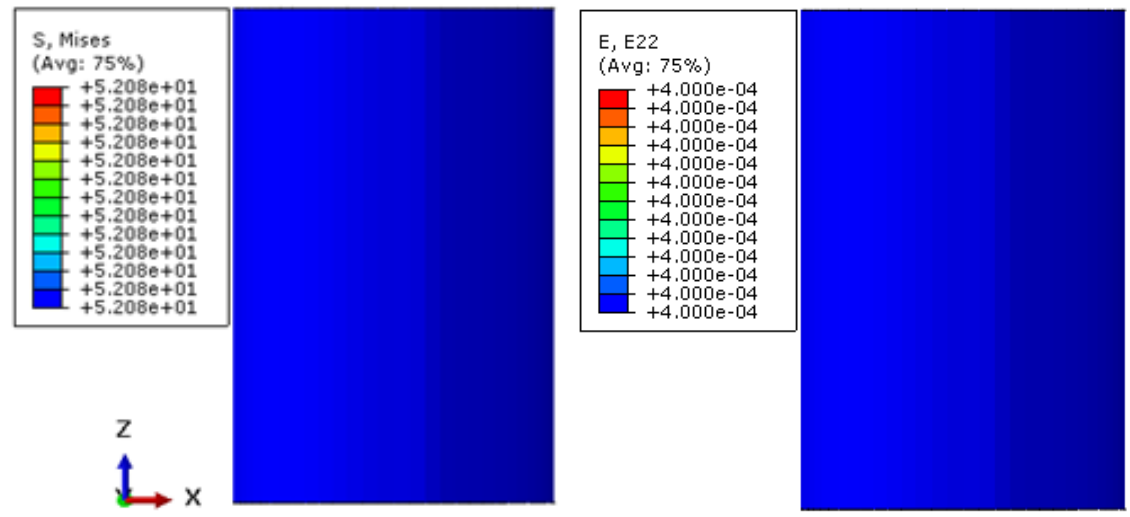

(a)

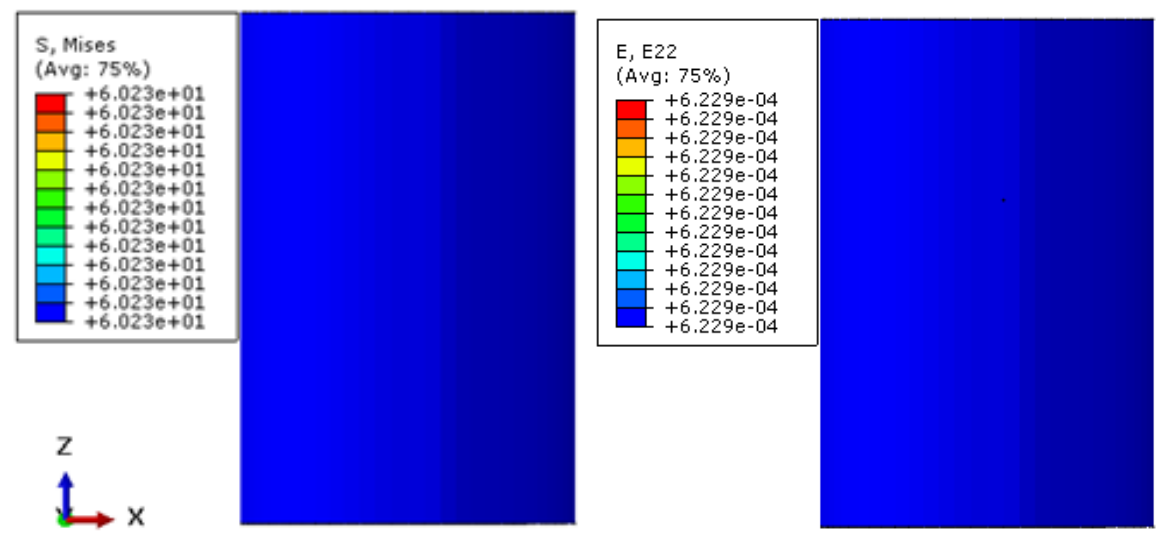

(b)
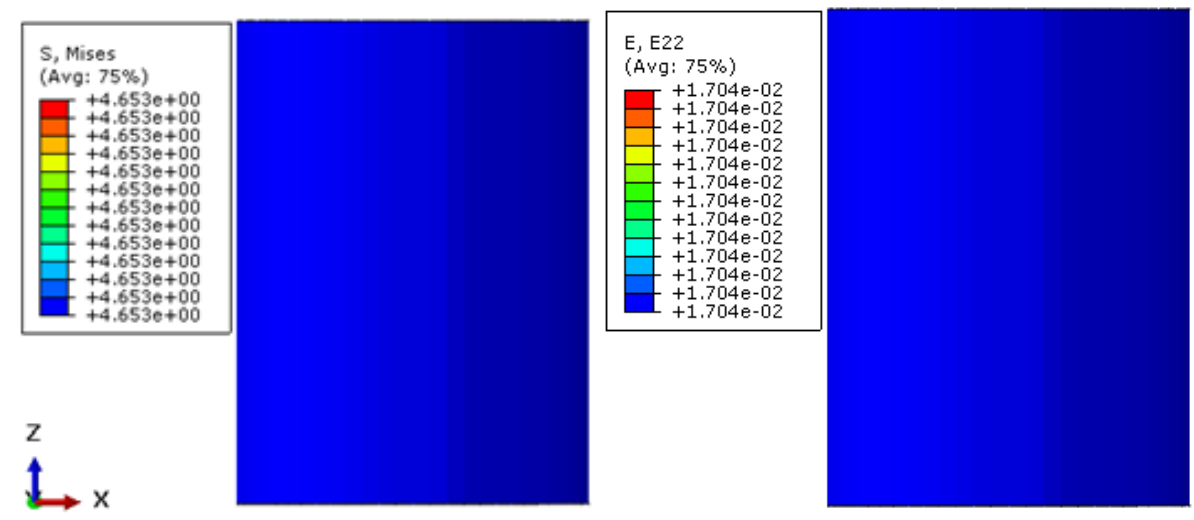

(c)

Figure 3.18: Contours of ECC cylinder for (a) displacement along the z-direction and (b) stress along the z-direction 

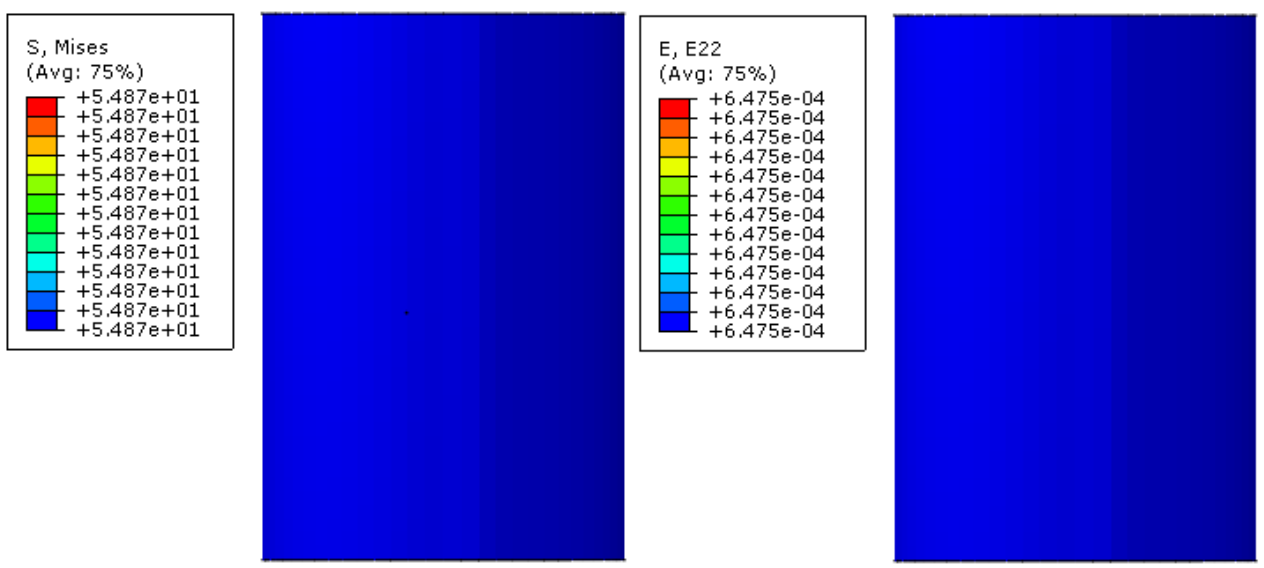

(a)
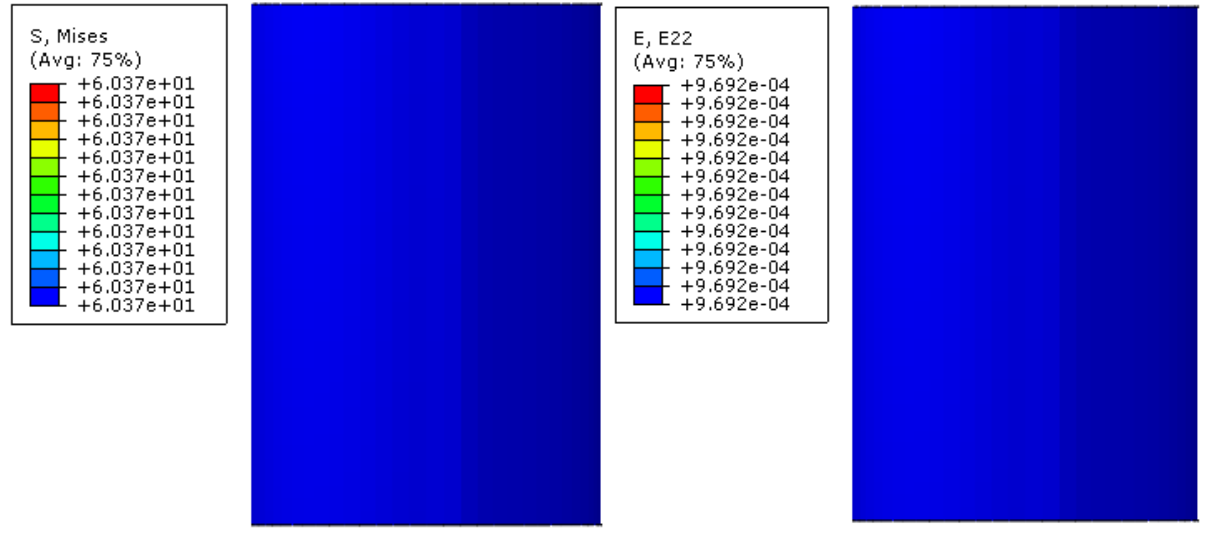

(b)
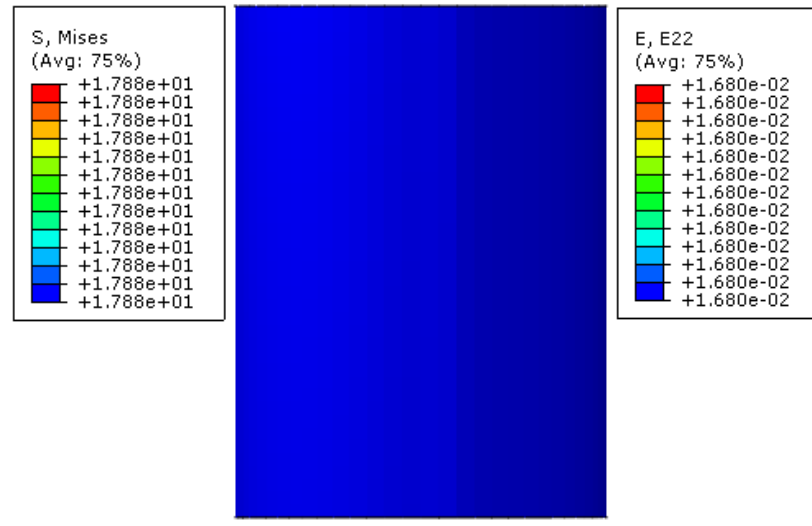

(c)

Figure 3.19: Contours of SCC cylinder for (a) displacement along the z-direction and (b) stress along the z-direction 

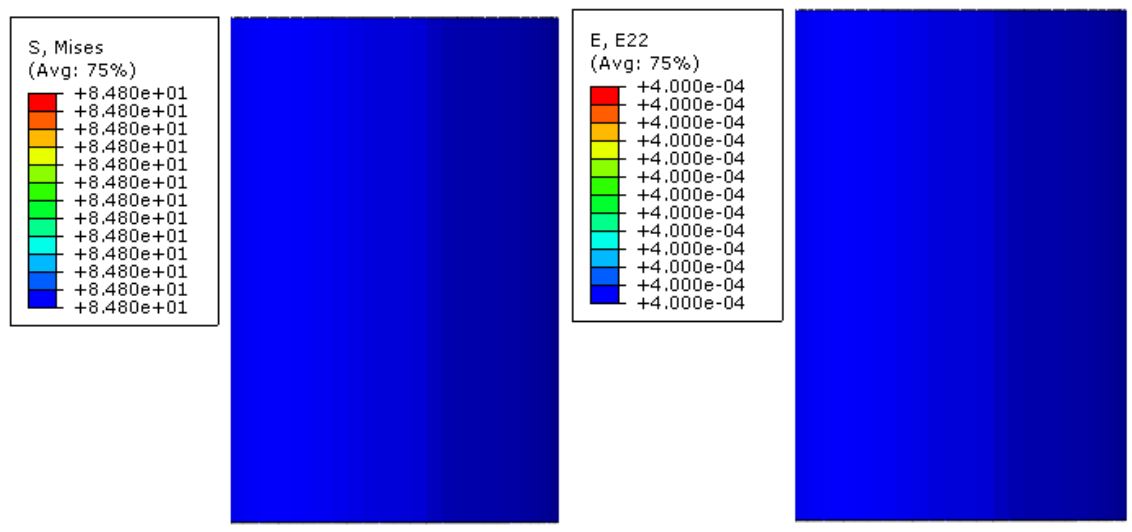

(a)
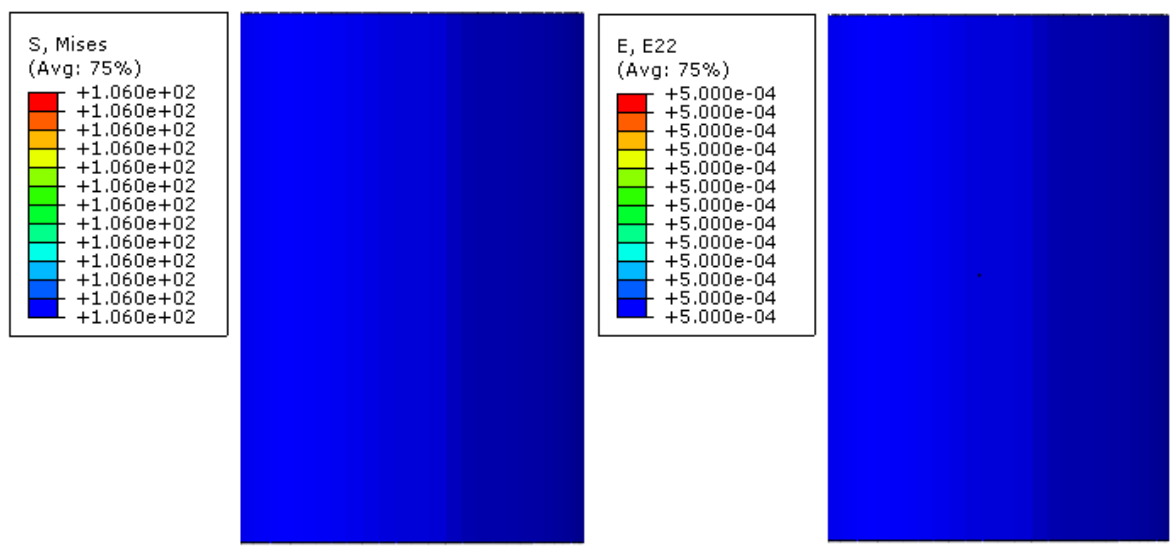

(b)
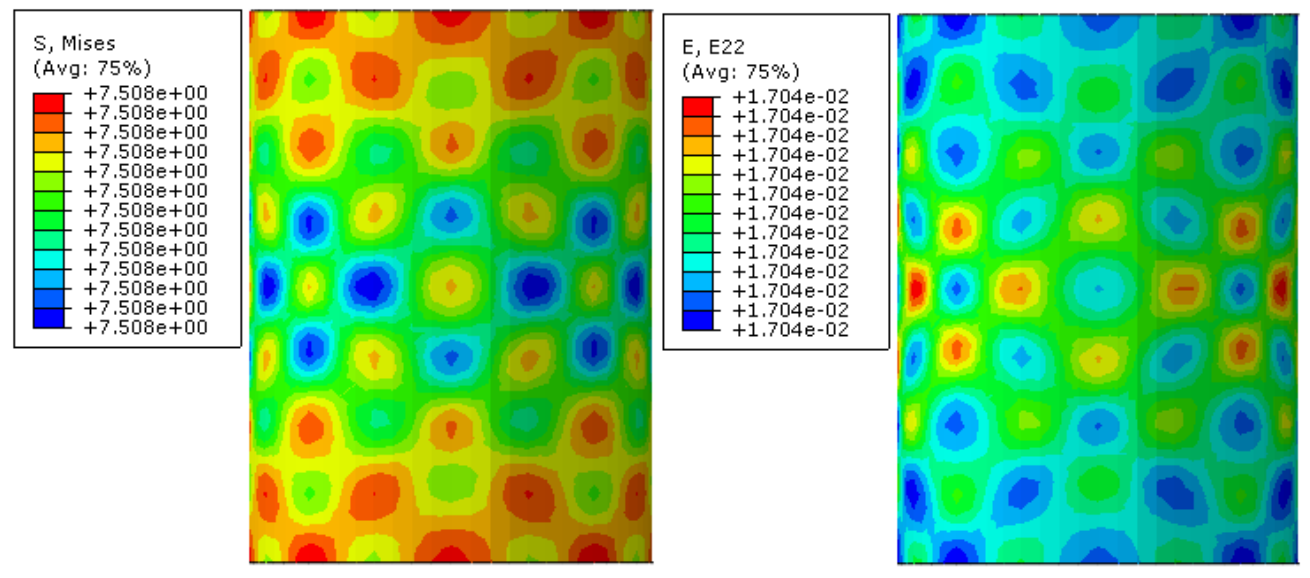

(c)

Figure 3.20: Contours of UHPC cylinder for (a) displacement along the z-direction and (b) stress along the z-direction 
Figures 3.18-3.20 show the stress and strain contours prior to reaching peak stress (a) upon reaching peak stress (b) and upon terminating the FE analysis (c). The figures are shown to portray the contours associated to three different points located in the pre-peak, peak and postpeak/softening response related to the stress vs. strain curves in Figures 3.21-23.

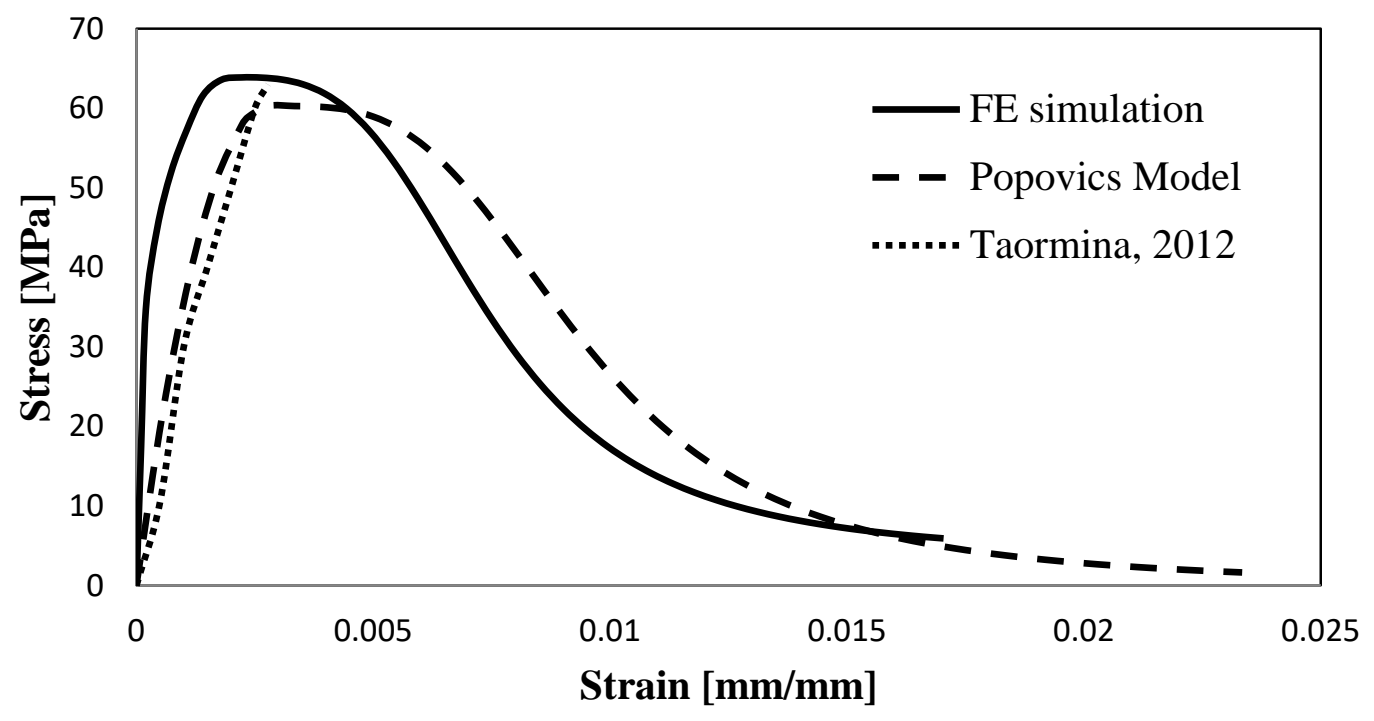

Figure 3.21: Stress vs. strain results obtained from experimental, FE simulation and predicted model for ECC

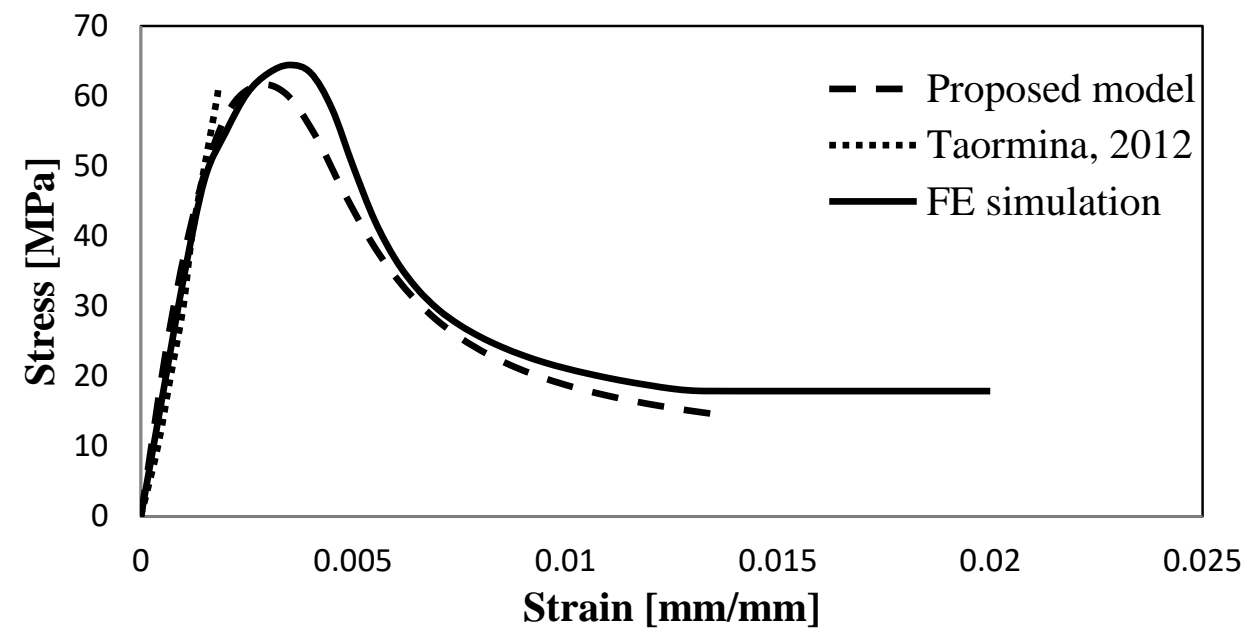

Figure 3.22: Stress vs. strain results obtained from experimental, FE simulation and predicted model for SCC 


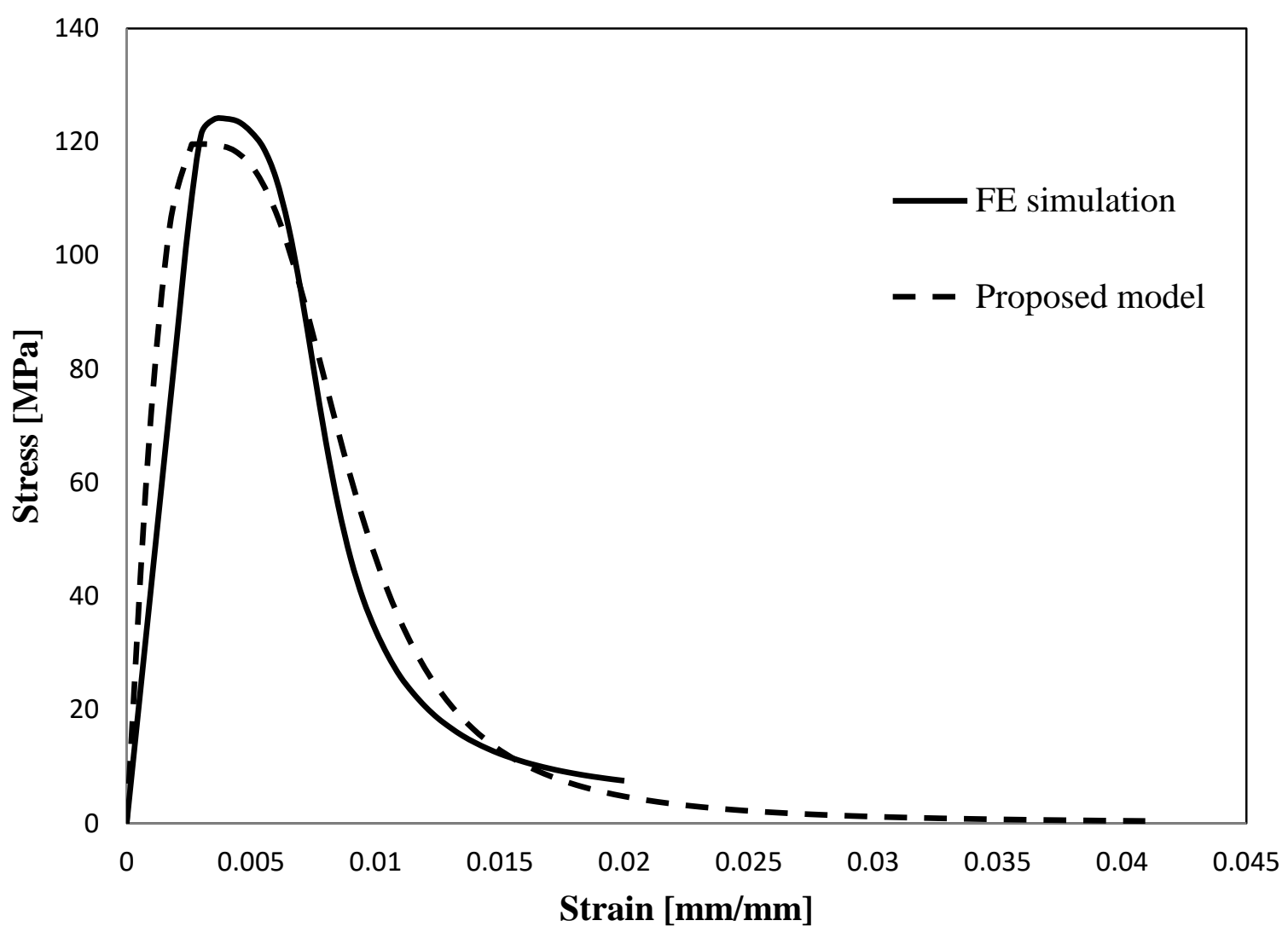

Figure 3.23: Stress vs. strain results obtained from experimental, FE simulation and predicted model for UHPC

Figures 3.21-23 show the validity of the proposed material model. As shown when comparing the proposed model and FE simulation, good agreement exists for all studied concrete alternatives. Such observation suggests that the proposed material models are indeed capable of predicting the structural behaviour of ECC, SCC and UHPC.

\subsection{Double Skin Composite Wall Model}

Finite element (FE) model for Double Skin Wall (DSCW) is presented. System assembly including boundary conditions (BCs) and FE mesh are described in this section. 


\subsubsection{Geometry and Boundary Conditions}

The FE model of the wall system is composed of three components with a concrete core confined by two profiled steel sheets and a loading plate. As shown in Figure 3.24, the loading plate is located top of the composite wall and it is used with the intent to apply load uniformly along the cross-section.

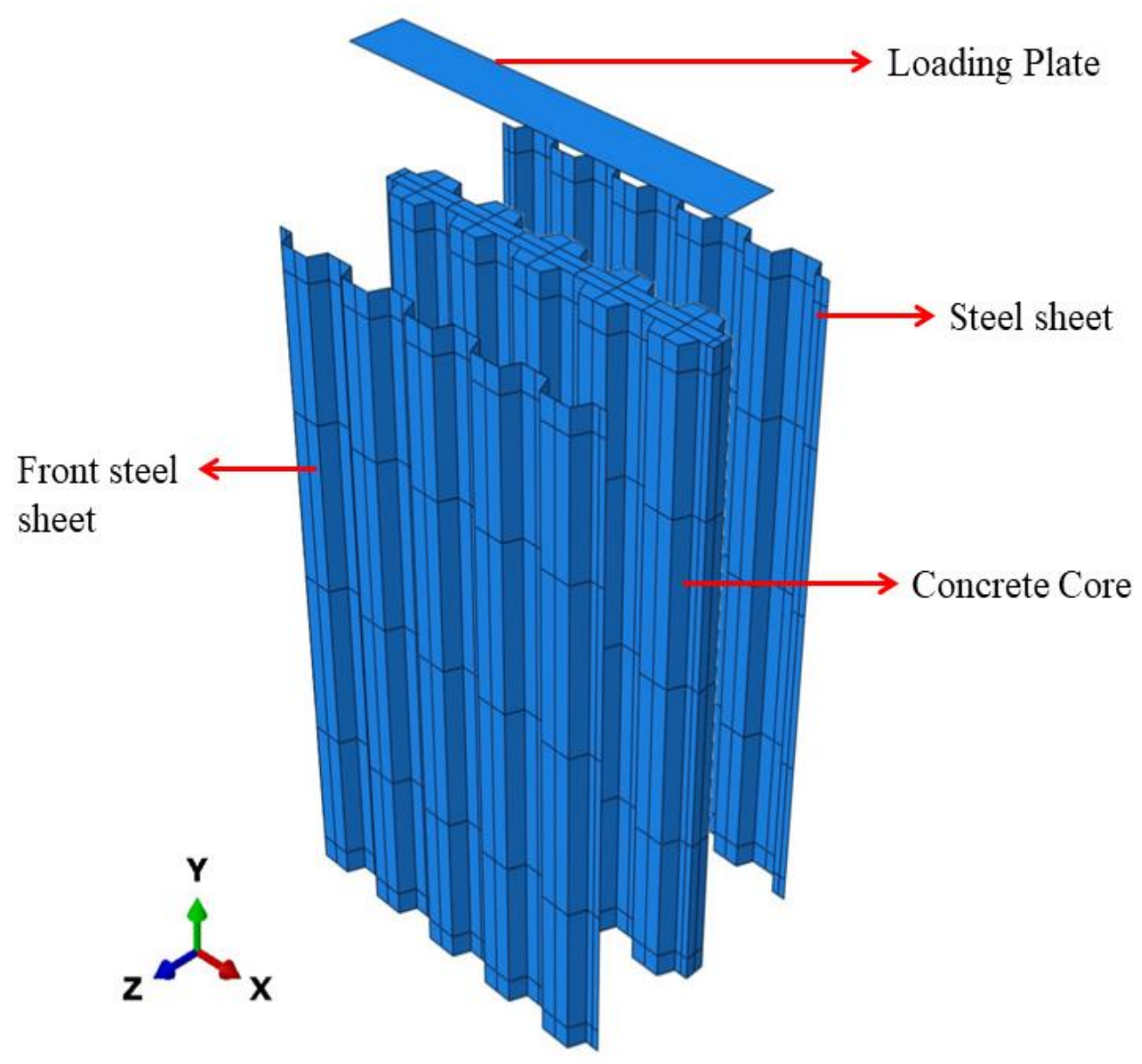

Figure 3.24: Sketch of the components of the composite wall

The BCs are developed for the FE model to simulate test experiments are included in Figure 3.25. The out-of-plane motion of the composite wall in the $\mathrm{z}$-direction is restrained through use of fasteners. In this case, the location of the fasteners is represented by nodes with U3=0 (U3motion in Z-direction). The loading plate is intended to mimic the loading system in test 
experiments. It is thus defined as a rigid part restrained on all directions but the U2-axis (Ydirection) where the load is applied. The BCs for the rigid plate are established though a reference point located at the centroid. Hence, motion of the rigid plate is restrained based on the defined $\mathrm{BC}$ of the reference point. A concentrated point load is directly applied on the reference point (RP) of the rigid plate. The point load is the $50 \mathrm{kN} / \mathrm{min}$ gradual rate applied in lab experiments. The loading plate is then connected to the top edge of the steel and concrete core through use of coupling and contact interactions respectively. The coupling method is especially effective when a group of nodes are constrained by the motion of a single node (ABAQUS, 2014). The proposed method is also effective when trying to distribute loads on a model, where the load distribution can be described with a moment-of-inertia expression (ABAQUS, 2014). The contact interaction on the other hand is a definition of how different parts of the model interact with one another and/or itself (ABAQUS, 2014). Any type of contact must be defined for proper compilation where the larger surface acts as the master surface. Kinematic coupling in the $\mathrm{U} 2$ direction is specified between the reference point of the plate and the top edges of the profiled steel. In addition, pending contact is defined for the interaction of concrete core and the loading plate with the bottom surface of the loading plate acting as the master surface and the top surface of the concrete core acting as the slave surface (Figure 3.25). Doing so, the FE model exactly exhibits the loading process that occurred in lab experiments. As for the bottom edge of the composite wall, a reference point is defined at centroid of the cross-section with the BCs of the steel sheets and the concrete core directly linked to the (RP). Pin BC where $\mathrm{U} 1=\mathrm{U} 2=\mathrm{U} 3=0$ (U1-motion in x-direction) is defined for the RP. Nodal based kinematic coupling of all directions is defined for the interaction between the RP and the steel sheet. On the other hand, surface based kinematic coupling is defined for the interaction existing between the RP and surface of the core of the concrete. Finally, three-dimensional smoothing option was included to minimize convergence problems. Using the geometry and boundary conditions of the FE model, the definition of the meshing and element types used to discretize the model can now be determined. The following subsection describes the element types, number of elements and meshing procedure used to discretize the model. 


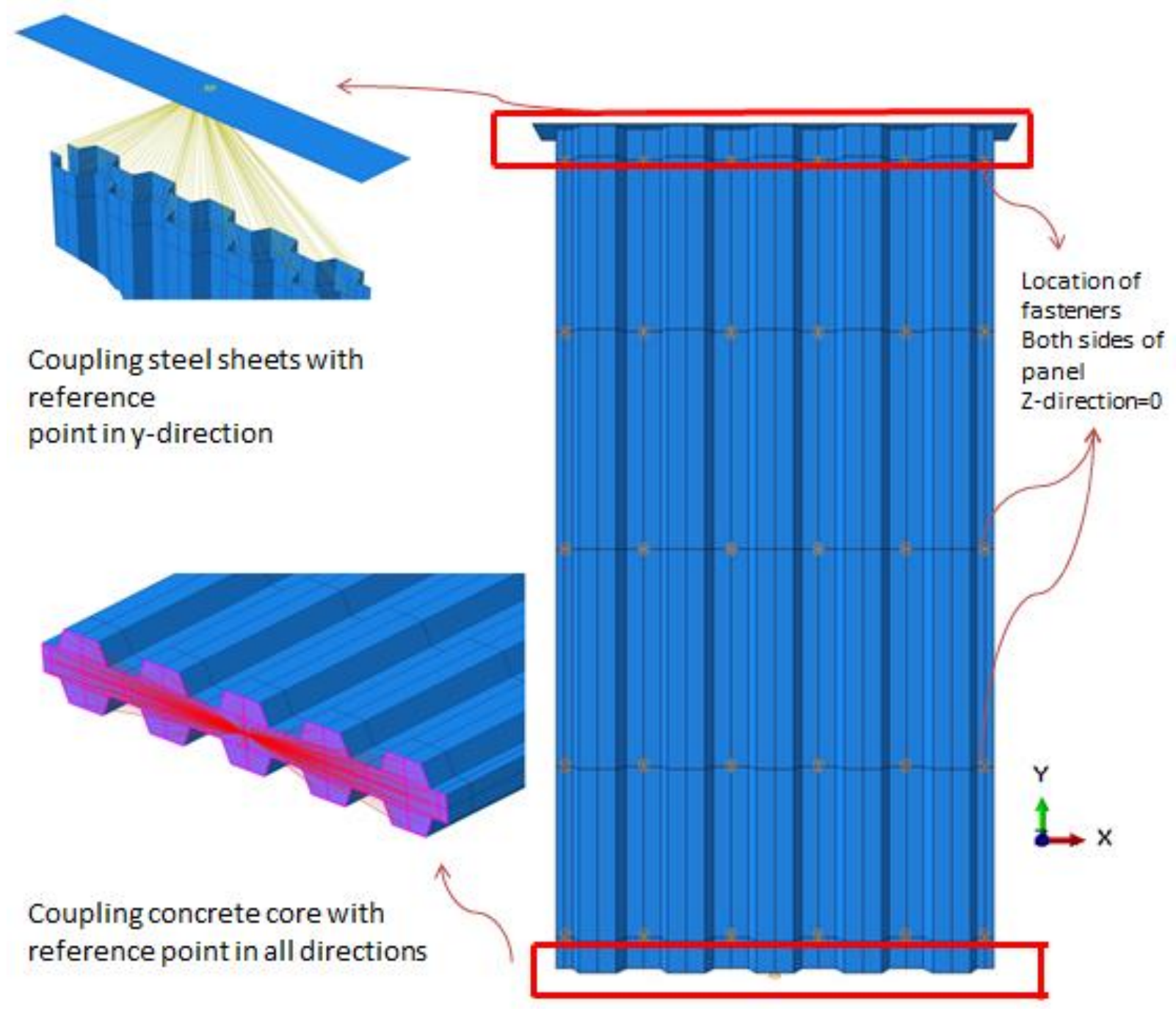

Figure 3.25: Boundary conditions and coupling of assembled model

\subsection{Finite Element Mesh}

A hybrid mesh consisting of both shell and solid elements is adopted to model the composite wall assembly. Since the depth to thickness ratio is bigger than 1000 ( $d / t>>1000)$, the profiled steel sheets are modelled as four-node shell elements (S4R elements) with reduced integration option (Cengel and Boles, 2002). The concrete core is modelled as a solid part using eight-node reduced integration elements (C3D8R elements). The loading plate is modelled as a 3dimensional (3D) discrete rigid part using four-node bilinear rigid quadrilateral (R3D4) elements. Although concrete is characterized as heterogeneous material, for convenience and 
simplicity, both steel and concrete materials are defined as isotropic homogenous (Rafiei, 2011). Due to the use of the reduced integration method, the hourglass option was selected in an attempt to prevent distortions of the mesh leading to computational errors (ABAQUS, 2014). This method reduces the required integration points in a given element to one point located at the centroid of the element. This reduces the amount of calculations needed and thus significantly improves compilation running time.

Since a CDP model is used to define the softening part of the concrete material, it is important to select appropriate mesh size in order to generate adequate FE results. A mesh sensitivity study performed by Genikomsou and Polak (2015) on punching shear of concrete slab concluded that due to the accumulation of strain-softening localization occurring in certain elements of the mesh set-up, most plasticity-based models fail to converge. In fact, according to this research study, the use of CDP model is treated as mesh dependant. Such observation was highlighted when FE model with mesh size of 15, 20 and $24 \mathrm{~mm}$ were generated and compared with test results. In this case, the use of $20 \mathrm{~mm}$ mesh size was characterized as leading to the most accurate results. The use of $15 \mathrm{~mm}$ mesh size led to early failure while the $24 \mathrm{~mm}$ mesh size led to failure occurring at a much later time when compared to test results. Although the presented research by Genikomsou and Polak (2015) deals with punching shear on concrete slab, the convergence problem can also be extended to static, quasi-static and dynamic FE analysis (Kwak and Gang, 2015). In order to avoid the limitations presented, a similar meshing setup to that presented in the study by Rafiei (2011) is used in this thesis. The size of the elements of profiled steel sheeting is maintained at $15 \mathrm{~mm}$ throughout the entire part while the size of the elements of the concrete core is maintained at $10 \mathrm{~mm}$. Although, mesh convergence for concrete occurs at meshing size of $5 \mathrm{~mm}$ for the heat transfer analysis (Rush, 2013), minimum allowable size of concrete element must be maintained at $10 \mathrm{~mm}$ to compensate for the size of the aggregates within the concrete mixture. The element size of the loading plate is of no importance to convergence errors however it does become important when defining surface interactions. Figures 3.26 and 3.27 show the discretization model for the steel and concrete core parts of the assembly. Figure 3.28 shows the meshing setup of the loading plate with element edge size maintained at $20 \mathrm{~mm}$ throughout the part. Table 3.8 summarizes the type and number of elements used to define the FE model. 


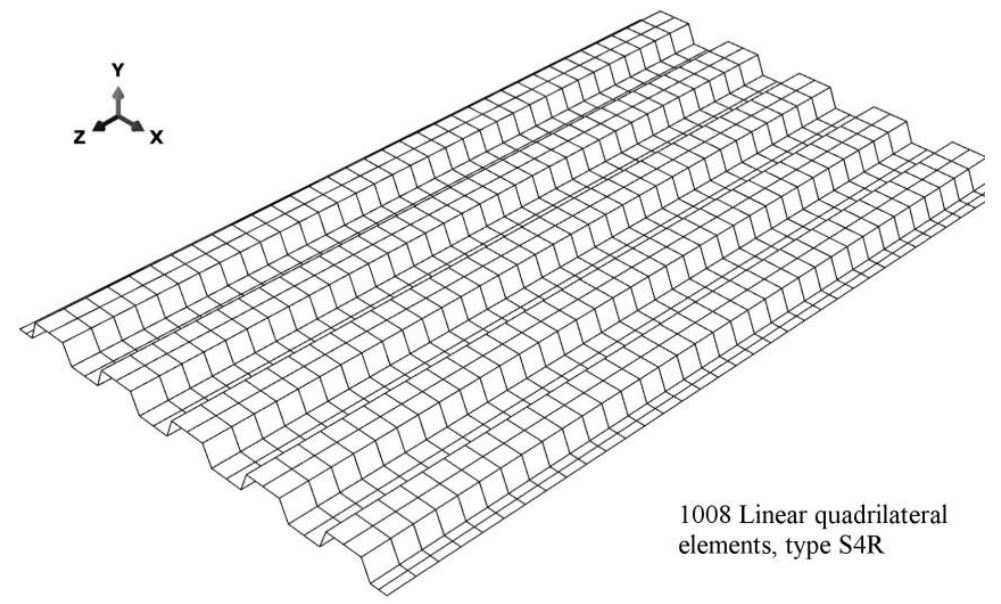

Figure 3.26: Meshing of steel sheets

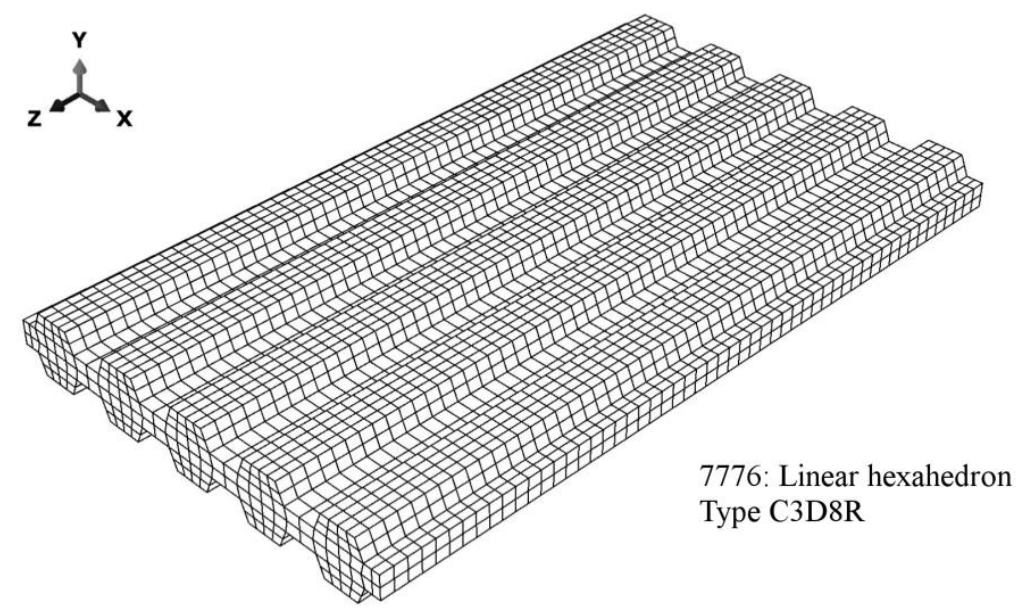

Figure 3.27: Meshing of concrete core

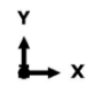

54-four-node rigid quadrilateral elements, type R3D4

\begin{tabular}{|l|l|l|l|l|l|l|l|l|l|l|l|l|l|l|l|l|l|}
\hline & & & & & & & & & & & & & & & & & \\
\hline & & & & & & & & & $R P$ & & & & & & & & \\
\hline & & & & & & & & & & & & & & & & & \\
\hline
\end{tabular}

Figure 3.28: Meshing of loading plate 
Table 3.8: Summary of number and type of elements

\begin{tabular}{|l|l|l|}
\hline & Element types & Number of elements \\
\hline Concrete core & Linear hexahedron, C3D8R & 7776 \\
\hline Steel sheets & Linear quadrilateral, S4R & $1088 \times 2$ \\
\hline Loading plate & Rigid quadrilateral, R3D4 & 54 \\
\hline \multicolumn{2}{|l|}{ Total number of elements } & 10006 \\
\hline
\end{tabular}

\subsection{Steel-concrete Interaction}

The exiting interface between the inner surface of profiled steel sheeting and concrete core can be defined as contact, tie or as a friction-based interaction. The tie interaction is used to restrain nodes and surface together for the duration of the analysis. The nodes identified as slave are constrained to the motion and the boundary conditions of the master nodes (ABAQUS, 2014). In fact, this method is used to fuse a set of nodes or surfaces together. The general contact interaction is used to define a set of surfaces and nodes that are in contact or interact with each other with no shear transmission occurring throughout the simulation. Abaqus ${ }^{\circledR}$ does not automatically detect contact surfaces based on the distance between the parts hence, interactions must be defined. The friction interaction is an alternative type of contact existing between surfaces with frictional and normal forces occurring between the surfaces. The Coulomb friction model is used to compute the maximum "sticking" stresses at the interface before sliding occurs (ABAQUS, 2014). This interaction option can be implemented by specifying a stiffness (penalty) method through use of a friction factor obtained from the literature.

A study comparing the use of tie and general contact interaction by Rafiei (2011) concluded that the use of general contact to describe the interaction in question resulted in more accurate results with lower computation time. The friction interaction is defined in both the normal and tangential directions. The hard contact option was used for normal behaviour indicating an existing pressure when surfaces are in contact while no pressure exists when the surfaces are not in contact. The tangential behaviour is defined with the friction penalty model using a coefficient 
of 0.25. This value was also used by Tao et al. (2013) and Han et al. (2014) as it was found to be suitable for defining the steel-concrete interaction.

\subsection{Finite Element Modelling Approach}

Quasi-static analysis is conducted to minimize convergence problems and generate the FE results of the model in question. A gradual compressive displacement is applied on the top reference point of the assembled model (Figures 3.24 and 3.25). The displacement is applied within a dynamic explicit analysis step with a total time period of $1 \mathrm{sec}$. The time period for analysis is greatly minimized to reduce the total compilation time. To account for reduction, a factor of $1 / 500$ is applied to all rate dependant variables. For the compressive models presented in this chapter, no material property is affected with the change in total time.

In another attempt to minimize computation time, a mass scaling factor is applied to the concrete core part of the model. The implementation of this method is useful in increasing the computational efficiency of quasi-static analyses. As shown in Equation 3.5 computational time in quasi-static analyses is partly governed by the mass/density of the model (ABAQUS, 2014). Equation 3.5 shows the direct square-root relationship existing between the two variables with the wave speed $\left(C_{d}\right)$ inversely related to the compilation time. The mass scaling method applies a specific factor to the current density of the model $\rho$, thus increasing the theoretical density, which in turn decreases the computational time. The higher the coefficient the less accurate the results become. The mass scaling factor of 8 was used as it is found to have relatively accurate results with effective computational cost.

$$
C_{d}=\sqrt{\frac{E}{\rho}}
$$

In Equation 3.5, E: modulus of elasticity of the element with the highest modulus; $\rho$ : density of the element with the largest density value; $C_{d}$ : wave speed of the material (ABAQUS, 2014). 


\subsection{Verification of Finite Element Models}

The results of the monotonic axial compressive loading of double skin composite wall models are presented in the following section. The results are reported in terms of the load vs. deflection curves with direct comparison with those obtained from lab experiments by Taormina (2012). The predicted compressive load vs. displacement curves of composite walls at ambient temperature are shown in the Figures 3.29-3.31. Three FE models are generated to validate the procedure used. Figures 3.29-3.31 summarize the FE predicted and test results for SCC, ECC and UHPC composite walls, respectively. It can be seen that the load vs. deformation obtained from the FE analysis closely resembles the measured experimental results. The curves are characterized by an upward trend until ultimate load is reached. This is then followed by a postpeak/softening region characterized by a gradual decline until failure. A comparison between the ultimate/peak load obtained from FE models and test experiments is summarized in Table 3.9. It is found that the average test to FE prediction ratio is 0.927 , suggesting that the proposed $\mathrm{FE}$ models are capable of predicting the structural compressive behaviour of composite walls.

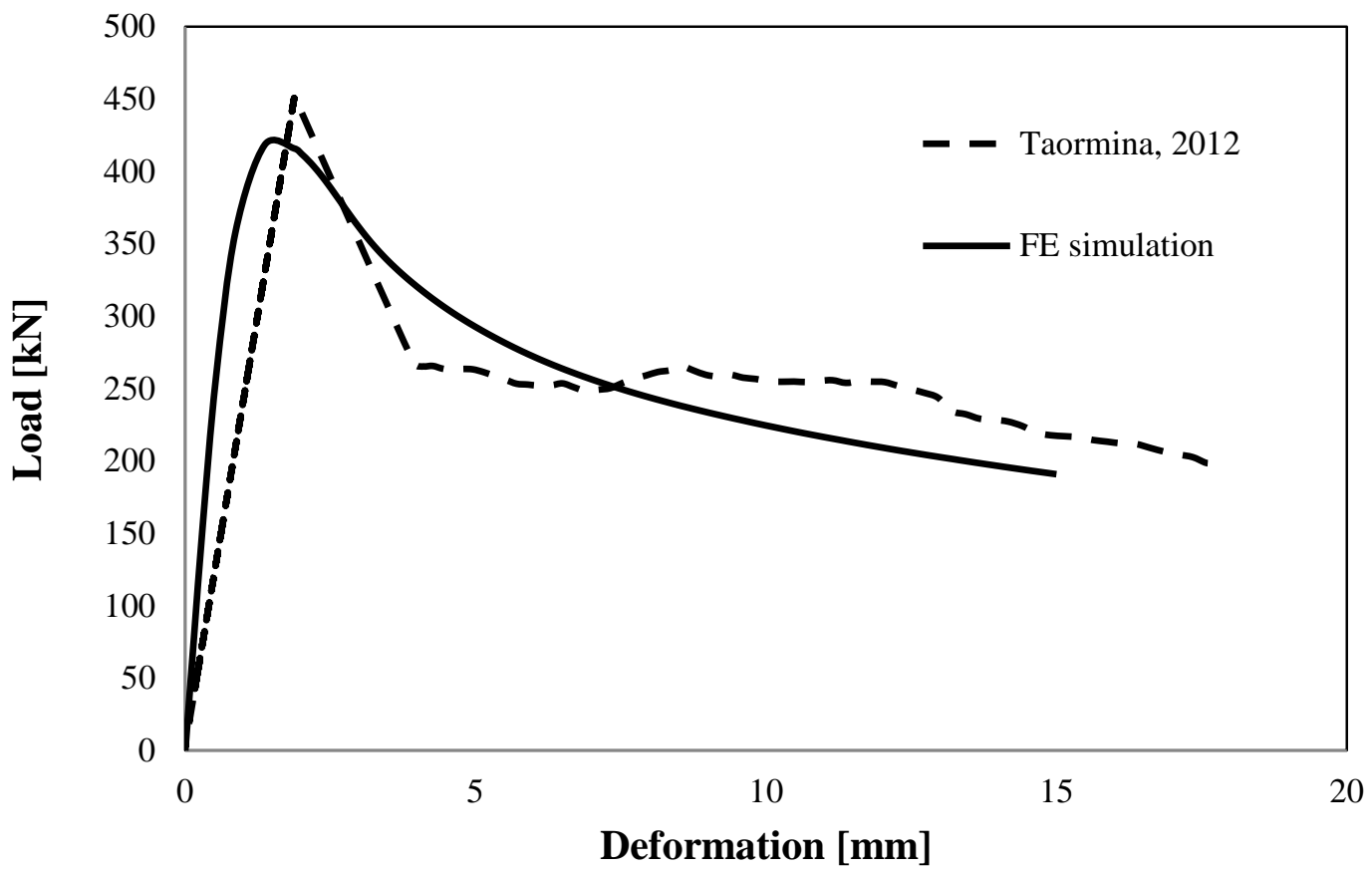

Figure 3.29: Axial load vs. deflection curve for SCC composite wall 


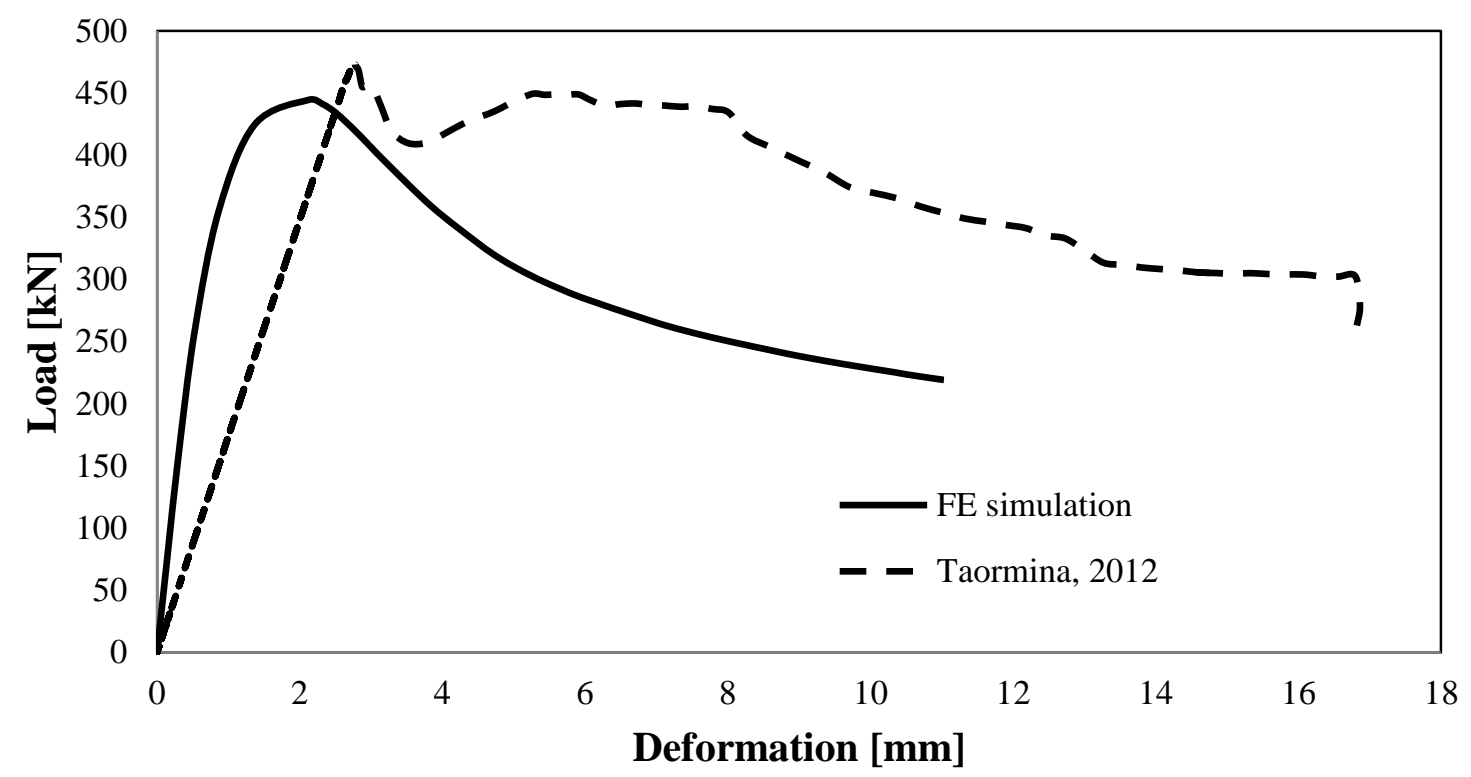

Figure 3.30: Axial load vs. deflection curve for ECC composite wall

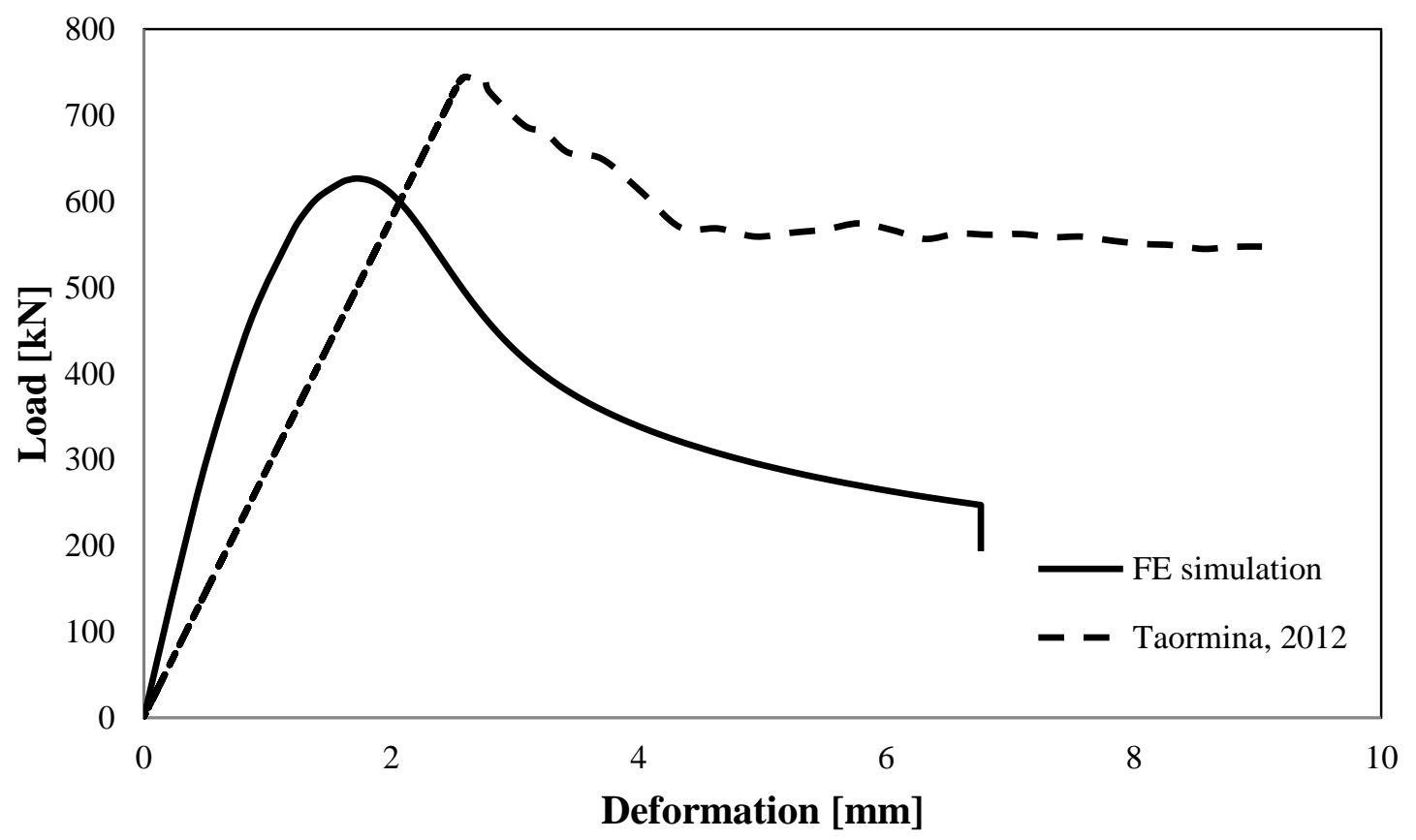

Figure 3.31: Axial load vs. deflection curve for UHPC composite wall 
Table 3.9: Summary of test and FE results

\begin{tabular}{|l|l|l|l|}
\hline Specimen & $\begin{array}{l}\text { Test Peak load } \\
(\mathrm{kN})\end{array}$ & $\begin{array}{l}\text { FEM Peak Load } \\
(\mathrm{kN})\end{array}$ & $\begin{array}{l}\text { Ratio: } \\
\text { Test/FEM }\end{array}$ \\
\hline SCC wall & 453 & 480 & 0.96 \\
\hline ECC wall & 473 & 505 & 0.95 \\
\hline UHPC wall & 745 & 761 & 0.87 \\
\hline Average & & & 0.93 \\
\hline
\end{tabular}

The contour graph for the stress (S22, Pa) and strain (E22) in the direction of the applied load (ydirection) for ECC composite wall specimen upon reaching applied load of 200 and $450 \mathrm{kN}$ as shown in Figure 3.32. In addition, the stress and strain contours at point of failure are also shown in Figure 3.32. General contours depicting the deformation at a specific point in the compressive behaviour of ECC-based DSCW are shown in Figure 3.33.
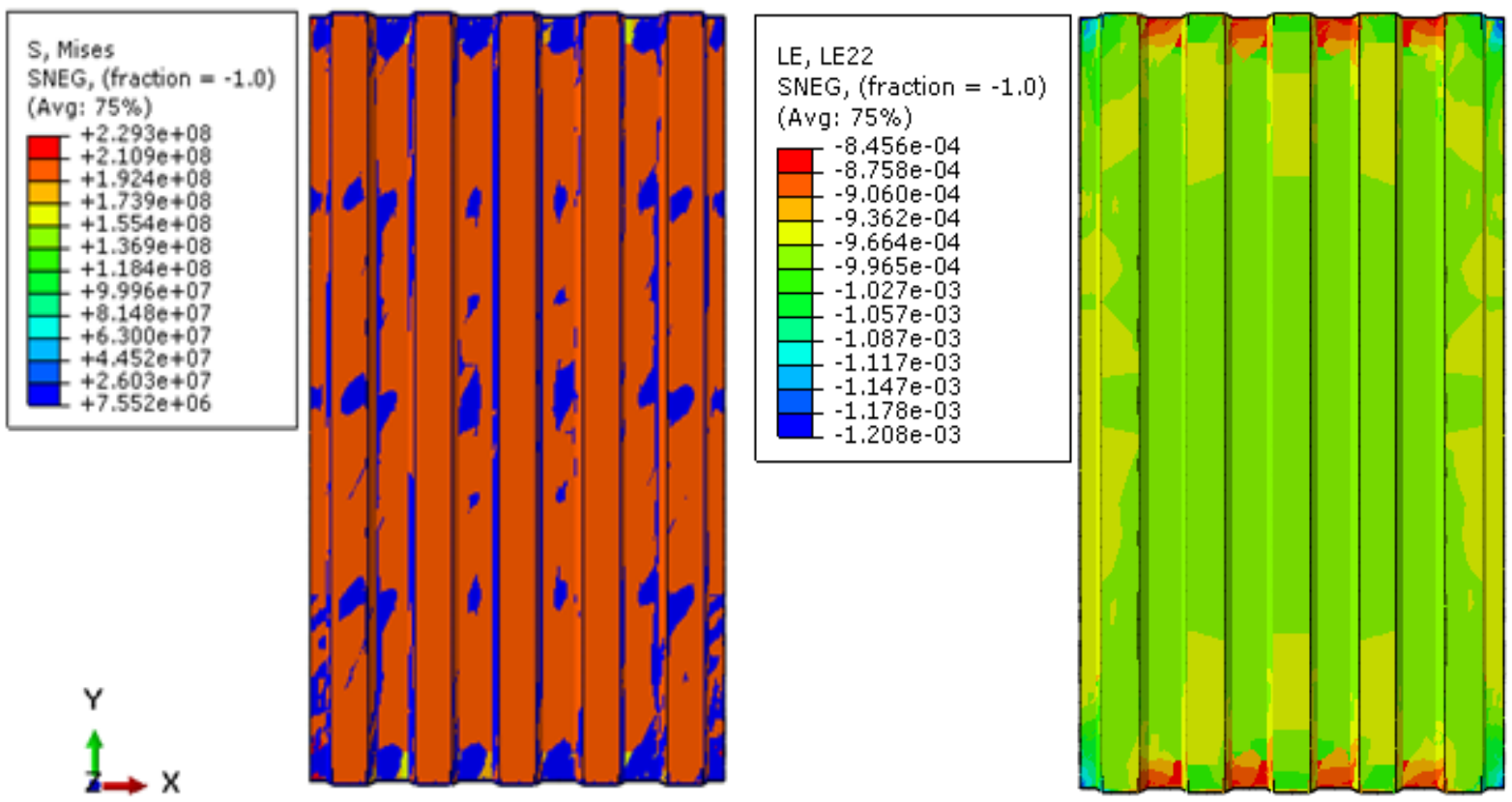

(a) 

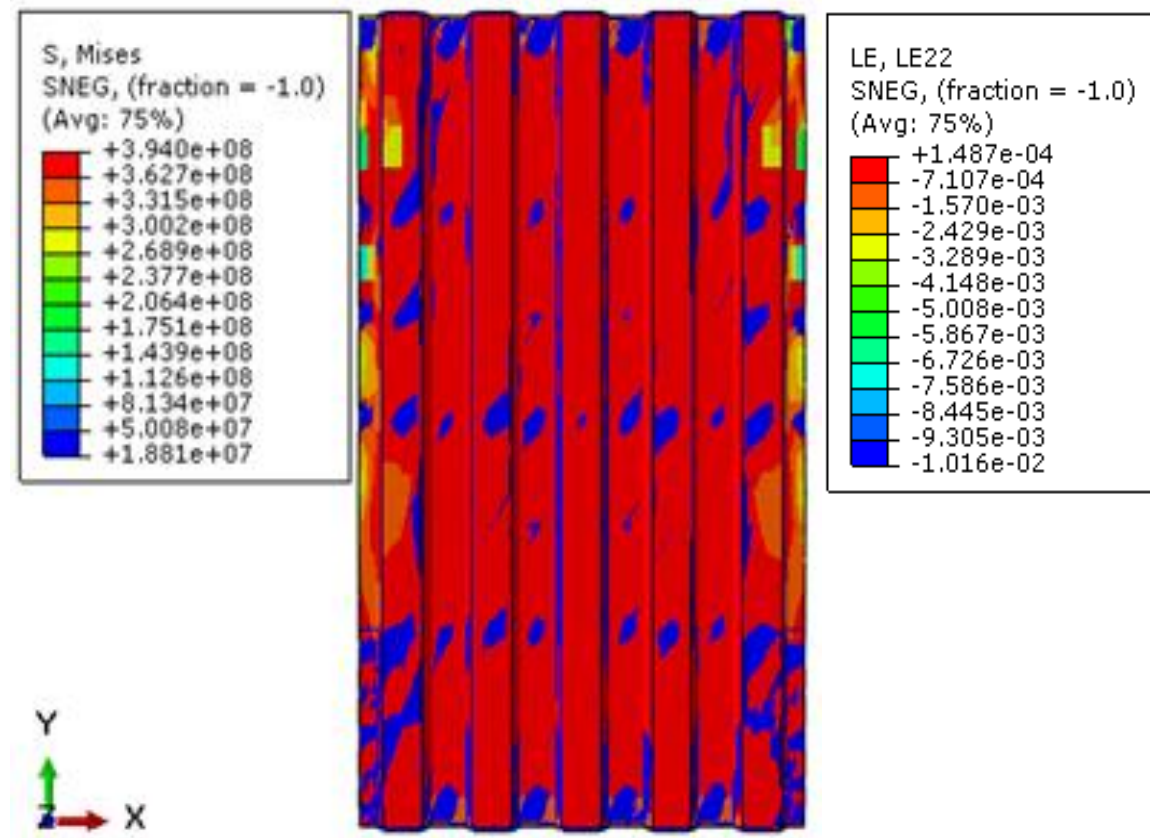

SNEG, $($ fraction $=-1.0$ )

(Avg: 75\%)

$+1.487 \mathrm{e}-04$
$-7.107 \mathrm{e}-04$

$-7.107 \mathrm{e}-04$

$-1.570 \mathrm{e}-03$

$\begin{array}{r}-2.429 \mathrm{e}-0.3 \\ -\quad 3.289 \mathrm{e}-03 \\ \hline\end{array}$

$-4.148 \mathrm{e}-03$

$-4.148 \mathrm{e}-03$

$-5.008 \mathrm{e}-03$
$--5.867 \mathrm{e}-03$

$-6.726 \mathrm{e}-03$

$-7.586 \mathrm{e}-03$

$-8.445 e-03$

$-9.305 e-03$

$-1.016 \mathrm{e}-02$

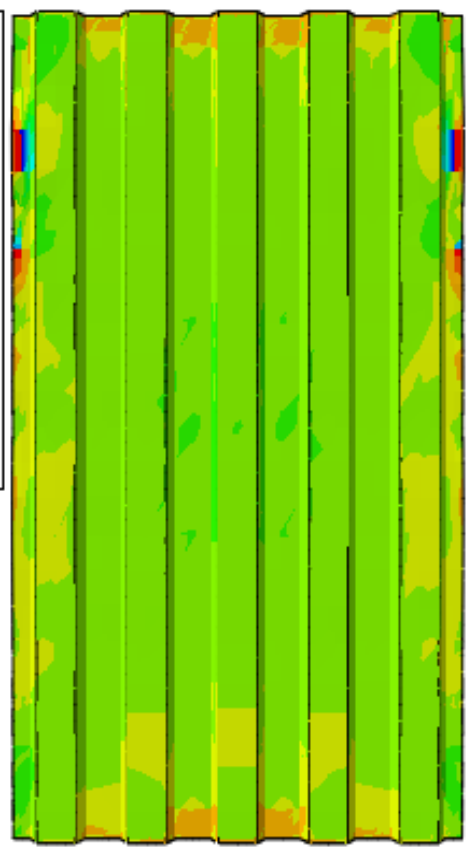

(b)
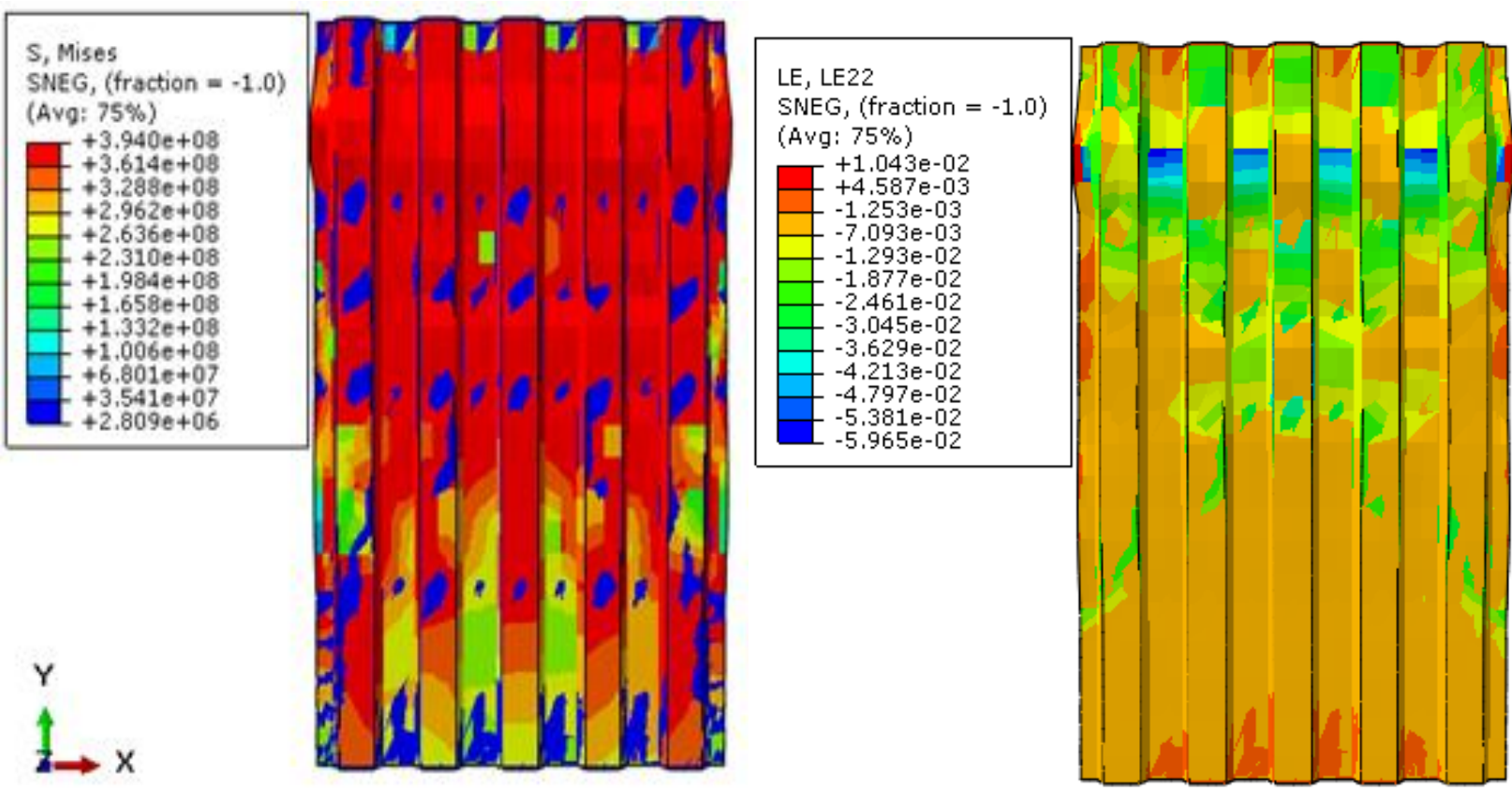

(c)

Figure 3.32: The contours for stress and strain in the y-direction at load level of (a) $204 \mathrm{kN}$ (b) $490 \mathrm{kN}$ and (c) $241 \mathrm{kN}$ 


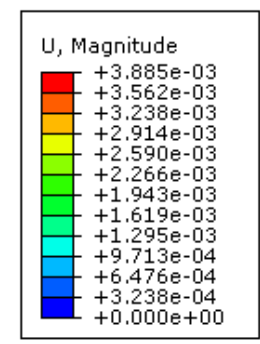

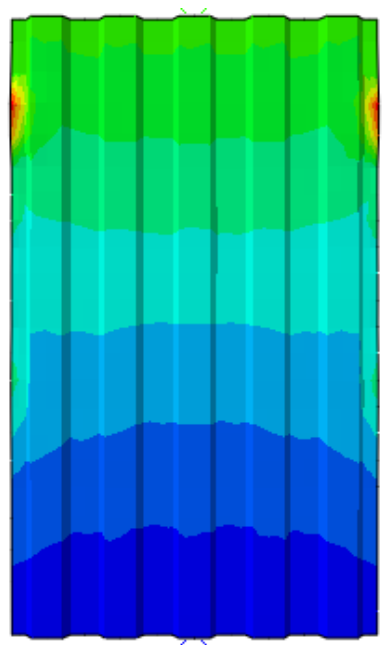

(a)
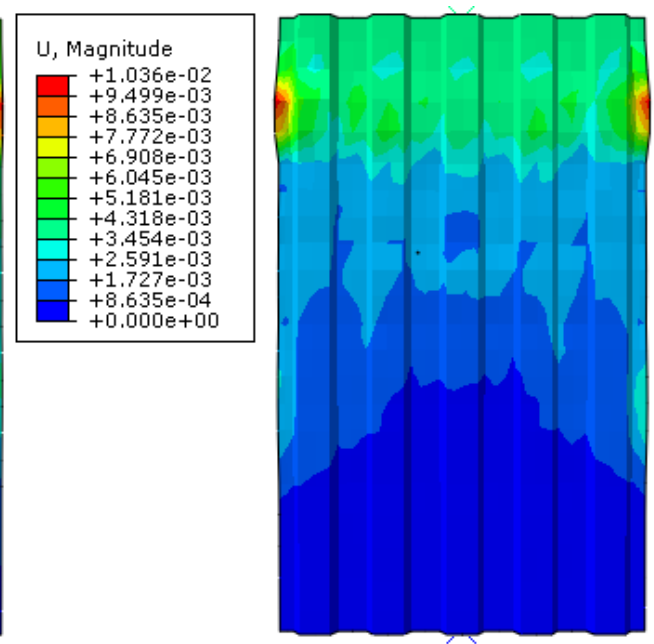

(b)

Figure 3.33: The contours for deformation after (a) $2 \mathrm{~mm}$ and (b) $4 \mathrm{~mm}$ of applied displacement for ECC-wall
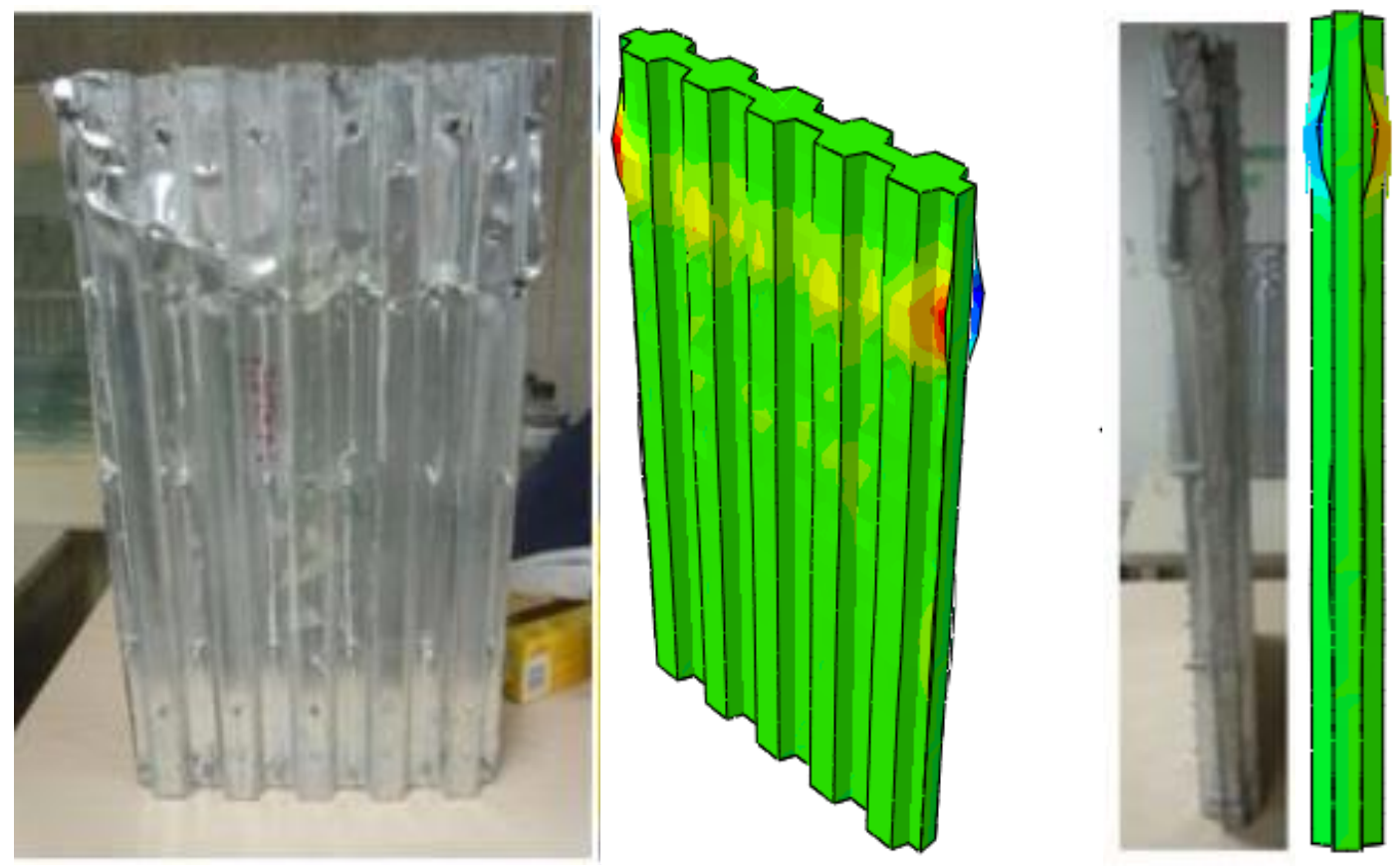

Figure 3.34: Experimental and FE failure shape for ECC-wall

Figure 3.32a shows the stress vs. strain contour for a typical point in the linear response shown in Figure 3.30. As can be expected, no buckling of the steel or crushing of the concrete or any other form of permanent plastic deformation has taken place. Upon reaching the peak load of $490 \mathrm{kN}$, the buckling of the steel sheets is observed between the $2^{\text {nd }}$ and $3^{\text {rd }}$ layer of fasteners. This is 
highlighted by the red contours located at the edges of the DSCW model as shown in Figure 3.32b. This indicates that failure is initiated by the buckling of the steel sheets. Similar failure behaviour was found in the study by Taormina (2012) where bucking of the steel sheet occurred prior to the crushing of the concrete. The last stress vs. strain point shown in Figure 3.32c shows the state of the composite wall at the onset of failure. In this case, a pronounced buckling of the steel sheets is observed along with a significant increase in the deformation of the concrete. This increase in concrete deformation is characterized by localized crushing in the lab experiment by Taormina (2012). Figure 3.34 shows a comparison of the FE failure mechanism to the one retrieved from experimental study by Taormina (2012).

Similarly, the contour graphs for the stress (S22, Pa) and strain (E22) in the direction of the applied load (y-direction) for SCC composite wall specimen upon reaching applied load of 200 and $450 \mathrm{kN}$ are shown in Figure 3.35. In additions, the stress and strain contours at point of failure are also shown in Figure 3.35. General contours depicting the deformation at a specific point in the compressive behaviour of SCC-based DSCW are shown in Figure 3.36.

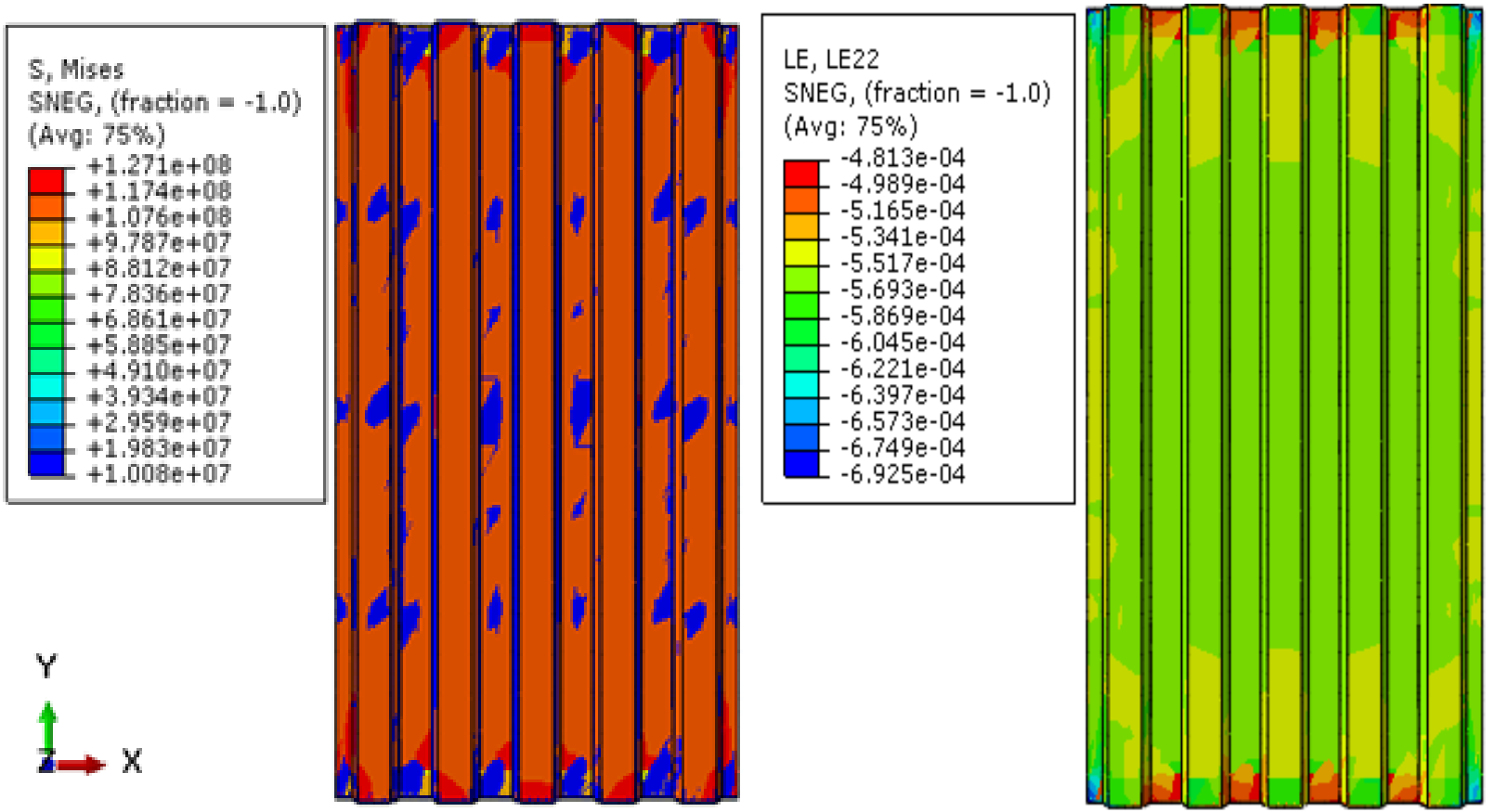

(a) 


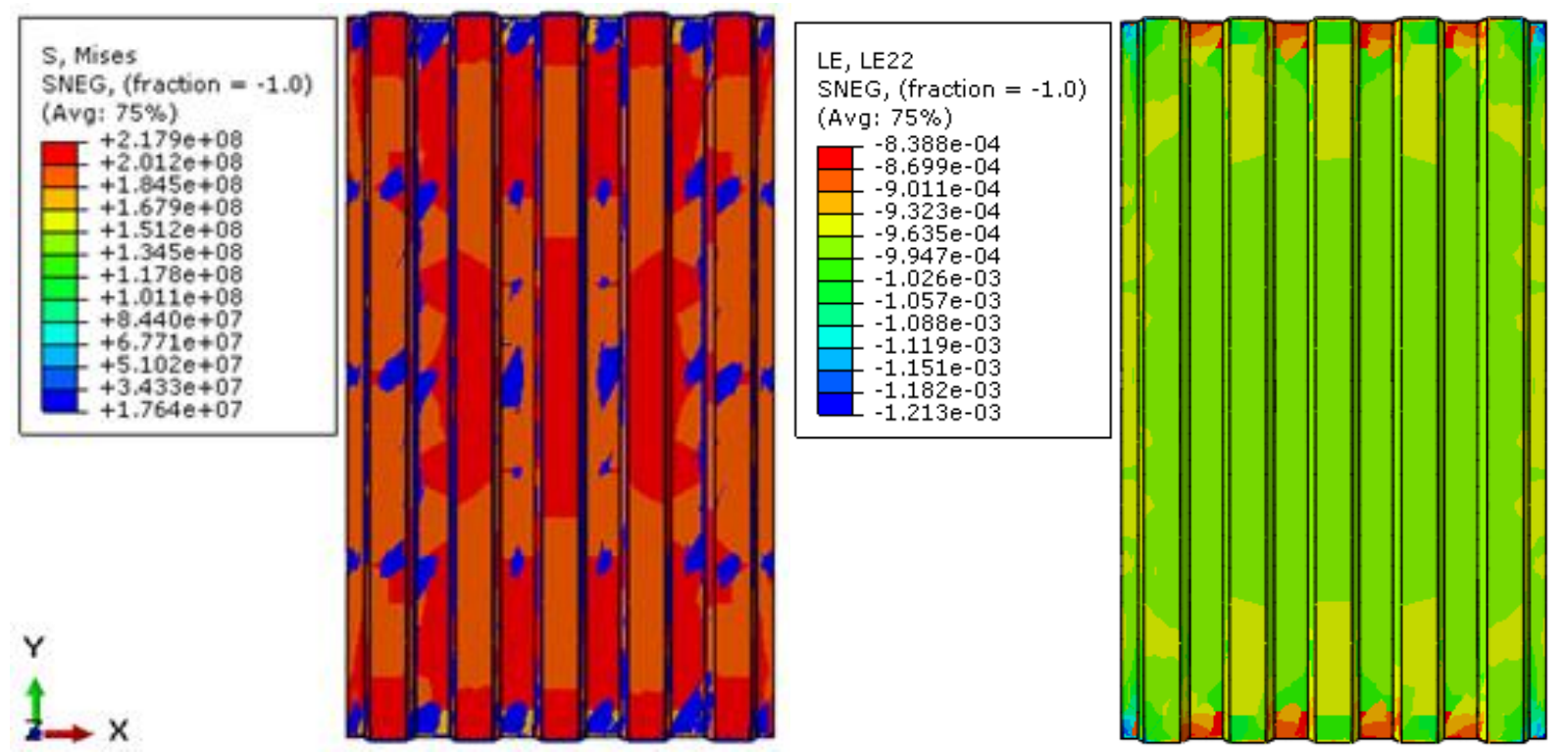

(b)
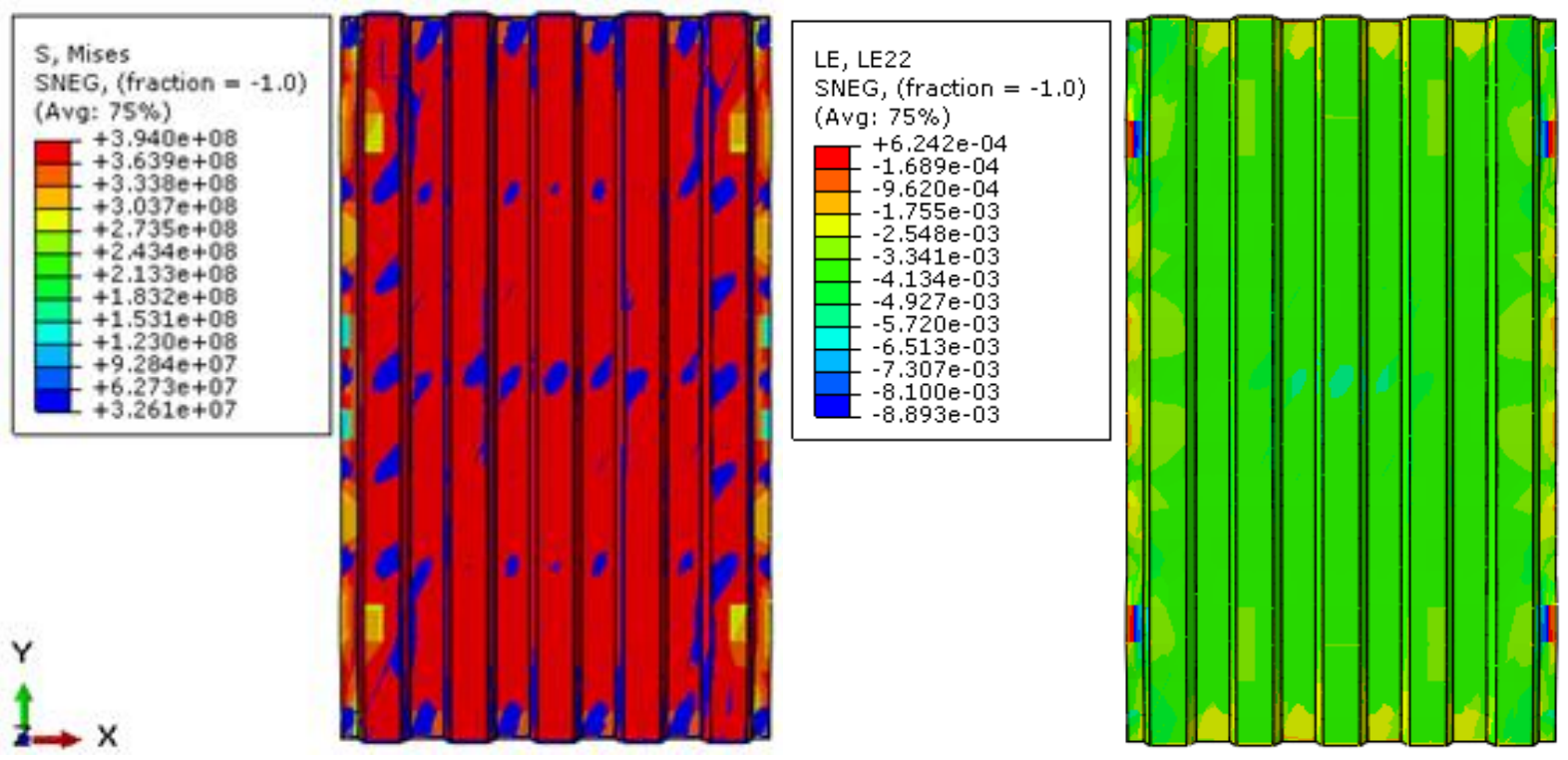

(c)

Figure 3.35: The contours for stress and strain in the y-direction at applied load of (a) $195 \mathrm{kN}$ (b)

$$
350 \mathrm{kN} \text { and (c) } 450 \mathrm{kN}
$$

In this case, Figure 3.35a shows the stress and strain contours for a typical point along the linear response for the compressive behaviour of SCC-based composite wall. Similar behaviour is observed to the one described in Figure 3.32a where the applied load of $195 \mathrm{kN}$ does not cause any permanent deformation in the steel or concrete core. Having established that the steel sheet 
buckles before the crushing of the concrete, Figure 3.35b shows the contours for the stress and strain at a point between the initial buckling of the steel and the compressive ultimate load of the concrete. In this case, the buckling of the steel sheets is observed along the top and bottom location of the composite wall. The yellow contours in Figure 3.35b highlight the buckling of the steel sheets. Finally, Figure 3.35c refers to the contours for stress and strain at yield point. In this case, prolonged buckling of the steel sheets is observed as shown by the red and blue contours. Figure 3.36 shows the failure shape obtained from Taormina (2012) for SCC-composite wall when compared with one retrieved from FE modelling. It is observed that a general agreement does exist with the exception of the added buckling of the steel sheets at the bottom of the composite wall. Although, such failure shape is not observed in experimental results, the proposed model does generate adequate load vs. deflection curves. It is important to note that discrepancy between the test and FE results is an eventuality that can take place, however, this does not mean that FE results are incompatible.
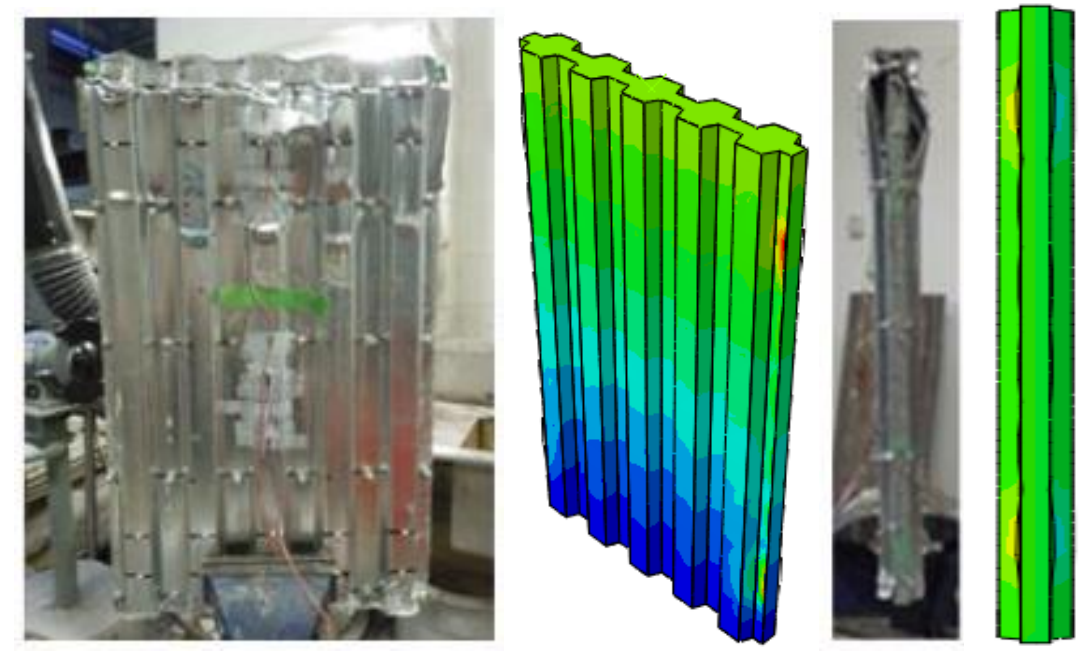

Figure 3.36: Experimental and FE failure shape for SCC-wall

Finally, the contour graph for the stress (von mises, Pa) and strain (E22) in the direction of the applied load (y-direction) for UHPC composite wall specimen upon reaching applied load of 377 and $614 \mathrm{kN}$ are shown in Figure 3.37. In addition, the stress and strain contours at point of failure are also shown in Figure 3.37. General contours depicting the deformation at a specific point in the compressive behaviour of UHPC-based DSCW are shown in Figure 3.38. 

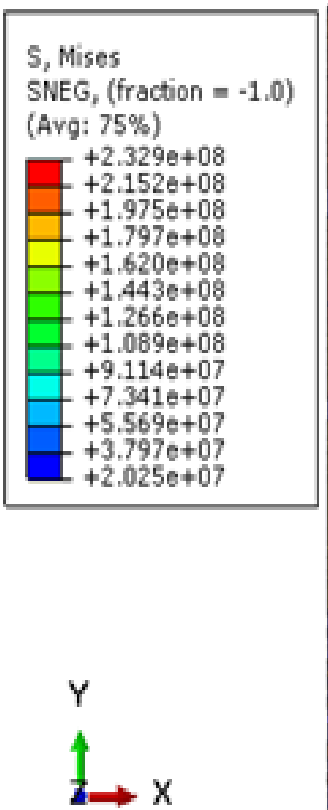

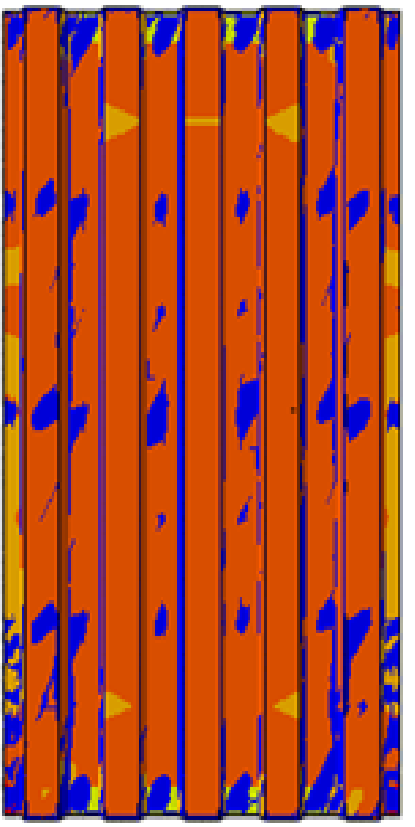

LE, LE22

SNEG, $($ fraction $=-1.0$ )

(Avg: 75\%)

$-8.372 \mathrm{e}-04$
$-8.686 \mathrm{e}-04$
$-9.000 \mathrm{e}-04$

$-9.000 e-04$

$-9.314 \mathrm{e}-04$

$-9.629 \mathrm{e}-04$
$-9.943 \mathrm{e}-04$

$-1.026 \mathrm{e}-03$

$-1.057 e-03$

$-1.089 \mathrm{e}-03$

$-1.120 \mathrm{e}-03$

$-1.151 \mathrm{e}-03$

$-1.183 \mathrm{e}-03$

$-1.214 \mathrm{e}-03$

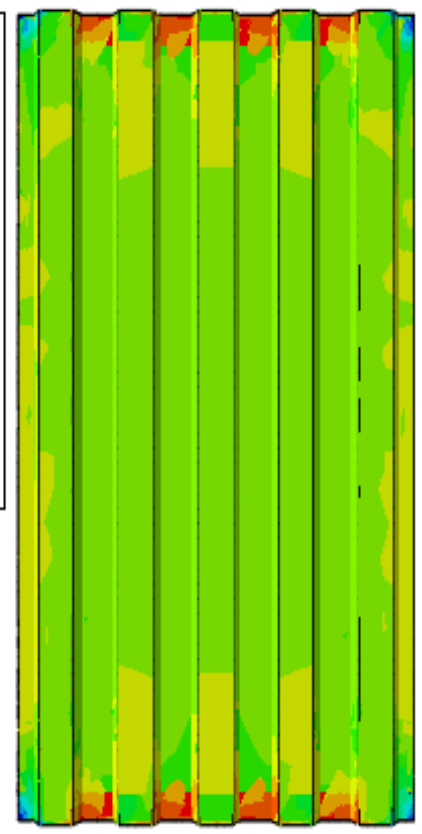

(a)

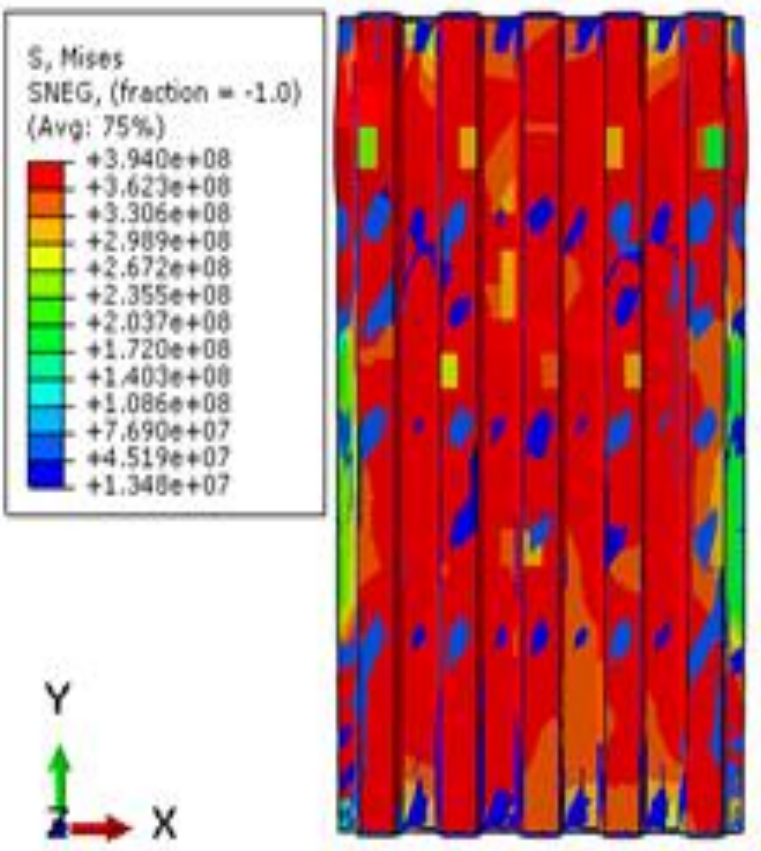

\begin{tabular}{l} 
LE, LE22 \\
SNEG, (fraction = -1.0) \\
(AVg: $75 \%$ ) \\
$\begin{aligned}+4.335 \mathrm{e}-03 \\
+1.224 \mathrm{e}-03 \\
-1.888 \mathrm{e}-03 \\
-4.999 \mathrm{e}-03 \\
-8.110 \mathrm{e}-03 \\
-1.122 \mathrm{e}-02 \\
-1.433 \mathrm{e}-02 \\
-1.744 \mathrm{e}-02 \\
-2.056 \mathrm{e}-02 \\
-2.367 \mathrm{e}-02 \\
-2.678 \mathrm{e}-02 \\
-2.989 \mathrm{e}-02 \\
-3.300 \mathrm{e}-02\end{aligned}$ \\
\hline
\end{tabular}

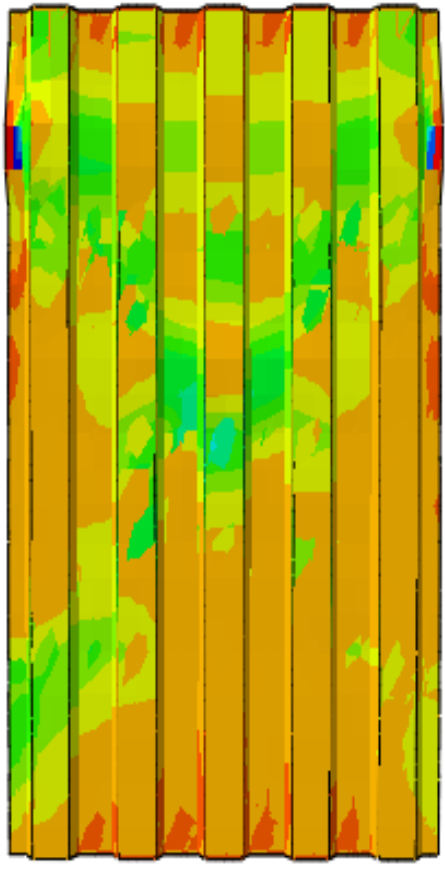

(b) 

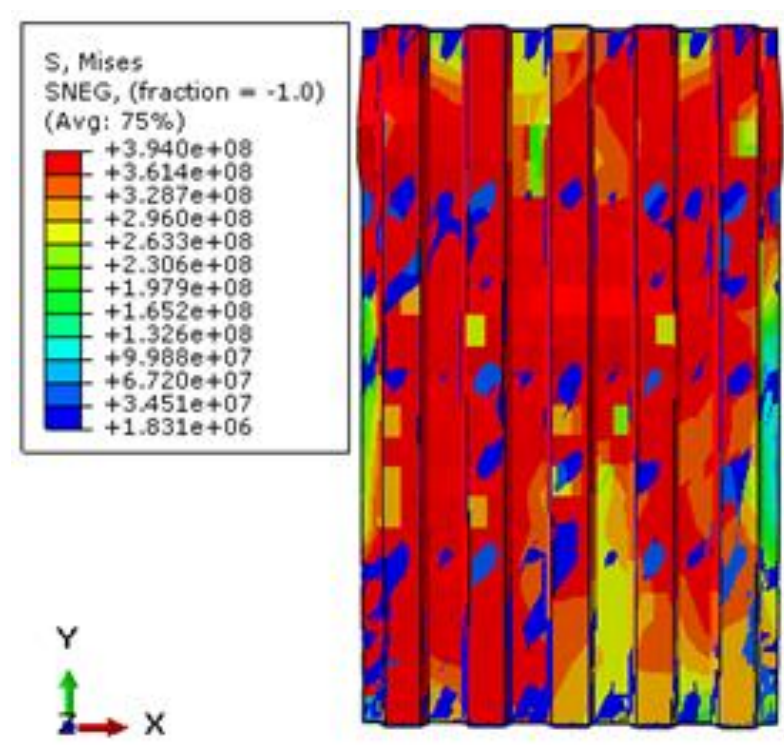

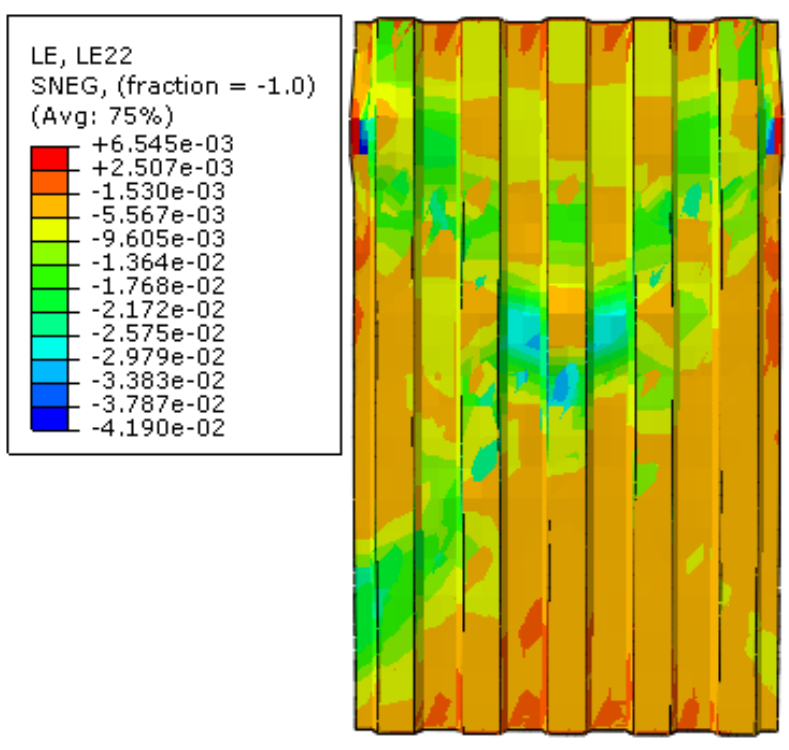

(c)

Figure 3.37: The contours for stress and strain in the y-direction at applied load of (a) $377 \mathrm{kN}$ (b) $614 \mathrm{kN}$ and (c) $391 \mathrm{kN}$

Figure 3.37a shows the stress and strain contours when a load of $377 \mathrm{kN}$ is applied on the UHPC-based composite wall. According to Figure 3.31, the stress and strain at this point is located within the elastic response of the composite wall confirming that no permanent deformation or buckling of the steel sheets is yet to occur. This is highlighted by the lack of buckling of steel sheet and crushing of concrete core when referring to Figure 3.37a. The stress and strain contours shown in Figure $3.37 \mathrm{~b}$ refer to the condition of the composite wall at peak load. As shown in the figure, buckling of the steel sheets is observed. It is important to note that no majour increase in the deformation of the composite wall is observed when comparing the strain values between Figures 3.37b and 3.37c. This suggests that the crushing of the concrete is occurring at a slow rate. This process was observed during the experimental test on the UHPCbased composite wall conducted by Taormina (2012). As a result, such observation validates the compressive behaviour of the composite wall in question. Figure 3.38 shows the FE failure shape compared with one retrieved from experimental test performed by Taormina (2012). According to Taormina (2012), the failure shape of UHPC follows that ECC due to the slow rate of concrete crushing observed. Similar observation is noted when comparing the failure shape of ECC and UHPC-based composite walls. This further strengthens the validity of the proposed compressive FE procedure. 

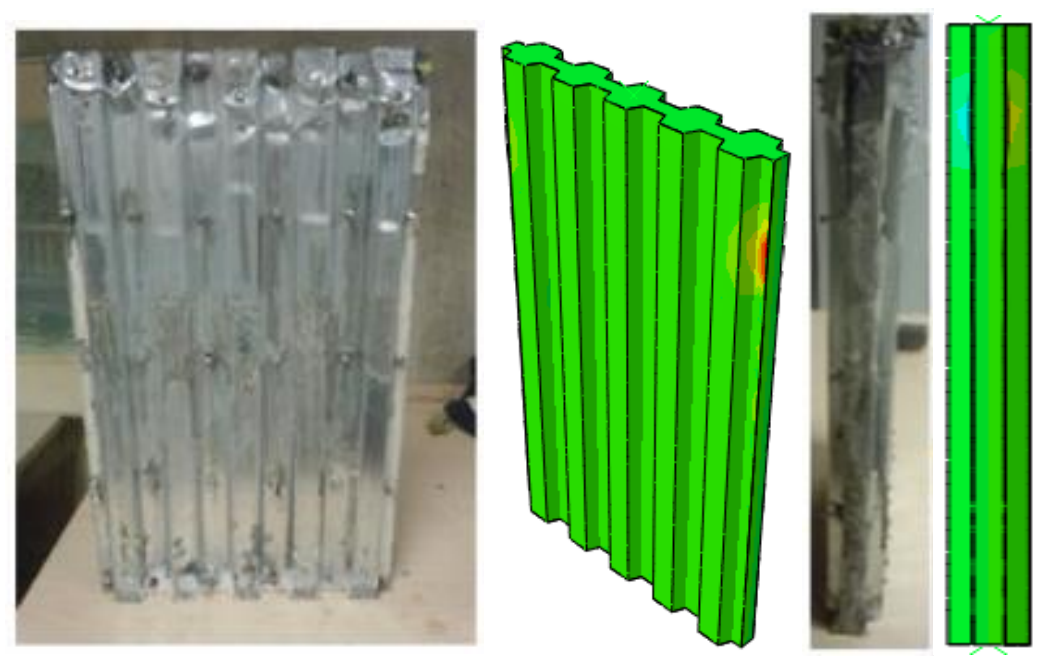

Figure 3.38: Experimental and FE failure shape for UHPC wall

\subsection{Chapter Summary}

Validating the proposed FE model used to determine the compressive behaviour of double skin composite wall (DSCW) specimens at ambient temperature is an imperative step in determining their fire resistance. This Chapter presents FE models generated to assess the compressive behaviour of DSCW systems with engineered cementitious concrete (ECC), self-consolidating concrete (SCC) and ultra-high strength/performance concrete (UHPC) as infill. The properties of the steel, ECC, SCC and UHPC are validated through use of FE simulations of steel tensile coupon and concrete crushing tests performed by Taormina (2012). After which FE models of DSCW are generated and validated against three composite walls each containing an alternative concrete core with test results retrieved from the experimental study by Taormina (2012). A comparison of the model and test results is made where an average test-to-FE predicted ultimate load is found to be 0.93 suggesting that the FE models are adequate to simulate compressive behaviour of composite walls. Finally, a discussion of the FE results for walls by illustrating stress and deformation contours is provided. 


\section{CHAPTER 4: Heat Transfer Analysis of DSCW}

\subsection{Introduction}

Heat transfer analysis is an essential step when modelling the response of double skin composite walls (DSCW) under the effect of high temperature. A change of temperature within an object leads to changes in its material properties and thus, a change in its structural behaviour when subject to loading. Heat transfer analysis describes the rate at which temperature changes with respect to time within a continuum medium. In this case, FE model for the behaviour of DSCW is a transient heat transfer process where the heat applied to the exterior steel sheets is gradually transferred to the inner concrete core through conduction, convection and radiation (Lu et al. 2011). Although several research papers are reported in the literature on heat transfer analysis of concrete surrounded by steel, there is currently no research related to double skin composite wall structures. In fact, most research papers for heat transfer are conducted for concrete filled steel tubular columns (CFST), where a hollow steel column is filled with a concrete core.

A total of 26 finite element (FE) models on heat transfer analysis are generated to analyze and validate the proposed DSCW FE model when subjected to high temperatures. This includes five simulations of DSCW while subjected to five different temperature curves. Each of the five simulations are performed with three different types of concrete leading to a total of $15 \mathrm{FE}$ heat transfer tests on DSCW. An additional $11 \mathrm{FE}$ tests on the thermal behaviour of concrete filled single/double tubular columns are then conducted to assess the validity of the proposed FE procedure used to generate heat transfer results for DSCW. Due to lab restrictions, no experimental results were available to determine the change in temperature within the composite wall when subjected to fire. As a result, experimental tests and FE models of CFST columns are used as means to validate the generated FE procedure. Several experiments and FE models have been developed by numerous researchers to conduct heat transfer analysis of CFST columns in fire (Lu et al. 2011; Usach 2015; Lie, 1994; Wang and Young 2013). From those papers, the thermal material models related to density, conductivity and specific for concrete and steel are obtained. In order to account for the moisture content in concrete, a hydro-thermal sequential analysis needs to be performed. This process is tedious and time consuming, as such the effect of moisture is represented by the specific heat capacity and a change of density with respect to 
temperature. Due to a lack of experimental data on the thermal behaviour of ECC, the thermal expansion model obtained from Eurocode 4 (2005) (EC4) for normal strength concrete (NSC) was used to define the changing expansion factor of ECC when exposed to elevated temperature. This alteration is based on the commentary retrieved from the study by JSCE (2008) where the properties of ECC were extensively researched. According to the study by JSCE (2008), the fire resistance of ECC is assumed to be similar to that of NSC since the varying thermal conductivity and specific heat between both concrete types cancel each other out leading to equivalent resistance values (JSCE, 2008). The following chapter includes a definition of the thermal properties of steel, self-consolidating concrete (SCC), engineered cementitious concrete (ECC) and ultra-high performance concrete (UHPC). The heat transfer study uses the same DSCW used by Taormina (2012) with dimensions defined in Figure 3.1 and 3.2 with ECC, SCC and UHPC alternatives and exposes the structure to five different temperature curves. This is followed by a description of the generated heat transfer FE models of DSCW. Results are validated based on several test and FE models of CFST columns currently existing in the literature. Upon validation, a detailed discussion and analysis of the results is then presented in terms of thermal isotherms and heat flux contours of DSCW models.

\subsection{Thermal Material Properties}

The thermal properties of steel, ECC, SCC and UHPC concrete alternatives are presented. The thermal properties for a given material are defined in terms of density, thermal conductivity, specific heat and thermal expansion factors.

\subsubsection{Thermal Properties of Steel}

The thermal material properties of carbon steel under the effect to elevated temperature are presented. As indicated earlier in Chapter 1, the density of steel remains unchanged when

subjected to high temperatures. As a result a constant value of $7850 \mathrm{~kg} / \mathrm{m}^{3}$ is used as density for steel (Eurocode 4, 2005).

Although, there are two common models for predicting the thermal conductivity and specific heat of steel materials in ASCE (1992) and Eurocode 4 (2005), there is very little difference between both models when compared with experimental data (Kodur et al. 2011; Kodur et al. 
2010). Equations defined in Chapter 2 obtained from Eurocode 4 (2005) are used to determine the thermal propreties of steel. Equation 4.16 and 4.17 are used to define the specific heat of steel and thermal comductivity, respectively (Eurocode 4, 2005). Figure 4.1 and 4.2 portray the conductivity and specific heat graphs used in this study.

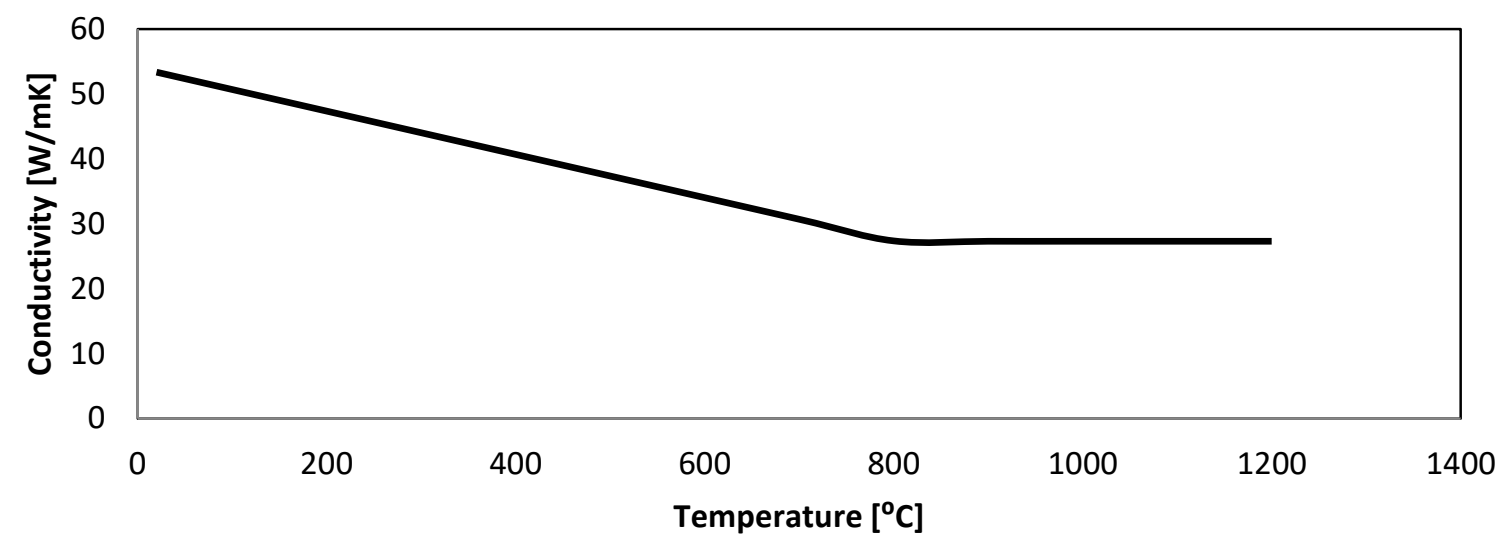

Figure 4.1: Thermal conductivity of steel (Eurocode 4, 2005)

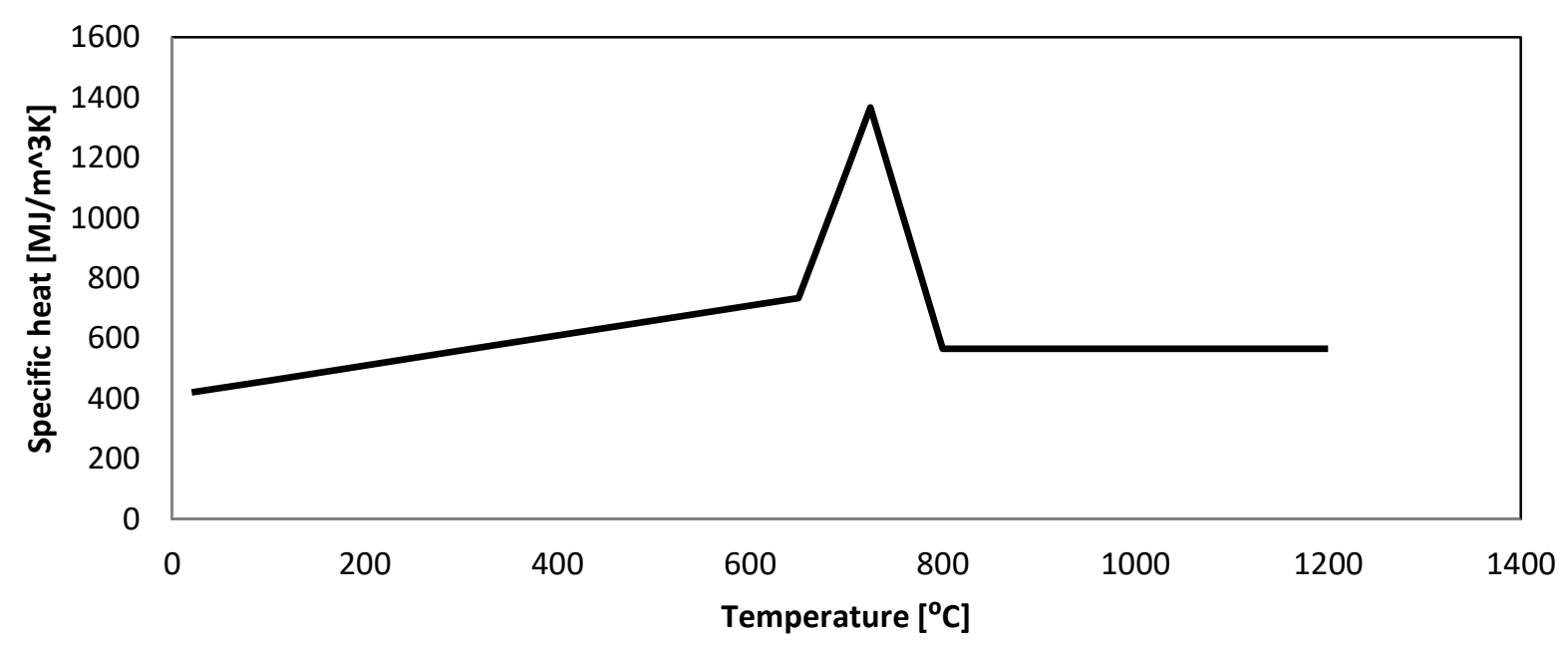

Figure 4.2: Specific heat of steel (Eurocode 3, 2005)

As indicated above, heat is transferred between the concrete and steel material through the process of convection, conduction (gap) and radiation. The radiation proprety is computed through use of Equation 4.1. $\left(\varepsilon_{s}\right)$ and $\left(\varepsilon_{f}\right)$ are referred to as the emmicivity coefficients of steel and fire respectively while $(\sigma)$ is the Stefen-Boltzman constant ( $\mathrm{Lu}$ et al. 2011). 


$$
q_{\text {radiation }}=\varepsilon_{f} \varepsilon_{m} \sigma\left[\left(T_{f}+T_{0}\right)^{4}-\left(T_{s}+T_{0}\right)^{4}\right]
$$

In Equation 4.1:

$q_{\text {radiation }}$ : radiation $\left[\mathrm{W} /\left(\mathrm{m}^{2} \cdot \mathrm{K}^{4}\right)\right] ; \quad \sigma$ : Stefen-Boltzman constant, $4.67 \times 10^{-8} \quad\left[\mathrm{~W} /\left(\mathrm{m}^{2} \cdot \mathrm{K}^{4}\right)\right]$; $\varepsilon_{f}$ : emissivity coefficient for fire, 0.8 (Eurocode 4, 2005); $\varepsilon_{m}$ : emissivity coefficient of steel, 0.7 (Eurocode 4, 2005); $T_{f}$ : temperature of fire $\left[{ }^{\circ} \mathrm{C}\right] ; T_{0}$ : temperature of steel $\left[{ }^{\circ} \mathrm{C}\right]$.

The convection propriety is computed through use of Equation 4.2, where $\left(h_{v}\right)$ is the convective heat coefficient defined as $25\left[\mathrm{~W} / \mathrm{m}^{2} \cdot \mathrm{K}\right]$ (Eurocode 4, 2005).

$$
q_{\text {convection }}=h_{v}\left(T_{f}-T_{s}\right)
$$

$q_{\text {convection }}:$ heat flux for convection $\left[\mathrm{W} / \mathrm{m}^{2}\right] ; T_{s}$ : temperature of steel [C].

\subsubsection{Thermal Properties of Concrete}

The density of concrete material depends on the moisture content, aggregate size, composition of concrete mix and elevated temperature (Naus, 2010; Naus, 2006; Kodur, 2014). The change in concrete density for NSC, SCC, ECC and UHPC is defined based on results obtained from experimental programs. Although, various equations are available in the literature to compute the density of concrete (Eurocode 4, 2005; Fares et al. 2009; Kodur, 2014; Kodur and Lie, 1996), these assumptions and equations heavily rely on the density of concrete before and after exposure to elevated temperatures. In this study, the experimental data on the mass loss of SCC concrete obtained from Taormina (2012) is used to determine the density of concrete at elevated temperatures. Due to lab restrictions, mass loss curves for ECC and UHPC were only obtained for a temperature range below 500 and $400^{\circ} \mathrm{C}$, respectively (Taormina, 2012). The use of this experimental data is thus inadequate since models considered in this study are exposed to temperatures rising above $800^{\circ} \mathrm{C}$. As such, changes in mass loss for $\mathrm{ECC}$ when exposed to elevated temperature are obtained from experimental results retrieved from research study performed by Sahmaran et al. (2009). As defined in Chapter 2, due to the spalling nature of UHPC, the value of mass was only obtained for temperatures below $400^{\circ} \mathrm{C}$. For this study, although spalling might occur, such behaviour will not have a majour impact on the compressive 
capacity of concrete since concrete is confined by steel throughout the entire time of temperature exposure. As such, density must still be defined for the entire temperature range. In this case, the values obtained from Taormina (2012) for temperatures up $400^{\circ} \mathrm{C}$ are used accompanied by the mass loss coefficients for HSC defined by Eurocode 2 (2005) for the remaining temperature range of $400-800^{\circ} \mathrm{C}$. According to clause 6.3 in Eurocode 2 (2005), the thermal properties of NSC can also be used to predict the properties of HSC. As such the mass loss model for NSC is used to determine the change in density for UHPC when exposed to elevated temperatures between 400 and $800^{\circ} \mathrm{C}$. Figure 4.3 shows the mass loss ratio $\left(M_{i} / M_{o}\right)$ vs. temperature curves for ECC, SCC and UHPC concrete. $M_{o}$ refers to mass of concrete material at room temperature $\left(20^{\circ} \mathrm{C}\right)$ while $M_{i}$ refers to the instantaneous mass of concrete at elevated temperature.

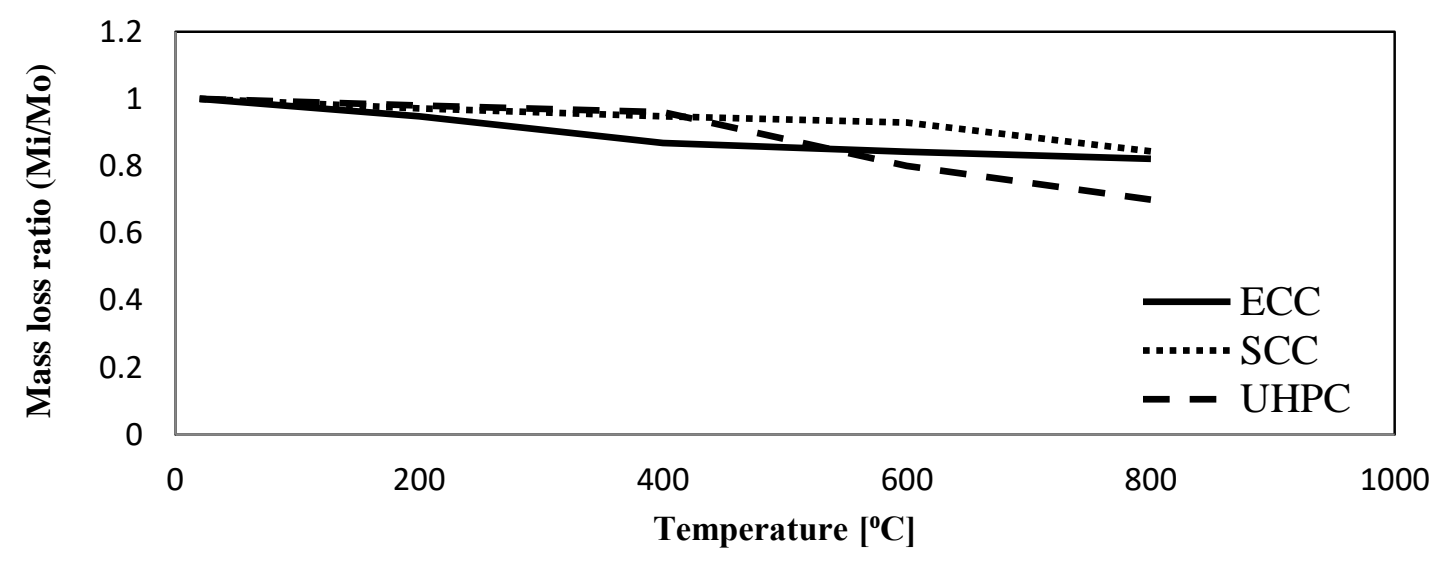

Figure 4.3: Percent (\%) mass loss vs. temperature curves for ECC, SCC and UHPC

As shown in Figure 4.3, a high percentage of mass loss is due to the evaporation of water when concrete is exposed to high temperature. Unbounded water fully evaporates at a temperature of $150^{\circ} \mathrm{C}$, while bounded water fully evaporates at a temperature of $300^{\circ} \mathrm{C}$ (Taormina, 2012). At a temperature range of $400-600^{\circ} \mathrm{C}$, mass loss of concrete is attributed to release of dehydrated sand, slag and cement paste (Taormina, 2012). Upon reaching a temperature of $800^{\circ} \mathrm{C}$, weakening of the bond between the aggregates and the cement past occurs, leading to the highest percentage of mass loss (Taormina, 2012).

The values of density at ambient temperature reported in Table 4.1 are obtained from experimental data in the literature. The densities for UHPC, ECC, SCC and NSC defined in Chapter 2 are used to generate the values in Table 4.1 .

Table 4.1: Density of concrete at elevated temperature 


\begin{tabular}{|l|l|l|l|l|}
\hline $\begin{array}{l}\text { Temperature } \\
{\left[{ }^{\circ} \mathrm{C}\right]}\end{array}$ & $\begin{array}{l}\text { Density of SCC } \\
{\left[\mathrm{kg} / \mathrm{m}^{3}\right](\text { Sahmaran et al. }} \\
2009, \text { Taormina, 2012) }\end{array}$ & $\begin{array}{l}\text { Density of UHPC } \\
{\left[\mathrm{kg} / \mathrm{m}^{3}\right] \text { (Eurocode } 2,} \\
2005)\end{array}$ & $\begin{array}{l}\text { Density of ECC } \\
{\left[\mathrm{kg} / \mathrm{m}^{3}\right](\text { Kim et al. 2010) }}\end{array}$ & $\begin{array}{l}\text { Density of NSC }\left[\mathrm{kg} / \mathrm{m}^{3}\right] \\
(\text { Eurocode 2, 2005) }\end{array}$ \\
\hline 20 & 2100 & 2500 & 1900 & 2300 \\
\hline 200 & 2040 & 2260 & 1800 & 2250 \\
\hline 400 & 1990 & 2000 & 1650 & 2185 \\
\hline 600 & 1950 & 1750 & 1600 & 2140 \\
\hline 800 & 1770 & 1560 & & \\
\hline
\end{tabular}

The thermal propreties in terms of specific heat and thermal conductucticity of SCC are presented in accordance to the experimental reseach conducted by Khaliq and Kodur (2011). Equations $2.7,2.14$ and 2.20 define specific heat $\left(C_{p}, \mathrm{MJ} / \mathrm{m}^{3}-{ }^{\circ} \mathrm{C}\right)$, the conductivity $\left(k_{t}, \mathrm{~W} / \mathrm{m}\right.$ $\left.{ }^{\circ} \mathrm{C}\right)$ and thermal expansion $\left(\varepsilon_{t h}, \%\right)$ of SCC repectively.

As indicated in Chapter 2, the thermal properties for UHPC are obtained by implying $0 \%$ moisture content to the thermal properties of HSC. Equations 2.8, 2.15 and 2.21 are used to compute specific heat $\left(C_{p}, \mathrm{MJ} / \mathrm{m} 3-{ }^{\circ} \mathrm{C}\right)$, the conductivity $\left(k_{t}, \mathrm{~W} / \mathrm{m}-{ }^{\circ} \mathrm{C}\right)$ and expansion coefficient of $\operatorname{UHPC}\left(\varepsilon_{t h}, \%\right)$ respectively.

Limited information on the thermal propreties of ECC currently exist in the literature relating to the fact that ECC was only recently introduced in the early 1990s ( $\mathrm{Li}, 2003)$. In this study, the thermal properties for ECC presented by Han et al. (2007) are used in contingency with the thermal properties for NSC defined by Eurocode 2 (2005). As indicated in Chapter 2, the thermal conductivity model defined by Han et al. (2007) is only attributed to plain concrete structures. The current study deals with composite structures, as such the use of the generated model by Han et al. (2007) for thermal conductivity would under-predict the actual thermal behaviour in DSCW models. To compensate for such difference, the lower limit thermal conductivity of NSC model defined by Eurocode 4 (2005) is used to generate the following models. The specific heat model for ECC presented by Han et al. (2007) is very similar to the one proposed by Eurocode 2 (2005) for NSC with only exception being the peak specific heat value occurring at temperature of $115^{\circ} \mathrm{C}$. To compensate for such difference, the heat transfer model presented by Eurocode 2 
(2005) is used in this thesis with peak specific heat value $\left(c_{p}\right)$ of $10000\left[\mathrm{~J} / \mathrm{kgm}^{3}\right]$. Due to the lack of information available in the literature, the thermal expansion presented by Lie (1994) for NSC is used to define the expansion coefficients for ECC at elevated temperature. Equations 2.4, 2.11 and 2.18 are used to compute the specific heat $\left(C_{p}, M J / m^{3}-{ }^{\circ} \mathrm{C}\right)$, conductivity $\left(k_{t}, \mathrm{~W} / \mathrm{m}-{ }^{\circ} \mathrm{C}\right)$ and expansion coefficient $\left(\varepsilon_{t h},\left[\mathrm{~m} / \mathrm{m}^{\circ} \mathrm{C}\right]\right)$ of ECC respectively.

Figures 4.4, 4.5 and 4.6 include the graphs for thermal expasion coeficients, thermal conductivity and specific for SCC, UHPC and ECC, respectively. Using the thermal propreties defined, it is now possible to generate an approach to perform FE analysis for heat transfer of DSCWs.

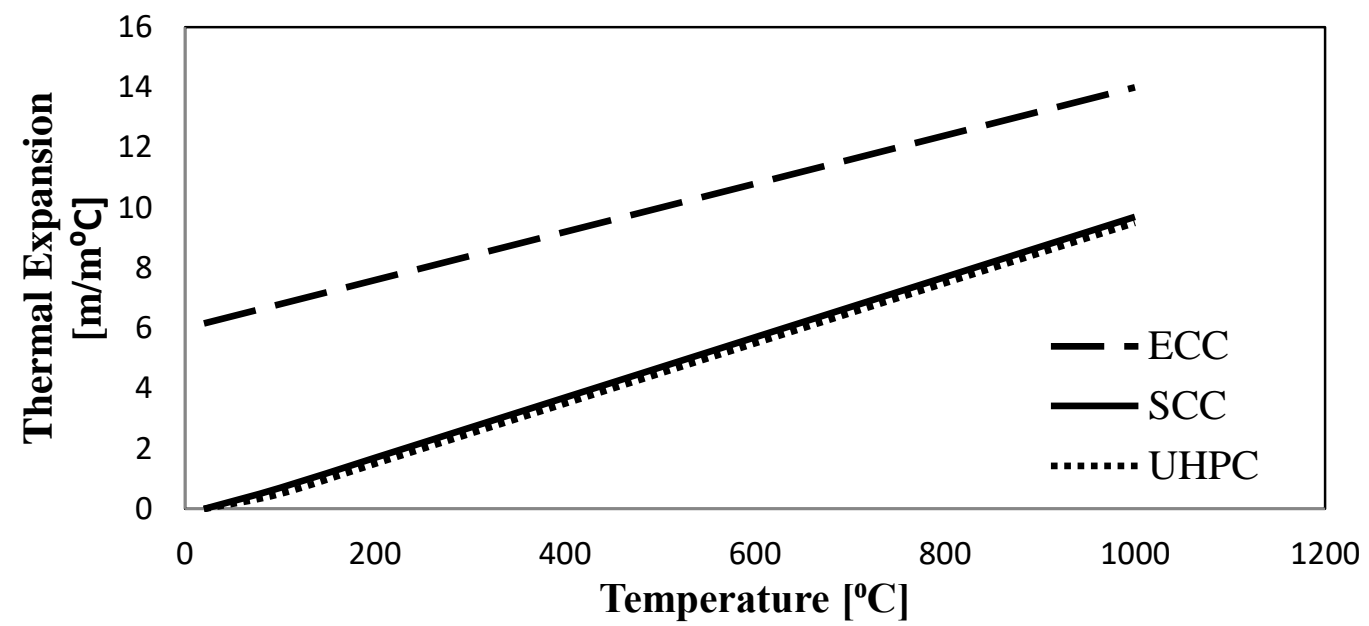

Figure 4.4: Thermal expansion vs. temperautre curves

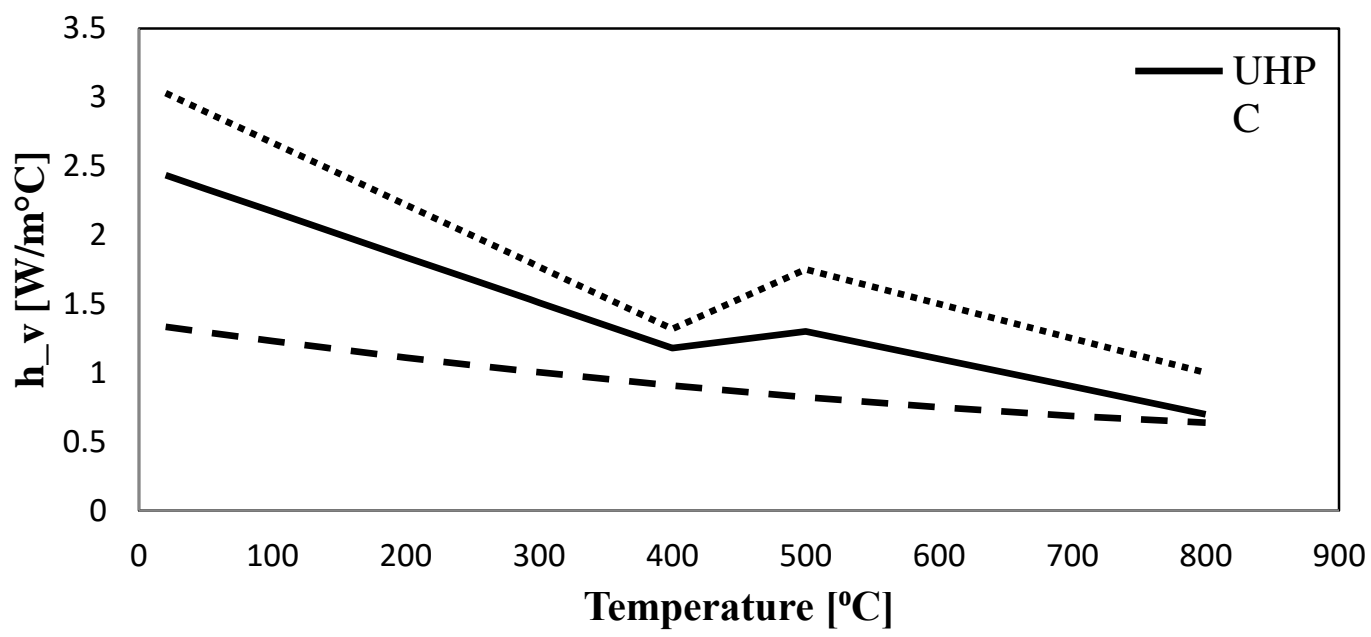

Figure 4.5: Thermal conductivity vs. temeprature curves 


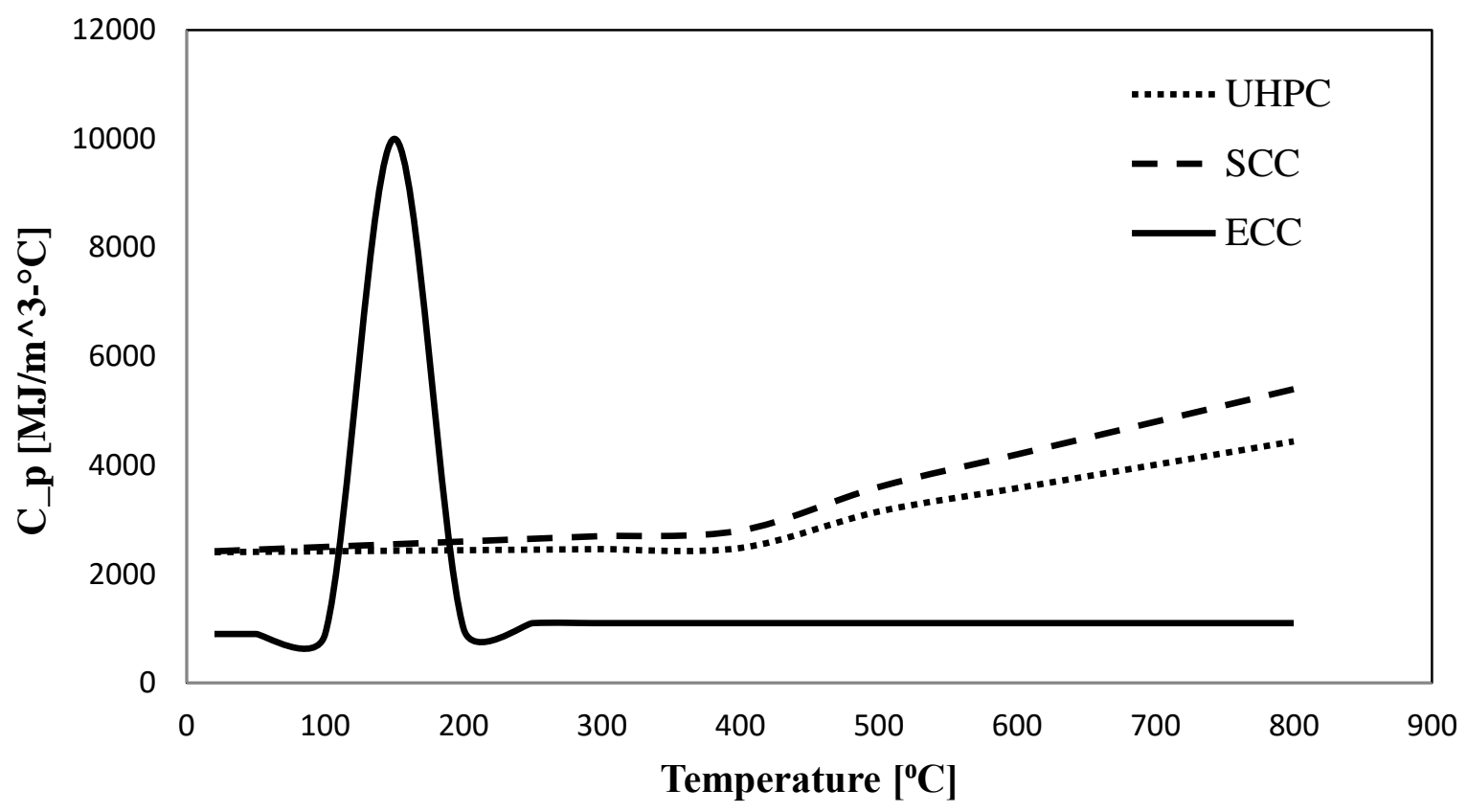

Figure 4.6: Specific heat vs. temperature curves

\subsection{Heat Transfer Model}

A three-dimensional (3D) finite element model for heat transfer analysis of DSCW is developed. System assembly including boundary conditions (BCs) and FE mesh are described in this section. Similar model presented in Chapter 3 is used for heat transfer analysis. As such the cross-sectional and profile dimensions of the generated DSCW are presented in Figure 3.1 and 3.2 , respectively. However, since no load is applied, the loading plate is omitted from the assembled model. Figure 4.7 shows the assembled model for heat transfer analysis. The concrete core is modelled as a solid part using eight-node linear heat transfer brick elements (DC3D8 elements). The profiled steel sheets are modelled as four-node heat transfer quadrilateral shell elements (DS4 elements) with reduced integration option. Study for appropriate meshing size for heat transfer analysis is omitted since mesh setup must match that of 3D stress analysis presented in Chapter 3. In order to perform the sequential analysis presented in Chapter 5, the results of the heat transfer model are uploaded into the 3D stress model. Thus, compatible meshing is required where both heat transfer and 3D stress models must have the same mesh division. As a result, general element sizes of 10 and $15 \mathrm{~mm}$ are used for the concrete core and steel elements, respectively. Figures 4.8 and 4.9 show the mesh for both the concrete and steel respectively. 
Table 4.2 summarizes the total number of elements used for each part of the model. The interaction between the applied heat, the steel sheets and the concrete core is defined in the following section.

Concrete is a heterogeneous medium with an average moisture content of about $4 \%$ by mass (Ichikawa and England, 2004). A change in temperature along the surface of the concrete causes part of the moisture at the surface to evaporate, while the other to move towards the core of the concrete, away from the applied heat. As heat moves along the cross-section through process of conduction, convection and radiation, the moisture that did not evaporate will keep moving towards the core of the concrete. This is referred to as moisture migration in concrete. A sequentially coupled thermo-hydraulic analysis is required to model the effects of moisture migration when concrete is subjected to elevated temperature. This process is tedious and time consuming. Since this process only affects heat transfer results for elements with temperatures under $100^{\circ} \mathrm{C}$, several researchers have decided against the use of thermo-hydraulic analysis (Lie, 1994; Lu et al. 2009; Xionga and Liew 2016). As a result, moisture content of $4 \%$ is considered through density and specific heat definitions while migration effects are neglected

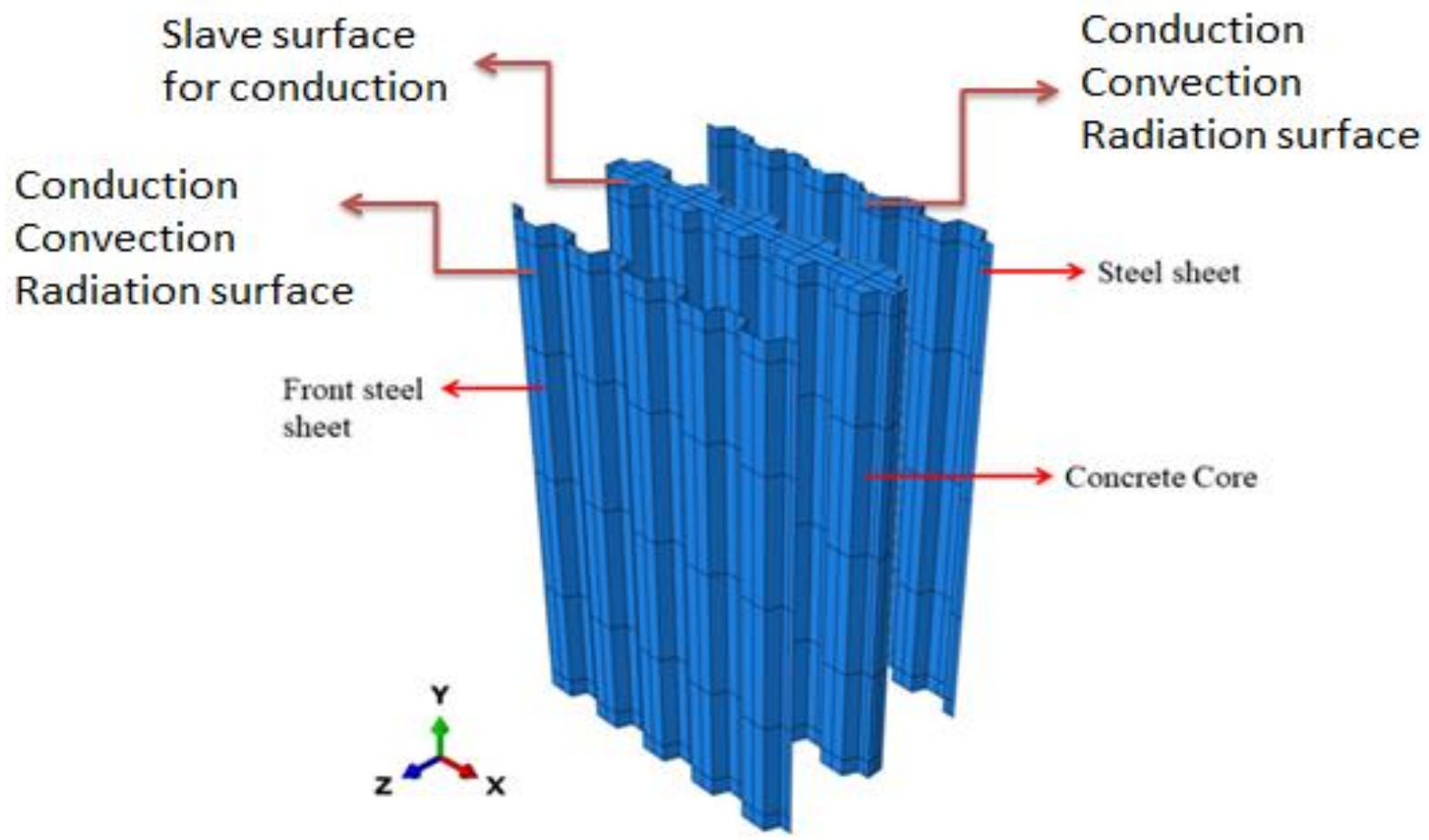

Figure 4.7: Assembled model for heat transfer analysis 


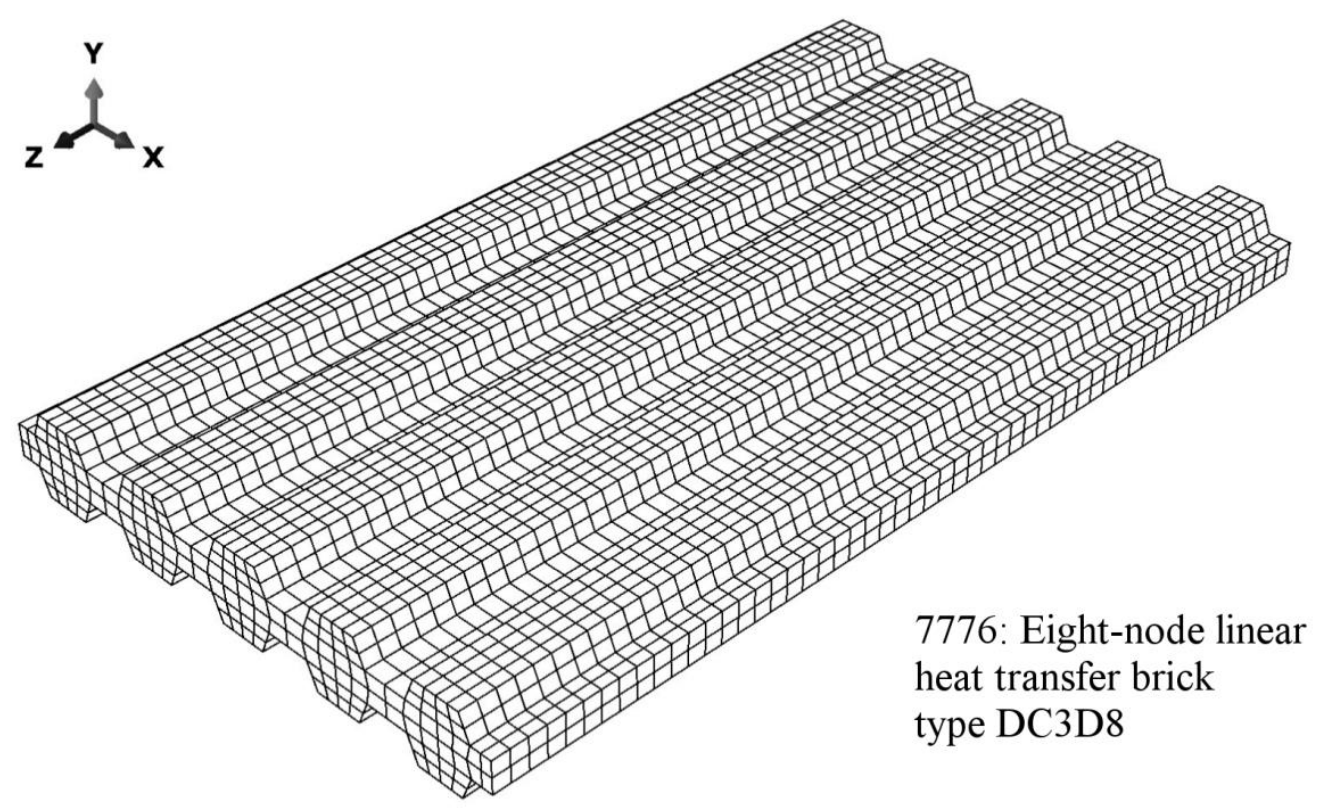

Figure 4.8: Meshing setup for concrete core

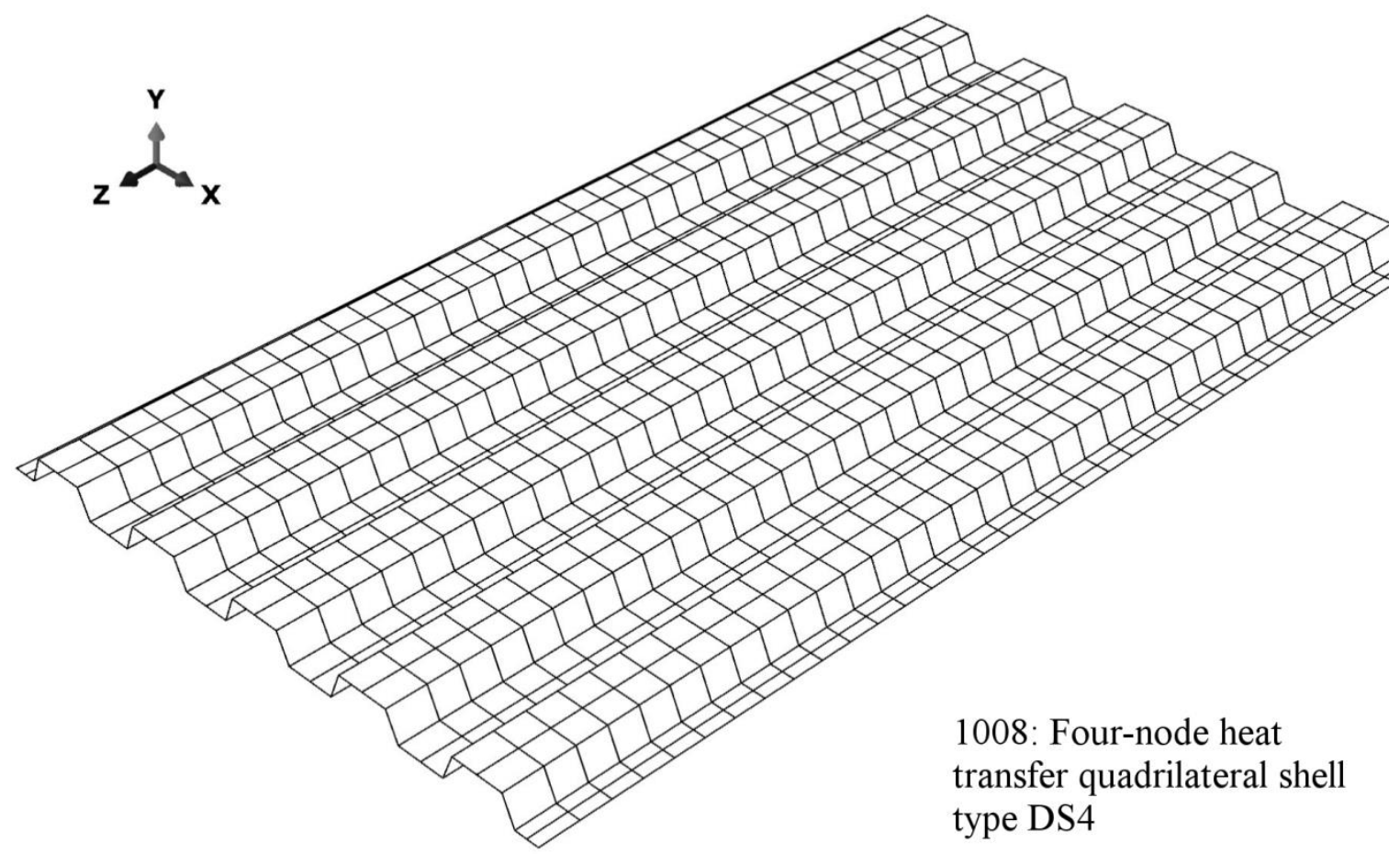

Figure 4.9: Meshing setup for steel sheets

Table 4.2: Summary of number and type of elements 


\begin{tabular}{|c|c|c|}
\hline & Element types & Number of elements \\
\hline Concrete core & Linear heat transfer, DC3D8 & 7776 \\
\hline Steel sheets & $\begin{array}{l}\text { Heat transfer quadrilateral, } \\
\text { D4R }\end{array}$ & $1088 \times 2$ \\
\hline \multicolumn{2}{|c|}{ Total number of elements } & 9952 \\
\hline
\end{tabular}

\subsection{Steel-concrete Interaction}

The steel sheets and concrete core are not in perfect contact, as a result, the temperature of both components at the interface is different. The concept of conductance is used to define the heat transferred from one component to another. Thermal contact conductance $\left(h_{j}\right)$ must be defined to account for heat resistance at the interface. Due to a lack of research on this subject, several research papers have developed different values for $\left(h_{j}\right)$ (Dai and Lam 2012; Espinos et al. 2010; Tao et al. 2013; Yao et al. 2016). In fact, such values are obtained through use of trial and error where the one leading to the most accurate results is selected. Some even consider perfect contact between the steel and the concrete, thus resulting in similar temperature between the steel and the outer surface of the concrete (Dai and Lam, 2012; Eurocode 4, 2005). Results from studies conducted by Ghojel (2002) and Tao et al. (2013) on determining the thermal contact conductance indicated that $h_{j}$ obtained from different locations throughout the interface are different. The experimental study by Tao et al. (2013) measured the thermal gap conductance between the steel and concrete through use of thermo-couples at different locations along the interface. Figure 4.10 shows the resulting conductance vs. temperature curves obtained from the four different points along the contact interface with the 'blue' curve indicating the average of the four points. Although the values of $h_{j}$ greatly differ, the shape of the curve remains the same. To account for this limitation, the common value of $200\left[\mathrm{~W} / \mathrm{m}^{2} \mathrm{~K}\right]$ is used in this study throughout the entire range of temperatures (Espinos et al. 2010; Ding and Wang 2008). 

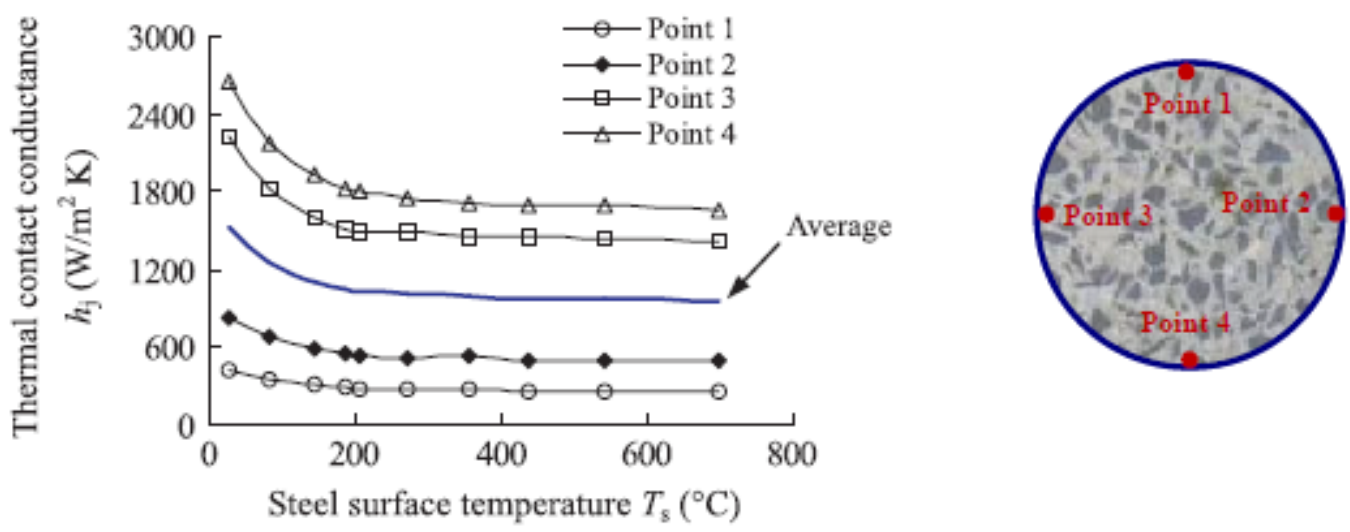

Figure 4.10: Thermal contact conductance along the contact interface (Tao et al. 2013)

According to the experimental study on the heat transfer of concrete filled steel tubular structures, the thermal contact conductance between the steel and concrete represents one of the most important factors influencing the accuracy of FE results (Tao et al. 2013). As such, limitations in defining the thermal gap conductance existing between the alternative concrete types investigated might cause slight inaccuracies when heat transfer FE and test results are compared in section 4.6 .

\subsection{Heat Transfer Analysis Results}

Results of heat transfer analysis for DSCW exposed to elevated temperatures are presented in this section. The goal is to determine the heat flux under different high temperatures including the ISO-834 fire temperature obtained through use of Equation 4.3 where $T_{f}$ is the temperature $\left[{ }^{\circ} \mathrm{C}\right]$ and $\tau$ is time [hours] (Lie, 1994). Temperature vs. time curves are generated for three specific nodal points on the cross-section (Figure 4.11). The assembled composite wall model is

exposed to various temperature curves shown in Figure 4.12. Figures 4.13, 4.14 and 4.15 describe the temperature distribution obtained from heat transfer analysis for SCC, UHPC and ECC based composite walls at points 1,2 and 3 respectively.

$$
T_{f}=20+750(1-\exp (-3.79553 \sqrt{\tau}))+170.41 \sqrt{\tau}
$$




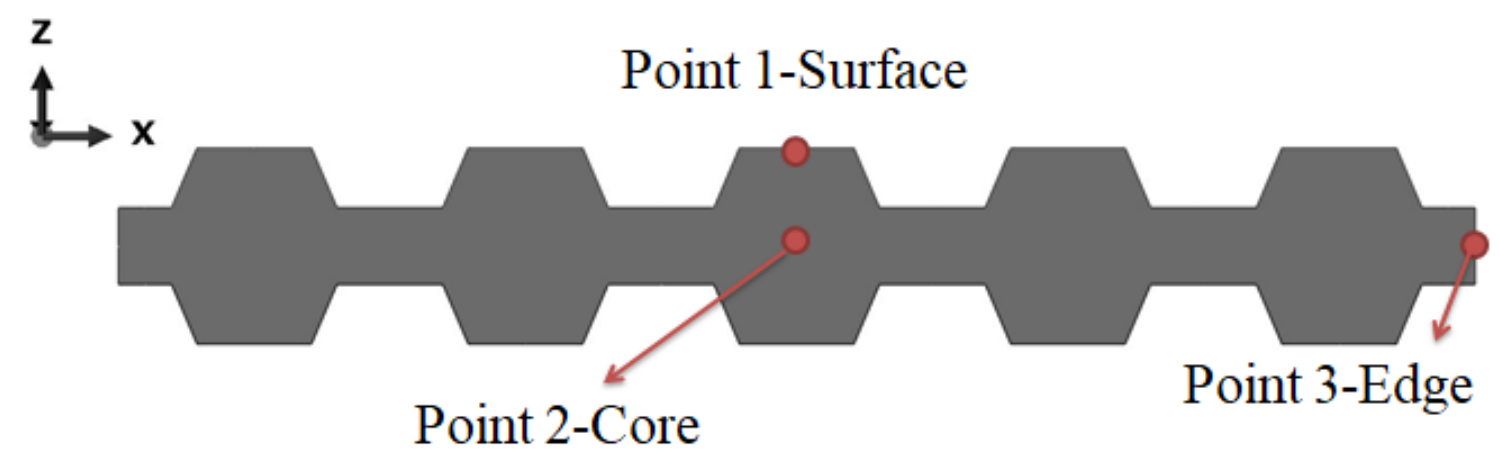

Figure 4.11: Desired points for temperature vs. time curves

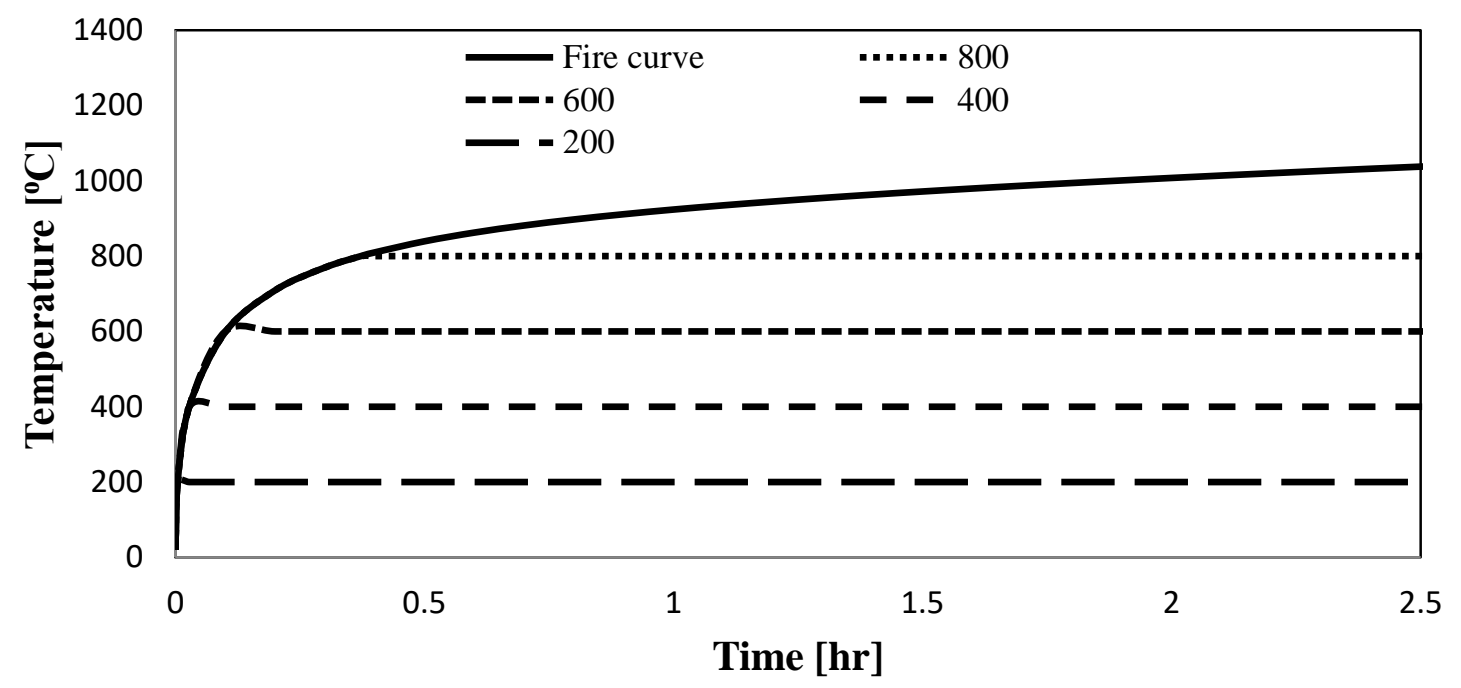

Figure 4.12: Temperature curves used in heat transfer analysis

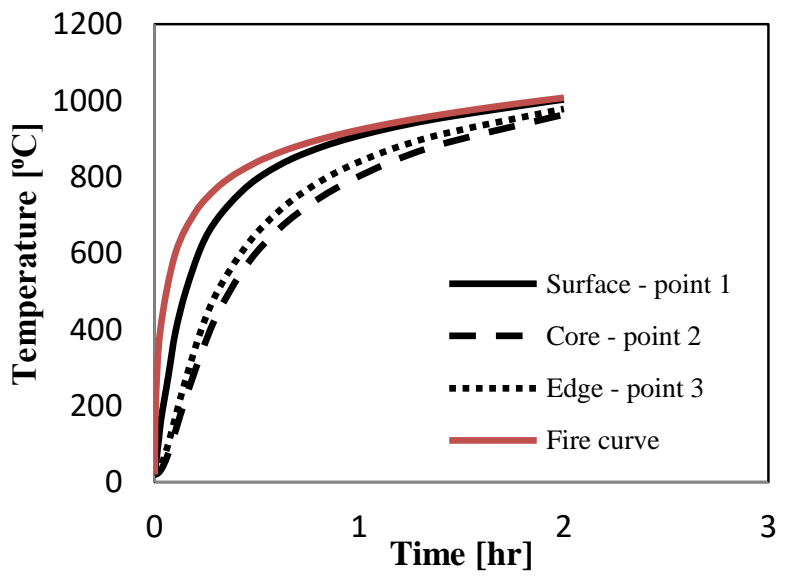

(a)

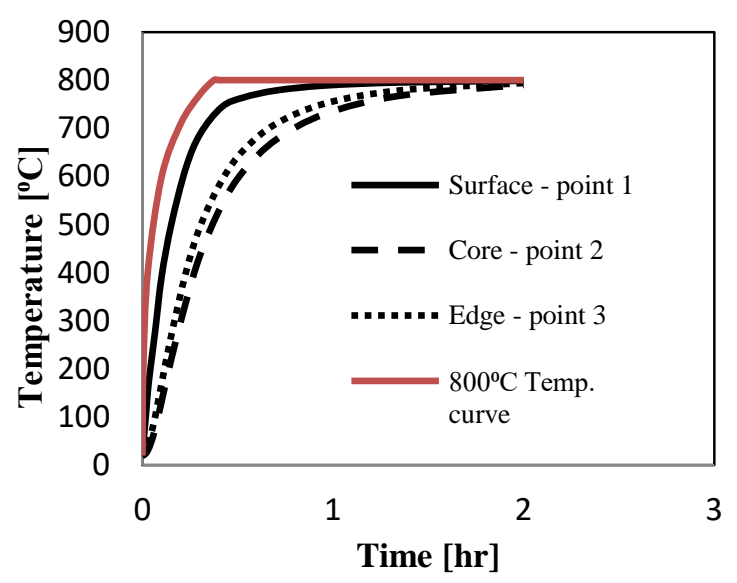

(b) 


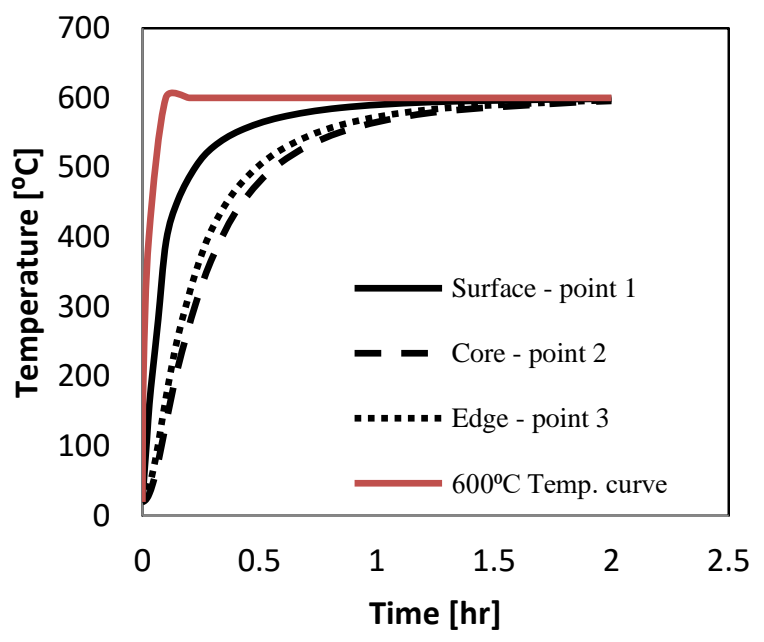

(c)

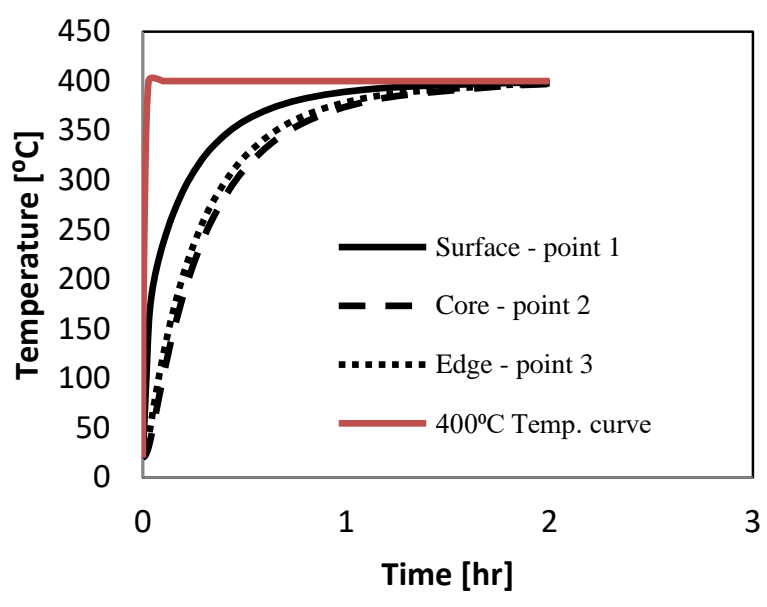

(d)

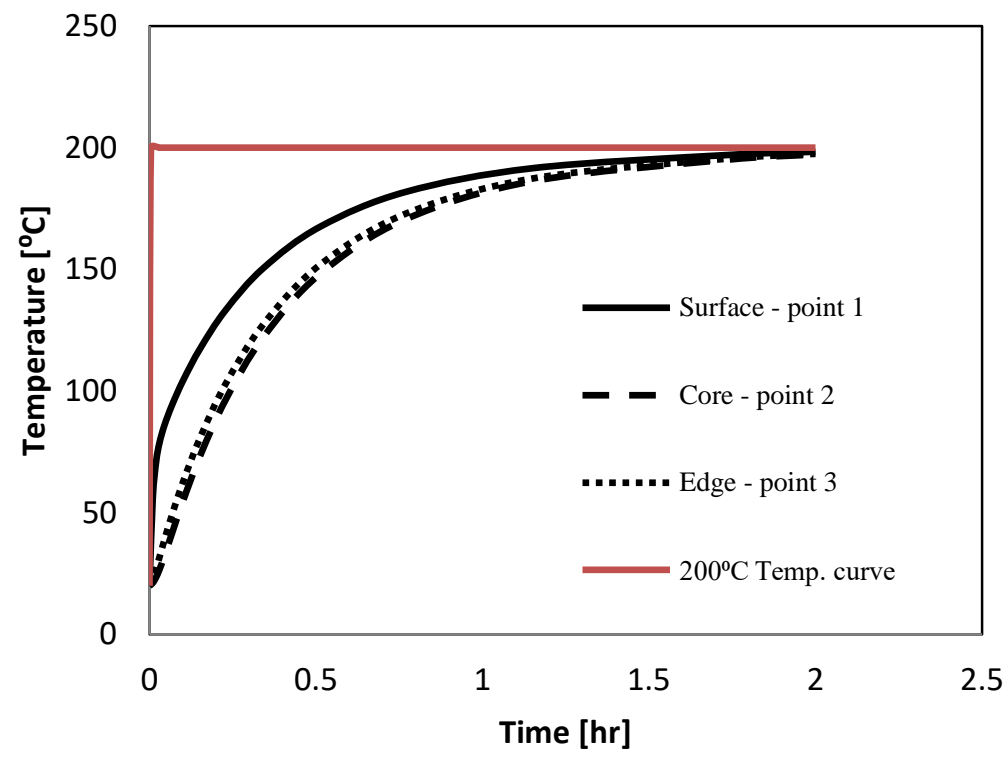

(d)

Figure 4.13: Temperature in SCC specimen when subjected to a) fire temperature, b) $800^{\circ} \mathrm{C}$ temperature curve, c) $600^{\circ} \mathrm{C}$ temperature curve d) $400^{\circ} \mathrm{C}$ temperature curve and e) $200^{\circ} \mathrm{C}$ temperature curve. 


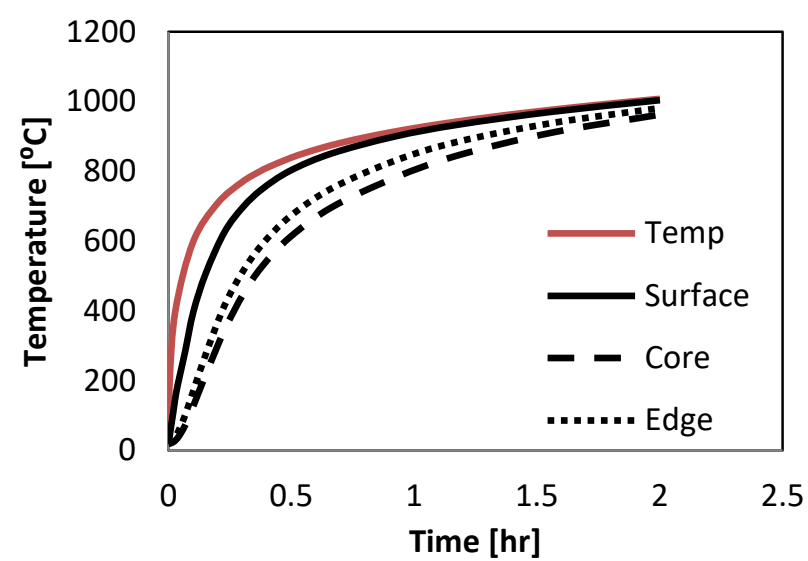

(a)

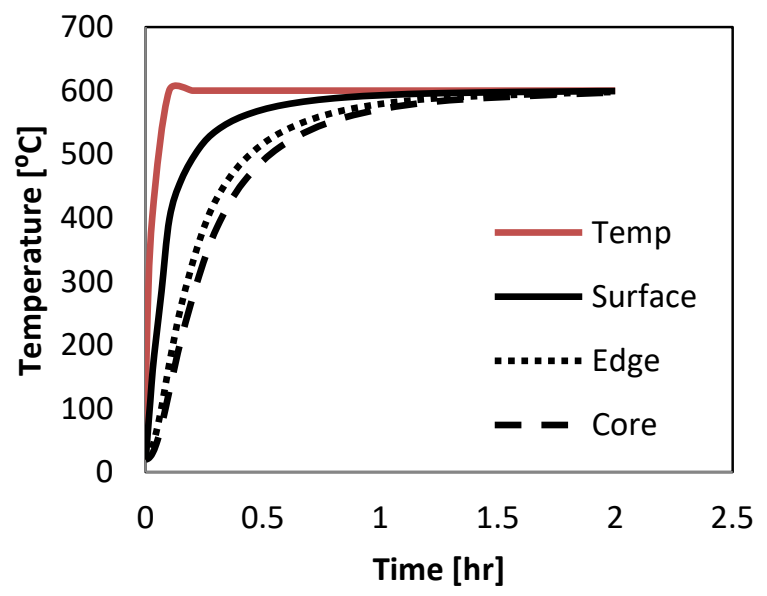

(c)

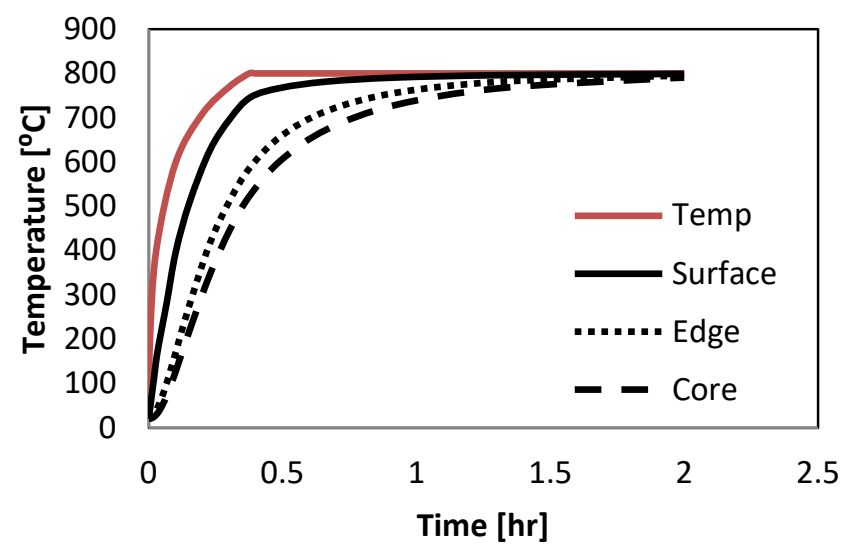

(b)

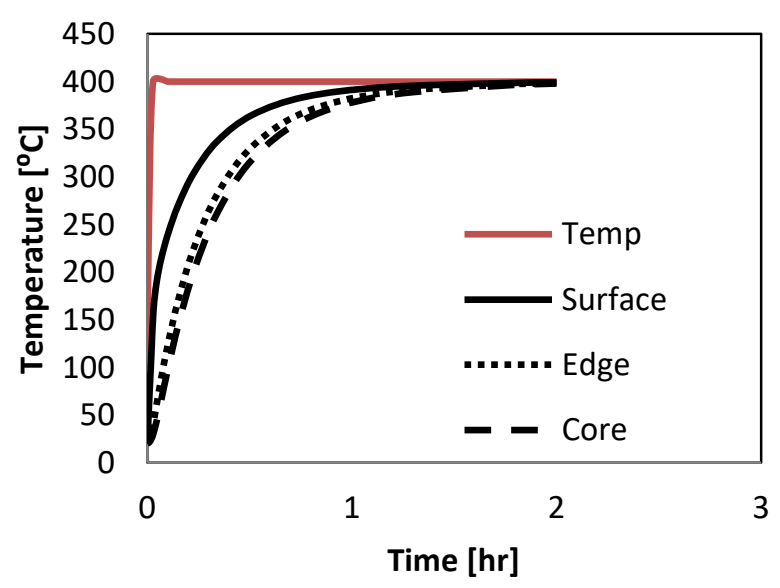

(d)

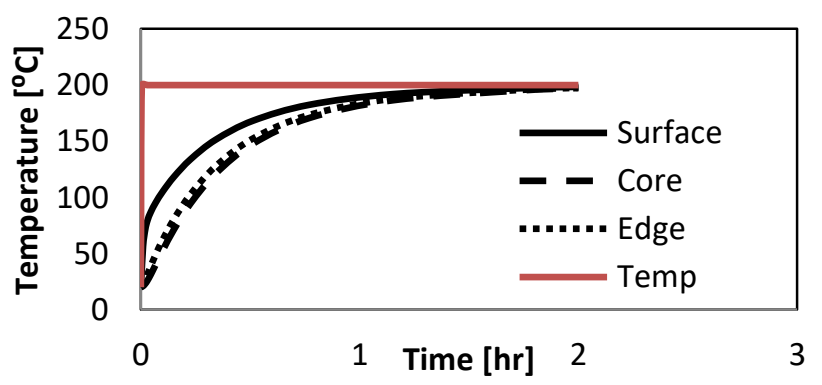

(e)

Figure 4.14: Temperature in UHPC specimen when subjected to a) fire temperature, b) $800^{\circ} \mathrm{C}$ temperature curve, c) $600^{\circ} \mathrm{C}$ temperature curve, d) $400^{\circ} \mathrm{C}$ temperature curve and e) $200^{\circ} \mathrm{C}$ temperature curve 


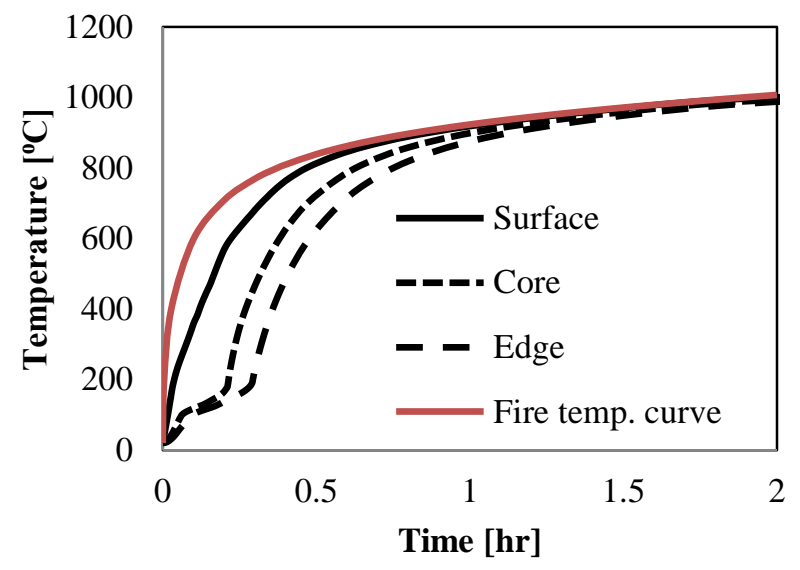

(a)

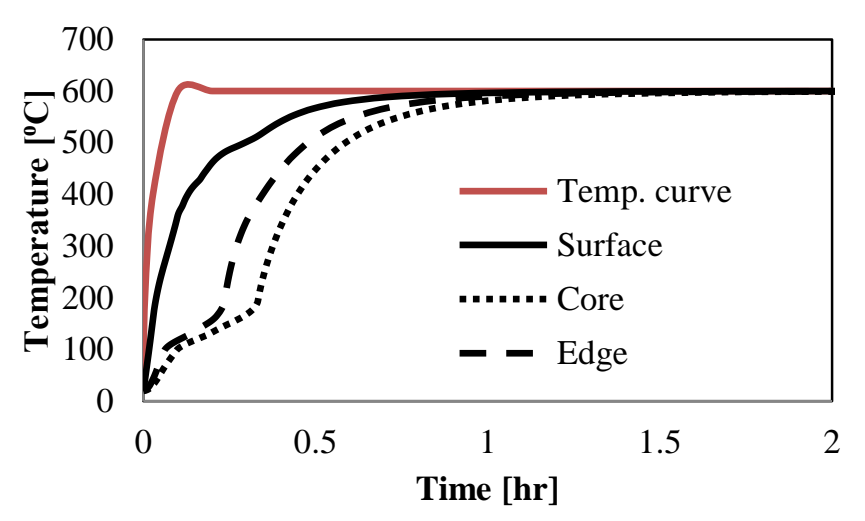

(c)

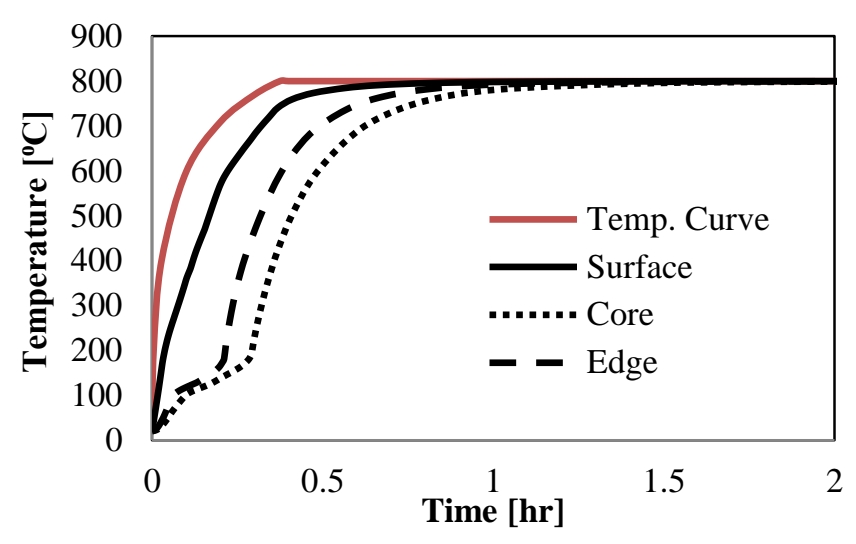

(b)

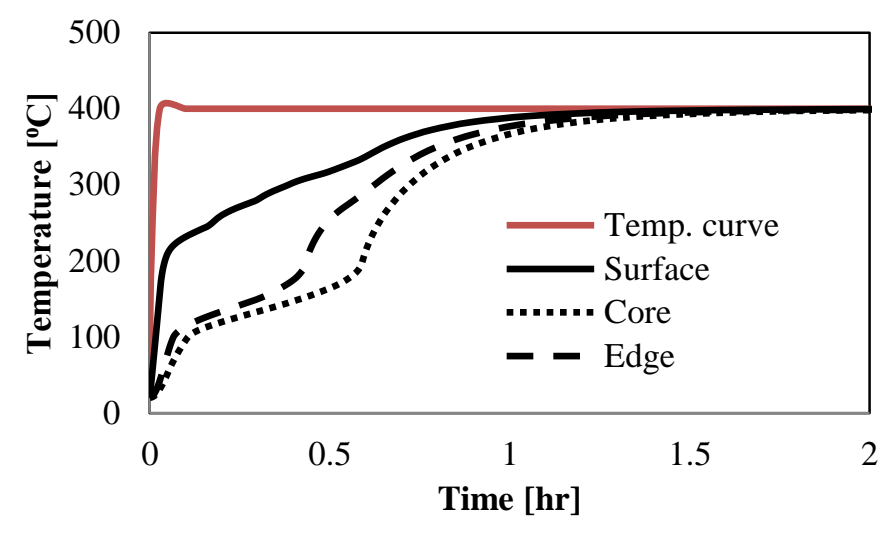

(d)

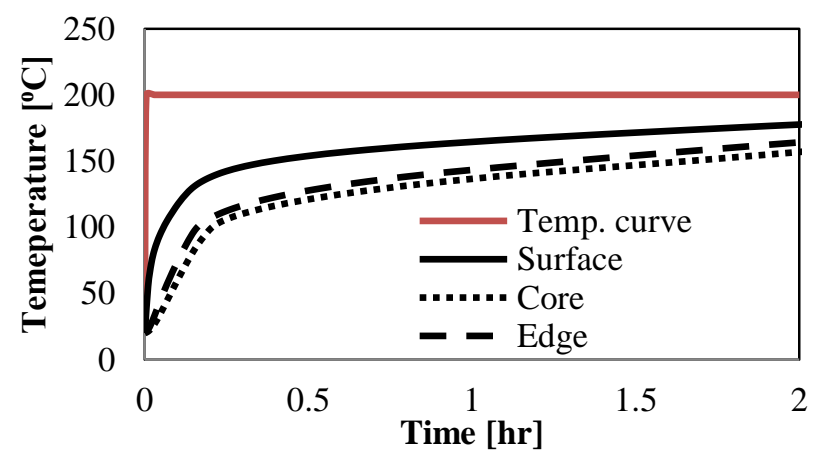

(d)

Figure 4.15: Temperature in ECC specimen when subjected to a) fire temperature, b) $800^{\circ} \mathrm{C}$ temperature curve, c) $600^{\circ} \mathrm{C}$ temperature curve, d) $400^{\circ} \mathrm{C}$ temperature curve and e) $200^{\circ} \mathrm{C}$ temperature curve 
As shown in Figures 4.13, 4.14 and 4.15, by increasing the fire exposure time, the temperature in the concrete increases accordingly until it matches that of the constant applied temperature curve. The temperature at the steel-concrete interface (point 1) is higher than the temperature at the concrete core (point 2) and concrete edge (point 3). Very little difference exists between the temperature distribution of points 2 and 3 suggesting that the temperature distribution along the centroidal $\mathrm{x}$-axis of concrete is similar. In addition, due to the low thickness of the concrete, the observed temperature curves at points 1,2 and 3 is of the same shape suggesting a low variation in temperature between the indicated points. Discussion of the temperature field results shown in Figures 4.13-4.15 is presented in section 4.7 after validation of the proposed FE model is established. Validation of the proposed models needs to be established prior to the discussion and analysis of the presented heat transfer results.

\subsection{Validation of Heat Transfer Analysis}

To the best of the author's knowledge, no study on the heat transfer (HT) of double skin composite wall currently exists. Thus, studies on the HT of concrete filled steel tubular (CFST) columns are used to establish the validity of the proposed temperature distributions. With concrete being confined by steel shells, CSFT columns are used for validation since the structure best mimics the thermal behaviour of DSCW. Data on fire tests of CFST columns subjected to ISO-834 fire temperature curves obtained from various research papers (Lie, 1994; Lu et al. 2009; Xionga and Liew, 2016) is simulated using the FE procedure described above. A total of eleven HT simulations of CFST columns were conducted. The thermal behaviour of four SCC, three UHPC and four NSC-based concrete in-fills were analyzed in an attempt to validate the proposed simulations and material models for SCC, UHPC and NSC, respectively. As shown in Table 4.3, the simulations vary in cross-sectional shape, diameter, width and concrete types. The investigated specimens shown in Table 4.3 were exposed to the designated ISO-834 fire temperature shown in Figure 4.12. Tests with SCC infill were obtained from the experimental investigation conducted by ( $\mathrm{Lu}$ et al. 2009) where the use of square and circular cross-sections was analyzed (Table 4.3). Other experimental tests on UHPC were obtained from Xionga and Liew (2016) were the behaviour of single and double tubular columns were investigated (Table 4.3). Due to the limited experiments on ECC concrete infill, investigation on the heat transfer of normal 
strength concrete infill is included in this chapter. These experiments are obtained from Lie (1994), where circular and square cross-sections are investigated. The results of the experiments are compared with FE simulations conducted through use of the outlined procedure above. The heat is applied uniformly throughout the profile surface of the subject leading to temperature differnetial throughout the cross-section while the profile temperature of the subject remains constant. As such, the height of the investigated speciemens presented in Table 4.3 is of no importance. The height parameter is thus not considered and only 2-dimensional (2-D) FE modelling is conducted to improve computation speed. The thermal propreties of steel and concrete alternatives described in section 4.2 are used to define the propreties of the materials considered in Table 4.3. The mechanical properties such as compressive/tensile strength and modulus of elasticity have no impact on the results of the heat transfer analysis. Mechical propreties are of importance when considering 3D stress problems where the specimen is subjected to various loads leading to initiation of stress within the material. Thus, the mechaincal properties associated to the specimens shown in Table 4.3 are omitted. Due to the high number of investigated specimens, it is impracticale to demonstrate the meshing and discretization of each investgated subject. As such, a meshing set-up for a typical circular, square, double circular and double square concrete filled section is shown in Figures 4.16, 4.17, 4.18 and 4.19, respectively. Similar to the proceedure outlined in section 4.3 , the concrete core is modelled as a solid part using eight-node linear heat transfer brick elements (DC3D8 elements), while the steel sheets are modelled as four-node heat transfer quadrilateral shell elements (DS4 elements). Figures 4.20, 4.21 and 4.22 include the comparison of the temerpature distributions between test and FE results for SCC, UHPC and NSC, respectively.

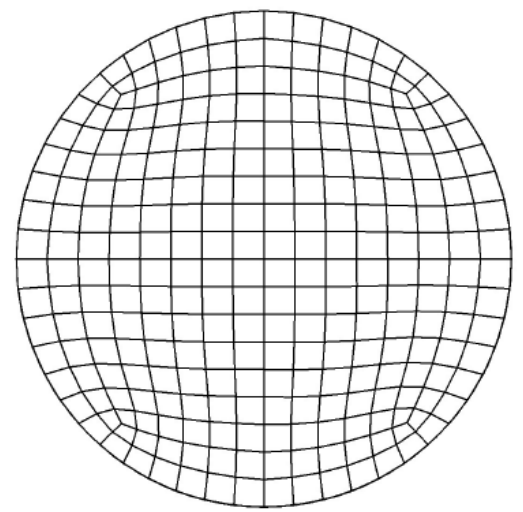

Figure 4.16: Meshing for NSC specimen with diameter of $159 \mathrm{~mm}$ and steel thickness of $6 \mathrm{~mm}$ 


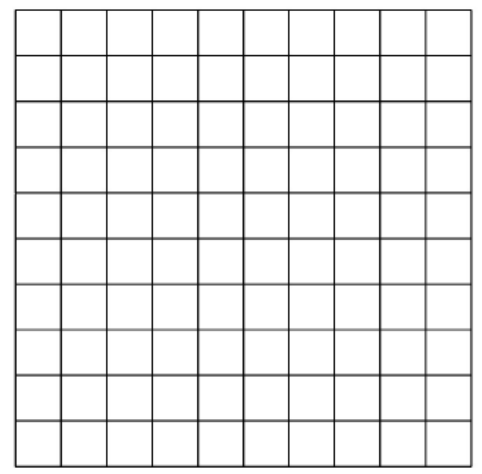

Figure 4.17: Meshing for NSC specimen with width of $200 \mathrm{~mm}$ and steel thickness of $5 \mathrm{~mm}$

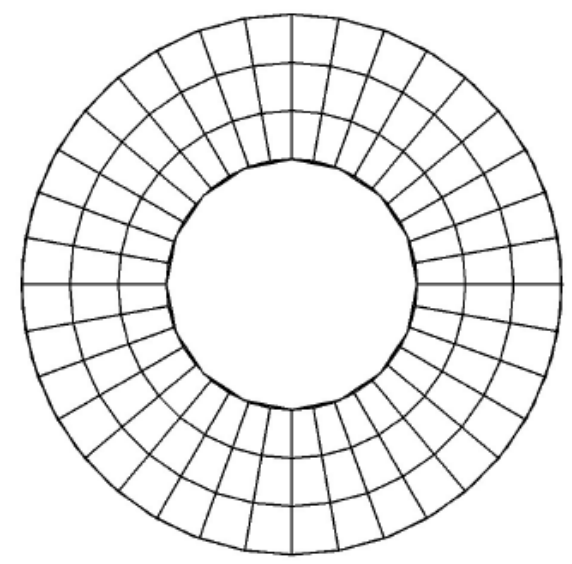

Figure 4.18: Meshing for UHPC specimen with outer diameter of $219.1 \mathrm{~mm}$ and steel thickness of $16 \mathrm{~mm}$

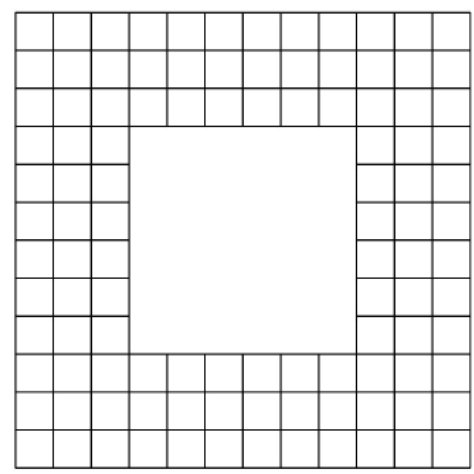

Figure 4.19: Meshing for UHPC specimen with outer width of $200 \mathrm{~mm}$ and steel thickness of 12 $\mathrm{mm}$ 
Table 4.3: Summury of test data for CFST columns

\begin{tabular}{|c|c|c|c|c|c|c|}
\hline $\begin{array}{l}\text { Section } \\
\text { shape }\end{array}$ & Number & $\begin{array}{l}\text { Concrete } \\
\text { type }\end{array}$ & $\begin{array}{l}\text { Diameter, D, } \\
(\mathrm{mm})\end{array}$ & $\begin{array}{l}\text { Width, B } \\
(\mathrm{mm})\end{array}$ & $\begin{array}{l}\text { Thickness, } \mathrm{t} \\
(\mathrm{mm})\end{array}$ & Source \\
\hline & 2 & SCC & $\begin{array}{l}406 / 164.1 \\
219.1 / 101.6\end{array}$ & - & $\begin{array}{l}8 / 3 \\
5 / 3.2\end{array}$ & (Lu et al. 2009) \\
\hline & 2 & SCC & - & $\begin{array}{l}150 / 90 \\
200\end{array}$ & $\begin{array}{l}6 \\
6\end{array}$ & (Lu et al. 2009) \\
\hline & 1 & UHPC & 219.1 & - & 16 & $\begin{array}{l}\text { Xionga and Liew } \\
\underline{2016)}\end{array}$ \\
\hline & 1 & UHPC & $219.1 / 114.3$ & - & $16 / 6.3$ & \\
\hline & 1 & UHPC & - & $200 / 100$ & $12 / 8$ & \\
\hline & 2 & NSC & $\begin{array}{l}273.1 \\
159\end{array}$ & - & $\begin{array}{l}6.35 \\
6\end{array}$ & $\begin{array}{l}\underline{(\mathrm{Lie}, 1994)} \\
(\text { Yaoa et al. 2016) }\end{array}$ \\
\hline & 2 & NSC & - & $\begin{array}{l}200 \\
200\end{array}$ & $\begin{array}{l}5 \\
12.5\end{array}$ & (Yaoa et al. 2016) \\
\hline
\end{tabular}

Figures 4.20, 4.21 and 4.22 show temperature distribution at various points along the crosssection. The locations of points 1,2 and 3 are highlighted in the indicated figures. The temperature vs. time curves for all three points within a cross-section are plotted and compared with experimental results. Temperature test results are obtained through use of thermocouples located within the concrete core. Once the column is subjected to a calibrated furnace temperature, the change in temperature is measured through the implemented thermocouples ( $\mathrm{Lu}$ et al. 2009). It is important to note that the measured temperature might not be accurate (Lu et al. 2009). This is mainly due to manner of placement of the thermocouples (Lu et al. 2009). In this case, in order to maintain accuracy in measured results, thermocouples are installed before casting concrete. However, movement, displacement or deformation of the concrete will affect the accuracy of the temperature measurements ( $\mathrm{Lu}$ et al. 2009). The element size for each of the tested FE models is indicated in Table 4.3. 
Table 4.4: Summury of element size for all generated FE models

\begin{tabular}{|l|l|l|}
\hline $\begin{array}{l}\text { Concrete } \\
\text { Material }\end{array}$ & $\begin{array}{l}\text { Dimensions } \\
\text { diameter/B-width) } \\
{[\mathrm{mm}]}\end{array}$ & $\begin{array}{l}\text { Approximate } \\
\text { element size } \\
{[\mathrm{mm}]}\end{array}$ \\
\hline NSC & $159(\mathrm{D})$ & 10 \\
\hline NSC & $250(\mathrm{~B})$ & 25 \\
\hline NSC & $300(\mathrm{~B})$ & 15 \\
\hline NSC & $273.1(\mathrm{D})$ & 10 \\
\hline UHPC & $219.1(\mathrm{D})$ & 5 \\
\hline UHPC & $219.1 / 114.3(\mathrm{D})$ & 5 \\
\hline UHPC & $200 / 100(\mathrm{~B})$ & 10 \\
\hline SCC & $406 / 164.1(\mathrm{D})$ & 20 \\
\hline SCC & $219.1 / 101.6(\mathrm{D})$ & 20 \\
\hline SCC & $150(\mathrm{~B})$ & 20 \\
\hline SCC & $200(\mathrm{~B})$ & \\
\hline
\end{tabular}




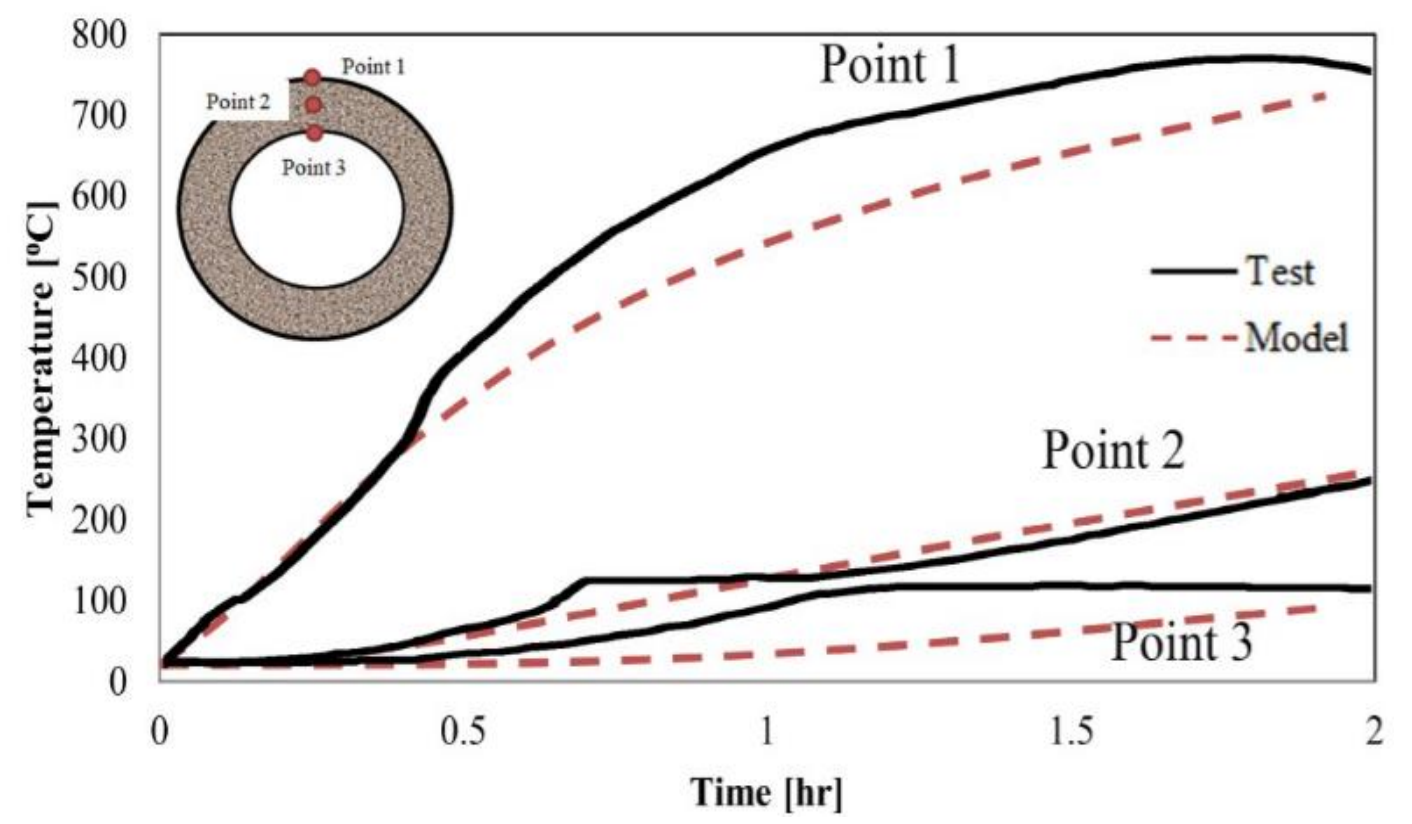

a) (Lu et al. 2009)

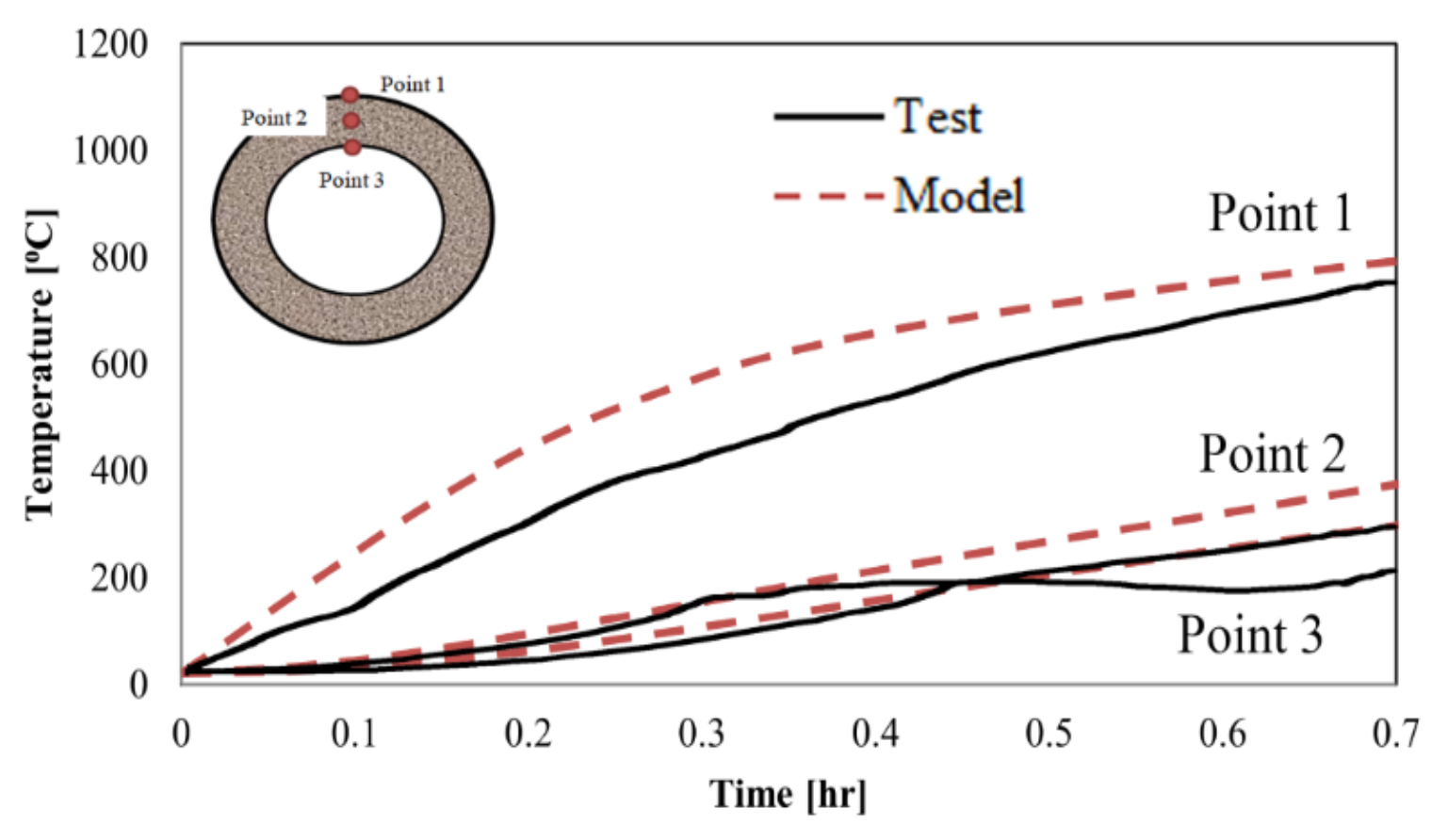

b) ( $\mathrm{Lu}$ et al. 2009) 


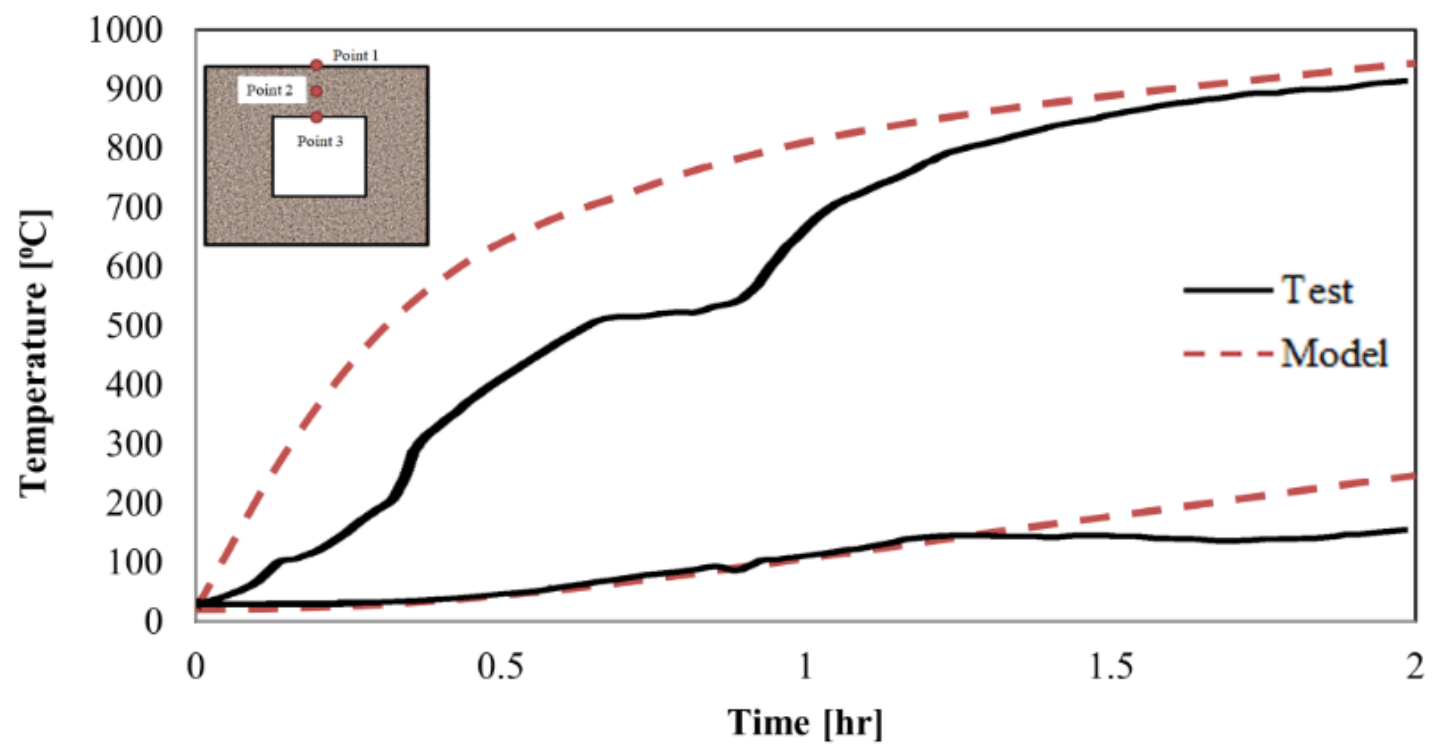

c) (Lu et al. 2009)

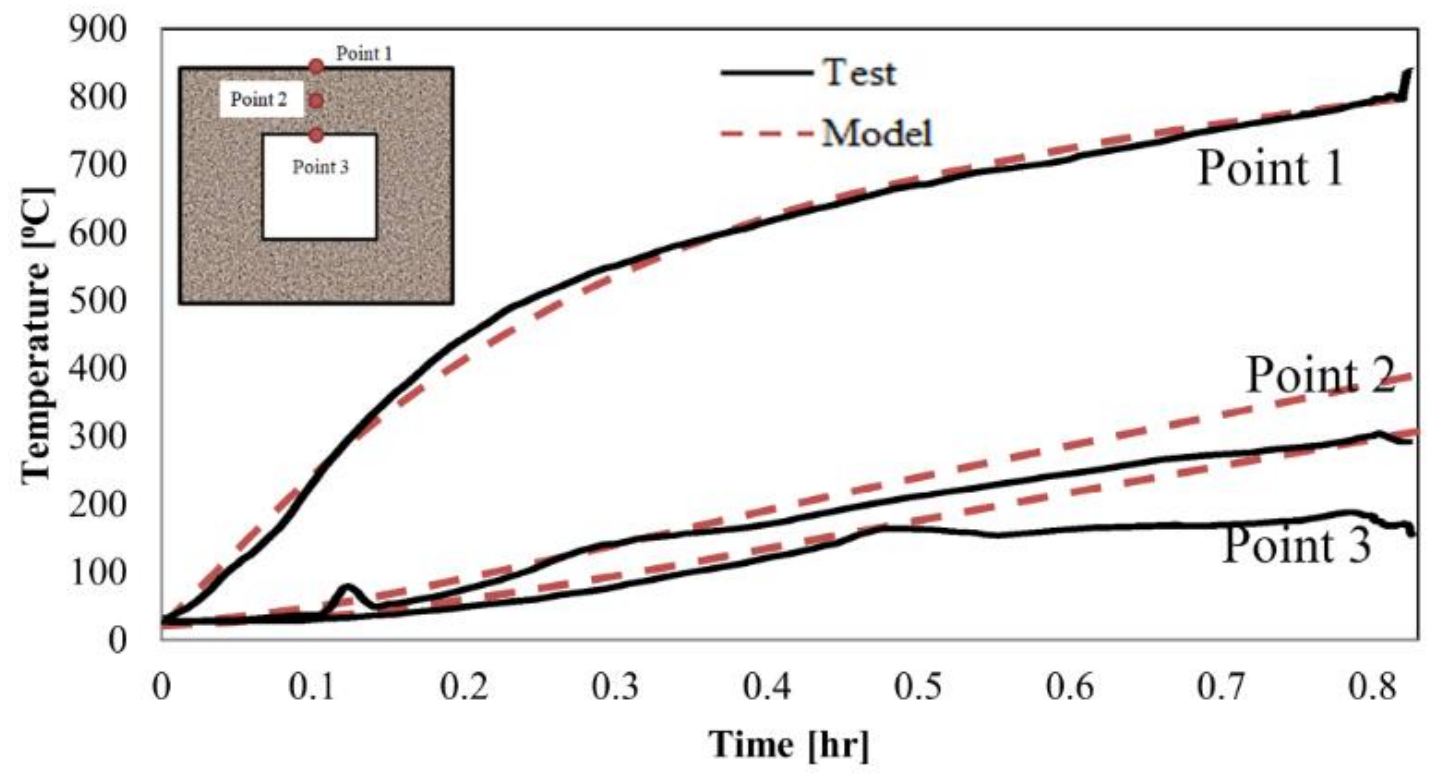

d) (Lu et al. 2009)

Figure 4.20: Comparison between predicted and experimental results for heat transfer of SCCbased CFST 


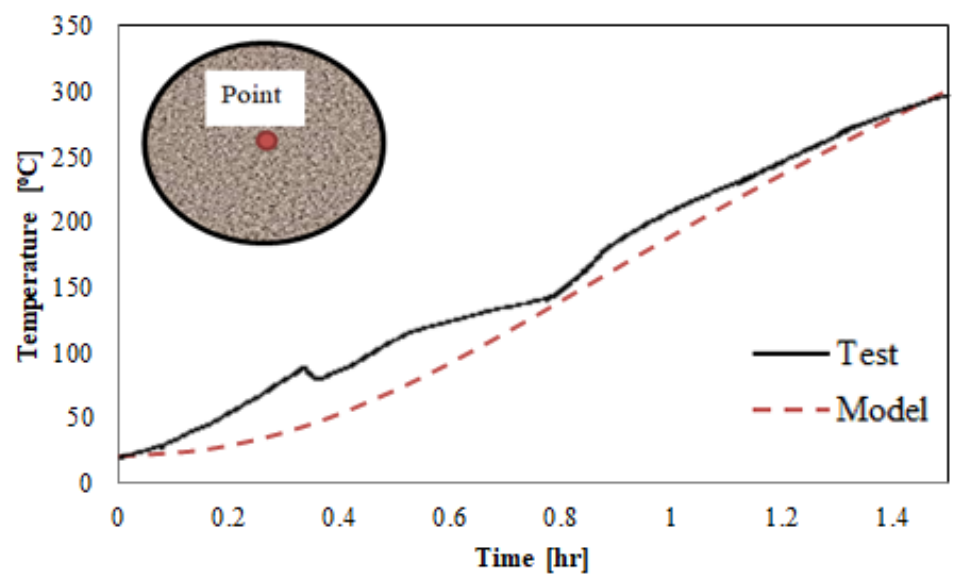

a) (Xionga and Liew 2016)

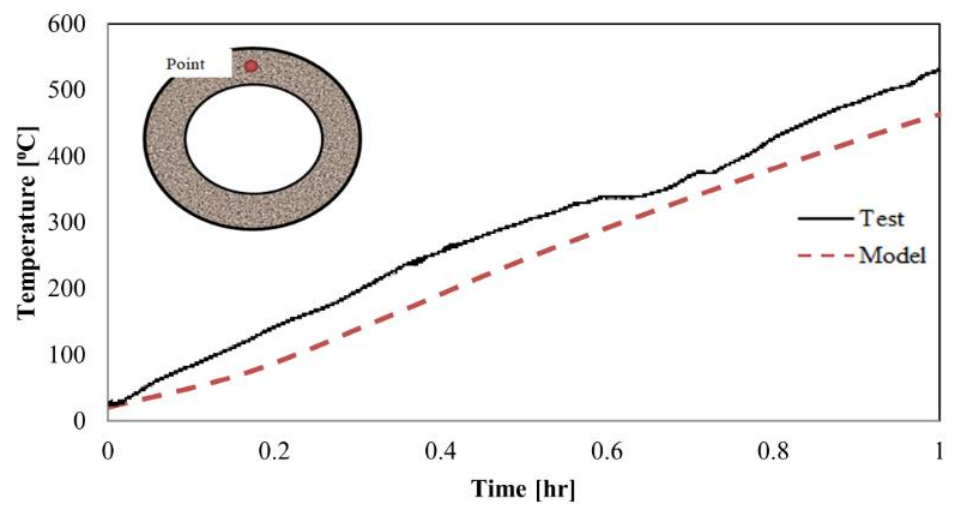

b) (Xionga and Liew 2016)

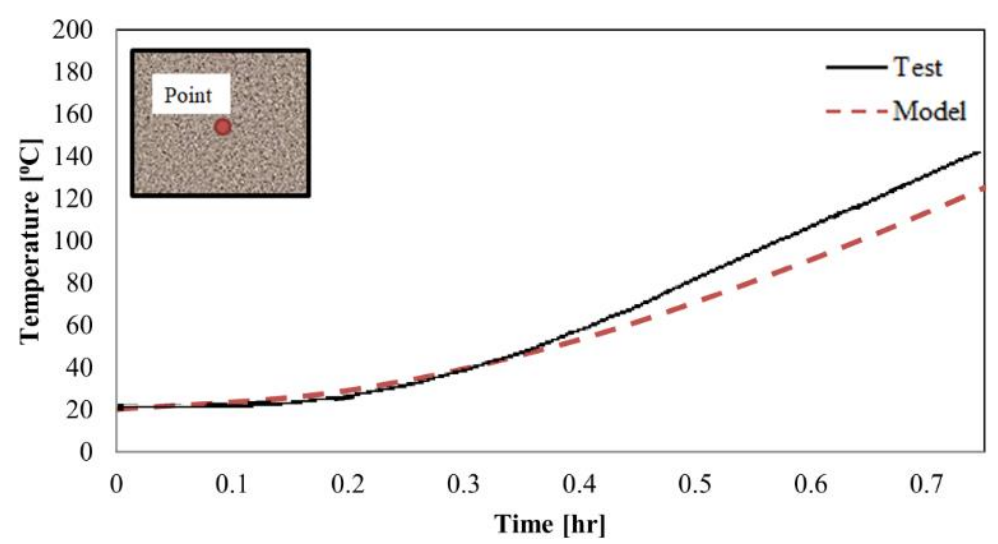

c) (Xionga and Liew 2016)

Figure 4.21: Comparison between predicted and experimental results for heat transfer of UHPCbased CFST 


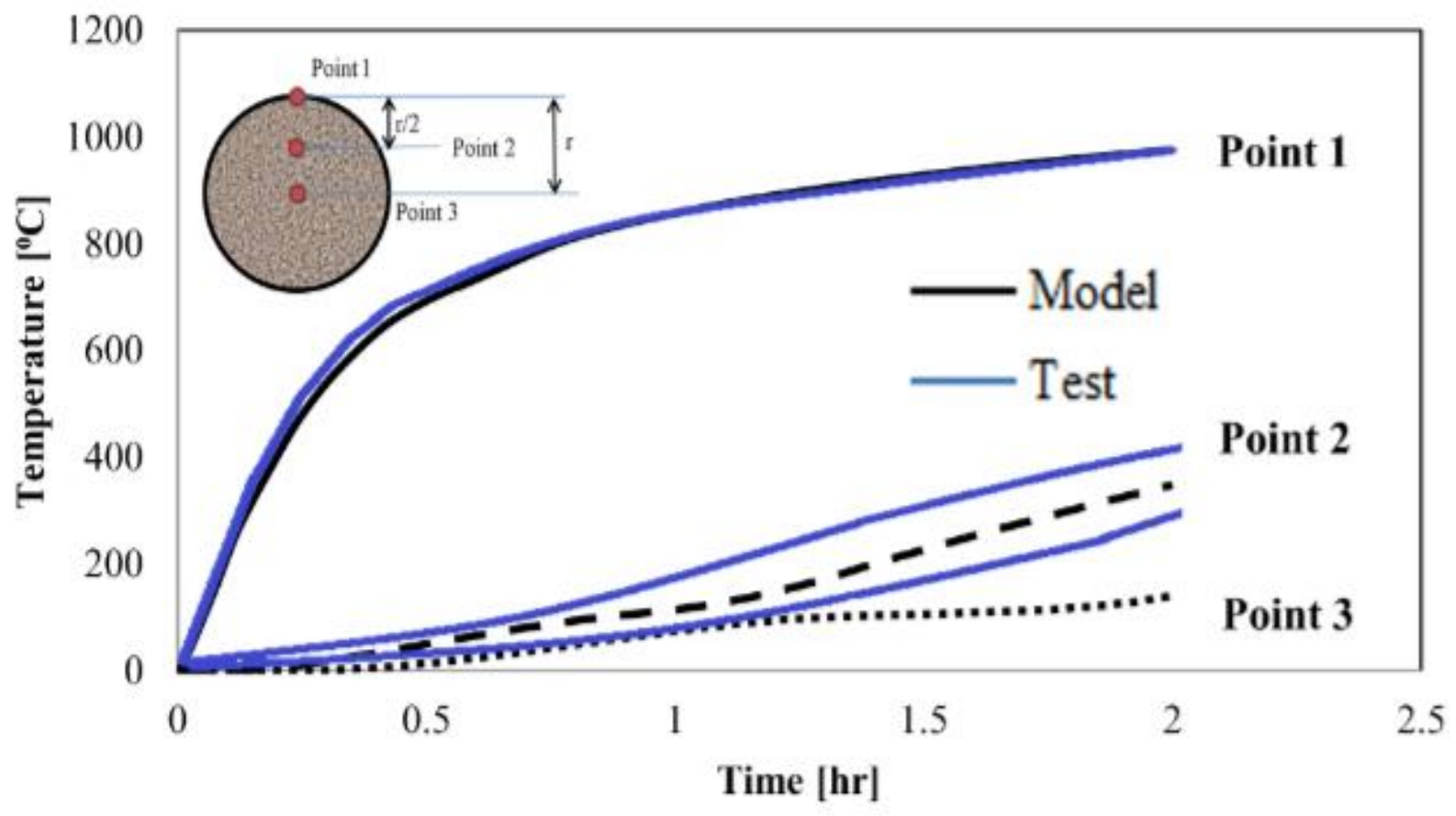

a) (Lie, 1994)

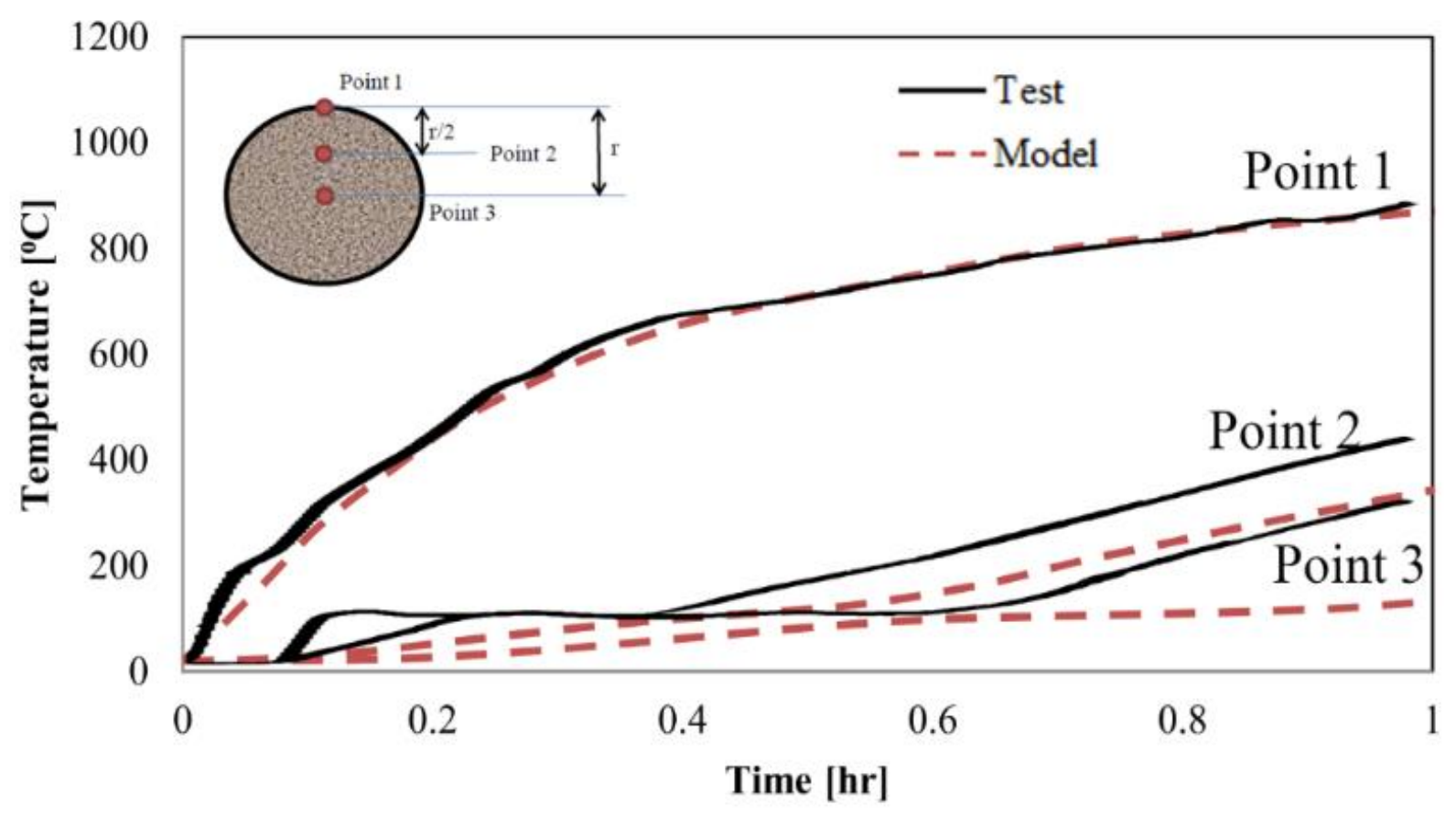

b) (Yaoa et al. 2016) 


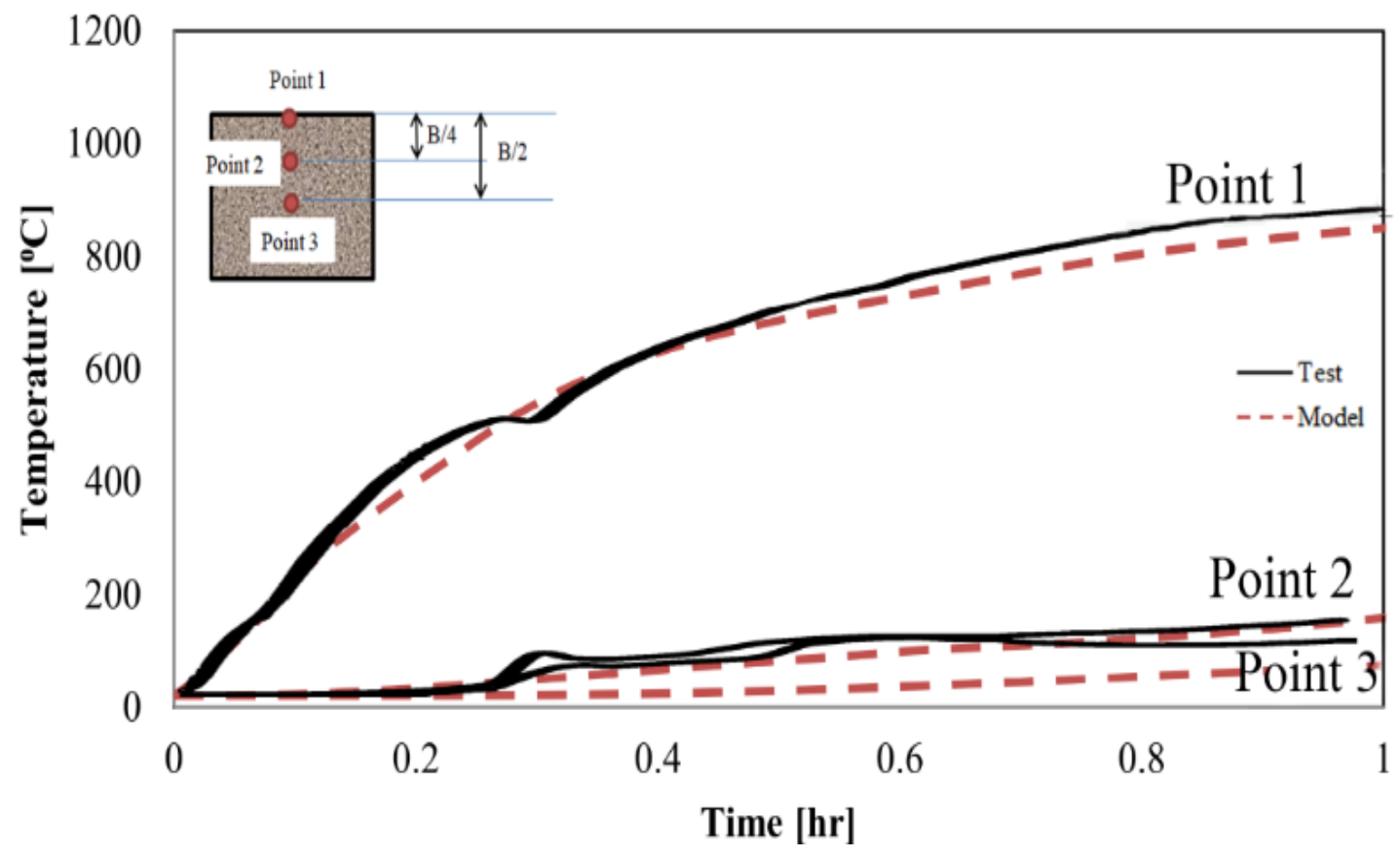

c) (Yaoa et al. 2016)

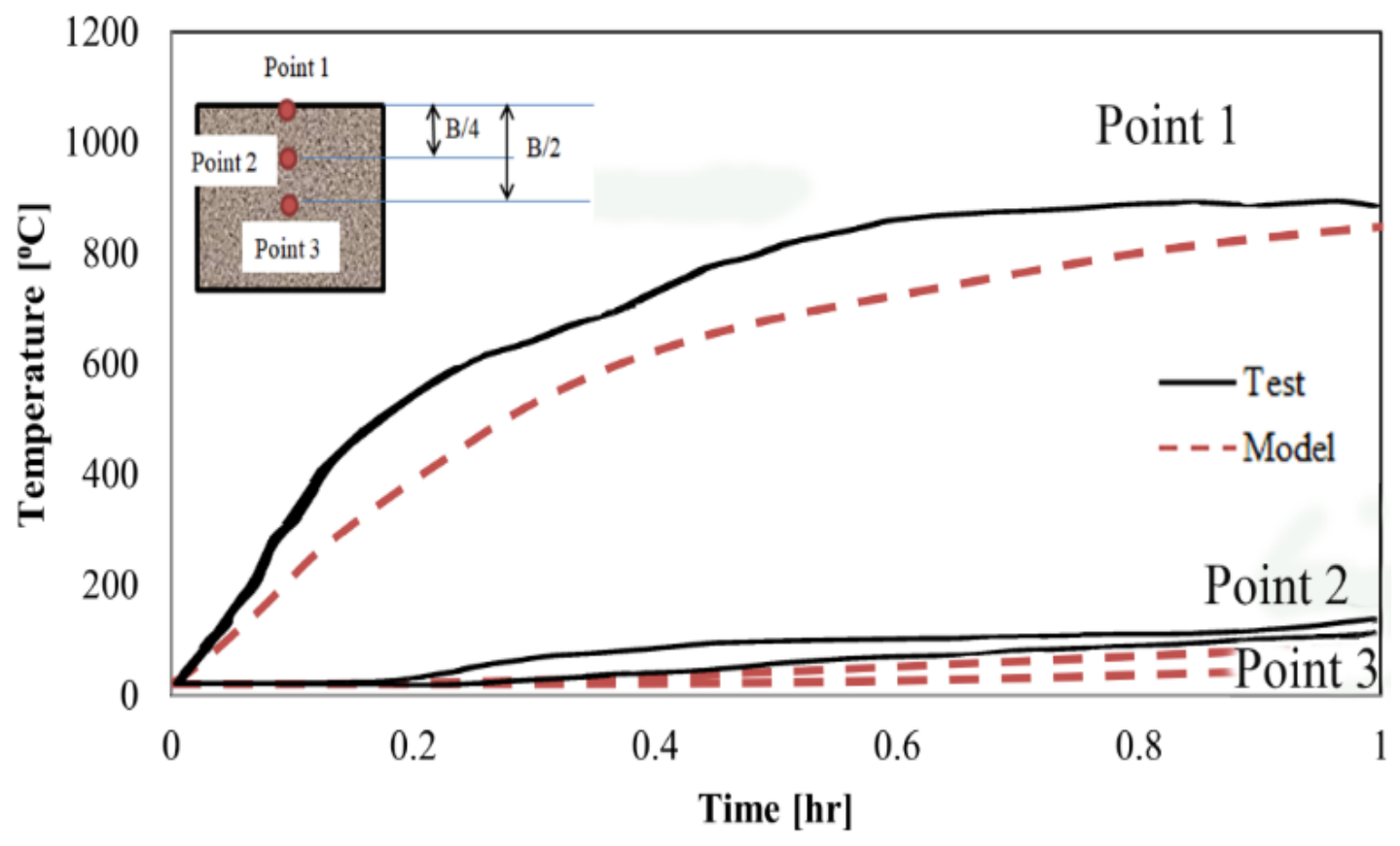

d) (Yaoa et al. 2016)

Figure 4.22: Comparison between predicted and experimental results for heat transfer of NSCbased CFST 
The predicted FE models closely follow the shape of the temperature vs. time curves obtained from experiments. Although Figures 4.20-4.22 do show some discrepancy when comparing test and predicted curves, this is to be expected since the predicted curves rarely follow test results exactly. It is only natural that there is some discrepancy between the test and predicted curves. Such divergence in results may be caused due to errors in experimental program or errors in the material properties of the FE models.

The models for NSC and UHPC show the greatest accuracy when compared to test results due to the low discrepancy and high accuracy of the results. This suggests that appropriate thermal material properties have been selected for NSC and UHPC-based CFST models.

The models for SCC show a higher discrepancy in accuracy when test and predicted curves are compared. SCC mixtures vary greatly in moisture content and percent fiber reinforcement leading to variations in the thermal properties of such concrete alternative. The model presented by (Kodur et al. 2010) generalizes the thermal properties of the varying SCC mixtures rending such thermal model less accurate when considering a specific concrete mixture. As shown in Figures 4.20-4.22, the temperature is not uniform in CFST columns along the cross-section, indicating a change in temperature distribution along the diagonal of the cross-section. This can also be seen in Figures 4.13-4.15 where a similar trend and shape of the temperature vs. time curves is observed in DSCW. In addition, it is important to note that a small difference does exist between the measured and predicted temperatures at the early stage of fire exposure. This is shown as divergence within the temperature range of $100-350^{\circ} \mathrm{C}$ for SCC concrete alternatives. A higher temperature is measured during early stages of fire exposure. This is believed to be caused by the thermally induced migration of the moisture away from the elevated temperature (Lie, 1994). As indicated earlier, moisture and water content in the concrete is taken into account by the change in density and specific heat. However, since thermo-hydraulic analysis is neglected due to the complexity of the problem and computation cost, the movement of moisture away from the surface of the steel is not taken into account (Lie, 1994). This limitation seems to result in the deviations of the measured and predicted response for element temperatures between $100-350^{\circ} \mathrm{C}$ (Lie, 1994). For later stages, good agreement is observed between predicted and observed. This is the most essential part since failure occurs during the final stages (Lie, 1994). Although heat transfer of CFST columns does provide adequate validation grounds for the 
predicting of heat transfer of composite walls, there are still questions on whether the change in cross-sectional shape does affect the predicted results. The following section discusses the effects of cross-sectional shape on heat transfer analysis.

\subsection{The Effect of Cross-sectional Shape on Heat Transfer Analysis}

In this section, a discussion on the effects of change in cross-section is presented. It is important to note that a high temperature build-up is observed for sections of acute angle with $90^{\circ}$ as presented in square and rectangular sections (Dai and Lam, 2012). The high build-up in temperature is noted along the steel tube at the location of the acute angle (Dai and Lam, 2012). This behaviour is indeed observed in Figure 4.23 where the thermal isotherm for circular and square NSC sections are compared. Figure 4.23 validates the uniform temperature field along the steel tube for circular cross-section and the build-up in thermal stress at the corners of square cross-section (Dai and Lam, 2012). However, since angles in the profiled steel sheets are higher than $90^{\circ}$, the so-called acute angles in profiled steel act as corner enhancements rather than temperature build-up zones. The use of corner enhancement is used to relieve the stress due to acute angles. Previous studies (Ghannam, 2015; Wang et al. 2014) concluded that the effect of the corner enhancement is not significant during fire exposure. This is mainly due to the fact that failure of structure exposed to fire occurs during the finals stages of the temperature vs. time curve (Ghannam, 2015). At this stage, the load is fully carried by the concrete and not the steel (as will be discussed in Chapter 5), thus the effect of corner enhancement in steel is irrelevant at this stage (Ghannam, 2015). As a result, no special conditions are applied when determining the heat transfer for structures with corner enhancement. This indicates that the established FE procedure described above is indeed adequate to model the profile cross-section of the composite wall specimen without additional alterations in the proposed model. A similar behaviour is observed when comparing CFST and CFDST sections - similar conductivity parameters exist between the concrete core and inner steel tube. Due to a lack in oxygen/air in the inner steel tube, the area is treated as a vaccum where no radiation or convection emmits from the inner surface of the steel tube. As such, it can be observed in Figures 4.23 and 4.24 that the addition of another inner circular/square tube does not affect the overall temperature distribution in the cross-section. In fact, the temperature distribution for all points in the core concrete section are similar when 
comparing for single and double tubular section. The benefits of double tubular sections are highlighted by their ability to have higher fire resistance values due to the influence of the inner steel tube in withstanding the compressive load while being protected from the external fire by the surrounding concrete core. Figure 4.24 shows the temperature profile for square and circular CFSDT sections. In the figures portraing thermal isotherms, "NT11" refers to the nodal temeprature with unites of $\left[{ }^{\circ} \mathrm{C}\right]$.
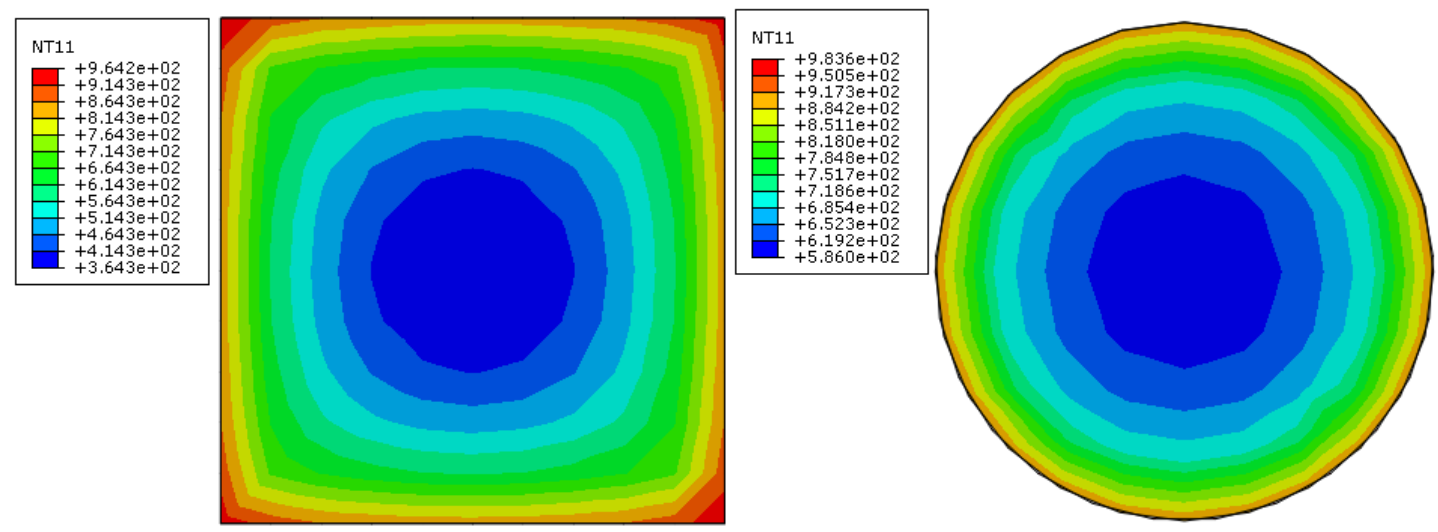

Figure 4.23: Temperature profile $\left({ }^{\circ} \mathrm{C}\right)$ for circular and square sections
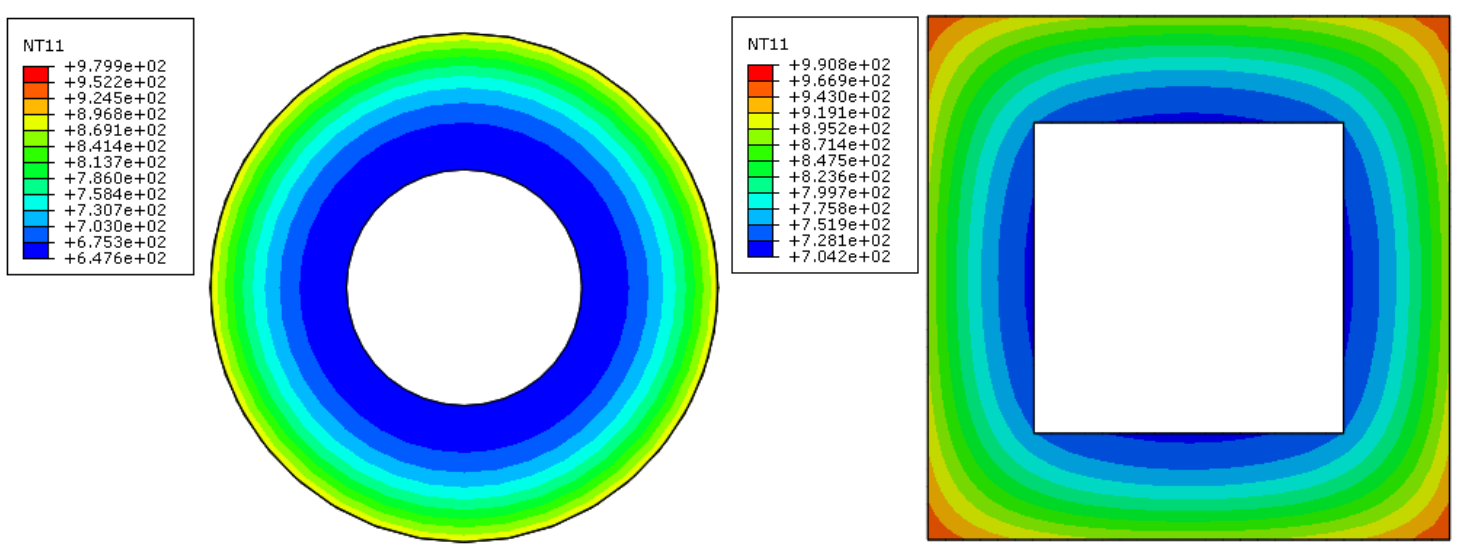

Figure 4.24: Temperature profile $\left({ }^{\circ} \mathrm{C}\right)$ for double circular and square sections

The high build up in thermal stress in the corners of the square sections is highlighted by the red isotherms. This is observed in the square section shown in Figure 4.23 where an even temperature distribution near the surface of the steel is observed. Such observation is not replicated in the inner tube of double tubular section. This is highlighted in Figure 4.24 where no thermal build-up is observed surrounding the inner steel. The isotherms shown in Figures 4.23 
and 4.24 validate the observed results by (Dai and Lam, 2012) where a build-up of thermal stress in square sections was determined to be the reason for resulting in low fire resistance values when compared to circular and spherical cross-sections.

\subsection{Thermal Distribution in CFST/CFDST Cross-sections}

In this section, the temperature profiles of square and circular CFST/CFDST sections defined in Table 4.3 for time periods of $1 \mathrm{hr}$ and $2 \mathrm{hr}$ are described. The specimens are referred to by the type of concrete, shape of cross-section and width/diameter of inner and outer steel tube. The specimen name of NSC-SC-159 refers to circular single (SC) section with normal strength concrete (NSC) and a diameter of $159 \mathrm{~mm}$.

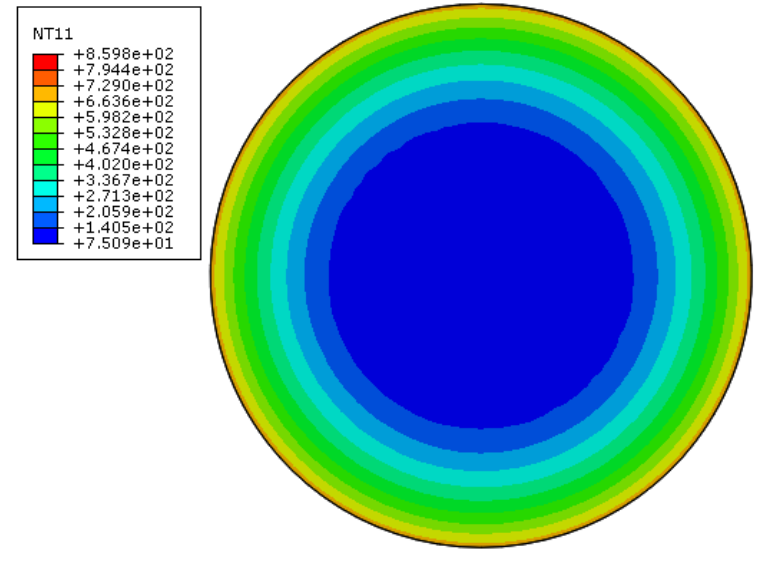

(a)

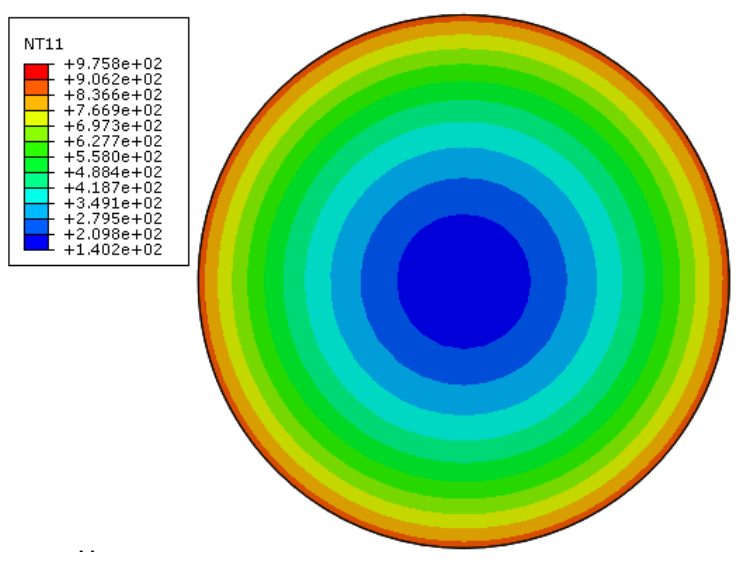

(b)

Figure 4.25: Temperature profile $\left({ }^{\circ} \mathrm{C}\right.$ ) for NSC-SC-273.1 at time period of (a) $60 \mathrm{~min}$ and (b) $120 \mathrm{~min}$

Summary of the temperature values at 60 and $120 \mathrm{~min}$ on the surface of the outer steel tube retrieved from the isotherms included in Figure 4.25-4.29 are shown in Table 4.5. In this case, Figures 4.25-4.29 portray the predicted isotherms at time periods of 60 and 120min of the temperature time curves for points 1, 2 and 3 shown in Figures 4.22a, Figure 4.20b, Figure 4.22c, Figure 4.20c and Figure 4.21a respectively. 


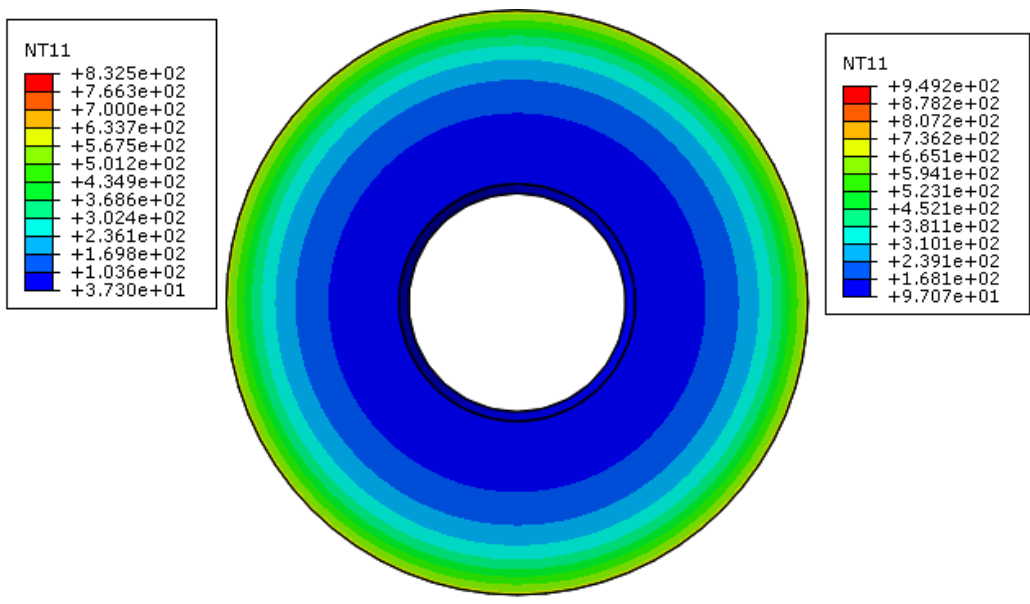

(a)

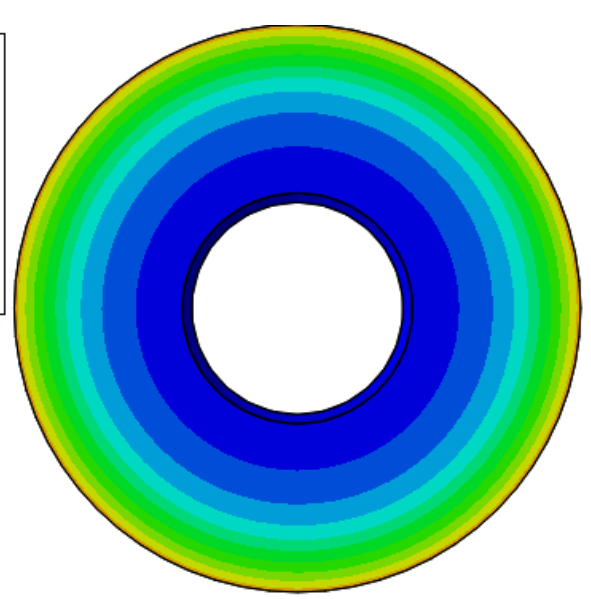

(b)

Figure 4.26: Temperature profile $\left({ }^{\circ} \mathrm{C}\right)$ for SCC-DC-219.1/101.6 at time period of (a) 60 min and (b) $120 \mathrm{~min}$

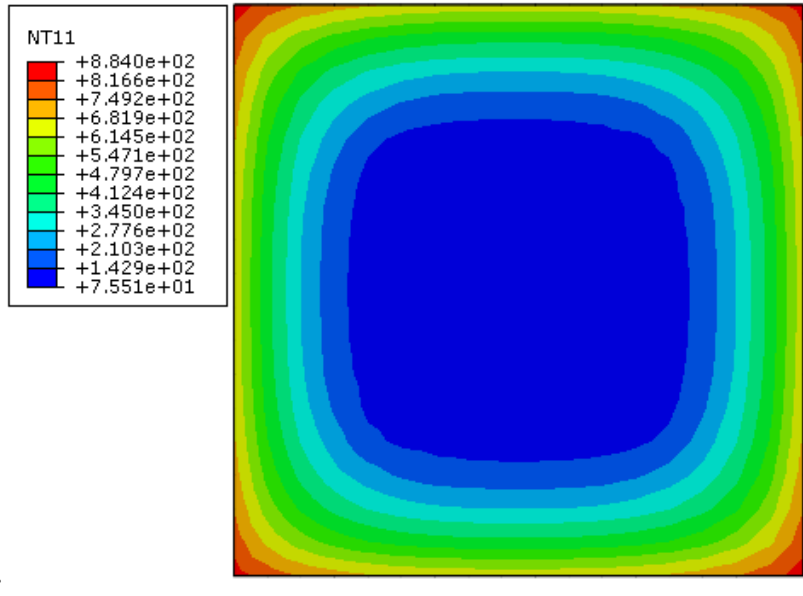

(a)

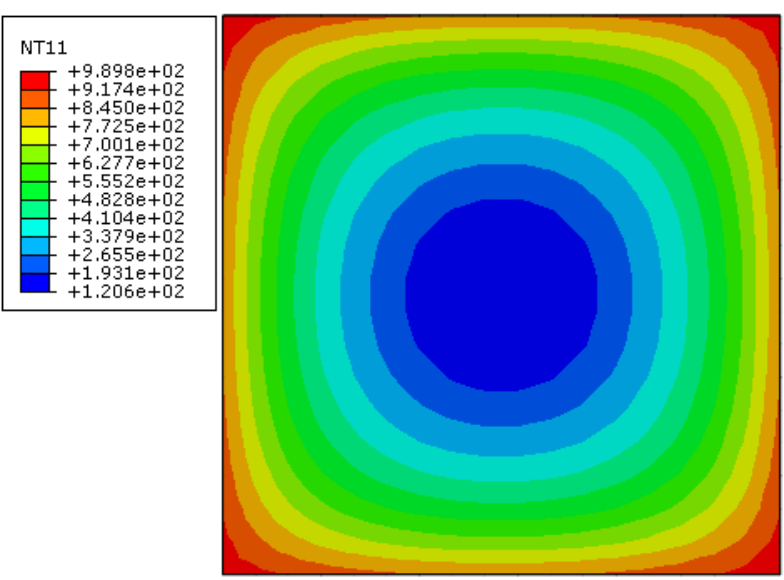

(b)

Figure 4.27: Temperature profile $\left({ }^{\circ} \mathrm{C}\right)$ for NSC-SS-250 at time period of (a) 60 min and (b) 120 $\min$

According to Table 4.5, the cross-section referred to as NSC-SS-250 suffers the highest surface temperature at the $60 \mathrm{~min}$ time period with a value of $884.0^{\circ} \mathrm{C}$ while SCC-DC-219.1/101.6 is observed to experience the lowest surface temperature with a value of $832.5^{\circ} \mathrm{C}$. This observation suggests higher surface temperatures for NSC when compared with UHPC and SCC-based crosssections with SCC being observed to have the lowest surface temperatures at the 60min time period. The surface temperature at any time period is directly related to the thermal properties of 
the concrete core, also referred to as the heat sink. In this case, the high conductivity for SCC help lead to rapid dissipation of thermal energy when directly applied to the surface of the steel.

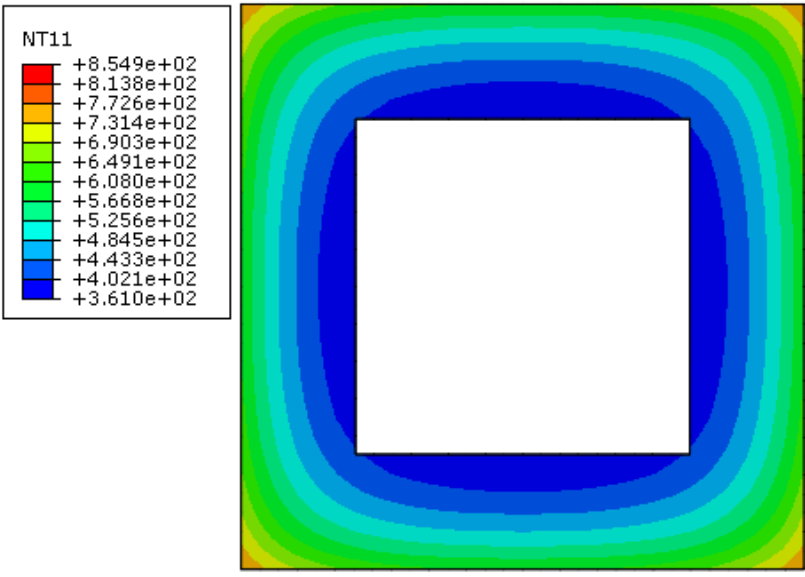

(a)
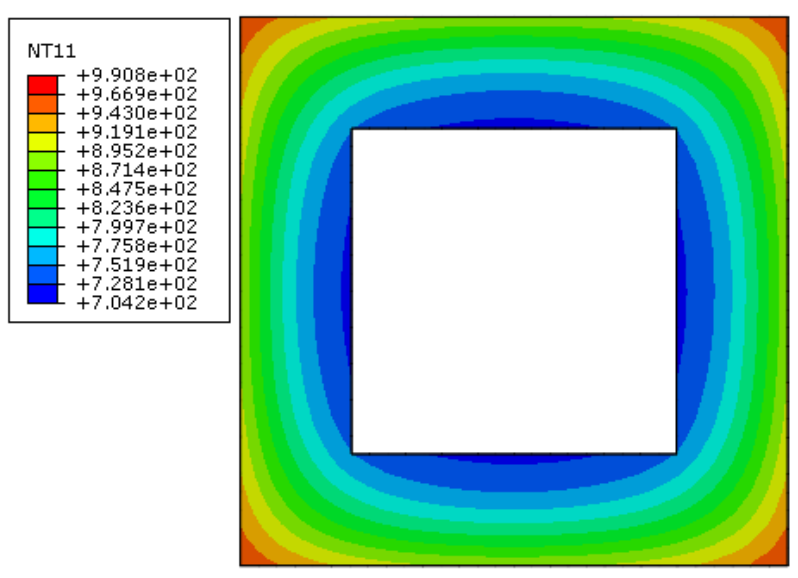

(b)

Figure 4.28: Temperature profile $\left({ }^{\circ} \mathrm{C}\right.$ ) for SCC-DS-150/90 at time period of (a) 60 min and (b) $120 \mathrm{~min}$
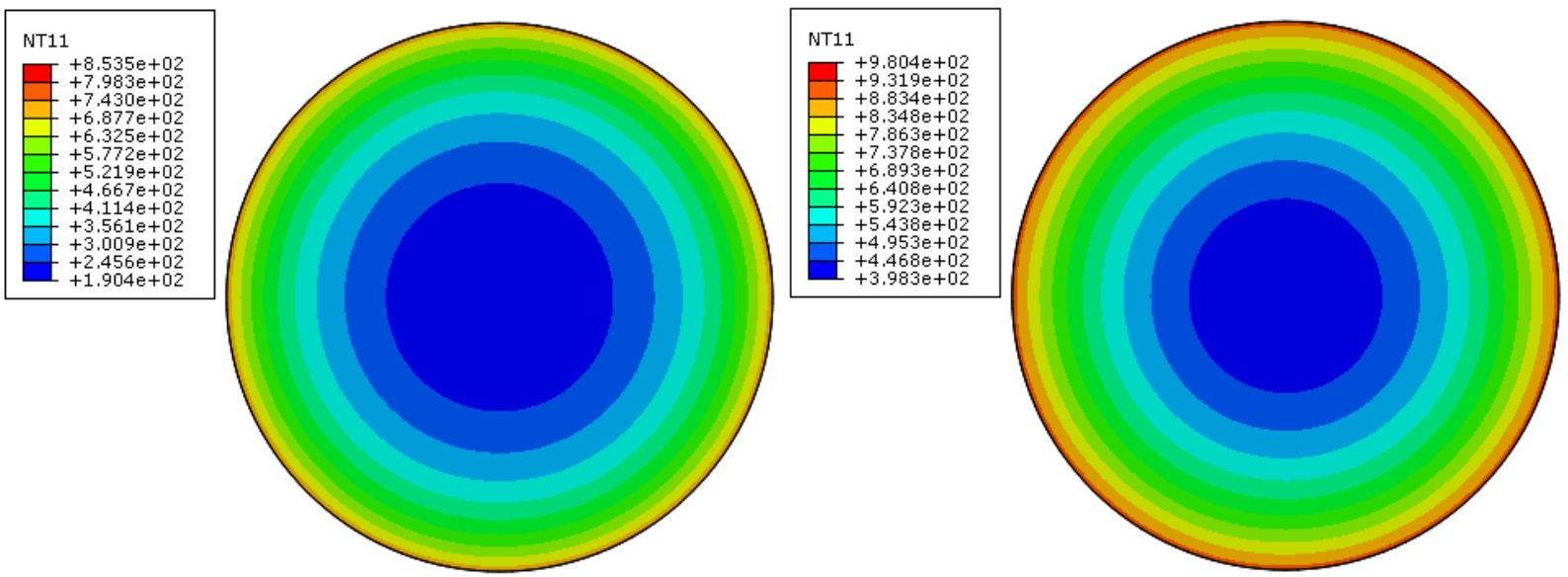

Figure 4.29: Temperature profile $\left({ }^{\circ} \mathrm{C}\right)$ for UHPC-SC-219.1 at time period of (a) 60 min and (b) $120 \mathrm{~min}$

This results in lower values for the surface temperature when compared to NSC and UHPCbased cross-sections. NSC is observed to have the highest surface temperatures due to the high specific heat of concrete at $115^{\circ}$. In this case, the specific heat acts as a resistance to the rapid heat transfer leading to higher values in the surface temperatures when compared to SCC and UHPC. Upon reaching $120 \mathrm{~min}$ of exposure time, the highest and lowest temperatures of 
$990.8^{\circ} \mathrm{C}$ and $949.2^{\circ} \mathrm{C}$ are observed in the SCC-DS-160/90 and SCC-DC-219.1/101.6 crosssections respectively. The low depth in concrete core of the SCC-DS-160/90 leads to a reduced capacity of the cross-section to withhold a specific amount of thermal energy. As such high temperatures distributions are observed throughout the cross-section.

Table 4.5: Surface temperature at 60 and $120 \mathrm{~min}$ for selected CFST/CFDST specimen

\begin{tabular}{|l|l|l|}
\hline Specimen & $\begin{array}{l}\text { Surface temperature at } \\
60 \mathrm{~min}\left[{ }^{\circ} \mathrm{C}\right]\end{array}$ & $\begin{array}{l}\text { Surface temperature at } \\
120 \mathrm{~min}\left[{ }^{\circ} \mathrm{C}\right]\end{array}$ \\
\hline NSC-SC-273.1 & 859.9 & 975.8 \\
\hline SCC-DC-219.1/101.6 & 832.5 & 949.2 \\
\hline NSC-SS-250 & 884.0 & 989.8 \\
\hline SCC-DS-160/90 & 854.9 & 990.8 \\
\hline UHPC-SC-219.1 & 853.5 & 980.4 \\
\hline
\end{tabular}

\subsection{Analysis and Discussion of Heat Transfer Results for DSCW Models}

Results in terms of temperature distribution and heat flux for ECC, SCC and UHPC composite walls after various periods of thermal exposure are presented. Figures 4.30-4.32 show the temperature field $\left({ }^{0} \mathrm{C}\right)$ of ECC, SCC and UHPC-based composite walls for time periods of 10 , 30, 60 and 120 min. Figure 4.33-4.35 include the change in heat flux [W/m²K] vs. time [hr] along points 1, 2 and 3 for SCC, UHPC and ECC-based composite walls, respectively. In addition, isotherms of the heat flux of the section for SCC, UHPC and ECC are presented in Figures 4.36-4.38, respectively.
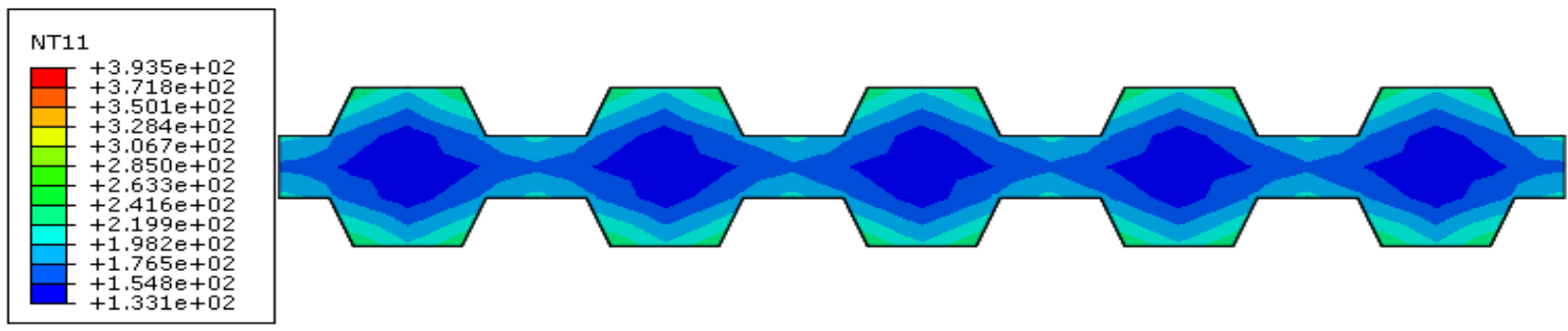

a) 

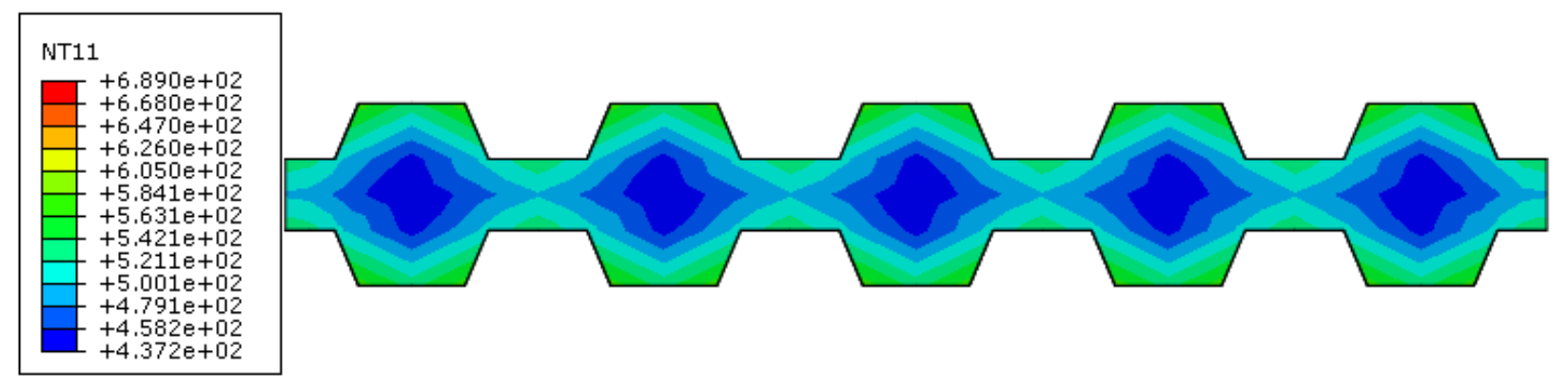

b)

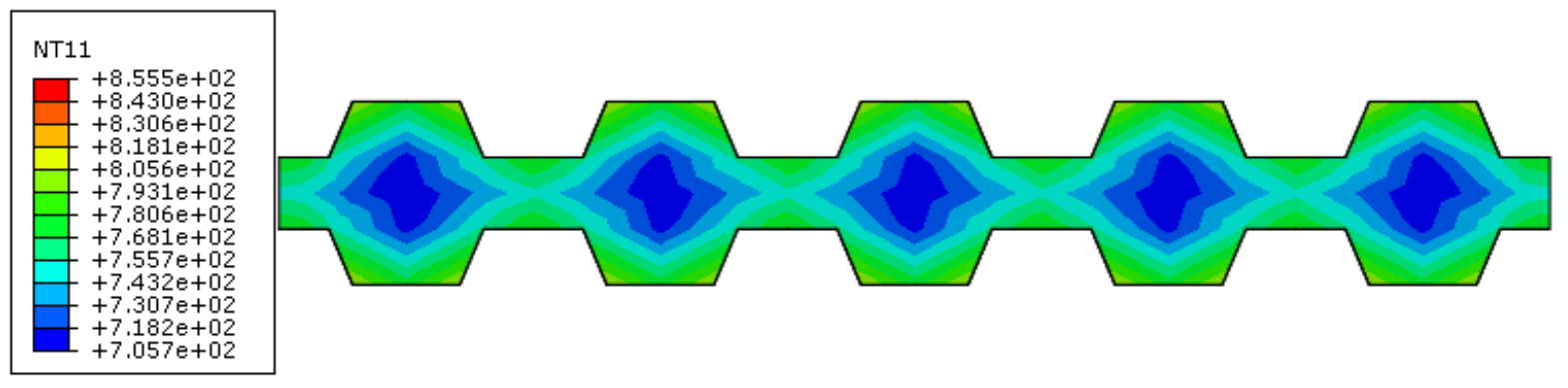

c)

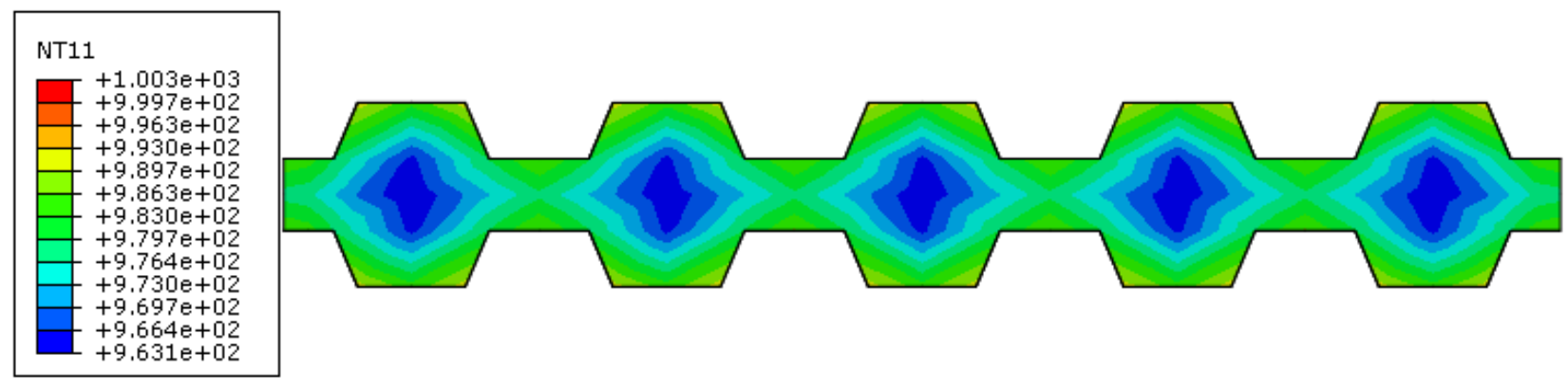

d)

Figure 4.30: Temperature profile $\left({ }^{\circ} \mathrm{C}\right)$ for SCC composite wall after fire exposure time of a) 10 min, b) $30 \mathrm{~min}$, c) $60 \mathrm{~min}$ and d) $120 \mathrm{~min}$.

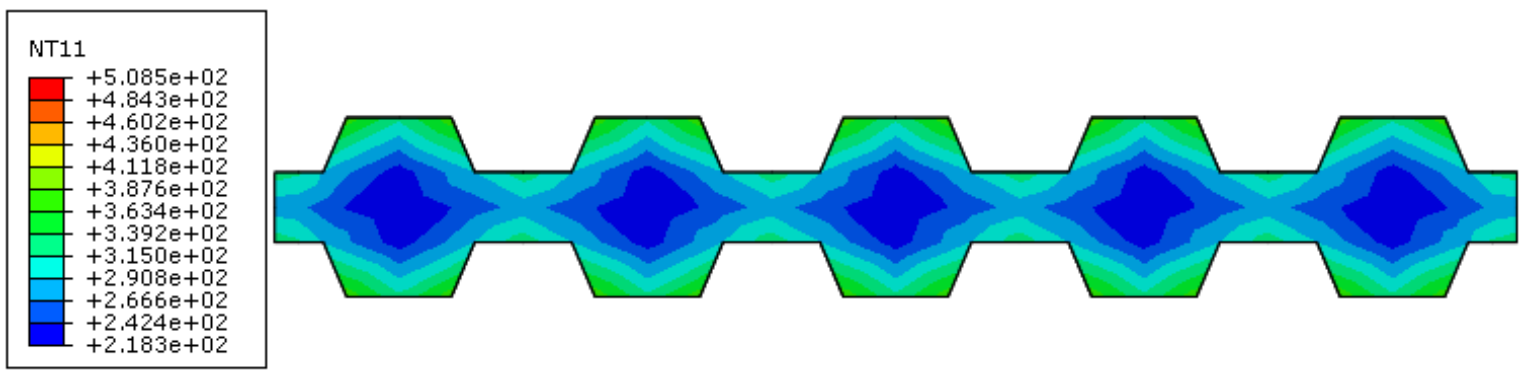

a) 

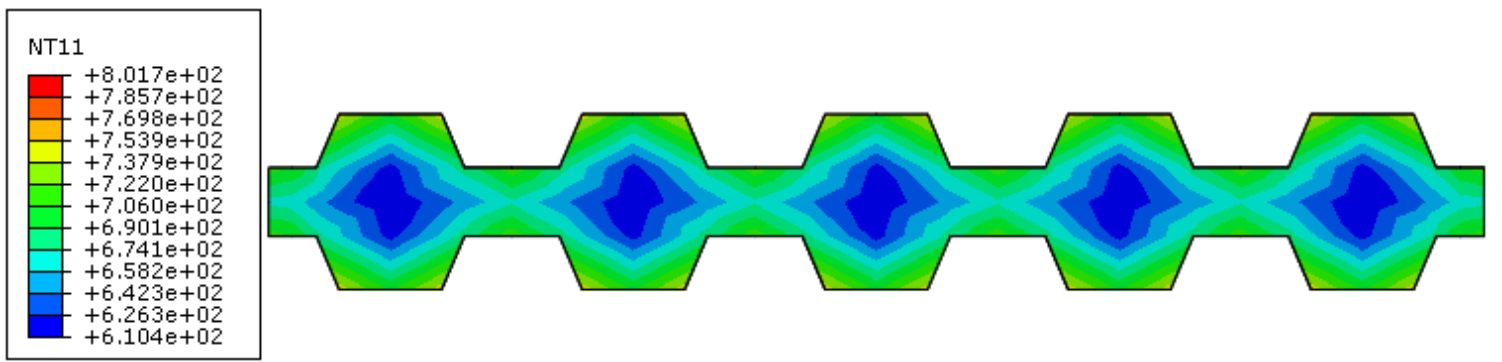

b)

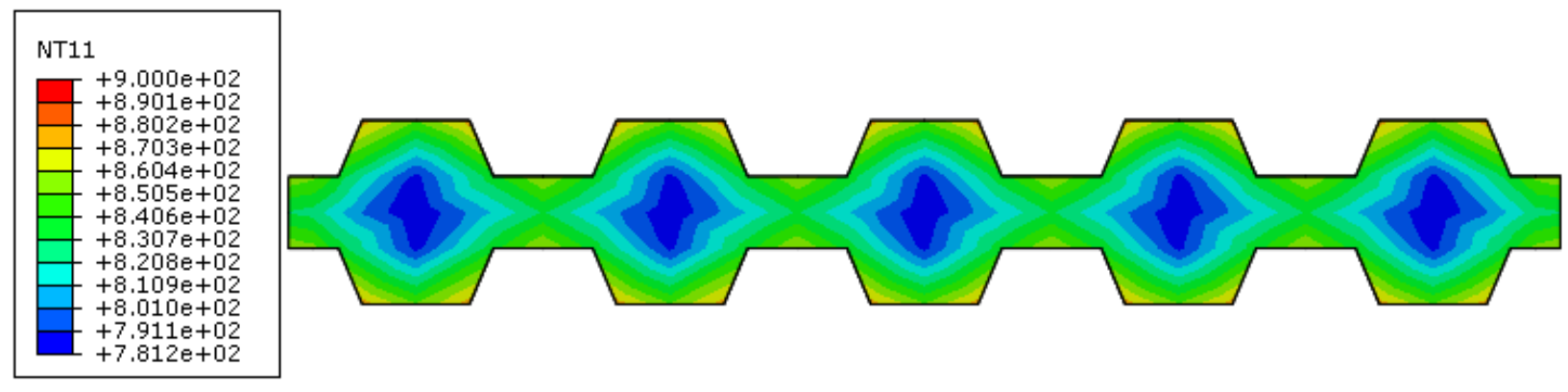

c)
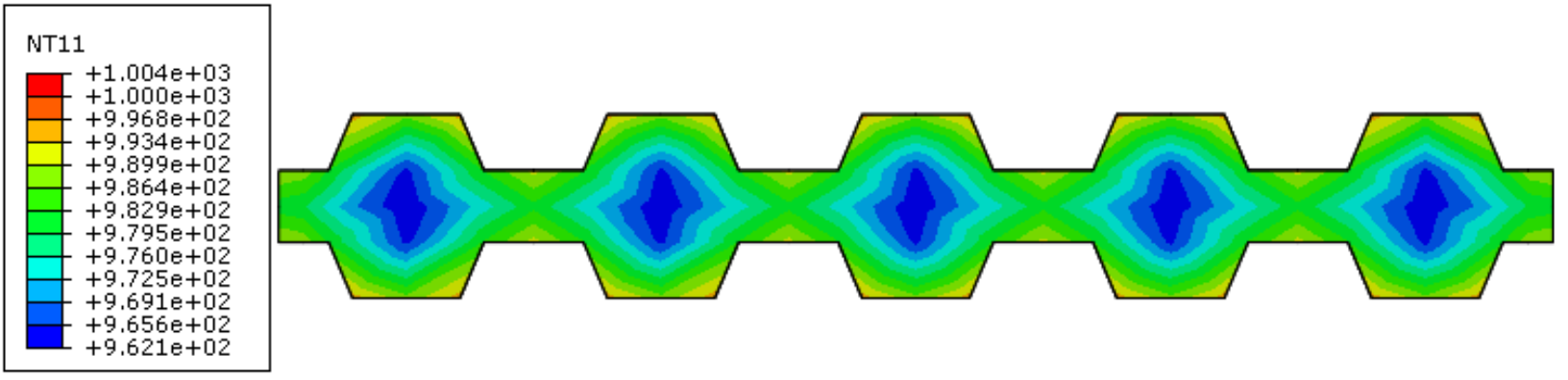

d)

Figure 4.31: Temperature profile $\left({ }^{\circ} \mathrm{C}\right)$ for UHPC composite wall after fire exposure time of a) 10 min, b) $30 \mathrm{~min}$, c) $60 \mathrm{~min}$ and d) $120 \mathrm{~min}$.
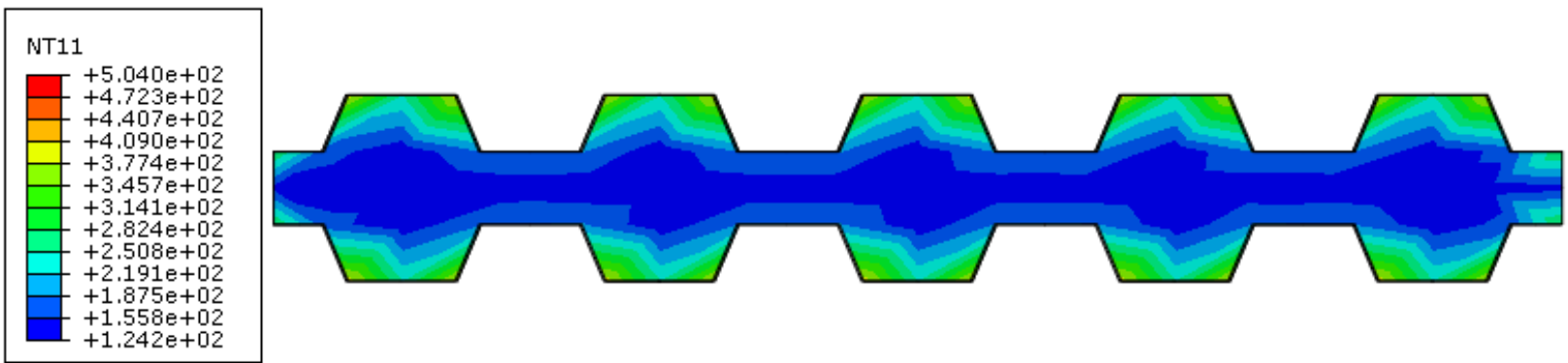

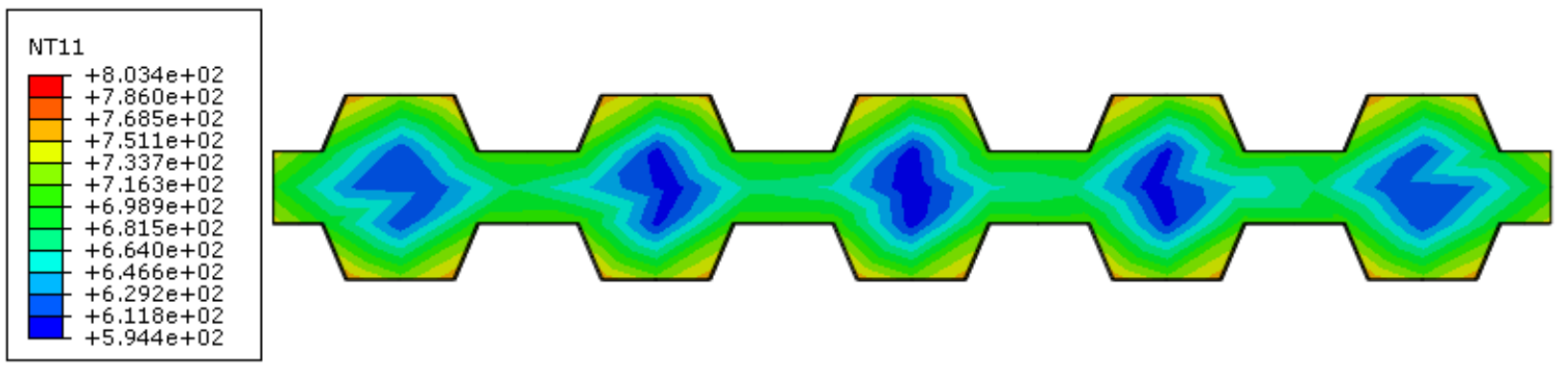

b)
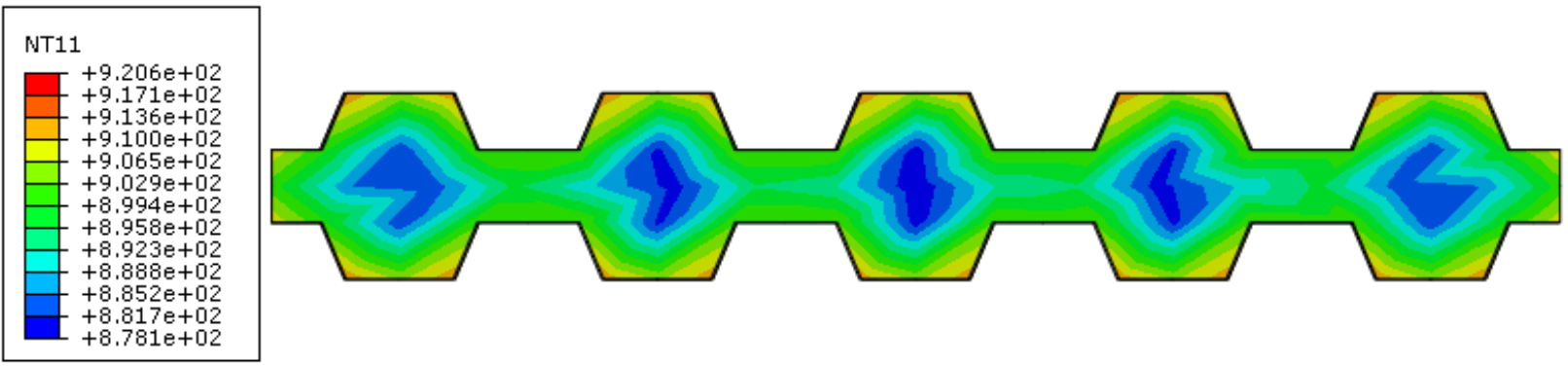

c)
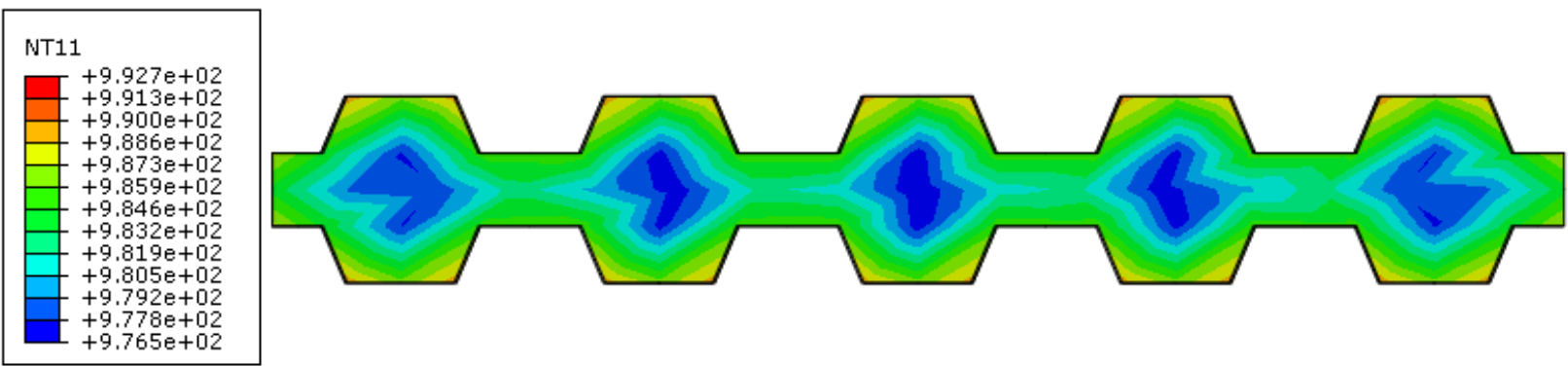

d)

Figure 4.32: Temperature profile $\left({ }^{\circ} \mathrm{C}\right)$ for ECC composite wall after fire exposure time of a) 10 min, b) $30 \mathrm{~min}$, c) $60 \mathrm{~min}$ and d) $120 \mathrm{~min}$. 


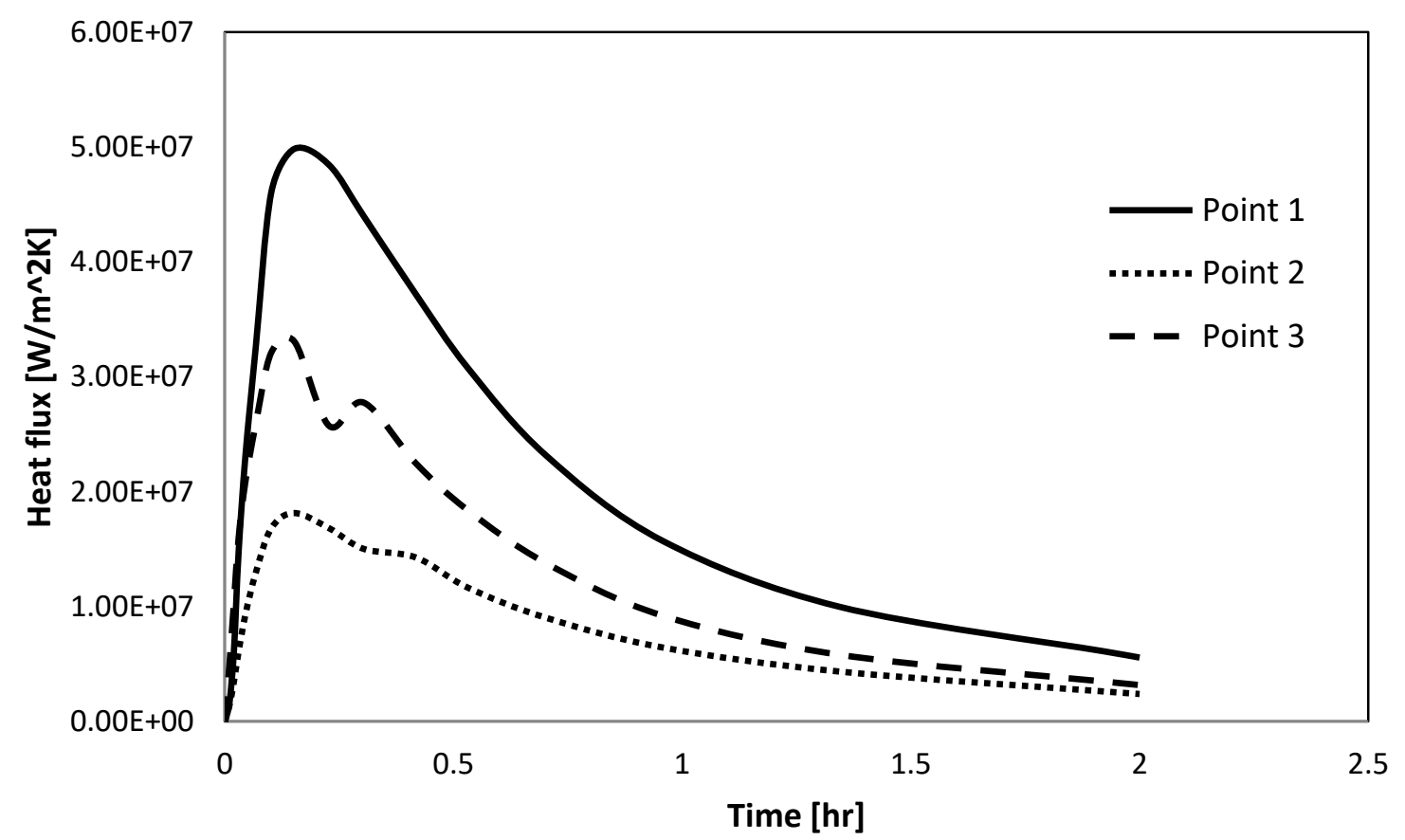

Figure 4.33: Heat flux $\left[\mathrm{W} / \mathrm{m}^{2} \mathrm{~K}\right]$ vs. time [hr] for SCC composite wall

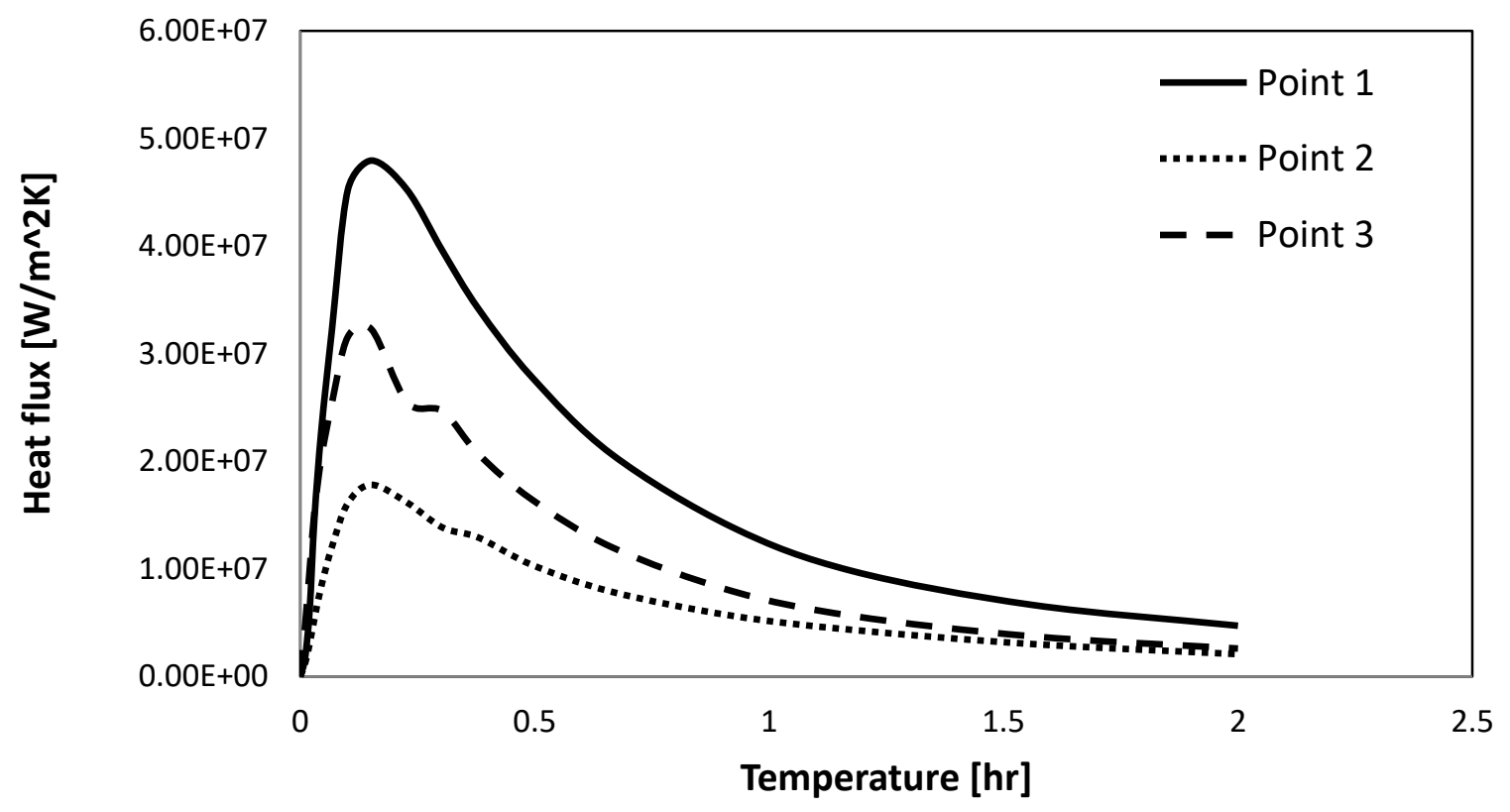

Figure 4.34: Heat flux [W/m² $\mathrm{K}]$ vs. time [hr] for UHPC composite wall 


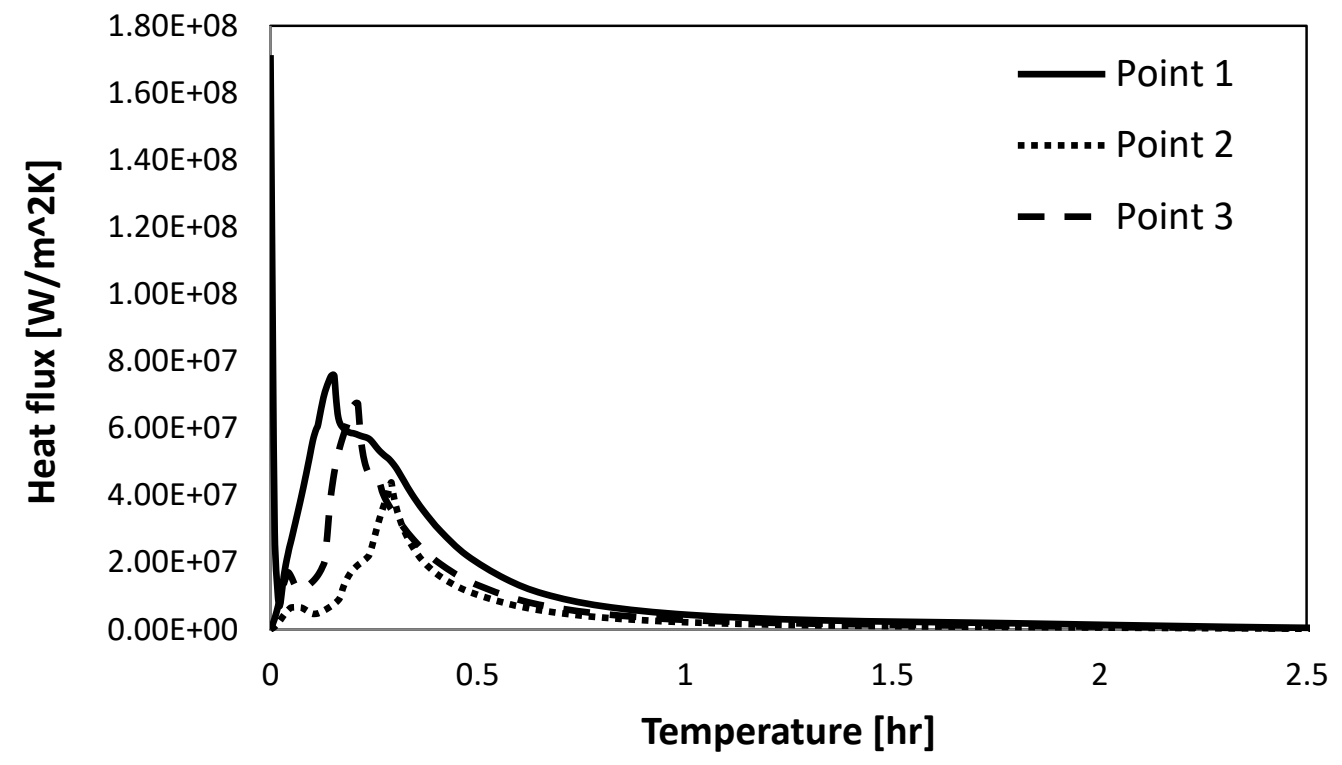

Figure 4.35: Heat flux [W/m² $\mathrm{K}]$ vs. time [hr] for ECC composite wall
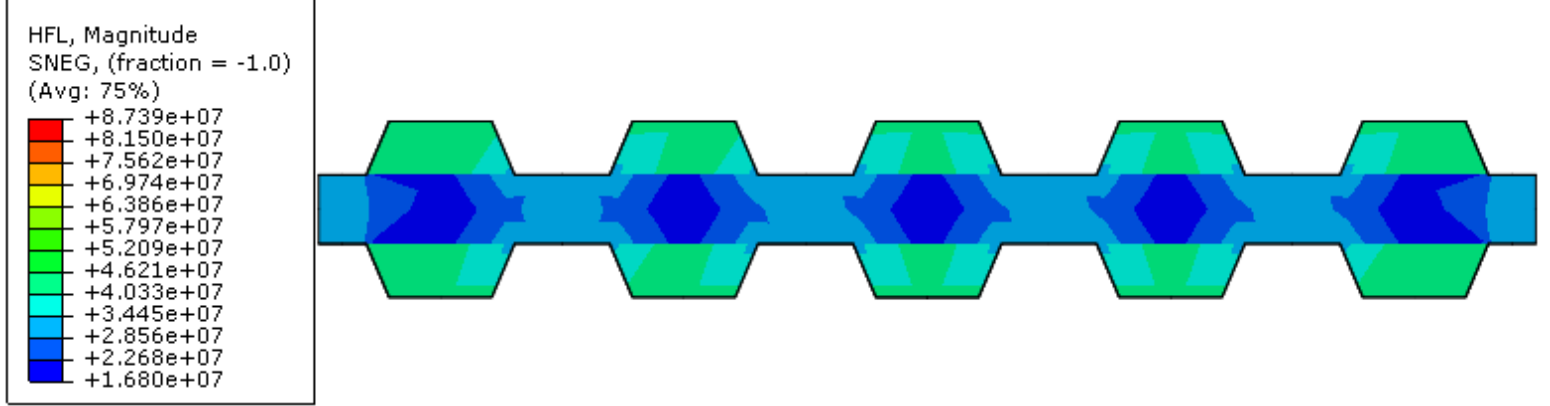

a)
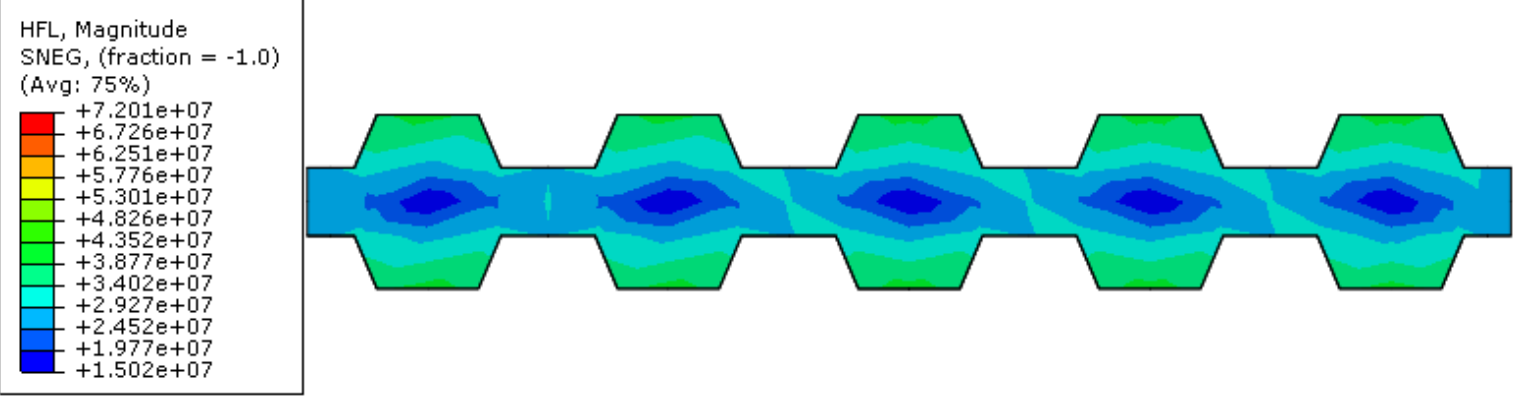

b) 

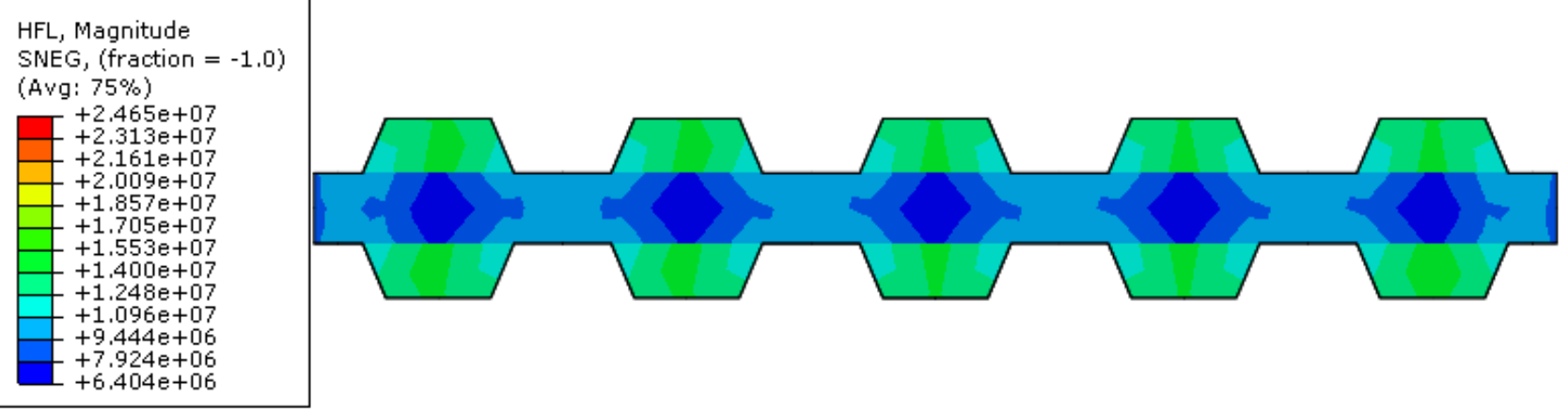

c)

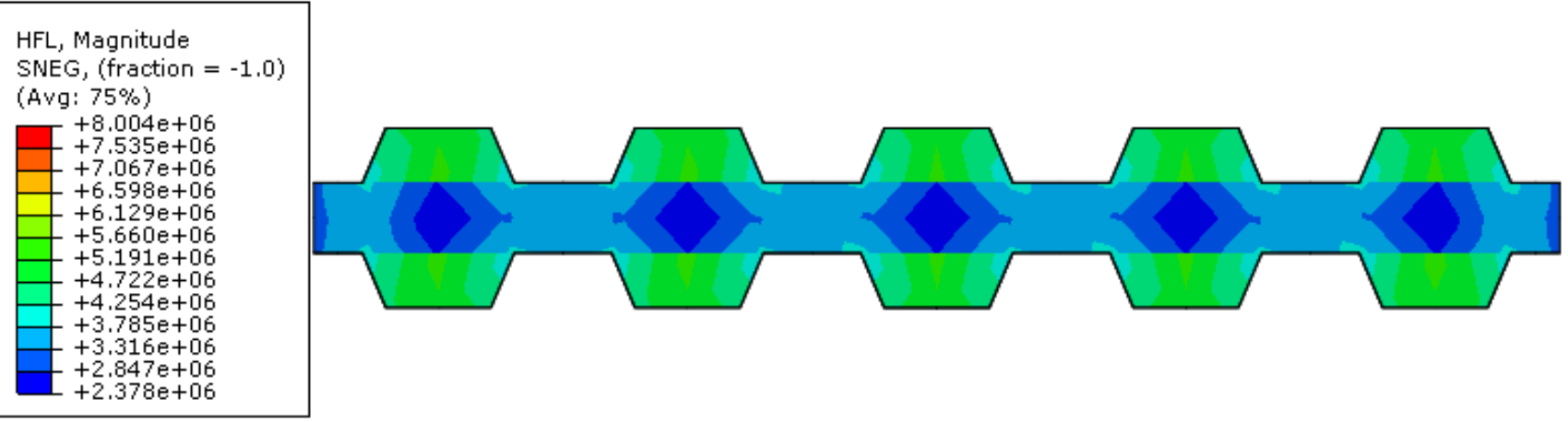

d)

Figure 4.36: Heat flux contours for SCC composite wall after fire exposure time of a) $10 \mathrm{~min}$, b) $30 \mathrm{~min}, \mathrm{c}) 60 \mathrm{~min}$ and d) $120 \mathrm{~min}$
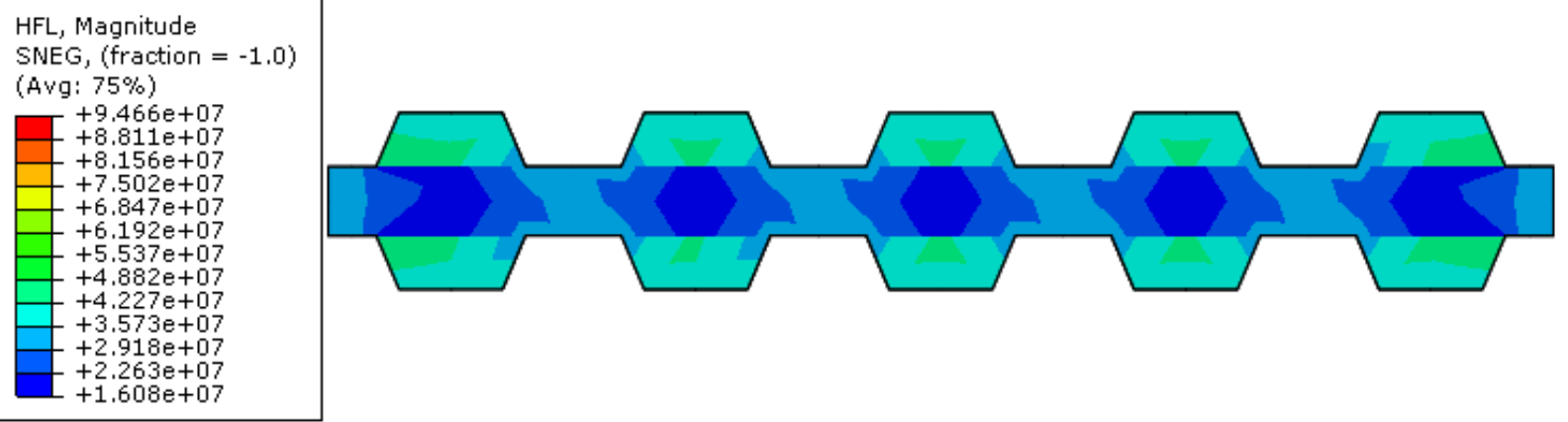

a) 

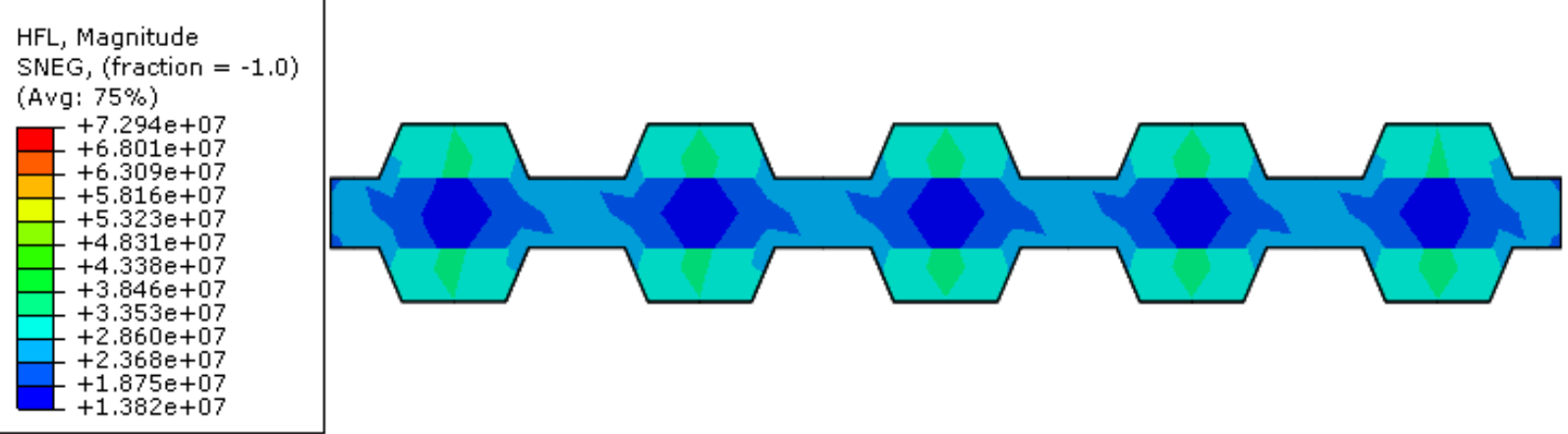

b)

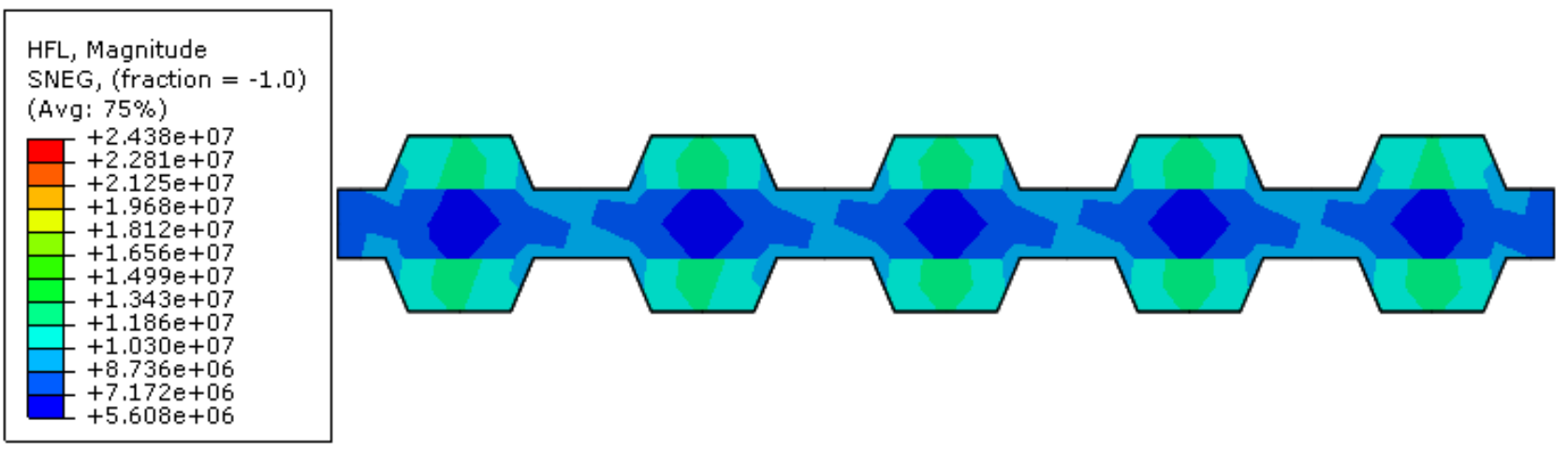

c)
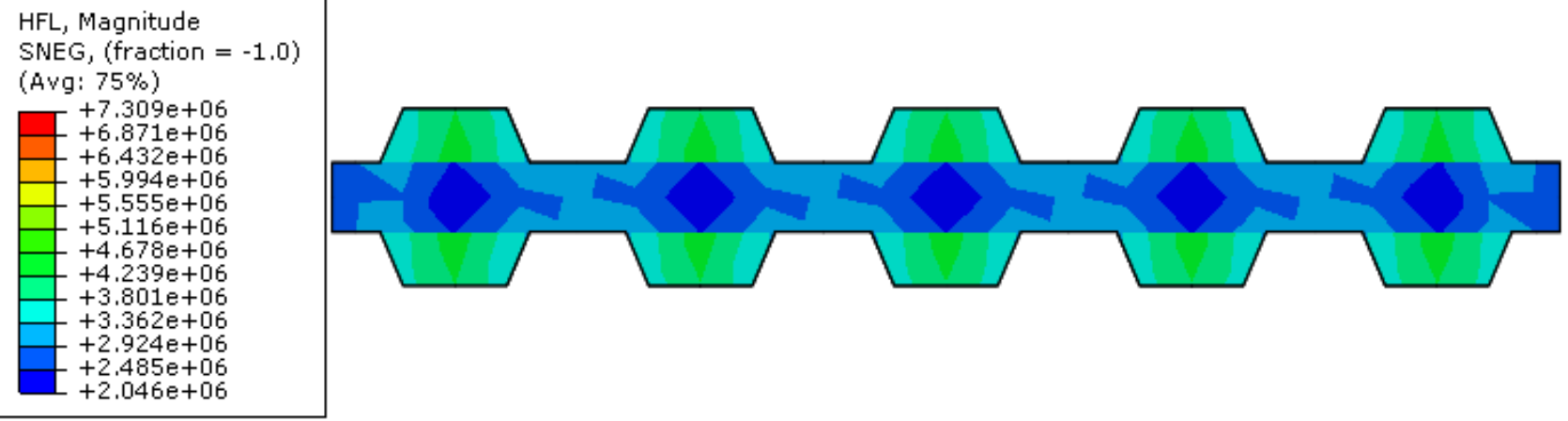

d)

Figure 4.37: Heat flux contours for UHPC composite wall after fire exposure time of a) $10 \mathrm{~min}$, b) $30 \mathrm{~min}$, c) $60 \mathrm{~min}$ and d) $120 \mathrm{~min}$ 

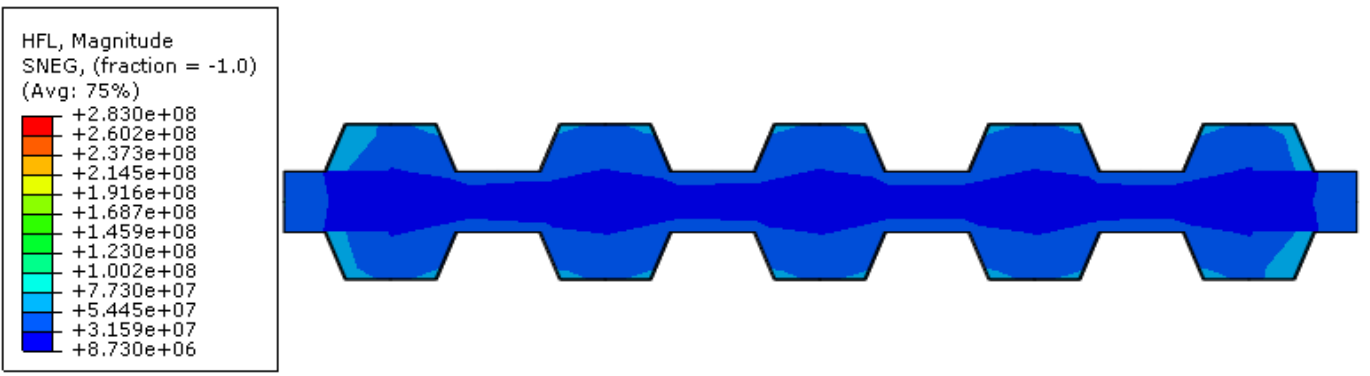

a)
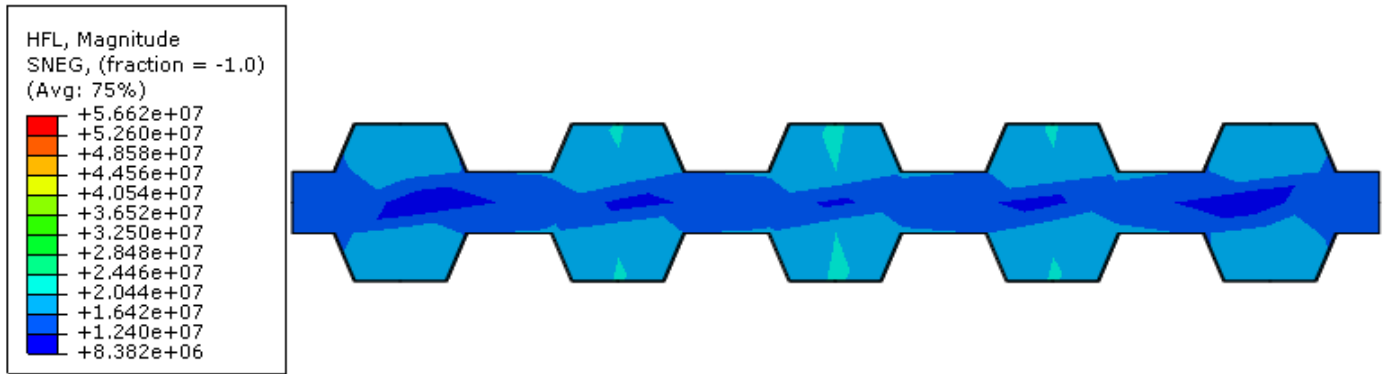

b)

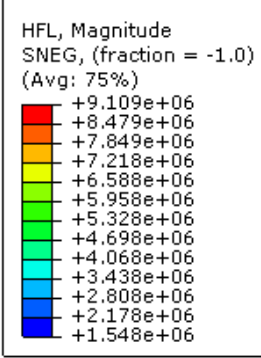

c)
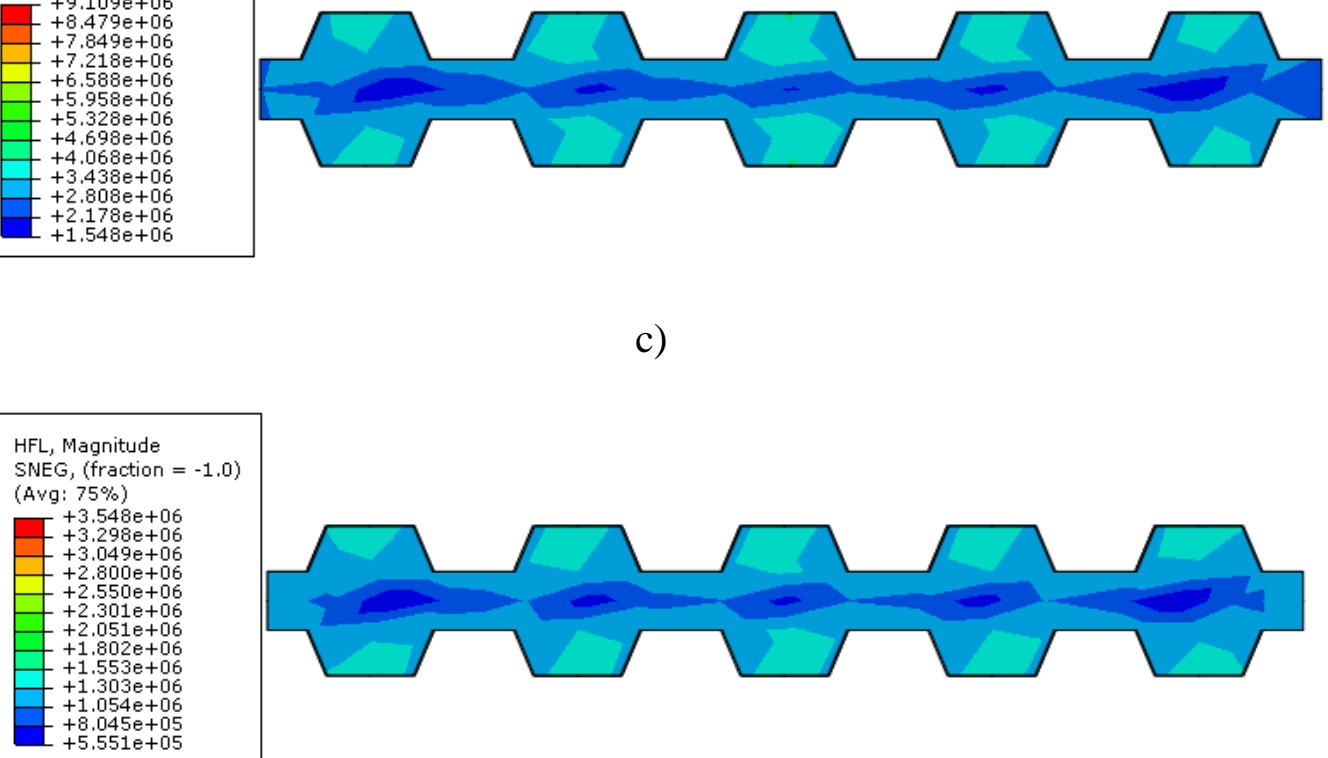

d)

Figure 4.38: Heat flux contours for ECC composite wall after fire exposure time of a) $10 \mathrm{~min}, \mathrm{~b}$ ) $30 \mathrm{~min}$, c) $60 \mathrm{~min}$ and d) $120 \mathrm{~min}$ 
According to Figures 4.30, 4.31 and 4.32, uniform temperature distribution along the steel sheet is observed. As explained earlier, this is to be expected since no acute angle of $90^{\circ}$ currently exists within the profiled structure. As a result, the build-up of temperature is absent and uniform temperature distribution along the steel sheet is observed. In addition, diamond-like isotherms are observed due to the shape of the profiled cross-section. Since the depth of concrete core is small, there is no big resistance to transfer of heat along the cross-section. This increases the temperature of the core of the concrete quite rapidly leading to structural failure. This is illustrated by comparing temperature curves for concrete core of DSCW section and that of a typical CFST column. As shown in Figures 4.13-15, the core temperature of the DSCW section quite closely follows the applied fire temperature with an average temperature difference of $100^{\circ} \mathrm{C}$ (Figure 4.12). A different behaviour is observed for the core temperature of CFST columns (Figure 4.22). This is characterized by the completely different shape in the predicted temperature curve. In this case, a very low rate of change of temperature is observed followed by a rapid increase up to an average temperature of $400^{\circ} \mathrm{C}$ (Figure 4.22).

Figures 4.33-4.35 illustrate the distribution and time dependent curves for heat flux, $Q_{h}\left[\mathrm{~W} / \mathrm{m}^{2} \mathrm{~K}\right]$ of different points along the cross-section. Non-uniform $Q_{h}$ is observed along the steel sheets with high values of $8 \mathrm{e}+6\left[\mathrm{~W} / \mathrm{m}^{2} \mathrm{~K}\right]$ along the interchange between the crest and trough of the profiled sheet. As a result higher change in temperature is observed along the angled part of the profiled wall leading to the formation of the diamond isotherms for temperature distribution. A low average value of $4.2 \mathrm{e}+6\left[\mathrm{~W} / \mathrm{m}^{2} \mathrm{~K}\right]$ for heat flux is observed along the trough of the steel sheet indicating a low change in temperature in the area. The observed behaviour for heat flux does abide by the laws of thermodynamics (Cengal and Boles, 2002) where higher change in heat is observed at acute angle of $45^{\circ}$. This phenomenon is shown Figure 4.39 where higher values of $Q_{h}$ for circular cross-section are observed along the $45^{\circ}$ diagonals. This validates the observed values of $Q_{h}$ for flat and angled surfaces along the profiled wall.

From Figures 4.33-4.35, the peak in heat flux corresponds to highest change in applied temperature. According to the indicated figures, the peak heat flux for SCC, UHPC and ECC occurs in the initial $10 \mathrm{~min}$ of fire exposure. This is to be expected since, the highest change in fire temperature shown in Figures 4.13-4.15 occurs in the early stages within the first 10 min of 
exposure. The post peak decline in heat flux is characterized by the steady state increase in temperature that takes place after the initial exponential increase in fire temperature (ISO-834).
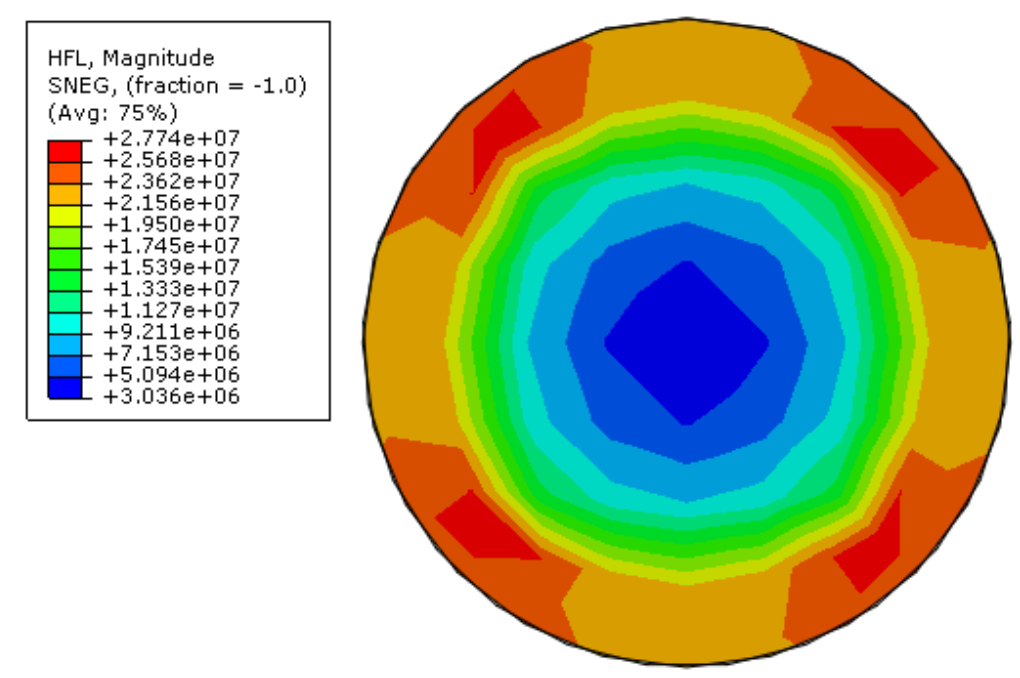

Figure 4.39: Areas of high heat flux occurring on $45^{\circ}$ diagonals in CFST

Figure 4.39 shows the time required for core temperature to reach the surface temperature of ECC, SCC and UHPC double skin composite walls. The surface and core temperatures refer to the temperature curves for point 1 and point 2 locations of a typical composite wall model as shown in Figure 4.11. The value of ' $t_{\text {core }}$ ' (time for core to reach surface temperature) is completely dependent on the thermal properties of the concrete material. In Figure 4.39, the value of " $t_{r}$ " is defined for temperature curves shown in Figure 4.12. Since the ISO-834 fire designated temperature curve as computed by Equation 4.1 is in constant increase, it is theoretically impossible for the surface and core temperature to be similar in value. For this reason, the value of ' $t_{\text {core }}$ ' cannot be determined when using the ISO-834 fire temperature. As a result, determining the value of $t_{\text {core }}$ when exposed to ISO-834 fire temperature is thus omitted. According to Figure 4.39, the highest value of ' $t_{\text {core }}$ ' is observed for the temperature curve of $200^{\circ} \mathrm{C}$. The value of ' $t_{\text {core }}$ ' is proportional to the applied heat energy and peak specific heat values. In fact, the specific heat property of the concrete material acts a resistance to the applied thermal energy. In this case, the thermal temperature of $200^{\circ} \mathrm{C}$ leads to low values of applied thermal energy, which in turn leads a to low thermal energy. As a result, the rate of transfer of heat between elements is low and a high time period is required for the core node to reach the 
temperature of the surface node. When exposed to the $200^{\circ} \mathrm{C}$ temperature curve, it is observedthat ECC has the highest temperature to core with a value of $519.6 \mathrm{~min}$. This is followed by SCC and UHPC encompassing $t_{\text {core }}$ values of 429 and 339 min respectively. In this case, the value of $t_{\text {core }}$ for all three concrete alternatives is directly linked to the specific heat property of each concrete type. According to Figure 4.6, ECC is observed to have the highest specific heat with a value of $10000\left[\mathrm{MJ} / \mathrm{m}^{3} \mathrm{C}\right]$, followed SCC and UHPC with specific heat values of 2100 and $2000\left[\mathrm{MJ} / \mathrm{m}^{3} \mathrm{C}\right]$ respectively. A higher value in specific heat leads to higher thermal resistance which in turn leads to higher values in $t_{c o r e}$ as observed in ECC-based DSCW. At $400^{\circ} \mathrm{C}$ temperature exposure, it is observed that SCC has highest $t_{\text {core }}$ with a value of

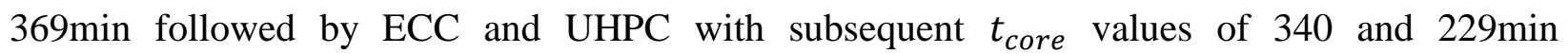
respectively. As discussed, SCC is observed to have the highest $t_{\text {core }}$ due to the high specific heat when compared to ECC and UHPC concrete alternatives. Although UHPC has a higher specific heat than ECC when exposed to $400^{\circ} \mathrm{C}$ temperature curve, it is important to note that the substantially lower thermal conductivity of ECC plays an important role in increasing the thermal resistance of the concrete. This difference in thermal conductivity increases the thermal resistance of ECC beyond that of UHPC, thus leading to higher values in $t_{\text {core }}$. The exact same scenario is observed under the exposure of the 600 and $800^{\circ} \mathrm{C}$ temperature curves. The response of $t_{\text {core }}$ with respect to increasing temperature is fully dependent on the existing interactions between the applied thermal energy, thermal conductivity and the specific heat of the concrete. According to Figure 4.40, a downward trend in the value of $t_{\text {core }}$ with increase in temperature is observed. Such response is to be expected as the increase in thermal energy would speed up the heat transfer, thus leading to a lower period of time for heat to dissipate from the surface to the core of the concrete thus reducing $t_{\text {core }}$ when temperature is increased. This is especially observed in ECC and UHPC where a decreasing trend is observed with increase in temperature. However, since the specific heat of SCC increases with higher temperatures, a higher resistance when exposed to elevated temperature is expected. This is highlighted by the increasing trend in $t_{\text {core }}$ for SCC at elevated temperatures. 


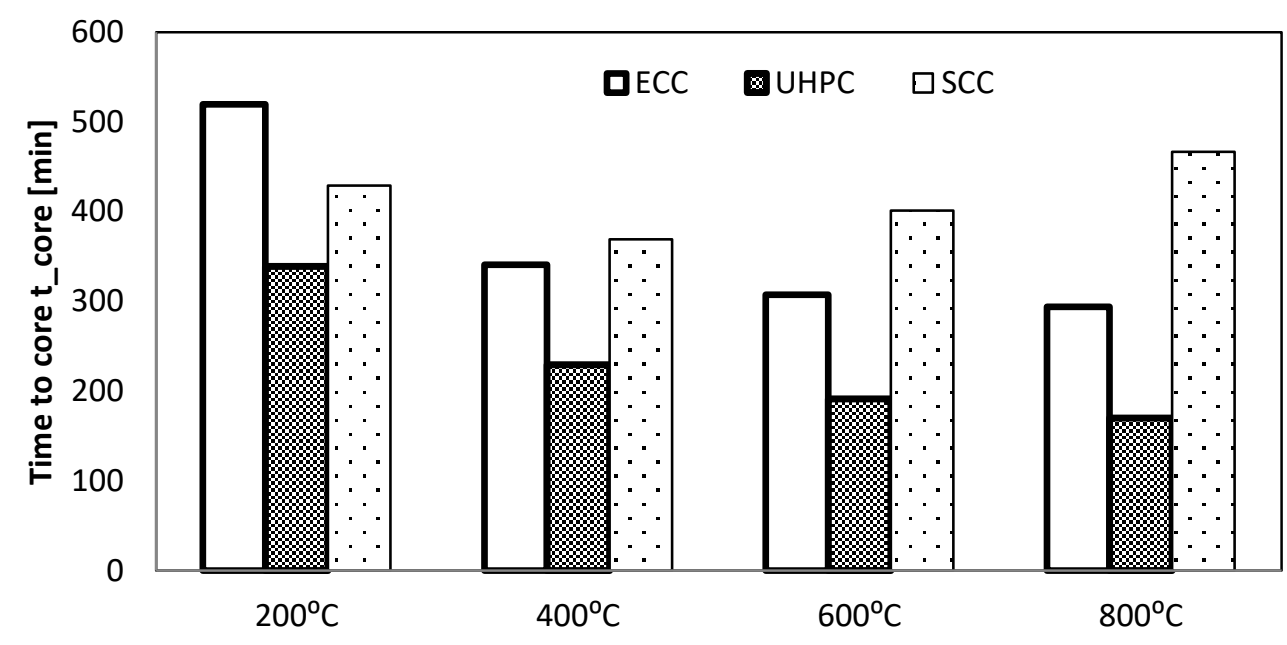

Figure 4.40: Time at which core temperature reaches surface temperature

\subsection{Chapter Summary}

Through use of developed FE models, the heat transfer characteristics of double skin composite wall is obtained. Using the developed thermal model, the temperature distribution at various points on the cross-section are obtained for SCC, ECC and UHPC walls. Due to a lack of data for heat transfer analysis of composite wall, available data on CFST columns is used as means to validate the developed heat transfer models for DSCW. A total of eleven CFST models were generated with alternating concrete in-fill of SCC, UHPC and NSC and cross-sectional shape. The heat transfer model for single and double tubular circle and square cross-sections were developed and compared with the experimental data obtained from extensive literature review. Good agreement between tested and predicted data occurred, emphasizing the ability of the generated model to predict the heat transfer behaviour of composite walls. Upon validation, analysis and discussion of results is then conducted. Temperature fields for time periods of 10min, 30min, 60min and 120min are presented in Figures 4.13, 4.14 and 4.15 for SCC, UHPC and ECC respectively. The profiles for heat flux, $Q_{h}$ for time periods of $10 \mathrm{~min}, 30 \mathrm{~min}, 60 \mathrm{~min}$ and 120min are presented for SCC, UHPC and ECC walls. Based on the results of heat transfer analysis, a sequentially coupled thermo-mechanical analysis is conducted in following Chapter 5 to determine the fire resistance of DSCW when subjected to combined load and temperature. 


\section{CHAPTER 5: Fire Resistance of Double Skin Composite Wall}

\subsection{Introduction}

This chapter describes the development and validation of finite element (FE) model using the commercially available Abaqus ${ }^{\circledR}$ software to simulate the fire resistance of double skin composite walls (DSCWs). Fire resistance is determined through use of deformation vs. time curves resulting from the combined effect of temperature and applied load. The effect of coupling the applied load and temperature on the DSCW system is analysed through use of the fully-coupled or sequentially coupled thermal-mechanical methods (ABAQUS, 2014).

In a fully coupled thermal-mechanical analysis, the thermal and mechanical solutions are strongly dependent on one another (ABAQUS, 2014). The heat generated from inelastic deformations in a mechanical analysis affects the generated solution for thermal analysis, while the thermal stresses resulting from applied temperature will affect the mechanical solution (ABAQUS, 2014). As the heat and load are applied, the gap clearance existing between the steel sheets and concrete core in the DSCW will change. The use of fully coupled thermal-mechanical analysis will capture the change in heat conductance occurring along the steel and concrete contact (ABAQUS, 2014). Although the use of this method does provide accurate results, it is time consuming and might even take days to compute (Ghannam, 2015). Hence, an alternative sequentially coupled thermal-mechanical analysis is used instead to determine the fire resistance of DSCW.

In a sequentially coupled thermal-mechanical analysis, the solution is dependent on the change in temperature with no reverse dependency (ABAQUS, 2014). Such procedure is a combination of a heat transfer and stress analysis. Results of heat transfer analysis are used in the stress analysis though use of predefined fields (ABAQUS, 2014). Although this method is less accurate, it does reduce computation time when compared to the fully coupled approach.

The nodal temperatures are obtained from the heat transfer analysis conducted in Chapter 4 and uploaded into the stress analysis solver. To avoid convergence problems, same meshing configuration defined in Chapter 4 is used in this analysis. In the following section, the material degradation in terms of modulus of elasticity and stress vs. strain curves is defined for carbon 
steel, ultra-high strength/performance concrete (UHPC), self-consolidating concrete (SCC) and engineered cementitious composite (ECC). FE modelling approach is then defined followed by results for fire resistance of DSCW. Finally, discussion and analysis of the results are provided followed by a parametric study with changes in load level, concrete depth, thickness of steel sheets and combination of fasteners.

\subsection{Material Model}

The material models for stress analysis at ambient temperature have already been defined in Chapter 3. This section intends to improve the suggested model by proposing degradation factors to account for the changes due to temperature. The strength of the material deteriorates when exposed to elevated temperature. Deterioration factors are defined for carbon steel, SCC, ECC and UHPC in terms of reductions in modulus of elasticity and stress vs. strain curves. The constitutive model proposed by Eurocode 3 (2005) is used to determine the strength degradation factors for carbon steel when exposed to elevated temperatures. The reduction factors for modulus elasticity and yield strength of steel subjected to elevated temperatures obtained from Eurocode 3 (2005) are summarized in Figure 2.47. Once the proportional limit $F_{p, T}$, yield strength $F_{y, T}$ and elastic modulus $\left(E_{S, T}\right)$ are determined, equations in Table 3.1 can then be used to obtain the stress vs. strain curves at the specified temperatures. Figure 5.1 shows the stress vs. strain curves at temperatures ranging between 20 and $1100^{\circ} \mathrm{C}$.

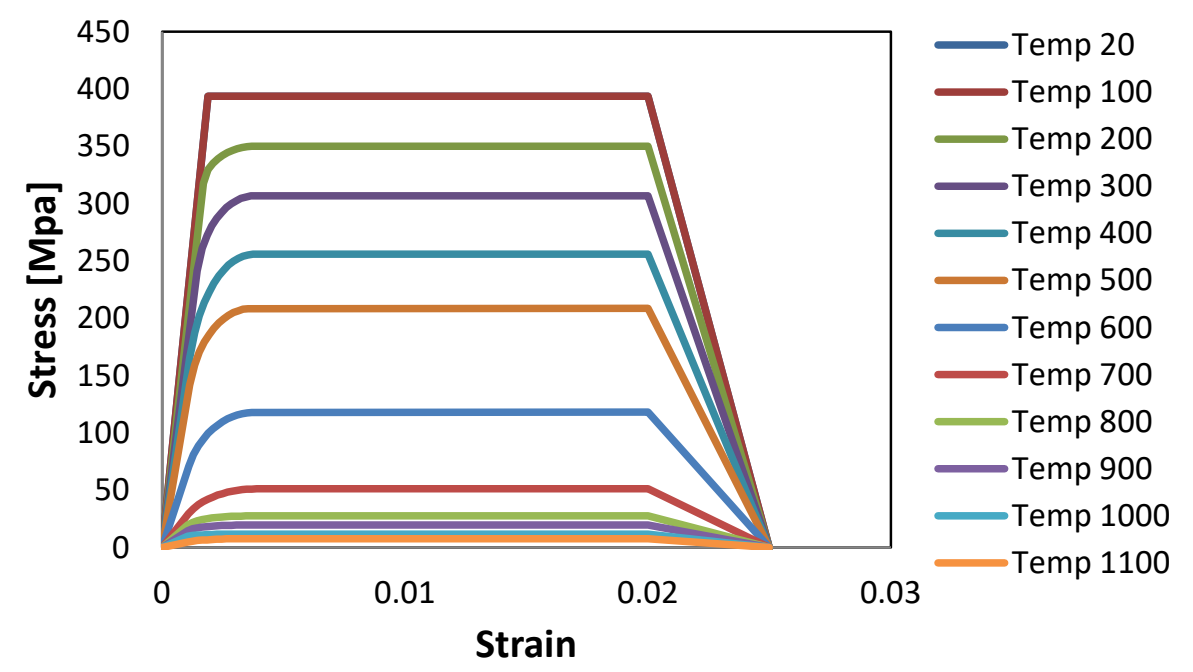

Figure 5.1: Stress vs. strain curves for carbon steel at elevated temperatures 
As indicated earlier, the fire resistance of ECC is approximated through use of available models for NSC. In this case, as discussed in section 2.6.2, the model proposed by Han et al. (2003) is used to determine the strength degradation of NSC when exposed to elevated temperature. In fact, according to the research study conducted by Lu et al. (2009) on the fire resistance of SCC filled CSFT columns, the same model by Han et al. (2003) can be used to determine the strength degradation of SCC. On summary, the proposed model by Han et al. (2003) is used to determine the strength degradation of SCC and ECC studied in this research. As such, Figures 5.2 and 5.3 show the maximum compressive strength of ECC and SCC at elevated temperatures as computed through use of Equation 2.23. Additional Equations 2.24-2.26 are used to generate the remaining components of the stress vs. strain curves.

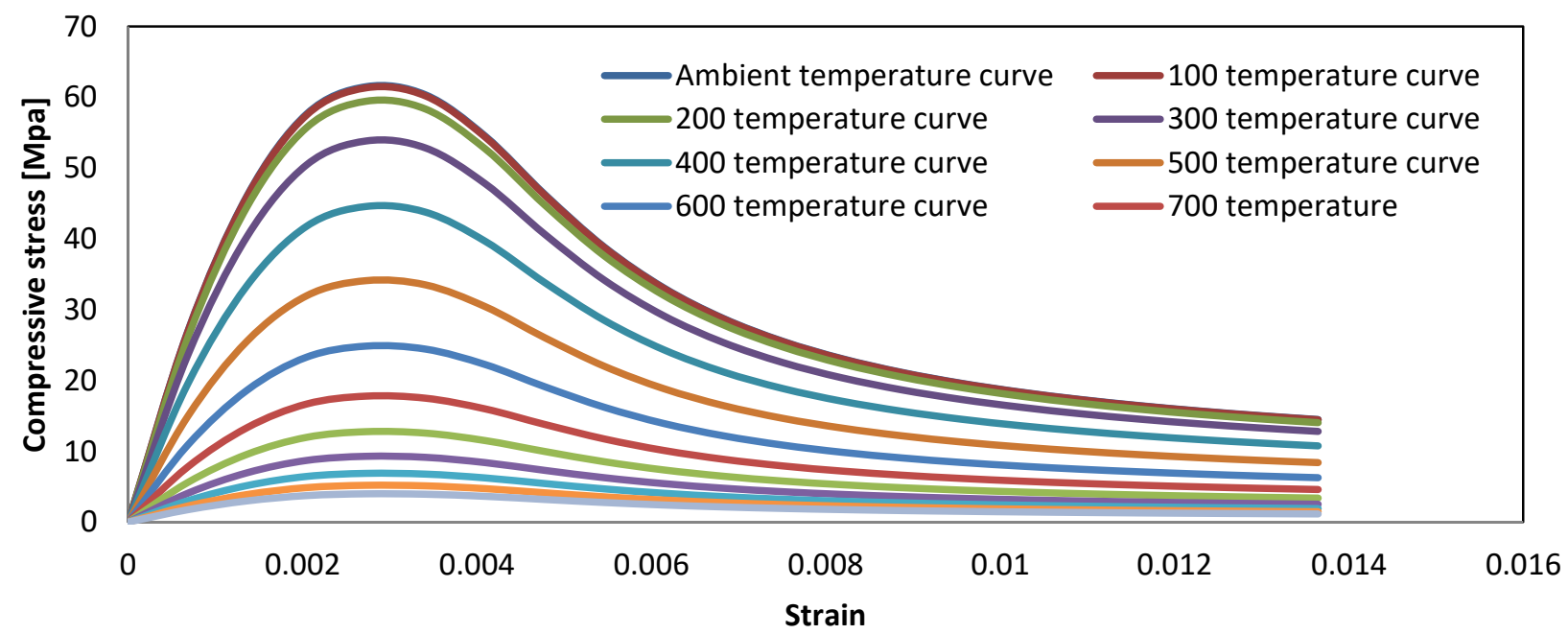

Figure 5.2: Stress vs. strain curves for SCC at elevated temperatures

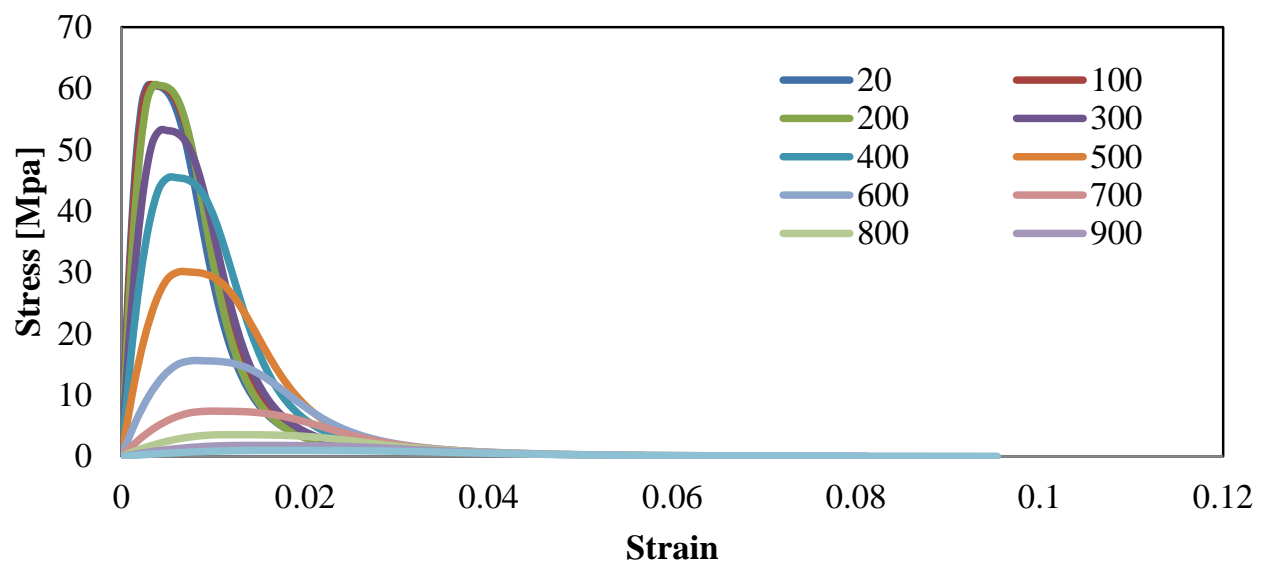

Figure 5.3: Stress vs. strain curves for ECC at elevated temperatures 
The reduction factors for UHPC are discussed in section 2.6.2 with the compressive strength and modulus of elasticity shown in Figure 2.45. Figure 5.4 shows the resulting stress vs. strain curves for UHPC at elevated temepratures.

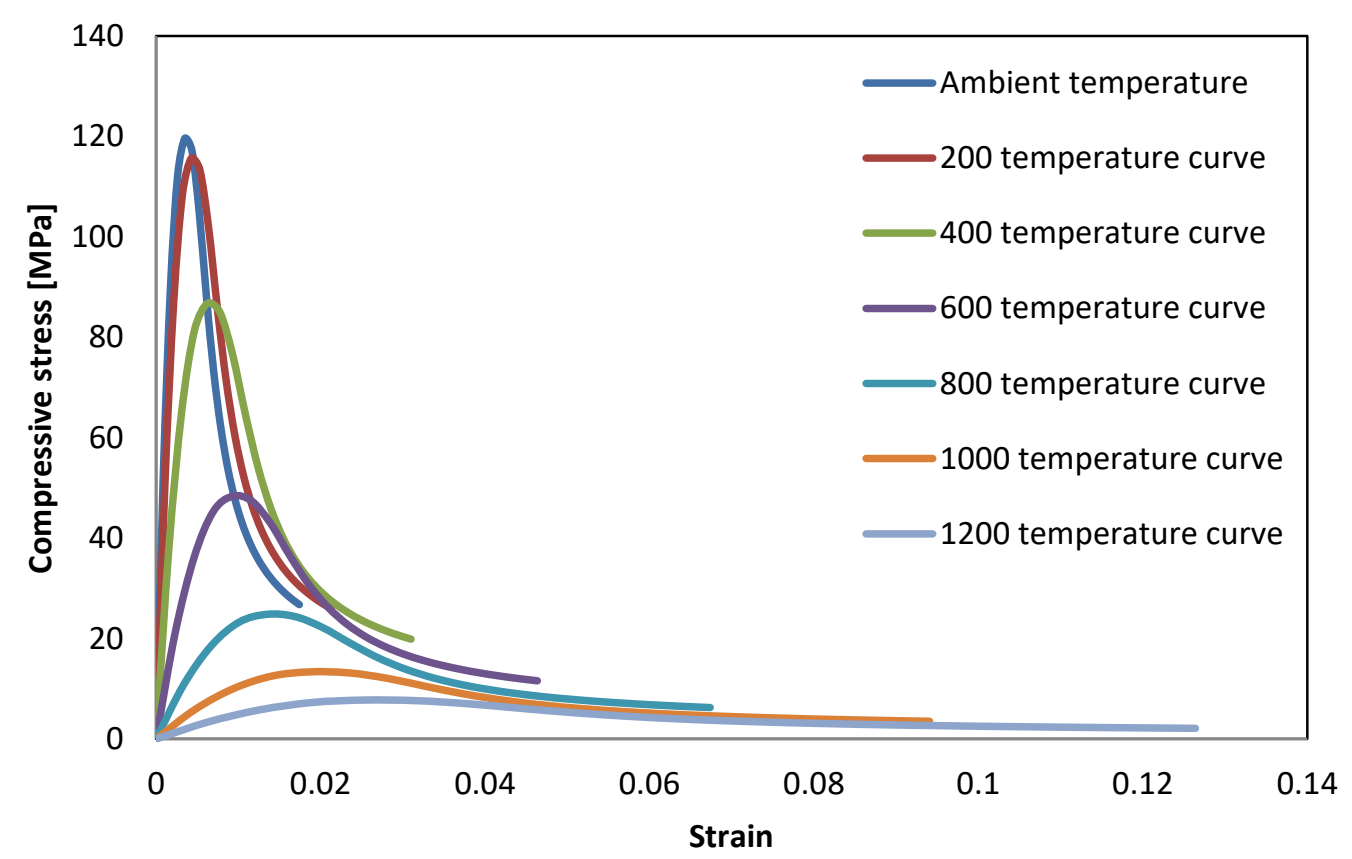

Figure 5.4: Stress vs. strain curves for UHPC at elevated temperatures

As indicated in Chapter 4, facture energy is used to define the tensile strength of concrete in order to avoid potential convergence problems when cracking occurs. To the author's best knowledge, no information is available on the effects of temperature on the fracture energy of concrete. To resolve such limitation, the Eurocode 2 standard assumes a linear relationship between the reduction in tensile strength and fracture energy with respect to temperature (Eurocode 2, 2005). A linear decrease from $100 \%$ at ambient temperature to $10 \%$ at $1000^{\circ} \mathrm{C}$ is assumed to define the change in fracture energy for SCC and UHPC (Lu et al. 2009).

Since the tensile model for ECC is defined through use of stress vs. strain curves, degradation factors shown in Figure 2.46 are used to determine the effects of temperature on tensile stress vs. strain curves for ECC. Figure 5.5 shows the tensile stress vs. strain of ECC when exposed to elevated temperature. 


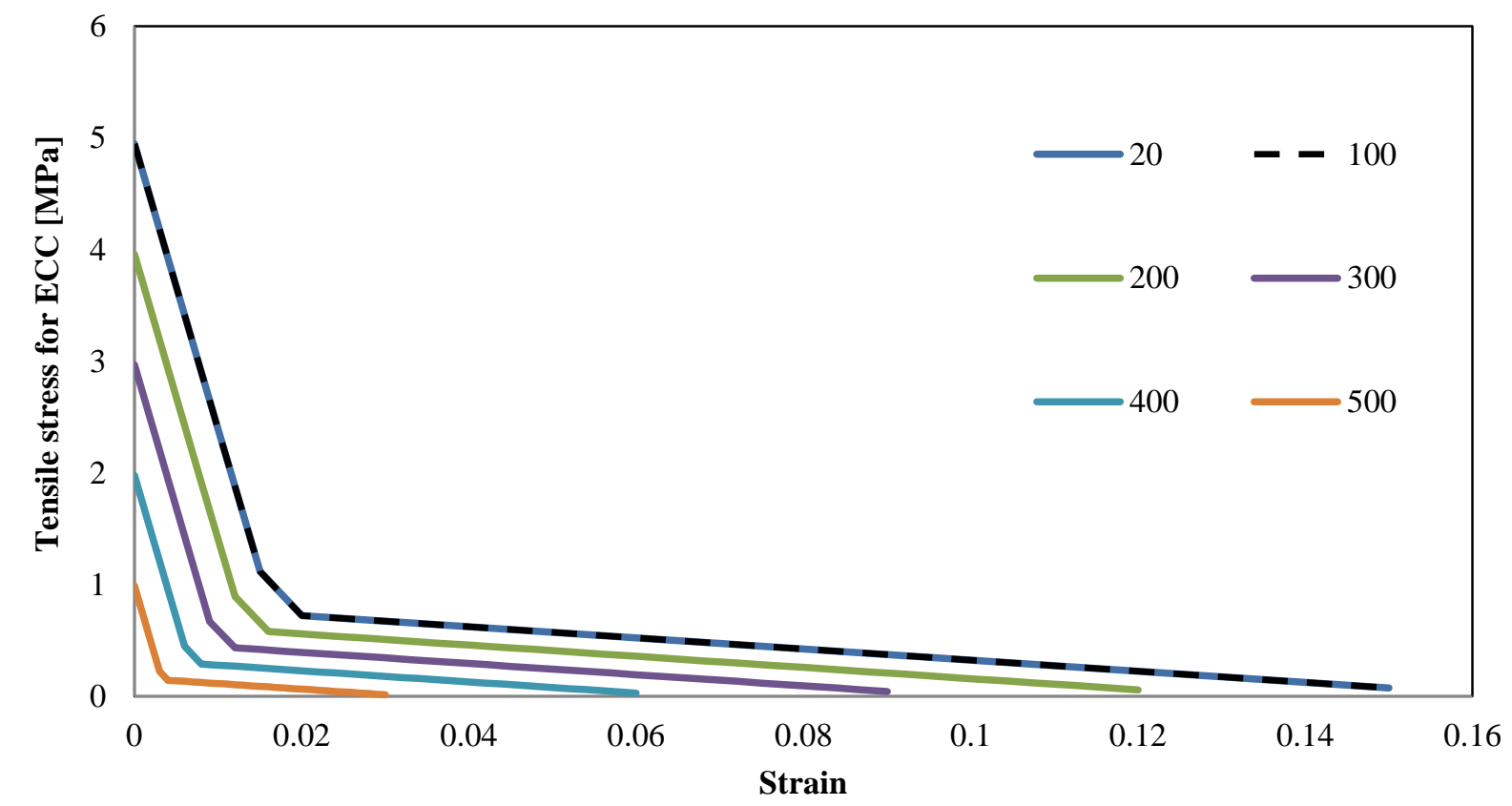

Figure 5.5: Tensile stress vs. strain curves for ECC at elevated temperatures (Eurocode 2, 2005) Poisson's ratio defined in Chapter 3 is maintained throughout the entire temperature range (Lu et al. 2009). The material model provided above is used in conjunction with the one presented in Chapter 3 to fully define the propreties of steel, ECC, SCC and UHPC at elevated temperatures. Generating an assembly for FE model is now nessecary to determine the fire resitance of DSCW. In summury, the material models for steel, ECC, SCC, and UHPC are all composed of mechincal and thermal propreties. The thermal proporeties include the thermal conduction, specific heat and density while the mechanical properties include the stress vs. strain behaviour, modulus of elasticity and thermal expansion factor. The thermal properties are defined in Chapter 4 while the machanical propreties are partly defined in Chapter 3 and in current Chapter 5.

\subsection{Finite Element Model}

The exact assembly and boundary conditions defined for axial compressive model for DSCW in Chapter 3 is used in this section. Figures 3.23 and 3.24 summarize the geometry and assembly of the generated model. A loading plate is used to uniformly apply the load throughout the steel sheets and concrete core. Pin boundary conditions at the bottom and top of the composite wall 
are defined. The top edge is restrained in the $\mathrm{z}$ and $\mathrm{x}$ directions while motion in the $\mathrm{y}$-direction is maintained to allow displacement due to thermal expansion and applied load. Displacements in the $\mathrm{x}, \mathrm{y}$ and $\mathrm{z}$-axes are restrained along the bottom edge of the composite wall. Kinematic coupling is defined between the reference point (RP) of the loading plate and the top edge of the steel sheets (Figure 3.24). Penalty contact interaction is used to define the contact between the loading plate and concrete core where the surface of the concrete is taken as the slave surface (Figure 3.24). Another coupling interaction is also defined for the lower edge of the composite wall (Figure 3.24). As suggested in Chapter 3, general contact with friction coefficient of 0.25 is used to define the interaction between the steel sheets and concrete. Hard and penalty friction interactions are selected to define the tangential and normal behaviour at the interaction.

As discussed earlier, a similar meshing set-up to the one presented in Chapter 3 and 4 is used. The size of the elements of profiled steel sheeting is maintained at $15 \mathrm{~mm}$ throughout the entire part while the size of the elements of the concrete core is maintained at $10 \mathrm{~mm}$. The size of the elements for the loading plate is maintained at $20 \mathrm{~mm}$ throughout the part. Figures 3.26-3.28 show the discretization model for the steel, concrete core and loading plate.

The concrete core is modelled as a solid part using eight-node reduced integration elements (C3D8I elements). Four-node shell elements (S4R elements) were used for the profiled steel sheets. The loading plate is modelled as a 3-dimensional (3D) discrete rigid part using four-node bilinear rigid quadrilateral (R3D4) elements. Summary of the number of elements in each part is shown in Table 3.8. Results of heat transfer analysis conducted in Chapter 4 are uploaded in the current stress model as a temperature predefined field. The heat transfer result file containing the nodal temperature is introduced in the loading step to account for the effects of loading and temperature on the structure. A constant applied load representing $20 \%$ of the ultimate axial compressive strength of the composite wall specimen is applied throughout the entire time of exposure. Although, it does not matter what load is being applied, the values of $20 \%$ is picked to allow the composite wall to experience all phases in terms of structural behaviour. In this case, the choice of a low applied load is expected to allow the expansion of steel and concrete before collapse. This however might not be true if a high value of applied load is picked, as this would result in direct compressive behaviour with no expansion of steel or concrete. In any case, the effect of alternative load level is investigated as parametric study in section 5.7. As a summary, a constant load of 120, 208 and $95 \mathrm{kN}$ representing a 0.2 ratio relative to the ultimate load at 
ambient temperature is applied on SCC, UHPC and ECC-based DSCW models respectively. Results in terms of load vs. deflection curves for SCC, ECC and UHPC composite walls exposed to the various temperature curves shown in Figure 4.12 are presented in the following section.

\subsection{Results of the Sequentially Coupled Analysis}

Fire resistance of the composite wall system is obtained by computing the strength as a function of time of fire exposure (Lie, 1994). Continual exposure to elevated temperature will lead to a gradual reduction in the strength of the wall. Once the strength of the wall becomes lower than the applied load, the wall would no longer be able to withstand the load leading to unstable conditions which in turn results in failure. The time period needed for this condition to occur is referred to as the fire resistance of the double skin composite wall. Load vs. deformation curves are obtained as means to determine the fire resistance of the composite wall. The outlined sequentially coupled procedure is used to generate deformation vs. time curves under various temperature and load parameters. The resulting curves obtained from the FE analysis for ECC, SCC and UHPC walls are presented in this section. Figures 5.6-5.8 show the deflection curves for SCC, UHPC and ECC-based composite wall, respectively. The values of fire resistance of the DSCW when subjected to the varying temperature curves shown in Figure 4.12 are summarized in Table 5.1.

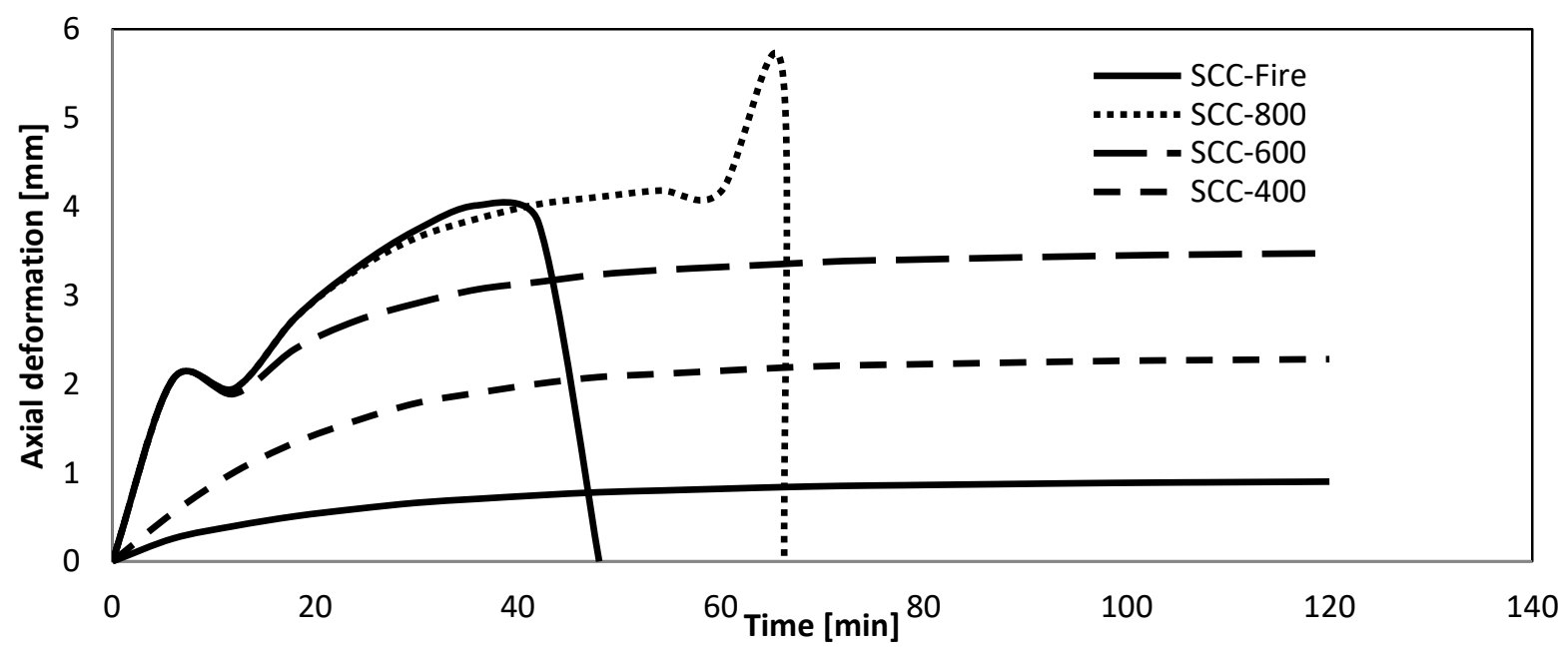

Figure 5.6: Axial deformation as a function of exposure time for SCC composite wall 


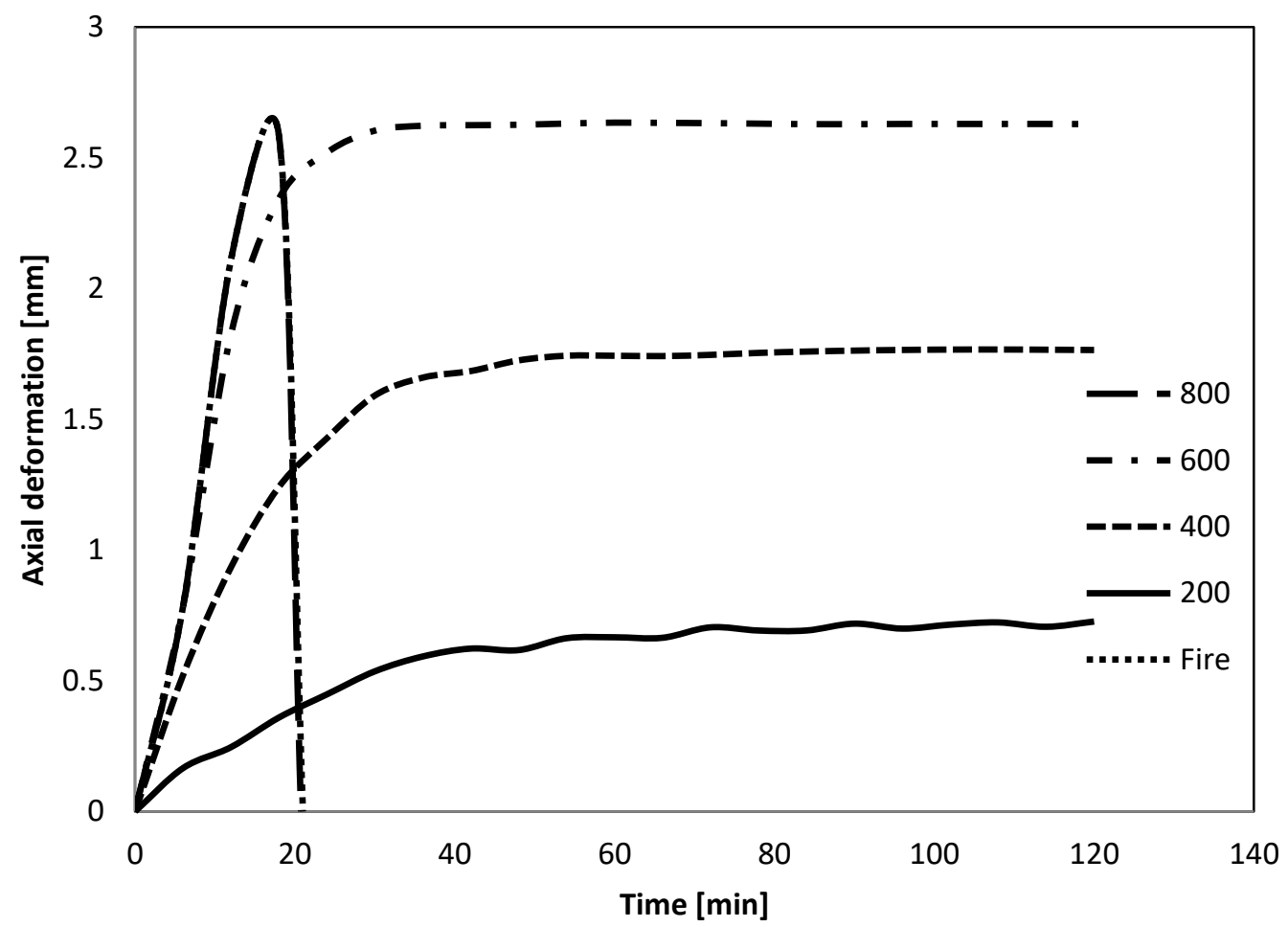

Figure 5.7: Axial deformation as a function of exposure time for UHPC composite wall

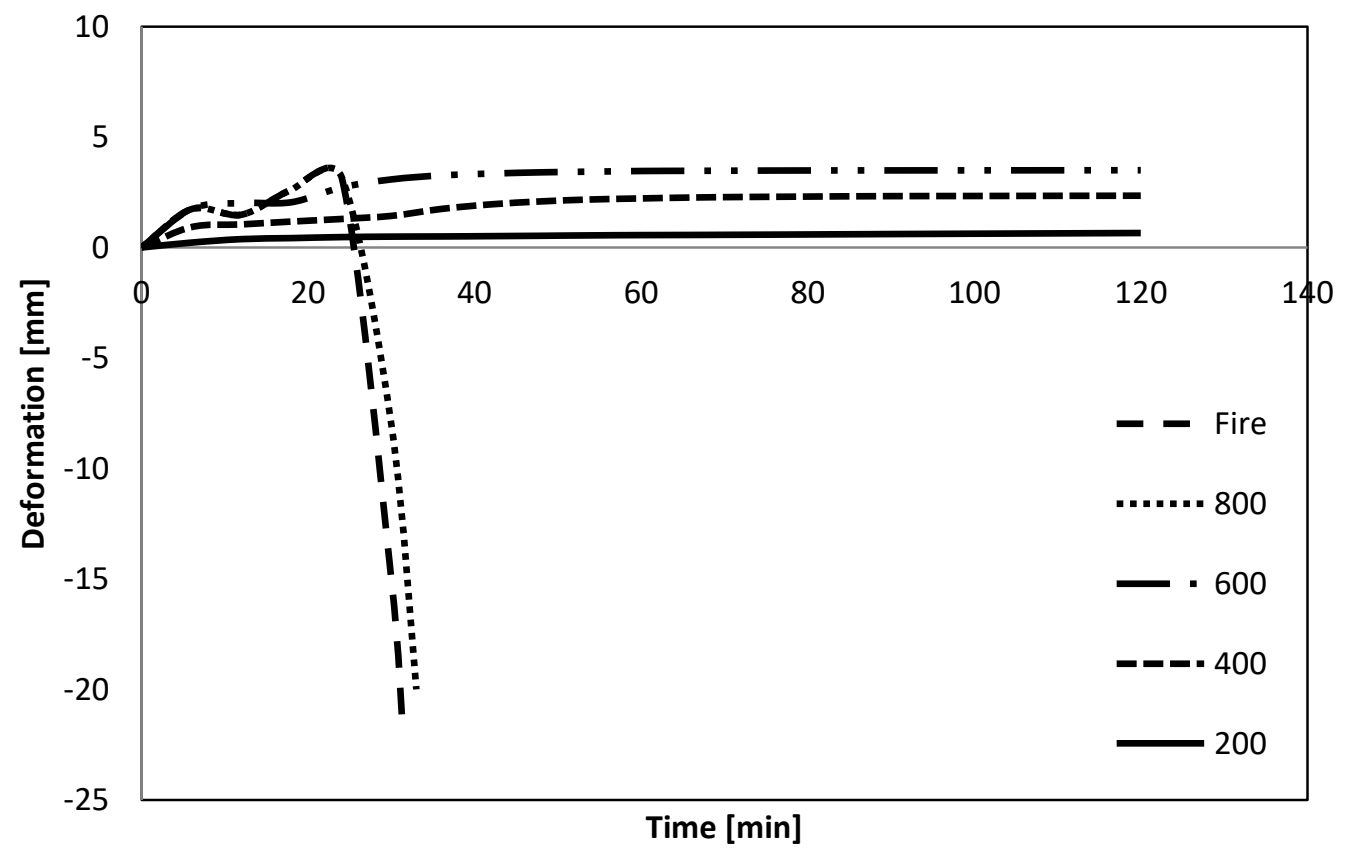

Figure 5.8: Axial deformation as a function of exposure time for ECC composite wall 
Table 5.1: Summary of predicted values for fire resistance

\begin{tabular}{|l|l|l|}
\hline Concrete type & Temperature $\left[{ }^{\circ} \mathrm{C}\right]$ & $\begin{array}{l}\text { Predicted Fire resistance } \\
{[\mathrm{min}]}\end{array}$ \\
\hline SCC & Fire & 48 \\
\hline SCC & 800 & 66 \\
\hline UHPC & Fire & 21 \\
\hline UHPC & 800 & 21 \\
\hline ECC & Fire & 32 \\
\hline ECC & 800 & 33 \\
\hline
\end{tabular}

According to the graphs (Figs. 5.6-5.8), failure due to elevated temperature of SCC, ECC and UHPC composite walls only occurred under the effects of fire and " $800^{\circ} \mathrm{C}$ " temperature curves shown in Figure 4.12. The curves in Figures 5.6-5.8 show no failure for temperature curves below $800^{\circ} \mathrm{C}$. The predicted time period prior to failure for SCC composite wall due to exposure to fire and " $800^{\circ} \mathrm{C}$ " temperature curves defined in Figure 4.12 were noted as 48 and $66 \mathrm{~min}$, respectively. The predicted time period prior to failure of UHPC composite wall for both fire and " $800^{\circ} \mathrm{C}$ " temperature curves were calculated as $21 \mathrm{~min}$. Finally, predicted time period prior to failure of ECC composite for both fire and " $800^{\circ} \mathrm{C}$ " temperature curves were calculated as 32 and $33 \mathrm{~min}$ (Table 5.1). Figures 5.9-5.11 show the stress (S22, Pa) and deformation (U, m) contours for ECC, SCC and UHPC composite wall models specified in direction of applied load (y-direction). Although, the wall is composed of various types of concrete infill, the failure of DSCW models are generally similar. 

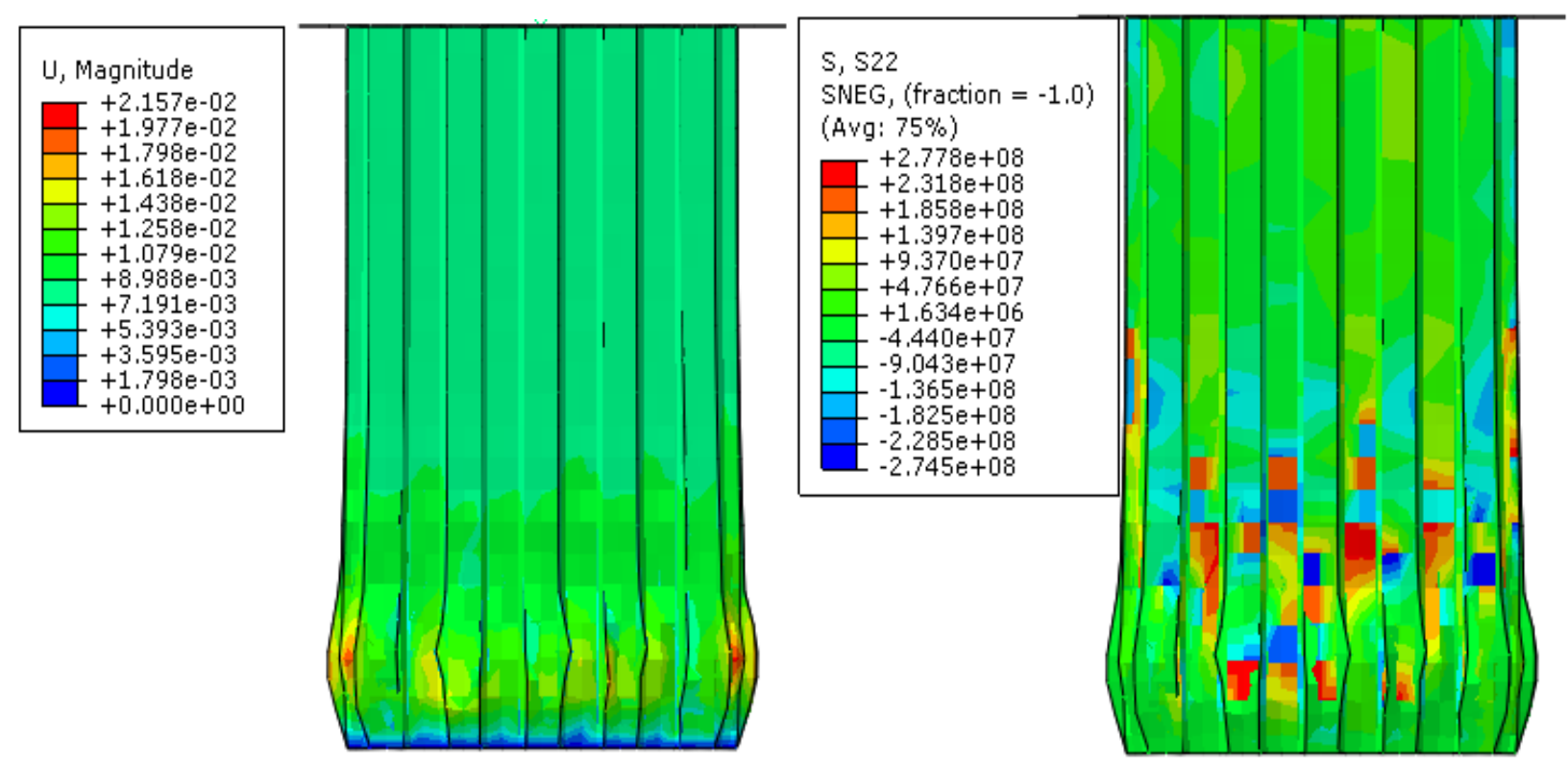

(a)
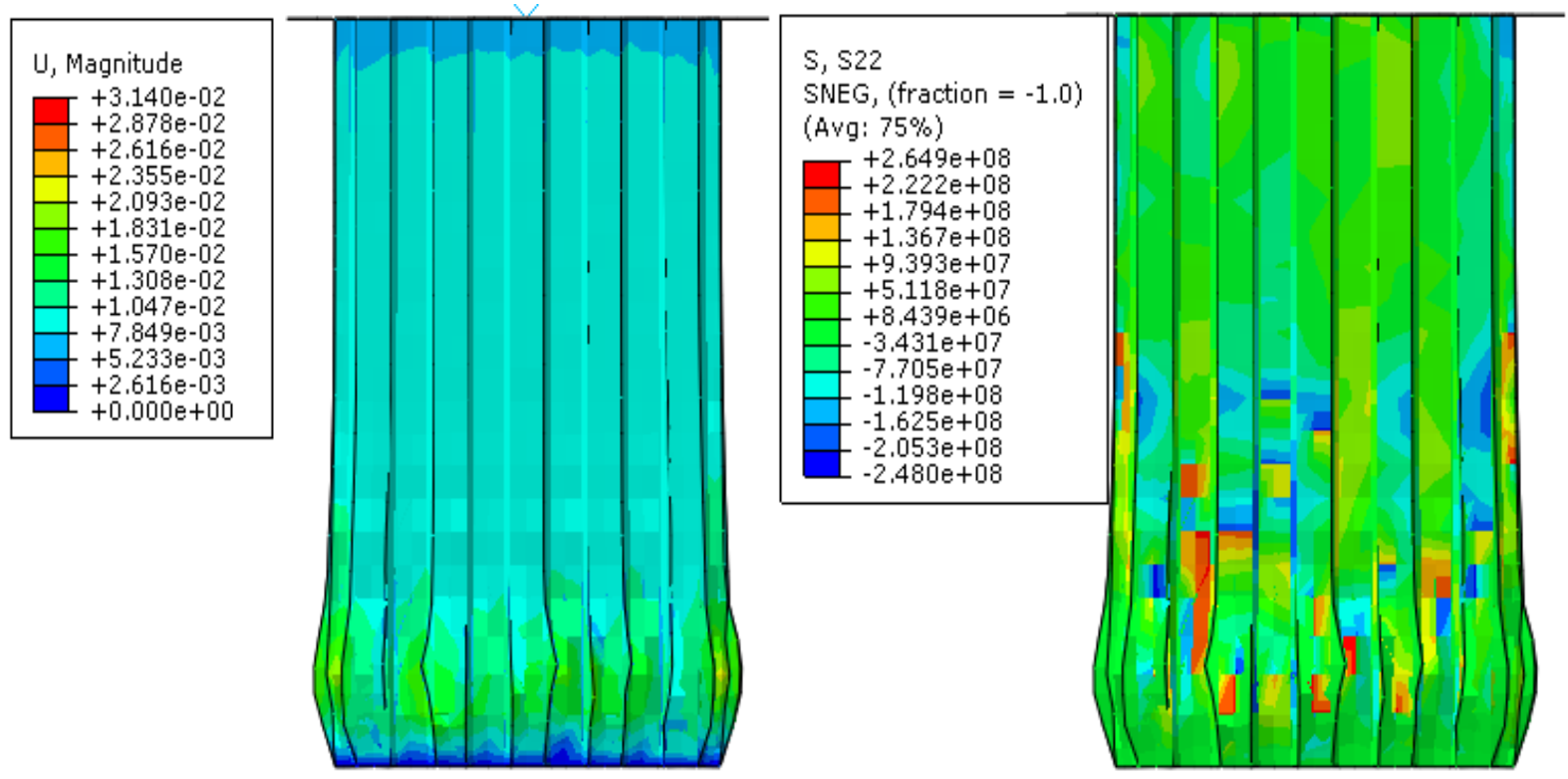

(b)

Figure 5.9: Stress (S22, Pa) and deformation (U, m) contours for ECC composite wall at a) 60 min and b) $120 \mathrm{~min}$ of exposure to $400^{\circ} \mathrm{C}$ temp. curve 

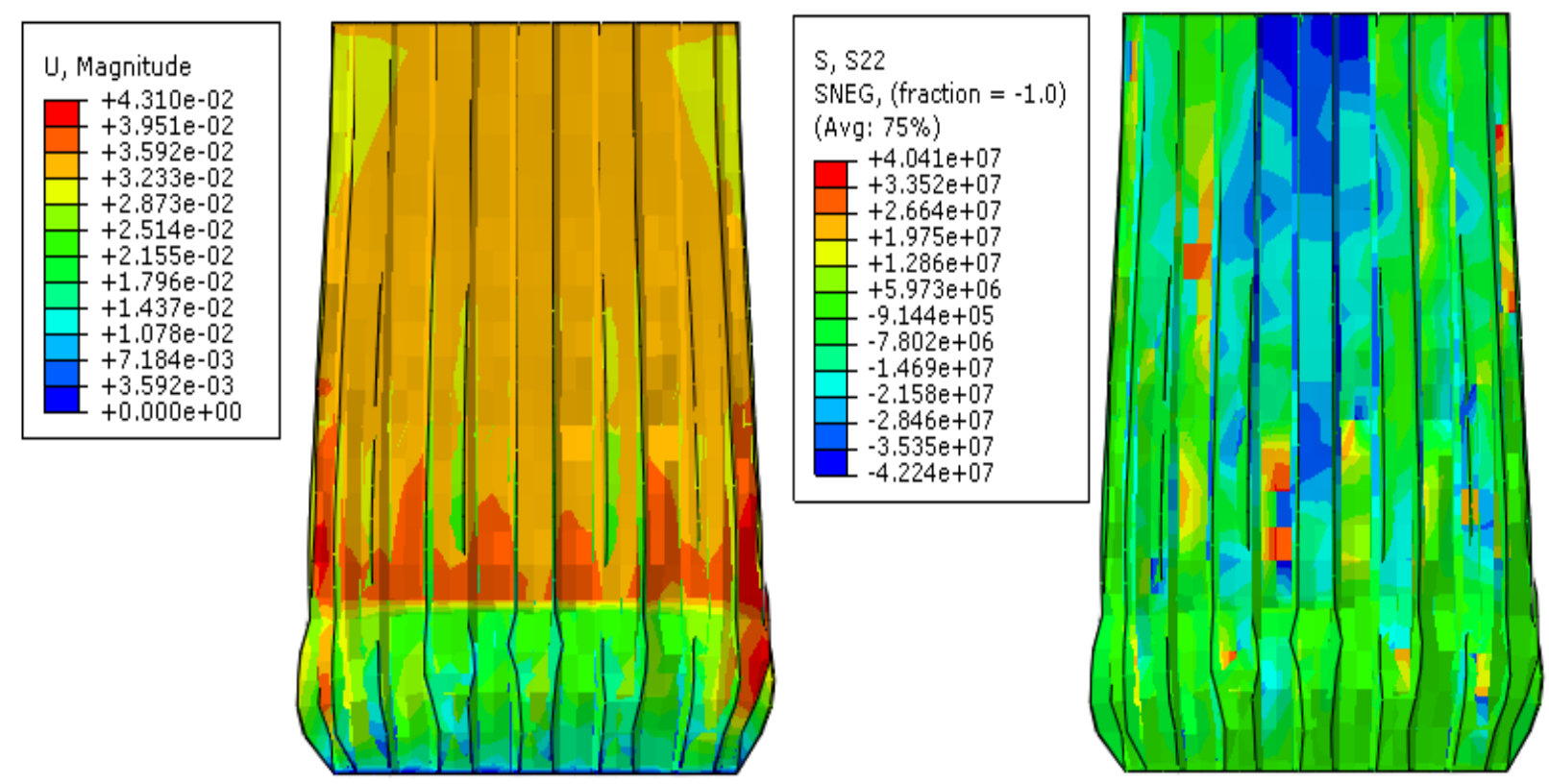

Figure 5.10: Stress (S22, Pa) and deformation (U, m) contours for ECC composite wall at 24 min of exposure to ISO-834 fire temp. curve
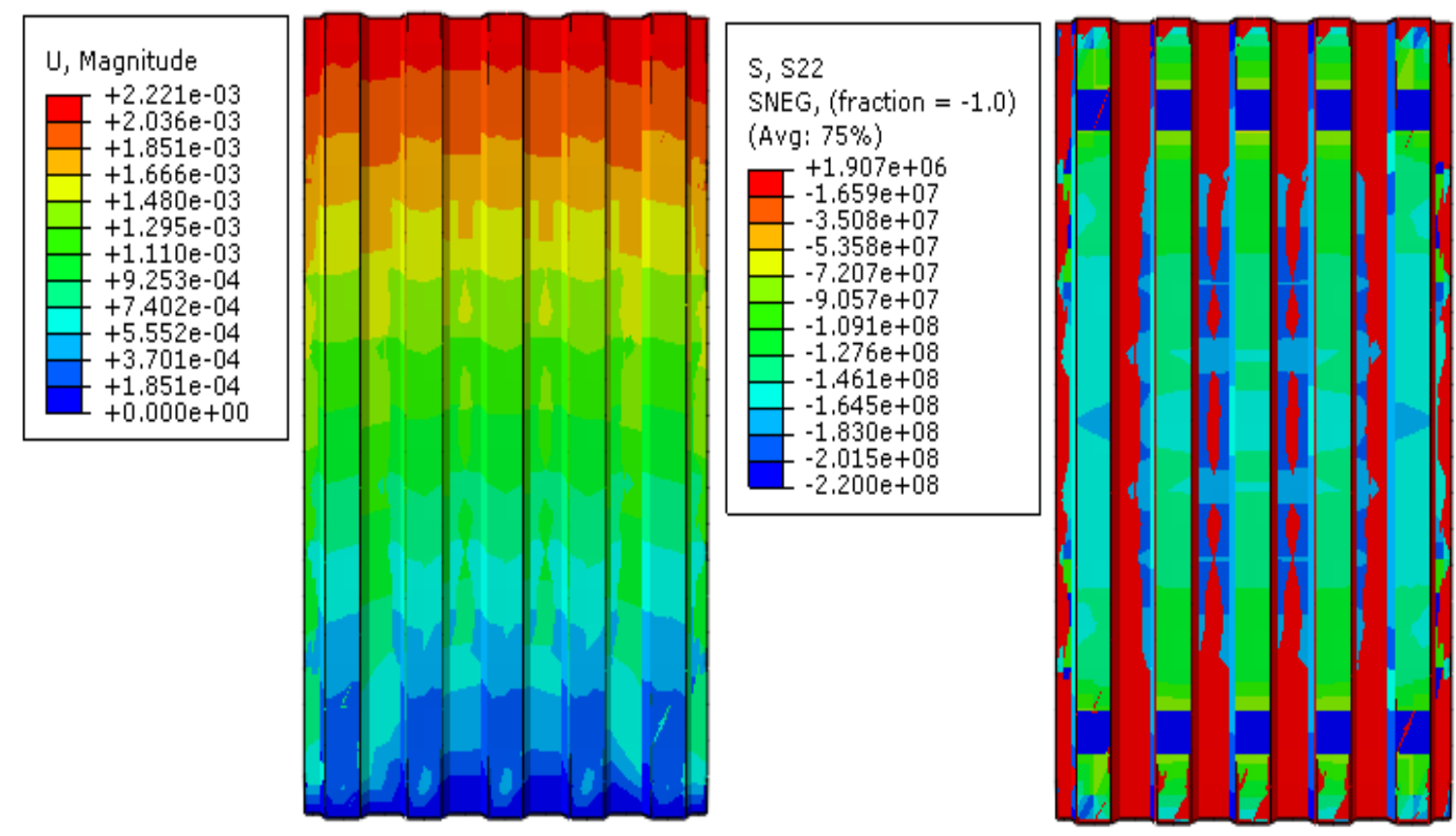

(a) 

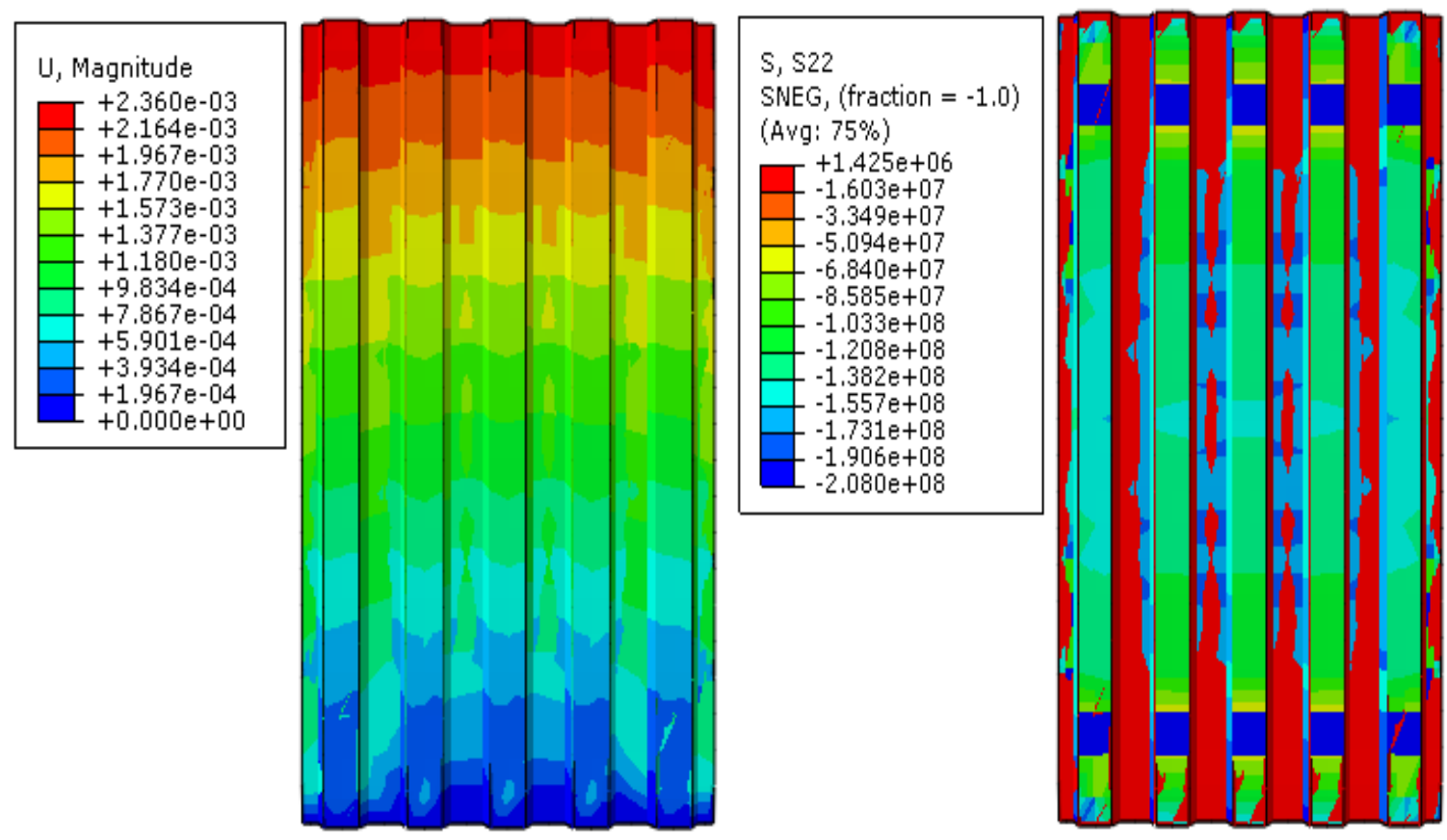

(b)

Figure 5.11: Stress (S22, Pa) and deformation (U, m) contours for SCC composite wall at a) 60 min and b) $120 \mathrm{~min}$ of exposure to $400^{\circ} \mathrm{C}$ temp. curve
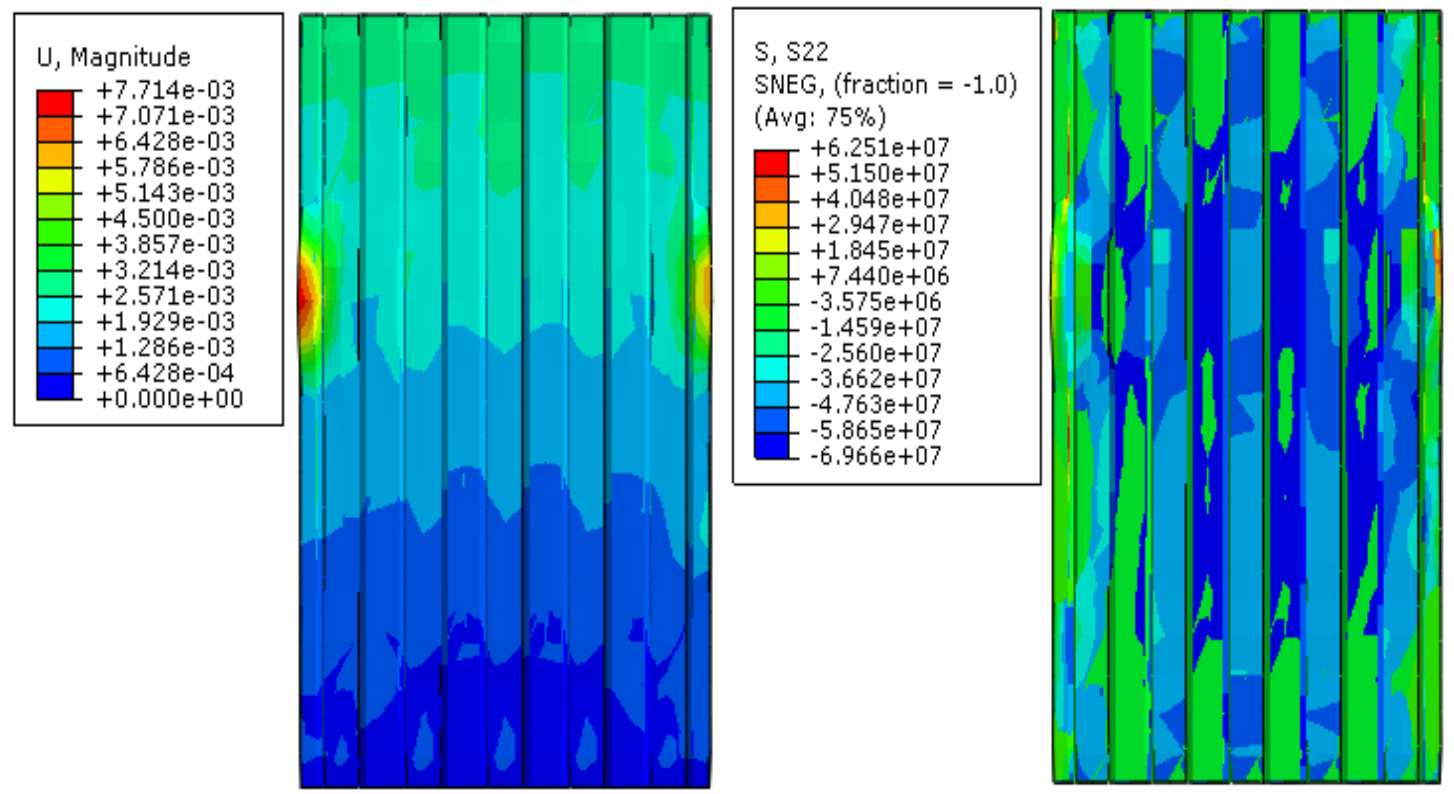

(a) 

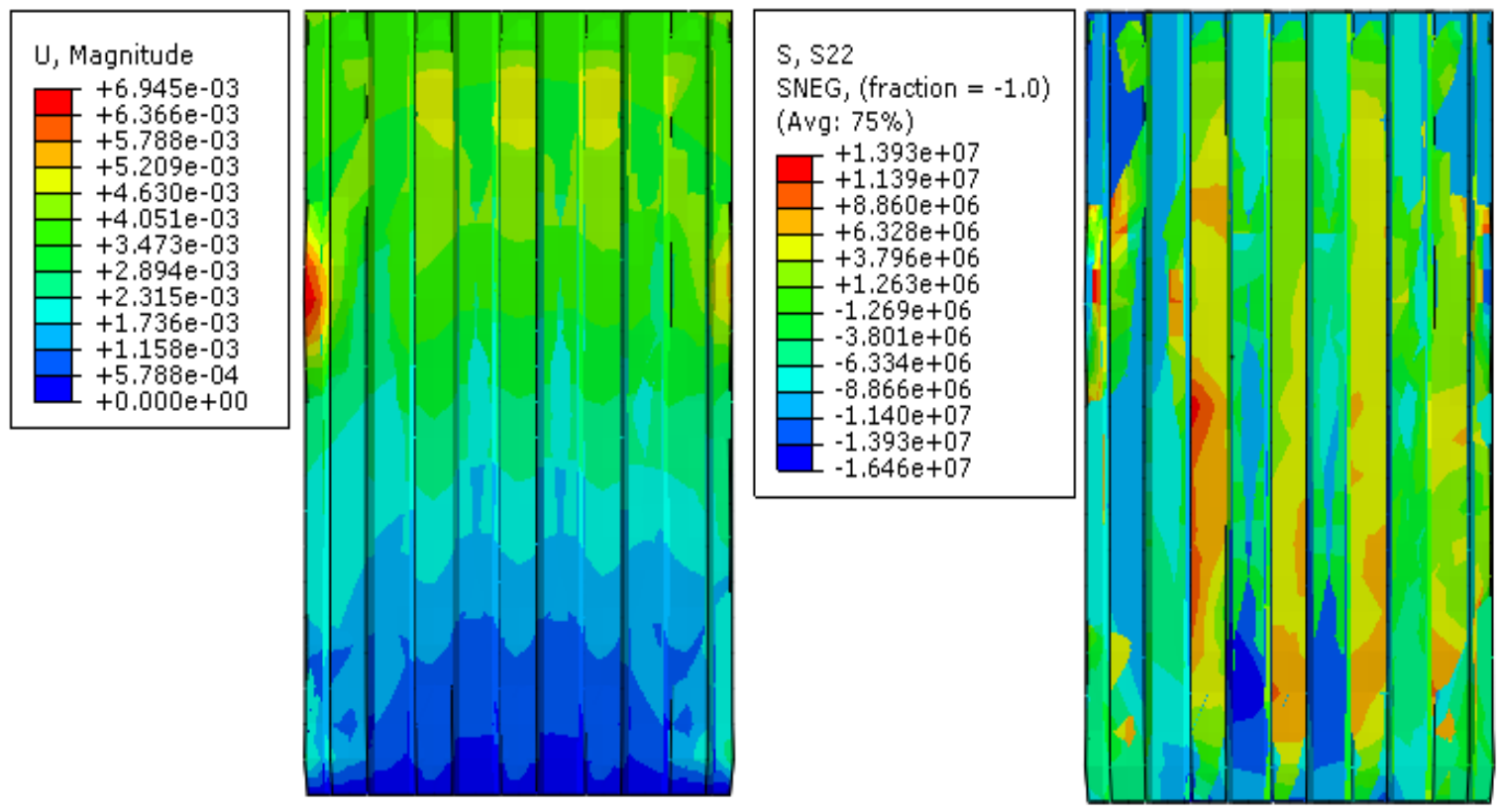

(b)

Figure 5.12: Stress (S22, Pa) and deformation (U, m) contours for SCC composite wall at a) 18 min and b) 42 min of exposure to ISO-834 fire temp. curve

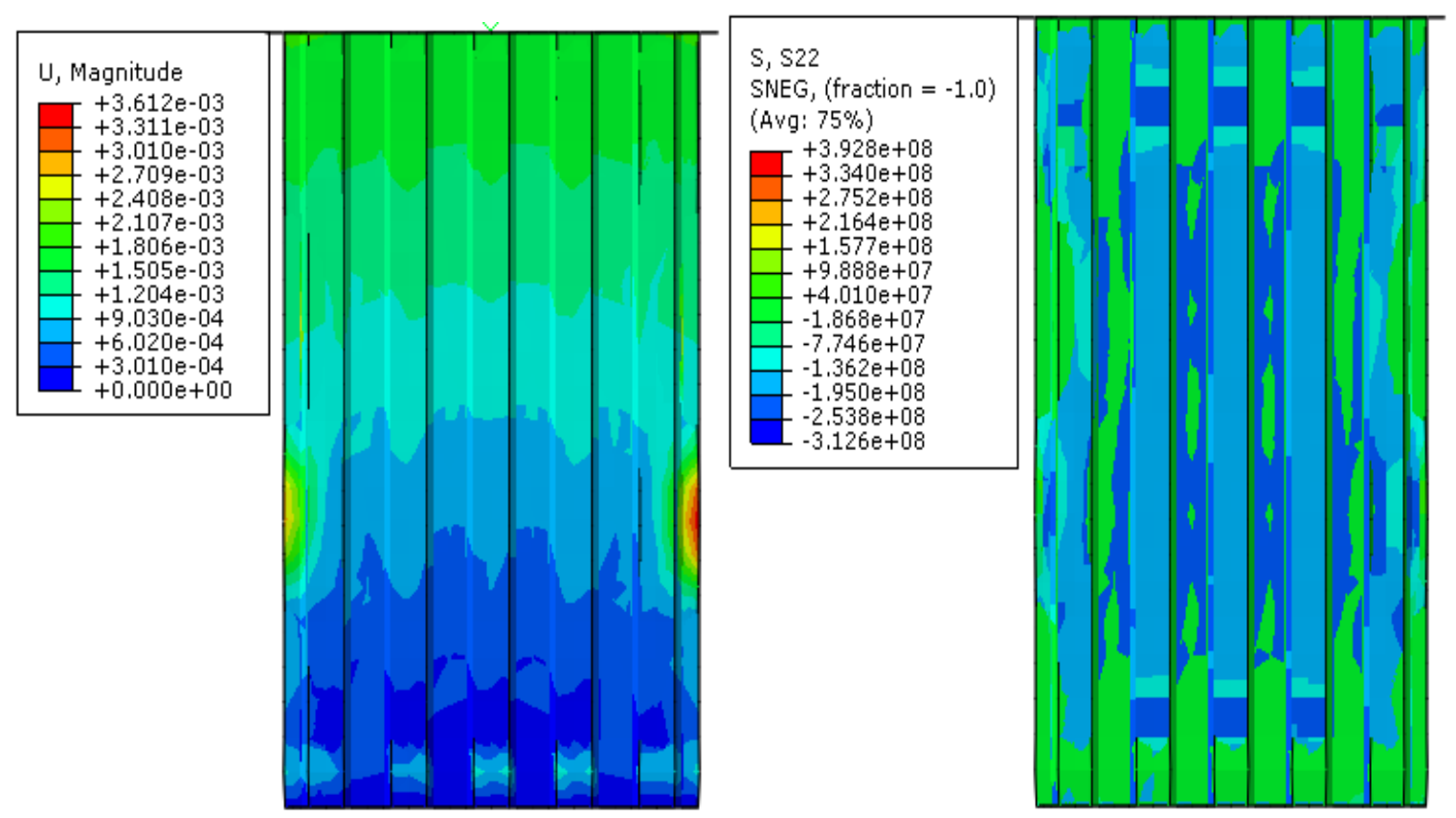

(a) 


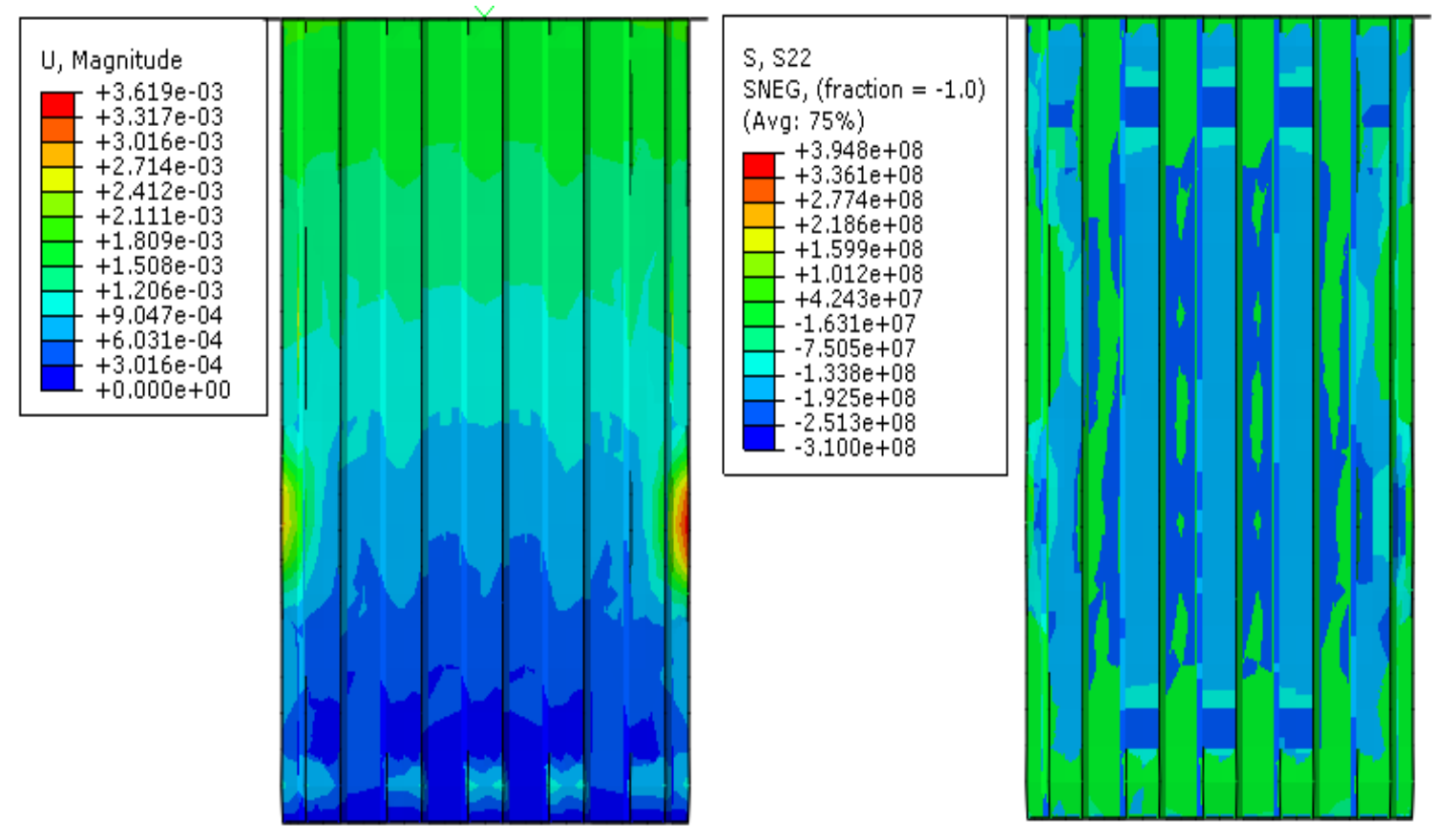

(b)

Figure 5.13: Stress (S22, Pa) and deformation (U, m) contours for UHPC composite wall at a) 60 min and b) 120 min of exposure to $400^{\circ} \mathrm{C}$ temp. curve
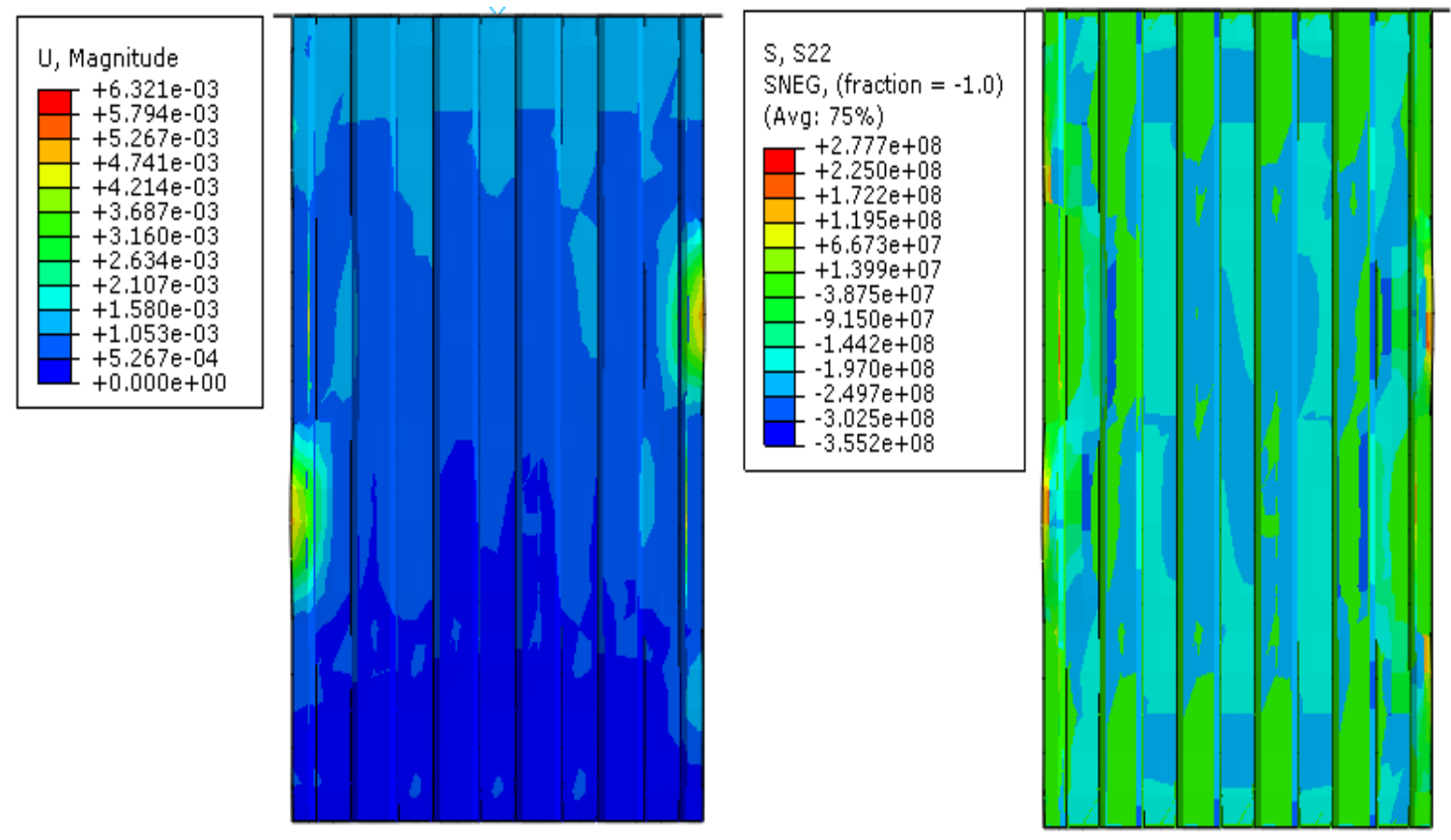

(a) 

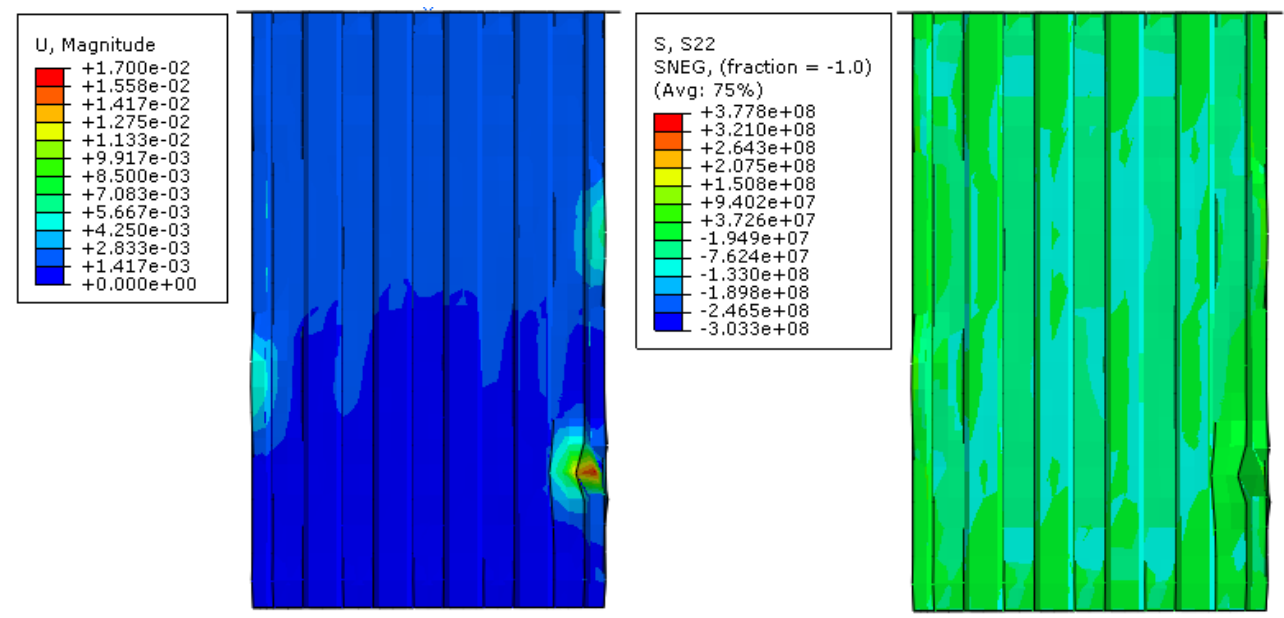

(b)

Figure 5.14: Stress (S22, Pa) and deformation (U, m) contours for UHPC composite wall at (a) $60 \mathrm{~min}$ and b) $120 \mathrm{~min}$ of exposure to $400^{\circ} \mathrm{C}$ temp. curve

Although there is divergence in the failure modes of the DSCW models shown in Figure 5.95.14 , the failure mechanism is generally the same. In this case, failure is caused due to buckling of the steel sheets and crushing of the concrete. Similar failure mechanism is also observed at ambient temperature where concrete crushing and local buckling of the steel sheet is observed between two layers of fasteners.

\subsection{Analysis and Discussion of Results}

Discussion and analysis of results using Figures 5.6 -5.14 are presented in this section. The axial deformation response is summarized into three categories. The typical axial deformation curves associated to each observed category are shown in Figures 5.15-5.18.

Figure 5.15 shows the axial deformation response leading to failure of the composite wall due to exposure to elevated temperature. Such response is observed when the ECC, SCC and UHPC composite walls are exposed to $800^{\circ} \mathrm{C}$ and fire temperature curves as shown in Figures 5.6-5.8. In this case, the axial behaviour is characterized by a high initial rate of increase in positive axial deformation due to rapid expansion of steel. This behaviour is referred to as "stage 1" in Figure 5.15. Once the steel sheets are no longer able to withstand the applied compressive load, 
compression in the steel sheets occurs. This is referred to as "stage 2" in Figure 5.15 indicating that the applied load is transferred from the steel sheets to the concrete core. Stage 3 initiates when the applied load is fully carried by the concrete core. The axial behaviour at the onset of stage 3 is fully dependant on the value of the applied load. Should the applied load be higher than the force resulting from the thermal expansion of the concrete, compression occurs in the composite wall system leading to a decrease in the axial deformation vs. time curve. However, if the applied load is lower than the force resulting from the thermal expansion of concrete, a rise in axial deformation is observed. It is quite difficult to quantify the force generated by the expansion of steel and concrete however, such phenomenon is clearly observed in Figure 5.6 in the "Fire" and "800" temperature curves where a dink is followed by an upward trend in the axial deformation after reaching the onset of stage 2. This upward trend is caused by the expansion of concrete being able to withstand the applied force. In fact, such behaviour of additional expansion of concrete is observed for SCC and ECC composite wall models. This is to be expected since only $20 \%$ of the ultimate compressive load of the DSCW is applied for both SCC and ECC models. Due to the continual exposure to elevated temperature, the strength of the concrete will the gradually reduce until failure occurs. Failure of the composite wall is referred to as "stage 4" in Figure 5.15.

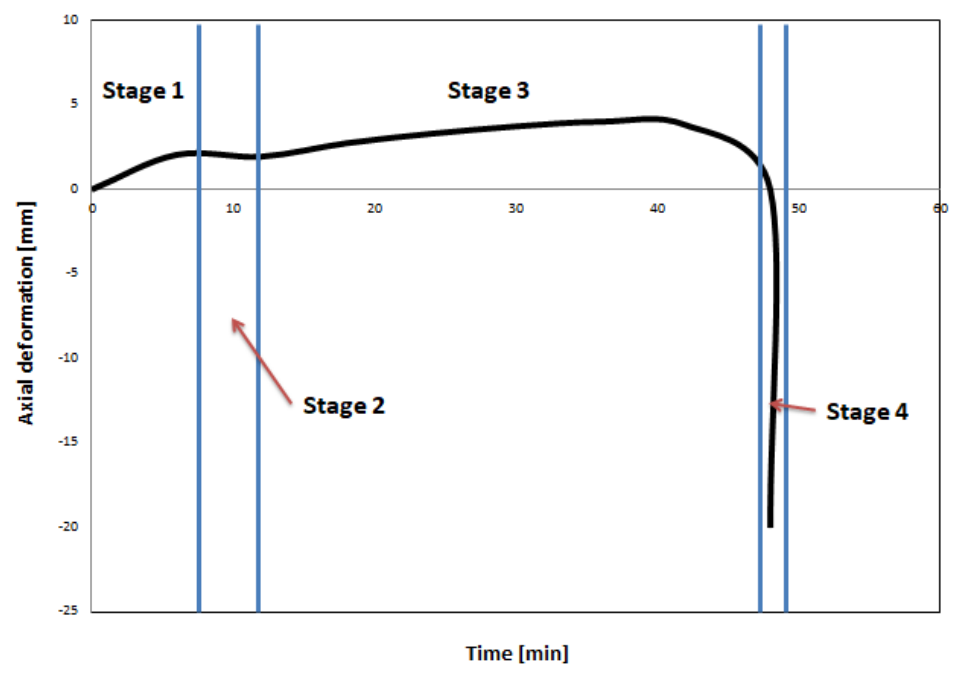

Figure 5.15: Axial deformation vs. time response for category 1

The second category of observed axial deformation response is summarized in Figure 5.16. A total of three stages are shown in the figure. Similar to the first category, stage 1 of the response 
curve includes the expansion of steel sheets until such component is no longer able to withstand the applied load due to strength degradation caused by the temperature of exposure. Failure of the steel leads to a downward kink the graph as shown in Figure 5.16 marking the initiation of stage 2 of the response curve. This kink occurs due to the high expansion coefficient of steel when compared to concrete. As indicated in section 2.6.2, the expansion coefficient of steel is around $1.2 \mathrm{e}-5 \mathrm{~m} / \mathrm{m}$ while the expansion of concrete is around $6.6 \mathrm{e}-6 \mathrm{~m} / \mathrm{m}$ which in turn suggests that steel will expand at a faster rate than concrete. The kink is caused by the difference in the amount of expansion of both components when the steel sheets fail. Stage 3 of the response curve begins when the full applied load is carried by the concrete core. In this category, the DSCW model does not fail, as such the concrete core is able to withstand the constant applied load. The sharp increase in the axial deformation at the beginning of stage 3 occurs as a result of the expansion coefficient and low average temperature of the concrete core. As time goes on, the average temperature of the concrete core increases leading to a loss in strength characterized by the strength degradation factors shown in section 2.6.2. As concrete loses strength, its ability to withstand the applied load decreases leading to the flattened axial deformation vs. temperature curve when nearing the end of stage 3. Although the concrete core is subjected to reduction factors, the temperature in the concrete is not high enough to cause failure. Such behaviour was observed in SCC and ECC composite wall models when exposed to the $600^{\circ} \mathrm{C}$ temperature curve defined in Figures 5.6 and 5.8, respectively. Such response is not observed in UHPC (Figure 5.7) because the expansion of the steel is not able to overcome the applied force of $208 \mathrm{kN}$.

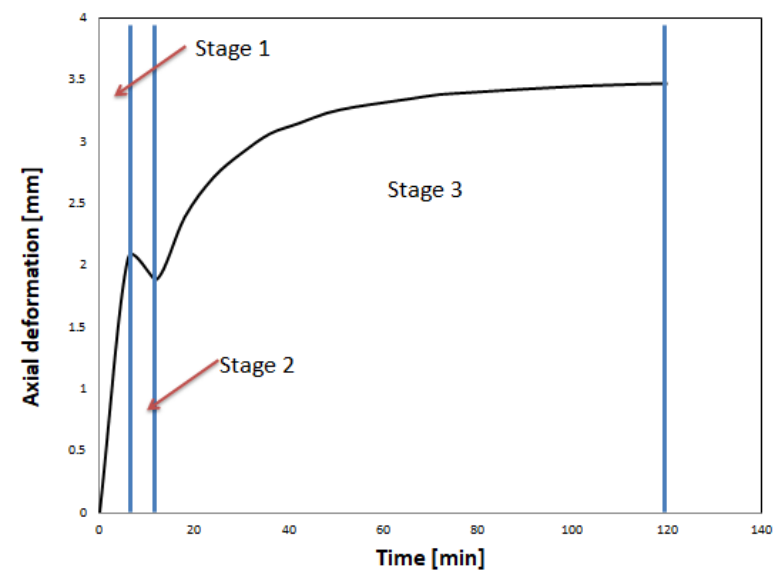

Figure 5.16: Axial deformation vs. time response for category 2 
The third category of observed results is shown in Figure 5.17. In this case, only the first stage of the overall behaviour is defined with the applied load being entirely carried by the steel sheets alone. The steels expands faster than concrete, thus enabling the steel sheets to carry to entire applied load while still maintaining a steady rate of positive axial expansion. Similar to the previous category, as the strength of the steel degrades with continual exposure to temperature, the rate of thermal expansion reduces with time. This is characterized by the fattening of the curve at high time values (Figure 5.17). It is important to note the absence of the kink observed in both previous categories 1 and 2. This is due to the steel being able to fully carry the applied load with no failure due to the low temperature of exposure. The computed reduction factors for strength of steel when exposed to temperature are not high enough to cause the steel to locally buckle. The temperature of exposure and applied load level of 0.2 are considered too low to generate concerns of buckling failure for the steel sheets. This response is observed when the temperature of exposure is lower than $600^{\circ} \mathrm{C}$ in all DCSW models.

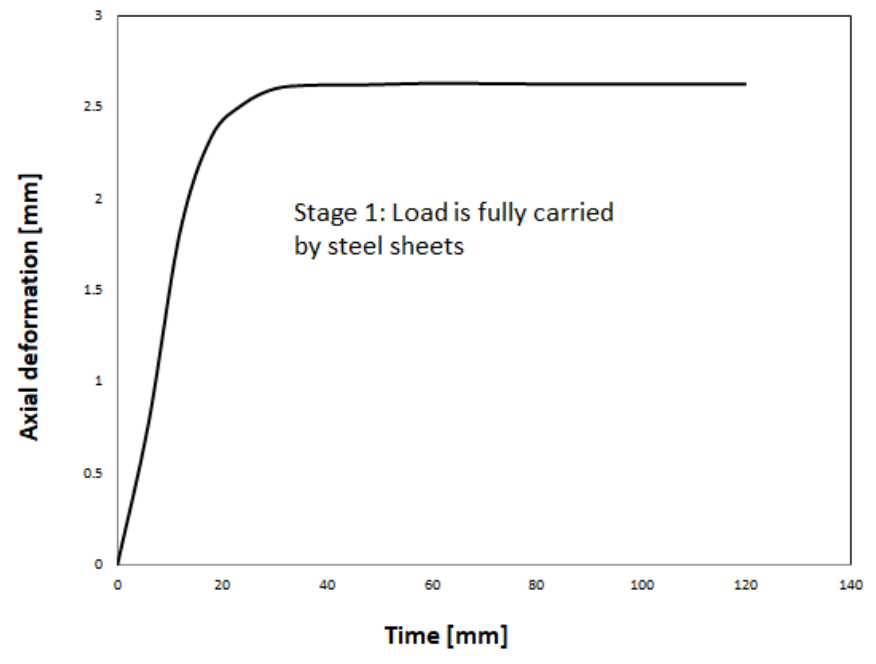

Figure 5.17: Axial deformation vs. time response for category 3

In summary, the axial deformation response of the DSCW under the effects of fire temperature is consistent with the resulting behaviour of CFST columns. As shown in Figure 5.18, all four stages described for category 1 of the fire behaviour of DSCW specimens are present in the axial behaviour of CSFT column (Ghannam, 2015). Figure 5.18 shows the typical deflection vs. time response of a typical slander CFST column with stage 1 highlighting the expansion of steel indicated from point 0-A (Ghannam, 2015). Point A is the time at which the steel is no longer able to withstand the applied load, at which point, a gradual transfer of load from the steel tube to 
the concrete core occurs (Ghannam, 2015). The time at which the entire load is transferred from the steel to the concrete core is referred to as point B (Ghannam, 2015). As the time of exposure increases, the average temperature of the concrete core increases accordingly. This will eventually lead to failure at point $C$ (Ghannam, 2015). In this case, point $C$ is referred to as the onset of failure while point $\mathrm{D}$ is referred to as the fire resistance time $t_{r}$.

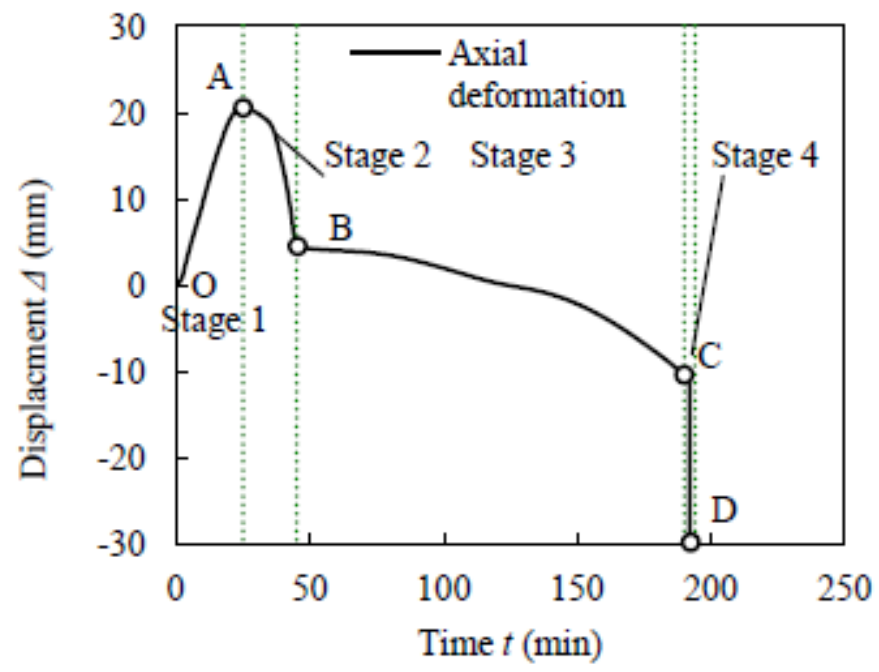

Figure 5.18: Typical axial deformation response for CFST columns (Ghannam, 2015)

\subsection{Core Temperature of DSCW Models at Failure}

The temperature of the concrete core at time of failure is investigated in this section. The core of the DSCW is defined as the center of gravity of the structure. Since the applied temperature is uniform throughout the profile of the composite wall, it is permissible to define the core as the $\mathrm{x}-\mathrm{y}$ plane passing through the center of gravity of the wall with $\mathrm{x}, \mathrm{y}$ and $\mathrm{z}$-directions outlined in Figure 3.23. The temperature distribution of any point within the specified $x-y$ plane is valid in determining the core temperature at failure. The temperature distribution curves obtained in Chapter 4 for the concrete core when subjected to ISO- 834 fire and $800^{\circ} \mathrm{C}$ temperature curves for ECC, SCC and UHPC composite wall are shown in Figures 5.19 and 5.20. 


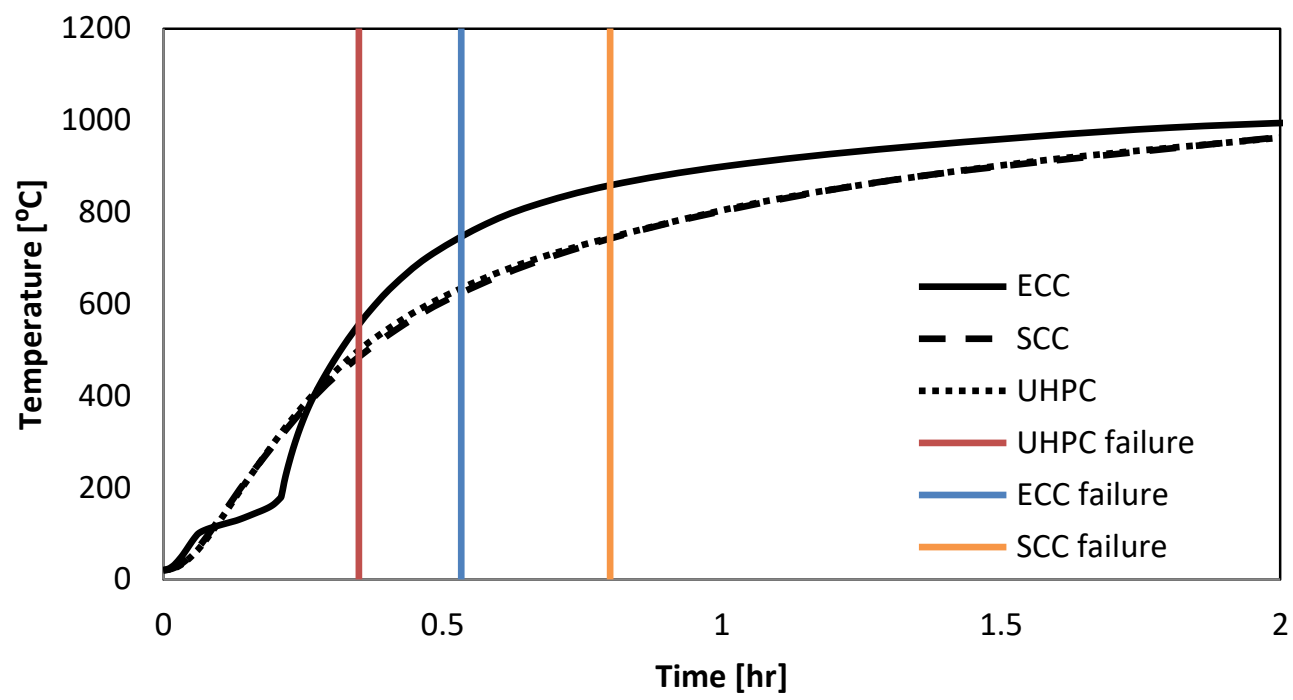

Figure 5.19: Temperature distribution at core for ECC, SCC and UHPC when exposed to ISO834 fire temperature

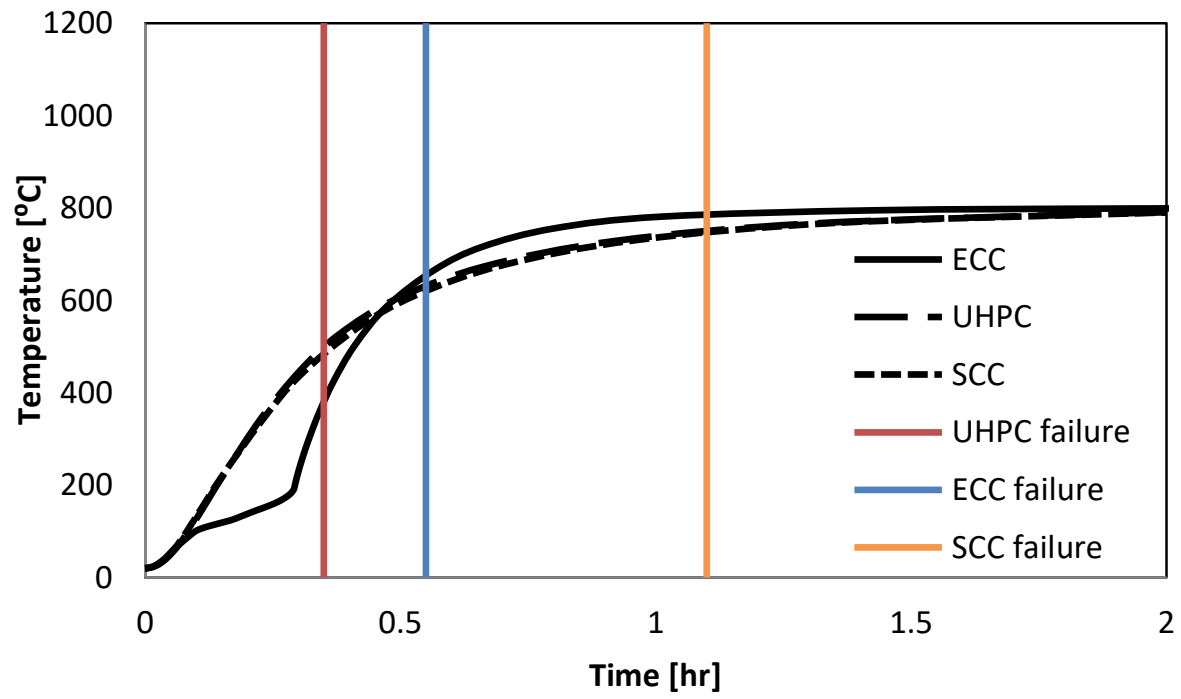

Figure 5.20: Temperature distribution at core for ECC, SCC and UHPC when exposed to $800^{\circ} \mathrm{C}$ fire temperature

Figures 5.19 and 5.20 are used to determine the core temperature at time of failure as noted in Table 5.1. Using this, the temperature at core of concrete at time of failure for ECC, SCC and UHPC-based composite wall models for ISO-834 fire and $800^{\circ} \mathrm{C}$ temperature curves are obtained and summarized in Table 5.2. 
Table 5.2: Core temperature at failure

\begin{tabular}{|l|l|l|l|}
\hline \multicolumn{5}{|c|}{ ISO-834 fire temperature curve } \\
\hline Type of wall & $\begin{array}{l}\text { Time at failure } \\
\left(t_{r}, \mathrm{~min}\right)\end{array}$ & $\begin{array}{l}\text { Core temperature } \\
{\left[{ }^{\circ} \mathrm{C}\right]}\end{array}$ & $\begin{array}{l}\text { Applied load } \\
{[\mathrm{kN}]}\end{array}$ \\
\hline UHPC & 21 & 496.8 & 148.97 \\
\hline ECC & 32 & 751.6 & 94.66 \\
\hline SCC & $48 \quad 759.3$ & 90.51 \\
\hline & $21 \quad 800^{\circ} \mathrm{C}$ temperature curve \\
\hline UHPC & 33 & 496.8 & 148.97 \\
\hline ECC & 66 & 760.0 & 94.66 \\
\hline SCC & 819.2 & 90.51 \\
\hline
\end{tabular}

According to Table 5.2, SCC-based DSCW is predicted to have the best fire resistance time prior to failure with values for $t_{r}$ of 48 and 66 min when exposed to ISO-834 fire and $800^{\circ} \mathrm{C}$ temperature curves, respectively. ECC-based DSCW is observed to have the second best fire behaviour with values for $t_{r}$ of 32 and 33 min when exposed to ISO-834 fire and $800^{\circ} \mathrm{C}$ temperature curves respectively. Finally, as can be expected, UHPC-based DSCW is shown to have the worst fire resistance by far with values for $t_{r}$ of 21 when exposed to both ISO-834 fire and $800^{\circ} \mathrm{C}$ temperature curves.

In this case, the UHPC-based composite wall is observed to fail when the temperature of the core is $496.8^{\circ} \mathrm{C}$. This is caused as a result of the low percentage of water content within the concrete matrix. The low amount of water causes spalling of concrete which reduces the cross-sectional area of the applied load. This reduces the strength capacity of the specimen which in turn leads to premature failure in the early stages of fire exposure. This response is coherent with the post-fire experimental response shown in Figure 5.21 as retrieved from (Taormina, 2012). In this case, UHPC-based DSCW is proved to have the worst post-thermal behaviour when compared to SCC and ECC alternatives. Figure 5.21 shows a plot the reduction factor (relative load) of the compressive strength of the composite wall defined as the ratio of ultimate compressive strength 
at ambient temperature and ultimate compressive strength once exposed to elevated temperature $\left(N_{e t} / N_{e 20}\right)$ as per Taormina (2012).

ECC-based DSCW is observed to have the second best fire resisting behaviour with core temperature of 760.0 and $751.6^{\circ} \mathrm{C}$ at time of failure when ISO-834 fire and $800^{\circ} \mathrm{C}$ temperature curves are applied respectively. Similar to that of UHPC-based composite wall, such fire behaviour is also coherent with the post-thermal response obtained in the experimental program conducted by (Taormina, 2012). This is shown in Figure 5.21 where ECC is classified as having the second best post-fire resistance. As shown in Figures 5.19 and 5.20, the temperature distribution of ECC core is divergent from that of UHPC and SCC at temperature of about $150^{\circ} \mathrm{C}$. This is directly associated to the high specific heat of ECC with value of $10000[\mathrm{~J} / \mathrm{mK}]$ spiking between the temperature range of $115-200^{\circ} \mathrm{C}$. In order to compensate for such high demand in thermal energy within this temperature range, a massive amount of energy needs to be absorbed prior to any significant change in the temperature of the concrete core. This process takes time while the applied fire temperature is continually increasing. Once the specific amount of thermal energy is absorbed, temperature of the concrete core may then begin to elevate. However, since this process takes up time, due to the gradual heat transfer within the concrete medium, the average temperature of the concrete would then be much higher than what it was prior to reaching the $115^{\circ} \mathrm{C}$ temperature mark. The specific heat value post $200^{\circ} \mathrm{C}$ returns to a low value of $900[\mathrm{~J} / \mathrm{mk}]$ which is significantly lower than the previous value of $10000[\mathrm{~J} / \mathrm{mk}]$ (Figure 4.6). Such low value in specific heat in conjunction with the high average temperature of concrete results in the rapid increase in core temperature distribution observed in Figures 5.19 and 5.20 leading to a core temperature higher than that of SCC and UHPC. This rapid increase leads to fast deterioration in the strength of the concrete, which in turn leads to premature failure compared to SCC-based DSCW.

SCC-based DSCW is observed to have the best fire resisting behaviour with core temperatures of 759.3 and $819.2^{\circ} \mathrm{C}$ at time of failure when ISO-834 fire and $800^{\circ} \mathrm{C}$ temperature curves are applied respectively. The fire resistance response is coherent with the post-thermal experimental results obtained from Taormina (2012) where SCC-based DSCW specimens showed to have the best post-fire behaviour (Figure 5.21). Due to the high flowability of SCC, the water content within the concrete mixture is expected to be much higher than that of UHPC. This nullifies the 
chance of concrete spalling at early stages of exposure, thus leading to higher values in fire resistance when compared to UHPC. As shown in Figure 4.6, the specific heat of SCC follows a more or less stable value of $2600[\mathrm{~K} / \mathrm{mk}]$ for the entire temperature range between $20-1000^{\circ} \mathrm{C}$ with no major spike existing in the specific heat curve. This results in the stable gradual increase in the temperature distribution of the concrete core as noted in Figures 5.19 and 5.20. Such steady specific heat curve for SCC prevents the occurrence of the sharp increase in core temperature experienced in ECC, thus resulting in an overall lower core temperature distribution when compared to ECC mixtures. This enables SCC-based DSCW to experience lower temperatures when compared to ECC-based DSCW at a given time. In addition, the high stiffness of SCC enables the composite wall to withstand load for a higher period of time prior to collapse. In this case, the modulus of elasticity for SCC is measured to be $33.6 \mathrm{GPa}$ while the modulus of elasticity of ECC is measured to be $25.0 \mathrm{GPa}$ (Taormina, 2012). Such high difference in stiffness enables SCC-based composite wall to sustain the applied load for longer period of time as highlighted in Figures 5.19 and 5.20.

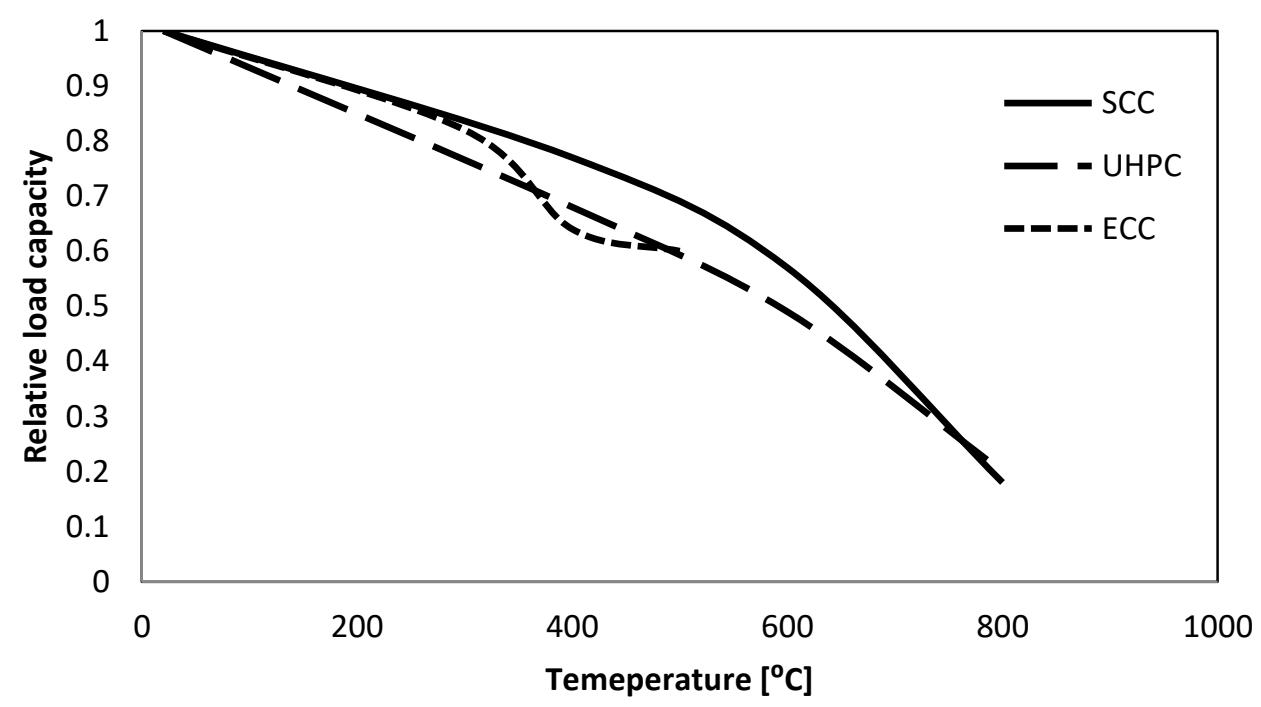

Figure 5.21: Post-fire compressive strength reduction factors for SCC, ECC and UHPC-based DSCW (Taormina, 2012)

In summary, it is predicted that SCC-based DSCW has the highest endurance in term of fire resistance when compared to its ECC and UHPC-based counterparts. FE models for fire resistance proved to match the concluding results of the post-thermal experimental behaviour 
highlighted by Taormina (2012). In both cases, SCC proved to respond best, followed by ECC while UHPC preformed worst in both fire and post-fire conditions. This similarity in the results highlights the credibility of the generated FE models. Although, experimental results for the fire resistance of DSCW are absent, the existing similarities of the FE models when compared to the post-fire experimental study by Taormina (2012) strengthen the credibility of the proposed FE study.

\subsection{Parametric Study}

This section includes a study on the effects of various parameters on the fire behaviour of DSCWs. Such parameters include variations in applied load, thickness of steel sheets, depth of concrete core and fastener arrangement.

\subsubsection{Effect of Load Level}

The effect of applied compressive load is examined by changing the load level with respect to the ultimate compressive capacity $\left(N_{e 20}\right)$ of ECC, SCC and UHPC composite walls. The DSCW FE model is exposed to ISO-834 fire temperature all the while a constant load is applied until failure occurs. A total of five different load levels $(0.2,0.4,0.5,0.6$ and 0.8$)$ are applied on the DSCW models with the associated axial deformation response shown in Figures 5.22-5.26 for SCC, UHPC and ECC composite wall. Summary for the values of applied load and resulting fire resistance $\left(\mathrm{t}_{\mathrm{r}}\right)$ are summarized in Table 5.3.

Figure 5.27 shows the existing relationship between the load level and obtained fire resistance of composite walls. In this case, the increase in load level results in a decrease in fire resistance of the composite wall. This is to be expected as the application of increased loading will result in higher stresses on the steel and concrete leading to early failure. Figures 5.22-5.26 also show that an increase in applied load results in a decrease in positive axial deformation of the composite wall. The applied load becomes higher than the reaction force caused by the thermal expansion of concrete, leading to a decrease in axial deformation of the composite wall. The response of the effect of varying the load level on the fire resistance time $\left(t_{r}\right)$ as shown in Figure 5.27 is identical to the varying load level with respect to $t_{r}$ for the CFST columns investigated by (Lu et al. 2011). As discussed in section 2.3, the increased load level drastically decreased the fire 
resistance of the investigated circular and square CFST columns investigated by (Lu et al. 2011). Figure 2.20 shows the effects of load level on the fire resistance of CFST column (Lu et al. 2011) with clear similarities drawn when compared to Figure 5.27 for DSCWs. This similar trend in the response further strengthens the validity of the proposed FE models.

Table 5.3: Summary of applied load level with resulting fire resistance $\left(t_{r}\right)$

\begin{tabular}{|l|l|l|l|l|l|l|}
\hline & \multicolumn{2}{|l|}{ SCC composite wall } & \multicolumn{2}{l|}{ UHPC composite wall } & \multicolumn{2}{l|}{ ECC composite wall } \\
\hline $\begin{array}{l}\text { Load } \\
\text { level }\end{array}$ & $\begin{array}{l}\text { Applied } \\
\text { load } \\
{[\mathrm{kN}]}\end{array}$ & $\begin{array}{l}t_{r} \\
{[\mathrm{~min}]}\end{array}$ & $\begin{array}{l}\text { Applied } \\
\text { load }[\mathrm{kN}]\end{array}$ & $\begin{array}{l}t_{r} \\
{[\mathrm{~min}]}\end{array}$ & $\begin{array}{l}\text { Applied } \\
\text { load } \\
{[\mathrm{kN}]}\end{array}$ & $\begin{array}{l}t_{r} \\
{[\mathrm{~min}]}\end{array}$ \\
\hline 0.2 & 90.6 & 48 & 149 & 21 & 95 & 32 \\
\hline 0.4 & 181.2 & 26 & 298 & 14 & 189 & 19 \\
\hline 0.5 & 226.5 & 20 & 372.5 & 12 & 236.5 & 16 \\
\hline 0.6 & 271.8 & 17 & 447 & 10 & 284 & 18 \\
\hline 0.8 & 362.4 & 13 & 596 & 7.2 & 378 & 13 \\
\hline
\end{tabular}

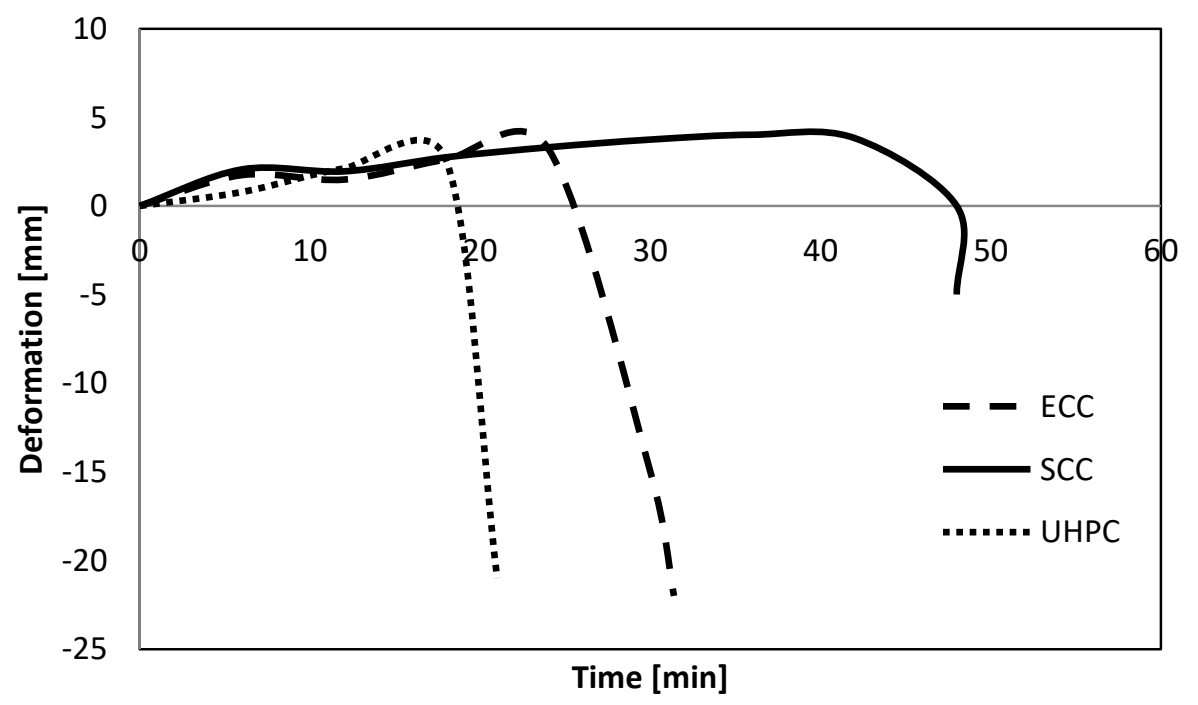

Figure 5.22: Axial deformation vs. time curves for 0.2 load level 


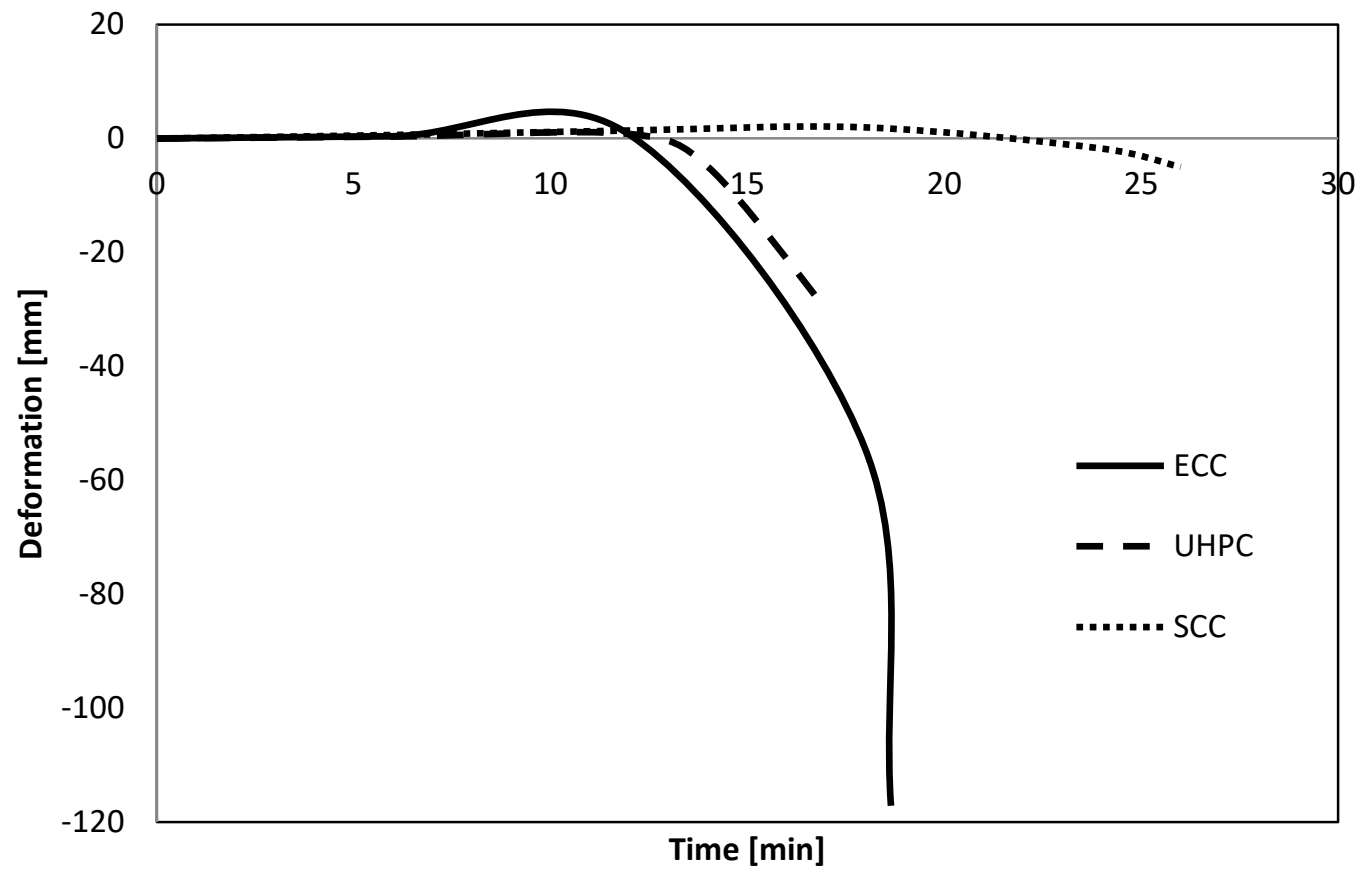

Figure 5.23: Axial deformation vs. time curves for 0.4 load level

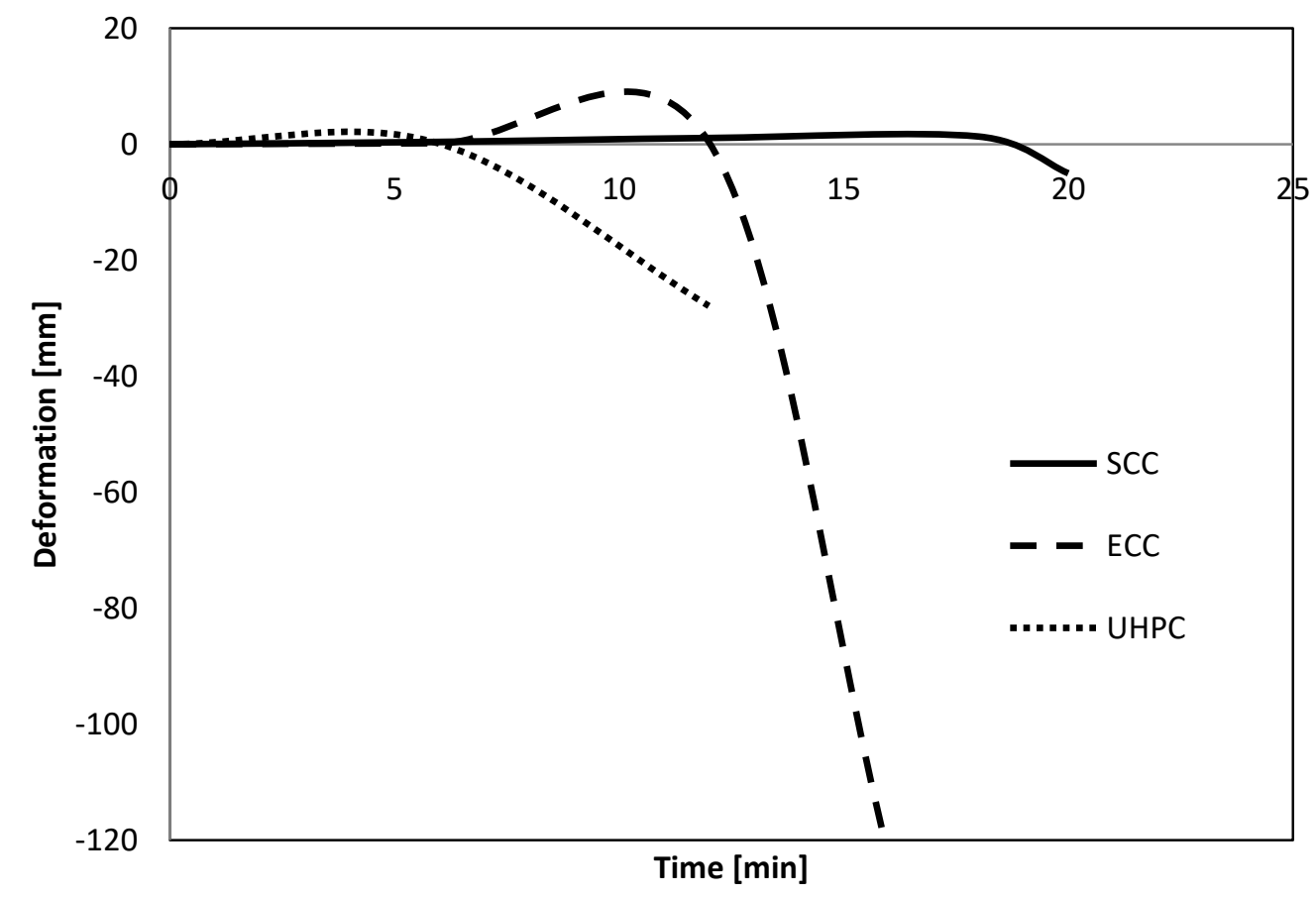

Figure 5.24: Axial deformation vs. time curves for 0.5 load level 


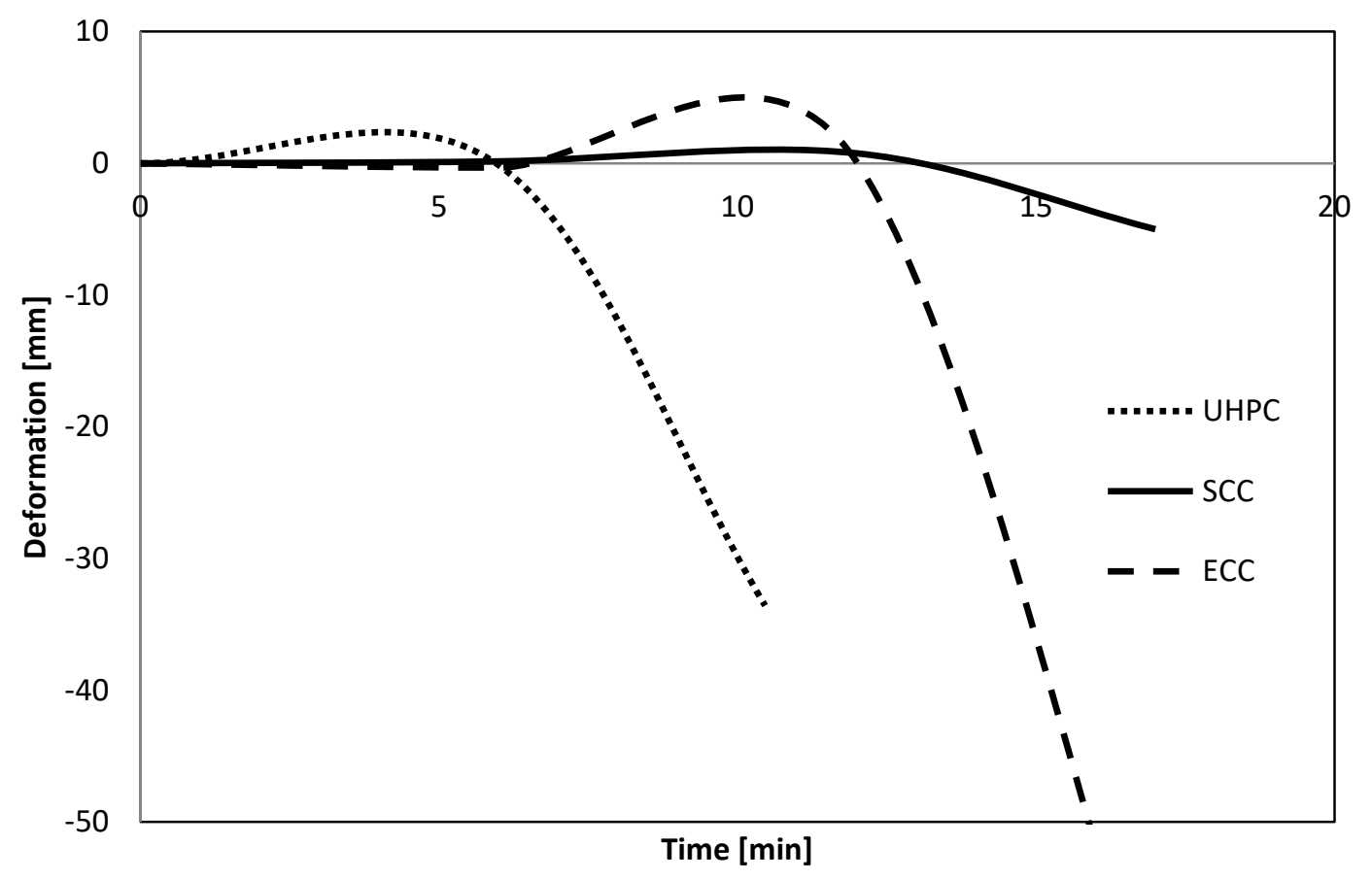

Figure 5.25: Axial deformation vs. time curves for 0.6 load level

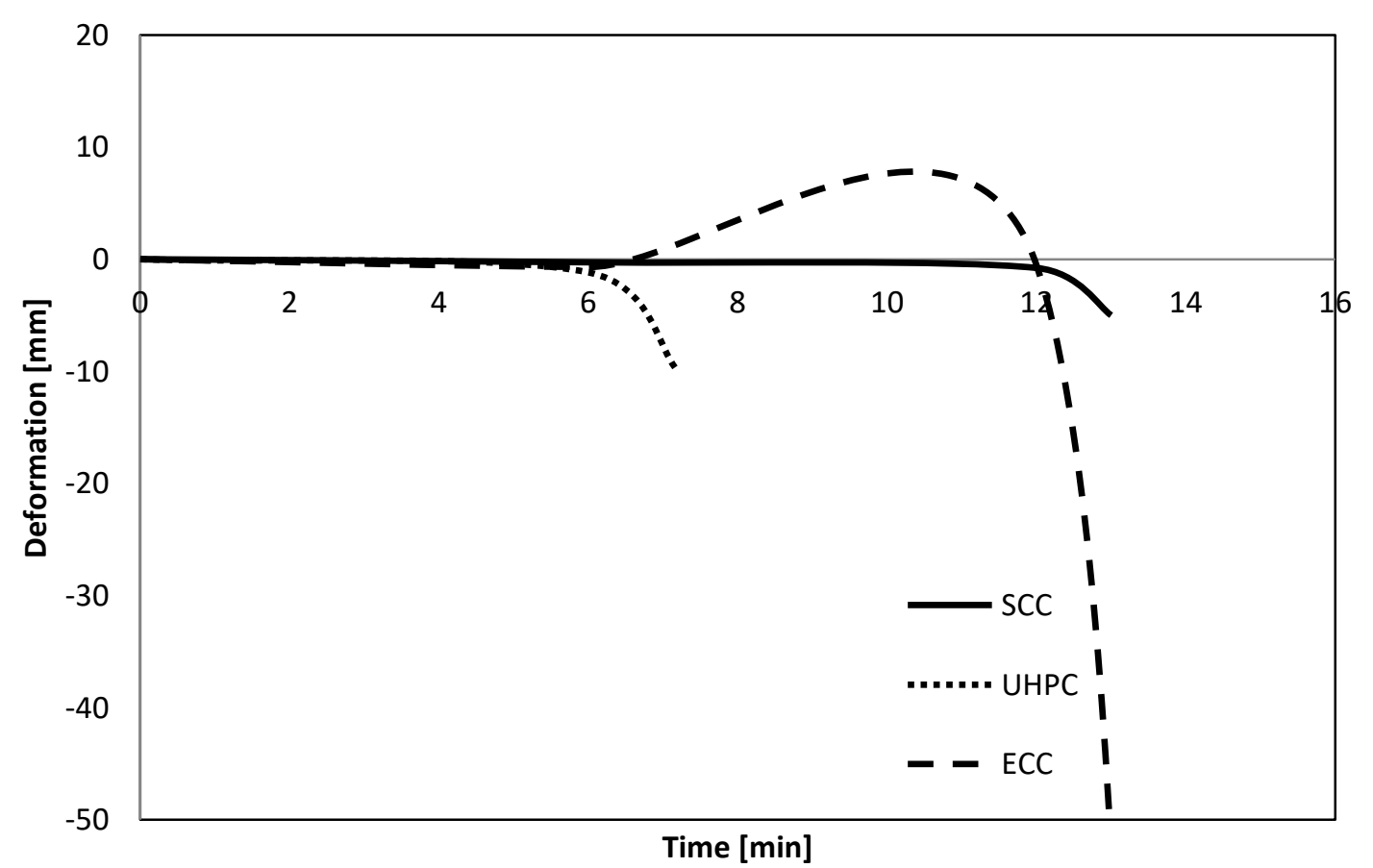

Figure 5.26: Axial deformation vs. time curves for 0.8 load level 


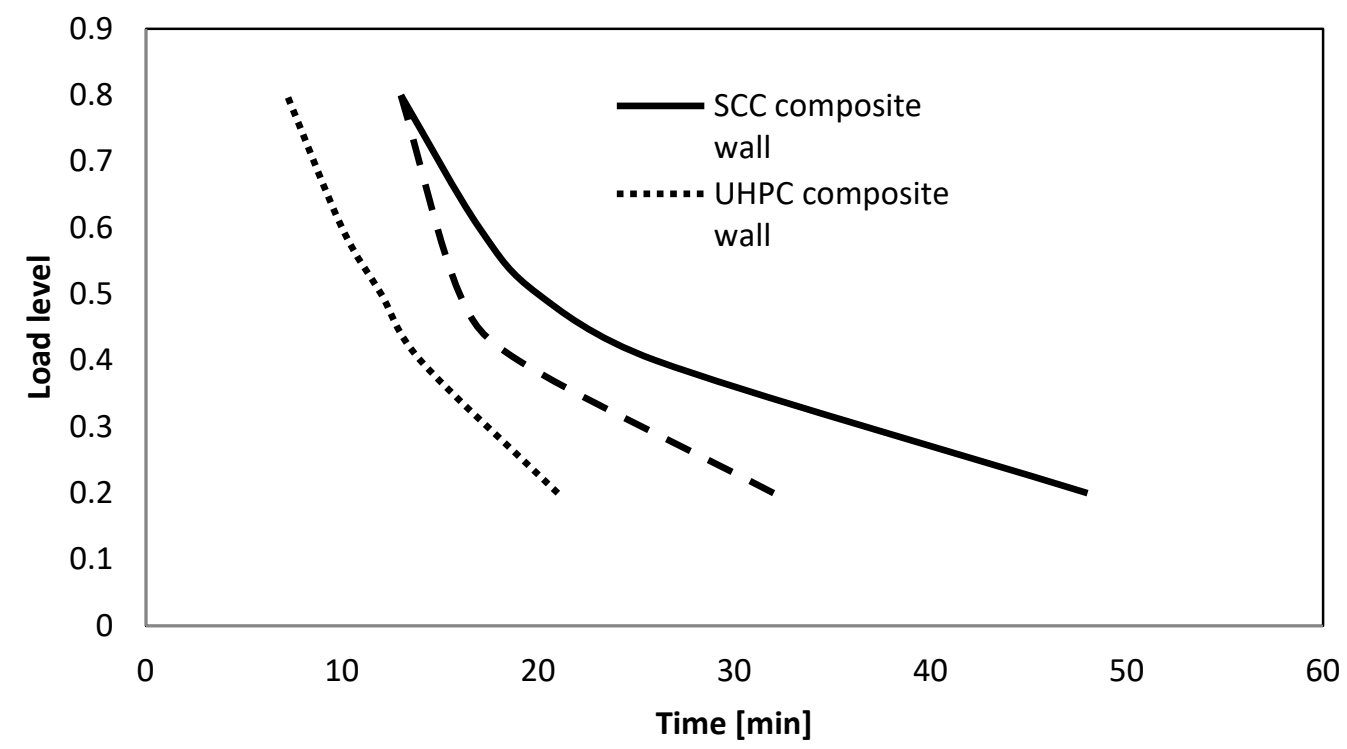

Figure 5.27: Load level vs. fire resistance time

\subsubsection{Effect of Thickness of Steel Sheets}

The effect of changing the thickness of the steel sheets on the fire resistance of DSCW for ECC, SCC and UHPC-based composite walls is investigated. Steel thickness values of 0.61, 1, 2, 3 and $5 \mathrm{~mm}$ were considered and the corresponding fire resistance when the composite wall model is subjected to ISO-834 fire temperature curve is obtained. $80 \%$ of the ultimate load is applied on the composite wall model with the thickness of the steel sheets varied. Figure 5.28 shows the effects of varying thickness on the axial behaviour of ECC, SCC and UHPC composite walls. Table 5.4 summarizes the obtained results.

Figure 5.28 shows that the increase in steel thickness of the steel sheets while maintaining a constant applied load leads to slight improvement in the fire resistance of SCC, ECC and UHPCbased DSCW. This is to be expected since the increase in thickness leads to an increase in the overall ultimate compressive strength of the composite wall. However, since the steel is directly exposed to elevated temperatures, the structural component is thus subjected to a rapid drop in strength. This is due to the high thermal conductivity of steel sheets. As such, the change in steel thickness has reduced influence on the fire resistance of DSCW. Due to the minimal increase in fire resistance time $\left(t_{r}\right)$ and high cost of steel, increasing the steel thickness is usually impractical in construction environments. Similar response was observed in a research study by Lu et al. (2011) on CFST columns where the thickness of the steel tube was increased from 10 to 
$100 \mathrm{~mm}$. Figure 2.23 indicates a $35 \mathrm{~min}$ increase in the fire resistance of square stubbed CFST columns associated to such high change in steel tube thickness ( $\mathrm{Lu}$ et al. 2011). As such, the response shown in Figure 5.28 is coherent with that shown in Figure 2.23 in indicating the impracticality of increasing the steel thickness for construction purposes to improve fire resistance.

Table 5.4: Summary of applied load level with resulting fire resistance $\left(\mathrm{t}_{\mathrm{r}}\right)$ and alternating steel sheet thickness $(\mathrm{t})$

\begin{tabular}{|l|l|l|l|}
\hline & SCC composite wall & UHPC composite wall & ECC composite wall \\
\hline $\begin{array}{l}\text { Steel thickness, } \mathrm{t} \\
{[\mathrm{mm}]}\end{array}$ & $t_{r}[\mathrm{~min}]$ & $t_{r}[\mathrm{~min}]$ & $t_{r}[\mathrm{~min}]$ \\
\hline 0.61 & 12 & 6 & 13.7 \\
\hline 1 & 12.5 & 8 & 12.8 \\
\hline 2 & 15 & 9.4 & 12 \\
\hline 3 & 20 & 10 & 12 \\
\hline 5 & 24 & 13 & 16.8 \\
\hline
\end{tabular}

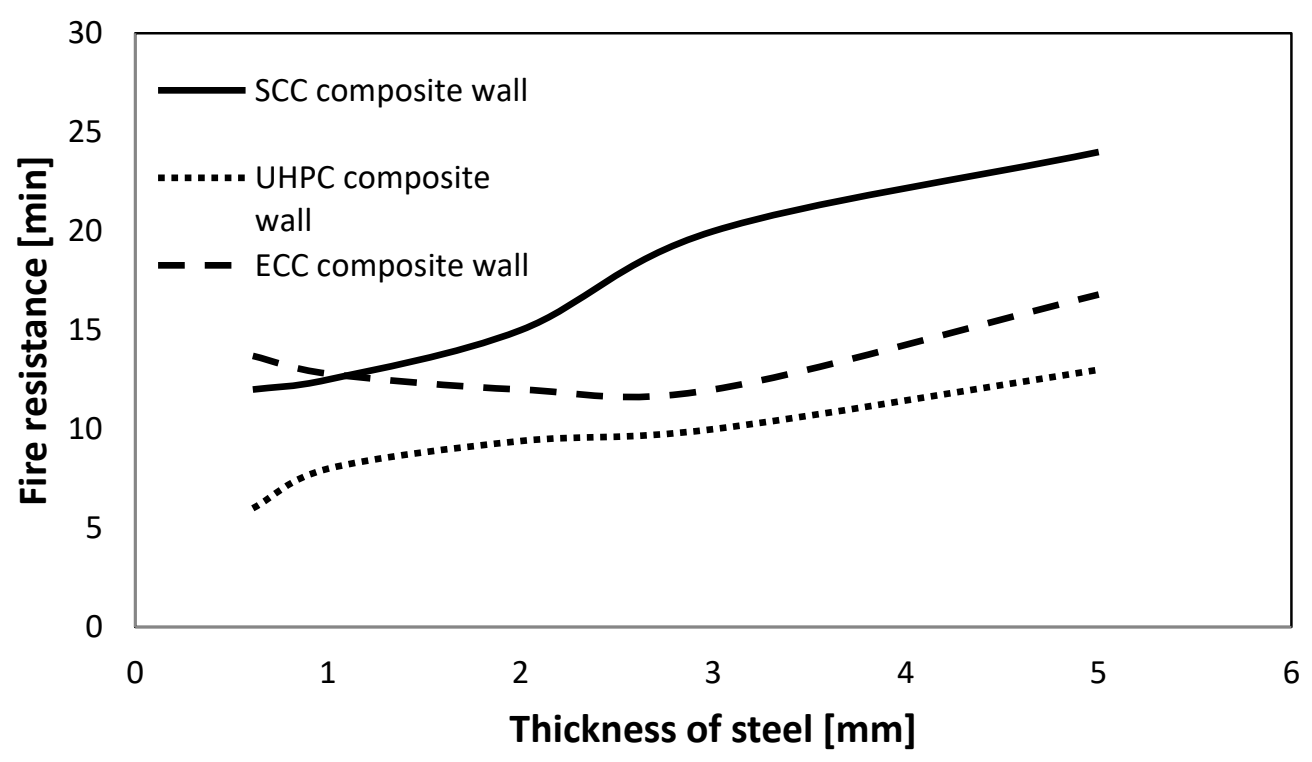

Figure 5.28: Fire resistance vs. steel sheet thickness 


\subsubsection{Effect of Varying Concrete Depth}

The effect of varying the depth of the concrete core within the composite wall structure is investigated in this subsection. It is important to note that varying the height of the composite wall is not a viable parameter to investigate since the buckling/failure mechanism of the wall at the desired investigated height is unknown. Depending of the chosen height of the wall, it is ambiguous whether global or local buckling might be the cause for failure. Should the composite wall fail due to global buckling, it is only logical that the load vs. time curve would significantly defer from a wall that experiences local bucking. As such, it is not possible to access the influence of the height since the buckling mode is unknown. In addition, variance in the width of the composite wall is considered irrelevant since the change in width would have no effect the temperature distribution along the cross-section of the composite wall. Changing the width would not have any impact on the average depth of the concrete, therefore heat transfer results would not be influenced. For such reasons, the change in the concrete depth parameter is chosen for further investigation since variations in this parameter is expected increase the heat sink capacity and overall strength of the composite wall. As shown in Figure 5.29, the depth of the wall is varied from the original $18 \mathrm{~mm}$ to 25 and $50 \mathrm{~mm}$, respectively. The corresponding fire resistance is obtained when the composite wall model is subjected to ISO-834 fire temperature curve and $80 \%$ of the ultimate load at original geometric depth of $18 \mathrm{~mm}$.

Figures 5.30-5.32 include the deformation vs. time curves generated from varying the value of concrete depth for ECC, SCC and UHPC-based DSCW, respectively. Summary of the results for fire resistance associated to each variation in concrete depth is portrayed in Table 5.5. As shown in Figures 5.30-5.32, the increase in the depth of concrete is shouldered with a subsequent increase in the fire resistance of the DSCW model. This is to be expected since the increase in the depth of the concrete core increases the heat sink of the structure. This enables the DSCW to hold higher values of thermal energy for the temperature of the core to increase. A higher concrete depth increases the travel distance for heat transfer analysis thus slowing the change in temperature within the concrete core. In addition, the increase in fire resistance time is also attributed to an increase in the overall strength of the DSCW. In this case, increasing the depth of the concrete enables the structure to withhold higher forces due to the increase in surface area. As such, the ultimate compressive strength of the DSCW is thus amplified resulting to an 
improvement in the fire resistance time. According to Table 5.5, all concrete alternatives experienced about equal amounts for improvement in fire resistance.

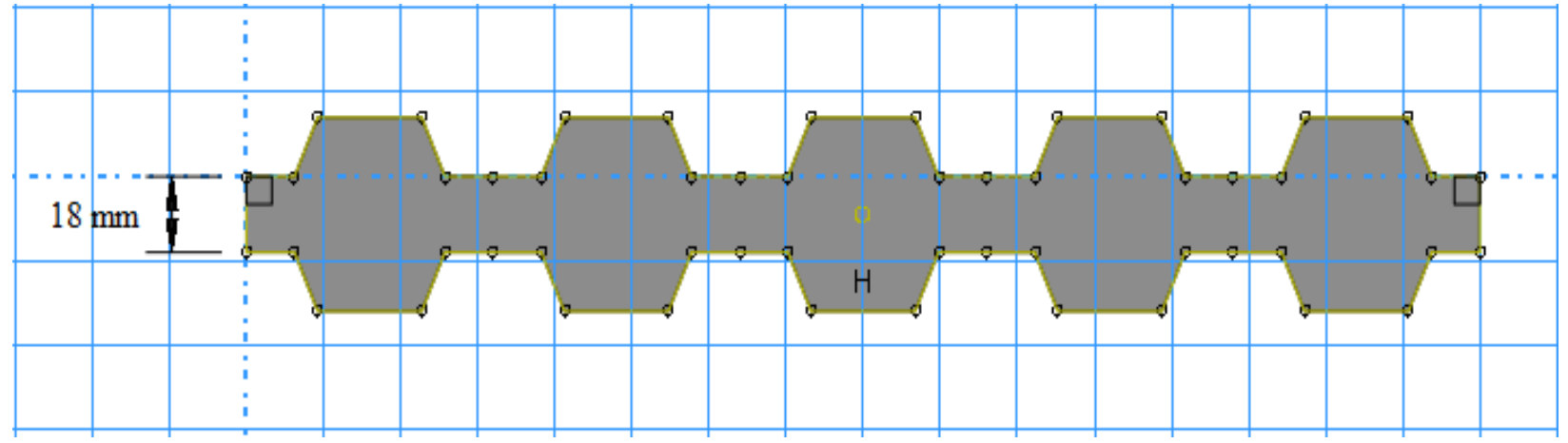

(a)

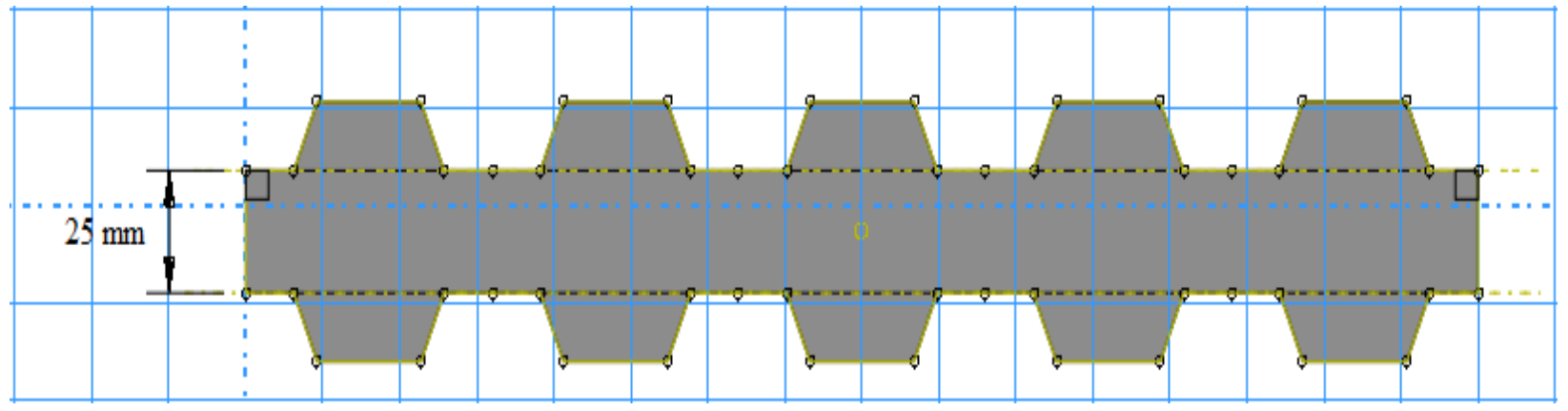

(b)

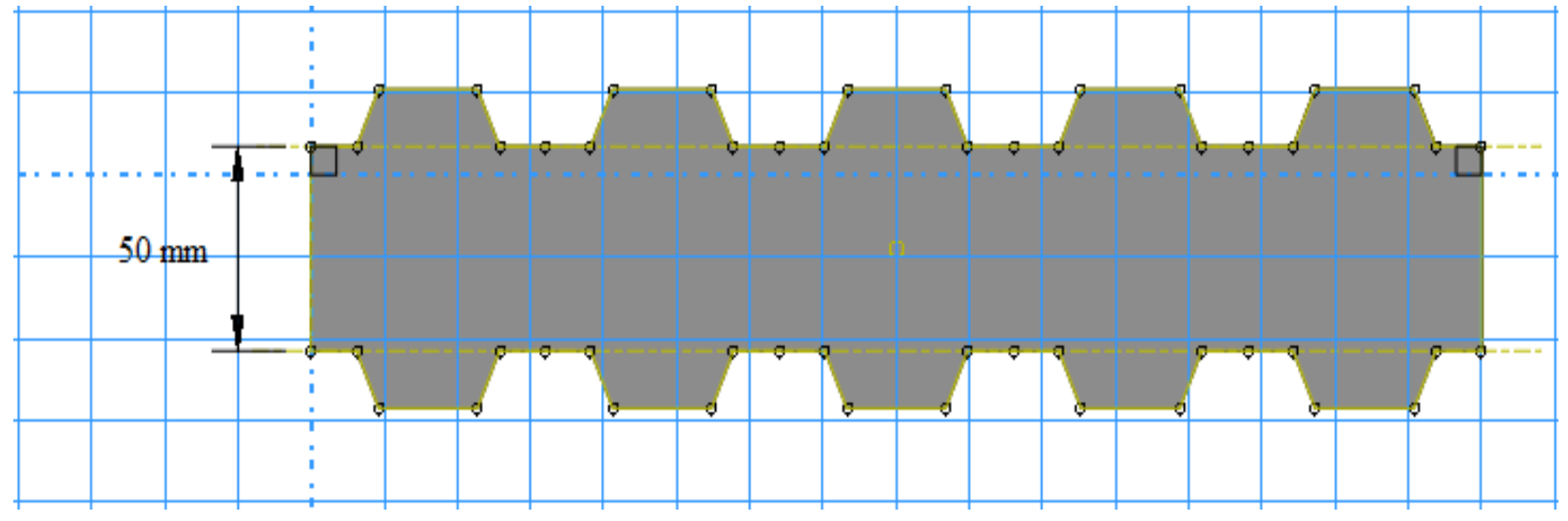

(c)

Figure 5.29: Varying depth of the concrete core 


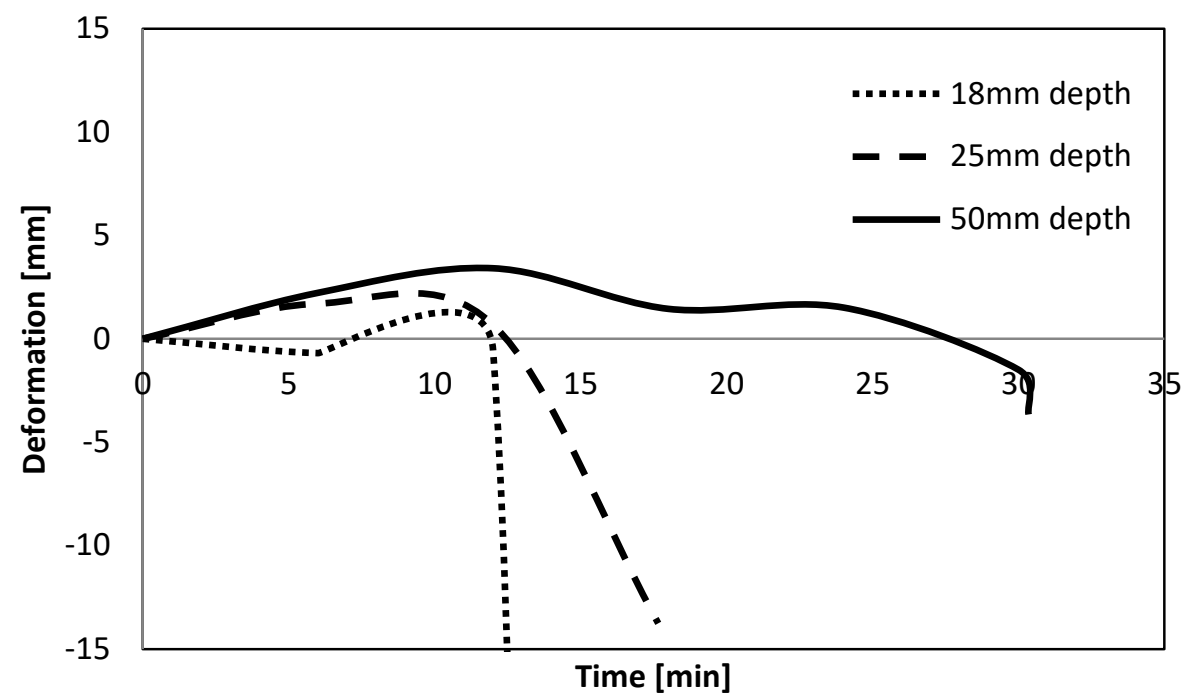

Figure 5.30: Axial deformation after varying concrete depth for ECC-based DSCW

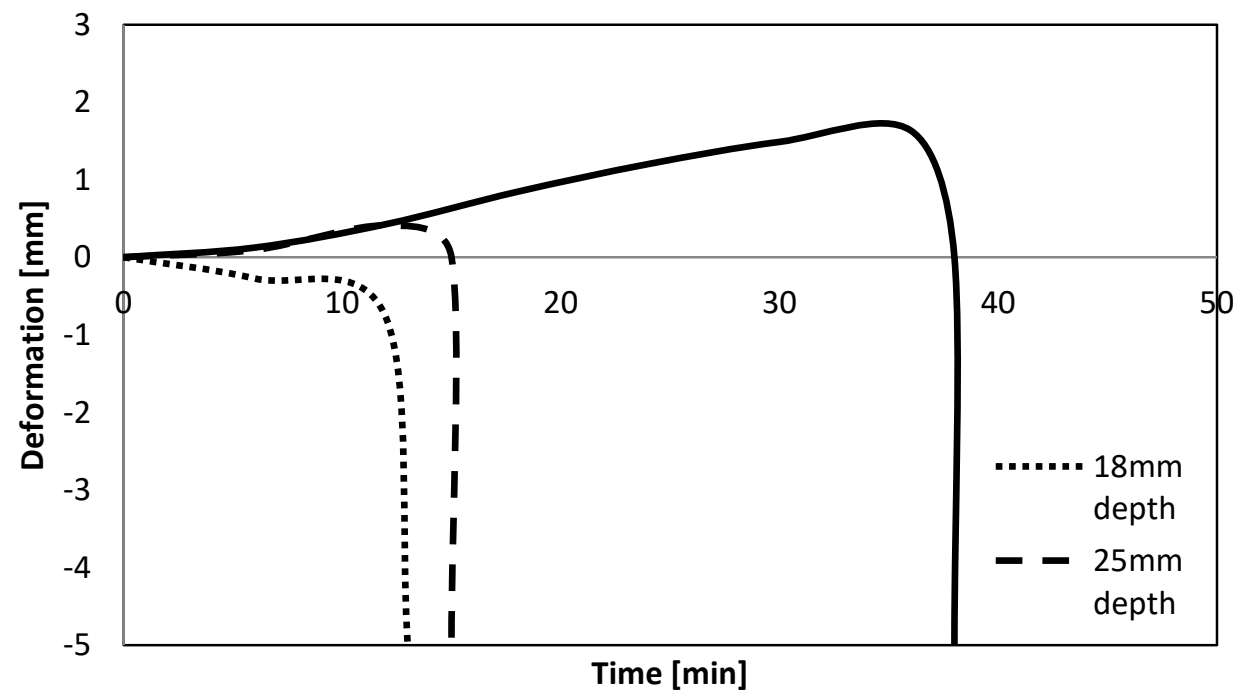

Figure 5.31: Axial deformation after varying concrete depth for SCC-based DSCW 


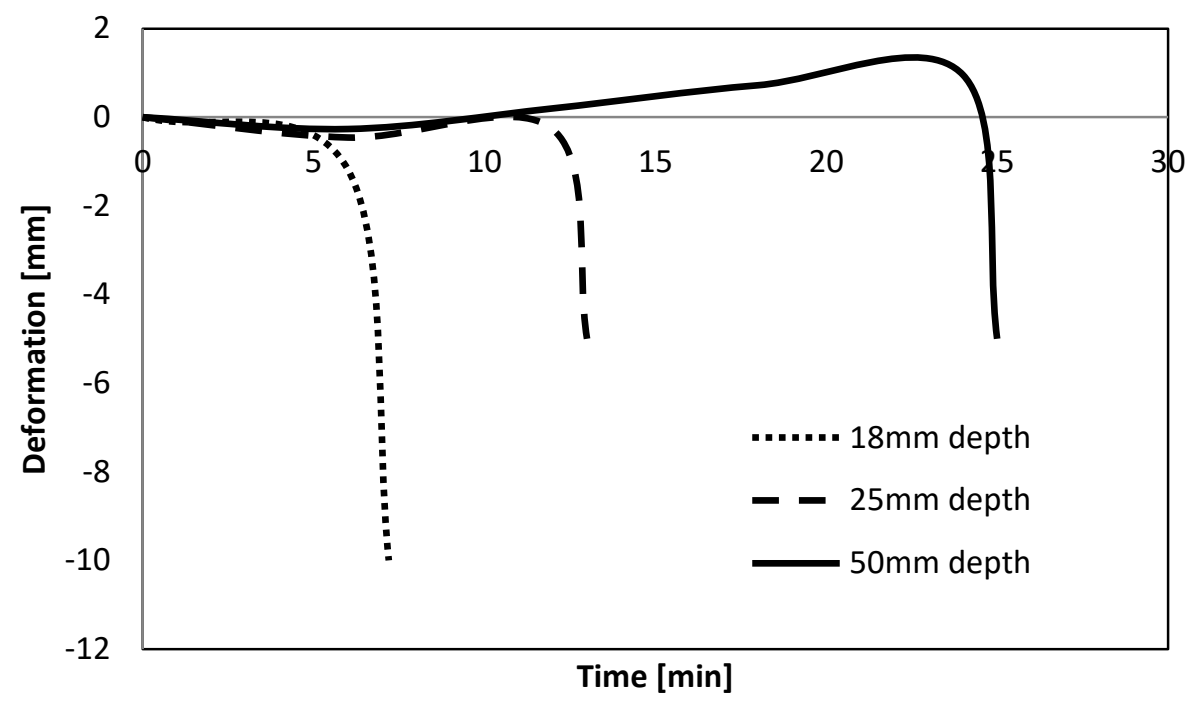

Figure 5.32: Axial deformation after varying concrete depth for UHPC-based DSCW

Table 5.5: Summary of fire resistance $\left(t_{r}\right)$ results when varying depth

\begin{tabular}{|l|l|l|l|}
\hline & SCC composite wall & UHPC composite wall & ECC composite wall \\
\hline $\begin{array}{l}\text { Concrete depth } \\
{[\mathrm{mm}]}\end{array}$ & $t_{r}[\mathrm{~min}]$ & $t_{r}[\mathrm{~min}]$ & $t_{r}[\mathrm{~min}]$ \\
\hline 18 & 12 & 7 & 13 \\
\hline 25 & 15 & 13 & 18 \\
\hline 50 & 38 & 25 & 30 \\
\hline
\end{tabular}

\subsubsection{Effect of Varying Arrangement of Fasteners}

The influence of the number of fasteners in the fire resistance of the DSCW structure is investigated. In this case, the original number of 30 fasteners with six in each row is increased to 54 fasteners distributed into nine rows with six in each row and 78 fasteners distributed into thirteen rows with six in each. Figure 5.33 shows the arrangement for each set of fasteners. 


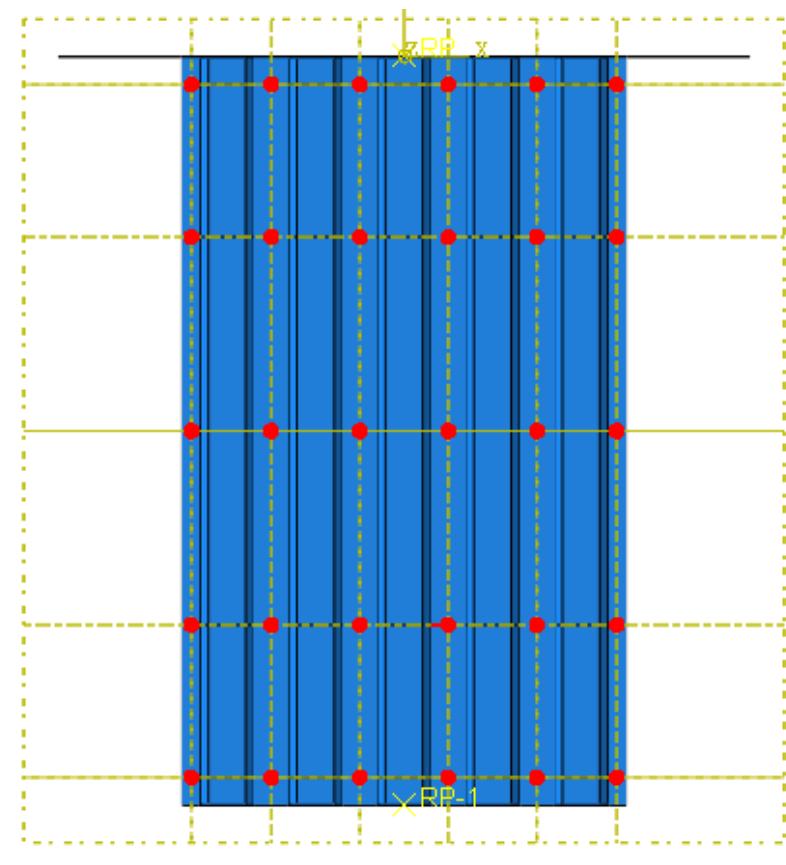

(a)

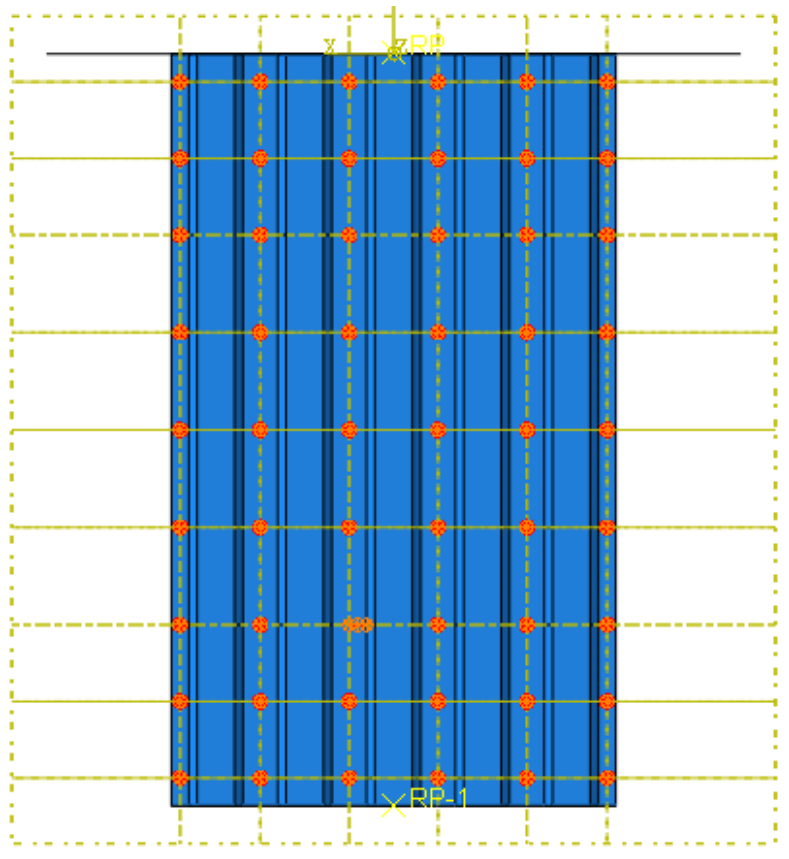

(b)

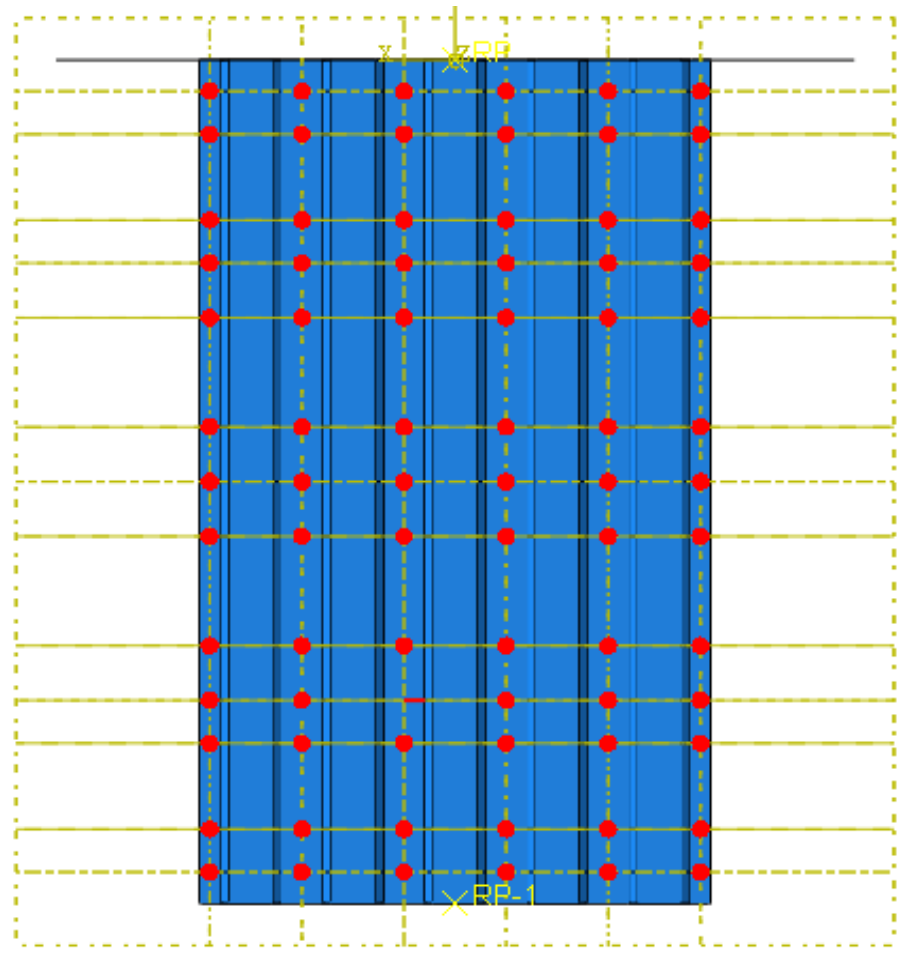

(c)

Figure 5.33: Varying fastener arrangement with the number of fasteners of (a) 30, (b) 54 and (c) 
Results for varying the fastener arrangement for ECC, SCC and UHPC-based composite wall specimens are shown in Figure 5.34. No significant change in the fire resistance is observed for all three types of DSCWs. The use of fasteners is introduced to prevent buckling of the steel sheets and improve the steel-concrete bond. When exposed to elevated temperature, the steel sheets lose strength at early stage, thus nullifying the advantage of having fasteners prolonging the steel contribution of withstanding load prior to buckling. In addition, due to the different values in expansion coefficients for steel and concrete, the steel component will separate from the concrete. As such the use of fasteners in increasing the frictional interaction between the concrete and steel is completely invalidated. Due to these factors, the number of fasteners, along with their arrangements do not have a significant influence on the fire resistance of the composite wall.

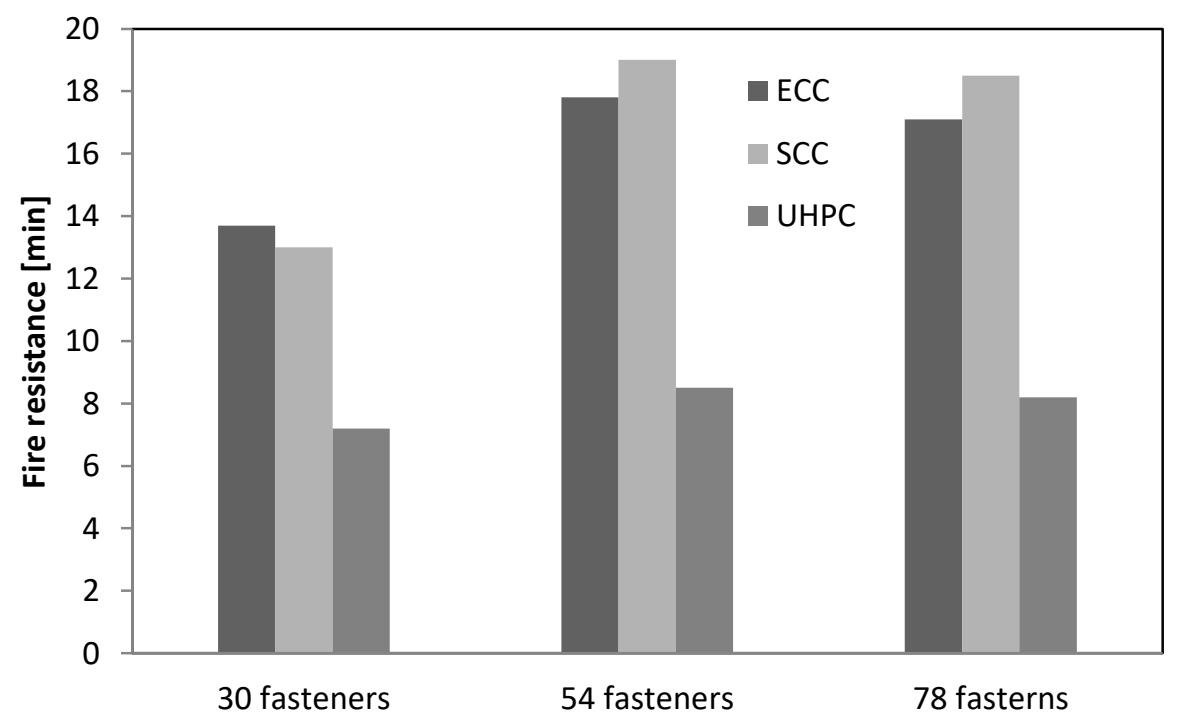

Figure 5.34: Relationship of fire resistance with varying fastener arrangement

\subsection{Chapter Summary}

This chapter investigates the behaviour of double skin composite wall (DSCW) under the combined effect of elevated temperature and applied compressive load. A sequentially coupled thermal-mechanical analysis is conducted through use of Abaqus ${ }^{\circledR}$ to generate FE models to determine the fire resistance of ECC, SCC and UHPC based composite walls. Results of heat transfer analysis generated in Chapter 4 are used in this chapter to obtain the axial deformation 
response. Three separate categories in response are observed from the axial behaviour of SCC, ECC and UHPC composite wall. In the first category, failure due to elevated temperatures was observed, leading to a definition for the fire resistance of the wall specimens. In the second category of results, no failure was observed but for the buckling of steel. In the third and final category of observed results, no failure in either the steel or concrete was observed mainly due to the low temperature of exposure. A parametric study on the effects of load level, steel thickness, depth of concrete core and fastener arrangement was then conducted. It was observed that increasing the load level led to a decrease in the fire resistance of the composite wall while the increase in concrete depth led to an increase in the fire resistance of the wall. Fastener arrangement and varying the thickness of the steel sheets showed no significant change in the fire resistance. 


\section{CHAPTER 6: Conclusions and Recommendations for Future Studies}

\subsection{Introduction}

This thesis presents a numerical finite element (FE) study of the behaviour of double skin composite wall (DSCW) under the effect of fire. FE models are generated to obtain the fire resistance of DSCW with various high performance concrete infill such as engineered cementitious concrete (ECC), self-consolidating concrete (SCC) and ultra-high strength/performance concrete (UHPC). Experimental results obtained from previous studies on the compressive behaviour of ECC, SCC and UHPC-based DSCWs at ambient temperature are used to validate the generated compressive FE model. The heat transfer results for DSCW model were generated and validated against test results on the thermal behaviour of concrete filled steel tubular (CFST) columns obtained from the literature. Once both the compressive and heat transfer models were validated, a sequentially coupled thermal-mechanical analysis was conducted to determine the fire resistance of ECC, SCC and UHPC-based DSCWs.

\subsection{Conclusions}

A FE model simulating axial compressive behaviour of DSCWs was developed in an attempt to mimic the results obtained from the previous experimental studies. DSCW specimens were loaded to failure through introduction of compressive concentric deformation in FE models. FE results in terms of axial load vs. deformation response and failure mechanism were generated and compared to those obtained from experiments. Load vs. deformation responses of ECC, SCC and UHPC-based DSCWs from FE models are found to correlate well with those obtained from experiments. The ratio of FE predicted to test peak/ultimate load values for SCC, ECC and UHPC-based walls were found to be $0.96,0.95$ and 0.87 , respectively thus highlighting the credibility of the proposed FE model. The failure mechanism for all FE walls seemed to be somewhat similar with buckling of the steel sheet occurring between two layers of fasteners and crushing of the concrete. Failure modes of FE walls are found to be similar to those obtained from tests, thus further strengthening the validity of the proposed model. 
A heat transfer FE analysis was performed to determine the temperature distribution along the cross-section of the DSCWs when exposed to elevated temperatures. Heat transfer analysis on a total of 11 concrete filled single/double tubular (CFST/CFDST) columns retrieved from the literature were generated to validate the heat FE model. In this case, very good agreement between the test and FE results were noted, thus highlighting the feasibility of using the procedure to determine the heat transfer characteristics of DSCWs specimens. The heat transfer analysis indicated that SCC took the longest time for the core temperature to match the temperature at the surface of the steel. This was followed by ECC and UHPC, respectively.

Through use of the validated axial compressive load and heat transfer models of DSCW, a sequentially coupled thermal-mechanical FE analysis was performed to determine the fire resistance of DSCW systems under simultaneous combined temperature and axial compressive loading. The fire resistance of DSCWs when exposed to $200,400,600,800^{\circ} \mathrm{C}$ and ISO-834 temperature curves was determined through FE modelling where three categories of responses were observed. In the first category, failure due to elevated temperatures was observed. In the second category of results, no failure was observed but for the buckling of steel. In the third and final category of observed results, no failure in either the steel or concrete was observed which was mainly due to the low temperature of exposure. Parametric studies (conducted on the influence of changing applied load, steel thickness, concrete depth and fastener arrangement) revealed that the fire resistance of DSCWs is heavily dependent on the load level relative to the ultimate load during fire exposure. A higher load level led to a decrease in fire resistance while a low load level led to an increase in fire resistance. The increase in thickness of profiled steel sheets did show some increase in the fire resistance, however such increase was deemed insignificant. The increase in concrete depth was directly related to an increase in the fire resistance of DSCWs due to increase in heat sink (depth of concrete core) and overall strength. Finally, arrangements of sheet-concrete fasteners proved to have no significant impact on the fire resistance. This was attributed to the presence of elevated temperature negating the effects of fasteners in the composite wall. Overall, SCC composite walls exhibited the best fire performance showing higher fire resistance time followed by ECC and UHPC walls. SCC-based DSCWs should also be an economical alternative compared to their costly ECC and UHPC counterparts. 


\subsection{Recommendations for Future Research Studies}

Possible future studies related to this topic are summarized as follows;

- Limited research is available on the fire resistance of DSCW. Experimental and analytical studies should be conducted to fill the void surrounding this topic.

- To the best of the author's knowledge, no full model currently exists to denote the changes in the thermal properties of confined engineered cementitious concrete (ECC). Assumptions were made in the thesis to account for such limitation. Research is needed in this direction.

- Further studies are also needed to determine the appropriate contact conductance property existing between the steel and concrete. Limited research is currently available on this topic resulting in inconclusive findings.

- No experimental results on the changes of temperature along the cross-section of the DSCW currently exist in the literature. Heat transfer analysis in this thesis was based on experimental results related to CFST column. Further studies are needed to obtain more accurate FE models for heat transfer.

- To the best of the author's knowledge, there are no guidelines or mathematical expressions to determine of material models of ECC, UHPC and SCC. Further analytical and experimental models are needed to determine the fracture energy, tensile stress vs. strain curves, compressive stress vs. strain curves, thermal expansion coefficients and etc.

- Since ECC and UHPC are relatively new concrete mixtures, there is very little information on the thermal behaviour of such concrete types. Experimental investigations are needed to determine the specific heat, thermal conductivity and thermal contact conductance of these new high performance concrete alternatives.

- Further studies are required to provide design guideline on the fire resistance of DSCW. Guideline on the fire resistance under the effects of eccentricity, additional of internal reinforcement and so on can also be generated as potential future work.

- Finally, additional research can also be done on the fire resistance of DSCW while considering the effects of joints and restraints from surrounding steel frames. 


\section{References}

ABAQUS. (2014). ABAQUS/CAE user's guide. (Version 6.14). Providence, RI, USA: Dassault Systèmes Corp.

Achenbach, M., Lahmer, T., \& Morgenthal, G. (2017). Identification of the thermal properties of concrete for the temperature calculation of concrete slabs and columns subjected to a standard fire-Methodology and proposal for simplified formulations. Fire Safety Journal, Vol. 87, 80-86.

ACI 318. (2011). Building Code Requirements for Structural Concrete and Commentary. Farmington Hills, Missouri, U.S: American Concrete Institute.

AIJ. (1997). Recommendations for design and construction of concrete filled steel tubular structures. Tokyo, Japan: Architectural Institute of Japan.

ASTM. (2011). Standard test method for determining specific heat capacity by differential scanning calorimetry (E1269 - 11). West Conshohocken, Pa, USA: ASTM International.

ASTM. (2007). Standard practice for making and curing concrete test specimens in the laboratory (C192). West Conshohocken, Pennsylvania, U.S: Annual Book of ASTM Standards.

ASCE. (1992). Structural fire protection (Manual No. 78). New York, USA: American Society of Civil Engineers.

Bilow, D.N., \& Kamara, M.E. (2008). Fire and concrete structures. Proceedings of the 2008 Structures Congress: Crossing Borders, ASCE, 1-10. doi: http://dx.doi.org/10.1061/41016(314)299.

Boughanem S., Jesson D.A., Smith P.A., Mulheron M.J., Eddie C., Psomas S., \& Rimes M. (2011). Engineered cement composites properties for civil engineering applications. Proceedings of the $18^{\text {th }}$ International Conference on Composite Materials (ICCM18), Jeju Island, Korea.

Bruneau, M., Varma, A.H., \& Hooper, J. (2016). Composite plate shear walls - Concrete filled. Proceedings of Steel Conference. Chicago: American Institute of Steel Construction. 
CEB-FIP. (1993). Comité Euro-International du Béton-Fédération Internationale de la Précontrainte. (Model code 1990), London, England: Thomas Telford.

Cengel, Y.A., \& Boles, M.A. (2002). Thermodynamics: An Engineering Approach, 4th ed. New York: McGraw-Hill.

Choe, G., Kim, G., Gucunski, N., \& Lee, S. (2015). Evaluation of the mechanical properties of $200 \mathrm{MPa}$ ultra-high-strength concrete at elevated temperatures and residual strength of column. Journal of Construction and Building Materials, Vol. 86, 159-168.

Dai, X.H., \& Lam, D. (2012). Shape effect on the behaviour of axially loaded concrete filled steel tubular stub columns at elevated temperature. Journal of Constructional Steel Research, Vol. 73, 117-127.

Ding, J., \& Wang, Y.C. (2008). Realistic modelling of thermal and structural behaviour of unprotected concrete filled tubular columns in fire. Journal of Constructional Steel Research, Vol. 64, No. 10, 1086-1102.

Ding, Z., Jiang, H., Zeng, J., Zhang, H., \& Du, G. (2011). An innovative application of SCS composite wall: Structural design of Yancheng TV Tower. Build. Struct., 87-91.

Eurocode-2. (2005). Design of concrete structures. (Part 1-2). London, UK: British Standards Institution.

Eurocode-3. (2005). Design of steel structures. (Part 1-2). London, UK: British Standards Institution.

Eurocode-4. (2005). Design of composite steel and concrete structures. (Part 1.2). London, UK: British Standards Institution.

Espinos, A., Romero, M.L., \& Hospitaler, A. (2010). Advanced model for predicting the fire response of concrete filled tubular columns. Journal of Constructional Steel Research, Vol. 66, No. 8, 1030-1046.

Fares, H., Noumowe, A., \& Remond, S. (2009). Self-consolidating concrete subjected to high temperature Mechanical and physicochemical properties. Cement and Concrete Research, Vol. 39, No, 12, 1230-1238. 
Genikomsou, A., \& Polak, M., (2015). Finite Element Analysis of Punching Shear of Concrete Slabs using Damaged Plasticity Model in ABAQUS. Engineering Structures, Vol. 98, $38-48$.

Ghannam, M.M.A. (2015). Behaviour of concrete-filled stainless steel columns under fire conditions (PhD. Thesis). University of Western Sydney: Sydney, Australia.

Ghojel, J. (2004). Experimental and analytical technique for estimating interface thermal conductance in composite structural elements under simulated fire conditions. Experimental Thermal and Fluid Science, Vol. 28, No. 4, 347-354.

Han, B.C., Kwon, Y.J., \& Kim, J.H. (2007). Behavior of fire resistance engineered cementitious composites (FR-ECC) under fire temperature. Journal of the Korea Concrete Institute, Vol. 19, No 2, 189-197. [In Korean].

Han L.H., Li W., \& Bjorhovde R. (2014). Developments and advanced applications of concretefilled steel tubular (CFST) structures: Members. Journal of Constructional Steel Research, Vol. 100, 211-228.

Han, L.H., Zhao, X-L., Yang, Y-F., \& Feng, J-B. (2003). Experimental study and calculation of fire resistance of concrete filled hollow steel columns. Journal of Structural Engineering, Vol. 129, No. 3, 346-56.

Hossain, K.M.A., \& Wright, H. (2004). Experimental and theoretical behaviour of composite walling under in-plane shear. Journal of Constructional Steel Research, Vol. 60, No. 1, $59-83$.

Hossain, K.M.A., Mol, L.K., \& Anwar, M.S. (2015). Axial load behaviour of pierced profiled composite walls with strength enhancement devices. Journal of Constructional Steel Research, Vol. 110, 48-64.

Huang, Z., \& Liew, R.L.Y. (2016). Structural behaviour of steel-concrete-steel sandwich composite wall subjected to compression and end moment. Thin-Walled Structures, Vol. $98,592-606$.

Huo, J., Huang, G., \& Xiao, Y. (2009). Effects of sustained axial load and cooling phase on postfire behaviour of concrete-filled steel tubular stub columns. Journal of Constructional Steel Research, Vol. 65, No. 8, 1664-1676. 
Ichikawa, Y., \& England, G.L. (2004). Prediction of moisture migration and pore pressure buildup in concrete at high temperatures. Nuclear Engineering and Design, Vol. 228, No. 1-3, 245- 259.

JSCE. (2008). Recommendations for design and construction of high performance fiber reinforced cement composites with multiple fine cracks (HPFRCC). (Concrete Engineering Series 82). Tokyo, Japan: Japanese Society of Civil Engineering.

JSCE. (1998). Guide to construction of high flowing concrete. Tokyo, Japan: Japanese Society of Civil Engineering.

Ji, X., Cheng, X., Jia, X., \& Varma, A.H. (2017). Cyclic in-plane shear behavior of double-skin composite walls in high-rise buildings. Journal of Structural Engineering, Vol. 143, No. 6, 04017025-1-04017025-12.

Kang, S.T., Kwon, S.H., \& Park, H.Y. (2012). Variation of stress - crack opening relationships for tensile cracking of self-consolidating concrete at early ages. Canadian Journal of Civil Engineering, Vol. 39, No. 2, 237-247.

Khaliq, W., \& Kodur, V. (2011). Thermal and mechanical properties of fiber reinforced high performance self-consolidating concrete at elevated temperatures. Cement and Concrete Research, Vol. 41, No. 11, 1112-1122.

Khaloo, A.R., Karimi, H., Asadollahi, S., \& Dehestani, M. (2017). A new mixture design method for ultra-high-strength concrete. ACI Materials Journal, Vol. 144, No. 2, 215224.

Kim, Y.J., Choi, Y.W., \& Lachemi, M. (2010). Characteristics of self-consolidating concrete using two types of lightweight coarse aggregates. Construction and Building Materials, Vol. 24, No. 1, 11-16.

Kodur, V. (2014). Properties of concrete at elevated temperatures. ISRN Civil Engineering, 2014, (468510). DOI: $10.1155 / 2014 / 468510$.

Kodur, V., Dwaikat, M., \& Fike, R. (2010). High-temperature properties of steel for fire resistance modeling of structures. Journal of Materials in Civil Engineering, Vol. 22, No. 5. 
Kodur, V., \& Khaliq, W. (2011). Effect of temperature on thermal properties of different types of high-strength concrete. Journal of Materials in Civil Engineering, Vo. 23, No. 6. 793801.

Kodur, V., \& Lie, T.T. (1996). Fire resistance of circular steel columns filled with fiberreinforced concrete. Journal of Structural Engineering, Vol. 122, No. 7, 776-782.

Kwak, H-G., \& Gang, H. (2015). An improved criterion to minimize FE mesh-dependency in concrete structures under high strain rate conditions, International Journal of Impact Engineering, Vol. 86, 84-95.

Li, V.C. (2003). Engineered cementitious composites (ECC) a review of the material and its applications. Journal of Advanced Concrete Technology, Vol. 1, No. 3, 215-230.

Li, V.C., Qian, S., Zhang, H., \& Keoleian, G.A. 2008. Sustainable infrastructure with durable fibre concrete material. Proceedings of Congress 2008 - Concrete: Construction's Sustainable Option. Dundee Scotland.

Liang, Q. Q. (2017). Nonlinear analysis of circular double-skin concrete-filled steel tubular columns under axial compression. Engineering Structures, Vol. 131, 639-650.

Lie, T.T. (1994). Fire resistance of circular steel columns filled with bar-reinforced concrete. Journal of Structural Engineering, Vol. 120, No. 5, 1489-1509.

Lie T. T., \& Caron, S. E. (1988). Fire resistance of circular hollow steel columns filled with siliceous aggregate concrete. Ottawa, Canada: Institute for Research in Construction, National Research Council of Canada (NRCC).

Liu, J., \& Zhou, X. (2010). Behavior and strength of tubed RC stub columns under axial compression. Journal of Constructional Steel Research, Vol. 66, No. 1, 28-36.

Long, W.J., Khayat, K.H., \& Hwang, S.D. (2013). Mechanical properties of prestressed selfconsolidating concrete. Materials and Structures, Vol. 46, No. 9, 1473-1487.

Lu, H., Han, L.H., \& Zhao X.L. (2010). Fire performance of self-consolidating concrete filled double skin steel tubular columns: experiments. Fire Safety Journal, Vol. 45, No. 2, 106115. 
Lu, H., Zhao, X. \& Han, L. (2011). FE modelling and fire resistance design of concrete filled double skin tubular columns. Journal of Constructional Steel Research, Vol. 67, No. 11, $1733-1748$.

Lu, H., Zhao, X.L., \& Han, L.H. (2009). Fire behaviour of high strength self-consolidating concrete filled steel tubular stub columns. Journal of Constructional Steel Research, Vol. 65, No. 10, $1995-2010$.

Morabito, P. (1989). Measurements of the thermal properties of different concretes. High Temperatures-High Pressures, Vol. 21, No. 1, 51-59.

Naus, D. (2010). A compilation of elevated temperature concrete material property data and information for use in assessments of nuclear power plant reinforced concrete structures. Washington, U.S.A: Division of Engineering Technology, Office of Nuclear Regulatory Research, U.S. Nuclear Regulatory.

Naus, D. J. (2006). The effect of elevated temperature on concrete materials and structures $-a$ literature review. (NUREG/CR-6900, ORNL/TM-2005/553). Washington, U.S.A: Division of Engineering Technology, Office of Nuclear Regulatory Research, U.S. Nuclear Regulatory.

National Fire Protection Association (NFPA). (2017, March 13). Fires in the U.S. Retrieved August 5, 2017, from http://www.nfpa.org/news-and-research/fire-statistics-andreports/fire-statistics/fires-in-the-us

Othman, H. (2016). Performance of ultra-high performance fiber reinforced concrete plates under impact loads (PhD. Thesis). Ryerson University, Toronto, Canada.

Othman, H., Marzouk, H. (2017). Finite-element analysis of reinforced concrete plates subjected to repeated impact loads. American Society for Civil Engineers, Vol. 173, No. 9, 04017120-1-04017120-16.

Özbay, E., Karahan, O., Lachemi, M., Hossain, K.M.A., \& Atis, C.D. (2012). Investigation of properties of engineered cementitious composites incorporating high volumes of fly ash and m-metakaolin. ACI Materials Journal, Vol. 109, No. 5, 565-571.

Popovics, S. (1973). A numerical approach to the complete stress-strain curve of concrete. Cement and Concrete Research, Vol. 3, No. 5, 583-599. 
Rafiei, S. (2011). Behaviour of double skin profiled composite shear wall system under in-plane monotonic, cyclic and impact loadings (PhD. Thesis). Ryerson University, Toronto, Canada.

Rafiei, S., Hossain, K.M.A., Lachemi, M., \& Behdinan, K. (2015). Profiled sandwich composite wall with high performance concrete subjected to monotonic shear. Journal of Constructional Steel Research, Vol. 107, 124-136.

Rafiei, S., Hossain, K.M.A., Lachemi, M., Behdinanb, K., \& Anwar, M.S. (2013). Finite element modeling of double skin profiled composite shear wall system under in-plane loadings. Engineering Structures, Vol. 56, No. 46-57.

Rush, D. (2013). Fire performance of unprotected and protected concrete filled steel hollow structural sections ( $\mathrm{PhD}$. Thesis). The University of Edinburgh, Edinburg, Scotland.

Şahmaran, M., Lachemi, M., Hossain, K.M.A, Ranade, R., \& Victor, C.L. (2009). Influence of aggregate type and size on ductility and mechanical properties of engineered cementitious composites. ACI Materials Journal, Vol 106, No. 3, 308-316.

Shen, L., Jovein, H.B., Sun, Z., Wang, Q., \& Li., W. (2015). Testing dynamic segregation of self-consolidating concrete. Construction and Building Materials, Vol. 75, 465-471.

Sherir, M.M.A., Hossain, K.M.A., \& Lachemi, M. (2014). Fracture energy, fatigue and creep properties of engineered cementitious composites incorporating fly ash/slag with different aggregates. 4th International Structural Specialty Conference, 28-31.

Tao, Z., \& Ghannam M. (2013). Heat transfer in concrete-filled carbon and stainless steel tubes exposed to fire. Fire Safety Journal, Vol. 61, 1-11.

Taormina, A. (2012). Axial load behaviour of double skin composite walls subjected to elevated temperatures (Master's thesis). Ryerson University, Toronto, Canada.

Taormina, A., \& Hossain, K.M.A. (2013). Post-fire axial load behaviour of double skin composite walls incorporating ultra-high performance concrete. $3^{\text {rd }}$ Specialty Conference on Material Engineering \& Applied Mechanics, CSCE. Québec: Montréal. 
Usach, C.I. (2015). Fire response analysis of circular concrete filled tubular columns and the effects of axial and rotational restraints (PhD thesis). The Technical University of Valencia, Valencia, Spain.

Wang, K., \& Young, B. (2013). Fire resistance of concrete-filled high strength steel tubular columns. Thin-Walled Structures, Vol. 71, No. 1, 46-56.

Wang, X.Q., Tao, Z., Song, T.Y., \& Han, L.H. (2014). Stress-strain model of austenitic stainless steel after exposure to elevated temperatures. Journal of Constructional Steel Research, Vol. 99, 129-139.

Wright, H. (1998). The axial load behaviour of composite walling. Journal Constructional Steel Research, Vol. 45, No. 3, 353-375.

Wright, H.D., \& Gallocher, S.C. (1995). The behaviour of composite walling under construction and service loading. Journal of Constructional Steel Research, Vol. 35, No. 3, 257-273.

Xionga, M.X., \& Liew, R. (2016). Mechanical behaviour of ultra-high strength concrete at elevated temperatures and fire resistance of ultra-high strength concrete filled steel tubes. Materials and Design, Vol. 104, 414-427.

Yang, Y., Liu, J., \& Fan, J. (2016). Buckling behavior of double-skin composite walls: An experimental and modeling study. Journal of Constructional Steel Research, Vol. 121, 126-135.

Yao, Y., Li, H. and Tan, K. (2016). Theoretical and numerical analysis to concrete filled double skin steel tubular columns under fire conditions. Thin-Walled Structures, Vol. 98, 547557.

Yaoa, Y., Lia, H., Guo, H., \& Tan, K. (2016). Fire resistance of eccentrically loaded slender concrete-filled steel tubular columns. Thin-Walled Structures, Vol. 106, 102-112.

Yuan, F., Pan, J., Xu, Z., \& Leung, C.K.Y. (2013). A comparison of engineered cementitious composites versus normal concrete in beam-column joints under reversed cyclic loading. Materials and Structures, Vol. 46, No. 1, 145-159.

Yin, J., Zha, X.X., \& Li, L.Y. (2006). Fire resistance of axially loaded concrete filled steel tube columns. Journal of Constructional Steel Research, Vol. 62, No. 7, 723-729. 
Zhao X.L., Han L.H., \& Lu H. (2010). Concrete-filled tubular members and connections. Abingdon, Oxon: Spon Press. 